\title{
DETAILED STUDY OF WOOD COMBUSTION IN A FIXED BED REACTOR UNDER OXY-FUEL CONDITION
}

JOSEPHAT KIPYEGON TANUI

\author{
A THESIS SUBMITTED IN PARTIAL FULFILMENT OF THE \\ REQUIREMENTS FOR THE AWARD OF THE DEGREE OF DOCTOR \\ OF PHILOSOPHY IN MECHANICAL ENGINEERING IN THE \\ SCHOOL OF ENGINEERING OF DEDAN KIMATHI UNIVERSITY OF \\ TECHNOLOGY
}

APRIL, 2020 


\section{DECLARATION}

This thesis is my original work and has not been presented in any other University/Institution for a degree or for consideration of any certification.

Sign.......

Date.

\section{Mr. Josephat K. Tanui,}

E321-01-1875/2017.

\section{Approval}

This research thesis has been submitted with our approval as University Supervisors.

Sign

Date.

\section{Prof. Ndirangu Kioni, PhD.}

School of Engineering,

Dedan Kimathi University of Technology.

Sign.

Date

\section{Prof. Nancy Karuri, PhD.}

School of Engineering,

Dedan Kimathi University of Technology. 


\section{DEDICATION}

This thesis is dedicated to my parents, my wife and my children. 


\section{ACKNOWLEDGEMENTS}

The conception, design, implementation and execution of this $\mathrm{PhD}$ thesis would not have been possible without God's favour, mercy and grace.

The success of this research work is also greatly owed to my first supervisor, Prof. P. N. Kioni. He provided a deep insight, great support and invaluable guidance throughout the work. He also dedicated his time and provided valuable materials for this work. For all these, I am very grateful to him. I also like to thank my second supervisor, Prof. N. W. Karuri for the contribution, support and guidance throughout this work. I am also greatly indebted to my German Professor, Prof. Dipl. Ing. T. Mirre for not only guiding and supporting me throughout the work but also providing CFD software CD-Adapco (STAR CCM+ version 11.04) and hosting me in his laboratory while undertaking this research in Technische Hochschule, Wildau Germany. I would also like to thank Mr. M. Nowitzki for training me on STAR CCM+ software and his contribution while performing most of the computational work.

My gratitude also goes to many people who have contributed to the success of this work in one way or another. I can only mention but a few; to all others, my most sincere gratitude. I would like to particularly mention Prof. P. Muchiri and Prof. M. Herzog for their role in organizing successful research visits to Technische Hochschule, Wildau Germany. I would also like to thank Prof. Herzog for hosting me in his laboratory and allowing me to use some of his equipment like Atlas LOI equipment. I would also not forget Mr. E. Kornejew for providing me with laboratory instructional manuals and his valuable advice in this work.

I am also very grateful for the financial support of both Dedan Kimathi University of Technology (DeKUT), Kenya, and Technische Hochschule Wildau, Germany. Special thank also goes to the German Academic Exchange Service (DAAD) for granting me stipend while 
undertaking this work at Technische Hochschule, Wildau, Germany. I would also thank my colleagues: Mr. Njeru, Mr. Mwangi, Mr. Kinyua, Mr. Nyakoe and Mr. Timothy of Advanced Design, Manufacturing Training Centre (ADMATC) for their assistance in the work that was done in DeKUT.

Finally, I fully appreciate the moral and spiritual support of my wife Fancy and my entire family throughout this period. 


\section{TABLE OF CONTENTS}

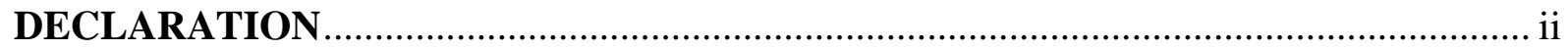

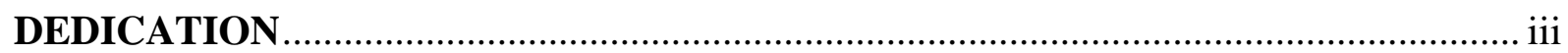

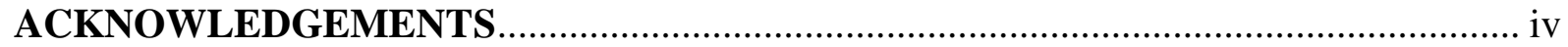

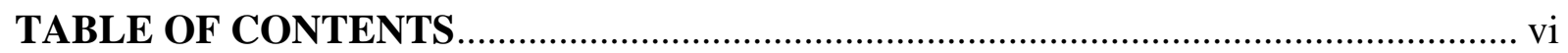

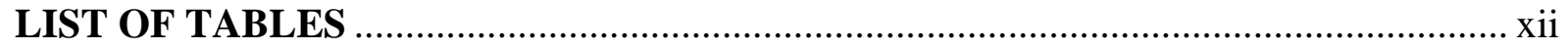

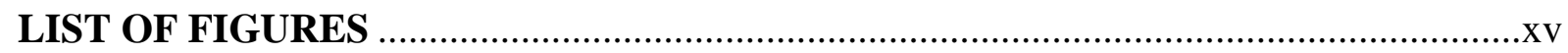

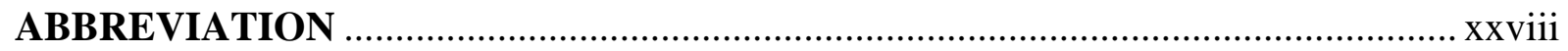

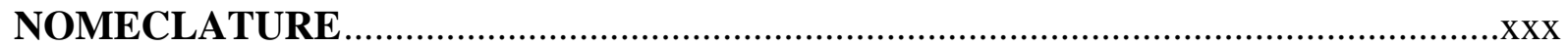

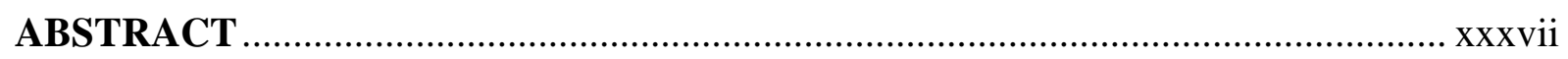

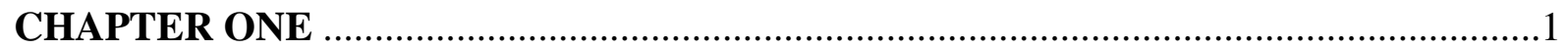

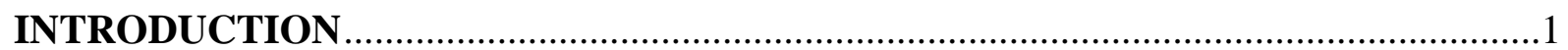

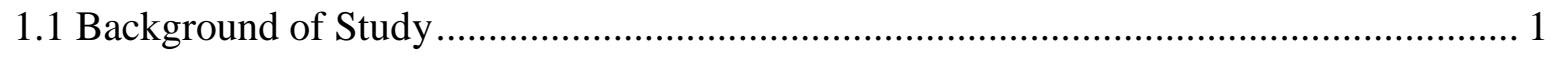

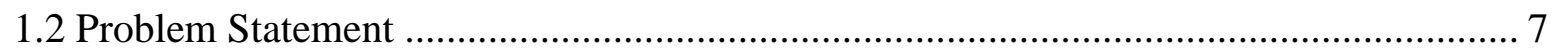

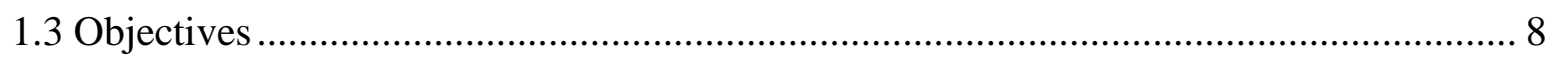

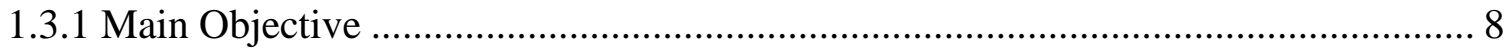

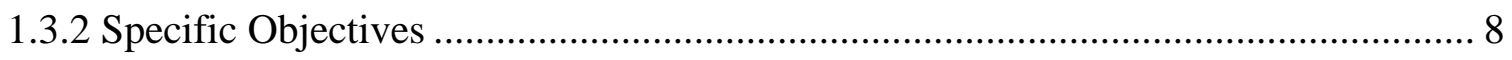

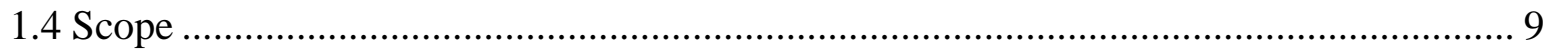

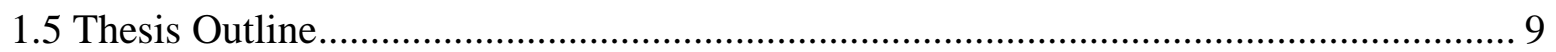

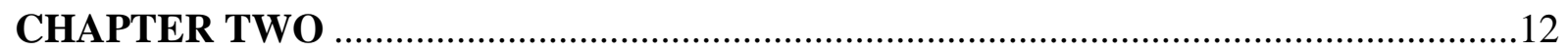

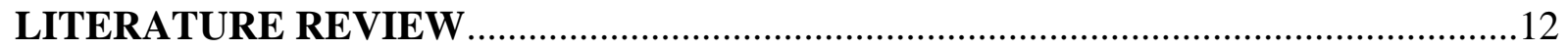

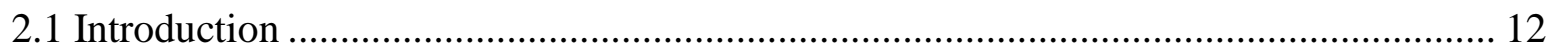

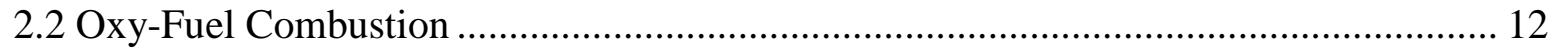




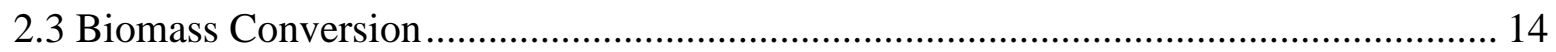

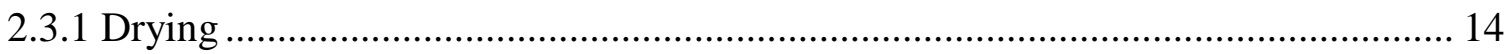

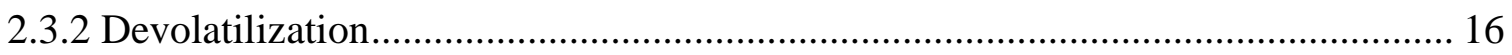

2.3.3 Gas Phase Reactions ……………....................................................................... 19

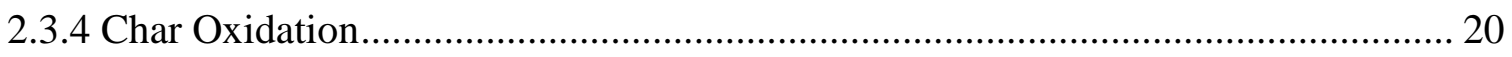

2.4 Effects of Oxy-Fuel Environment on Biomass Combustion Properties.......................... 21

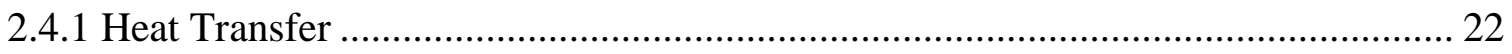

2.4.2 Drying under Oxy-fuel Environment............................................................... 25

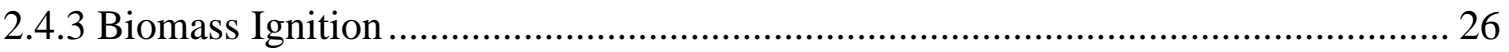

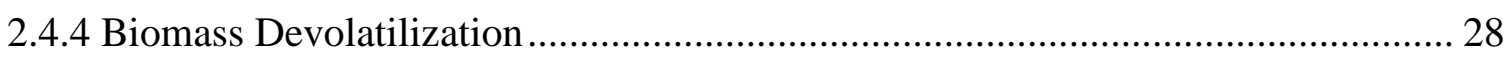

2.4.5 Char Formation and Combustion........................................................................ 29

2.4.6 Chemical Effect of $\mathrm{CO}_{2}$ on Homogeneous Reactions ........................................... 31

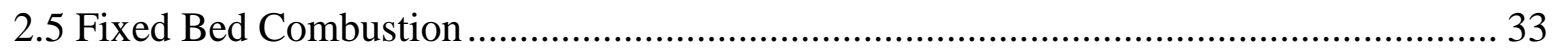

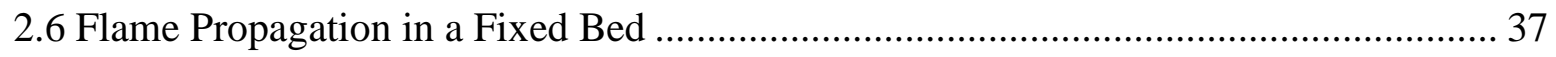

2.7 Modeling Approaches for a Fixed Bed ..................................................................... 40

2.8 Modeling Shrinkage in Biomass Combustion ............................................................... 41

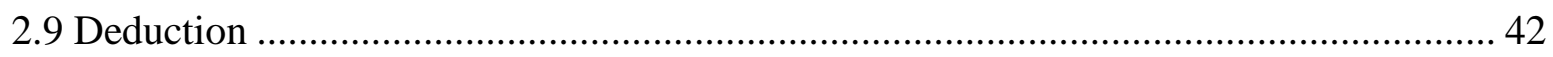

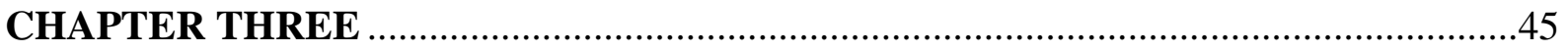

LABORATORY EXPERIMENTS AND RESULTS ....................................................45

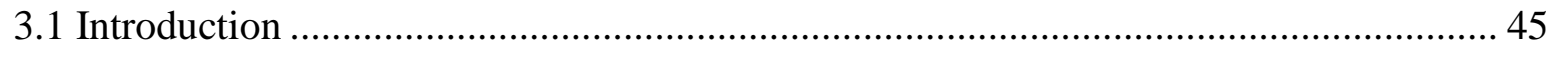

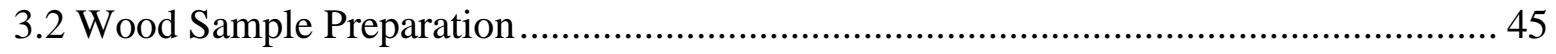

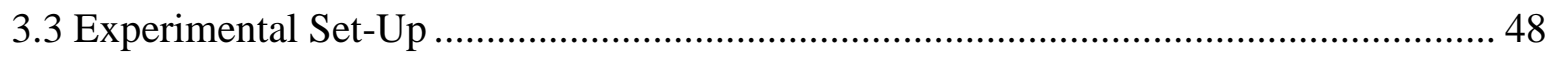

3.4 Determination of Combustion Parameters ………..................................................... 52 


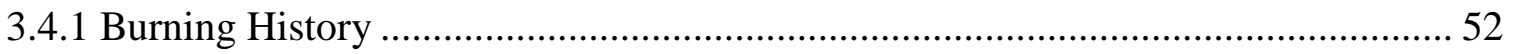

3.4.2 Flame Front Propagation Speed........................................................................... 52

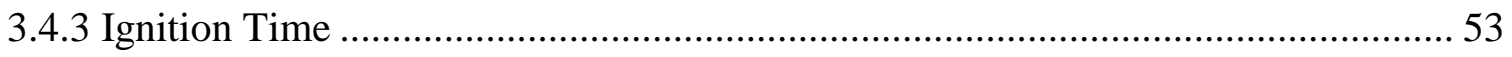

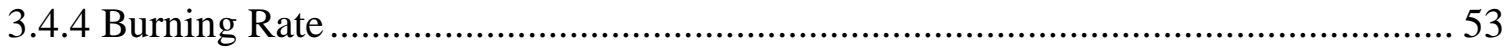

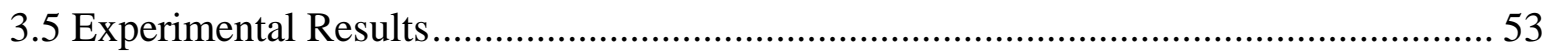

CHAPTER FOUR

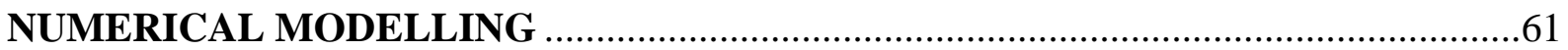

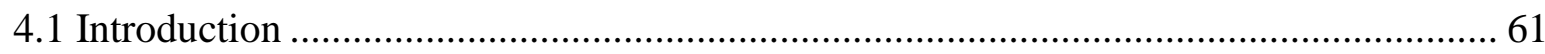

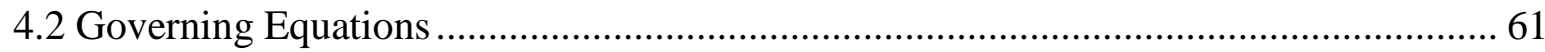

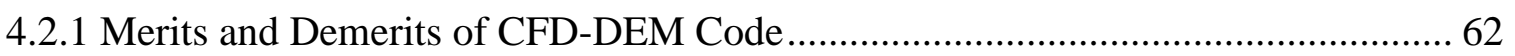

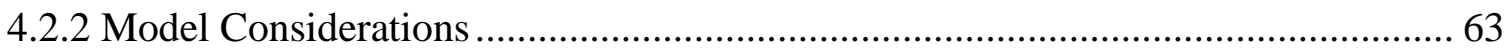

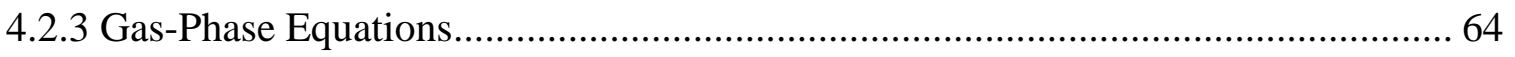

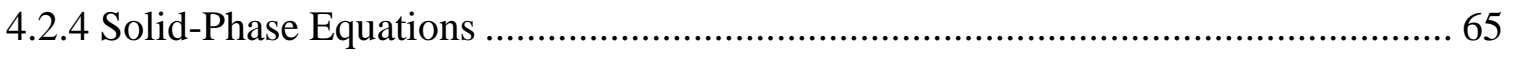

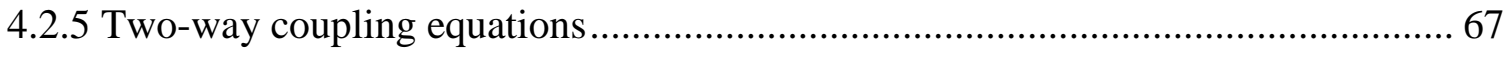

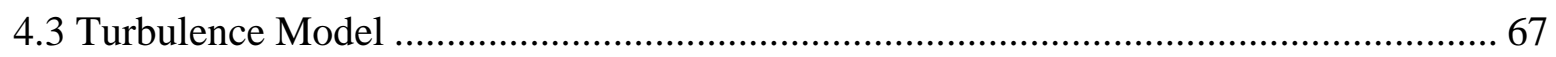

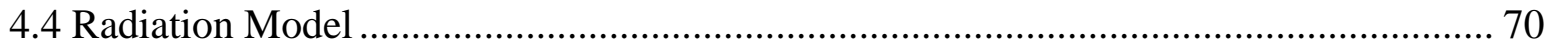

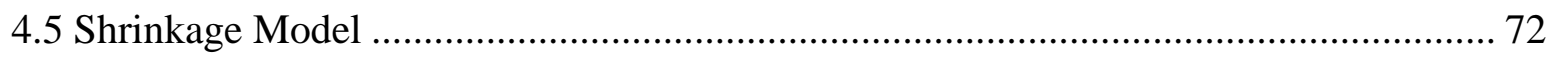

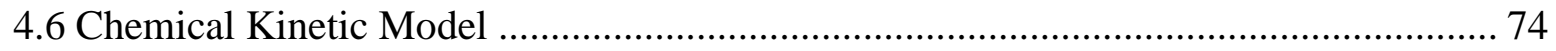

4.7 Thermodynamic and Transport Properties of Gas-Phase ................................................. 76

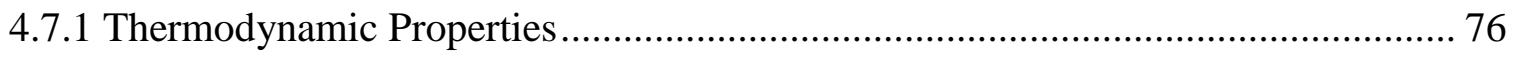

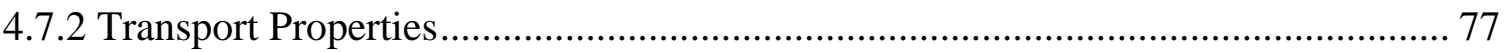

4.8 Thermodynamic and Transport Properties of Solid-Phase............................................ 79

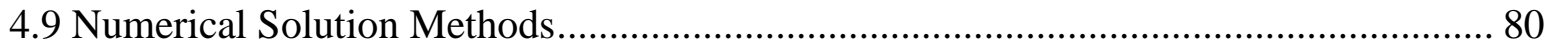




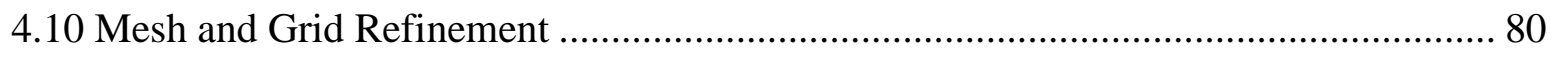

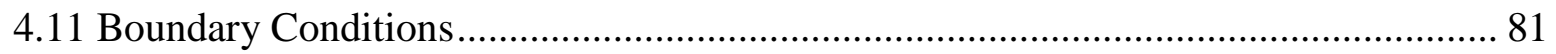

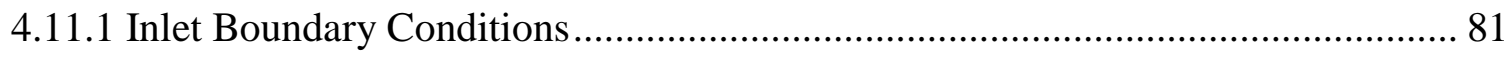

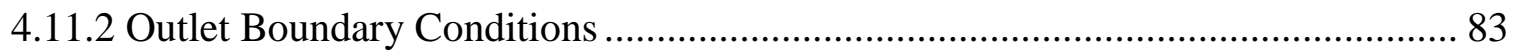

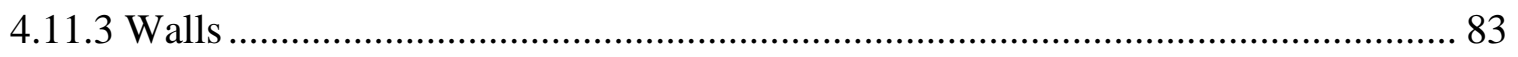

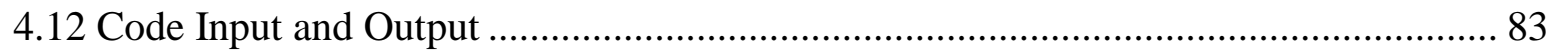

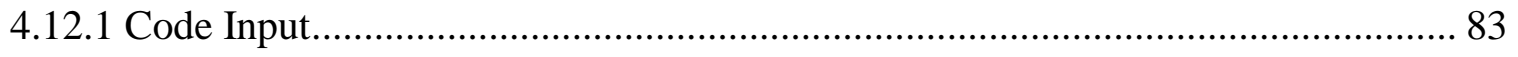

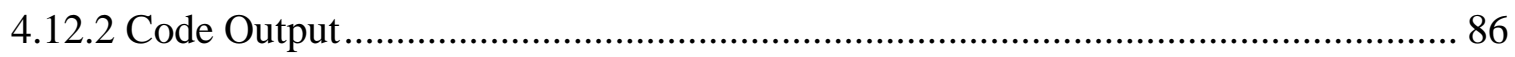

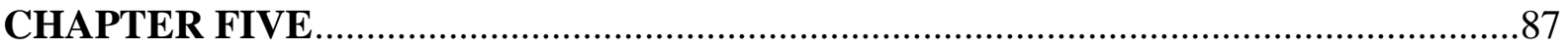

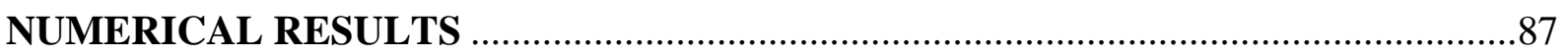

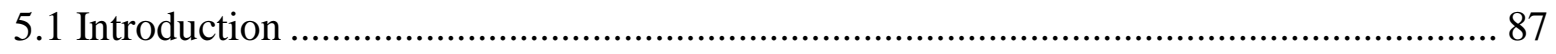

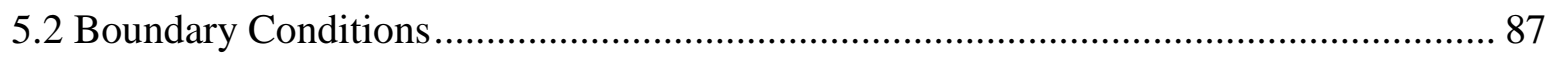

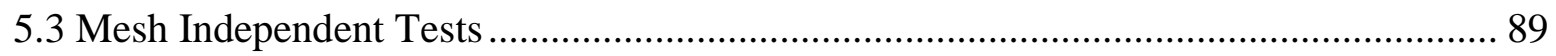

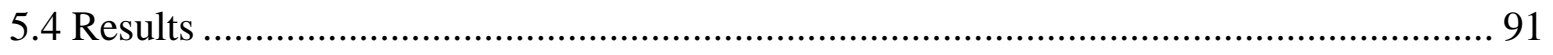

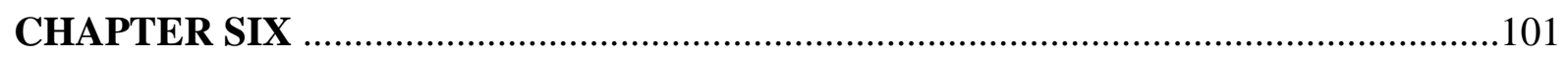

CFD-DEM MODEL VALIDATION, RESULTS AND DISCUSSIONS ........................101

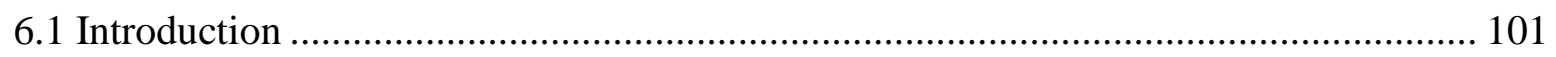

6.2 CFD-DEM Method and Code Validation ............................................................. 101

6.2.1 Temperature Distribution................................................................................ 101

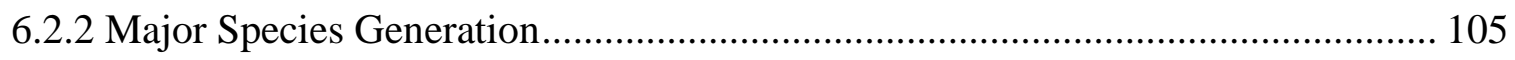

6.3 Flame Structure of Fixed-Bed Wood Combustion under Oxy-Fuel Conditions .......... 110

6.3.1 Mass Loss History ……………………………......................................... 110

6.3.2 Flame Front Propagation Speed......................................................................... 115 
6.3.3 Species Generation under Oxy-Fuel Conditions .................................................. 118

6.4 Particle Packing Density.................................................................................... 124

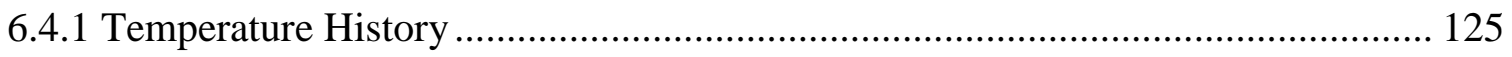

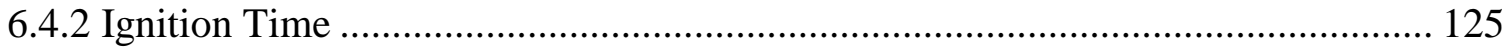

6.4.3 Wood Conversion and Char Formation Rates ………………….......................... 129

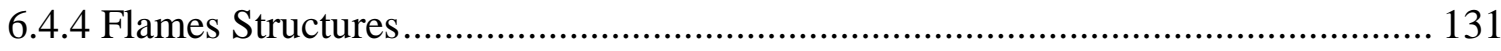

6.5 Chemical, Thermal and Dilution Effects of Carbon Dioxide..................................... 139

6.5.1 Overall Effect of $\mathrm{CO}_{2}$ on Wood Conversion Processes......................................... 139

6.5.2 Isolation of $\mathrm{CO}_{2}$ Effects on Wood Conversion Processes ..................................... 148

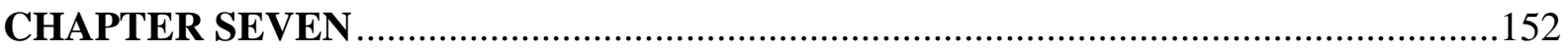

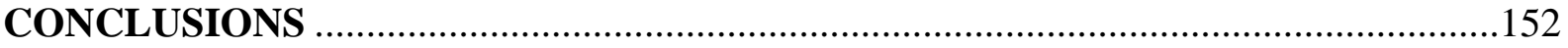

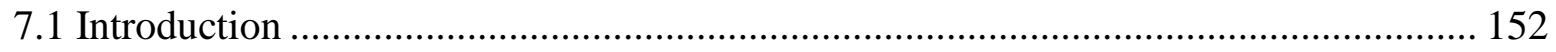

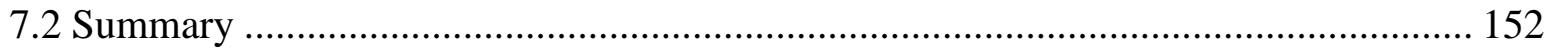

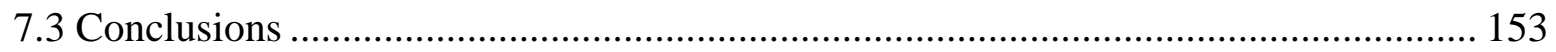

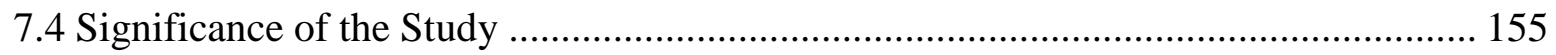

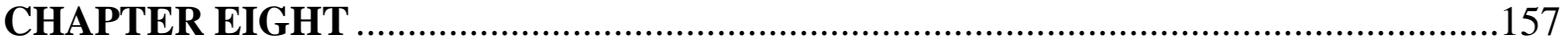

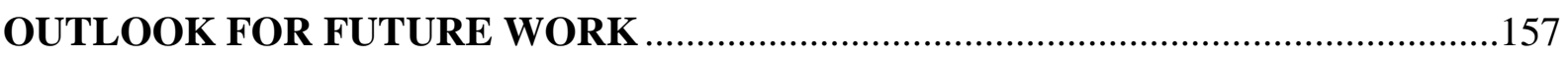

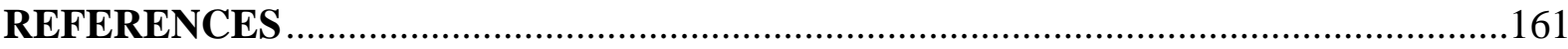

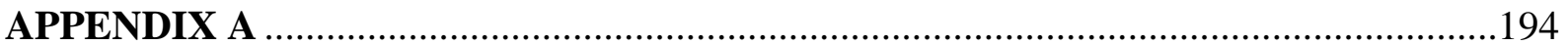

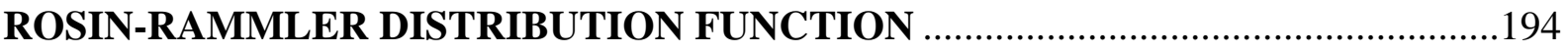

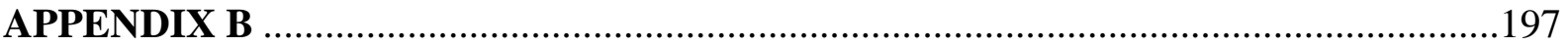

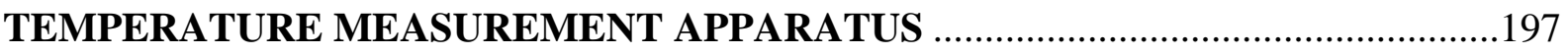

B.1 Determination of Individual Uncertainty Components .............................................. 198 
B.2 Calibration of Thermocouple Data Acquisition System....................................... 202

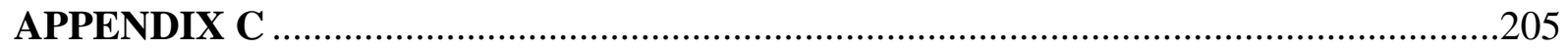

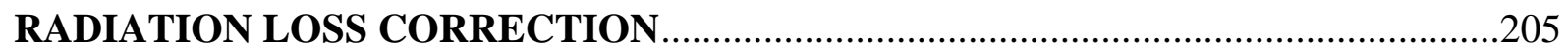

C.1 Model Equations for Bare-Bead Thermocouple .................................................. 205

C.2 Model Equations for Single-Shielded Thermocouple ......................................... 207

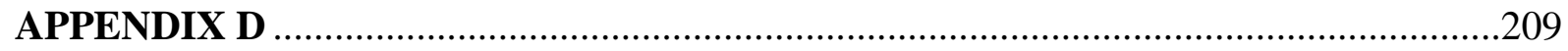

NUMERICAL MODELLING TECHNIQUES .......................................................209

D.1 Radiation Model Formulation ....................................................................... 209

D.2 Finite Volume Discretization for Continuous Phase ............................................. 214

D.3 Lagrange Phase Formulation ................................................................... 218

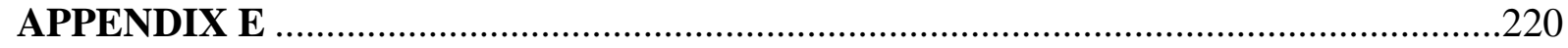

SPECIES GENERATION AND DEPLETION IN FUEL BED ................................220

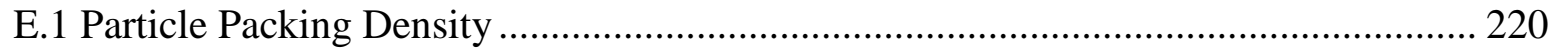

E.2 Wood Combustion in a Fixed Bed under Oxy-fuel Condition ................................ 228

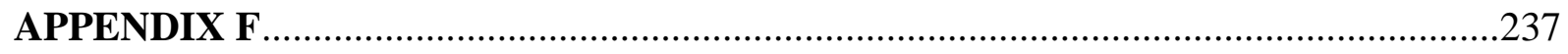

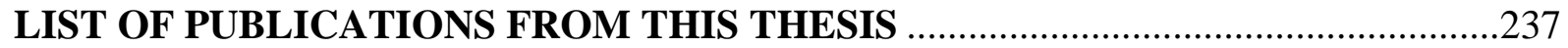




\section{LIST OF TABLES}

Table 2.1: Typical range of flame front speed for various biomass fuels burned under

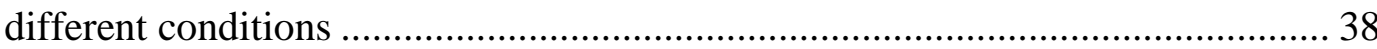

Table 3.1: Proximate and ultimate analysis of fuel sample .............................................. 46

Table 3.2: Properties of wood samples and fixed bed................................................ 48

Table 3.3: Volumetric flow rates for $\mathrm{O}_{2} / \mathrm{N}_{2}$ and $\mathrm{O}_{2} / \mathrm{CO}_{2}$ supplied at $T=295 \mathrm{~K}, p=5$ bar and operating condition of $m=0.1 \mathrm{~kg} / \mathrm{m}^{2} / \mathrm{s}$. ........................................ 50

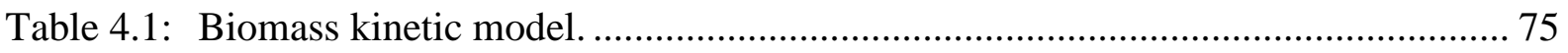

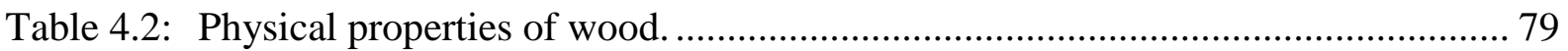

Table 5.1: Composition of the oxidizer mixture for different oxy-fuel conditions............... 88

Table 6.1: Peak values of major combustible species and temperature profiles for wood combustion under oxy-fuel environment for different $\mathrm{O}_{2} / \mathrm{CO}_{2}$ mixtures when the flame front is at $4 \mathrm{~cm}$ from the grate.

Table 6.2: Composition, combined heat capacity and $\mathrm{O}_{2}$ diffusion coefficient of the four mixtures at different temperatures.

Table A.1: Particle size distribution of wood particles samples. 195

Table A.2: Characteristic size of different fuel samples. 196

Table B.1: Uncertainty analysis of temperature measurement apparatus.

Table B.2: Calibration of thermocouple data acquisition system. 203

Table E.1: Peak values of temperature and the major combustible species mole fraction along the axial length of the fixed bed for fuel type SD1 burning under oxyfuel condition. 
Table E.2: Peak values of temperature and the major combustible species mole fraction along the axial length of the fixed bed for fuel type WC + SD1 burning under oxy-fuel condition.

Table E.3: Peak values of temperature and the major combustible species mole fraction along the axial length of the fixed bed for fuel type SD2 burning under oxyfuel condition.

Table E.4: Peak values of temperature and the major combustible species mole fraction along the axial length of the fixed bed for fuel type WC + SD2 burning under oxy-fuel condition.

Table E.5: Peak values of temperature and the major combustible species mole fraction along the axial length of the fixed bed for fuel type WC burning under oxyfuel condition.

Table E.6: Peak values of temperature and the major combustible species mole fraction along the axial length of the fixed bed for wood combustion burning under oxy-fuel condition of $21 \% \mathrm{O}_{2} / 79 \% \mathrm{CO}_{2}$

Table E.7: Peak values of temperature and the major combustible species mole fraction along the axial length of the fixed bed for wood combustion burning under oxy-fuel condition of $30 \% \mathrm{O}_{2} / 70 \% \mathrm{CO}_{2}$.

Table E.8: Peak values of temperature and the major combustible species mole fraction along the axial length of the fixed bed for wood combustion burning under oxy-fuel condition of $40 \% \mathrm{O}_{2} / 60 \% \mathrm{CO}_{2}$ 
Table E.9: Peak values of temperature and the major combustible species mole fraction along the axial length of the fixed bed for wood combustion burning under

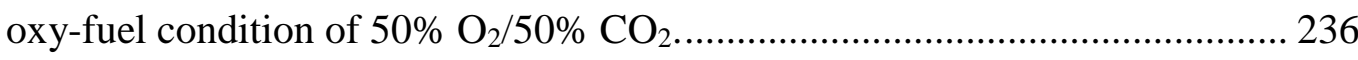




\section{LIST OF FIGURES}

Figure 1.1: The isolated thermal, dilution, and chemical effects of $\mathrm{CO}_{2}$ on the specific oxidation rate $\left(\mathrm{R}_{\mathrm{sp}}\right)$ of the ethylene flame soot (Al-Qurashi et al., 2011)............. 3

Figure 2.1: A typical atmospheric combustion system applied in a power plant that uses coal and operates in oxy-fuel environment (Scheffknecht et al., 2011).

Figure 2.2: Illustration of different conversion processes in a small biomass particle (Loo \& Koppejan, 2008)

Figure 2.3: Illustration of different conversion processes in a large biomass particle ( $\mathrm{He}$ \& Behrendt, 2011) 15

Figure 2.4: Two-stage semi-global reaction mechanism for (a) cellulose; (b) wood (Di Blasi, 2008). 18

Figure 2.5: Heat transfer processes for the thermal conversion of a biomass particle

(Chen, 2013). 26

Figure 2.6: A typical fixed bed combustion furnace. 33

Figure 2.7: Fixed bed operation modes: (a) downdraft - co-current; (b) downdraft countercurrent; (c) updraft - countercurrent; (d) updraft - co-current. 38

Figure 2.8: Two-regime classification of fixed bed combustion (Fatehi \& Kaviany, 1994).

Figure 2.9: Three-regime classification of fixed bed combustion (Porteiro et al., 2010)..... 40

Figure 3.1: Wood fuel samples. 47

Figure 3.2: Schematic diagram of the experimental set-up................................................ 48

Figure 3.3: A photo of laboratory set-up... 49 
Figure 3.4: Measured mass loss history for wood combustion in fixed bed at $21 \%$ $\mathrm{O}_{2} / 79 \% \mathrm{~N}_{2}$ and $21 \% \mathrm{O}_{2} / 79 \% \mathrm{CO}_{2}$ mixtures.

Figure 3.5: Measured temperature profiles at various distances from the bed bottom for wood combustion in (a) $21 \% \mathrm{O}_{2} / 79 \% \mathrm{~N}_{2}$ mixture and (b) $21 \% \mathrm{O}_{2} / 79 \% \mathrm{CO}_{2}$ mixture.

Figure 3.6: Measured temperature profiles at various heights above the grate for particle types (a) WC $(\chi=0.51),(b) \operatorname{WCSD} 2(\chi=0.56),(\mathrm{c}) \operatorname{SD} 2(\chi=0.61),(\mathrm{d})$ $\operatorname{WCSD} 1(\chi=0.68)$ and $(\mathrm{e}) \operatorname{SD} 1(\chi=0.74)$ 56

Figure 3.7: Measured ignition time for fixed bed combustion of wood in $\mathrm{N}_{2}$ and $\mathrm{CO}_{2}$ environments.

Figure 3.8: Measured ignition time for wood combustion in $21 \% \mathrm{O}_{2} / 79 \% \mathrm{CO}_{2}$ mixture for different initial bed porosity.

Figure 3.9: Measured flame front propagation speed for fixed bed combustion of wood in $\mathrm{N}_{2}$ and $\mathrm{CO}_{2}$ environments 58

Figure 3.10: Measured flame front propagation speed for wood combustion in in $21 \%$ $\mathrm{O}_{2} / 79 \% \mathrm{~N}_{2}$ and $21 \% \mathrm{O}_{2} / 79 \% \mathrm{CO}_{2}$ mixtures for different initial bed porosity.

Figure 3.11: Measured burning rate for fixed bed combustion of wood in $\mathrm{N}_{2}$ and $\mathrm{CO}_{2}$ environments

Figure 4.1: Processes of a fuel bed thermal conversion.

Figure 4.2: Shrinkage model where particle porosity increases while the original diameter is maintained. 
Figure 4.3: Shrinkage model where particle diameter decreases while maintaining zero porosity. 73

Figure 4.4: Shrinkage model where particle porosity increases while the diameter decreases.

Figure 4.5: Computational mesh for the fixed bed; (a) highly refined mesh in fuel bed and grate; (b) prismatic layers near the wall. 82

Figure 4.6: Illustration of details input in the code for (a) geometrical model and (b) mesh specification. 84

Figure 4.7: Specification of material properties and reactions in a multiphase flow for (a) multi-component gas and (b) multi-component solid.

Figure 4.8: $\quad \mathrm{x}-\mathrm{y}$ graph plots for temperature and $\mathrm{CH}_{4}$ created in STAR CCM+ code. 86

Figure 5.1: Comparison of temperatures profiles along axial length of the reactor for wood combustion in $21 \% \mathrm{O}_{2} / 79 \% \mathrm{CO}_{2}$ mixtures at (a) $450 \mathrm{~s}$ and (b) $600 \mathrm{~s}$ when applying different computational mesh sizes.

Figure 5.2: Comparison of tar mass fraction along axial length of the reactor for wood combustion in $21 \% \mathrm{O}_{2} / 79 \% \mathrm{CO}_{2}$ mixtures at (a) $450 \mathrm{~s}$ and (b) $600 \mathrm{~s}$ when applying different computational mesh sizes.

Figure 5.3: Comparison of temperature profiles along the axial length of the bed for particle type (a) WC $(\chi=0.51)$ and (b) SD1 $(\chi=0.74)$ when reaction front is at $4 \mathrm{~cm}$ from the grate applying different computation mesh sizes.

Figure 5.4: Predicted temperature profiles at $5 \mathrm{~cm}$ from the bed bottom for wood combustion under oxy-fuel environment for different mesh sizes. 
Figure 5.5: Predicted mass loss history for wood combustion in fixed bed at $21 \%$ $\mathrm{O}_{2} / 79 \% \mathrm{~N}_{2}$ and $21 \% \mathrm{O}_{2} / 79 \% \mathrm{CO}_{2}$ mixtures.

Figure 5.6: Predicted temperature profiles at various heights above the grate for particle types (a) WC $(\chi=0.51),(b) \operatorname{WCSD} 2(\chi=0.56)$, (c) $\operatorname{SD} 2(\chi=0.61),(d)$ $\operatorname{WCSD} 1(\chi=0.68)$ and $(\mathrm{e}) \operatorname{SD} 1(\chi=0.74)$

Figure 5.7: Predicted species concentration and temperature during entire combustion time in $21 \% \mathrm{O}_{2} / 79 \% \mathrm{CO}_{2}$ taken at $4 \mathrm{~cm}$ from the grate for particle type $\mathrm{WC}$ $(\chi=0.51)$

Figure 5.8: Predicted species and temperatures profiles along axial length of the reactor for wood combustion in $21 \% \mathrm{O}_{2} / 79 \% \mathrm{~N}_{2}$ mixture at different times: (a) 200

s, (b) $300 \mathrm{~s}$ (c) $400 \mathrm{~s}$ and (d) $1000 \mathrm{~s}$. 95

Figure 5.9: Predicted species and temperatures profiles along axial length of the reactor for wood combustion in $21 \% \mathrm{O}_{2} / 79 \% \mathrm{CO}_{2}$ mixture at different times: (a) 300 $\mathrm{s}$, (b) $450 \mathrm{~s}(\mathrm{c}) 600 \mathrm{~s}$ and (d) $1100 \mathrm{~s}$ 96

Figure 5.10: Predicted ignition time for fixed bed combustion of wood in $\mathrm{N}_{2}$ and $\mathrm{CO}_{2}$ environments

Figure 5.11: Predicted ignition time for wood combustion under oxy-fuel condition for different initial bed porosity.

Figure 5.12: Predicted flame front propagation speed for fixed bed combustion of wood in $\mathrm{N}_{2}$ and $\mathrm{CO}_{2}$ environments

Figure 5.13: Measured and predicted flame front propagation speed for wood combustion in $\mathrm{N}_{2}$ and $\mathrm{CO}_{2}$ environments for different initial bed porosity. 
Figure 5.14: Predicted burning rates for fixed bed combustion of wood in $\mathrm{N}_{2}$ and $\mathrm{CO}_{2}$ environments

Figure 6.1: Measured and predicted temperature profiles at $5 \mathrm{~cm}$ from fuel bottom for wood combustion at $21 \% \mathrm{O}_{2} / 79 \% \mathrm{~N}_{2}$.

Figure 6.2: Gas-phase and particle surface temperature distribution in the wood fuel bed burning at $21 \% \mathrm{O}_{2} / 79 \% \mathrm{~N}_{2}$ at different times.

Figure 6.3: Tar mass fraction distribution in the wood fuel bed burning at $21 \% \mathrm{O}_{2} / 79 \%$

$\mathrm{N}_{2}$ at different times.

Figure 6.4: $\mathrm{CO}$ mass fraction distribution in the wood fuel bed burning at $21 \% \mathrm{O}_{2} / 79 \%$

$\mathrm{N}_{2}$ at different times.

Figure 6.5: $\mathrm{O}_{2}$ mass fraction distribution in the wood fuel bed burning at $21 \% \mathrm{O}_{2} / 79 \%$

$\mathrm{N}_{2}$ at different times.

Figure 6.6: $\mathrm{H}_{2} \mathrm{O}$ mass fraction distribution in the wood fuel bed burning at $21 \% \mathrm{O}_{2} / 79 \%$

$\mathrm{N}_{2}$ at different times.

Figure 6.7: $\mathrm{CO}_{2}$ mass fraction distribution in the wood fuel bed burning at $21 \% \mathrm{O}_{2} / 79 \%$

$\mathrm{N}_{2}$ at different times.

Figure 6.8: Major species and temperatures profiles at different position from fuel bed bottom for wood combustion at $21 \% \mathrm{O}_{2} / 79 \% \mathrm{~N}_{2}$.

Figure 6.9: Mass loss history for wood combustion in fixed bed at $21 \% \mathrm{O}_{2} / 79 \% \mathrm{~N}_{2}$ and $21 \% \mathrm{O}_{2} / 79 \% \mathrm{CO}_{2}$ mixtures.

Figure 6.10: Temperature distribution in the wood fuel bed burning at $21 \% \mathrm{O}_{2} / 79 \% \mathrm{~N}_{2}$ at different times. 
Figure 6.11: Temperature distribution in the wood fuel bed burning at $21 \% \mathrm{O}_{2} / 79 \% \mathrm{CO}_{2}$ at different times.

Figure 6.12: Temperature distribution in the wood fuel bed burning at $30 \% \mathrm{O}_{2} / 70 \% \mathrm{CO}_{2}$ at different times.

Figure 6.13: Predicted and measured peak temperatures in the wood fuel bed burning at different $\mathrm{CO}_{2}$ atmospheres.

Figure 6.14: Predicted and measured flame front position for wood combustion in fixed bed at $21 \% \mathrm{O}_{2} / 79 \% \mathrm{~N}_{2}$ and $21 \% \mathrm{O}_{2} / 79 \% \mathrm{CO}_{2}$ mixtures. Fuel bed top is taken as datum.

Figure 6.15: Predicted and measured flame front propagation speed in the wood fuel bed burning at different $\mathrm{CO}_{2}$ atmospheres.

Figure 6.16: Species and temperatures profiles along axial length of the reactor for wood combustion in $\mathrm{O}_{2} / \mathrm{N}_{2}$ and $\mathrm{O}_{2} / \mathrm{CO}_{2}$ mixtures when reaction front is at $5 \mathrm{~cm}$ from fuel bottom: (a) $79 \% \mathrm{~N}_{2}$ at $200 \mathrm{~s}$, (b) $79 \% \mathrm{CO}_{2}$ at $300 \mathrm{~s}$ and (c) $70 \%$ $\mathrm{CO}_{2}$ at $200 \mathrm{~s}$.

Figure 6.17: Species and temperatures profiles along axial length of the reactor for wood combustion in $\mathrm{O}_{2} / \mathrm{N}_{2}$ and $\mathrm{O}_{2} / \mathrm{CO}_{2}$ mixtures when reaction front is at $4 \mathrm{~cm}$ from fuel bottom(a) $79 \% \mathrm{~N}_{2}$ at $300 \mathrm{~s}$, (b) $79 \% \mathrm{CO}_{2}$ at $450 \mathrm{~s}$ and (c) $70 \% \mathrm{CO}_{2}$ at $300 \mathrm{~s}$

Figure 6.18: Species and temperatures profiles along axial length of the reactor for wood combustion in $\mathrm{O}_{2} / \mathrm{N}_{2}$ and $\mathrm{O}_{2} / \mathrm{CO}_{2}$ mixtures when reaction front is at $3 \mathrm{~cm}$ from fuel bottom: (a) $79 \% \mathrm{~N}_{2}$ at $400 \mathrm{~s}$, (b) $79 \% \mathrm{CO}_{2}$ at $600 \mathrm{~s}$ and (c) $70 \%$ $\mathrm{CO}_{2}$ at $400 \mathrm{~s}$. 
Figure 6.19: Species and temperatures profiles along axial length of the reactor for wood combustion in $\mathrm{O}_{2} / \mathrm{N}_{2}$ and $\mathrm{O}_{2} / \mathrm{CO}_{2}$ mixtures during char combustion stage: (a) $79 \% \mathrm{~N}_{2}$ at $1000 \mathrm{~s}$, (b) $79 \% \mathrm{CO}_{2}$ at $1100 \mathrm{~s}$ and (c) $70 \% \mathrm{CO}_{2}$ at $1000 \mathrm{~s}$.

Figure 6.20: Measured and predicted temperature profiles at various heights above the grate for particle types (a) WC $(\chi=0.51),(b) \operatorname{WCSD} 2(\chi=0.56),(c) \operatorname{SD} 2(\chi$ $=0.61),(\mathrm{d}) \operatorname{WCSD} 1(\chi=0.68)$ and $(\mathrm{e}) \operatorname{SD} 1(\chi=0.74)$.

Figure 6.21: Measured and predicted ignition time for wood combustion under oxy-fuel condition for different initial bed porosity. Error bars are the standard deviations.

Figure 6.22: Measured and predicted flame front propagation speed for wood combustion in $\mathrm{N}_{2}$ and $\mathrm{CO}_{2}$ environments for different initial bed porosity. Error bars are the standard deviations.

Figure 6.23: Predicted (a) wood conversion and (b) char formation of the particles with the same amount of mass initially located at $4 \mathrm{~cm}$ from the grate for different fuel particle types.

Figure 6.24: Predicted rate of (a) wood conversion and (b) char formation of the particles with the same amount of mass initially located at $4 \mathrm{~cm}$ from the grate for different fuel particle types.

Figure 6.25: Predicted species concentration and temperature during entire combustion time taken at $4 \mathrm{~cm}$ from the grate for particle types (a) WC $(\chi=0.51)$, (b) $\operatorname{WCSD} 2(\chi=0.56),(\mathrm{c}) \operatorname{SD} 2(\chi=0.61),(\mathrm{d}) \operatorname{WCSD} 1(\chi=0.68)$ and (e) SD1 $(\chi=0.74)$ 
Figure 6.26: Predicted major species concentration and temperature along axial length of the bed for particle types (a) WC $(\chi=0.51)$, (b) WCSD2 $(\chi=0.56)$, (c) SD2 $(\chi=0.61),(d) \operatorname{WCSD} 1(\chi=0.68)$ and (e) SD1 $(\chi=0.74)$ when the reaction front is at $4 \mathrm{~cm}$ from the grate.

Figure 6.27: Predicted peak values of major combustible species concentration at fuel bed top for different fuel types during entire combustion time.

Figure 6.28: Measured and predicted temperature profiles at $5 \mathrm{~cm}$ from the bed bottom for wood combustion in $21 \% \mathrm{O}_{2} / 79 \% \mathrm{~N}_{2}$ and $21 \% \mathrm{O}_{2} / 79 \% \mathrm{CO}_{2}$ mixtures..... 140

Figure 6.29: Predicted temperature profiles at $5 \mathrm{~cm}$ from the bed bottom for wood combustion in different combustion atmospheres.

Figure 6.30: Measured and predicted ignition time for fixed bed combustion of wood in $\mathrm{N}_{2}$ and $\mathrm{CO}_{2}$ environments

Figure 6.31: Measured and predicted burning rates for fixed bed combustion of wood in $\mathrm{N}_{2}$ and $\mathrm{CO}_{2}$ environments

Figure 6.32: Measured and predicted flame front propagation speed for fixed bed combustion of wood in $\mathrm{N}_{2}$ and $\mathrm{CO}_{2}$ environments.

Figure 6.33: Species and temperature profiles along axial length of the bed when the flame front is at $4 \mathrm{~cm}$ from the grate for (a) $21 \% \mathrm{O}_{2} / 79 \% \mathrm{CO}_{2}$ and (b) $30 \%$ $\mathrm{O}_{2} / 70 \% \mathrm{CO}_{2}$

Figure 6.34: Species and temperature profiles along axial length of the bed when the flame front is at $4 \mathrm{~cm}$ from the grate for (a) $40 \% \mathrm{O}_{2} / 60 \% \mathrm{CO}_{2}$ and (b) $50 \%$ $\mathrm{O}_{2} / 50 \% \mathrm{CO}_{2}$ 
Figure 6.35: Predicted temperature profiles at $5 \mathrm{~cm}$ from the bed bottom for wood combustion in four combustion environments.

Figure 6.36: Predicted separate effects of $\mathrm{CO}_{2}$ on burning rates for wood combustion in four combustion environments.

Figure 6.37: Predicted contributions of separate effects of $\mathrm{CO}_{2}$ on burning rates for wood combustion in four combustion environments.

Figure A.1: RR diagram for fuel sample SD1 196

Figure B.1: Temperature data acquisition system. 197

Figure C.1: Heat transfers in a bare-bead thermocouple. 206

Figure C.2: Heat transfers in a single-shielded aspirated thermocouple. 207

Figure D.1: Illustration of a discrete solid angle used for DOM solution. 211

Figure D.2: Discretization of diffusion flux at an interior face.

Figure E.1: Comparison of species concentration profiles along axial length of the bed for different fuel types burning under oxy-fuel condition when reaction front is at $4 \mathrm{~cm}$ from the grate: (a) Tar mole fraction (b) $\mathrm{CO}$ mole fraction.

Figure E.2: Comparison of species concentration profiles along axial length of the bed for different fuel types burning under oxy-fuel condition when reaction front is at $4 \mathrm{~cm}$ from the grate: (a) $\mathrm{CH}_{4}$ mole fraction (b) $\mathrm{H}_{2}$ mole fraction.

Figure E.3: Comparison of species concentration profiles along axial length of the bed for different fuel types burning under oxy-fuel condition when reaction front is at $4 \mathrm{~cm}$ from the grate: (a) $\mathrm{O}_{2}$ mole fraction (b) $\mathrm{H}_{2} \mathrm{O}$ mole fraction 
Figure E.4: Comparison of species concentration profiles along axial length of the bed for different fuel types burning under oxy-fuel condition when reaction front is at $3 \mathrm{~cm}$ from the grate: (a) Tar mole fraction (b) $\mathrm{CO}$ mole fraction.

Figure E.5: Comparison of species concentration profiles along axial length of the bed for different fuel types burning under oxy-fuel condition when reaction front is at $3 \mathrm{~cm}$ from the grate: (a) $\mathrm{CH}_{4}$ mole fraction (b) $\mathrm{H}_{2}$ mole fraction. 222

Figure E.6: Comparison of species concentration profiles along axial length of the bed for different fuel types burning under oxy-fuel condition when reaction front is at $3 \mathrm{~cm}$ from the grate: (a) $\mathrm{O}_{2}$ mole fraction (b) $\mathrm{H}_{2} \mathrm{O}$ mole fraction 223

Figure E.7: Comparison of species concentration profiles along axial length of the bed for different fuel types burning under oxy-fuel condition when reaction front is at $2 \mathrm{~cm}$ from the grate: (a) Tar mole fraction (b) $\mathrm{CO}$ mole fraction.

Figure E.8: Comparison of species concentration profiles along axial length of the bed for different fuel types burning under oxy-fuel condition when reaction front is at $2 \mathrm{~cm}$ from the grate: (a) $\mathrm{CH}_{4}$ mole fraction (b) $\mathrm{H}_{2}$ mole fraction.

Figure E.9: Comparison of species concentration profiles along axial length of the bed for different fuel types burning under oxy-fuel condition when reaction front is at $2 \mathrm{~cm}$ from the grate: (a) $\mathrm{O}_{2}$ mole fraction (b) $\mathrm{H}_{2} \mathrm{O}$ mole fraction 224

Figure E.10: Comparison of species concentration profiles along axial length of the bed for different fuel types burning under oxy-fuel condition when reaction front is at $1 \mathrm{~cm}$ from the grate: (a) Tar mole fraction (b) $\mathrm{CO}$ mole fraction. 225 
Figure E.11: Comparison of species concentration profiles along axial length of the bed for different fuel types burning under oxy-fuel condition when reaction front is at $1 \mathrm{~cm}$ from the grate: (a) $\mathrm{CH}_{4}$ mole fraction (b) $\mathrm{H}_{2}$ mole fraction.

Figure E.12: Comparison of species concentration profiles along axial length of the bed for different fuel types burning under oxy-fuel condition when reaction front is at $1 \mathrm{~cm}$ from the grate: (a) $\mathrm{O}_{2}$ mole fraction (b) $\mathrm{H}_{2} \mathrm{O}$ mole fraction. 226

Figure E.13: Comparison of species concentration profiles along axial length of the bed burning under oxy-fuel condition for different $\mathrm{O}_{2} / \mathrm{CO}_{2}$ mixtures when reaction front is at $4 \mathrm{~cm}$ from the grate: (a) Tar mole fraction (b) $\mathrm{CO}$ mole fraction.

Figure E.14: Comparison of species concentration profiles along axial length of the bed burning under oxy-fuel condition for different $\mathrm{O}_{2} / \mathrm{CO}_{2}$ mixtures when reaction front is at $4 \mathrm{~cm}$ from the grate: (a) $\mathrm{CH}_{4}$ mole fraction (b) $\mathrm{H}_{2}$ mole fraction.

Figure E.15: Comparison of species concentration profiles along axial length of the burning under oxy-fuel condition for different $\mathrm{O}_{2} / \mathrm{CO}_{2}$ mixtures when reaction front is at $4 \mathrm{~cm}$ from the grate: (a) $\mathrm{O}_{2}$ mole fraction (b) $\mathrm{H}_{2} \mathrm{O}$ mole fraction.

Figure E.16: Comparison of species concentration profiles along axial length of the bed burning under oxy-fuel condition for different $\mathrm{O}_{2} / \mathrm{CO}_{2}$ mixtures when reaction front is at $3 \mathrm{~cm}$ from the grate: (a) Tar mole fraction (b) $\mathrm{CO}$ mole fraction. 
Figure E.17: Comparison of species concentration profiles along axial length of the bed burning under oxy-fuel condition for different $\mathrm{O}_{2} / \mathrm{CO}_{2}$ mixtures when reaction front is at $3 \mathrm{~cm}$ from the grate: (a) $\mathrm{CH}_{4}$ mole fraction (b) $\mathrm{H}_{2}$ mole fraction.

Figure E.18: Comparison of species concentration profiles along axial length of the bed burning under oxy-fuel condition for different $\mathrm{O}_{2} / \mathrm{CO}_{2}$ mixtures when reaction front is at $3 \mathrm{~cm}$ from the grate: (a) $\mathrm{O}_{2}$ mole fraction (b) $\mathrm{H}_{2} \mathrm{O}$ mole fraction.

Figure E.19: Comparison of species concentration profiles along axial length of the bed burning under oxy-fuel condition for different $\mathrm{O}_{2} / \mathrm{CO}_{2}$ mixtures when reaction front is at $2 \mathrm{~cm}$ from the grate: (a) Tar mole fraction (b) $\mathrm{CO}$ mole fraction

Figure E.20: Comparison of species concentration profiles along axial length of the bed burning under oxy-fuel condition for different $\mathrm{O}_{2} / \mathrm{CO}_{2}$ mixtures when reaction front is at $2 \mathrm{~cm}$ from the grate: (a) $\mathrm{CH}_{4}$ mole fraction (b) $\mathrm{H}_{2}$ mole fraction

Figure E.21: Comparison of species concentration profiles along axial length of the bed burning under oxy-fuel condition for different $\mathrm{O}_{2} / \mathrm{CO}_{2}$ mixtures when reaction front is at $2 \mathrm{~cm}$ from the grate: (a) $\mathrm{O}_{2}$ mole fraction (b) $\mathrm{H}_{2} \mathrm{O}$ mole fraction.

Figure E.22: Comparison of species concentration profiles along axial length of the bed burning under oxy-fuel condition for different $\mathrm{O}_{2} / \mathrm{CO}_{2}$ mixtures when 
reaction front is at $1 \mathrm{~cm}$ from the grate: (a) Tar mole fraction (b) $\mathrm{CO}$ mole fraction.

Figure E.23: Comparison of species concentration profiles along axial length of the bed burning under oxy-fuel condition for different $\mathrm{O}_{2} / \mathrm{CO}_{2}$ mixtures when reaction front is at $1 \mathrm{~cm}$ from the grate: (a) $\mathrm{CH}_{4}$ mole fraction (b) $\mathrm{H}_{2}$ mole fraction.

Figure E.24: Comparison of species concentration profiles along axial length of the bed burning under oxy-fuel condition for different $\mathrm{O}_{2} / \mathrm{CO}_{2}$ mixtures when reaction front is at $1 \mathrm{~cm}$ from the grate: (a) $\mathrm{O}_{2}$ mole fraction (b) $\mathrm{H}_{2} \mathrm{O}$ mole fraction. 


\section{ABBREVIATION}

\begin{tabular}{ll} 
AMG & Algebraic Multi-Grid \\
ASU & Air Separation Unit \\
CCS & Carbon Capture and Storage \\
CFD & Computational Fluid Dynamics \\
CPU & Carbon Dioxide Purification Unit \\
DEM & Discrete Element Method \\
DNS & Direct Numerical Simulation \\
DOM & Discrete Ordinate Method \\
ESP & Electrostatic Precipitation \\
FGD & Flue Gas Desulphurization \\
FGR & Flue Gas Recycle system \\
LES & Large Eddy Simulation \\
PAHs & Polyaromatic Hydrocarbons \\
RANS & Reynold-Averaged Naviers Stoke \\
RTE & Radiative Transfer Equation \\
SD1 & Eucalyptus sawdust with characteristic particle size diameter of 1.28 mm \\
SD2 & Eucalyptus sawdust with characteristic particle size diameter of 2.91 mm \\
SCR & Selective Catalytic Reduction \\
SGS & Subgrid Scales \\
SIMPLE & Semi-Implicit Method for Pressure-Linked Equations \\
TC & Thermocouple \\
WC & Wood Chips \\
\hline
\end{tabular}


WS

WSGGM
Wood Spheres

Weight-Sum-of-Gray-Gas-Model 


\section{NOMECLATURE}

The notations used in this thesis are grouped into Roman letters, Greek symbols, superscripts, subscripts, dimensionless parameters and operators.

\section{Roman Letters}

$A$

$A_{b}$

$A_{f}$

$A_{o}$

$A_{p}$

$A_{s}$

$a_{\kappa}$

$C_{1}$

$C_{2}$

$C_{g}$

$C_{\text {olg }}$

$C_{p i}$

$C_{\varepsilon 1}$

$C_{\varepsilon 2}$

$C_{\varepsilon 3}$

$C_{\mu}$

$c_{p}$

D

$D_{b}$
Arrhenius pre-exponential factor $\left[\mathrm{s}^{-1}\left(\mathrm{~mol} / \mathrm{m}^{3}\right)\right]$

Thermocouple bead surface area $\left[\mathrm{m}^{2}\right]$

Flame surface area $\left[\mathrm{m}^{2}\right]$

Thermocouple outermost shield surface area $\left[\mathrm{m}^{2}\right]$

Char surface area $\left[\mathrm{m}^{2}\right]$

Particle surface area $\left[\mathrm{m}^{2}\right]$

Weight factor [-]

Permeability $\left[\mathrm{m}^{2}\right]$

Inertia loss coefficient $\left[\mathrm{m}^{-1}\right]$

Overall gas concentration $\left[\mathrm{mol} \mathrm{m} \mathrm{m}^{-3}\right]$

Oxidizer concentration $\left[\mathrm{mol} \mathrm{m}^{-3}\right]$

Molar heat capacity of species $\left.i\left[\mathrm{~J} \mathrm{~mol}^{-1} \mathrm{~K}^{-1}\right]\right]$

$k-\varepsilon$ model coefficient (take as 1.44) [-]

$k-\varepsilon$ model coefficient (take as 1.92) [-]

$k-\varepsilon$ model coefficient (take as 1 for $\mathrm{Gb} \geq 1$ and 0 for $\mathrm{Gb}<0$ ) $[-]$

$k-\varepsilon$ model coefficient (take as 0.9) [-]

Specific heat capacity $\left[\mathrm{J} \mathrm{kg}^{-1} \mathrm{~K}^{-1}\right.$ ]

Diffusivity $\left[\mathrm{m}^{2} \mathrm{~s}^{-1}\right]$

Thermocouple bead diameter [m] 
Deq Diameter of the particle which is equal to that of volume-equivalent sphere $[\mathrm{m}]$
$D_{i j} \quad$ Binary diffusion coefficient for species $i$ and $j\left[\mathrm{~m}^{2} \mathrm{~s}^{-1}\right]$
$D_{T, i} \quad$ Thermal diffusion coefficient for species $i\left[\mathrm{~kg} \mathrm{~m}^{-1} \mathrm{~s}^{-1}\right]$
$\mathrm{d} \quad$ Mesh size of the sieve [m]
$\bar{d} \quad$ Characteristics size $[\mathrm{m}]$
$d_{p} \quad$ Particle diameter $[\mathrm{m}]$
$E \quad$ Activation energy $\left[\mathrm{J} \mathrm{mol}^{-1}\right]$
$G \quad$ Incident radiative heat flux $\left[\mathrm{W} \mathrm{m}^{-2}\right]$
$G_{b} \quad$ Production of turbulent kinetic energy, $k$ due to buoyancy $\left[\mathrm{m}^{2} \mathrm{~s}^{-3}\right]$
$G_{k} \quad$ Production of turbulent kinetic energy, $k$ due to Reynolds Stresses $\left[\mathrm{m}^{2} \mathrm{~s}^{-3}\right]$
g Gravity $\left[\mathrm{m} \mathrm{s}^{-2}\right]$
$H \quad$ Molar enthalpy $\left[\mathrm{J} \mathrm{mol}^{-1}\right]$
$H_{i} \quad$ Enthalpy of formation of species $i\left[\mathrm{~J} \mathrm{~kg}^{-1}\right]$

$h_{a b} \quad$ Heat transfer coefficient between aspirating gas flow and bare thermocouple bead $\left[\mathrm{W} \mathrm{m}^{-2} \mathrm{~K}^{-1}\right]$

$h_{\text {as }} \quad$ Heat transfer coefficient between aspirating gas flow and thermocouple shield $\left[\mathrm{W} \mathrm{m}{ }^{-2} \mathrm{~K}^{-1}\right]$

$h_{b g} \quad$ Heat transfer coefficient between external gas flow and bare thermocouple bead $\left[\mathrm{W} \mathrm{m}^{-2} \mathrm{~K}^{-1}\right]$

$h_{g s} \quad$ Heat transfer coefficient between external gas flow and thermocouple shield $\left[\mathrm{W} \mathrm{m}^{-2} \mathrm{~K}^{-1}\right]$

$h_{c} \quad$ Heat transfer coefficient $\left[\mathrm{W} \mathrm{m}^{-2} \mathrm{~K}^{-1}\right]$ 


\begin{tabular}{|c|c|}
\hline$h$ & Enthalpy $\left[\mathrm{J} \mathrm{kg}^{-1}\right]$ \\
\hline$I_{b \lambda}$ & Black body intensity at wavelength $\lambda\left[\mathrm{W} \mathrm{m}^{-1} \mathrm{sr}^{-1}\right]$ \\
\hline$I_{\lambda}$ & Radiative intensity at wavelength $\lambda\left[\mathrm{W} \mathrm{m}^{-1} \mathrm{sr}^{-1}\right]$ \\
\hline$J$ & Diffusion mass flux $\left[\mathrm{kg} \mathrm{m}^{-2} \mathrm{~s}^{-1}\right]$ \\
\hline$K$ & Total number of gray gases [-] \\
\hline$K_{i}$ & Rate constant for $i^{\text {th }}$ reaction $\left[\mathrm{s}^{-1}\left(\mathrm{~mol} / \mathrm{m}^{3}\right)\right]$ \\
\hline$K_{p l}$ & Rate constant for heterogeneous reaction $\left[\mathrm{s}^{-1}\left(\mathrm{~mol} / \mathrm{m}^{3}\right)\right]$ \\
\hline$k$ & Turbulent kinetic energy $\left[\mathrm{J} \mathrm{kg}^{-1} \mathrm{~s}^{-1}\right]$ \\
\hline$k_{a \lambda}$ & Absorption coefficient at wavelength $\lambda\left[\mathrm{m}^{-1}\right]$ \\
\hline$k_{c p l}$ & Mass transfer coefficient $[-]$ \\
\hline$k_{p a \lambda}$ & Particle absorption coefficient at wavelength $\lambda\left[\mathrm{m}^{-1}\right]$ \\
\hline$k_{p s \lambda}$ & Particle scattering coefficient at wavelength $\lambda\left[\mathrm{m}^{-1}\right]$ \\
\hline$k_{s \lambda}$ & Scattering coefficient at wavelength $\lambda\left[\mathrm{m}^{-1}\right]$ \\
\hline$\dot{m}_{b}$ & Biomass burning rate $\left[\mathrm{kg} \mathrm{m}^{-2} \mathrm{~s}^{-1}\right]$ \\
\hline$\dot{m}_{i}$ & Biomass ignition rate $\left[\mathrm{kg} \mathrm{m}^{-2} \mathrm{~s}^{-1}\right]$ \\
\hline$\dot{m}_{m}$ & Mixture mass flow rate $\left[\mathrm{kg} \mathrm{s}^{-1}\right]$ \\
\hline$m_{p}$ & Particle mass $[\mathrm{kg}]$ \\
\hline$N_{g}$ & Number of gas species [-] \\
\hline$n$ & Number of ordinates $[-]$ \\
\hline$n_{R}$ & The parameter of Rosin-Rammler distribution [-] \\
\hline$p$ & Pressure $[\mathrm{Pa}]$ \\
\hline$Q$ & Volumetric flow rate $\left[\mathrm{m}^{3} \mathrm{~s}^{-1}\right]$ \\
\hline$Q_{a, p}$ & Particle absorption coefficient [-] \\
\hline
\end{tabular}




\begin{tabular}{|c|c|}
\hline$q_{R}$ & Radiative heat flux $\left[\mathrm{W} \mathrm{m} \mathrm{m}^{-2}\right]$ \\
\hline$q_{P R}$ & Radiative heat flux for particle $\left[\mathrm{W} \mathrm{m}^{-2}\right]$ \\
\hline$R$ & Specific gas constant $\left[\mathrm{J} \mathrm{kg}^{-1} \mathrm{~K}^{-1}\right]$ \\
\hline$R_{R}$ & Percentage of accumulated oversized mass (\%) \\
\hline$R_{u}$ & Universal gas constant $\left[\mathrm{J} \mathrm{mol}^{-1} \mathrm{~K}^{-1}\right]$ \\
\hline$r_{b}$ & Total reaction rate for biomass particle $\left[\mathrm{kg} \mathrm{s}^{-1}\right]$ \\
\hline$r_{c}$ & Overall combined char reaction rate $\left[\mathrm{kg} \mathrm{s}^{-1}\right]$ \\
\hline$r_{p}$ & Particle radius $[\mathrm{m}]$ \\
\hline$S_{E}$ & Energy source term $\left[\mathrm{J} \mathrm{m}^{-3} \mathrm{~s}^{-1}\right]$ \\
\hline$S_{i}$ & Molar entropy of species $i\left[\mathrm{~J} \mathrm{~mol}^{-1} \mathrm{~K}^{-1}\right]$ \\
\hline$S_{m}$ & Momentum source term $\left[\mathrm{kg} \mathrm{m}^{-2} \mathrm{~s}^{-2}\right]$ \\
\hline$s$ & Distance in $\Omega$ direction $[\mathrm{m}]$ \\
\hline$s_{i}$ & Specific entropy of species $i\left[\mathrm{~J} \mathrm{~kg}^{-1} \mathrm{~K}^{-1}\right]$ \\
\hline$T$ & Temperature $[\mathrm{K}]$ \\
\hline$T_{b}$ & Thermocouple bead temperature $[\mathrm{K}]$ \\
\hline$T_{D}$ & Display temperature $[\mathrm{K}]$ \\
\hline$T_{M}$ & Temperature at measuring point $[\mathrm{K}]$ \\
\hline$T_{o}$ & Temperature of thermocouple outermost shield $[\mathrm{K}]$ \\
\hline$T_{\infty}$ & Average effective temperature of surrounding $[\mathrm{K}]$ \\
\hline$t$ & Time $[s]$ \\
\hline$V_{F}$ & Flame front propagation speed $\left[\mathrm{m} \mathrm{s}^{-1}\right]$ \\
\hline$V_{p}$ & Particle volume $\left[\mathrm{m}^{3}\right]$ \\
\hline$v$ & Velocity $\left[\mathrm{m} \mathrm{s}^{-1}\right]$ \\
\hline
\end{tabular}




\begin{tabular}{|c|c|}
\hline $\bar{v}_{l}$ & Mean velocity component $\left[\mathrm{m} \mathrm{s}^{-1}\right]$ \\
\hline$v^{\prime}$ & Fluctuating velocity component $\left[\mathrm{m} \mathrm{s}^{-1}\right]$ \\
\hline$W_{g}$ & Molecular weight for gas $\left[\mathrm{kg} \mathrm{mol}^{-1}\right]$ \\
\hline$W_{h p}$ & Molecular weight for char $\left[\mathrm{kg} \mathrm{mol}^{-1}\right]$ \\
\hline$W_{i}$ & Molecular weight of species $i\left[\mathrm{~kg} \mathrm{~mol}^{-1}\right]$ \\
\hline$w_{i}$ & Rate of production of species $i\left[\mathrm{~kg} \mathrm{~m}^{-3} \mathrm{~s}^{-1}\right]$ \\
\hline$w_{j}$ & Quadrature weight [-] \\
\hline$X$ & Mole fraction [-] \\
\hline$x_{i}$ & Coordinate in $i$-direction $[\mathrm{m}]$ \\
\hline$x_{j}$ & Coordinate in $j$-direction $[\mathrm{m}]$ \\
\hline$Y$ & Mass fraction [-] \\
\hline & Greek Symbols \\
\hline$\alpha$ & Exponent factor [-] \\
\hline$\alpha_{t}$ & Total absorptivity of gray gas medium [-] \\
\hline$\beta$ & Thermal expansion coefficient [-] \\
\hline$\beta_{\lambda}$ & Extinction coefficient [-] \\
\hline$\delta_{i j}$ & Kronecker delta [-] \\
\hline$\epsilon$ & Emissivity [-] \\
\hline$\epsilon_{b}$ & Thermocouple bead emissivity [-] \\
\hline$\epsilon_{i}$ & Lennard-Jones potential well depth \\
\hline$\epsilon_{o}$ & Thermocouple outermost shield emissivity [-] \\
\hline$\varepsilon$ & Turbulent dissipation rate $\left[\mathrm{J} \mathrm{kg}^{-1} \mathrm{~s}^{-1}\right]$ \\
\hline$\zeta_{p l}$ & Particle pore area coefficient [-] \\
\hline
\end{tabular}




\begin{tabular}{|c|c|}
\hline$\theta$ & Particle porosity [-] \\
\hline$\kappa$ & Total gray gas absorption coefficient [-] \\
\hline$\kappa_{\kappa}$ & Absorption coefficient of each gray gas [-] \\
\hline$\lambda$ & Wavelength [m] \\
\hline$\lambda_{g}$ & Thermal conductivity for gas-phase $\left[\mathrm{W} \mathrm{m}{ }^{-1} \mathrm{~K}^{-1}\right]$ \\
\hline$\lambda_{s}$ & Thermal conductivity for solid-phase $\left[\mathrm{W} \mathrm{m} \mathrm{m}^{-1} \mathrm{~K}^{-1}\right]$ \\
\hline$\mu$ & Dynamic viscosity $\left[\mathrm{kg} \mathrm{m}^{-1} \mathrm{~s}^{-1}\right]$ \\
\hline$\mu_{t}$ & Turbulent viscosity $\left[\mathrm{kg} \mathrm{m}^{-1} \mathrm{~s}^{-1}\right]$ \\
\hline$\rho$ & Density $\left[\mathrm{kg} \mathrm{m}^{-3}\right]$ \\
\hline$\rho_{b}$ & Bulk density $\left[\mathrm{kg} \mathrm{m}^{-3}\right]$ \\
\hline$\sigma$ & Stefan-Boltzmann constant $\left[\mathrm{W} \mathrm{m}{ }^{-2} \mathrm{~K}^{-4}\right]$ \\
\hline$\tau$ & Shear stress tensor $[\mathrm{Pa}]$ \\
\hline $\bar{\tau}_{i j}$ & Mean shear stress tensor $[\mathrm{Pa}]$ \\
\hline$\chi$ & Region or bed porosity [-] \\
\hline$\psi$ & Sphericity [-] \\
\hline$\Omega$ & Solid angle $[\mathrm{sr}]$ \\
\hline & Subscripts \\
\hline 0 & Initial state of the particle \\
\hline$a$ & Air-fuel conditions \\
\hline$e$ & Effective \\
\hline$f$ & Flame \\
\hline$g$ & Gas \\
\hline$i, g$ & Gaseous species $i$ \\
\hline
\end{tabular}




$\begin{array}{ll}i, s & \text { Solid-phase species } i \\ o x & \text { Oxy-fuel conditions } \\ p & \text { Particle } \\ s & \text { Solid }\end{array}$

\section{Superscripts}

Heterogeneous reaction

\section{Dimensionless Parameters}

$B i$

Biot number $\left(B i=h_{c} d_{p} / \lambda_{s}\right)$

$N u$

Nusselt number $\left(N u=h_{c} d_{p} / \lambda_{g}\right)$

$\operatorname{Pr}$

Prandtl number $\left(\operatorname{Pr}=\mu c_{p} / \lambda_{g}\right)$

$\operatorname{Pr}_{t}$

Turbulent Prandtl number $\left.\left(P r_{t}=\mu_{t} c_{p} / \lambda_{g}\right)\right)$

$\operatorname{Re}$

Reynold number $(R e=\rho v L / \mu)$

\section{Operators}

$\nabla$

$\nabla \cdot$
Gradient operator

Divergence operator 


\begin{abstract}
Biomass fuel is the major source of energy for a significant proportion of the world population. Conventionally, biomass is burned in combustors that use air as oxidizer. The need for efficiency and reduced emissions has led to development of clean combustion technologies such as oxy-fuel combustion. In oxy-fuel combustion technique, fuel is burnt in $\mathrm{O}_{2} / \mathrm{CO}_{2}$ environment instead of $\mathrm{O}_{2} / \mathrm{N}_{2}$ environment. In spite of biomass being used under oxy-fuel conditions using fixed bed furnaces, there is no detailed study of biomass combustion in fixed bed reactors under oxy-fuel condition. The studies only cover combustion under air-fuel condition. There is no report in the literature on important combustion parameters, viz., flame propagation speed, temperature profiles, ignition time, and species evolution in the fixed bed combustion under oxy-fuel conditions; the studies have been only in air. This work extends the research on biomass conversion to combustion under oxy-fuel conditions. To address these knowledge gaps, this $\mathrm{PhD}$ thesis focused on establishing and isolating the role of various $\mathrm{CO}_{2}$ effects on biomass combustion properties using a laboratory fixed bed reactor through experiments and numerical modeling. The fixed bed reactor used in this study was operated in counter-current flame propagation mode. Oxidizer was a mixture of pure $\mathrm{O}_{2}$ and $\mathrm{N}_{2}$ or $\mathrm{CO}_{2}$. Measurement were made for airfuel condition, oxy-fuel condition of different $\mathrm{O}_{2} / \mathrm{CO}_{2}$ mixtures and various initial bed porosity. In this work, all numerical simulations were carried out using a commercial CFD software CD-Adapco (STAR $\mathrm{CCM}+$ version 11.04). Euler-Lagrange (CFD-DEM) approach was used to model biomass conversion in a packed bed. Solid particles and their conversion were modeled using DEM while fluid phase was modeled as a continuous phase using CFD. Biomass conversion was modeled by four sub-models, namely, drying, pyrolysis, gas-phase reactions and char oxidation models. These models were adopted and improved from previous research on wood combustion. To account for oxy-fuel combustion environment, reaction involving $\mathrm{CO}_{2}$ which has been identified as the dominant reaction pathway as well as its associated chain-branching reactions were incorporated in homogeneous reaction sub-model. In order to separate effects of $\mathrm{CO}_{2}$ on wood combustion, four different mixtures of $\mathrm{O}_{2}$ and $\mathrm{Ar} / \mathrm{CO}_{2} / \mathrm{N}_{2}$ were designed and simulated. Temperature in $\mathrm{O}_{2} / \mathrm{CO}_{2}$ combustion environment was adjusted to be equal to that of $\mathrm{O}_{2} / \mathrm{N}_{2}$ environment by adding an appropriate amount of $\mathrm{Ar}$ while $\mathrm{O}_{2}$ amount remained the same. The results showed that flame front propagation speed in oxy-fuel atmosphere reduced to $78 \%$ of that of the air-fuel condition with similar $\mathrm{O}_{2}$ concentration. The CFD-DEM model agreed very well with experimental values for mass loss, propagation speed and flame front positions. However, peak temperatures were poorly predicted at lower oxygen concentrations. The accuracy of temperature prediction improved at higher oxygen concentrations. It was noted that oxy-fuel peak temperature is lower than air-fuel temperature by about $200 \mathrm{~K}$. For oxy-fuel combustion, peak temperature value and propagation speed increases as $\mathrm{O}_{2}$ concentration is increased. The results showed that at any given oxygen concentration, ignition time in oxy-fuel environment is almost twice that of corresponding airfuel condition. It was established that the packing density affects combustion process by changing the burning conditions and limits. Furthermore, the study revealed that there is an optimum packing density, $\chi=0.71$, beyond which the efficiency falls due to the onset of quenching in the spaces. It was concluded that dilution effect is the most influential parameter on the burning rate of wood combustion in an oxyfuel system. In a future study, the model prediction could be improved by including ash inhibition submodel and using a full chemical kinetic mechanism for hydro-carbon combustion. It was also recommended that a detail analysis of heat transfer in the bed could be investigated in a future study. The findings from this work are important and may be useful when designing burners which operate under oxy-fuel combustion conditions.
\end{abstract}




\section{CHAPTER ONE \\ INTRODUCTION}

\subsection{Background of Study}

Biomass fuel is the major source of energy for a significant proportion of the world population. Conventionally, biomass is burned in combustors that use air as oxidizer. The need for efficiency and reduced emissions has led to development of clean combustion technologies such as oxy-fuel combustion. In oxy-fuel combustion technique, fuel is burnt in $\mathrm{O}_{2} / \mathrm{CO}_{2}$ environment instead of $\mathrm{O}_{2} / \mathrm{N}_{2}$ environment. This is a clean energy technology where $\mathrm{CO}_{2}$ is captured through recycling of flue gas and at the same time nitrogen oxides $\left(\mathrm{NO}_{\mathrm{x}}\right)$ emissions are reduced. Even though oxy-fuel combustion of biomass is a clean combustion technology, it has been established that it reduces flame temperature (Pohlmann, Osório, Vilela, Diez, \& Borrego, 2017), increases ignition delay time (Shan et al., 2017) and reduces combustion rate (Riaza et al., 2014).

Oxy-fuel combustion of coal has been extensively studied (Maffei et al., 2013; Zhou et al. 2016). This is because coal still contributes to a large share of the world total electricity production as per International Energy Agency Report (2016). However, coal has significant impact on environmental pollution. In order to reduce this impact, coal demand in high income economies like United States and European Union is expected to decrease by $40 \%$ and $60 \%$, respectively, by 2040. On the other hand, biomass is an attractive energy source as compared to coal because it is clean and affordable. In fact, most of the energy scenarios for the future indicates that it will increasingly be used to meet energy demand.

Combustion of coal and biomass in oxy-fuel environment have been investigated in previous studies. The studies range from laboratory research to tests in actual power plants. The tests 
have been carried out in pilot scale, industrial scale and full scale power plant (Scheffknecht, Al-Makhadmeh, Schnell, \& Maier, 2011). Large scale oxy-fuel coal power plant, which ranges between 30 and $300 \mathrm{MW}_{\text {th }}$ have been established and installed worldwide (Scheffknecht et al., 2011). Most of these power plants are coal-fired. Biomass-fired and co-fired power plants also exist in various parts of the world (Domenichini, Gasparini, Cotone, \& Santos, 2011; Jiménez \& Ballester, 2005). In addition, biomass-fired boilers are used for steam generation for use in process industries such as tea production. In Kenya, for example, most of tea industries use wood-fired boilers.

The studies on fundamental combustion phenomena occurring in oxy-fuel combustion such as transport, chemistry and thermodynamics processes are based on models and experiments on laboratory-scale devices. Such small-scale devices have been used previously by other researchers to study combustion in oxy-fuel environment; ignition delay time in coal (Shaddix \& Molina, 2009), burnout, ignition temperature and $\mathrm{NO}_{\mathrm{x}}$ generation in biomass/coal blends (Riaza et al., 2012) and gaseous emissions from biomass/coal co-firing (Álvarez et al., 2014). Such devices provide insights into combustion phenomena in practical oxy-fuel environment (Riaza et al., 2012; Álvarez et al., 2014). The presence of $\mathrm{CO}_{2}$ in oxidizer alters gas properties such as density, heat capacity, diffusivity and gas emissivity with consequences on fuel reactivity, flame temperature and emissions. Unlike inert species such as argon and nitrogen which have thermal and dilution effects on combustion processes, addition of reactive species such as $\mathrm{CO}_{2}$ results in chemical effect in addition to the first two effects. The dilution effect is the reduction of concentration of reactive species $\mathrm{O}_{2}$ due to addition of $\mathrm{CO}_{2}$ while thermal effect is the reduction of flame temperature due to addition of $\mathrm{CO}_{2}$. On the other hand, chemical effect is the direct active participation through chemical reaction. The chemical effect is associated 
with the dominant reaction pathway and important chain branching step in hydrocarbon combustion in which $\mathrm{CO}_{2}$ plays an active role. These are, according to Liu et al. (2001), reaction Eqs (1.1) and (1.2) below.

$$
\begin{gathered}
\mathrm{CO}+\mathrm{OH} \leftrightarrow \mathrm{CO}_{2}+\mathrm{H} \\
\mathrm{H}+\mathrm{O}_{2} \leftrightarrow \mathrm{O}+\mathrm{OH}
\end{gathered}
$$

The three roles played by $\mathrm{CO}_{2}$ addition can be separated by adjusting the flame temperature to a value corresponding to a reference condition without change in oxidizer and fuel concentration (Al-Qurashi, Lueking, \& Boehman, 2011; Du, Axelbaum, \& Law, 1991). Figure 1.1 shows the various effects of $\mathrm{CO}_{2}$ addition on specific oxidation rates of ethylene soot flame (Al-Qurashi et al., 2011). This technique has been applied to study the effect of $\mathrm{CO}_{2}$ on soot formation but it can also be applied on other combustion properties (Zhou et al., 2016).

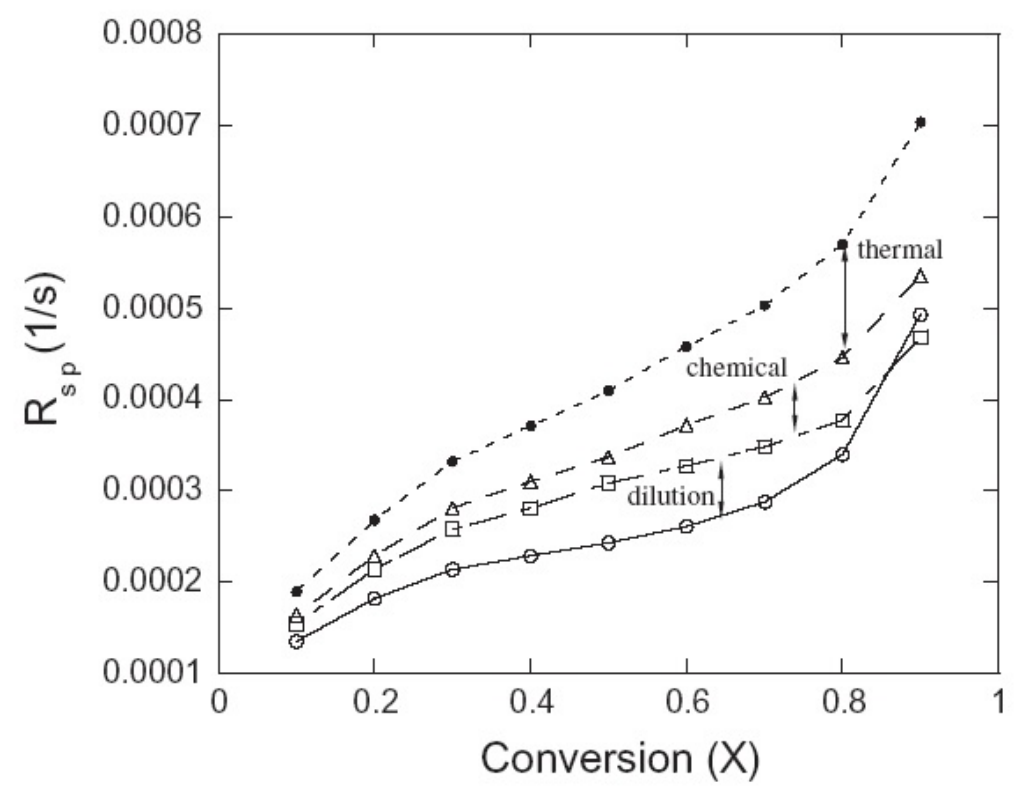

Figure 1.1: The isolated thermal, dilution, and chemical effects of $\mathrm{CO}_{2}$ on the specific oxidation rate $\left(\mathrm{R}_{\mathrm{sp}}\right)$ of the ethylene flame soot (Al-Qurashi et al., 2011). 
Biomass conversion to energy entails several processes, viz., drying, devolatilization/ pyrolysis, gas-phase reactions of volatile and heterogeneous reaction of char. The processes are coupled and occur simultaneously when biomass is burning. The overall kinetic model of biomass combustion constitutes these four processes.

Biomass contain a certain amount of water content that need to be dried before combustion. Water in biomass exists in two forms: free water and bound water. Fibre saturation point is the criterion for distinguishing the two forms of water. There are three major ways of modeling drying: the first is thermal method where drying begins when fuel reaches a predefined temperature which is usually the prevailing boiling point, the second is use of algebraic expression for temperature as function of moisture content (evaporation temperature is not constant) and, the third is treating drying process as additional chemical reaction (first-order kinetic rate model). The third is the most common method where water and vaporization scheme is added to the overall kinetic scheme.

During combustion, dry wood decomposes into primary components char, tar and gas through pyrolysis or devolatilization processes. Devolatilization is the release of volatile matter by thermal decomposition under oxidizing atmosphere. On the other hand, if this process occurs in inert atmosphere, then it is referred to as pyrolysis. In both processes, $\mathrm{CO}_{2}, \mathrm{H}_{2} \mathrm{O}, \mathrm{CO}, \mathrm{H}_{2}$, light hydrocarbon in gaseous form and heavy hydrocarbons in liquid form are released from biomass fuel. The kinetics of dry wood conversion into tar, char and gas have been developed and applied in Computational Fluid Dynamics (CFD) models (Di Blasi, 2000; Mahmoudi, Hoffmann, Markovic, Peters, \& Brem, 2016). Tar may undergo secondary cracking reaction to release $\mathrm{CO}, \mathrm{CO}_{2}, \mathrm{H}_{2}, \mathrm{CH}_{4}$ and inert tar (Mahmoudi, Markovic, Peters, \& Brem, 2015). Gas species considered in homogenous gas-phase reactions are those generated from drying, 
devolatilization, tar cracking and char heterogeneous reactions. Char consumption is through heterogeneous reactions. These reactions represent char oxidation and gasification by $\mathrm{CO}_{2}$ and $\mathrm{H}_{2} \mathrm{O}$.

Several research studies have been geared toward understanding oxy-fuel combustion in biomass fuel. Shan et al. (2017) investigated the effects of $\mathrm{CO}_{2}$ environment on ignition and combustion characteristics of single biomass pellets. The authors found out that $\mathrm{CO}_{2}$ environment increased ignition delay time. A similar behaviour has been observed for oxy-coal combustion (Molina \& Shaddix, 2007). This was attributed to a decrease in particle surface heating rate due to decreased co-flow temperature associated with the higher specific heat capacity of $\mathrm{CO}_{2}$ than $\mathrm{N}_{2}$ and low oxygen diffusion rate in $\mathrm{CO}_{2}$. According to Molina \& Shaddix (2007), other possible reasons for increased ignition delay time are radical formation suppression by $\mathrm{CO}_{2}$ chemical effects and thermal decomposition of $\mathrm{CO}_{2}$. It has been observed that internal ignition temperature of the pellet decreased with increased $\mathrm{O}_{2}$ concentration (Shan et al., 2017). However, they concluded that oxidation temperature effects on internal ignition temperature were more than oxygen concentration effects. In addition, volatile combustion time was increased (Riaza et al., 2014; Shan et al., 2017), while combustion temperature was reduced (Riaza et al., 2014) when $\mathrm{N}_{2}$ was replaced with $\mathrm{CO}_{2}$ with $21 \% \mathrm{O}_{2}$ by volume. Riaza et al. (2014) reported that the intensity of combustion of a single biomass particle was reduced in $\mathrm{CO}_{2}$ environment with $21 \% \mathrm{O}_{2}$ by volume. As $\mathrm{O}_{2}$ was increased to $28-35 \%$, combustion intensity attained a value similar to that of air.

Oxy-fuel combustion of biomass co-firing with coal has also been studied (Álvarez et al., 2014; Farrow, Sun, \& Snape, 2013; Yuzbasi \& Selçuk, 2011). Co-firing of biomass with coal has been preferred because it reduces $\mathrm{CO}_{2}, \mathrm{NO}_{\mathrm{x}}$ and $\mathrm{SO}_{\mathrm{x}}$ emission as compared to pure coal plant. 
In addition, alkali metals present in biomass fuel provides catalytic effects on oxidation and gasification reactions (Farrow et al., 2013). Indeed, the catalytic effect has been found to be more pronounced under oxy-fuel combustion conditions. In addition, Irfan et al. (2012) observed that there were improved ignition properties for coal/biomass blends in both oxy-fuel and air conditions. However, Gil et al. (2012a) work on kinetics and thermal reactivity of coal/biomass char blends in oxy-fuel combustion conditions did not show much effects of biomass.

Oxy-fuel combustion of pulverized biomass was studied by Pohlmann et al. (2016). They reported on the effects of $\mathrm{O}_{2} / \mathrm{CO}_{2}$ and $\mathrm{O}_{2} / \mathrm{N}_{2}$ environment on char reactivity and burnout of pulverized torrefied and carbonized biomass burned in a drop tube furnace. They found out that $\mathrm{CO}_{2}$ environment increased the burnout of biomass fuel. In addition, char surface area was increased. Char particles from $\mathrm{CO}_{2}$ devolatilization environment are small in size and have low reactivity (Gil, Riaza, Álvarez, Pevida, \& Rubiera, 2015; Hanaoka, Sakanishi, \& Okumura, 2012). Improved char burnout in $\mathrm{CO}_{2}$ has been attributed to contribution from $\mathrm{CO}_{2}$ gasification (Gubba et al., 2011; Pohlmann et al., 2016; Wang et al., 2014). Even though the burnout time is high, the release of volatile matter is low under fast heating conditions in drop tube furnace operated under oxy-fuel environment (Heuer et al., 2016; Pohlmann et al., 2016). For entrained flow reactor, Gil et al. (2015) observed a high apparent volatile yield during devolatilization of biomass under $\mathrm{CO}_{2}$ environment.

Flame propagation rate in biomass fixed bed gasifiers has been investigated under different operating conditions (Dasappa \& Paul, 2001; Ryu et al., 2006; Sakthivadivel \& Iniyan, 2018; Yang et al., 2005) although not in oxy-fuel environment. It is affected by various factors such as biomass fuel type, density, size, ultimate and proximate analysis and superficial velocity. 
Based on superficial velocity, operation regimes have been classified either as two-regime (Fatehi \& Kaviany, 1994) or three-regime (Porteiro et al., 2010). In the two-regime classification, propagation speed increases in the fuel rich regime and decreases in the fuel lean regime. On the other hand, three-regime classification has fuel rich regime, fuel lean regime and convective cooling regime where propagation speed increases rapidly, gradually and decreases rapidly, respectively. Furthermore, the role of ash in flame propagation speed has been assessed (Varunkumar, 2012). Ash affects radiative heat transfer to the unburnt biomass, hence affecting the flame propagation. Although numerous works on flame propagation rate of biomass combustion in fixed bed have been done, none addresses an oxy-fuel environment.

Even though several contributions have been made on oxy-fuel combustion of biomass, the mechanisms through which $\mathrm{CO}_{2}$ environment affects fundamental combustion phenomena such as flame propagation speed, burning rates, particulate matter characteristics and gas emissions have not been fully resolved. To address this knowledge gap, this work intends to establish and isolate the role of various $\mathrm{CO}_{2}$ effects on wood combustion properties.

\subsection{Problem Statement}

Oxy-fuel combustion is a clean energy combustion technology that involves burning of fuels in $\mathrm{O}_{2} / \mathrm{CO}_{2}$ environment instead of $\mathrm{O}_{2} / \mathrm{N}_{2}$ environment. However, it has been established that oxyfuel combustion of biomass reduces flame temperature, increases ignition delay time and reduces combustion rate. Furthermore, under oxy-fuel combustion environment, other flame parameters are negatively affected by the quenching effects of $\mathrm{CO}_{2}$. If oxy-fuel combustion environment is not properly designed with regards to flame parameters and the operating conditions, the quenching effects of $\mathrm{CO}_{2}$ cause a decrease in overall efficiency. In spite of biomass being used under oxy-fuel conditions using fixed bed furnaces, there is no detailed 
study of biomass combustion in fixed bed reactors under oxy-fuel condition. The studies only cover combustion under air-fuel condition. There is no report in the literature on important combustion parameters, viz., flame propagation speed, temperature profiles, ignition time, and species evolution in the fixed bed combustion under oxy-fuel conditions; the studies have been only in air. This work extends the research on biomass conversion to combustion under oxyfuel conditions. Appropriate chemical kinetic model that takes into account the presence of $\mathrm{CO}_{2}$ in oxy-fuel combustion of biomass does not exist. In addition, the influence of particle packing density on combustion properties of oxy-fuel combustion of biomass have not been done. Furthermore, the roles and mechanisms through which $\mathrm{CO}_{2}$ environment affects important combustion parameters have not been fully resolved.

\subsection{Objectives}

\subsubsection{Main Objective}

The main objective of this study was to establish and isolate roles and mechanisms through which $\mathrm{CO}_{2}$ affects fundamental combustion properties of wood burning in a fixed bed operated under oxy-fuel environment.

\subsubsection{Specific Objectives}

The specific objectives were to

1. determine the influence of $\mathrm{CO}_{2}$ environment on main combustion parameters, viz., temperature profiles, ignition time, burning rate, flame propagation speed and species evolution in the bed;

2. develop a kinetic model for wood pyrolysis, gasification and oxidation which can predict combustion behaviour in an oxy-fuel environment; 
3. establish the influence of packing of fuel particle and bed porosity on combustion of wood in a fixed bed under oxy-fuel environment;

4. isolate the role of chemical, thermal and dilution effects of $\mathrm{CO}_{2}$ on wood combustion properties through numerical simulation.

\subsection{Scope}

This study is focused on flame propagation speed under oxy-fuel conditions, particle packing density and separate effects of $\mathrm{CO}_{2}$ in oxy-fuel combustion. A fixed bed combustion of wood is considered and other combustion technologies are beyond the scope of this work. The study is narrowed down to an investigation of combustion properties of a single type of wood, i.e., eucalyptus, in order to obtain detail information. The experimental investigation is limited to measurements of temperature and mass loss history but volume change in bed layers and species generation measurements are not possible in this study. However, all these combustion parameters are modelled through numerical technique. Furthermore, this study is limited to investigation of combustion parameters and does not consider formation of pollutants such as particulate matter, soot, nitrogen oxides and sulphur oxides.

\subsection{Thesis Outline}

This study deals with modeling and experimental work on oxy-fuel combustion of wood in a laboratory fixed bed reactor. These experiments and simulations have been done with an aim of establishing and isolating the role of various $\mathrm{CO}_{2}$ effects on wood combustion properties in an oxy-fuel environment. In this chapter, background, problem statement, objectives and scope of the study have been presented. 
A detailed literature review is presented in chapter two. First, a review of oxy-fuel combustion system and description of various components incorporated in biomass oxy-fuel power plant are presented. Biomass thermal conversion processes such as drying, devolatilization, homogeneous reactions and heterogeneous reactions are then discussed in detail. Subsequently, the effects of oxy-fuel conditions on combustion properties of biomass fuels are explained in detail. Secondly, a review on fixed bed combustion technologies. In addition, fixed bed operation and flame propagation modes are reviewed. Finally, modeling approaches for combustion of biomass in fixed bed are presented. Computational Fluid Dynamics - Discrete Element Method (CFD-DEM) modeling technique and shrinkage models are emphasized.

Experimental techniques used in determination of the fuel properties as well as in the laboratory test of wood combustion in a fixed bed under air and oxy-fuel environment are presented in chapter three. The techniques for determining combustion parameters, namely, mass history, temperature profiles, burning rates, ignition rates, bed porosity and flame front and propagating velocity are discussed. Experimental results are presented in the last section of chapter three.

Presented in chapter four are the numerical modelling techniques which were used in simulation of wood combustion in a fixed bed. The governing equations for both solid phase and gas phase as well as coupling equations are presented. Furthermore, other specific models which are required during computation such as turbulence models, radiation models, shrinkage models and kinetics models are also discussed. Finally, numerical solution methods employed, geometry and boundary conditions formulations and computational meshes are discussed.

In chapter five, numerical results of the three cases simulated in this study, viz., the effects of $\mathrm{CO}_{2}$ environment on flame propagation speed and flames structures, the influence of particle packing density on combustion of wood in an oxy-fuel burning environment, and the separate 
effects of $\mathrm{CO}_{2}$ in oxy-fuel combustion are presented. The chapter begins by a description of the boundary conditions applied for each case. The mesh independent tests which were done to ensure independency of results on the grid size are then presented. Finally, the numerical results are presented.

Presented in chapter six are the CFD-DEM model validation results and discussions on the experimental and numerical study of wood conversion in a fixed bed under oxy-fuel environment. In the first section, CFD-DEM method and code validation are presented. Temperature distribution and species generation in the bed are discussed. The next section presents an investigation of wood combustion under oxy-fuel combustion environment using CFD-DEM numerical method. Effects of $\mathrm{CO}_{2}$ combustion environment on mass loss history, flame propagation speed, flame fronts positions and flame structures are discussed. The influence of packing of fuel particle and bed porosity on combustion of wood in a fixed bed under oxy-fuel environment are then presented. Temperature history, ignition time, wood and char conversion rates and reaction zone thickness are discussed in detail. The last section presents the role of various $\mathrm{CO}_{2}$ effects on burning rate. The overall and individual contribution of various $\mathrm{CO}_{2}$ effects on wood conversion processes are discussed.

Chapter seven contains a summary of the main findings of this study; and conclusions arising out of the study. Future outlook of the study is in chapter eight. 


\section{CHAPTER TWO \\ LITERATURE REVIEW}

\subsection{Introduction}

In this chapter, detailed review of oxy-fuel combustion system and description of various components incorporated in biomass oxy-fuel power plant are presented. Biomass thermal conversion processes such as drying, devolatilization, homogeneous reactions and heterogeneous reactions are also discussed in detail. Effects of oxy-fuel conditions on biomass combustion properties are then explained in detail. Fixed bed combustion technologies are also discussed. In addition, fixed bed operation and flame propagation modes are reviewed. Finally, modeling approaches for biomass combustion in fixed bed are presented. CFD-DEM modeling technique and shrinkage models are emphasized.

\subsection{Oxy-Fuel Combustion}

Oxy-fuel combustion technique in coal-power plants was first introduced in 1982 (Scheffknecht et al., 2011). Since then, a lot of research have been done to understand the combustion phenomenon. This technique is also applicable to combustion of other fuels such as liquid and gas fuel. Special considerations are made when designing combustion device used for $\mathrm{CO}_{2}$ rich environment due to the alteration of combustion processes introduced by replacing $\mathrm{N}_{2}$ with $\mathrm{CO}_{2}$ (Chui, Majeski, Douglas, Tan, \& Thambimuthu, 2004). A typical atmospheric combustion system applied in a power plant that uses coal and operates in oxy-fuel environment is shown in Fig. 2.1 (Scheffknecht et al., 2011). In addition to other devices used in air-fired systems, it consists of air separation unit (ASU), carbon dioxide purification unit (CPU) and flue gas recycle system (FGR). Pure $\mathrm{O}_{2}$ is obtained from air by separating it from $\mathrm{N}_{2}$ in ASU. Cryogenic distillation is normally used because it meets large scale demands for oxygen purity and amount. CPU consists of selective catalytic reduction (SCR) unit for removing nitrogen oxides, 
$\mathrm{NO}_{\mathrm{x}}$, electrostatic precipitator (ESP)) unit for removing particulate matter and flue gas desulphurization (FGD) unit for removing sulphur oxides, $\mathrm{SO}_{\mathrm{x}}$. These units are connected to the exhaust gas port of the combustion chamber. FGR are positioned down stream of economizer such that flue gas is recycled either as wet or dry.

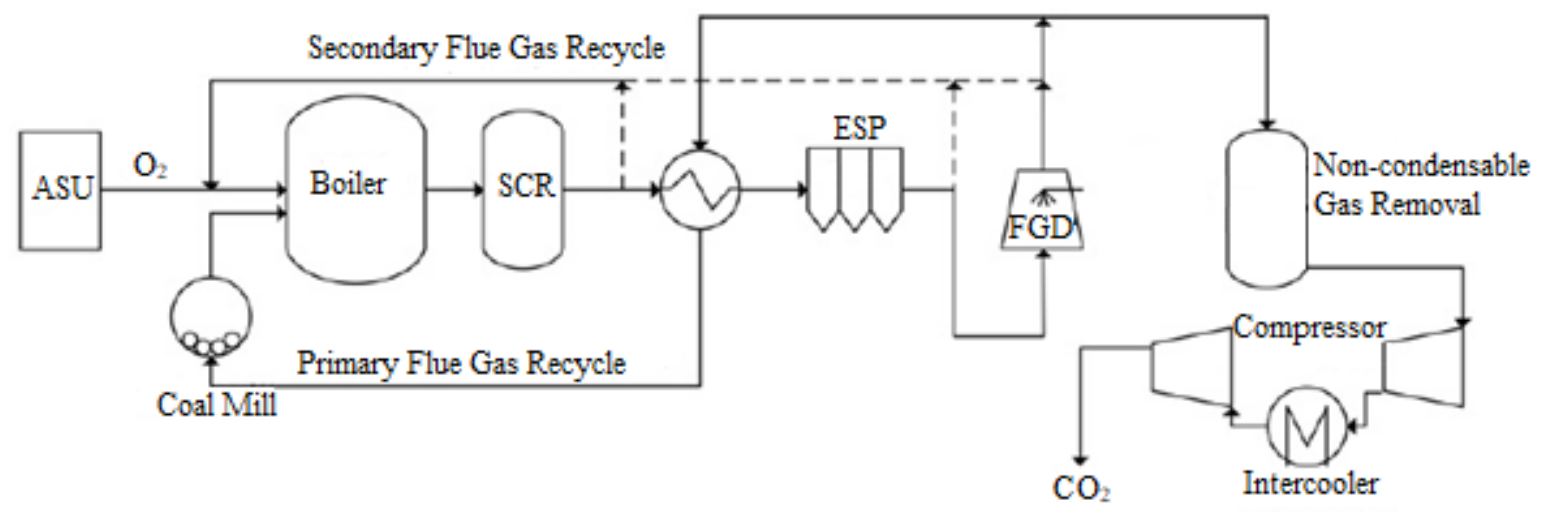

Figure 2.1: A typical atmospheric combustion system applied in a power plant that uses coal and operates in oxy-fuel environment (Scheffknecht et al., 2011).

After purification, recycled flue gas which is mostly $\mathrm{CO}_{2}$ and $\mathrm{H}_{2} \mathrm{O}$ is compressed and stored in order to be utilized in oxy-fuel combustion system. The process of separating $\mathrm{O}_{2}$ from $\mathrm{N}_{2}$ in the air, purifying and compressing $\mathrm{CO}_{2}$ takes a significant proportion of power from the system. Therefore, there is a decrease in the overall efficiency of the system. It has been established that the reduction in efficiency is about 8 to $12 \%$ (Scheffknecht et al., 2011). Combustion properties of an oxy-fuel system is determined by the flue gas recycle ratio. In case of retrofitting existing air-fuel power plant to operate properly under oxy-fuel condition, it is important to match their combustion characteristics (Khare et al., 2008). It has been shown that the adiabatic flame temperature similar to that attained in air-fuel conditions is achieved in oxy-fuel condition when it is operating at about $69 \%$ flue gas recycle ratio (Smart, O’Nions, Riley, \& Jamieson, 2009). 


\subsection{Biomass Conversion}

Thermo-chemical conversion of biomass by direct combustion is the process in which heat is released. It involves several chemical and physical processes. These include drying, devolatilization, homogenous and heterogeneous combustion. The entire conversion of biomass may either be continuous or batch depending on the design and the nature of application. For instance, wood combustion in a wood stove occurs in batch mode while a moving grate furnace is a continuous combustion mode where fuel is continuously fed into the combustion chamber. Homogenous and heterogeneous combustion may occur simultaneously, or consecutively with a degree of overlap. For small particles, the processes are more distinct as compared to those in large particles which have high degree of overlap between the various stages. These processes for small and large biomass particles are illustrated in Fig. 2.2 (Loo \& Koppejan 2008) and Fig. 2.3 (He \& Behrendt 2011), respectively, and discussed in subsequent subsections.

\subsubsection{Drying}

Biomass contain a certain amount of water, which may exist either as bound water or free water. The two forms of water are distinguished using the fibre saturation point criterion. The amount of water present in biomass need to be dried before combustion. Drying is the first step in biomass combustion. Drying is an endothermic process which absorb energy during combustion of biomass. Subsequently, it reduces the flame temperature in the combustion region and also lowers reaction rates of combustion. A very high amount of water in biomass

inhibit combustion since it needs a lot of energy to evaporate it. It has been established that biomass with moisture content that exceeds 60\% does not sustain (Goh et al., 1999; Zakaria et al., 2000). 


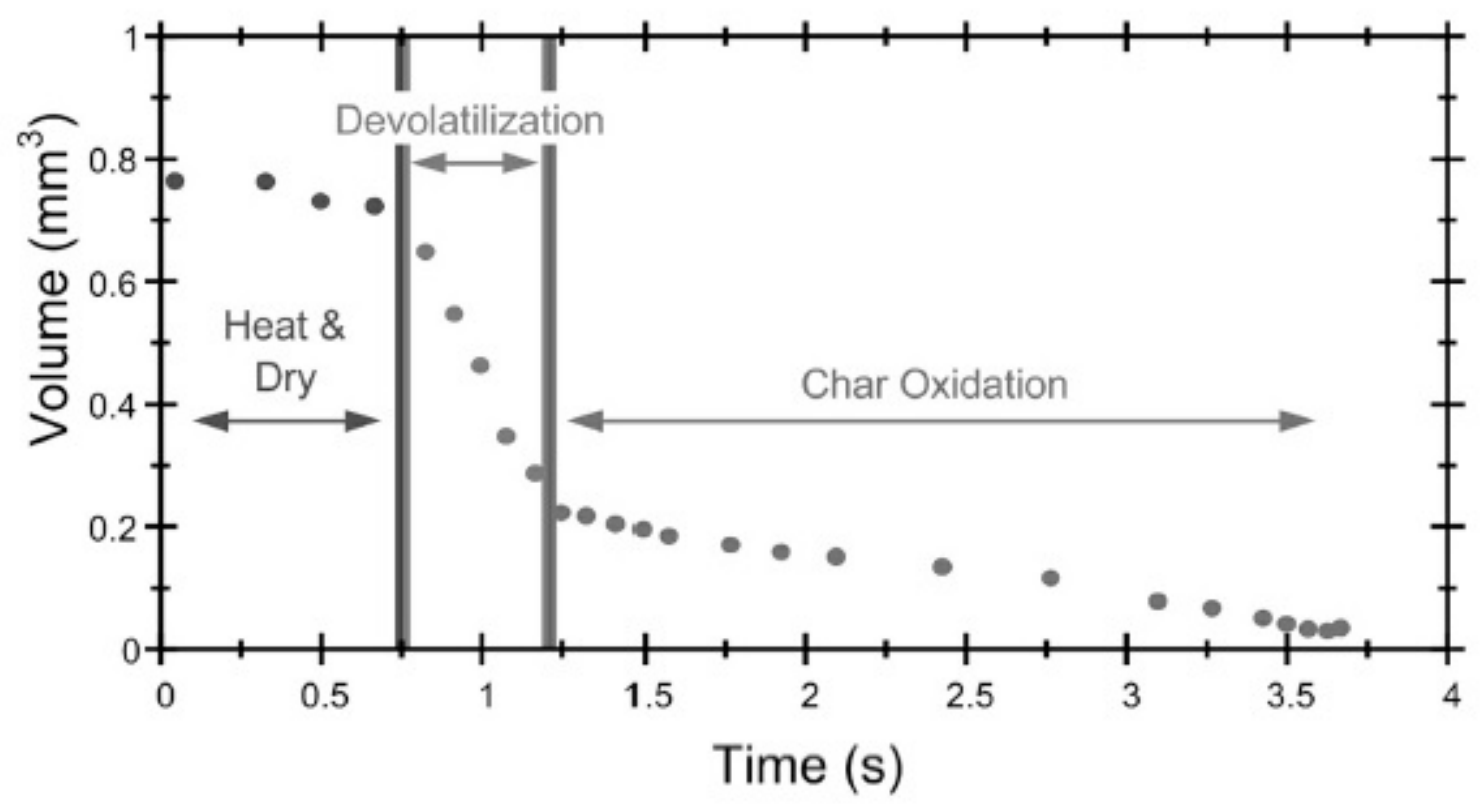

Figure 2.2: Illustration of different conversion processes in a small biomass particle (Loo \& Koppejan, 2008).

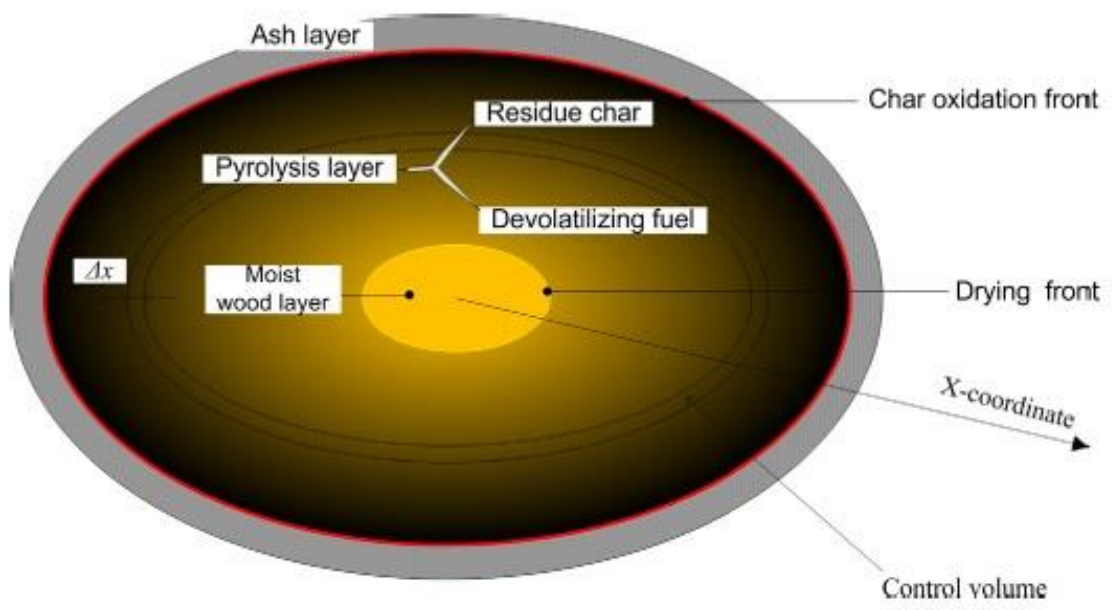

Figure 2.3: Illustration of different conversion processes in a large biomass particle (He \& Behrendt, 2011).

There are three major ways of modeling drying: (1) thermal method where drying begins when fuel reaches predefined temperature which is usually $100^{\circ} \mathrm{C},(2)$ use of algebraic expression for 
temperature as a function of moisture content and the evaporation temperature is not constant and, (3) treating drying process as additional chemical reaction and expressed as a first-order kinetic rate model. The latter is the most common method where water and vaporization scheme is added to the overall kinetic scheme. Reaction rate is expressed in first-order Arrhenius form:

$$
\text { Moisture } \rightarrow \text { Water }
$$

\subsubsection{Devolatilization}

Devolatilization is the process of releasing volatile matter through thermal decomposition. Thermal decomposition of biomass starts at a temperature of about $500 \mathrm{~K}$ (Antal \& Varhegyi, 1995; Pyle \& Zaror, 1984; Shafizadeh, 1985). Devolatilization is also an endothermic process which absorbs energy from combustion. Thus it reduces flame temperatures and lowers combustion rates. As a result of devolatilization, combustible gases are released and the solid biomass particle remaining is char. The gases diffuse toward the surface of the particle where they are combusted within or in its vicinity. The composition and amount of volatiles and char depends on fuel type and chemical composition, decomposing temperature, particle sizes, pressure and heating rates.

Typical gases released are $\mathrm{CO}_{2}, \mathrm{H}_{2} \mathrm{O}, \mathrm{CO}, \mathrm{H}_{2}$ and light hydrocarbons in gaseous form and heavy hydrocarbons in liquid form (Di Blasi, Branca, Santoro, \& Gonzalez Hernandez, 2001; Piskorz, Majerski, Radlein, Scott, \& Bridgwater, 1998; Scott, Piskorz, Bergougnou, Graham, \& Overend, 1988). The latter are referred to as tar. The chemical composition of tar is a function of decomposition temperature and the time it stays in the combustion environment (Evans \& Milne, 1997; Kinoshita, Wang, \& Zhou, 1994; Meier, Oasmaa, \& Peacocke, 1997). Tar are normally classified as primary, secondary and tertiary depending on their chemical composition. Primary, secondary and tertiary tar are oxygenated, hydrocarbon and aromatic 
compounds, respectively. Primary tar is produced at low decomposition temperature of 673773 K (Padban, Wang, Ye, Bjerle, \& Odenbrand, 2000) while secondary tar is produced at 7731173 K (Morf, Hasler, \& Nussbaumer, 2002) and tertiary tar is produced at 1173-1273 K (Branca, Giudicianni, \& Di Blasi, 2003).

Several biomass devolatilization models have been developed (Di Blasi, 2008). They are generally classified into three categories, namely, one-step global mechanism, one-step multireaction mechanisms and multi-step semi-global mechanisms. In one-step global mechanism, the products of biomass pyrolysis are char and volatiles. Alternatively, the products may be gases, tar and char, as shown in reactions Eqs. (2.2) and (2.3) (Di Blasi, 2000).

$$
\begin{gathered}
\text { Biomass } \rightarrow \text { Volatiles }+ \text { Char } \\
\text { Biomass } \rightarrow \text { Gases }+ \text { Tar }+ \text { Char }
\end{gathered}
$$

Arrhenius equation is used to express the reaction rate constant. The kinetic parameters, viz., pre-exponential factor, exponent and activation energy are evaluated through measurement data from experiments using devices such as thermogravimetric analysis (TGA) and tube furnace. The main short coming for this model is the inability to model the exact amount and percentage of volatiles constituents. In addition, all the components of original biomass are not accounted by the model. In one-step multi-reaction mechanism, biomass is converted into products which are then converted to volatiles and char, as illustrated in Eqs (2.4) and (2.5) (Caballero, Conesa, Font, \& Marcilla, 1997; Varhegyi, Gronli, \& Di Blasi, 2004) :

$$
\begin{gathered}
\text { Biomass } \rightarrow(\text { products })_{j} \\
\text { Biomass }(\text { products })_{j} \rightarrow \text { Volatiles }+ \text { Char }
\end{gathered}
$$


where $j$ represents the individual products of biomass pyrolysis. The model does not include cracking of tar into light hydrocarbon gases that is experienced in high temperature and has long residence times.

In multi-step semi-global mechanism, biomass decomposes into active intermediate species with lower degree of polymerization which are further converted to other product, as illustrated in Fig. 2.4 (Di Blasi, 2008; Varhegyi, Szabo, \& Antal, 1994).

(a)

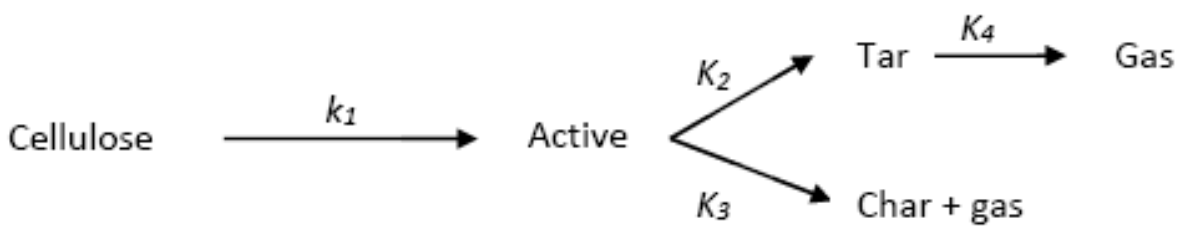

(b)

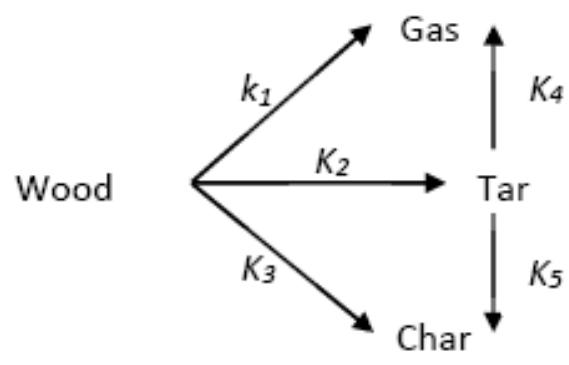

Figure 2.4: Two-stage semi-global reaction mechanism for (a) cellulose; (b) wood (Di Blasi, 2008).

Tar from devolatilization may undergo secondary cracking reaction to release $\mathrm{CO}, \mathrm{CO}_{2}, \mathrm{H}_{2}$, $\mathrm{CH}_{4}$ and inert tar according to the reaction below (Mahmoudi et al., 2015).

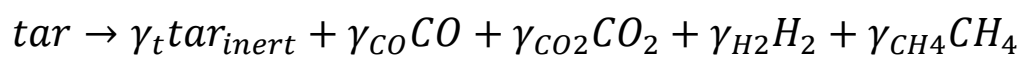


where $\gamma_{t}, \gamma_{\mathrm{CO}}, \gamma_{\mathrm{CO} 2}, \gamma_{\mathrm{H} 2}$ and $\gamma_{\mathrm{CH} 4}$ are mass fractions of $\mathrm{CO}, \mathrm{CO}_{2}, \mathrm{H}_{2}, \mathrm{CH}_{4}$ and inert tar whose amounts are $0.22,0.564,0.111,0.017$ and 0.088, respectively (Mahmoudi et al., 2015; Wurzenberger, Wallner, Raupenstrauch, \& Khinast, 2002).

\subsubsection{Gas Phase Reactions}

Volatile gases from devolatilization undergo chemical reactions with oxygen. Gas species considered in homogenous gas-phase reactions are those generated from drying, devolatilization, tar cracking and char heterogeneous reactions. In order to model emissions which normally occur in gas-phase such as nitrogen oxides $\left(\mathrm{NO}_{\mathrm{x}}\right)$ and sulphur oxides $\left(\mathrm{SO}_{\mathrm{x}}\right)$, chemical reaction sub-models that have their formation routes are required.

Gas-phase combustion of $\mathrm{CO}, \mathrm{H}_{2}, \mathrm{CH}_{4}$ and other gas species, is modelled using appropriate reaction mechanism, which may be one-step global reaction, reduced reaction mechanism or detailed reaction mechanism. There are several detailed reaction mechanisms for modelling hydrocarbons. For instance, GRI Mech 3.0 mechanism (Smith et al., 1999) and detailed chemical kinetic model (DCKM) suggested by Glarborg \& Bentzen (2008). These mechanisms are usually applied to air-fuel combustion environment. They have also been shown to work well in oxy-fuel combustion environment (Chen, 2013). However, in order to model chemical effects of $\mathrm{CO}_{2}$, these kinetic models require to be modified by adding relevant reactions.

Application of detailed reaction mechanism in CFD modelling of biomass combustion is usually challenging since they require high computational power. Reduced reaction mechanisms have been developed for modelling hydrocarbon combustion in oxy-fuel environment. These include two-step reaction mechanism suggested by Westbrook \& Dryer (1981), three-step reaction mechanism suggested by Toporov et al. (2008) and four-step reaction mechanism suggested by Jones \& Lindstedt (1988). 


\subsubsection{Char Oxidation}

Char reaction with $\mathrm{O}_{2}$ is referred to as oxidation while its reaction with other gases is referred to as gasification. Heterogeneous reactions are influenced by char structure, local temperature and pressure, local gas concentration and total active surface area. The overall scheme is defined by three main steps, namely, (1) heat and mass transfer by diffusion in the boundary layer of the particle, (2) heat and mass transfer by diffusion in the porous structure of char and, (3) heterogeneous reactions of gases and char surface. The heterogeneous reaction at the surface is expressed as follow:

$$
\text { Char }+ \text { oxidizer } \rightarrow \text { products }
$$

There are three possible gases which react with char: $\mathrm{O}_{2}, \mathrm{CO}_{2}$ and $\mathrm{H}_{2} \mathrm{O}$. Their reactions are given as follows:

$$
\begin{gathered}
\Omega \mathrm{C}+\mathrm{O}_{2} \rightarrow 2(\Omega-1) \mathrm{CO}+(2-\Omega) \mathrm{CO}_{2} \\
\mathrm{C}+\mathrm{CO}_{2} \rightarrow 2 \mathrm{CO} \\
\mathrm{C}+\mathrm{H}_{2} \mathrm{O} \rightarrow \mathrm{CO}+\mathrm{H}_{2}
\end{gathered}
$$

The parameter $\Omega$ in reaction Eq. (2.8) control the ratio of $\mathrm{CO}_{2}$ to $\mathrm{CO}$ emitted when char is burning.

The rate of char oxidation can either be treated as first order or half-order. For both cases, the oxidizer diffuses from the bulk gas phase to char surface where heterogeneous reaction take place. The rate limiting steps are the gas phase diffusion and heterogeneous reaction. For first order char oxidation, heterogeneous reactions are considered as first-order in the concentration 
of the oxidizer at the surface. Overall combined char reaction rate, $r_{c}$ is given by an implicit expression (CD-Adapco, 2017):

$$
r_{c}=\frac{A_{p}^{2} W_{h p} W_{g} \Omega K_{c p l} K_{p l} \zeta_{p l} C_{o l g} C_{g}}{A_{p} W_{g} C_{g}\left(K_{p l} \zeta_{p l}+K_{c p l}\right)+r_{b}}
$$

where $A_{p}$ is the char surface area, $W_{h p}$ and $W_{g}$ are molecular weight for char and gas mixture, respectively, $K_{c p l}$ is the coefficient of mass transfer, $\zeta_{p l}$ is the coefficient of the particle pore area, $C_{\text {olg }}$ is oxidizer concentration, $C_{g}$ is the overall gas concentration, $r_{b}$ is the total reaction rate for biomass particle and $K_{p l}$ is the rate constant for heterogeneous reaction given by Arrhenius expression:

$$
K_{p l}=A T_{p}^{n} \exp \left(-\frac{E}{R_{u} T_{p}}\right)
$$

where $A$ is the Arrhenius pre-exponential factor, $T_{p}$ is the particle temperature, $E$ is the activation energy, $R_{u}$ is the universal gas constant.

For half order char oxidation, heterogeneous reactions are considered as half-order in the concentration of the oxidizer at the surface. Overall combined char reaction rate, $r_{c}$ is expressed by an implicit equation (CD-Adapco, 2017):

$$
r_{c}=\Omega K_{c p l} A_{p} W_{h p}\left[C_{o l g}-\left(\frac{r_{c}}{\Omega K_{p l} A_{p} W_{h p} \zeta_{p l}}\right)^{2}\right]
$$

\subsection{Effects of Oxy-Fuel Environment on Biomass Combustion Properties}

$\mathrm{CO}_{2}$ has different physical and thermal properties as compared to those of $\mathrm{N}_{2}$. Therefore, combustion of biomass under $\mathrm{CO}_{2}$ environment is different from $\mathrm{N}_{2}$ environment. The 
properties affected include heat transfer, ignition, drying, devolatilization, char formation and homogeneous reactions. They are discussed in the following subsections.

\subsubsection{Heat Transfer}

\section{Radiative Heat Transfer}

Radiation heat transfer is important when considering thermal conversion of biomass in a fixed bed combustion chamber. Flue gas compositions of biomass combustion under $\mathrm{CO}_{2}$ burning conditions is not similar to that under air-fuel environment. Hence, radiative heat transfer is not the same in the two environments. The total radiative energy, $q_{R}$, from flame can be estimated by considering the whole flame as a uniform radiation source and may be expressed using Stefan-Boltzmann law, Eq. 2.14 (Chen, 2013).

$$
q_{R} \propto \epsilon A_{f} \sigma T_{f}^{4}
$$

where $A_{f}$ is the flame surface area, $T_{f}$ is the flame temperature, $\epsilon$ is the average flame emissivity and $\sigma$ is the Stefan-Boltzmann constant. Thus Eq. (2.14) shows that temperature has a significant effect since it is the highest order term. Therefore, temperature in oxy-fuel environment should be raised to match that of air-fuel environment so as to achieve the same amount of radiative heat transfer.

$\mathrm{CO}_{2}$ and $\mathrm{H}_{2} \mathrm{O}$ are the main products of combustion in an oxy-fuel environment. This is not the same as air-fuel environment where $\mathrm{N}_{2}$ is also dominant in addition to these gases. $\mathrm{CO}_{2}$ and $\mathrm{H}_{2} \mathrm{O}$ are triatomic gases which make them not transparent to radiation (Chen, 2013). On the other hand, the emissivity and absorptivity of combustion gases in a $\mathrm{CO}_{2}$ rich environment are higher because they have higher partial pressure as compared to air-fuel conditions under the same gas temperature (Chen, 2013). The overall effect is that radiative heat transfer is promoted 
in a $\mathrm{CO}_{2}$ rich environment. Since the absorptivity is not continuous over entire spectrum, its effective value for gas mixture is evaluated by integration of the governing equation over the entire spectrum. Thus it is difficult to achieve and requires high computing resources, hence, most CFD studies use gray gas.

Weighted-sum-of-gray-gas-model (WSGGM) is a widely used radiation model (Andersson \& Johnsson, 2007). It was primarily developed for air-fuel conditions (Smith, Shen, \& Friedman, 1982). However, under appropriate conditions, it can also be used in oxy-fuel environment. There have been several efforts to develop improved radiation heat transfer models for application in oxy-fuel environment. Among them are the following non-gray models: Statistical narrow band model (Johansson, Andersson, Leckner, \& Thunman, 2010); exponential wide band model (Yin, Johansen, Rosendahl, \& Kær, 2010); and empirical correlation (Krishnamoorthy et al., 2010). Usage of these improved models significantly enhance prediction accuracy for oxy-fuel combustion. A comparison of radiative heat transfer behavior in a furnace in term of incident radiation flux, heat sources and temperature distribution predicted using gray and non-gray oxy-fuel WSGGMs and air-fuel WSGGM were reported by Yin (2012). There is a significant difference between prediction of non-gray and gray computation using the same oxy-fuel WSGGMs and is more pronounced than those in airfuel WSGGM. Yin (2012) concluded that the difference observed in oxy-fuel WSGGMs is not very critical. However, non-gray oxy-fuel WSGGM model showed improved prediction accuracy for large-scale oxy-fuel furnace.

\section{Convective Heat Transfer}

The rate of convective heat transfer, $\dot{q}_{c o n v}$, is estimated using Newton law of cooling, Eq. 2.15. 


$$
\dot{q}_{\text {conv }}=h_{c} \Delta T,
$$

where $h_{c}$ is the convective heat transfer coefficient and $\Delta T$ is the temperature difference between flue gas and heated body. Convective heat transfer is expressed in terms of Nusselt number, $N u$, which is a function of Reynolds number, Re, and Prandtl number, $P r$. The correlation between these non-dimensional numbers are based on the shape of the heated body and the flow conditions (Incropera, DeWitt, Bergman, \& Lavine, 2006; Whitaker, 1972). Consequently, $h_{c}$ is a function of physico-chemical properties of gas such as density, thermal conductivity, viscosity and heat capacity. Based on non-dimensional numbers, convective heat transfer coefficients in $\mathrm{CO}_{2}$ burning conditions, $h_{c, o x}$, and air-fuel conditions, $h_{c, a}$, may be compared using the following expression (Payne, Chen, Wolsky, \& Richter, 1989):

$$
\frac{h_{c, o x}}{h_{c, a}}=\left(\frac{R e_{o x}}{R e_{a}}\right)^{m}\left(\frac{P r_{o x}}{P r_{a}}\right)^{n}\left(\frac{\lambda_{o x}}{\lambda_{a}}\right),
$$

where $m$ and $n$ are constants that depend on shapes of the heated body, $\lambda$ is thermal conductivity and subscript $o x$ and $a$ represent oxy-fuel and air-fuel conditions, respectively. Physicochemical properties of $\mathrm{CO}_{2}$ are different from those of $\mathrm{N}_{2}$, therefore, convective heat transfers are also different. Under the same conditions, $\mathrm{CO}_{2}$ has a higher thermal conductivity and lower kinematic viscosity than those of $\mathrm{N}_{2}$ (Nozaki, Takano, Kiga, Omata, \& Kimura, 1997). Therefore, the overall effect is a higher convective heat transfer coefficient in a $\mathrm{CO}_{2}$ rich environment. For coal burning in a $\mathrm{CO}_{2}$ rich environment, $h_{c, o x} / h_{c, a}$ has been found to increase with increase in flue gas recycle ratio (Liu, Zailani, \& Gibbs, 2005a, 2005b). Convective heat transfer coefficient of oxy-fuel environment may be matched to that in air-fuel by operating the power plant at appropriate flue gas recycle ratio (Smart, O'Nions, \& Riley, 2010; Toftegaard, 
Brix, Jensen, Glarborg, \& Jensen, 2010). Therefore, existing air-fuel operated power plants may be retrofitted as oxy-fuel operated power plant without replacing the burners.

\subsubsection{Drying under Oxy-fuel Environment}

Drying of biomass particle in oxy-fuel combustion environment is different from an air-fuel burning environment because the two environments have different heat transfer processes. The rate of heating and drying of particles is influenced by heat transfer processes (Chen, Wu, \& Agarwal, 2000; Topuz, Gur, \& Gul, 2004; Wang, 2007). A simplified heat transfer model for the thermal conversion of a biomass particle is shown in Fig. 2.5 (Chen, 2013). The energy conservation in the biomass particle may be expressed as follows (Ceylan, Aktaş, \& Doğan, 2007; Celma, Rojas, \& Lopez-Rodríguez, 2008; Sander, 2007):

$$
\frac{4}{3} \pi r_{p}^{3} \rho_{p} c_{p} \frac{d T}{d t}=4 \pi r_{p}^{2} h_{c}\left(T_{g}-T_{p}\right)+4 \pi r_{p}^{2} \sigma\left(\epsilon_{f} T_{f}^{4}-\epsilon_{p} T_{p}^{4}\right)
$$

where $c_{p}$ is the specific heat capacity for the particle, $h_{c}$ is the convective heat transfer, $r_{p}$ is the particle radius, $T_{f}, T_{g}$ and $T_{p}$ are the flame temperature, hot gas temperature and particle temperature, respectively, $t$ is the time, $\rho_{p}$ is the particle density, $\sigma$ is the Stefan-Boltzmann constant, $\epsilon_{f}$ and $\epsilon_{p}$ are emissivity for gas and particle, respectively.

Equation (2.17) shows that flame and gas temperatures have a significant effect in the determination of the heating rate of a particle. In case of combustion in a $\mathrm{CO}_{2}$ rich environment, flame temperatures have low values in comparison to those of air-fuel conditions with the same $\mathrm{O}_{2}$ concentration. Subsequently, the heating rate of a particle in a $\mathrm{CO}_{2}$ rich environment is expected to be lower than in air-fuel environment. In addition, convective heat transfer coefficient is also different in the two environments. This also affects the heating rate of $\mathrm{CO}_{2}$ rich conditions. 


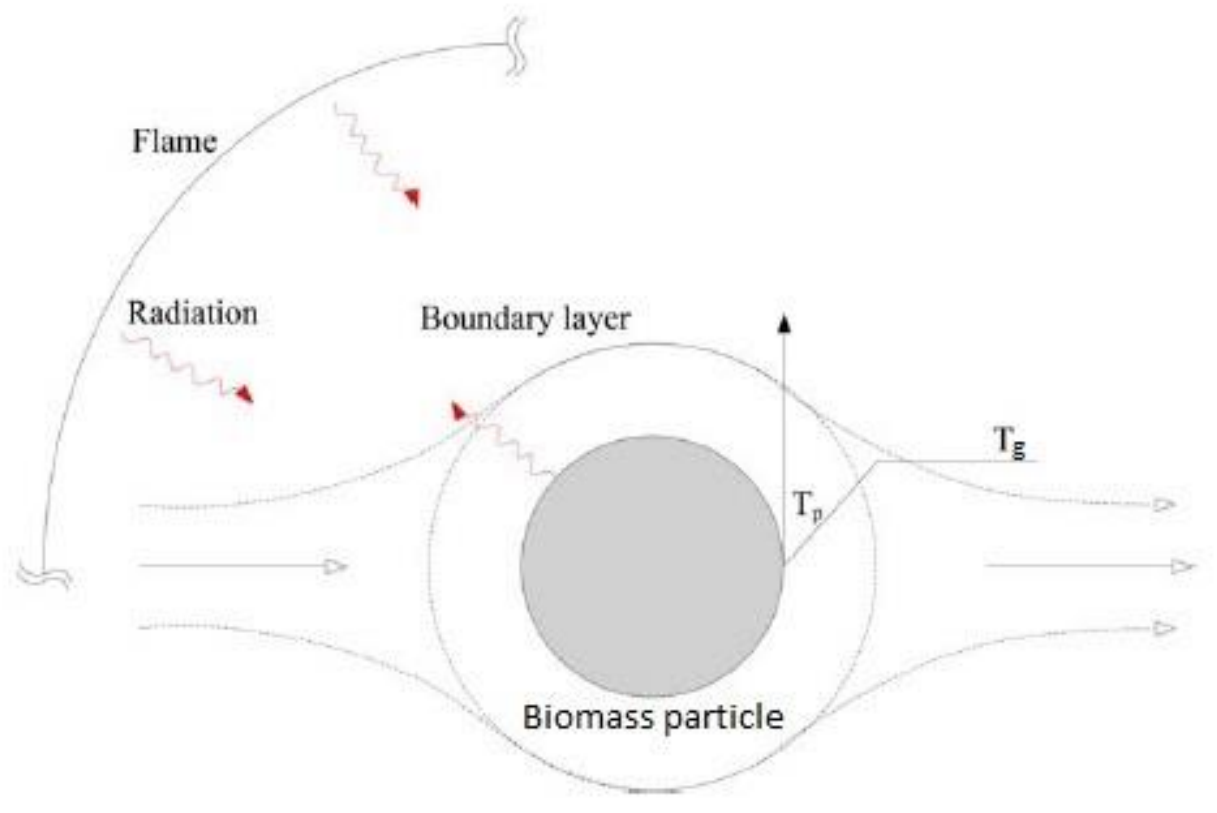

Figure 2.5: Heat transfer processes for the thermal conversion of a biomass particle (Chen, 2013).

Chen, Yong \& Ghoniem (2012) calculated drying times for particles conversion in $\mathrm{O}_{2} / \mathrm{N}_{2}$ and $\mathrm{O}_{2} / \mathrm{CO}_{2}$ environments using droplet evaporation model. It was observed that the drying time in both $\mathrm{N}_{2}$ and $\mathrm{CO}_{2}$ environments were similar. This is because the experiments were carried out at low Reynolds number flow conditions which makes thermal conductivity dominant over convective heat transfer. However, Chen (2013) concluded that combustion temperature plays a more significant role in influencing heating rate than the role of gas composition.

\subsubsection{Biomass Ignition}

There are two types of ignition for solid fuels, namely heterogeneous ignition and homogeneous ignition (Essenhigh, Misra, \& Shaw, 1989; Howard \& Essenhigh, 1967a, 1967b). Homogenous ignition occurs when volatiles and oxygen mixture are heated to auto-ignition temperature. For this case, ignition does not occur on the fuel solid surface. On the other hand, heterogeneous 
ignition occurs on the solid surface for fuel with less volatiles and high oxygen concentration (Levendis, Joshi, Khatami, \& Sarofim, 2011; Ponzio, Senthoorselvan, Yang, Blasiak, \& Eriksson, 2008). For both types of ignition, the ignition time and temperature of biomass particles depends on the fuel properties, size, oxygen concentration, gas flow and heating rate.

Shan et al. (2017) investigated ignition and combustion characteristics of wood pellets in airfuel and $\mathrm{CO}_{2}$ rich environments. The investigations were done for different flow conditions, gas temperature and oxygen concentration. Ignition delay is higher in oxy-fuel environment than in air-fuel environment (Khatami, Stivers, Joshi, Levendis, \& Sarofim, 2012; Liu, Geier, Molina, \& Shaddix, 2011; Zhou, Lin, Hu, Hu, \& Song, 2016). A similar behaviour has also been observed in coal combustion in oxy-fuel environment (Shaddix \& Molina, 2009). This is attributed to the high heat capacity of $\mathrm{CO}_{2}$ and low diffusivity of oxygen in $\mathrm{CO}_{2}$ which results in slow heating rates of particles. For the same temperature, ignition delay decrease with increasing oxygen concentration. This is because as oxygen is increased, heat generation and transfer is enhanced, hence, ignition is also enhanced. When the gas flow is increased at the same temperature and oxygen concentration, ignition delay is reduced. A high gas flow increases turbulence which improves heat transfer and subsequently ignition of biomass fuels.

Internal ignition temperature of biomass fuels in $\mathrm{N}_{2}$ and $\mathrm{CO}_{2}$ environments have also been investigated (Kijo-Kleczkowska, Środa, Kosowska-Golachowska, Musiał, \& Wolski, 2016; Kimura, Omata, Kiga, Takano, \& Shikisima, 1995; Lu et al., 2010). Under the same gas temperature and flow conditions, internal ignition temperature is inversely proportional to oxygen concentration changes. However, as oxygen concentration is increased beyond 50\%, the decrease is minimal. For the same oxygen concentration and gas flow condition, increase in gas temperature decreases internal ignition temperature. In fact, Shan et al. (2017) concluded 
that the influence of gas temperature on internal ignition temperature is more pronounced than that of oxygen concentration.

\subsubsection{Biomass Devolatilization}

When biomass is heated beyond $300{ }^{\circ} \mathrm{C}$, it undergoes devolatilization whereby volatiles such as light gases, tar and vapour are released. Devolatilization is highly influenced by temperature change in the particle as it is an endothermic process. Moreover, it is also affected by pressure and gasifying agent (Gibbins-Matham \& Kandiyoti, 1988; Ko et al., 1989; Suuberg et al., 1980). In addition, the amount and composition of volatiles released depend on biomass type and its chemical composition (Anthony, Howard, Hottel, \& Meissner, 1976; Balat, Balat, Kırtay, \& Balat, 2009a, 2009b).

Gasifying agents that can be used during biomass devolatilization include nitrogen, air and $\mathrm{CO}_{2}$. Research work on devolatilization of biomass in $\mathrm{CO}_{2}$ rich environment have been reported (Nakayama et al., 1992; Tan, Croiset, Douglas, \& Thambimuthu, 2006). Wijayanta et al. (2012) reported on the influence of different $\mathrm{CO}_{2}$ concentration on major species and polyaromatics hydrocarbons (PAHs) production during biomass combustion. In general, volatiles yield is lower in $\mathrm{N}_{2}$ burning environment than in $\mathrm{CO}_{2}$ burning environment (Rathnam, Elliott, Wall, Liu, \& Moghtaderi, 2009). It has been found out that there is a relatively higher amount of $\mathrm{H}_{2}$ in $\mathrm{N}_{2}$ burning environment than in oxy-fuel environment (Bautista, Russel, \& Seville, 1986).

On the other hand, the concentration of $\mathrm{CO}$ is high in oxy-fuel condition as compared to $\mathrm{N}_{2}$ burning environment (Serio, Hamblen, Markham, \& Solomon, 1987). This has been attributed to Boudouard reaction Eq. 2.9, whereby char is consumed by $\mathrm{CO}_{2}$ to produce $\mathrm{CO}$. In addition, for air-fuel environment reaction Eq. (2.18);

$$
\mathrm{H}+\mathrm{O}_{2} \leftrightarrow \mathrm{O}+\mathrm{OH}
$$


is a dominant chain branching step due to high amount of $\mathrm{H}_{2}$ which break into $\mathrm{H}$-atoms, while in oxy-fuel environment, reaction Eq. (2.19) is dominant because of high amount of $\mathrm{CO}_{2}$ (Glarborg \& Bentzen, 2008).

$$
\mathrm{H}+\mathrm{CO}_{2} \leftrightarrow \mathrm{CO}+\mathrm{OH}
$$

Reactions Eq. (2.18) and Eq. (2.19) show that for oxy-fuel conditions, H-atoms are competed for by $\mathrm{O}_{2}$ and $\mathrm{CO}_{2}$. Hence, for a high concentration of $\mathrm{CO}_{2}$, a high amount of $\mathrm{CO}$ is produced through reaction Eq. (2.19). Moreover, the amount of CO in oxy-fuel environment is influenced by water-gas-shift reaction Eq. 2.20 (Glarborg \& Bentzen, 2008).

$$
\mathrm{H}_{2} \mathrm{O}+\mathrm{CO} \leftrightarrow \mathrm{CO}_{2}+\mathrm{H}_{2}
$$

\subsubsection{Char Formation and Combustion}

During combustion of biomass, char is a product of devolatilization process. Char properties, combustion and gasification characteristics is greatly influenced by its formation process, viz., the preceding devolatilization. Biomass char obtained from devolatilization under air-fuel environment is different from that from oxy-fuel environment because $\mathrm{CO}_{2}$ plays a reactive role in the process whereas $\mathrm{N}_{2}$ is inert. The properties of char that are affected include structure, porosity, surface area and morphology (Riaza et al., 2011), all of which influence the reactivity of char (Pohlmann et al., 2010).

Char formation under different devolatilization environments have been the subject of many researchers (Borrego \& Alvarez, 2007; Gil et al., 2012a; Li et al., 2010). The studies have been done in different combustion systems, namely, drop tube furnace (Li et al., 2010) and entrained flow reactor (Borrego \& Alvarez, 2007; Gil et al., 2012a). For these cases, chars were obtained at a wide range of operating temperatures; $800-1400{ }^{\circ} \mathrm{C}$ (Borrego et al., 2009). These studies 
showed that $\mathrm{CO}_{2}$ reacts with char during high temperatures. Gil et al. (2012a) investigated the structure and morphology of biomass char obtained under $\mathrm{N}_{2}$ and $\mathrm{CO}_{2}$ environment. For char produced under $\mathrm{N}_{2}$ environment, the particle swells and melts before releasing volatiles. They did not observe any evidence of swelling for char obtained from $\mathrm{CO}_{2}$ devolatilization environment. They concluded that melting and fusion have greater impact on structural properties of char produced under oxy-fuel conditions than that of swelling. Consequently, char formed under $\mathrm{CO}_{2}$ environment are spherical particles and have smooth surface. Conversely, char particles formed in $\mathrm{N}_{2}$ environment have hollow surface (Brix, Jensen, \& Jensen, 2010; Cetin, Moghtaderi, Gupta, \& Wall, 2004).

According to Gil et al. (2012a), for all conversion values, reactivity of char produced under airfuel devolatilization environment are higher than those of char produced in oxy-fuel environment. A decrease in the reactive part of char due to consumption by $\mathrm{CO}_{2}$ causes a reduction in the reactivity. The effects of $\mathrm{CO}_{2}$ on char reactivity is more pronounced at high temperatures (Naredi \& Pisupati, 2011; Niu, Han, \& Lu, 2011; Wang, Zhang, Liu, \& Che, 2012) because of gasification of char through reaction Eq. 2.9.

Combustion characteristics of chars in $\mathrm{CO}_{2}$ rich environment is different from those of air-fuel environment. Chen \& Sheng (2016) investigated the effects of gas properties and $\mathrm{CO}_{2}$ gasification on combustion characteristics of char in a $\mathrm{CO}_{2}$ rich oxy-fuel environment. They demonstrated that changes in gas properties significantly reduces combustion temperatures. Oxy-fuel environment has low $\mathrm{O}_{2}$ diffusivity and high thermal conductivity of gas mixture which result in temperature reduction (Bejarano \& Levendis, 2008; Tolvanen \& Raiko, 2014).They also showed that influence of $\mathrm{O}_{2}$ diffusivity and high thermal conductivity of gas mixture are dominant at lower and higher $\mathrm{O}_{2}$ concentration, respectively. 
Char conversion by oxidation and gasification is also affected by the oxy-fuel environment. Haugen et al. (2015) investigated the effects of $\mathrm{CO}_{2}$ concentration, carbon to mass ratio and equivalence ratio on char. They showed that for high equivalence ratio, char conversion takes longer time. On the other hand, char conversion in $\mathrm{CO}_{2}$ gasification is faster. Conversion rate is affected by several factors such as temperature, oxidizer concentration, equivalence ratio (Croiset, Thambimuthu, \& Palmer, 2000; Gonzalo-Tirado \& Jiménez, 2015). For oxy-fuel environment, $\mathrm{CO}_{2}$ gasification, which is an endothermic process greatly reduces the flame temperature in the combustion region. Low temperatures inhibit char conversion rate. But char conversion rate is enhanced through gasification with $\mathrm{CO}_{2}$. The effect of the latter is more pronounced due to high amount of $\mathrm{CO}_{2}$ in oxy-fuel environment. Subsequently, char conversion rate in oxy-fuel conditions are increased (Geier, Shaddix, Davis, \& Shim, 2012; Mitchell, Kee, Glarborg, \& Coltrin, 1991).

\subsubsection{Chemical Effect of $\mathrm{CO}_{2}$ on Homogeneous Reactions}

Previous research (Kiga et al., 1997; Suda, Masuko, Sato, Yamamoto, \& Okazaki, 2007; Zhu, Egolfopoulos, \& Law, 1989) have shown that $\mathrm{CO}_{2}$ is not inert in gas-phase reactions, but undergo reaction with other species and affects combustion phenomena of the system. The dominant reaction through which $\mathrm{CO}_{2}$ plays an active role in combustion is given by reaction Eq. (2.19). In addition to this reaction, chain branching step Eq. (2.18) is also important. Furthermore, the following reactions are also responsible for $\mathrm{CO}_{2}$ active role in combustion but to a lesser extent (Liu et al., 2001):

$$
\begin{aligned}
& \mathrm{CO}_{2}+\mathrm{CH} \leftrightarrow \mathrm{HCO}+\mathrm{CO} \\
& \mathrm{CO}_{2}+\mathrm{OH} \leftrightarrow \mathrm{CO}+\mathrm{HO}_{2}
\end{aligned}
$$




$$
\begin{gathered}
\mathrm{CO}_{2}+\mathrm{M} \leftrightarrow \mathrm{CO}+\mathrm{O}+\mathrm{M} \\
\mathrm{CO}_{2}+\mathrm{O} \leftrightarrow \mathrm{CO}+\mathrm{O}_{2} \\
\mathrm{CO}_{2}+\mathrm{H} \leftrightarrow \mathrm{HCO}+\mathrm{O} \\
\mathrm{CO}_{2}+\mathrm{CH}_{3} \leftrightarrow \mathrm{CH}_{3} \mathrm{CO}+\mathrm{O}
\end{gathered}
$$

Through these reactions, $\mathrm{CO}_{2}$ affects various combustion processes. For instance, addition of $\mathrm{CO}_{2}$ to diffusion flames have been shown to reduce soot formation (Haynes \& Wagner, 1981; McLintock, 1968; Schug, Manheimer-Timnat, Yaccarinc, \& Glassman, 1980). According to Mclintock (1968), $\mathrm{CO}_{2}$ accelerates soot burnout when it is present at soot oxidation zone. Du et al. (1991) suggested that $\mathrm{CO}_{2}$ decreases the formation of soot through thermal, chemical and dilution effects. $\mathrm{CO}_{2}$ promotes production of oxygen atoms and hydroxyl which increases soot oxidation. Liu, Guo, \& Smallwood (2003) investigated the influence $\mathrm{CO}_{2}$ chemical effects on major species generation in a $\mathrm{C}_{2} \mathrm{H}_{4}$ diffusion flame. They observed a decrease of $\mathrm{CO}_{2}$ concentration in fuel side which is an indication that it is consumed by chemical reactions. Mass fraction of $\mathrm{CO}$ and $\mathrm{H}_{2} \mathrm{O}$ increases. Addition of $\mathrm{CO}_{2}$ to oxidizer also has effects on burning velocities of gaseous fuel mixtures (Ju, Masuya, \& Ronney, 1998; Masri, Dibble, \& Barlow, 1992; Ruan, Kobayashi, Niioka, \& Ju, 2001). Liu et al. (2001) isolated the role of $\mathrm{CO}_{2}$ chemical effect on burning velocity of methane and hydrogen flames. They used a fictitious species, $\mathrm{FCO}_{2}$, which has similar transport and thermal properties of $\mathrm{CO}_{2}$ but is not allowed to participate in reactions. The difference between the results of $\mathrm{CO}_{2}$ and $\mathrm{FCO}_{2}$ addition show the role played through chemical reaction. They showed that $\mathrm{CO}_{2}$ significantly reduce burning velocity of the flames through chemical reactions. 


\subsection{Fixed Bed Combustion}

A typical fixed bed combustion system consists of a primary air supply port, grate, fuel bed, secondary air supply port and exhaust port, as illustrated in Fig. 2.6 (Loo \& Koppejan, 2008). Fixed bed reactors usually operate with superficial velocity of between 0.3 to $1.2 \mathrm{~m} / \mathrm{s}$ (Mathekga, Oboirien, \& North, 2016). Fuel particles located in the fuel bed undergo various processes of biomass thermal conversion, namely, drying, devolatilization, gas-phase reactions and char combustion. Primary air is supplied at the bottom through grate to the fixed bed. Homogeneous reactions take place in region above fixed bed, also known as freeboard region. Secondary air may be supplied in this region for complete combustion of pyrolysis gases.

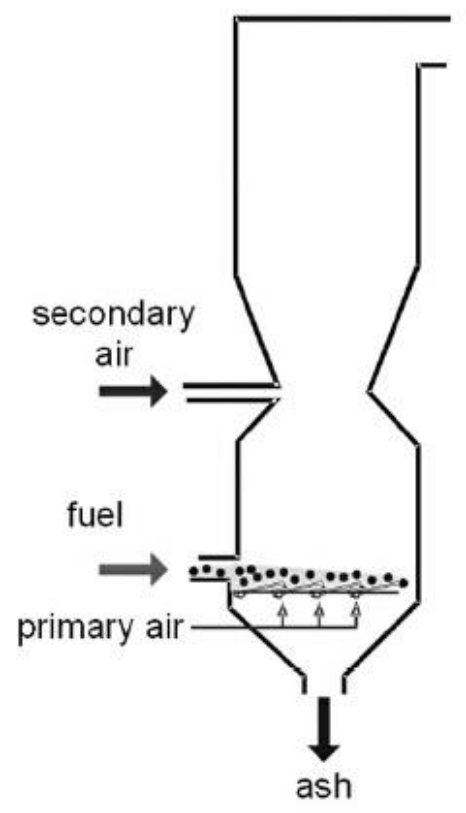

Figure 2.6: A typical fixed bed combustion furnace.

Combustion of wood in a fixed bed is favourable because of its simplicity. Consequently, this technique has been applied in most biomass power plants all over the world (Hermansson \& Thunman, 2011). This has created a lot of research interests which is aimed at improving 
combustion efficiency and reduction of emission (Costa et al., 2014; Guo et al., 2017; Yahaya, Somalu, Muchtar, Sulaiman, \& Daud, 2019). Over the past, studies of a wide range of biomass fuels have been carried out in a fixed bed operated with air as the oxidizer (Abrego, AtienzaMartínez, Plou, \& Arauzo, 2019; Chen, Annamalai, Ansley, \& Mirik, 2012; Meng et al., 2018; Plis \& Wilk, 2011). However, there has been a growing interest for combustion of biomass in a $\mathrm{CO}_{2}$ rich burning environment.

Typical devices used in a fixed bed combustion system includes grate furnaces and underfeed stokers. The choice of combustion technology depends on fuel type and properties. Careful consideration is required in order to obtain optimum efficiency and reduced exhaust emissions. Grate furnace type has a grate through which primary air is supplied to fuel bed. The design of the grate is use to differentiate the various types of grate furnaces which may be moving, fixed, rotating, traveling or vibrating. Grate furnace is suitable for fuel with high moisture content, wide particle variation and high ash content (Yang, Sharifi, \& Swithenbank, 2004; Yang, Goh, Zakaria, Nasserzadeh, \& Swithenbank, 2002). On the other hand, underfeed stoker is a furnace where fuel particles are fed into the burning region using a screw conveyor located at the bottom where it is transferred upward using a grate which is either on the outer or inner side. They are suitable for small and medium scale power plant with capacity of up to $60 \mathrm{MW}_{\text {th }}$ (Hermansson \& Thunman, 2011).

In practice, wood particles of different shapes and sizes are normally burned in a fixed bed. The packing and arrangement of fuel particles affect bed porosity. Bed porosity is a complex parameter which is not only affected by this factor but also changes as combustion progresses due to bed shrinkage (Khodaei, Al-Abdeli, Guzzomi, \& Yeoh, 2015; Porteiro, Granada, Collazo, Patiño, \& Morán, 2007). 
Thermal conversion of biomass in a fixed bed is affected by fuel particle size and shape. The shape influence is through the following four ways: particle overlapping; grain direction; geometry and packing in the bed. Particles with flat or concave surface may overlap in the bed. On the other hand, surface with convex surface like a sphere do not overlap. Overlapping of surfaces reduces effective surfaces for fluid flow and chemical reactions. The influence of particle overlapping is analyzed by defining a particle surface availability (Trudel \& Hallet, 2017). Alternatively, its effect is determined using a shape factor included in heat and mass transfer correlations (Glaser \& Thodos, 1958).

Biomass fuels are made of fibres which are normally arranged along one another. It has been shown that pyrolysis rate is faster along the fibres than across them (Larfeldt, Leckner, \& Melaaen, 2000). Volatiles also flow faster along the fibres as compared to movement across them (Henriksen, Hindsgaul, Qvale, Fjellerup, \& Jensen, 2006). Char produced through pyrolysis under low heating rates have fibres arrangement similar to those of raw biomass since they are not destroyed (Trudel et al., 2018). Consequently, porosity is high across the fibres. This cause a higher gas permeability along the grain (Larfeldt et al., 2000). It has been observed that char conversion rate is higher on surface normal to the fibres (Trudel et al., 2018). Thus aspect ratio plays an important role in wood and char gasification (Pattanotai, Watanabe, \& Okazaki, 2015).

The geometry of a particle affects biomass conversion through surface area. Most biomass particles utilized in power plants have wide ranges of shapes which are normally irregular. The shape of a particle is defined in terms of sphericity. It has been shown that sphericity of particles have correlation with ignition rate and bed porosity (Horttanainen, Saastamoinen, \& Sarkomaa, 
2002). Particles with high sphericity have decreased surface area which impact negatively on burning times (Huff, 1985).

The shape and the size of fuel particles also have great impact on the packing of the bed. Consequently, hydrodynamics of flow, heat and mass transfer in the bed are affected. In fact, theories and correlations for pressure loss, heat and mass transfer are based on hydraulic diameter of bed (Comiti \& Renaud, 1991; Whitaker, 1972). The size of fuel particles affects wood conversion in a packed bed through convective and radiation heat transfer, gas species and energy dispersion by turbulence, mass transfer and mixing rate of volatiles and air in the bed. Subsequently, it affects the amount of volatiles released (Yang, Ryu, Khor, Sharifi, et al., 2005), reaction zone thickness (Yang, Ryu, Khor, Yates, et al., 2005), operational limit of air flow rate (Horttanainen et al., 2002), burning rate (Ryu et al., 2006) and ignition front velocity (Porteiro et al., 2010).

Operation mode of the fixed bed is classified as either updraft or downdraft (La Villetta, Costa, \& Massarotti, 2017; Mahapatra, Kumar, \& Dasappa, 2016; Martínez, Mahkamov, Andrade, \& Silva Lora, 2012). These classification depends on the flow direction of oxidizer relative to fuel movement. The various fixed bed operation modes are illustrated in Fig. 2.7. Updraft operation mode is where air is supplied at the bottom and moves upward while the fuel is supplied at the top. Downdraft operation mode is where oxidizer is supplied at the top and moves downward (Pérez, Melgar, \& Tinaut, 2014). Fuel is also filled up from the top side of the bed. This configuration of fixed bed is useful when generating devolatilization gases, viz., $\mathrm{CO}, \mathrm{H}_{2}$ and $\mathrm{CH}_{4}$ which can be used in internal combustion engines (Lapuerta, Hernández, Pazo, \& López, 2008; Melgar, Pérez, Laget, \& Horillo, 2007; Tinaut, Melgar, Pérez, \& Horrillo, 2008). 
Despite the significance of fixed bed combustion technology in power generation, there are no studies of oxy-fuel combustion of biomass in a fixed bed. The effects of bed porosity on wood conversion in a fixed bed under oxy-fuel environment have not been reported.

\subsection{Flame Propagation in a Fixed Bed}

Flame propagation mode in a fixed bed may be classified as either co-current or counter current as illustrated in Fig. 2.7. For co-current flame propagation mode, flame front moves in the same direction as the air movement. On the other hand, counter-current flame propagation is where flame front moves in the opposite direction as air movement. When calculating effective flame speed propagation, bed movement due to shrinkage is taken into consideration. The rate of flame front propagation in biomass fixed bed reactors have been investigated by several researchers, (Dasappa \& Paul, 2001; Ryu et al., 2006; Sakthivadivel \& Iniyan, 2018). It is affected by various factors such as biomass fuel type, density, size, ultimate and proximate analysis and superficial velocity (Gort \& Brouwers, 2001; Horttanainen et al., 2002; Mahapatra, 2016; Thunman \& Leckner, 2005). Flame front speed have been shown to increase with increase in air mass flux up to a peak point where it starts to decrease (Dasappa \& Paul, 2001). Typical range of flame front speed for various biomass fuels burned under different conditions are summarized in Table 2.1.

Operation regimes of fixed bed reactor have great impact on flame front propagation rate. Based on superficial velocity, operation regimes have been classified either as two-regime (Fatehi \& Kaviany, 1994;Shin \& Choi, 2000) or three-regime (Porteiro et al., 2010). In the two-regime classification, propagation speed increases in the fuel rich regime and decreases in the fuel lean regime, as illustrated in Fig. 2.8 (Fatehi \& Kaviany, 1994). In this case, flame front propagation 
are estimated using classical asymptotic analysis analogous to a premixed flame (Dosanjh, Pagni, \& Fernandez-Pello, 1987).

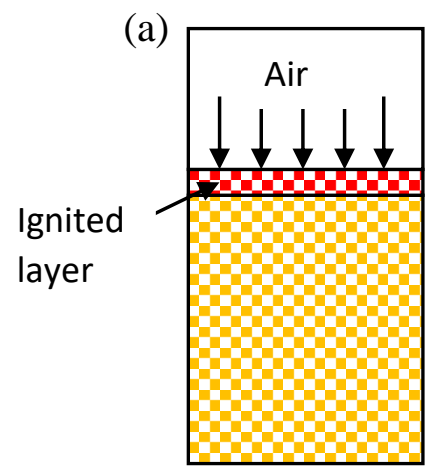

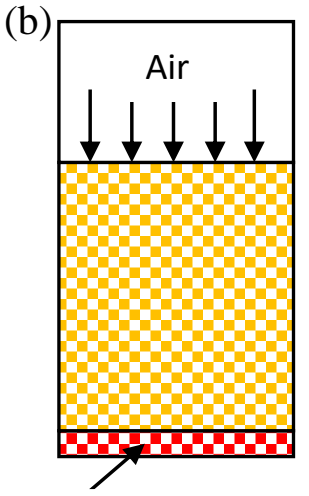

Ignited layer (c)

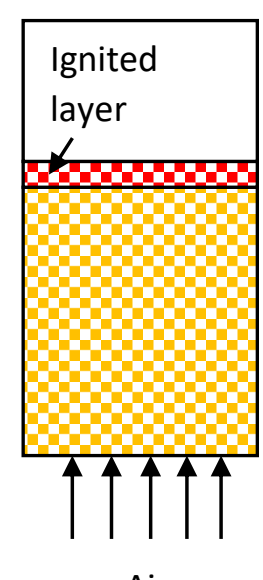

Air

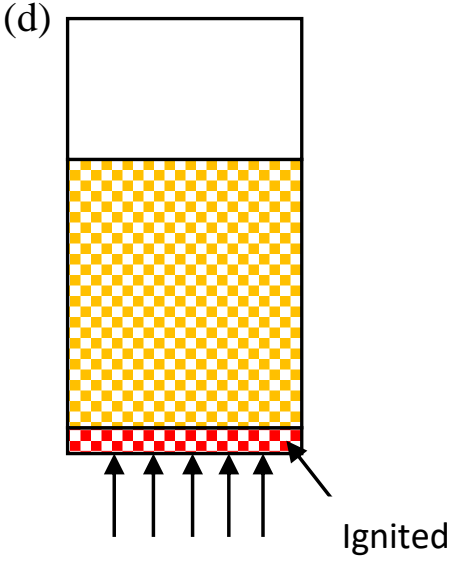

Air layer

Figure 2.7: Fixed bed operation modes: (a) downdraft - co-current; (b) downdraft countercurrent; (c) updraft - countercurrent; (d) updraft - co-current.

Table 2.1: Typical range of flame front speed for various biomass fuels burned under different conditions

\begin{tabular}{|c|c|c|c|}
\hline Fuel type & $\begin{array}{l}\text { Air flow rate } \\
\left(\mathrm{kg} / \mathrm{m}^{2} / \mathrm{s}\right)\end{array}$ & $\begin{array}{l}\text { Propagation } \\
\text { speed }(\mathbf{m m} / \mathbf{s})\end{array}$ & Source \\
\hline Casuarina wood & $0.06-0.20$ & $0.04-0.089$ & Mahapatra et al. (2016). \\
\hline Char particles & $0.015-0.28$ & $0.06-0.30$ & Dasappa \& Paul (2001) \\
\hline Pine wood & 0.1 & 0.24 & Yang et al. (2005). \\
\hline Straw & $0.013-0.062$ & $0.94-3.58$ & Khor et al. (2007) \\
\hline Switch grass & $0.017-0.070$ & $0.83-2.89$ & Khor et al. (2007) \\
\hline Reed canary grass & $0.017-0.046$ & $0.39-1.47$ & Khor et al. (2007) \\
\hline Coconut shells & not provided & 0.063 & Sakthivadivel \& Iniyan (2018) \\
\hline Prosopis juliflora & not provided & 0.071 & Sakthivadivel \& Iniyan (2018) \\
\hline Tamarind seed pellets & not provided & 0.05 & Sakthivadivel \& Iniyan (2018) \\
\hline
\end{tabular}

On the other hand, three-regime classification has fuel rich regime, fuel lean regime and convective cooling regime where propagation speed increases rapidly, gradually and decreases rapidly, respectively. This is illustrated in Fig. 2.9 (Porteiro et al., 2010). A different three- 
regime classification which is based on exit gas composition was presented by Rönnbäck et al. (2008). In this classification, the three regimes are sub-stoichiometric combustion with incomplete consumption of oxygen where flame front speed increases rapidly, stoichiometric combustion regime with complete consumption of oxygen where flame front speed increases gradually and over stoichiometric combustion regime where flame front speed decreases. Furthermore, the role of ash in flame propagation speed has been assessed (Cooper \& Hallett, 2000; Ryan \& Hallett, 2002; Varunkumar, 2012). Ash affects radiative heat transfer to the unburnt biomass, hence affecting the flame propagation.

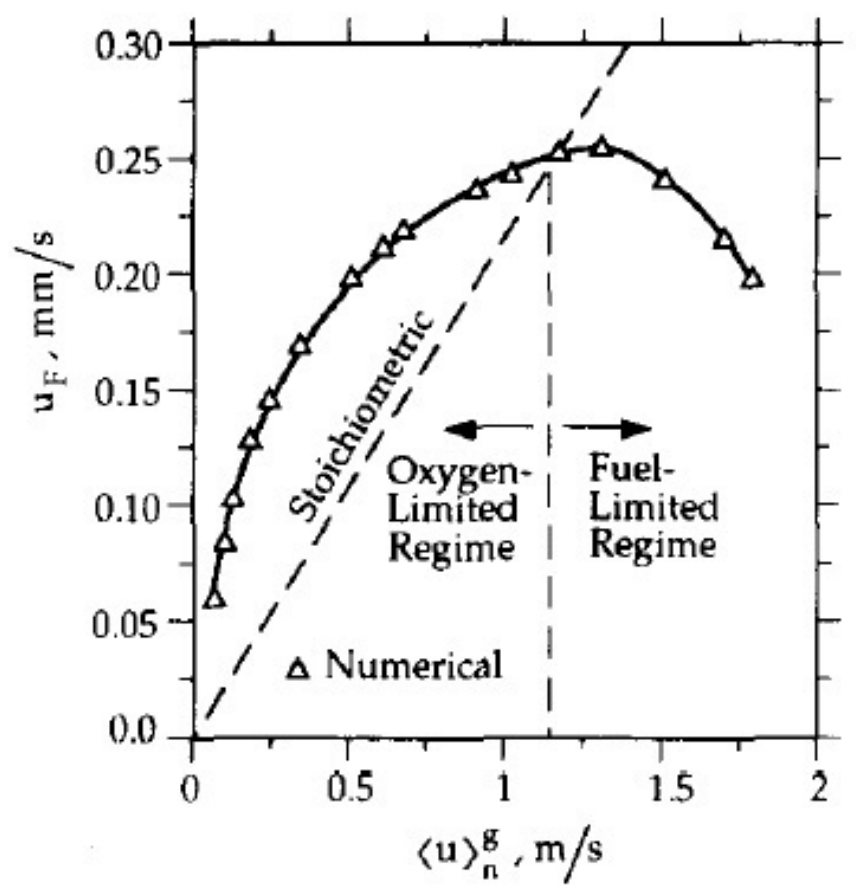

Figure 2.8: Two-regime classification of fixed bed combustion (Fatehi \& Kaviany, 1994).

Although numerous works on flame propagation rate of biomass combustion in fixed bed have been done, none addresses an oxy-fuel environment. 


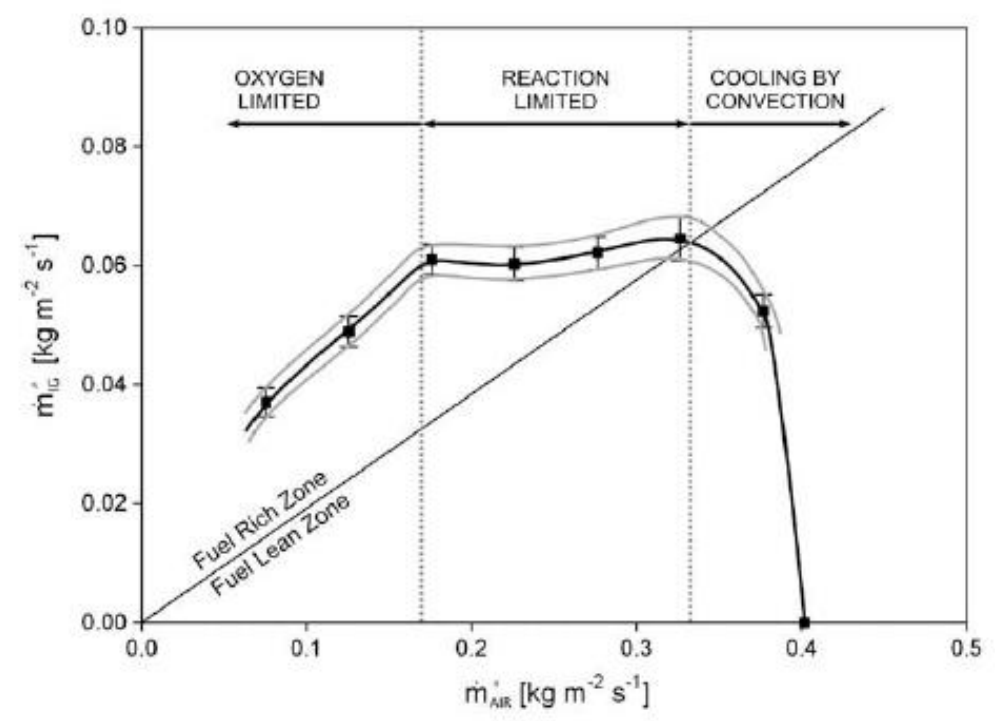

Figure 2.9: Three-regime classification of fixed bed combustion (Porteiro et al., 2010).

\subsection{Modeling Approaches for a Fixed Bed}

Modeling of the various thermal conversion of biomass in a fixed bed have been approached differently. One approach is the consideration of fixed bed as a continuous system made of two phases: a gas phase and a solid phase. Using one-dimensional models, different researchers (Fatehi \& Kaviany, 1994; Saastamoinen \& Taipale, 2000), have studied the propagation of ignition front and the reactions for biomass fuels burning in a fixed bed combustion chamber. In these cases, 1D and transient conservational equations for solid and gaseous phases are used to model fixed bed combustion. Since these models do not consider individual particles, they do not accurately predict thermal conversion of fixed bed and requires experimentally determined empirical correlation.

Another approach is single particle model, where the sum of individual particles processes constitutes the conversion of the packed bed. Ha \& Choi (1994) investigated the effects of initial relative velocity, free stream oxygen concentration, the particle size, pre-exponential factor and 
particle entrainment on conversion of a single particle using 2D, unsteady, laminar conservation equations. Similarly, Lee, Yetter \& Dryer (1995) used a fully transient formulation to compute oxidation of a single carbon particle with focuses on flow field at the boundary layer. Peters (2002) developed a 1D transient particle model which addresses reactions and temperature distribution in the particle. Haseli, Oijen \& Goey (2011) also developed a 1D model for thermal conversion of a wood particle in which they assumed that biomass pyrolysis is by three independent reactions that yield gas, tar and char, respectively. Recently, three-dimensional models for simulating combustion in fixed bed have been developed (Collazo, Porteiro, Patiño, \& Granada, 2012; Mahmoudi, Hoffmann, Markovic, et al., 2016). Collazo et al. (2012) simulated fixed bed reaction using 3D model for both solid and gaseous phases. However, the model did not consider the shrinkage of fuel bed which normally occur in the last phase of combustion. A model that consider bed movement was proposed by Mahmoudi et al. (2015). In the model, gas phase was modeled in three-dimensional, while solid phase was model in one dimension. The model was tested in a fixed bed for various characteristics of biomass combustion including self-heating and self-ignition in a packed bed (Mahmoudi, Hoffmann, Markovic, et al., 2016). Furthermore, Mahmoudi, Hoffmann, \& Peters (2016) propose a model that has improved flow field description by fully resolving solid phase and semi resolving gas phase. The gas phase is described on a length scale smaller than solid particle. The model was implemented on Euler-Lagrange simulation framework.

\subsection{Modeling Shrinkage in Biomass Combustion}

During biomass combustion, shrinking or local collapse occurs in the fuel bed. There are several methods of modeling shrinkage in biomass combustion. These models determine the behavior in which a particle that burns internally changes through the course of the particle reaction. 
Consequently, it represents the way the particle losses mass, that is, by either increase in particle porosity or decrease in the diameter. Shrinkage models have been developed for both single particle and fixed bed combustion. For a single particle, a model where the particle density remains constant while the mass reduces was implemented by Villermaux et al. (1986). This model does not take into consideration the porosity change that take place in actual particle combustion. In case of a fixed bed, a model which considers constant porosity while particles shrink have been implemented by Cooper \& Hallett (2000), Shin \& Choi (2000) and Zhou et al. (2005). The problem with this model is that it does not consider heterogeneities produced by combustion. Collazo et al. (2012) presented a model in which particle porosity varied but with no contraction in the bed. Consequently, the bed size remained almost the same. A model which considered both bed shrinkage and porosity change was implemented by Hermansson \& Thunman (2011). Even though the model had improved accuracy, it didn't consider local shrinkage of the bed. To address this issue, Gomez et al. (2014) presented a model which considered both local consumption of particle leading to the change in porosity and local shrinkage of bed caused by collapsing of areas due to combustion. This model showed an improved accuracy in prediction of some of the combustion parameters.

As combustion progresses, bed shrinkage is affected by packing and arrangement of fuel particles. Consequently, bed porosity also varies during combustion. Although there are numerous studies on fixed bed shrinkage, the influence of particle packing density on combustion properties of oxy-fuel combustion of biomass have not been done.

\subsection{Deduction}

Different aspects of biomass combustion in a fixed bed have been studied through both experimental and numerical modeling. These studies reported cases where biomass is burnt 
conventionally under air-fuel conditions. The properties investigated include ignition time and temperature, mass loss history, species history, temperature profiles and emission characteristics of single biomass pellets, biomass co-fired with coal and pulverized biomass. But these properties have not been studied in oxy-fuel environment. Chemical kinetics for biomass conversion have also been well developed. The need for efficiency and reduced emissions has led to development of clean combustion technologies such as oxy-fuel combustion. Even though several contributions have been made on oxy-fuel combustion of biomass, there are several knowledge gaps that need to be studied. The following knowledge gaps are to be addressed in study:

- In spite of biomass being used under oxy-fuel conditions using fixed bed furnaces, there is no detailed study of biomass combustion in fixed bed reactors under oxy-fuel condition. The studies only cover combustion under air-fuel condition.

- There is no report in the literature on important combustion parameters, viz., flame propagation speed, temperature profiles, ignition time, and species evolution in the fixed bed combustion under oxy-fuel conditions; the studies have been only in air. This work extends the research on biomass conversion to combustion under oxy-fuel conditions.

- Appropriate chemical kinetic model that takes into account the presence of $\mathrm{CO}_{2}$ in oxyfuel combustion of biomass does not exist.

- Although there are numerous studies on fixed bed shrinkage, the influence of particle packing density on combustion properties of oxy-fuel combustion of biomass have not been done. 
- The roles and mechanisms through which $\mathrm{CO}_{2}$ environment affects fundamental combustion phenomena such as flame propagation speed, temperature profiles, ignition time, burning rates and species evolution have not been fully resolved. 


\section{CHAPTER THREE \\ LABORATORY EXPERIMENTS AND RESULTS}

\subsection{Introduction}

Presented in this chapter are the experimental techniques used in determination of the fuel properties as well as in the laboratory test of wood combustion in a fixed bed under air and oxyfuel environment. The techniques for determining combustion parameters, namely, mass history, temperature profiles, burning rates, ignition time, bed porosity and flame front propagating velocity are discussed. Experimental results are presented in the last section of this chapter.

\subsection{Wood Sample Preparation}

In this work, the biomass fuel is eucalyptus wood. Eucalyptus is the main source of fuel for wood-fired boilers used for steam generation in process industries such as tea production in Kenya. Eucalyptus tree is an attractive source because it takes a short time to mature. Ash, volatile matter, gross calorific value and moisture contents of the fuels were determined in accordance to European standards CEN-TS 14775: 2009, CEN-TS 15148:2009, CEN-TS 14918:2009, CEN-TS 14774-2:2009, respectively, and presented in Table 3.1. In addition, ultimate analysis for the samples is presented in Table 3.1.

For studies on packing density, fuel sample sizes were determined in accordance to BS EN 15149 - 2:2010 (2010). The samples were sieved using Fritsch vibratory sieve shaker. In every sieving conducted, an amplitude of $3 \mathrm{~mm}$ and time of $15 \mathrm{~min}$ was used.

The fuel particles were grouped into four categories according to their sizes, viz., sawdust 1 (SD1), sawdust 2 (SD2), wood chips (WC) and wood spheres (WS), as shown in Fig. 3. 1. The 
characteristic size, $\bar{d}$, of each group was best fitted using Rosin-Rammler distribution, Eq. (3.1)

(Williams et al., 2016).

$$
R_{R}(d)=100\left(\exp \left(-\frac{d}{\bar{d}}\right)^{n_{R}}\right)
$$

where $d$ is the particle diameter or mesh size, $n_{R}$ is the parameter of Rosin-Rammler distribution and $R_{R}$ is the percentage of accumulated oversize mass. $n_{R}$ was determined according to the method on Brezáni \& Zeleňák (2010). More details about Rosin-Rammler distribution are provided in Appendix A.

Table 3.1: Proximate and ultimate analysis of fuel sample.

\begin{tabular}{lcl}
\hline Proximate Analysis & $($ wt \%) & Standards \\
Moisture & 10.3 & CEN-TS 14774-2:2009 \\
Volatile matter (wt\% dry basis) & 84.9 & CEN-TS 15148:2009 \\
Fixed carbon (wt\% dry basis) - by difference & 14.9 & - \\
Ash (wt\% dry basis) & 0.2 & CEN-TS 14775:2009 \\
& & \\
Ultimate Analysis & (wt \% dry basis) & Standards \\
C & 50.87 & CEN-TS 15104:2011 \\
H & 5.73 & CEN-TS 15104:2011 \\
N & 0.3 & CEN-TS 15104:2011 \\
O (by difference) & 43.1 & - \\
& & \\
Gross calorific value (MJ/kg) & 19.3 & CEN-TS 14918:2009 \\
\hline
\end{tabular}

The size and shape of the particle were used to determine its sphericity, $\psi$ (Trudel et al., 2018) which is expressed as follows:

$$
\psi=\frac{\pi D_{e q}^{2}}{A_{s}}=\frac{\pi^{1 / 3}\left(6 V_{p}\right)^{2 / 3}}{A_{s}}
$$

where $A_{s}$ is the particle surface area, $V_{p}$ is the particle volume, $D_{e q}$ is the particle diameter which is equivalent to that of a sphere with the same volume. $D_{e q}$ is expressed as follows: 


$$
D_{e q}=\left(\frac{6 V_{p}}{\pi}\right)^{1 / 3} .
$$

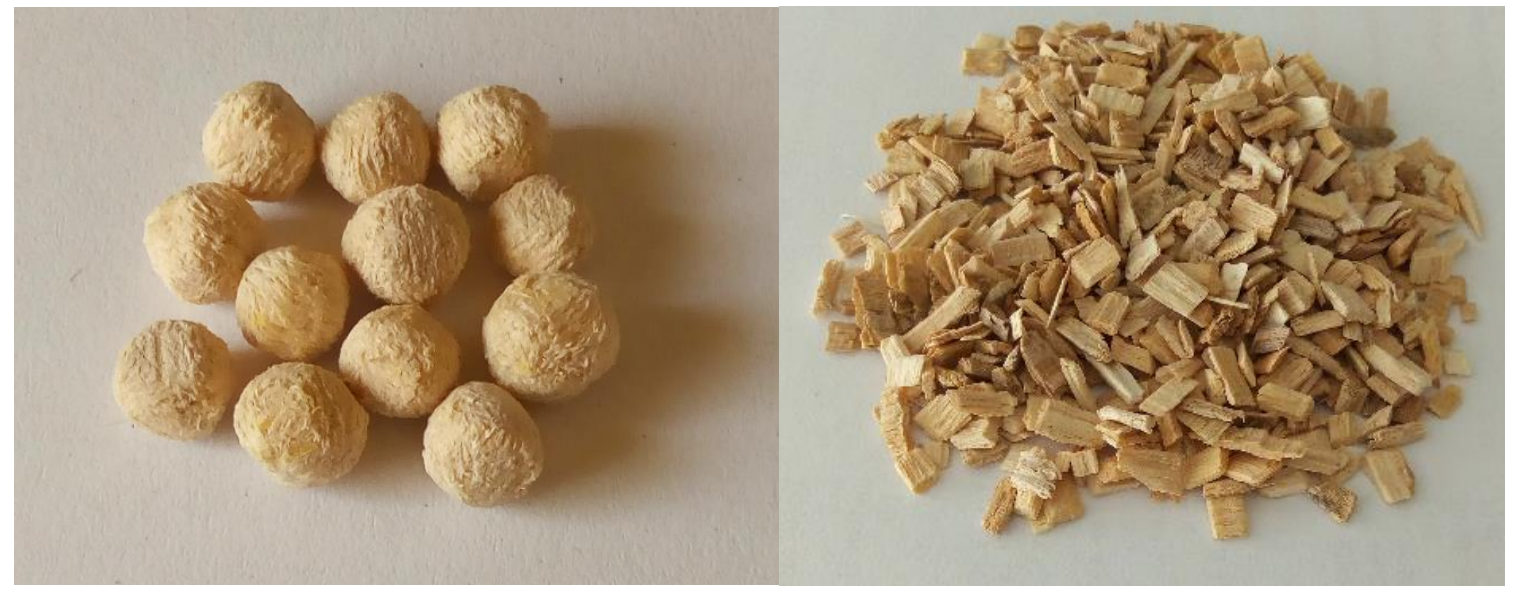

(a) Wood spheres (WS)

(b) Wood chips (WC)

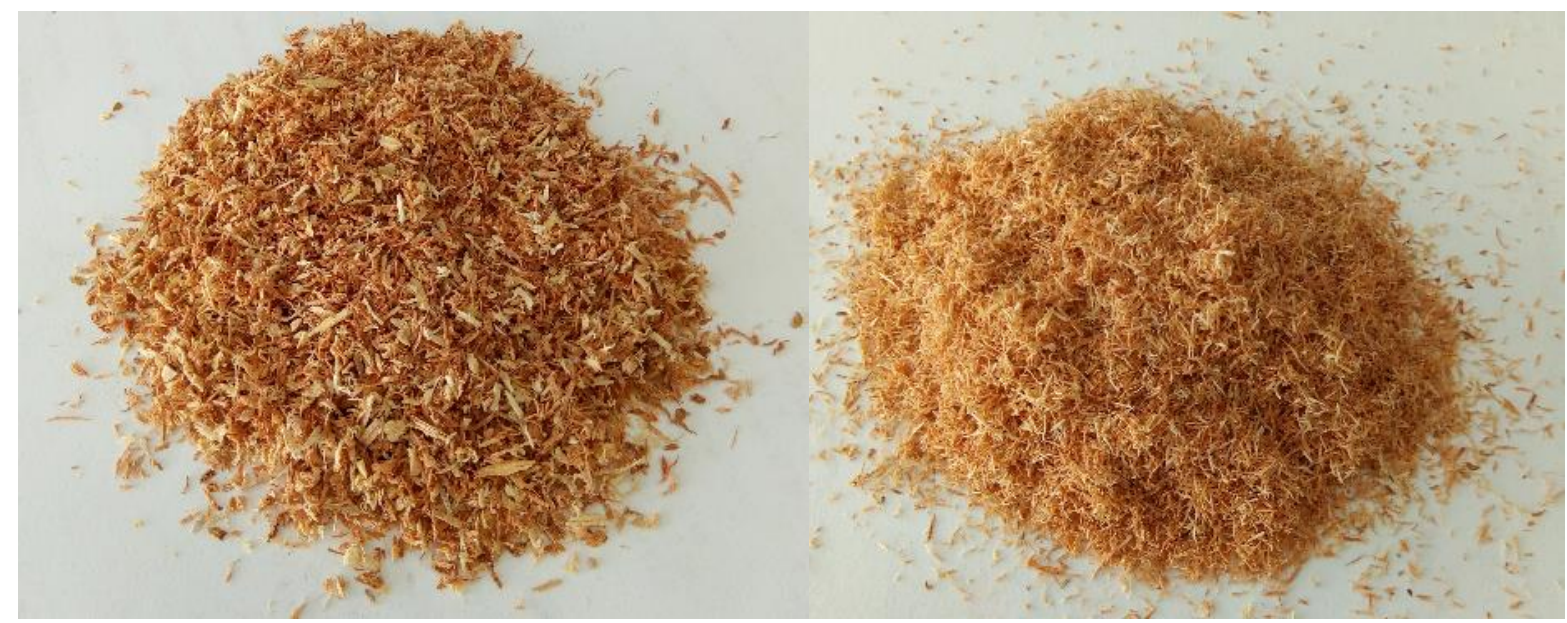

(c) Sawdust 2 (SD2)

(d) Sawdust 1 (SD1)

Figure 3.1: Wood fuel samples.

Bed porosity, $\chi$, was determined from the measured fuel bed density, $\rho_{b}$, and density of wood particle, $\rho_{p}$, which were related through Eq. (3.4) (Horttanainen et al., 2002):

$$
\chi=1-\frac{\rho_{b}}{\rho_{p}}
$$


The sphericity, equivalent diameters and bed porosity of different fuel samples used in this study are presented in Table 3.2.

Table 3.2: Properties of wood samples and fixed bed.

\begin{tabular}{lccccc}
\hline Fuel type & $\rho_{b}\left(\mathrm{~kg} / \mathrm{m}^{3}\right)$ & $\rho_{p}\left(\mathrm{~kg} / \mathrm{m}^{3}\right)$ & $D_{e q}(\mathrm{~mm})$ & $\psi(-)$ & $\chi(-)$ \\
\hline Wood chips (WC) & 597 & 1220 & 5.25 & 0.30 & 0.51 \\
Sawdust 1 (SD1) & 321 & 1220 & 1.28 & 0.25 & 0.74 \\
Sawdust 2 (SD2) & 477 & 1220 & 2.91 & 0.29 & 0.61 \\
$\begin{array}{l}\text { Mixture of WC and SD1 } \\
\text { (25\% of WC) }\end{array}$ & 390 & 1220 & 3.27 & 0.28 & 0.68 \\
$\begin{array}{l}\text { Mixture of WC and SD2 } \\
(50 \% \text { each) }\end{array}$ & 537 & 1220 & 4.08 & 0.30 & 0.56 \\
\hline
\end{tabular}

\subsection{Experimental Set-Up}

A schematic diagram of the experimental set up and a photo of the laboratory setup used in this work are shown in Fig. 3.2 and 3.3, respectively.

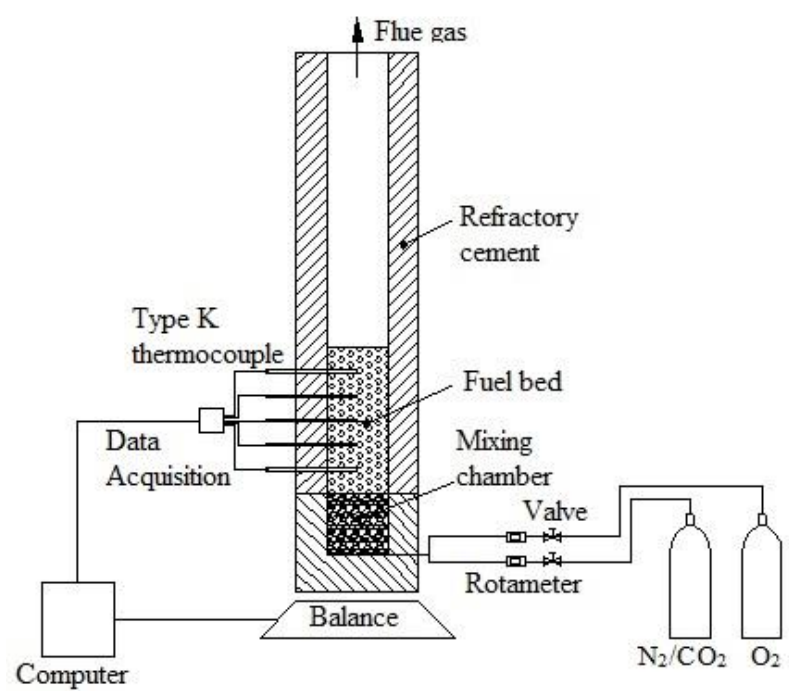

Figure 3.2: Schematic diagram of the experimental set-up.

It is a laboratory fixed bed reactor, which has provision for regulating the ratio of $\mathrm{O}_{2} / \mathrm{CO}_{2}$ and $\mathrm{O}_{2} / \mathrm{N}_{2}$ during combustion. It has an internal diameter of $40 \mathrm{~mm}$ and a height of $200 \mathrm{~mm}$. It has 
provisions for thermocouple insertions located at $10 \mathrm{~mm}$ intervals. Internal and external parts are made of stainless steel and between them is a $20 \mathrm{~mm}$ thick refractory cement for insulation. Thermal conductivity of refractory cement is 0.34 W/m.K (Lienhard IV \& Lienhard V, 2003). Critical insulation radius for this material, considering typical values of convective heat transfer coefficient for air in natural convection as $10-20 \mathrm{~W} / \mathrm{m}^{2} . \mathrm{K}$ (Incropera et al., 2006) lies between 17 and $34 \mathrm{~mm}$. An external radius of $40 \mathrm{~mm}$ used in this reactor is, therefore, sufficient for heat insulation. Fuel bed is held by a stainless steel grate.

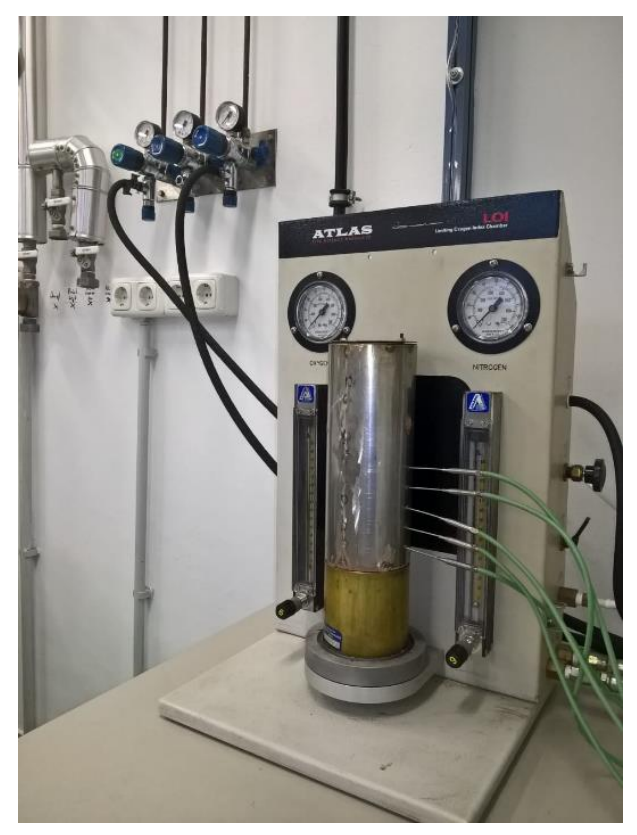

Figure 3.3: A photo of laboratory set-up.

The reactor was operated in counter-current flame propagation mode. Top fuel was ignited initially and the flame front propagates downward into the virgin fuel. Oxidizer was supplied from the bottom. For this arrangement, there is no fuel bed movement. The fuel bed was ignited using methane gas flame with a flow rate of $0.051 \mathrm{~m}^{3} / \mathrm{h}$. Ignition time was about $10 \mathrm{~s}$. The amount of methane used in ignition was estimated to be $94 \mathrm{mg}$ and released a total amount of 
heat of $4719 \mathrm{~J}$. It was expected that this amount of heat ignites a top layer of wood of about $2.26 \mathrm{~g}$, therefore, wood temperature during ignition was raised to about $1182^{\circ} \mathrm{C}$.

Oxidizer was a mixture of pure $\mathrm{O}_{2}$ and $\mathrm{N}_{2}$ or $\mathrm{CO}_{2}$ in various composition. The different gas components were supplied independently through a perforated bottom plate of a $100 \mathrm{~mm}$ long mixing chamber made of brass. The chamber was filled with $8 \mathrm{~mm}$ long hollow glass with internal diameter of $4 \mathrm{~mm}$ for settling and generating a relatively uniform flow. A constant mass flow rate of $0.1 \mathrm{~kg} / \mathrm{m}^{2} / \mathrm{s}$ was used for all the tests carried out. Gas flow rates were measured using variable area flowmeters (rotameters) in-build in Atlas LOI equipment with a tolerance of $\pm 2 \%$. The flow rate of the mixture for various $\mathrm{O}_{2}$ concentration was calculated based on Eqn. (3.5) and tabulated in Table 4.3.

$$
\dot{m}_{m}=Q_{O_{2}}\left(\frac{p}{R T}\right)_{O_{2}}+Q_{D}\left(\frac{p}{R T}\right)_{D}
$$

where $p$ is the supply pressure, $T$ is the supply temperature, $\dot{m}_{m}$ is the mixture mass flow rate (kg/s) and $Q_{O_{2}}$ and $Q_{D}$ are volumetric flow rate of $\mathrm{O}_{2}$ and diluent, $\mathrm{N}_{2}$ or $\mathrm{CO}_{2}$, respectively.

Table 3.3: Volumetric flow rates for $\mathrm{O}_{2} / \mathrm{N}_{2}$ and $\mathrm{O}_{2} / \mathrm{CO}_{2}$ supplied at $T=295 \mathrm{~K}, p=5$ bar and operating condition of $\dot{m}=0.1 \mathrm{~kg} / \mathrm{m}^{2} / \mathrm{s}$.

\begin{tabular}{|c|c|c|c|c|}
\hline \multirow{2}{*}{$\begin{array}{l}\mathrm{O}_{2} \\
\text { composition } \\
(\% \text { vol })\end{array}$} & \multicolumn{2}{|c|}{$\mathrm{O}_{2} / \mathrm{N}_{2}$ mixture } & \multicolumn{2}{|c|}{$\mathrm{O}_{2} / \mathrm{CO}_{2}$ mixture } \\
\hline & $\begin{array}{l}\mathrm{O}_{2} \text { flow rate } \\
\text { (l/min) }\end{array}$ & $\begin{array}{l}\mathrm{N}_{2} \text { flow rate } \\
\text { (l/min) }\end{array}$ & $\begin{array}{l}\mathrm{O}_{2} \text { flow rate } \\
\text { (l/min) }\end{array}$ & $\begin{array}{l}\mathrm{CO}_{2} \text { flow rate } \\
(\mathrm{l} / \mathrm{min})\end{array}$ \\
\hline 21 & 0.057 & 0.213 & 0.039 & 0.148 \\
\hline 25 & 0.067 & 0.201 & 0.047 & 0.142 \\
\hline 30 & 0.080 & 0.186 & 0.058 & 0.135 \\
\hline 35 & 0.093 & 0.172 & 0.068 & 0.127 \\
\hline 40 & 0.105 & 0.158 & 0.079 & 0.119 \\
\hline 45 & 0.117 & 0.143 & 0.091 & 0.111 \\
\hline 50 & 0.130 & 0.130 & 0.102 & 0.102 \\
\hline
\end{tabular}


During combustion, the reactor was placed on a weighting balance in order to obtain mass loss history. The weighing balance has an accuracy of $\pm 0.01 \mathrm{~g}$. Temperature in the fuel bed was monitored by five Type $\mathrm{K}$ thermocouples. They are connected to a data acquisition system that records temperature every second. Temperature measurement and data acquisition using Type K thermocouples were done in accordance to ASTM MNL12 (Park et al., 1993). In this regard, temperature measurement uncertainty and calibration of thermocouples were done. Uncertainty of thermocouple data acquisition system is dependent on combustion zone temperature. For the whole range of thermocouple measurement, it is between $\pm 2.184{ }^{\circ} \mathrm{C}$ and $\pm 6.630{ }^{\circ} \mathrm{C}$ (for more details see Appendix B). In addition, temperature measured by thermocouple may differ significantly from the true gas temperature because of radiation heat loss from the thermocouple surface to the cooler surrounding walls. Error due to radiation loss was corrected according to the methodology developed by Blevins \& Pitts (1999) and have been applied by other researchers (Brohez, Delvosalle, \& Marlair, 2004; Rashidian, Al-Abdeli, Yeoh, Patiño, \& Guzzomi, 2017; Roberts, Coney, \& Gibbs, 2011). In this method, maximum and minimum measurement error which occur when using bare bead and single shielded aspirated thermocouple (TC), respectively, are used to estimate the error in sheathed thermocouple with the same bead size (for more details see Appendix C).

Measurement of combustion properties were made for different $\mathrm{O}_{2} / \mathrm{CO}_{2}$ mixtures which varied in composition of $\mathrm{O}_{2}$ in $\mathrm{CO}_{2}$ from $21 \%$ to $50 \%$ by volume. For comparison purposes, measurements of combustion properties were made for air-fuel condition. The gaseous mixtures were supplied at room temperature $(295 \mathrm{~K})$. Each test was done in three replicate to check repeatability. 


\subsection{Determination of Combustion Parameters}

\subsubsection{Burning History}

Burning history for the fuel bed was monitored by temperature and mass loss measurement. A $6 \mathrm{~cm}$ fuel bed were combusted. For each test, bulk density of the bed was determined. Despite using the same particle size and bed height, there were slight variations of the bulk density, \pm 2 $\mathrm{kg} / \mathrm{m}^{2}$, because of random fuel and void arrangement in the bed. For all the particle type studied, a bulk density of 402 to $597 \mathrm{~kg} / \mathrm{m}^{2}$ were recorded during experiments.

Temperature at five equidistant vertical locations, $10 \mathrm{~mm}$ apart, were measured using type $\mathrm{K}$ thermocouple. A data acquisition device was used to record temperature with respect to time. The mass of the bed was continuously monitored using a weighting balance.

\subsubsection{Flame Front Propagation Speed}

The flame front propagation speed, $V_{F}$, is estimated from distance and time data of temperature measuring points (Sakthivadivel \& Iniyan, 2018; Yang, Ryu, Sharifi, \& Swithenbank, 2006). It is calculated as follows:

$$
V_{F}=\frac{\Delta x}{\Delta t}
$$

where $\Delta x$ is the distance between two thermocouples and $\Delta t$ is the time between the abrupt increase in temperature of thermocouples from ambient value to peak value.

Another parameter that was used to quantify combustion in the bed is reaction zone thickness. It is regarded to be the physical distance in the flame front where the bed temperature rises from ambient value to peak value. A stiff temperature rise represents a thin reaction front whereas a gradually changing temperature rise represents a thick reaction front. 


\subsubsection{Ignition Time}

Ignition time is considered to be the time at which devolatilization starts where a sustainable combustion is achieved. In this work, ignition of fuel at any part of the bed was assumed to take place when there is an abrupt increase of temperature from ambient value to peak value.

\subsubsection{Burning Rate}

Burning rate, $\dot{m}_{b}$, represent the rate of biomass consumption which include both devolatilization and char combustion. It is defined as the rate of mass loss per unit crosssectional area (Khor et al., 2007; Yang, Ryu, Khor, Yates, et al., 2005). It was determined by considering the amount of fuel burnt, given by the measured change in weight of the column, and the total time of combustion;

$$
\dot{m}_{b}=\frac{\text { Fuel weight }(\mathrm{kg})}{\text { Combustion time }(\mathrm{s}) \times \text { Cross sectional area }\left(\mathrm{m}^{2}\right)}
$$

The difference between burning rate and ignition rate is the rate of mass accumulation above the ignition front.

\subsection{Experimental Results}

Presented in this section are the experimental results of temperature profiles, mass loss history, ignition times, flame front propagation speeds and burning rates. The results are for combustion of wood in different $\mathrm{O}_{2} / \mathrm{N}_{2}$ and $\mathrm{O}_{2} / \mathrm{CO}_{2}$ mixtures and for various bed porosity. In all the results presented, error bars are the standard deviations.

Figure 3.4 shows the mass loss history measured during entire combustion period for wood combustion in a fixed bed at $21 \% \mathrm{O}_{2} / 79 \% \mathrm{~N}_{2}$ and $21 \% \mathrm{O}_{2} / 79 \% \mathrm{CO}_{2}$ mixtures. In both cases, the graph clearly depicts three phases of wood conversion, namely, drying phase represented 
by the first region of slow mass loss, devolatilization phase represented by a slightly fast mass loss, and char combustion phase with the slowest changes in mass. The deviation of experimental values of mass loss from their respective mean values ranges between $2 \%$ and $17 \%$. Thus the experimental values showed a good repeatability.

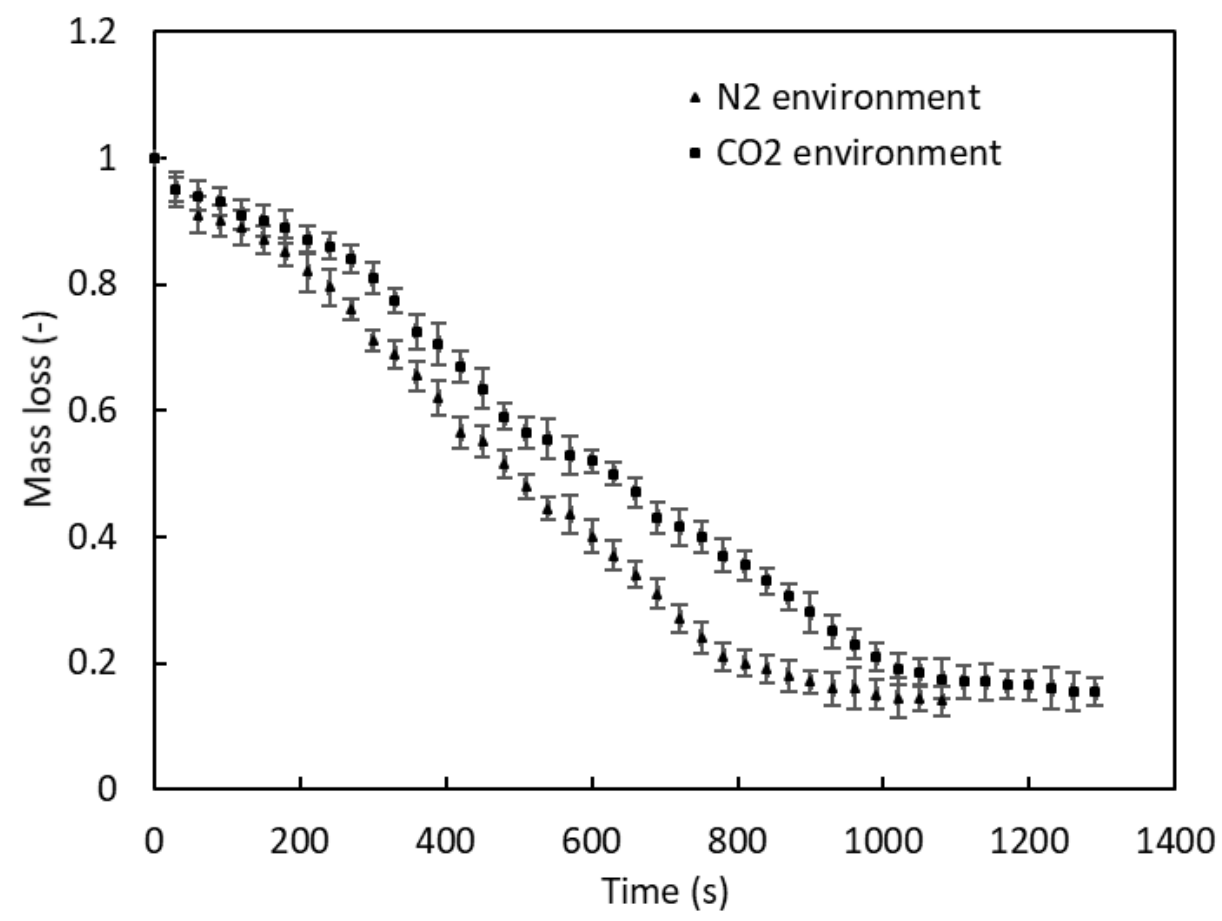

Figure 3.4: Measured mass loss history for wood combustion in fixed bed at $21 \% \mathrm{O}_{2} / 79 \% \mathrm{~N}_{2}$ and $21 \% \mathrm{O}_{2} / 79 \% \mathrm{CO}_{2}$ mixtures.

Temperature distributions at different height above the grate were measured and recorded by thermocouples. Fig. 3.5 presents results of temperature for combustion of spherical wood particles in a fixed bed in $21 \% \mathrm{O}_{2} / 79 \% \mathrm{~N}_{2}$ mixture and $21 \% \mathrm{O}_{2} / 79 \% \mathrm{CO}_{2}$ mixture while Fig. 3.6 presents results of temperature for combustion of wood in $21 \% \mathrm{O}_{2} / 79 \% \mathrm{CO}_{2}$ with various bed porosity; $\chi=0.51$ to $\chi=0.74$. In Fig. 3.5, the graph shows that the temperature profile for both $\mathrm{N}_{2}$ and $\mathrm{CO}_{2}$ environment have two distinct temperature peaks. The peak temperature is lower 
in $\mathrm{CO}_{2}$ environment as compared to $\mathrm{N}_{2}$ environment. Low porosity beds have two distinct temperature peaks, Figs 3.6(a) and (b), while high porosity beds have single temperature peak, Figs 3.6 (a)-(c). Furthermore, high porosity beds attained relatively higher values of temperature at the peak than those for the first peaks of low porosity beds. For each case, errors are shown for data of a representative thermocouple. The deviation of experimental values of temperature from their respective mean values for all points ranges between $1.8 \%$ and $7.7 \%$. This also indicates a good repeatability.
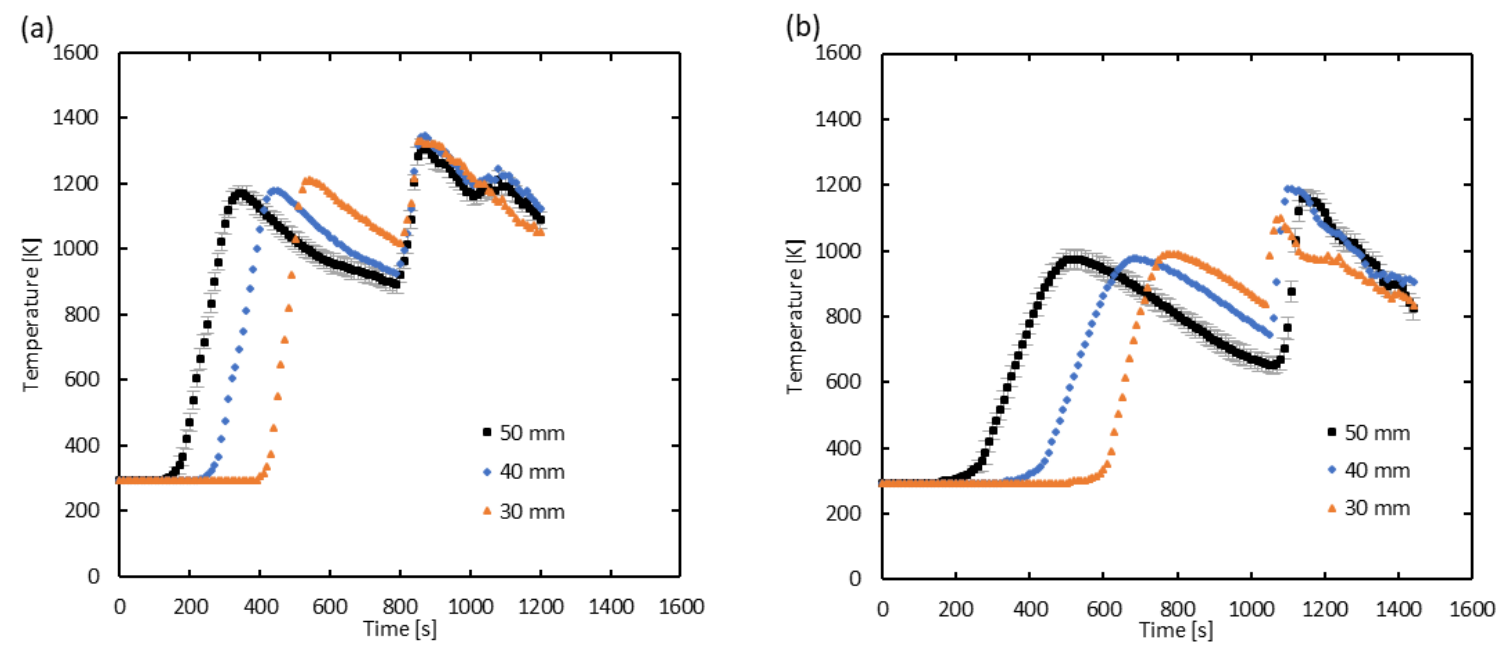

Figure 3.5: Measured temperature profiles at various distances from the bed bottom for wood combustion in (a) $21 \% \mathrm{O}_{2} / 79 \% \mathrm{~N}_{2}$ mixture and (b) $21 \% \mathrm{O}_{2} / 79 \% \mathrm{CO}_{2}$ mixture.

The ignition times for fixed bed combustion of spherical wood measured in various $\mathrm{O}_{2} / \mathrm{N}_{2}$ and $\mathrm{O}_{2} / \mathrm{CO}_{2}$ mixtures are shown in Fig. 3.7 while for various bed porosity is shown in Fig. 3.8. In both $\mathrm{N}_{2}$ and $\mathrm{CO}_{2}$ environments, the graph shows that ignition times decrease with increase in $\mathrm{O}_{2}$ concentration. The ignition times at corresponding oxygen concentration are higher in $\mathrm{CO}_{2}$ environment than in $\mathrm{N}_{2}$ environment. The standard deviations of experimental values of ignition times from their corresponding mean values ranges from $2.2 \%$ to $18 \%$. 

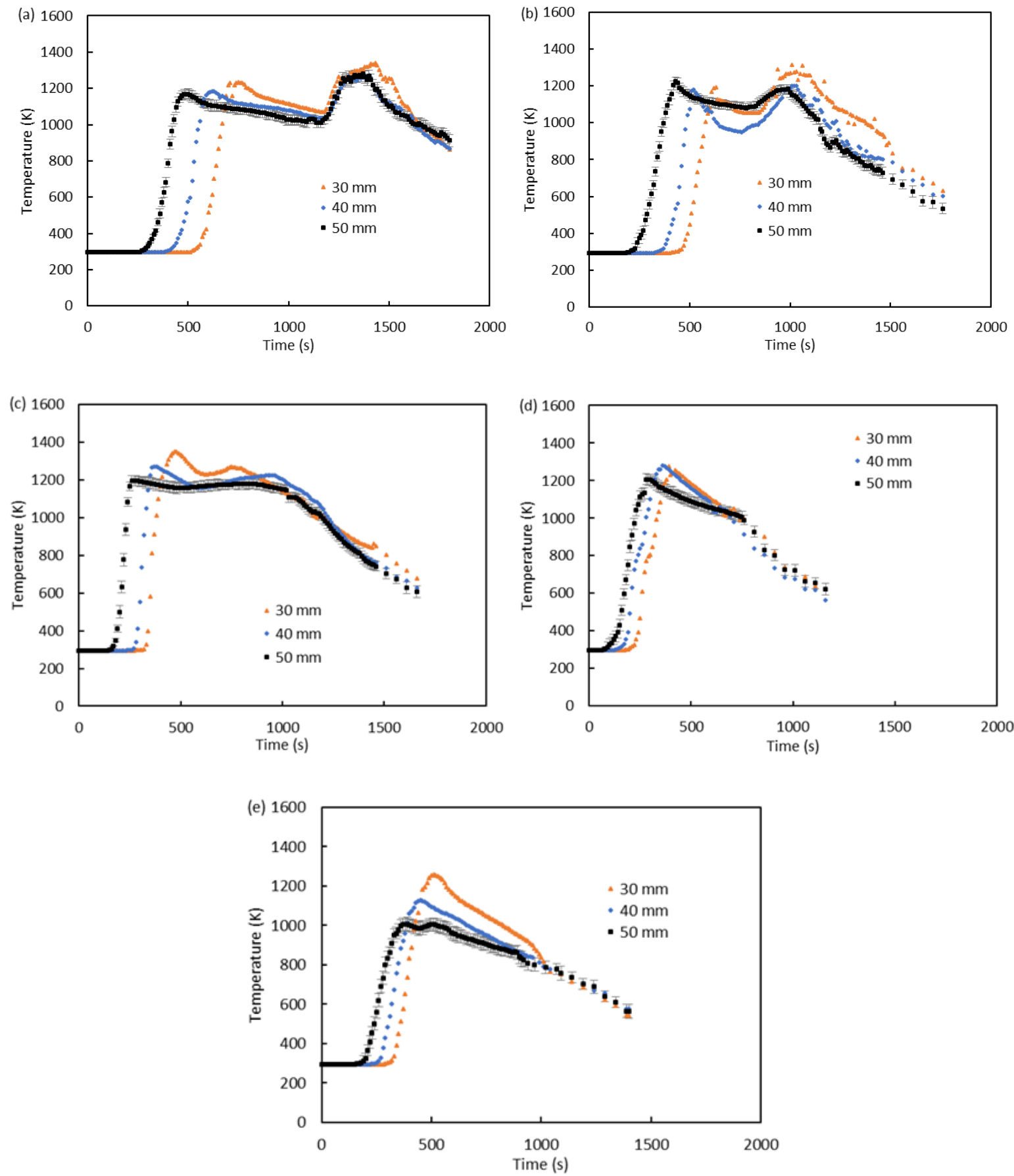

Figure 3.6: Measured temperature profiles at various heights above the grate for particle types

(a) WC $(\chi=0.51)$, (b) WCSD2 $(\chi=0.56)$, (c) SD2 $(\chi=0.61)$, (d) WCSD1 $(\chi=0.68)$ and (e) $\operatorname{SD1}(\chi=0.74)$. 


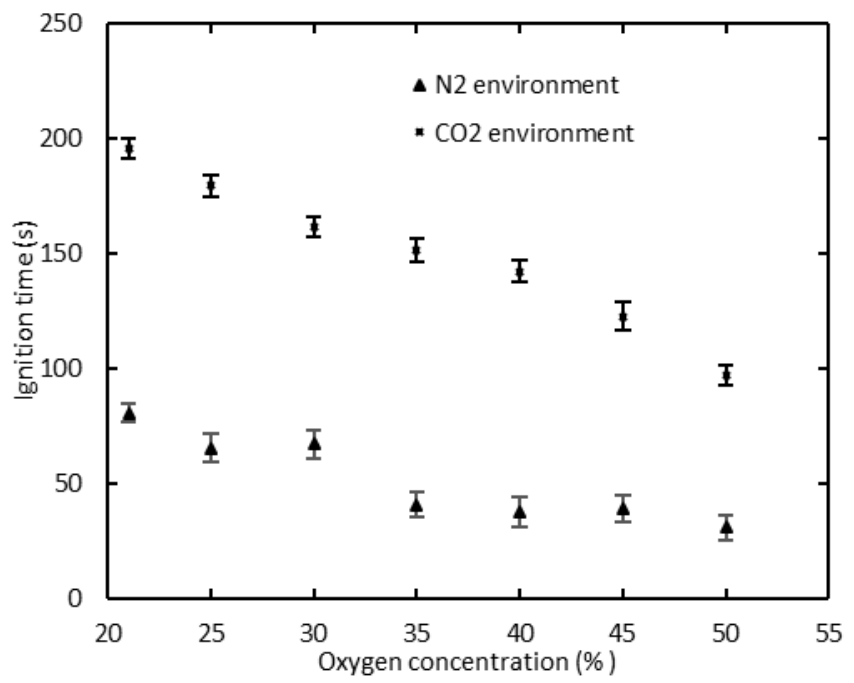

Figure 3.7: Measured ignition time for fixed bed combustion of wood in $\mathrm{N}_{2}$ and $\mathrm{CO}_{2}$ environments.

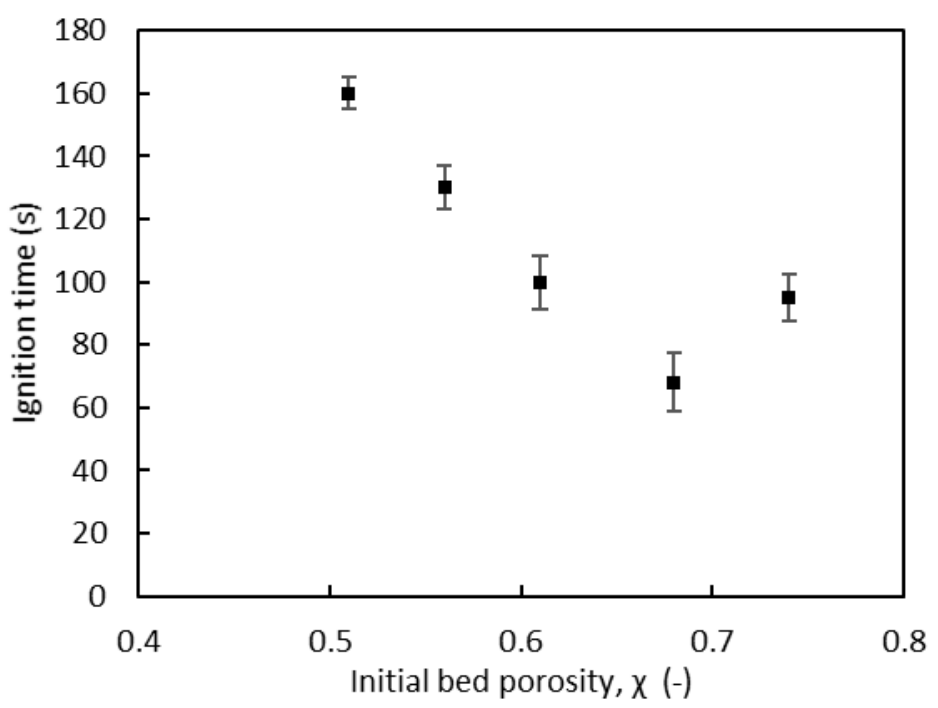

Figure 3.8: Measured ignition time for wood combustion in $21 \% \mathrm{O}_{2} / 79 \% \mathrm{CO}_{2}$ mixture for different initial bed porosity.

The flame front propagation speed for fixed bed combustion of spherical wood measured in various $\mathrm{O}_{2} / \mathrm{N}_{2}$ and $\mathrm{O}_{2} / \mathrm{CO}_{2}$ mixtures are shown in Fig. 3.9 while for various bed porosity is 
shown in Fig. 3.10. The graph shows that flame front propagation speed is directly proportional to $\mathrm{O}_{2}$ concentration in both $\mathrm{N}_{2}$ and $\mathrm{CO}_{2}$ environments. The flame front propagation speed at corresponding oxygen concentration are higher in $\mathrm{N}_{2}$ environment than in $\mathrm{CO}_{2}$ environment. The standard deviations of experimental values of flame front propagation speed from their corresponding mean values ranges from $3 \%$ to $12.6 \%$. The lower flame speed observed in $\mathrm{CO}_{2}$ environment could be attributed to its higher specific heat capacity which reduces its flame temperature. As a result, the heating rates of the fuel particles in the bed is decreased and lead to a decrease in flame speed.

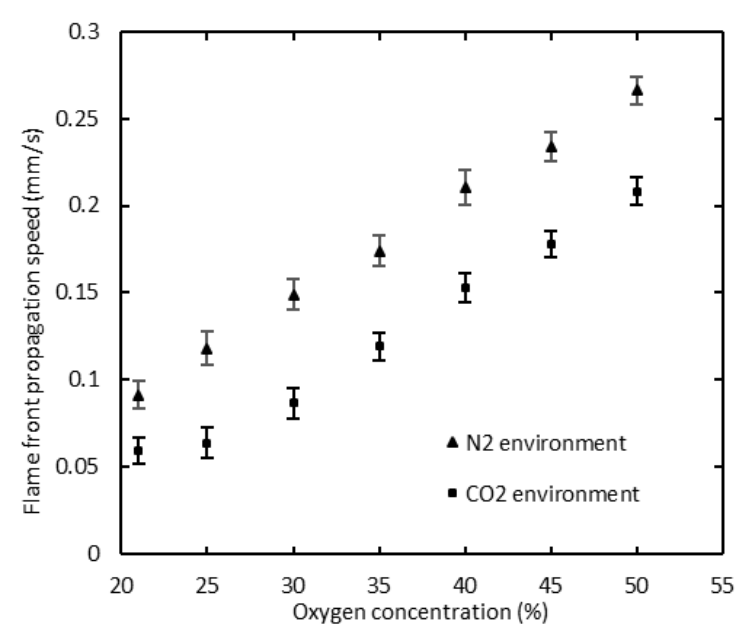

Figure 3.9: Measured flame front propagation speed for fixed bed combustion of wood in $\mathrm{N}_{2}$ and $\mathrm{CO}_{2}$ environments.

The burning rates for fixed bed combustion of spherical wood measured in various $\mathrm{O}_{2} / \mathrm{N}_{2}$ and $\mathrm{O}_{2} / \mathrm{CO}_{2}$ mixtures are shown in Fig. 3.11. The graph shows that burning rates increase with increase in $\mathrm{O}_{2}$ concentration in both $\mathrm{N}_{2}$ and $\mathrm{CO}_{2}$ environments. The burning rates at corresponding oxygen concentration are higher in $\mathrm{N}_{2}$ environment than in $\mathrm{CO}_{2}$ environment. The standard deviations of experimental values of burning rates from their corresponding mean values ranges from $2.9 \%$ to $10.8 \%$. The burning rate of a fuel is highly depended on the 
combustion temperature which affects the heating rate of the particles. The lower burning rates in $\mathrm{CO}_{2}$ environment is associated to its lower combustion temperature, as noted in Fig. 3.5. Furthermore, $\mathrm{O}_{2}$ diffusivity in $\mathrm{CO}_{2}$ environment is low since $\mathrm{CO}_{2}$ is a heavy gas (Suda et al., 2007). Therefore, the reduced amount of $\mathrm{O}_{2}$ at the particles' reactive surface causes a decrease in its consumption as well as the burning rate.

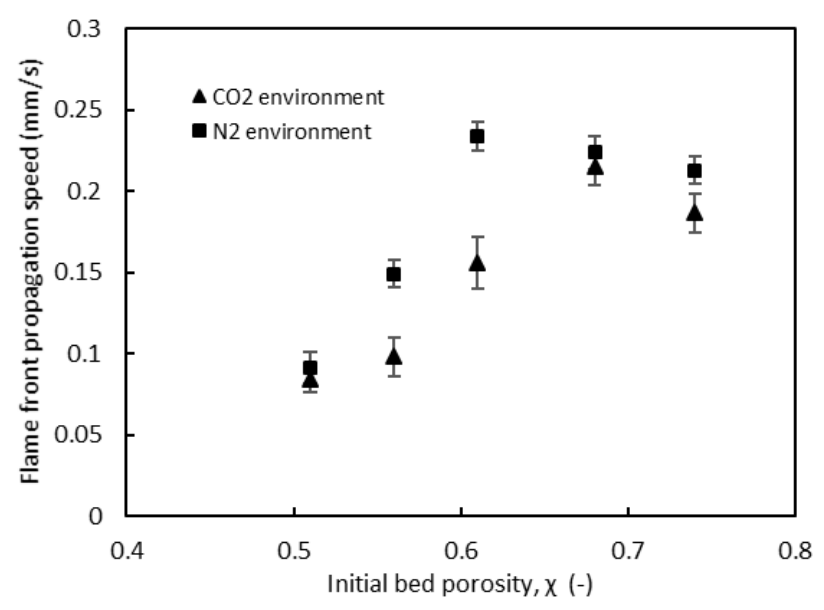

Figure 3.10: Measured flame front propagation speed for wood combustion in in $21 \% \mathrm{O}_{2} / 79 \%$ $\mathrm{N}_{2}$ and $21 \% \mathrm{O}_{2} / 79 \% \mathrm{CO}_{2}$ mixtures for different initial bed porosity.

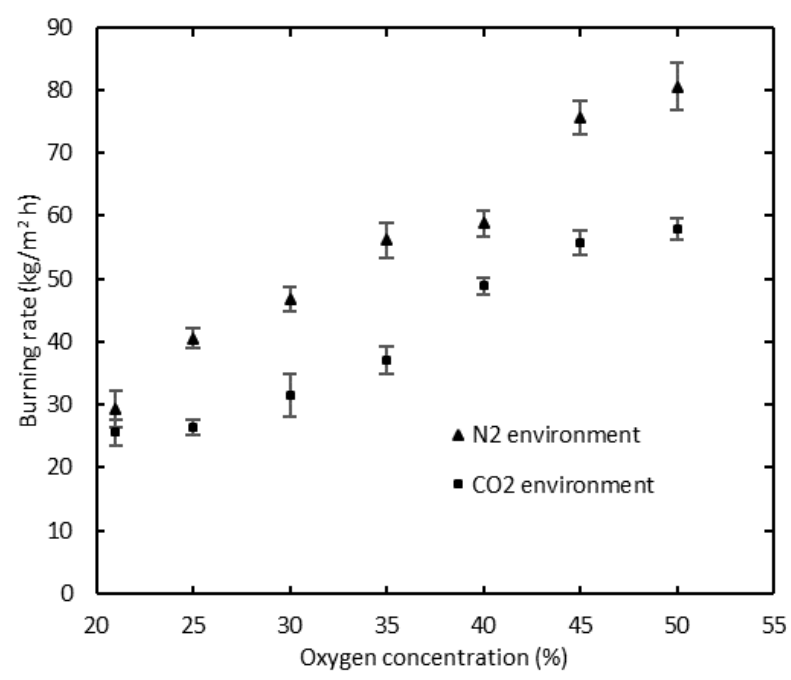

Figure 3.11: Measured burning rate for fixed bed combustion of wood in $\mathrm{N}_{2}$ and $\mathrm{CO}_{2}$ environments. 
In overall, the experimental results showed a good repeatability with most of the points having a standard deviation from their respective mean values being below $18 \%$. 


\section{CHAPTER FOUR \\ NUMERICAL MODELLING}

\subsection{Introduction}

Presented in this chapter are the numerical simulation of wood combustion in a fixed bed. The governing equations for both solid phase and gas phase as well as coupling equations are presented. Furthermore, specific models for the various physico-chemical processes, viz., turbulence, radiation, fuel shrinkage and chemical kinetics are also discussed. Numerical solution methods employed, geometry and boundary conditions formulations and computational meshes are also presented.

\subsection{Governing Equations}

A fixed bed of solid fuel consists of particles which interact with one another in terms of heat exchange by conduction and radiation. They also interact with gas phase surrounding them in the void spaces. In addition, they undergo conversion through several processes, viz., drying, pyrolysis and char oxidation. All these processes are illustrated in Fig. 4.1. To model particles conversion in a fuel bed, all these processes must be accounted. This section presents governing equations for both solid phase and gas phase as well as coupling equations and other specific models which are required during computation of wood combustion in a fixed bed.

In this work Euler-Lagrangian model have been used to model biomass conversion in a fixed bed. Computational Fluid Dynamics - Discrete Element Method (CFD-DEM) simulation method was used in this study. Solid particles and their conversion have been modeled using DEM while fluid phase have been modeled as a continuous phase using CFD. The two phases are coupled together. The interaction between the phases is enabled by two-way coupling equations. 


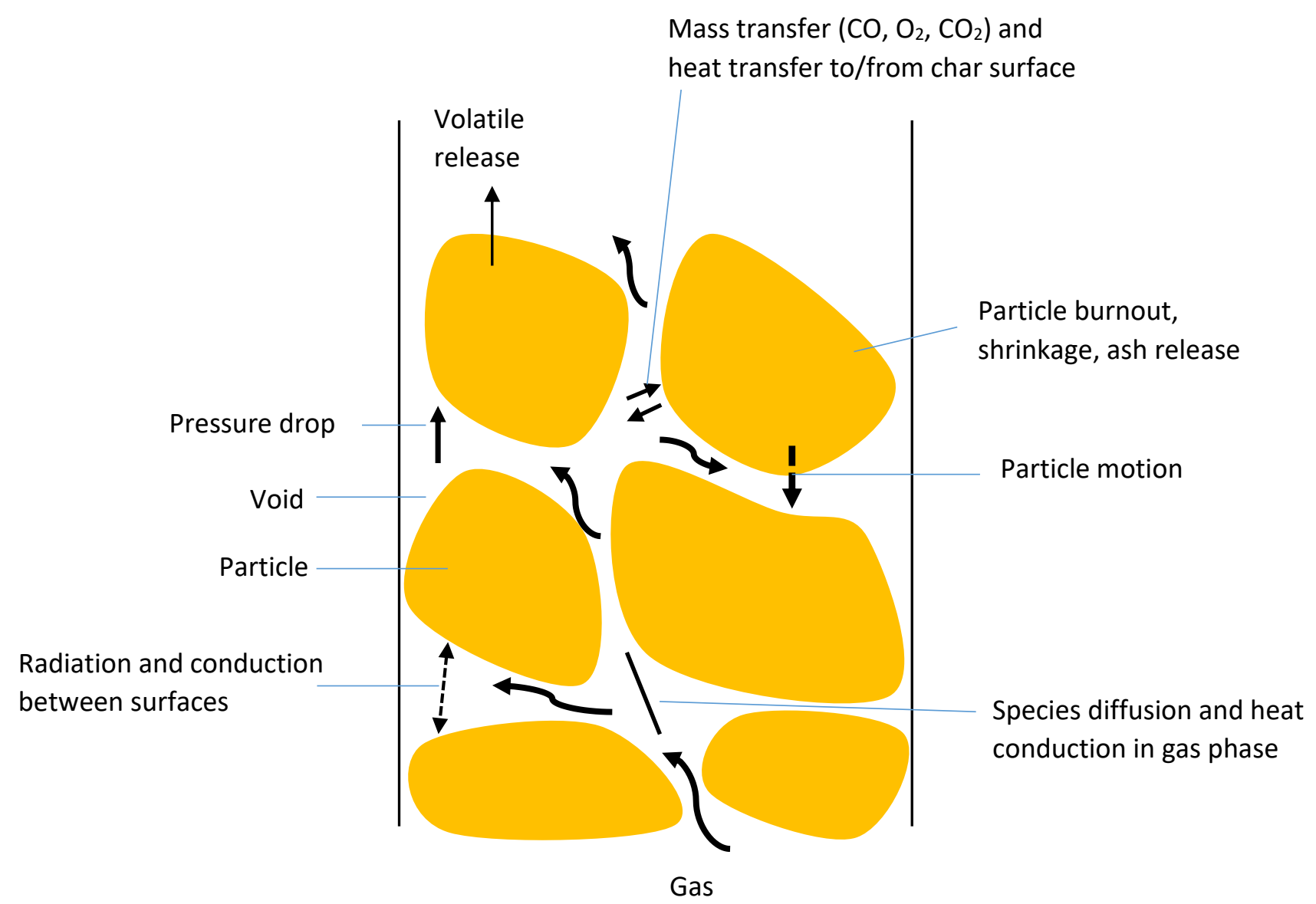

Figure 4.1: Processes of a fuel bed thermal conversion.

\subsubsection{Merits and Demerits of CFD-DEM Code}

In this work, numerical simulations of wood conversion in a fixed bed using CFD-DEM approach were implemented through a commercial software STAR CCM+ version 11.04 (CDAdapco, 2017). CFD-DEM code considers the conversion of each particle, which are sum to obtain the conversion in the bed. The code has the following merits and demerits:

\subsubsection{Merits}

- Solid-phase is modeled using single particle technique. Detailed information for mass, species and energy are captured for each particle. Therefore, the prediction accuracy of the entire fuel bed conversion is improved. 
- Empirical correlations which are experimentally determined are not required since the conversion of each particle is considered. Hence, the method is independent of particular experimental conditions.

- Shrinkage of fuel bed is easily implemented in this method by considering a suitable particle shrinkage model.

\subsubsection{Demerit}

The method requires high computing power. This is because it solves transport equations of energy, mass and species for each particle. In addition, it requires a computer with a large storage that is capable of storing all information for mass, species and energy for each particle.

\subsubsection{Model Considerations}

To model a fixed bed combustion, the following main considerations have been made:

1. Wood fuel is considered to be spherical particles. Each particle is modeled as thermally thin, that is, it has low Biot number, $\mathrm{Bi}<0.1$, which causes negligible internal temperature gradient. Therefore, each particle is assumed to be internally homogeneous. The physical properties of the wood and char used in simulations are presented in section 4.8 .

2. Fuel bed is considered as a porous media where the pressure loss is accounted for by Ergun equation (Mehrabian, Shiehnejadhesar, Scharler, \& Obernberger, 2014). This is incorporated as a source term in gas-phase momentum equation.

3. For the conditions tested in this study, the Reynolds Number, Re, for the gas flow in the bed was evaluated to be in the range of 3200 to 4820 , which is in the turbulent flow regime. Therefore, turbulent combustion model was considered in the simulation. 
4. Gas phase and solid phase interact by exchanging mass, species and energy. Heat is exchanged between solid-phase and gas-phase by convection and radiation while within solid phase is by conduction and radiation.

5. Porosity of the particle, denoted by $\theta$, is assumed to vary during bed thermal conversion as a result of local consumption of solid phase. Therefore, the particle diameter slightly shrinks producing a slight change in the bed size during entire combustion period.

These considerations are discussed here below.

\subsubsection{Gas-Phase Equations}

The conservation equations governing multi-component, chemically reacting, gas mixtures applicable to a fixed bed are presented below (CD-Adapco, 2017; Mehrabian, 2013; Wehinger, 2016):

- Mass conservation equation:

$$
\frac{\partial}{\partial t}\left(\chi \rho_{g}\right)+\nabla \cdot\left(\rho_{g} \mathbf{v}_{\boldsymbol{g}}\right)=\sum_{i, g} w_{i, g}^{g s}
$$

- Momentum conservation equation:

$$
\frac{\partial}{\partial t}\left(\chi \rho_{g} \mathbf{v}_{\boldsymbol{g}}\right)+\nabla \cdot\left(\rho_{g} \mathbf{v}_{\boldsymbol{g}} \mathbf{v}_{\boldsymbol{g}}\right)=-\nabla p+\nabla \cdot \tau+\rho_{g} g+S_{m}
$$

where is $S_{m}$ momentum source term given as;

$$
S_{m}=-\left(\frac{\mu}{C_{1}} \mathbf{v}_{\boldsymbol{g}}+C_{2} \rho_{g}\left|\mathbf{v}_{\boldsymbol{g}}\right| \mathbf{v}_{\boldsymbol{g}}\right)
$$

- Energy conservation equation: 


$$
\begin{gathered}
\frac{\partial}{\partial t}\left(\chi \rho_{g} h_{\boldsymbol{g}}\right)+\nabla \cdot\left(\rho_{g} \mathbf{v}_{\boldsymbol{g}} h_{\boldsymbol{g}}\right)=\frac{\partial}{\partial t}(\chi p)+\nabla \cdot\left(\lambda_{g, e} \nabla T_{\boldsymbol{g}}-\sum_{\boldsymbol{i = 1}}^{N_{\boldsymbol{g}}} h_{i, \boldsymbol{g}} J_{\boldsymbol{i}, \boldsymbol{g}}\right) \\
+\nabla \cdot\left(\mathbf{v}_{\boldsymbol{g}} p\right)-\nabla \cdot\left(\tau \cdot \mathbf{v}_{\boldsymbol{g}}\right)+S_{E}
\end{gathered}
$$

where $S_{E}$ is energy source term given as;

$$
S_{E}=A_{s} h_{c}\left(T_{s}-T_{g}\right)-\sum_{i, g} w_{i, g}^{g s} H_{i, g}+q_{R}
$$

- Species conservation equation for a species $i, g$ :

$$
\frac{\partial}{\partial t}\left(\chi \rho_{g} Y_{i, g}\right)+\nabla \cdot\left(\rho_{g} \mathbf{v}_{\boldsymbol{g}} Y_{i, g}\right)=\nabla \cdot\left(\rho_{g} D \nabla Y_{i, g}\right)+w_{i, g}^{g s}
$$

In Eqs (4.1) - (4.6), $A_{s}$ is the particle surface area, $C_{1}$ is the permeability, $C_{2}$ is the inertia loss coefficient, $D$ is the diffusivity, $g$ is the gravity, $H_{i, g}$ is the enthalpy of formation of gas-phase species $i, h_{c}$ is the heat transfer coefficient, $h_{g}$ is the enthalpy of gas-phase mixture, $h_{i, g}$ is the enthalpy of gas-phase species $i, J_{i, g}$ is the diffusion mass flux of gas-phase species $i, N_{g}$ is the number of gas species, $p$ is the hydrostatic pressure, $q_{R}$ is the radiant heat flux vector, $T_{g}$ is the gas-phase temperature, $t$ is the time, $T_{s}$ is the solid-phase temperature, $\mathbf{v}_{\boldsymbol{g}}$ is the gas-phase velocity vector, $\lambda_{g, e}$ is the effective gas-phase thermal conductivity, $\mu$ is the coefficient of dynamic viscosity, $\rho_{g}$ is the gas-phase mass density, $\chi$ is the void fraction, $\tau$ is the shear stress

tensor, $Y_{i, g}$ is the mass fraction of gaseous species $i, g$ and $w_{i, g}^{g s}$ is the rate of production of gaseous species $i, g$ heterogeneous chemical reactions.

\subsubsection{Solid-Phase Equations}

In this thesis, fixed bed is treated as a collection of particles and conversion of each particle is modeled using DEM. Conversion of the bed is equal to the summation of all the particles processes. 
Conservation equations for a multi-component solid particle employed in STAR CCM+ are summarized below (CD-Adapco, 2017; van Kuijk, 2008):

- Mass conservation:

$$
\frac{\partial}{\partial t}\left((1-\chi) \rho_{s}\right)=\sum_{i, s} w_{i, s}^{g s}
$$

- Species conservation:

$$
\frac{\partial}{\partial t}\left((1-\chi) \rho_{s} Y_{i, s}\right)=w_{i, s}^{g s}
$$

- Energy conservation:

$$
\begin{gathered}
\rho_{s} c_{p s}(1-\chi) \frac{\partial T_{p}}{\partial t}=\underbrace{\nabla \cdot\left(\lambda_{s, e} \nabla T_{s}\right)}_{1}+\underbrace{A_{s} h_{c}\left(T_{g}-T_{s}\right)}_{2} \\
+\underbrace{\frac{A_{s}}{4} Q_{a, p}\left(G-4 \sigma T_{s}^{4}\right)}_{3}+\underbrace{\sum_{i, s} w_{i, s}^{g s} H_{i, s}}_{4} ;
\end{gathered}
$$

where term 1 in Eq. (4.9) is the heat transfer by conduction within the particle, term 2 is the heat flux at the particle surface due to convection, term 3 is the radiation heat flux at the particle surface and term 4 is the energy change due to enthalpy of formation of species $i$.

In Eqs (4.7) - (4.9), besides the symbols defined earlier, $\rho_{s}$ is the particle density, $Y_{i, s}$ is the mass fraction of solid-phase species $i, s, w_{i, s}^{g s}$ is the rate of production of solid-phase species $i, s$ by heterogeneous chemical reactions, $c_{p s}$ is the specific heat capacity of the particle, $T_{p}$ is the particle temperature, $\lambda_{s, e}$ is the effective solid phase thermal conductivity, $Q_{a, p}$ is the absorption efficiency of the particle, $G$ is the incident radiative heat flux, and $\sigma$ is the Stefan-Boltzmann constant, $H_{i, s}$ is enthalpy of formation of solid-phase species $i$.

The heat transfer coefficient, $h_{c}$ is given in terms of the particle Nusselt number, $N u_{p}$ : 


$$
N u_{p}=\frac{h_{c} d_{p}}{\lambda_{g}}
$$

where $d_{p}$ is the particle diameter. $N u_{p}$ for spherical particles in flows of up to Reynolds number, $R e_{p} \cong 5000$ can be defined using Ranz-Marshall correlation (Incropera et al., 2006):

$$
N u_{p}=2\left(1+0.3 \operatorname{Re}^{1 / 2} \operatorname{Pr}^{1 / 3}\right)
$$

where $\operatorname{Pr}$ is the Prandtl number of the continuous phase.

\subsubsection{Two-way coupling equations}

Two-way coupling equations allow particle phase to exchange mass, species and energy with the continuous phase. These equations are described below (CD-Adapco, 2017):

- Mass conservation:

$$
\sum_{i, g} w_{i, g}^{g s}=-\sum_{i, s} w_{i, s}^{g s}
$$

- Species conservation equation for species $i, s$ :

$$
w_{i, g}^{g s}=-w_{i, s}^{g s}
$$

- Energy conservation - The interaction between solid-phase and gas-phase in terms of convective and radiation heat transfer is enabled by a source term added to solid phase energy equation, Eq. (4.9), and subtracted in gas-phase energy equation, Eqs. (4.4) and (4.5).

\subsection{Turbulence Model}

There are three main frameworks for computing turbulent flows which are reactive, viz.; (1) Reynolds-Averaged Naviers Stokes (RANS), (2) Direct Numerical Simulations (DNS) and, (3) Large Eddy Simulation (LES). In DNS the three-dimensional unsteady governing equations are fully solved with regard to time, velocity and the scalar fields. The time and length scales are 
fully solved. Therefore, it requires trillions of grids points and very numerous number of time steps. Current state of the art DNS is able to compute problems with domain which are very close to actual systems, i.e., with one order of magnitude less than the practical combustion devices. The main challenge of DNS is the temporal integration of conservation equations.

In LES, contribution of large eddies is considered through spatial filtration of governing equations. In this method, scale separation approach is utilized. Scale separation is made on large eddies that have energy and small eddies or subgrid scales (SGS) which dissipate energy. The advantage of LES is that it takes into consideration large scale information in the governing equations. Consequently, the importance of large scale eddies on mixing and reactions rates is realized in LES.

RANS is based on time or ensemble averaged of instantaneous transport equations for mass, momentum and reactive scalars. Turbulent motion and combustion are not resolved in time and length scales. This method requires closure models in order to address unresolved terms.

In this work RANS modeling approach has been used. RANS equations are obtained by decomposing instantaneous transport equations for various conservation quantities into two components, i.e., mean and fluctuating parts. As a results of Reynold decomposition, an additional term arises in momentum transport equation. This new term is referred to as Reynold stress, as illustrated in the Reynold-averaged momentum equation (Wehinger, 2016):

$$
\frac{\partial}{\partial t}\left(\rho_{g} \bar{v}_{i}\right)+\frac{\partial}{\partial x_{j}}\left(\rho_{g} \bar{v}_{i} \bar{v}_{j}+\rho_{g} \overline{v_{l}^{\prime} v_{J}^{\prime}}\right)+\frac{\partial \bar{p}}{\partial x_{i}}+\frac{\partial \bar{\tau}_{i j}}{\partial x_{j}}=\rho_{g} g_{i}
$$

where $\bar{v}_{i}$ and $\bar{v}_{j}$ are the mean velocity component in $i$ and $j$ direction, $v_{i}^{\prime}$ and $v_{j}^{\prime}$ are the fluctuating velocity component in $i$ and $j$ direction, $x_{i}$ and $x_{j}$ are the Cartesian co-ordinates, $\bar{p}$ is the mean pressure, $\bar{\tau}_{i j}$ is the mean stress tensor and $\rho_{g} \overline{v_{l}^{\prime} v_{J}^{\prime}}$ is the Reynolds stresses. $\rho_{g} \overline{v_{l}^{\prime} v_{J}^{\prime}}$ is modeled using Boussinesq approximation (Echekki \& Mastorakos, 2011; Wehinger, 2016): 


$$
-\rho_{g} \overline{v_{l}^{\prime} v_{J}^{\prime}}=\mu_{t}\left(\frac{\partial v_{i}}{\partial x_{j}}+\frac{\partial v_{j}}{\partial x_{i}}\right)-\frac{2}{3}\left(\rho_{g} k+\mu_{t} \frac{\partial v_{i}}{\partial x_{i}}\right) \delta_{i j}
$$

where $\mu_{t}$ is the turbulent viscosity, $k$ is turbulent kinetic energy and $\delta_{i j}$ is the Kronecker delta which is unity for $i=j$ else zero.

Closure models utilized in STAR CCM+ are eddy viscosity models and Reynolds stress transport models. Eddy viscosity models use the concept of a turbulent viscosity, $\mu_{t}$ to model the Reynolds stresses as a function of mean flow quantities, for example Boussinesq approximation Eq. (4.15). Other models in this category which require additional transport equations includes $k-\varepsilon$ models, $k-\omega$ models and Spalart-Allmaras models (Knaus et al., 2000; Shur, Spalart, Strelets, \& Travin, 2008). In this work, $k-\varepsilon$ model was used. In this model, the additional transport equations required are for turbulent kinetic energy, $k$ and turbulence dissipation rate, $\varepsilon$. Various forms of $k-\varepsilon$ model exists, for example, standard, standard two-layer, standard low-Re and realizable model. Standard $k-\varepsilon$ model was used in this work because it is easy to implement and suitable at all Reynolds numbers.

In standard $k-\varepsilon$ model, the additional equations used are those which were proposed by Jones \& Launder (1972) and coefficients proposed by Launder \& Sharma (1974). These equations are expressed as follows:

$$
\begin{gathered}
\frac{\partial}{\partial t}\left(\rho_{g} k\right)+\frac{\partial}{\partial x_{i}}\left(\rho_{g} v_{i} k\right)=\frac{\partial}{\partial x_{i}}\left[\left(\mu+\frac{\mu_{t}}{\sigma_{k}}\right) \frac{\partial k}{\partial x_{i}}\right]+G_{k}+G_{b}-\rho_{g} \varepsilon \\
\frac{\partial}{\partial t}\left(\rho_{g} \varepsilon\right)+\frac{\partial}{\partial x_{i}}\left(\rho_{g} v_{i} \varepsilon\right)=\frac{\partial}{\partial x_{i}}\left[\left(\mu+\frac{\mu_{t}}{\sigma_{k}}\right) \frac{\partial \varepsilon}{\partial x_{i}}\right]+C_{\varepsilon 1} \frac{\varepsilon}{k}\left[G_{k}+\left(1-C_{\varepsilon 3}\right) G_{b}\right]-C_{\varepsilon 2} \rho_{g} \frac{\varepsilon^{2}}{k}
\end{gathered}
$$

where $G_{k}$ is the production of turbulent kinetic energy, $k$ due to Reynolds stresses;

$$
G_{k}=-\rho_{g} \overline{v_{l}^{\prime} v_{J}^{\prime}} \frac{\partial v_{j}}{\partial x_{i}}
$$


$G_{b}$ is production of turbulent kinetic energy, $k$ due to buoyancy;

$$
G_{b}=-\beta g_{i} \frac{\mu_{t}}{P r_{t}} \frac{\partial T_{g}}{\partial x_{i}}
$$

$P r_{t}$ is the turbulent Prandtl number, $\beta$ is the thermal expansion coefficient and $C_{\varepsilon 1}, C_{\varepsilon 2}$ and $C_{\varepsilon 3}$ are model coefficients which are taken as $C_{\varepsilon 1}=1.44, C_{\varepsilon 2}=1.92$,

$$
C_{\varepsilon 3}=\left\{\begin{array}{l}
1 \text { for } G_{b} \geq 0 \\
1 \text { for } G_{b}<0
\end{array}\right.
$$

Turbulent viscosity is computed as follows:

$$
\mu_{t}=\rho C_{\mu} k T
$$

where $C_{\mu}$ is a constant taken as 0.09 .

\subsection{Radiation Model}

In this work, radiation energy exchange between continuous region and particles have been considered. A participation media radiation model (Fiveland, 1988) also known as Discrete Ordinate Method (DOM) have been implemented. The model simulates thermal radiation exchange between diffuse/specular surfaces which forms a closed set. The radiative properties of the surface are specified in terms of diffuse/specular reflectivity, emissivity and radiation temperature. The region between the surfaces are filled with media which absorb, emit and scatter radiation. The media include both the fuel particles and the gases. Therefore, apart from surface's optical properties and thermal boundary conditions, the amount of radiation emitted and received by the surface depends on this effect.

The presence of high concentration of $\mathrm{H}_{2} \mathrm{O}$ and $\mathrm{CO}_{2}$ gases in an oxy-fuel combustion environment alters radiative gas properties. The choice of the property model affects the accuracy of the overall radiation model. Some models use oversimplified approach, for 
example, gray gas model, while others use comprehensive approach, for example, wavelength dependent property models. A widely used model is weighted-sum-of-gray-gas-model (WSGGM) which works well in an air-fuel combustion environment (Smith et al., 1982). There have been some efforts, for instance Yin et al. (2012), to modify WSGGM so as to improve its accuracy in predicting radiation in an oxy-fuel combustion environment. It has been noted that modified WSGGM model has significant improvement on the accuracy when considering large scale reactors (Álvarez et al., 2014; Park et al., 2012). A minimal change of less than 1\% on temperature was noted when applied on a small scale reactor (Álvarez et al., 2014). The reactor used in this study is small, therefore, unmodified WSGGM was implemented with an expectation that it would not significantly affects the results.

In WSGGM model, the radiative properties of the medium are considered to be constant in the entire spectrum. The method assumed that the medium is made up of different amount of gray gases with different absorption coefficients. In WSGGM method, $\mathrm{H}_{2} \mathrm{O}$ and $\mathrm{CO}_{2}$ are the only gases considered because they are the main products of combustion with significant influence on absorption and emission of radiation.

Bouguer-Lambert law (Malinin \&Yoe, 1961) defines the relationship between the total gray gas absorption coefficient, $\kappa$ and the total absorptivity for a gray medium, $\alpha_{t}$ :

$$
\alpha_{t}=1-e^{-\kappa s}
$$

where $s$ is the optical path length.

A weighted-sum of several gray gases is use to approximate the total absorptivity:

$$
\alpha_{t} \approx \sum_{\kappa=0}^{K} a_{\kappa}\left(1-e^{-\kappa_{\kappa} s}\right)
$$


where $K$ is the total number of gray gases, $a_{\kappa}$ is the weight factor and $\kappa_{\kappa}$ is the absorption coefficient of each gray gas. The total gray gas absorption coefficient, $\kappa$, which is represented in RTE Eq. (D.1) as $k_{a}$, Appendix D, is obtained by solving Eqs (4.22) and (4.23).

\subsection{Shrinkage Model}

In this thesis, the porosity of the particle, $\theta$ was modeled according to Eqs (4.24) and (4.25):

$$
\begin{gathered}
\frac{d_{p}}{d_{p, 0}}=\left(\frac{m_{p}}{m_{p, 0}}\right)^{\frac{\alpha}{3}}, \\
\theta=1-\left(\frac{m_{p}}{m_{p, 0}}\right)^{1-\alpha},
\end{gathered}
$$

where $d_{p}$ is the particle diameter, $m_{p}$ is the particle mass, $\alpha$ is the exponent factor $(0 \leq \alpha \leq 1)$ and $O$ is the initial state of the particle.

The particle volume, $V_{p}$, is obtained from the following expression:

$$
V_{p}=\frac{m_{p}}{(1-\theta) \rho}
$$

and the diameter, $d_{p}$ is evaluated using Eq. (3.3). And the apparent density, $\rho_{\text {apparent }}$ is evaluated as follows:

$$
\rho_{\text {apparent }}=(1-\theta) \rho,
$$

The diameter of the particle is then used to evaluate the surface area of the particle, $A_{s}$. When the surface area of a particle changes, the overall reaction rate is affected. Through Eqs (4.24) and (4.25), the following shrinkages models are possible: 
1. Particles can lose mass by increasing porosity yet maintaining the original diameter ( $\alpha$ $=0$ ), as illustrated in Fig. 4.2.

2. Particles can lose mass by decreasing in diameter yet maintaining zero porosity $(\alpha=1)$, as illustrated in Fig. 4.3.

3. Particles can lose mass by decreasing in diameter and increasing porosity $(0<\alpha<1)$, as illustrated in Fig. 4.4.

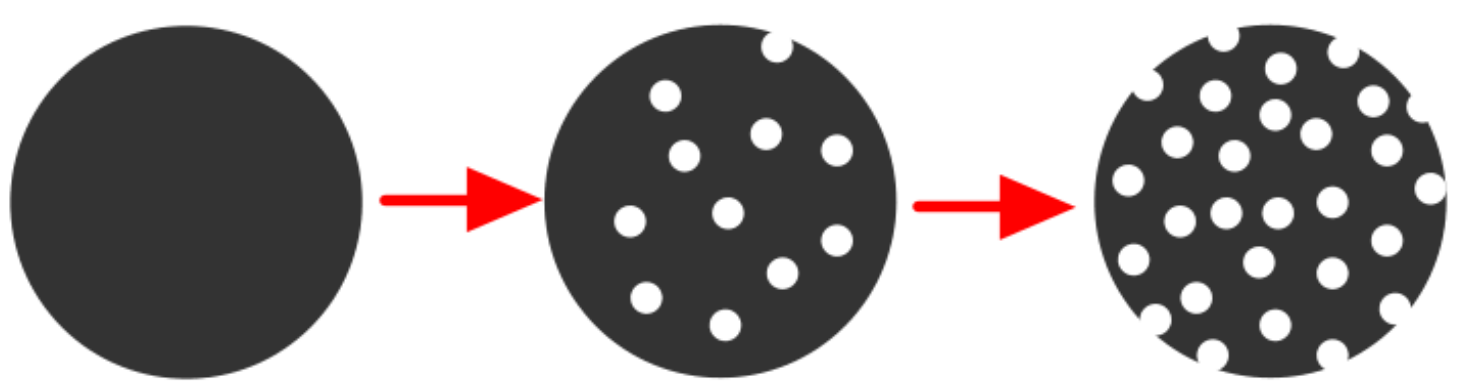

Figure 4.2: Shrinkage model where particle porosity increases while the original diameter is maintained.
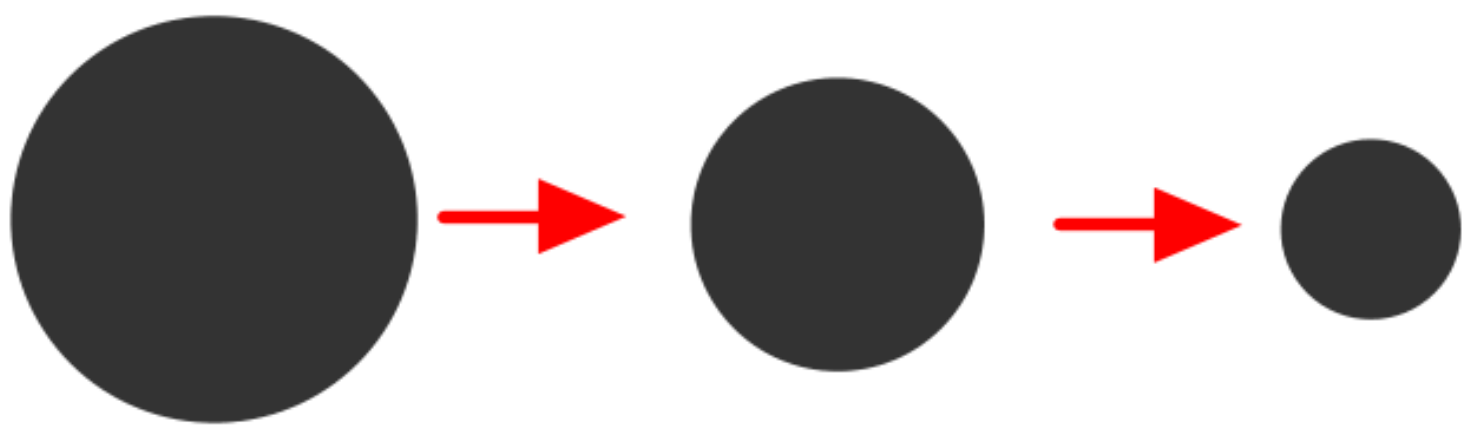

Figure 4.3: Shrinkage model where particle diameter decreases while maintaining zero porosity. 

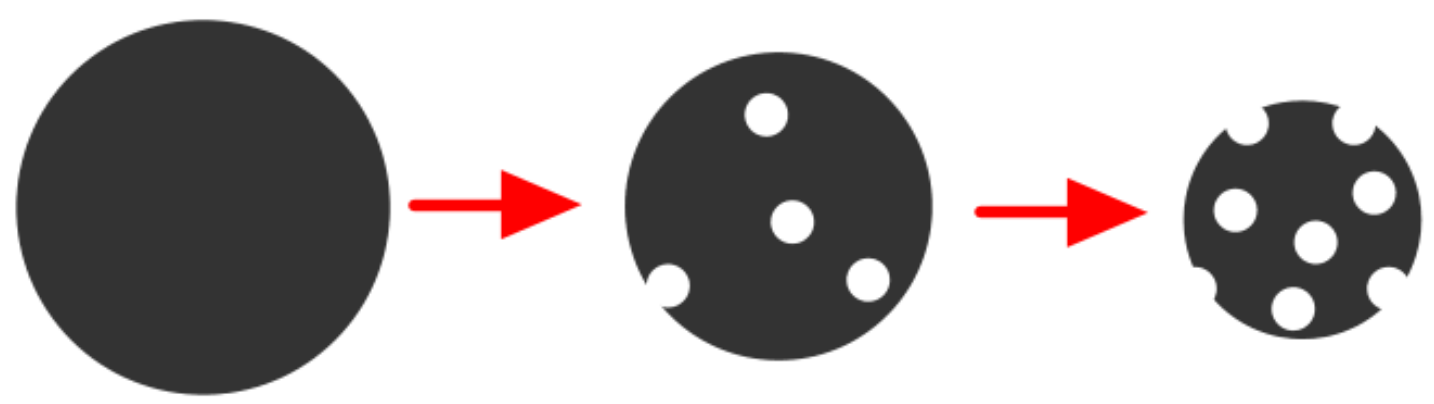

Figure 4.4: Shrinkage model where particle porosity increases while the diameter decreases.

In this work a model which considered both shrinkage of particles and porosity variation was implemented, i.e., $0 \leq \alpha \leq 1$. In this model local consumption of particle leads to the change in porosity and local shrinkage of bed is caused by collapsing of areas due to combustion. The model was chosen because of its improved accuracy in prediction of the combustion parameters (Gómez, Porteiro, Patiño, \& Míguez, 2014).

\subsection{Chemical Kinetic Model}

Biomass conversion was modeled by four sub-models, namely, drying, pyrolysis, gas-phase reactions and char oxidation models. The overall kinetic model used in this work is presented in Table 4.1. Drying of the wet wood was modeled by a first-order kinetic rate model, shown in reaction $\mathrm{R}(1)$ (Johansson, Thunman, \& Leckner, 2007).

Dry wood decomposed into primary components char, tar and gas through pyrolysis process. The kinetics of dry wood conversion into tar, char and gas is given by reactions $R(2)-R(4)$ while the tar cracking is reaction $\mathrm{R}(5)$. The mass fractions for gas species from wood pyrolysis in reaction $R(2)$ were specified according to Mahmoudi et al. (2016) and Di Blasi (2000). The components of tar cracking reaction $\mathrm{R}(5)$ are inert tar, $\mathrm{CO}, \mathrm{CO}_{2}, \mathrm{H}_{2}$ and $\mathrm{CH}_{4}$ whose mass fractions amounts are 0.22, 0.564, 0.111, 0.017 and 0.088, respectively (Mahmoudi et al., 2015; Wurzenberger et al., 2002). 
Table 4.1: Biomass kinetic model.

\begin{tabular}{|c|c|c|c|c|}
\hline \multicolumn{2}{|r|}{ Drying } & \multicolumn{2}{|c|}{ Rate expression } & \multirow{2}{*}{$\begin{array}{l}\text { Source } \\
\text { Johansson } \text { et al. (2007) }\end{array}$} \\
\hline $\mathrm{R}(1)$ & Wet wood $\rightarrow$ Dry wood $+\mathrm{H}_{2} \mathrm{O}(\mathrm{g})$ & \multicolumn{2}{|c|}{$R_{d r y}=Y_{\mathrm{m}} \rho_{\mathrm{b}, \text { wet }} 1.6 \times 10^{27} \exp \left(-25000 / \mathrm{T}_{\mathrm{s}}\right)$} & \\
\hline & Pyrolysis Reactions & Rate expression, & Kinetics: & Source \\
\hline & & $K_{i}=A_{i} T^{n} \exp \left(-E_{i} / R T\right)$ & $\mathrm{A}\left(\mathrm{s}^{-1}\right), \mathrm{E}(\mathrm{kJ} / \mathrm{mol})$ & \\
\hline $\mathrm{R}(2)$ & Dry wood $\rightarrow$ gas & $\dot{w}_{b}^{\prime}=K_{2} \rho_{b, d r y}$ & $\mathrm{~A}_{2}=111 \times 10^{9}, \mathrm{E}_{2}=177$ & Gómez et al. (2016) \\
\hline $\mathrm{R}(3)$ & Dry wood $\rightarrow$ Tar & $\dot{w}_{b}^{\prime}=K_{3} \rho_{b, d r y}$ & $\mathrm{~A}_{3}=9.28 \times 10^{9}, \mathrm{E}_{3}=149$ & Gómez et al. (2016) \\
\hline $\mathrm{R}(4)$ & Dry wood $\rightarrow$ char & $\dot{w}_{b}^{\prime}=K_{4} \rho_{b, d r y}$ & $\mathrm{~A}_{4}=30.5 \times 10^{9}, \mathrm{E}_{4}=125$ & Gómez et al. (2016) \\
\hline $\mathrm{R}(5)$ & $\begin{array}{l}\mathrm{Tar} \rightarrow \gamma_{\mathrm{t}} \operatorname{Tar}_{\text {inert }}+\gamma_{\mathrm{CO}} \mathrm{CO}+\gamma_{\mathrm{CO} 2} \mathrm{CO}_{2} \\
+\gamma_{\mathrm{H} 2} \mathrm{H}_{2}+\gamma_{\mathrm{CH} 4} \mathrm{CH}_{4}\end{array}$ & $\dot{w}_{T a r}^{\prime}=K_{5} \rho_{T a r}$ & $\mathrm{~A}_{5}=9.55 \times 10^{4}, \mathrm{E}_{5}=93.37$ & Mahmoudi et al. (2016) \\
\hline \multirow{2}{*}{\multicolumn{2}{|c|}{ Homogeneous Gas-Phase Reactions }} & Rate expression, & Kinetics: & Source \\
\hline & & $\mathrm{K}_{\mathrm{i}}=\mathrm{A}_{\mathrm{i}} \mathrm{T}^{\mathrm{n}} \exp \left(-\mathrm{E}_{\mathrm{i}} / \mathrm{RT}\right)$ & $\mathrm{A}\left(\mathrm{s}^{-1}\right), \mathrm{E}(\mathrm{kJ} / \mathrm{mol})$ & \\
\hline $\mathrm{R}(6)$ & $2 \mathrm{CO}+\mathrm{O}_{2} \rightarrow 2 \mathrm{CO}_{2}$ & $\mathrm{R}_{\mathrm{CO}}=\mathrm{K}_{6}[\mathrm{CO}]\left[\mathrm{O}_{2}\right]^{0.25}\left[\mathrm{H}_{2} \mathrm{O}\right]^{0.5}$ & $\begin{array}{l}\mathrm{A}_{6}=2.24 \times 10^{12}, \mathrm{n}=0, \mathrm{E}_{6}= \\
167.36\end{array}$ & Mahmoudi et al. (2016) \\
\hline $\mathrm{R}(7)$ & $\mathrm{CH}_{4}+2 \mathrm{O}_{2} \rightarrow \mathrm{CO}_{2}+2 \mathrm{H}_{2} \mathrm{O}$ & $\mathrm{R}_{\mathrm{CH} 4}=\mathrm{K}_{7}\left[\mathrm{CH}_{4}\right]^{0.7}\left[\mathrm{O}_{2}\right]^{0.8}$ & $\begin{array}{l}\mathrm{A}_{7}=11.58 \times 10^{13}, \mathrm{n}=0, \mathrm{E}_{7}= \\
202.5\end{array}$ & Mahmoudi et al. (2016) \\
\hline $\mathrm{R}(8)$ & $2 \mathrm{H}_{2}+\mathrm{O}_{2} \rightarrow 2 \mathrm{H}_{2} \mathrm{O}$ & $\mathrm{R}_{\mathrm{H} 2}=\mathrm{K}_{8}\left[\mathrm{H}_{2}\right]\left[\mathrm{O}_{2}\right]$ & $\mathrm{A}_{8}=2.19 \times 10^{9}, \mathrm{n}=0, \mathrm{E}_{8}=109.2$ & Mahmoudi et al. (2016) \\
\hline $\mathrm{R}(9)$ & $\mathrm{Tar}+2.9 \mathrm{O}_{2} \rightarrow 6 \mathrm{CO}+3.1 \mathrm{H}_{2}$ & $\mathrm{R}_{\mathrm{Tar}}=\mathrm{K}_{9}[\mathrm{Tar}]^{0.5}\left[\mathrm{O}_{2}\right]$ & $\mathrm{A}_{9}=9.2 \times 10^{6}, \mathrm{n}=0, \mathrm{E}_{9}=80.2$ & Mahmoudi et al. (2016) \\
\hline $\mathrm{R}(10)$ & $\mathrm{CO}+\mathrm{OH} \rightarrow \mathrm{CO}_{2}+\mathrm{H}$ & $\mathrm{R}_{\mathrm{CO}}=\mathrm{K}_{10}[\mathrm{CO}][\mathrm{OH}]$ & $\begin{array}{l}\mathrm{A}_{10}=4.76 \times 10^{7}, \mathrm{n}=1.3, \mathrm{E}_{10}= \\
0.293\end{array}$ & Smith et al. (1999) \\
\hline $\mathrm{R}(11)$ & $\mathrm{H}+\mathrm{O}_{2} \rightarrow \mathrm{O}+\mathrm{OH}$ & $\mathrm{R}_{\mathrm{H}}=\mathrm{K}_{11}[\mathrm{O}][\mathrm{OH}]$ & $\begin{array}{l}\mathrm{A}_{11}=2.65 \times 10^{16}, \mathrm{n}=-0.671, \mathrm{E}_{11} \\
=71.347\end{array}$ & Smith et al. (1999) \\
\hline $\mathrm{R}(12)$ & $\mathrm{H}_{2}+\mathrm{O}_{2} \rightarrow \mathrm{OH}+\mathrm{OH}$ & $\mathrm{R}_{\mathrm{H} 2}=\mathrm{K}_{12}\left[\mathrm{H}_{2}\right]\left[\mathrm{O}_{2}\right]$ & $\begin{array}{l}\mathrm{A}_{12}=2.51 \times 10^{12}, \mathrm{n}=0, \mathrm{E}_{12}= \\
163.075\end{array}$ & Westbrook et al. (1984) \\
\hline $\mathrm{R}(13)$ & $\mathrm{H}_{2} \mathrm{O}+\mathrm{CO} \rightarrow \mathrm{CO}_{2}+\mathrm{H}_{2}$ & $\mathrm{R}_{\mathrm{H} 2 \mathrm{O}}=\mathrm{K}_{13}\left[\mathrm{H}_{2} \mathrm{O}\right][\mathrm{CO}]$ & $\mathrm{A}_{13}=2.78, \mathrm{n}=0, \mathrm{E}_{13}=12.55$ & Gómez et al. (2016) \\
\hline \multirow[t]{3}{*}{$\mathrm{R}(14)$} & $\mathrm{CO}_{2}+\mathrm{H}_{2} \rightarrow \mathrm{H}_{2} \mathrm{O}+\mathrm{CO}$ & $\mathrm{R}_{\mathrm{CO} 2}=\mathrm{K}_{14}\left[\mathrm{CO}_{2}\right]\left[\mathrm{H}_{2}\right]$ & $\mathrm{A}_{14}=93.69, \mathrm{n}=0, \mathrm{E}_{14}=46.594$ & Gómez et al. (2016) \\
\hline & Heterogeneous Reactions & Rate expression, & Kinetics: & Source \\
\hline & & $K_{i}=A_{i} T^{n} \exp \left(-E_{i} R T\right)$ & $A\left(s^{-1}\right), E(k J / m o l)$ & \\
\hline $\mathrm{R}(15)$ & $\Omega \mathrm{C}+\mathrm{O}_{2} \rightarrow 2(\Omega-1) \mathrm{CO}(2-\Omega) \mathrm{CO}_{2}$ & $\dot{w}_{\text {char }, 02}^{\prime}=K_{15} P_{O 2} S_{a, \text { char }}$ & $\mathrm{A}_{15}=2.54 \times 10^{-3}, \mathrm{E}_{15}=74.8$ & Mahmoudi et al. (2016) \\
\hline $\mathrm{R}(16)$ & $\mathrm{C}+\mathrm{CO}_{2} \rightarrow 2 \mathrm{CO}$ & $\dot{w}_{c h a r, C O 2}^{\prime}=K_{16} P_{C O 2} S_{a, \text { char }}$ & $\mathrm{A}_{16}=1.81 \times 10^{-2}, \mathrm{E}_{16}=130$ & Mahmoudi et al. (2016) \\
\hline $\mathrm{R}(17)$ & $\mathrm{C}+\mathrm{H}_{2} \mathrm{O} \rightarrow \mathrm{CO}+\mathrm{H}_{2}$ & $\dot{w}_{\text {char }, H 2 O}^{\prime}=K_{17} P_{H 2 O} S_{a, \text { char }}$ & $\mathrm{A}_{17}=1.81 \times 10^{-2}, \mathrm{E}_{17}=130$ & Mahmoudi et al. (2016) \\
\hline
\end{tabular}

Gas species considered in homogenous gas-phase reactions $R(6)-R(14)$ are those generated from drying, $\mathrm{H}_{2} \mathrm{O}$, devolatilization, i.e., $\mathrm{CO}_{2}, \mathrm{H}_{2} \mathrm{O}, \mathrm{CO}, \mathrm{H}_{2}, \mathrm{CH}_{4}$, tar cracking and char heterogeneous reactions. Oxidation of $\mathrm{CO}, \mathrm{CH}_{4}, \mathrm{H}_{2}$ and tar are represented by reactions $\mathrm{R}(6)$ $R(9)$. For the purpose of checking the chemical effect in oxy-fuel environment reaction $R(10)$, which has been identified as dominant reaction pathway (Liu et al., 2003; Liu et al., 2001) is incorporated into the mechanism. Important chain-branching steps of $\mathrm{H}_{2}(\mathrm{R}(11), \mathrm{R}(12))$ relevant 
to this reaction are included. Furthermore, the forward and reverse reactions $\mathrm{R}(13)$ and $\mathrm{R}(14)$ for $\mathrm{H}_{2} \mathrm{O}$ and $\mathrm{CO}$ have been considered (Gómez et al., 2014; Johansson et al., 2007).

Char consumption is represented by heterogeneous reactions $\mathrm{R}(15)-\mathrm{R}(17)$. Char oxidation is given by reaction $\mathrm{R}(15)$ while its gasification by $\mathrm{CO}_{2}$ and $\mathrm{H}_{2} \mathrm{O}$ is by reactions $\mathrm{R}(16)$ and $\mathrm{R}(17)$, respectively. Char combustion rate were evaluated based on partial pressure of $\mathrm{O}_{2}, \mathrm{CO}_{2}$ and $\mathrm{H}_{2} \mathrm{O}$ available at its surface (Evans \& Emmons, 1977). The parameter $\Omega$ in reaction $\mathrm{R}(15)$ control the ratio of $\mathrm{CO}_{2}$ to $\mathrm{CO}$ emitted when char is burning. It is expressed as a function of char surface temperature (Johansson et al., 2007; Thunman, Leckner, Niklasson, \& Johnsson, 2002):

$$
\Omega=\frac{2\left(1+4.3 \exp \left[-\frac{3390}{T_{\text {particle }}}\right]\right)}{2+4.3 \exp \left[-\frac{3390}{T_{\text {particle }}}\right]} .
$$

\subsection{Thermodynamic and Transport Properties of Gas-Phase}

\subsubsection{Thermodynamic Properties}

Gas thermodynamic properties required during computation of biomass combustion in a fixed bed are the frozen specific heat capacities at constant pressure of the pure species $i, c_{p i}$, the frozen specific heat capacity at constant pressure of the gas mixture, $c_{p}$, and the enthalpy, $h_{i}$, for pure species $i$.

The polynomial curve fits of NASA type are used to calculate the gas thermodynamic properties (Burcat \& Ruscic, 2005). Specifically, the properties are given as follows:

- Molar heat capacity at constant pressure, $C_{p i}$ :

$$
\frac{C_{p i}}{R_{0}}=a_{1}+a_{2} T+a_{3} T^{2}+a_{4} T^{3}+a_{5} T^{4}
$$


- Molar enthalpy, $H_{i}$ :

$$
\frac{H_{i}}{R_{0}}=a_{6}+a_{1} T+\frac{a_{2}}{2} T^{2}+\frac{a_{3}}{3} T^{3}+\frac{a_{4}}{4} T^{4}+\frac{a_{5}}{5} T^{5} ;
$$

- Molar entropy, $S_{i}$ :

$$
\frac{S_{i}}{R_{0}}=a_{7}+a_{1} \ln T+a_{2} T+\frac{a_{3}}{2} T^{2}+\frac{a_{4}}{3} T^{3}+\frac{a_{5}}{4} T^{4} ;
$$

Here $a_{1}-a_{7}$ are polynomial coefficients. The thermodynamic database has two set of polynomial coefficients; the first set is for the high temperature range, 1000-6000 K, and the second set for the low temperature range of $300-1000 \mathrm{~K}$. The molar quantities $C_{p i}, H_{i}$ and $S_{i}$ are related to the respective mass-based quantities through $C_{p i}=c_{p i} W_{i}, H_{i}=h_{i} W_{i}$ and $S_{i}=s_{i} W_{i}$. The mass-based mixture frozen specific heat capacity, enthalpy and entropy are given by the following expressions:

$$
c_{p}=\sum_{i}^{N} Y_{i} c_{p i}, \quad h=\sum_{i}^{N} Y_{i} h_{i}, \quad \text { and } s=\sum_{i}^{N} Y_{i} s_{i},
$$

\subsubsection{Transport Properties}

The transport properties required during computation of biomass combustion in a fixed bed are the dynamic viscosity, $\mu$, of the gas mixture, the thermal conductivity, $\lambda$, of the gas mixture, and the ordinary mixture-averaged and thermal diffusion coefficients for species $i, D_{i}$, and $D_{T i}$, respectively.

A detailed modeling of molecular transport data as presented in CD-Adapco (2017) may be summarized as follows:

- Dynamic viscosity of species $i, \mu_{i}$ : 


$$
\mu_{i}=\frac{5}{16} \frac{\sqrt{\pi m_{i} K_{B} T}}{\pi \sigma_{i}^{2} \Omega^{(2,2) *}},
$$

where $\sigma$ is the Lennard-Jones collision diameter, $m_{i}$ is the mass of the molecule, $K_{B}$ is the Boltzmann constant, $\Omega^{(2,2) *}$ is collision integral, which is a function of the reduced temperature, $T^{*}$ and dipole moment, $\delta^{*}$. The quantities $T^{*}$ and $\delta^{*}$ are given as: $T^{*}=T_{i}^{*} \equiv\left(K_{B} T / \epsilon_{i}\right)$ and $\delta^{*}=\delta_{i}^{*}=(1 / 2)\left(d_{i}^{2} / \epsilon_{i} \sigma_{i}^{3}\right)$, here $d_{i}$ is the dipole moment of species $i, \epsilon_{i}$ is its Lennard-Jones potential well depth.

- Dynamic viscosity of the mixture, $\mu$ :

$$
\mu=\frac{1}{2}\left(\sum_{i=1}^{N} X_{i} \mu_{i}+\frac{1}{\sum_{i=1}^{N}\left(X_{i} / \mu_{i}\right)}\right) ;
$$

- $\quad$ Thermal conductivity of species $i, \lambda i$ :

$$
\lambda_{i}=\frac{\mu_{i}}{W_{i}}\left(f_{\text {trans }} C_{v, \text { trans }}+f_{\text {rot }} C_{v, \text { rot }}+f_{v i b} C_{v, v i b}\right) ;
$$

where $f_{\text {trans }}, f_{\text {rot }}$, and $f_{\text {vib }}$ are the species' translational, rotational and vibrational degrees of freedom, respectively, and $C_{v, \text { trans }}, C_{v, \text { rot }}, C_{v, v i b}$ are the respective contribution to the molar heat capacity at constant volume, $C_{v}$, of species $i$.

- Thermal conductivity of the mixture, $\lambda$ :

$$
\lambda=\frac{1}{2}\left(\sum_{i=1}^{N} X_{i} \lambda_{i}+\frac{1}{\sum_{i=1}^{N}\left(X_{i} / \lambda_{i}\right)}\right) ;
$$

- Binary diffusion coefficient, $D_{i j}$ :

$$
D_{i j}=\frac{3}{16} \frac{\sqrt{2 \pi K_{B}^{3} T^{3} / W_{i j}}}{p \pi \sigma_{i j}^{2} \Omega^{(1,1) *}} .
$$


Besides the quantities defined before, $W_{i j}=2 W_{i} W_{j} /\left(W_{i}+W_{j}\right)$ is the reduced molar mass for the pair of species, $i, j$, and $\sigma_{i j}$ is the average collision diameter. The mixture average diffusion coefficient, $D_{i}$ is given as

$$
D_{i}=\frac{1-X_{i}}{\sum_{\substack{j=1 \\ j \neq i}}^{N}\left(X_{j} / D_{i j}\right)}
$$

- Thermal diffusion coefficient of species $i, D_{T i}$ :

$$
D_{T i}=\frac{\theta_{i} D_{i}}{X_{i}},
$$

where $\theta_{i}$ is the thermal diffusion ratio of species $i$.

\subsection{Thermodynamic and Transport Properties of Solid-Phase}

The physical, thermodynamics and transport properties required during computation of biomass combustion in a fixed bed are the density, $\rho_{s}$, the porosity, $\theta$, the specific heat capacity at constant pressure, $c_{p, s}$, and the thermal conductivity, $\lambda_{s}$. The physical, thermodynamics and transport properties of the wood and char used in this work are presented in Table 4.2.

Table 4.2: Physical properties of wood.

\begin{tabular}{ll}
\hline Eucalyptus wood & \\
Density, $\rho\left(\mathrm{kg} / \mathrm{m}^{3}\right)$ & 1220 \\
Porosity, $\theta$ & 0.64 \\
Specific heat, $\mathrm{c}_{\mathrm{p}}(\mathrm{J} / \mathrm{kgK})$ & $1500+T_{s}$ \\
Conductivity, $\lambda_{\mathrm{s}}(\mathrm{W} / \mathrm{mK})$ & 0.2 \\
& \\
Char & \\
Density, $\rho\left(\mathrm{kg} / \mathrm{m}^{3}\right)$ & 250 \\
Porosity, $\theta$ & 0.85 \\
Specific heat, $\mathrm{c}_{\mathrm{p}}(\mathrm{J} / \mathrm{kgK})$ & $420+2.09 T_{s}-6.85 \times 10^{-4} T^{2}{ }_{s}$ \\
Conductivity, $\lambda_{\mathrm{s}}(\mathrm{W} / \mathrm{mK})$ & 0.1 \\
\hline
\end{tabular}




\subsection{Numerical Solution Methods}

Numerical simulations of combustion of biomass in fixed bed were carried out using a commercial CFD software CD-Adapco (STAR CCM+ version 11.04), CD-Adapco (2017). Unsteady state solver was employed to solve the governing equations in which the pressurevelocity coupling was enabled by using Pressure Implicit with Splitting of Operators (PISO) algorithm. The PISO algorithm is suited for transient cases. PISO is faster than Semi-Implicit Method for Pressure-Linked Equations (SIMPLE) at short time-steps, though both algorithms have the same level of temporal accuracy (Issa, Gosman, \& Watkins, 1986).

Second-order upwind scheme was used for the discretization of momentum, species, energy and radiation transport equations, as described in Appendix D. The transient terms were discretized using a second-order implicit scheme.

The criterion of convergence of solution was enabled by setting residual values for continuity, species, momentum, energy and radiation. The residuals for all the variables were set to converge at $10^{-6}$. Under-relaxation factor (URF) was adjusted in order to accelerate convergence of numerical stable solutions. Appropriate values of URF for each equation were selected by performing several trials and also by reference to previous research (Kangwanpongpan, 2013). URFs for various equations which improved convergence of numerical stable solutions were as follows: for density $=0.85$; for momentum $=0.85$; for turbulence $=0.85 ;$ for radiation $=0.85 ;$ for species $=0.95$.

\subsection{Mesh and Grid Refinement}

Computational domain representing the burner was meshed into highly-refined unstructured grids which ensured grid independent solutions. The burner was considered to have double 
symmetry. Therefore, a quarter of the burner with the dimensions described in section 3.3 was used in all simulated cases in order to reduce the computational time.

Mesh independent test was carried out to determine appropriate number of cells. The cells were dense in the fuel bed region in order to improve the accuracy of the solution, Fig 4.5(a). The cells were made of polyhedral elements and prismatic layers near the wall, as shown in Fig. 4.5(b). Based on the mesh independent test results (Chapter five), a computational mesh with 200,0000 cells was selected for all the cases computed.

\subsection{Boundary Conditions}

\subsubsection{Inlet Boundary Conditions}

The inlet boundary was at the bottom of the fixed bed. At this boundary, mass flow rate, species mass fraction, temperature, pressure, turbulence intensity and turbulence viscosity ratio were specified using Dirichlet boundary condition as follows:

$$
\dot{m}=\dot{m}_{L}, T=T_{L}, p=p_{L}, Y_{i}=Y_{i, L} \text {, for } i=1, \ldots, N, I=I_{L} \text { and } \mu_{r}=\mu_{r, L} .
$$

where subscript $L$ represent the value at the inlet boundary. Turbulent kinetic energy, $k$ and turbulent dissipation rate, $\varepsilon$ in this boundary are calculated using the specified turbulence intensity $I$ and turbulent viscosity ratio, $\mu_{r}$ using Eqs. (4.40) and (4.41), respectively.

$$
\begin{aligned}
k & \approx \frac{3}{2}(I \vartheta)^{2} . \\
\varepsilon & \approx \frac{\rho C_{\mu} k^{2}}{\mu_{r} \mu}
\end{aligned}
$$

where $\mu_{r}=\mu_{t} / \mu, \vartheta$ is the turbulent velocity scale and $C_{\mu}$ is the coefficient of the model. 


\section{STAR-CCM+}

(a)
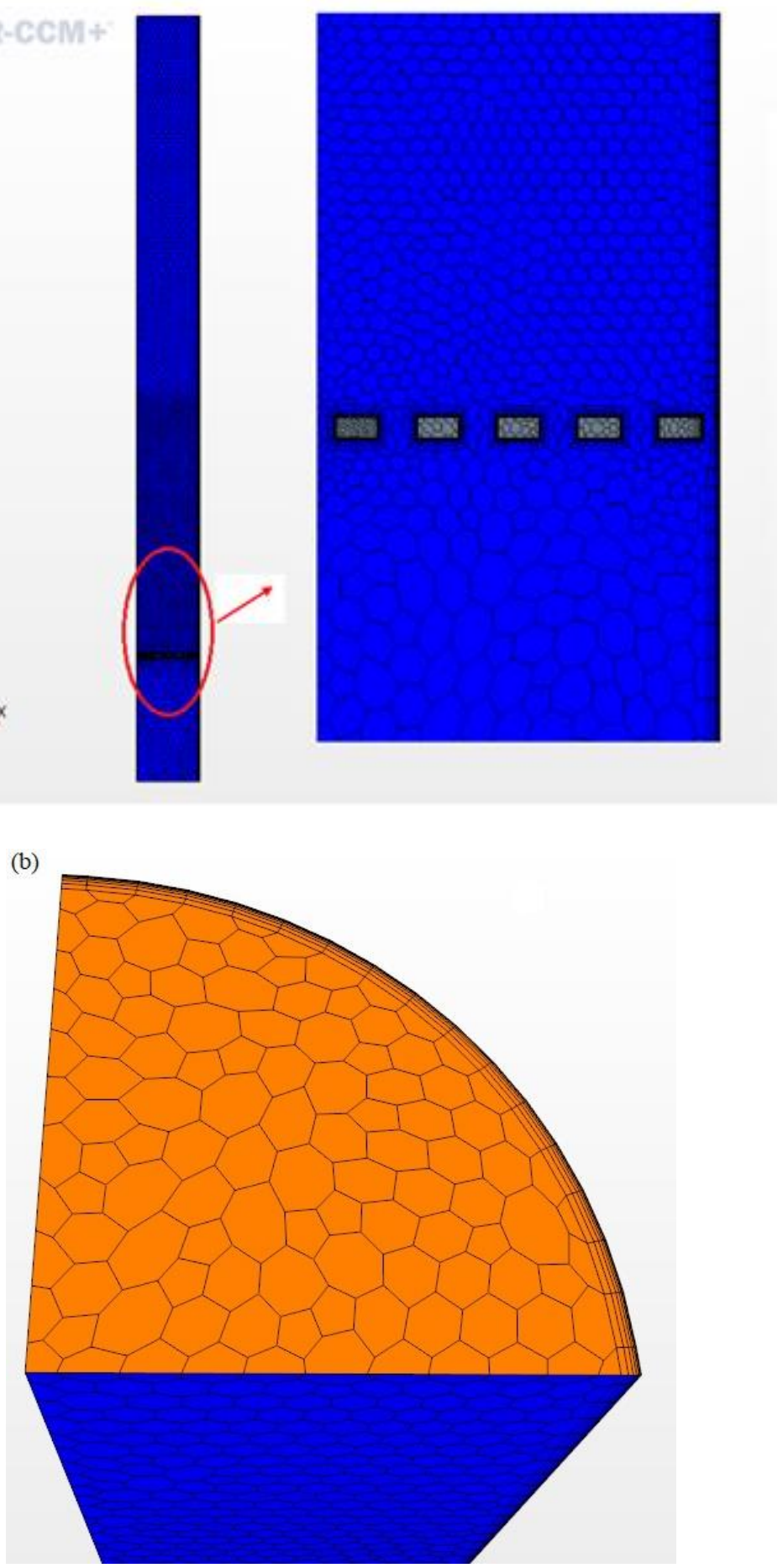

Figure 4.5: Computational mesh for the fixed bed; (a) highly refined mesh in fuel bed and grate; (b) prismatic layers near the wall. 


\subsubsection{Outlet Boundary Conditions}

The outlet boundary was at the top of the fixed bed. At this boundary, pressure, turbulence intensity and turbulence viscosity ratio were specified using Dirichlet boundary conditions as in the case for inlet boundary conditions. However, species mass fraction and temperature were specified using Neumann boundary condition as follows:

$$
\partial T / \partial x_{j}=0 \text { and } \partial Y_{i} / \partial x_{j}=0, \text { for } i=1, \ldots, N
$$

where $x_{j}$ is the direction normal to the outlet boundary.

\subsubsection{Walls}

A stationary wall with no-slip conditions was considered; the tangential velocity at the wall was explicitly set to zero. Thermal boundary condition at the walls were modeled as a mixture of convective and radiation heat transfer. Convective heat flux at the wall was selected, which requires a specification of heat transfer coefficient. Similarly, to account for radiation heat transfer, a specification of emissivity at the wall is required and computed.

At walls, a Neumann boundary condition is used for the turbulent kinetic energy, $k$, that is $\partial T /\left.\partial \eta\right|_{w}=0$

\subsection{Code Input and Output}

\subsubsection{Code Input}

Code input includes:

1. Geometrical model - the first step in simulating combustion in STAR CCM+ code is to input the geometry of the burner. The code provides two ways of inputting the geometry, namely, importing a geometrical model prepared previously in a CAD package into the 
code and direct creation of a geometrical model using 3D-CAD module within the code.

Fig. 4.6(a) shows a geometrical model details.

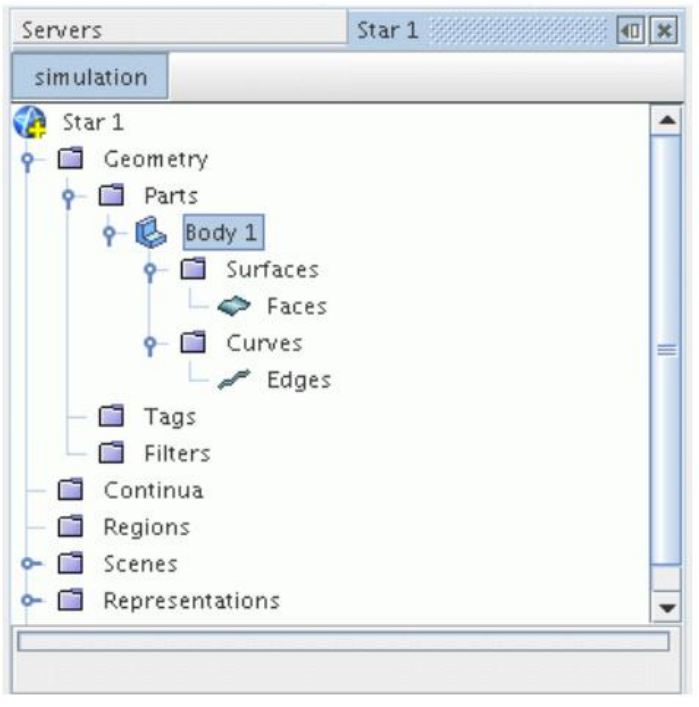

(a)

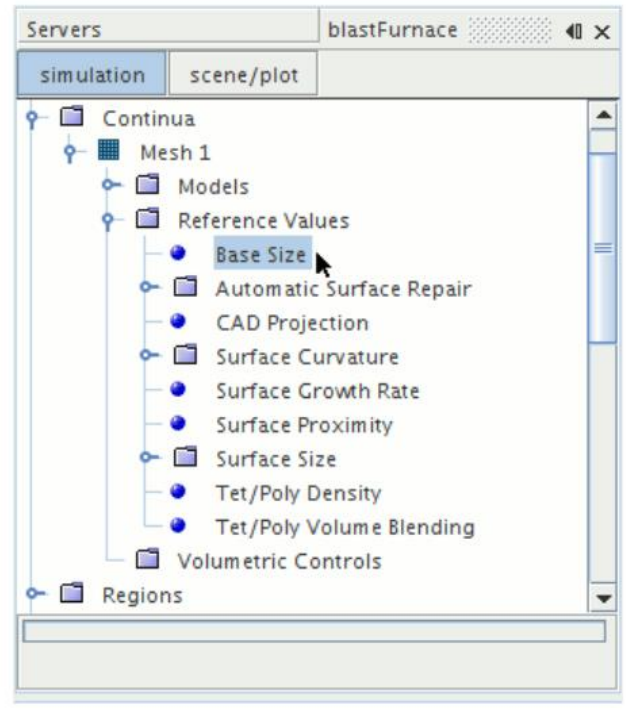

(b)

Figure 4.6: Illustration of details input in the code for (a) geometrical model and (b) mesh specification.

2. Mesh details specification and generation - the geometrical model is meshed by specifying the type, size and number of cells. An example of mesh details input in the code is shown in Fig. 4.6(b).

3. Physics model - the physics model defines the primary variables of the simulation such as temperature, pressure and velocity and the type of mathematical formulation to be used to generate the solution. In this work, the flow involves a turbulent, compressible, multiphase flow whose components are reacting chemically.

4. Material properties - material properties of the gas mixture and solid phase species that are to be input in the model are required. Method of determining dynamics viscosity 
and thermal conductivity of the gas mixture as a whole is specified. Then the method of calculating specific heat for each gas component is set. An interface for material properties selection in the code is shown in Fig. 4.7(a).

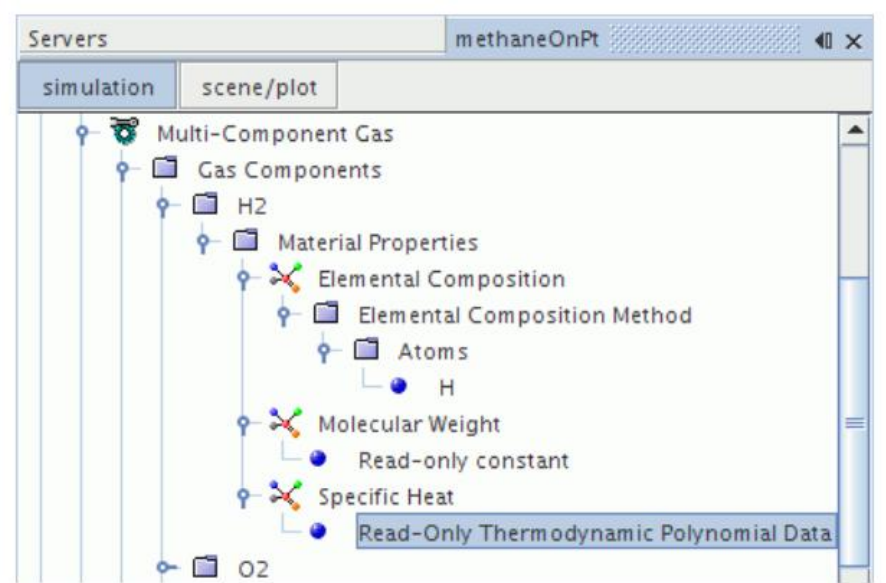

(a)

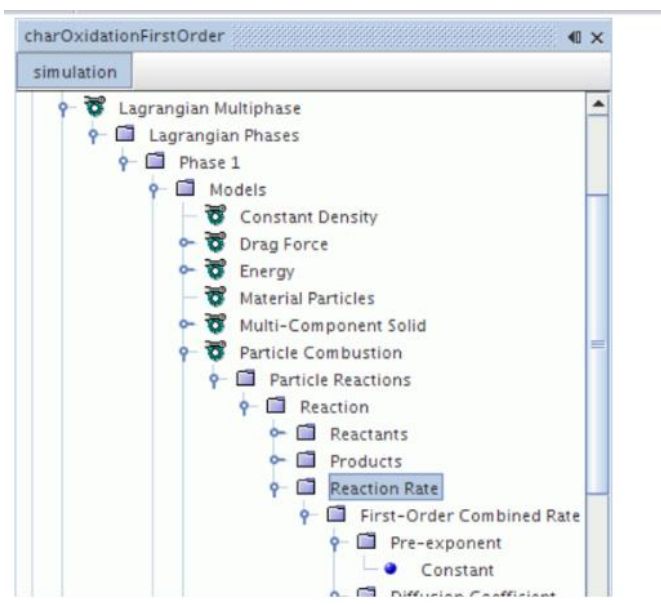

(b)

Figure 4.7: Specification of material properties and reactions in a multiphase flow for (a) multi-component gas and (b) multi-component solid.

5. Reactions - reaction involves in both phases, gas-phase and solid-phase, are input in the model. The code has provision for specifying the reactants, products and rate constants for each reaction. Fig. 4.7(b) shows specification of the reaction for the solid phase components.

6. Initial conditions for species, temperature, turbulence and pressure are specified and input in the code.

7. The boundary conditions at the walls, inlet and outlet are defined and input in the code.

8. Solvers parameters such as type of the solver, URF, convergence criterion, order of accuracy are defined and input in the model. 


\subsubsection{Code Output}

Code output includes:

1. Report - it defines the quantity of interest and the region where it is being monitored.

2. Monitor - it is use to dynamically monitor any quantity while the solution develops.

3. Plot $-x-y$ graph plots are created for any quantity defined, for instance, temperature and $\mathrm{CH}_{4}$ shown in Fig. 4.8. Plots may be exported as graphs or tabulated data.

\begin{tabular}{|c|c|c|c|}
\hline Servers & & methaneOnPt & 四 $x$ \\
\hline simulation & scene/plot & & \\
\hline P- $\square$ Plots & & & - \\
\hline - $-\mathrm{Re}$ & siduals & & \\
\hline$-\approx \mathrm{Te}$ & mperature Plot & & \\
\hline $\mathrm{P}$ & 4 Plot & & \\
\hline$\therefore \square$ & X Type & & 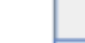 \\
\hline$\therefore \square$ & YTypes & & T \\
\hline$-\square$ & Tabular & & \\
\hline$\circ \square$ & Axes & & 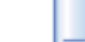 \\
\hline L・ & Legend & & \\
\hline$-\square$ scenes & & & 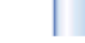 \\
\hline
\end{tabular}

Figure 4.8: $\mathrm{x}-\mathrm{y}$ graph plots for temperature and $\mathrm{CH}_{4}$ created in STAR CCM+ code.

4. Scene - allows the user to visualize the model. A scene is a summary of the complete representation of the components that are required to generates an image or animation including: lights, cameras, parts, properties, transformation, geometry and texture. An example of the scene is the image of grids shown in Fig. 4.5. 


\section{CHAPTER FIVE \\ NUMERICAL RESULTS}

\subsection{Introduction}

In this chapter, numerical results of the three cases simulated in this study, viz., the effects of $\mathrm{CO}_{2}$ environment on flame propagation speed and flames structures, the influence of particle packing density on combustion of wood in an oxy-fuel burning environment, and the separate effects of $\mathrm{CO}_{2}$ in oxy-fuel combustion are presented. The chapter begins by a description of the boundary conditions applied for each case. The mesh independent tests which were done to ensure independency of results on the grid size are then presented. Finally, the numerical results are presented.

\subsection{Boundary Conditions}

Three cases were simulated in this study, namely, the effects of $\mathrm{CO}_{2}$ environment on flame propagation speed and flames structures, the influence of particle packing density on combustion of wood in an oxy-fuel burning environment, and the separate effects of $\mathrm{CO}_{2}$ in oxy-fuel combustion. In all the cases, the inlet boundary was at the bottom of the fixed bed. At this boundary, mass flow rate, species mole fraction and temperature were specified using Dirichlet boundary condition. The mass flux of the mixture at the inlet was $0.1 \mathrm{~kg} / \mathrm{m}^{2} / \mathrm{s}$ while mass fraction of $\mathrm{O}_{2}$ and $\mathrm{N}_{2}$ or $\mathrm{CO}_{2}$ were specified according to the case tested and was supplied at a temperature of $295 \mathrm{~K}$. The mass fraction of $\mathrm{O}_{2}$ and $\mathrm{N}_{2}$ or $\mathrm{CO}_{2}$ for each case are described here below.

For the numerical simulation of wood combustion in a fixed bed on the effect of $\mathrm{CO}_{2}$ environment on flame propagation speed and flame structures, a summary of the composition of the oxidizer mixture is presented in Table 5.1. 
Table 5.1: Composition of the oxidizer mixture for different oxy-fuel conditions.

\begin{tabular}{ccccccccccc}
\hline & \multicolumn{2}{c}{ Mixture 1 } & \multicolumn{2}{c}{ Mixture 2 } & \multicolumn{2}{c}{ Mixture 3 } & \multicolumn{2}{c}{ Mixture 4 } & \multicolumn{2}{c}{ Mixture 5 } \\
\cline { 2 - 10 } Cases & $\mathrm{O}_{2}$ & $\mathrm{~N}_{2}$ & $\mathrm{O}_{2}$ & $\mathrm{CO}_{2}$ & $\mathrm{O}_{2}$ & $\mathrm{CO}_{2}$ & $\mathrm{O}_{2}$ & $\mathrm{CO}_{2}$ & $\mathrm{O}_{2}$ & $\mathrm{CO}_{2}$ \\
\hline $\begin{array}{c}\text { Concentration } \\
(\% \text { vol })\end{array}$ & 21 & 79 & 21 & 79 & 30 & 70 & 40 & 60 & 50 & 50 \\
\hline
\end{tabular}

In the second case where the influence of particle packing density on fixed bed combustion of wood in an oxy-fuel burning environment is investigated, the oxidizer mixture constituted of $21 \% \mathrm{O}_{2}$ and $79 \% \mathrm{CO}_{2}$, by volume.

Finally, for the numerical simulation of the role of various carbon dioxide effects on the burning rate, the concentration of oxygen and $\mathrm{N}_{2} / \mathrm{CO}_{2} / \mathrm{Ar}$ were set in accordance to the required predesigned conditions. In the first set of experiments, $\mathrm{O}_{2}$ concentration by volume was varied between $21 \%$ and $50 \%$ with diluent as either $\mathrm{N}_{2}$ or $\mathrm{CO}_{2}$. In addition, four mixtures were designed to separate the effects of $\mathrm{CO}_{2}$ environment. The four mixtures were denoted by letters $\mathrm{A}, \mathrm{B}, \mathrm{C}$ and and $\mathrm{D}$ and their composition by volume were: $21 \% \mathrm{O}_{2} / 79 \% \mathrm{~N}_{2} ; 21 \% \mathrm{O}_{2} / 22.5 \%$ $\mathrm{CO}_{2} / 56.5 \%$ Ar; $40 \% \mathrm{O}_{2} / 60 \% \mathrm{CO}_{2} ;$ and $40 \% \mathrm{O}_{2} / 47 \% \mathrm{CO}_{2} / 13 \%$ Ar, respectively.

In all the cases, the outlet boundary was at the top of the fixed bed. At this boundary, species concentration and temperature gradients were set to zero using Neumann boundary condition. A stationary wall with no-slip conditions was considered; the tangential velocity at the wall was explicitly set to zero. Thermal boundary conditions at the wall was modeled as a mixture of convective and radiation heat transfer. Typical values of convective heat transfer coefficient for air in natural convection is $10-20 \mathrm{~W} / \mathrm{m}^{2} . \mathrm{K}$, Incropera et al. (2006). Therefore, convective heat flux at the wall was selected with an adopted heat transfer coefficient of $10 \mathrm{~W} / \mathrm{m}^{2} . \mathrm{K}$. An emissivity of 0.8 was adopted because the wall was made from stainless steel, Incropera et al. (2006). 


\subsection{Mesh Independent Tests}

Computation were done on an unstructured grid that consisted of cells which were made of polyhedral elements. The cells closed to the walls were made of prism layers. Solutions which are independent of grid size were ensured by performing a mesh independent test. Consequently, the choice of mesh size was based on this test whose results are shown in Figs

\section{$5.1-5.4$}
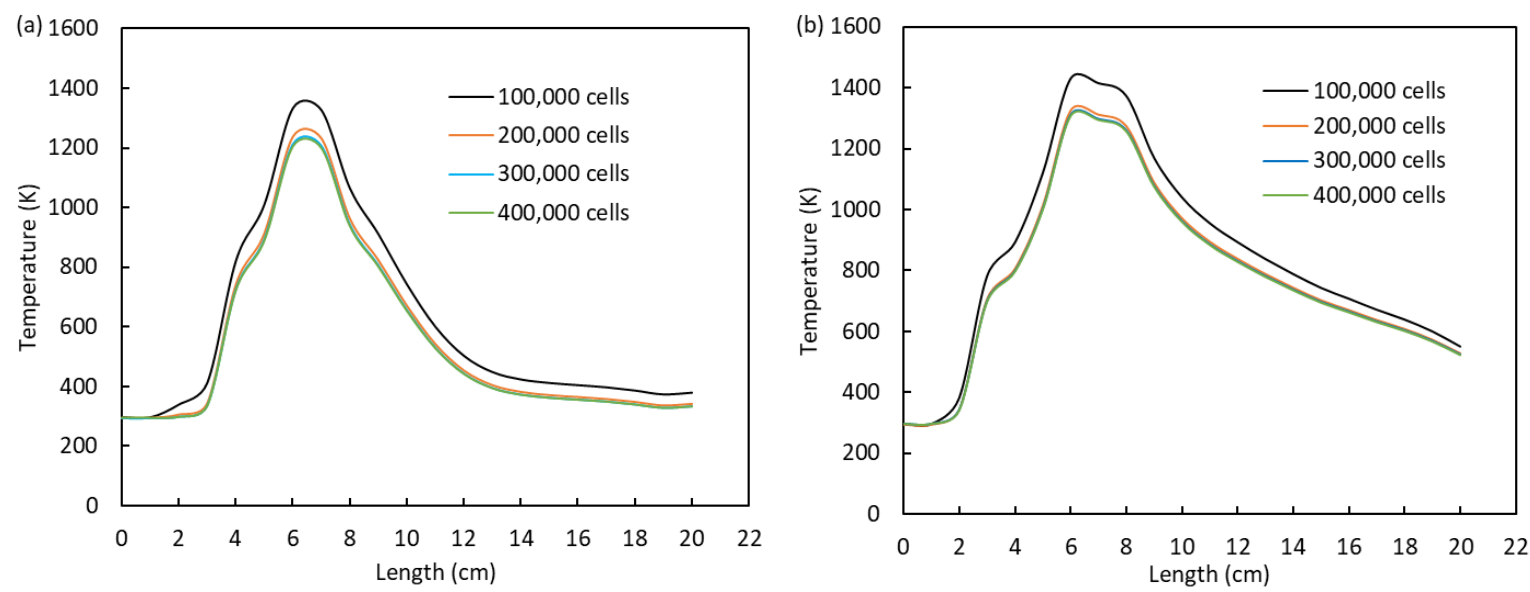

Figure 5.1: Comparison of temperatures profiles along axial length of the reactor for wood combustion in $21 \% \mathrm{O}_{2} / 79 \% \mathrm{CO}_{2}$ mixtures at (a) $450 \mathrm{~s}$ and (b) $600 \mathrm{~s}$ when applying different computational mesh sizes.

The prediction of temperature profiles along axial length of the reactor for oxy-fuel environment at two different times applying different computational mesh sizes are shown in Figs 5.1(a) and (b). In both cases, there was a significant change in results when mesh size was increased from 100,000 to 200,000 cells. But the predictions using 200,000, 300,000 and 400,000 cells did not have much differences. The prediction of tar mass fraction along axial length of the reactor at two different times applying different computational mesh is shown in Figs 5.2(a) and (b). The behaviour is similar to that of temperature predictions, i.e., there is a 
significant change in prediction for 100,000 to 200,000 cells but there are no much differences for 200,000, 300,000 and 400,000 cells.
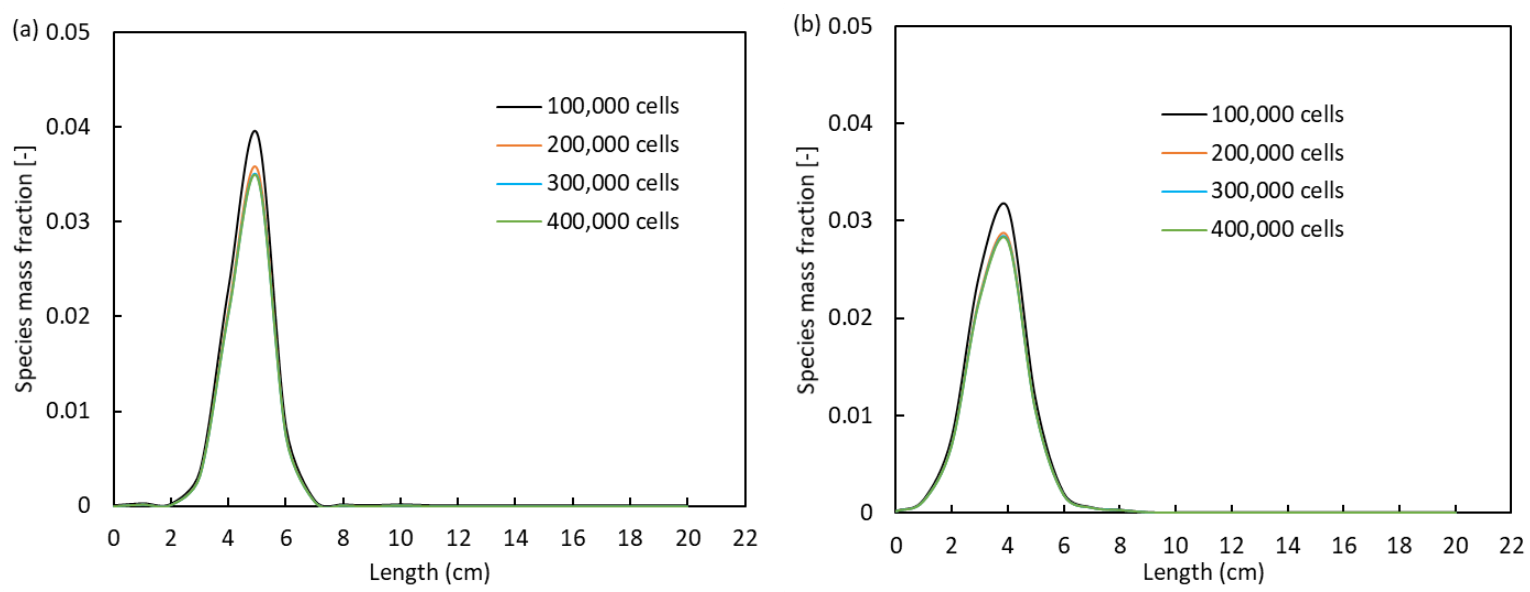

Figure 5.2: Comparison of tar mass fraction along axial length of the reactor for wood combustion in $21 \% \mathrm{O}_{2} / 79 \% \mathrm{CO}_{2}$ mixtures at (a) $450 \mathrm{~s}$ and (b) $600 \mathrm{~s}$ when applying different computational mesh sizes.

Temperature profiles along the axial length of the bed for combustion of fuel type WC and SD1 predicted using different mesh sizes is shown in Figs 5.3(a) and (b), respectively. In both fuel types, temperature predicted using a mesh size with 100,000 cells showed a significant difference from that predicted using a mesh size of 200,000 cells. However, changing of mesh size to 300,000 and 400,000 cells, respectively, did not significantly changed prediction when compared to that of 200,000 cells.

The predicted temperature profile at $5 \mathrm{~cm}$ from bed bottom under oxy-fuel condition is shown in Fig. 5.4. The graph show that the temperature is significantly different when using a mesh that consists of 100,000 cells as compared to that of 200,000 cells. The difference in temperature profiles is negligible for mesh that consist of 200,000, 300,000 and 400,000 cells, respectively. Therefore, a computational mesh with 200,0000 cells was selected for all the cases computed. 

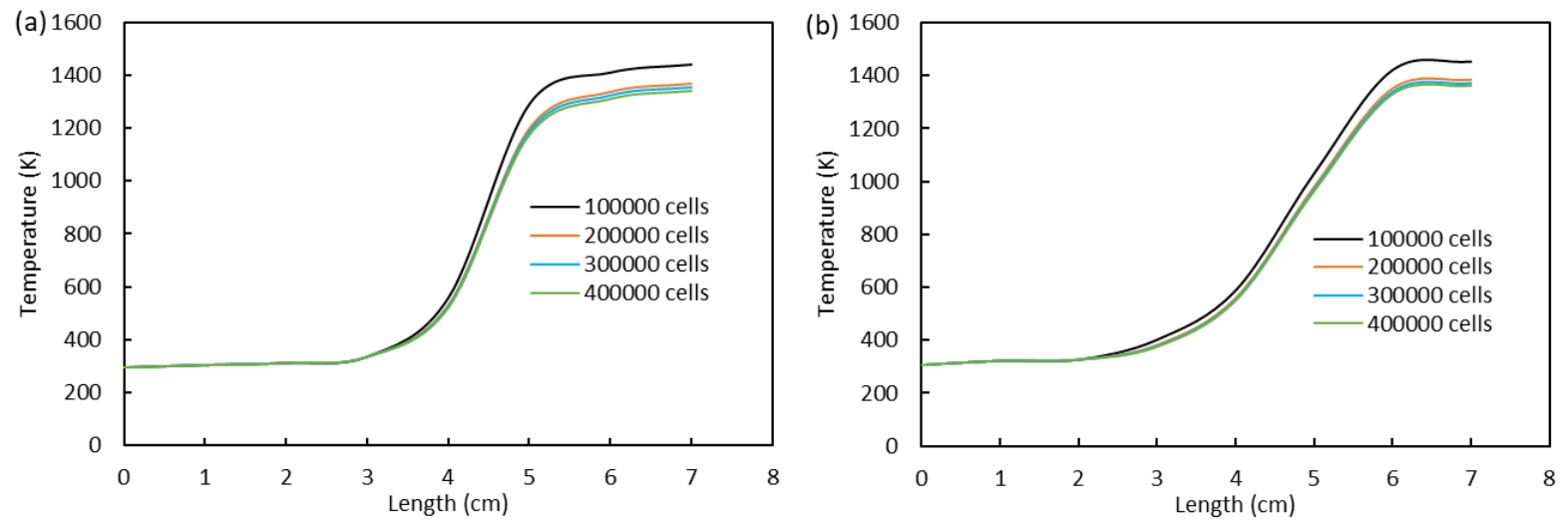

Figure 5.3: Comparison of temperature profiles along the axial length of the bed for particle type (a) WC $(\chi=0.51)$ and (b) SD1 $(\chi=0.74)$ when reaction front is at $4 \mathrm{~cm}$ from the grate applying different computation mesh sizes.

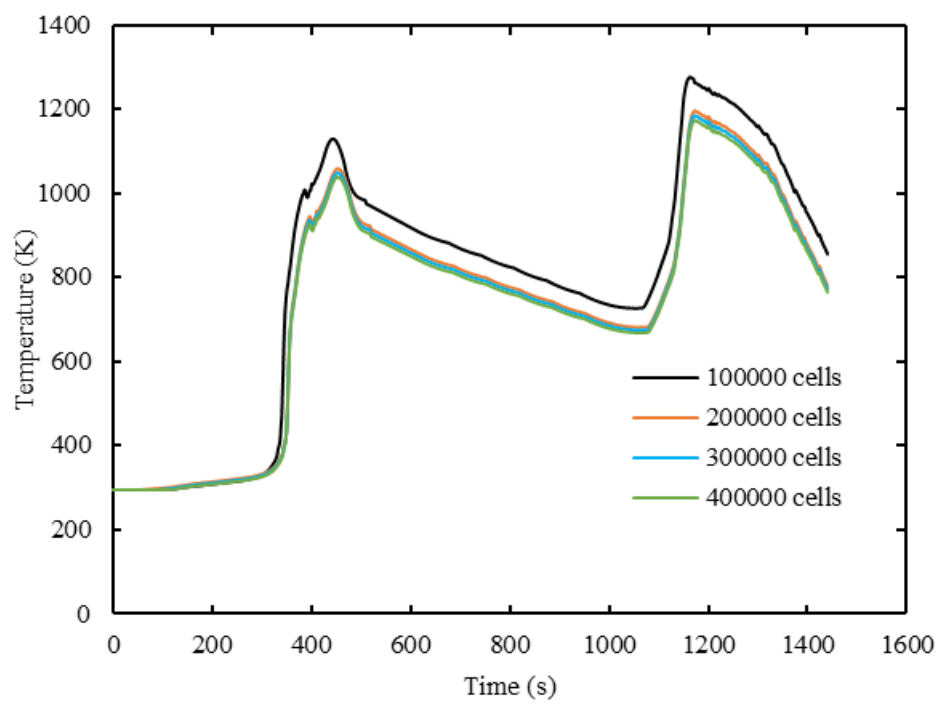

Figure 5.4: Predicted temperature profiles at $5 \mathrm{~cm}$ from the bed bottom for wood combustion under oxy-fuel environment for different mesh sizes.

\subsection{Results}

Numerical results of mass loss history, temperature profiles, species concentration profiles, ignition times, burning rates and flame front propagation speed are presented. Fig. 5.5 shows 
the mass loss history predicted by the model for spherical wood combustion in a fixed bed under both $\mathrm{N}_{2}$ and $\mathrm{CO}_{2}$ environments. The graph reveals that the rate of consumption of wood in a $\mathrm{N}_{2}$ environment is faster than in a $\mathrm{CO}_{2}$ environment. Consequently, the drying time, devolatilization time and char combustion time are relatively longer in $\mathrm{CO}_{2}$ environment. The low rate of consumption of wood particles in oxy-fuel environment is linked to higher molecular weight of $\mathrm{CO}_{2}$ gas. $\mathrm{O}_{2}$ diffusivity to the active surface of the particle in $\mathrm{CO}_{2}$ gas is decreased because it is a heavy gas. Therefore, the rate of consumption of the fuel particle by oxidation is lowered in $\mathrm{CO}_{2}$ than in $\mathrm{N}_{2}$ environment.

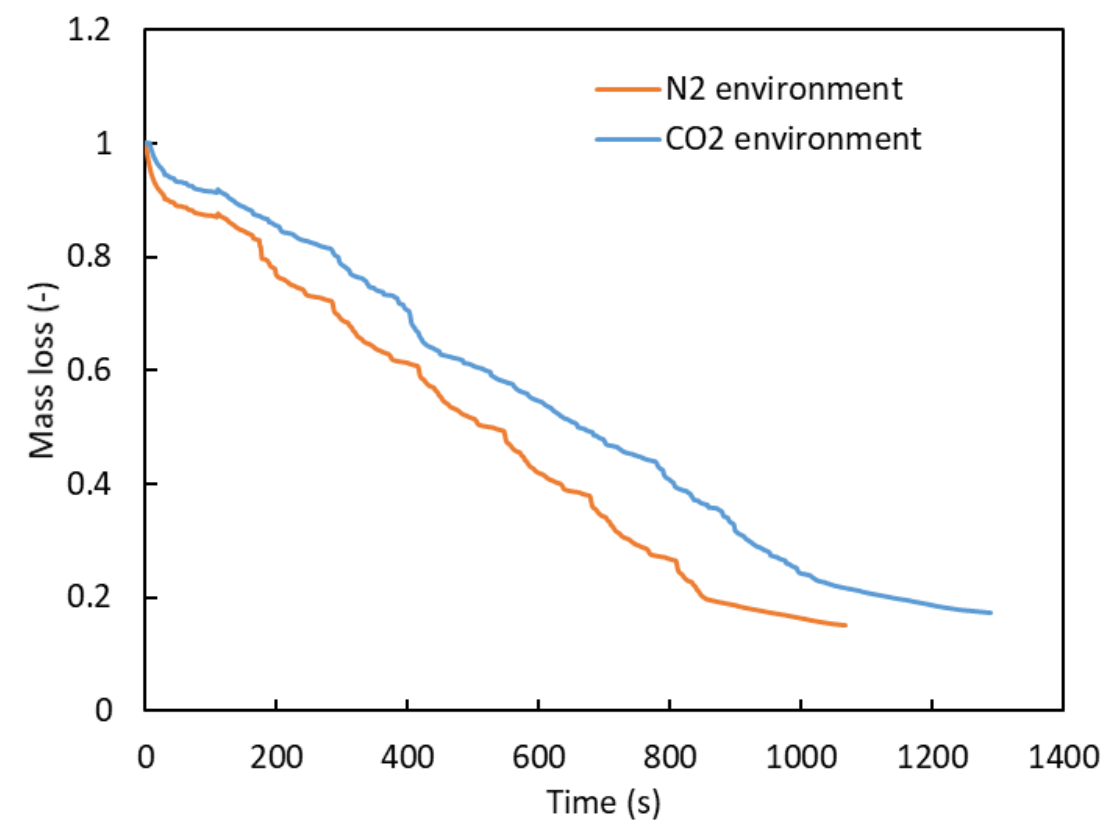

Figure 5.5: Predicted mass loss history for wood combustion in fixed bed at $21 \% \mathrm{O}_{2} / 79 \% \mathrm{~N}_{2}$ and $21 \% \mathrm{O}_{2} / 79 \% \mathrm{CO}_{2}$ mixtures.

Figure 5.6 shows the temperature profiles predicted by the model at various heights above the grate for different bed porosity; $\chi=0.51$ to $\chi=0.74$. Temperature profiles in low porosity 

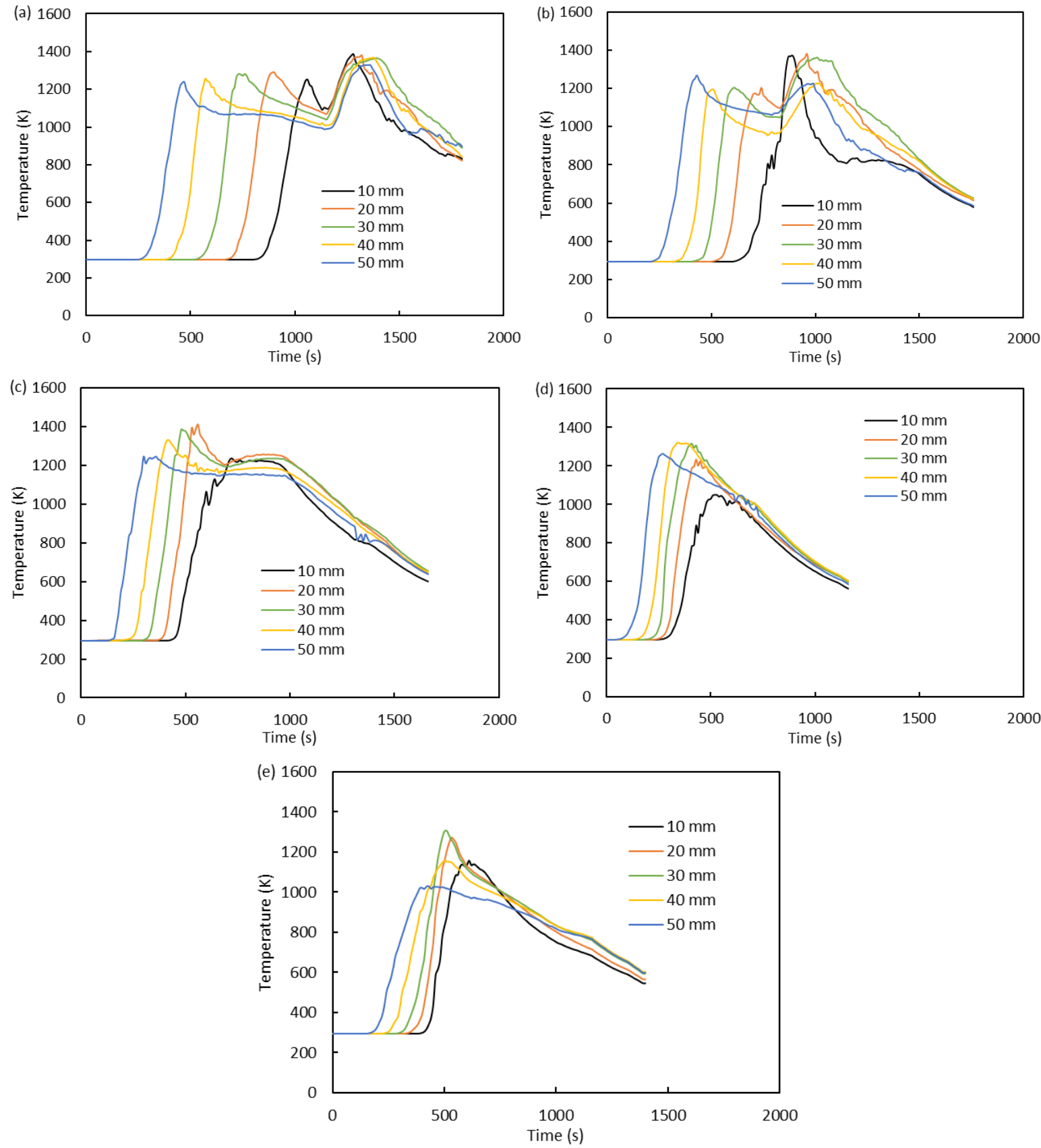

Figure 5.6: Predicted temperature profiles at various heights above the grate for particle types (a) WC $(\chi=0.51)$, (b) WCSD2 $(\chi=0.56)$, (c) SD2 $(\chi=0.61)$, (d) WCSD1 $(\chi=0.68)$ and (e) $\operatorname{SD} 1(\chi=0.74)$.

beds, Figs 5.6(a) and (b), have two distinct peaks which are achieved during ignition propagation phase and char combustion phase, respectively. On the other hand, high porosity 
beds, Figs 5.6(d) and (e) have a single temperature peak which indicates that devolatilization and char combustion phases occur concurrently. The transition from two temperature peak points to a single peak point occurs at a bed porosity of 0.61 .

Concentration of major combustion species $-\operatorname{tar}, \mathrm{CO}$ and $\mathrm{H}_{2}$ - predicted by the model in the bed during the entire combustion time is shown in Fig. 5.7. The products of combustion, $\mathrm{CO}_{2}$ and $\mathrm{H}_{2} \mathrm{O}$ as well as $\mathrm{O}_{2}$ predicted by the model are also shown in the graph. The species are plotted at $4 \mathrm{~cm}$ from the grate for wood combustion in $21 \% \mathrm{O}_{2} / 79 \% \mathrm{CO}_{2}$ mixture and a bed porosity of 0.51 . At this location, the flame front passes at $410 \mathrm{~s}$, devolatilization phase ends at $1210 \mathrm{~s}$ and char combustion phase ends at $1550 \mathrm{~s}$.

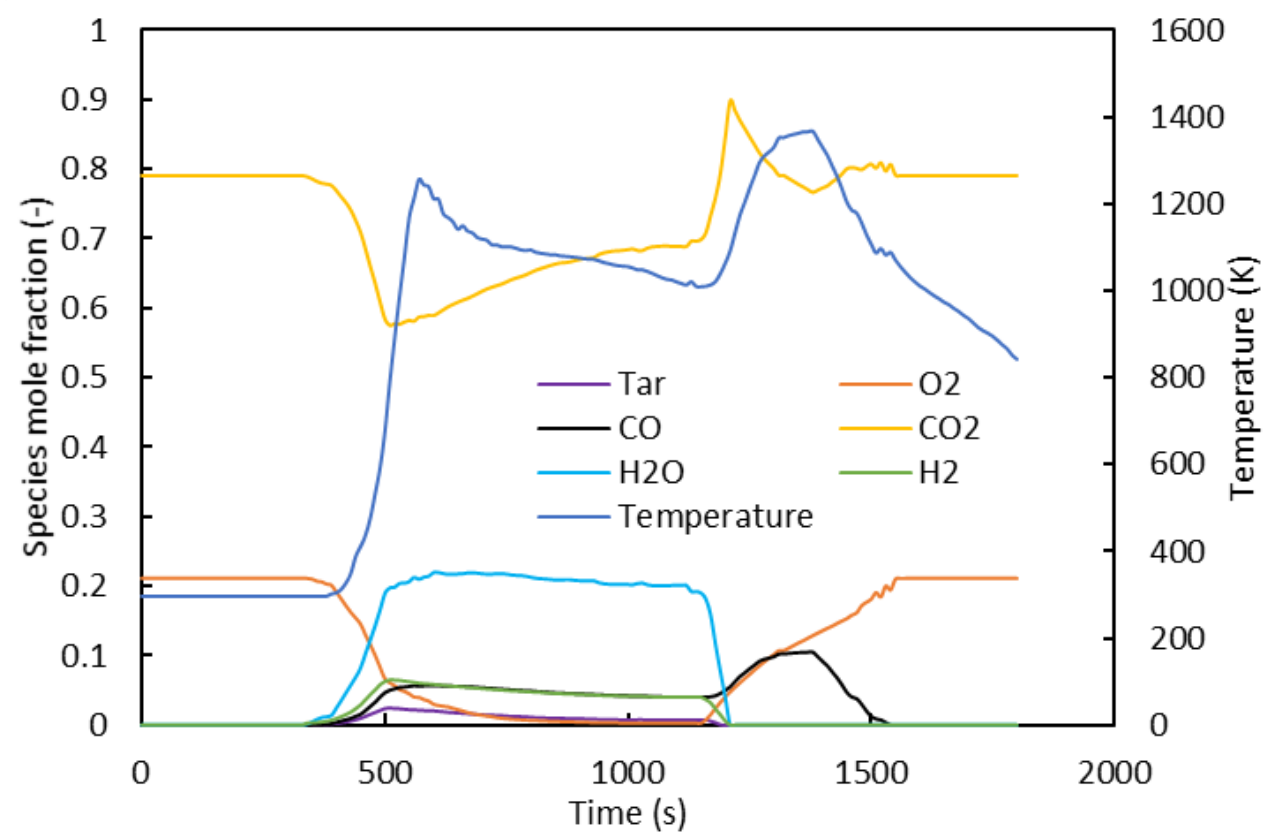

Figure 5.7: Predicted species concentration and temperature during entire combustion time in $21 \% \mathrm{O}_{2} / 79 \% \mathrm{CO}_{2}$ taken at $4 \mathrm{~cm}$ from the grate for particle type $\mathrm{WC}(\chi=0.51)$.

Flame structures along axial length of the bed for wood combustion in $21 \% \mathrm{O}_{2} / 79 \% \mathrm{~N}_{2}$ and $21 \% \mathrm{O}_{2} / 79 \% \mathrm{CO}_{2}$ mixtures are shown in Figs 5.8 and 5.9, respectively. The flame front positions are clearly indicated by both graphs. For $21 \% \mathrm{O}_{2} / 79 \% \mathrm{~N}_{2}$ mixture, the flame front 
passes through (a) $5 \mathrm{~cm}$ point at $200 \mathrm{~s}$, Fig. 5.8(a), (b) $4 \mathrm{~cm}$ point at $300 \mathrm{~s}$, Fig. 5.8(b) and, (c) $3 \mathrm{~cm}$ point at $400 \mathrm{~s}$ Fig. $5.8(\mathrm{c})$. On the other hand, for $21 \% \mathrm{O}_{2} / 79 \% \mathrm{CO}_{2}$ mixture, the flame front passes through (a) $5 \mathrm{~cm}$ point at $300 \mathrm{~s}$, Fig. 5.9(a), (b) $4 \mathrm{~cm}$ point at $450 \mathrm{~s}$, Fig. 5.9(b) and, (c) $3 \mathrm{~cm}$ point at $600 \mathrm{~s}$ Fig. 5.9(c). The fuel bed is entirely under char combustion phase at 1000 $\mathrm{s}$ in $21 \% \mathrm{O}_{2} / 79 \% \mathrm{~N}_{2}$ mixture, Fig. 5.8(d) and at $1100 \mathrm{~s}$ in $21 \% \mathrm{O}_{2} / 79 \% \mathrm{CO}_{2}$ mixture, Fig. 5.9(d).
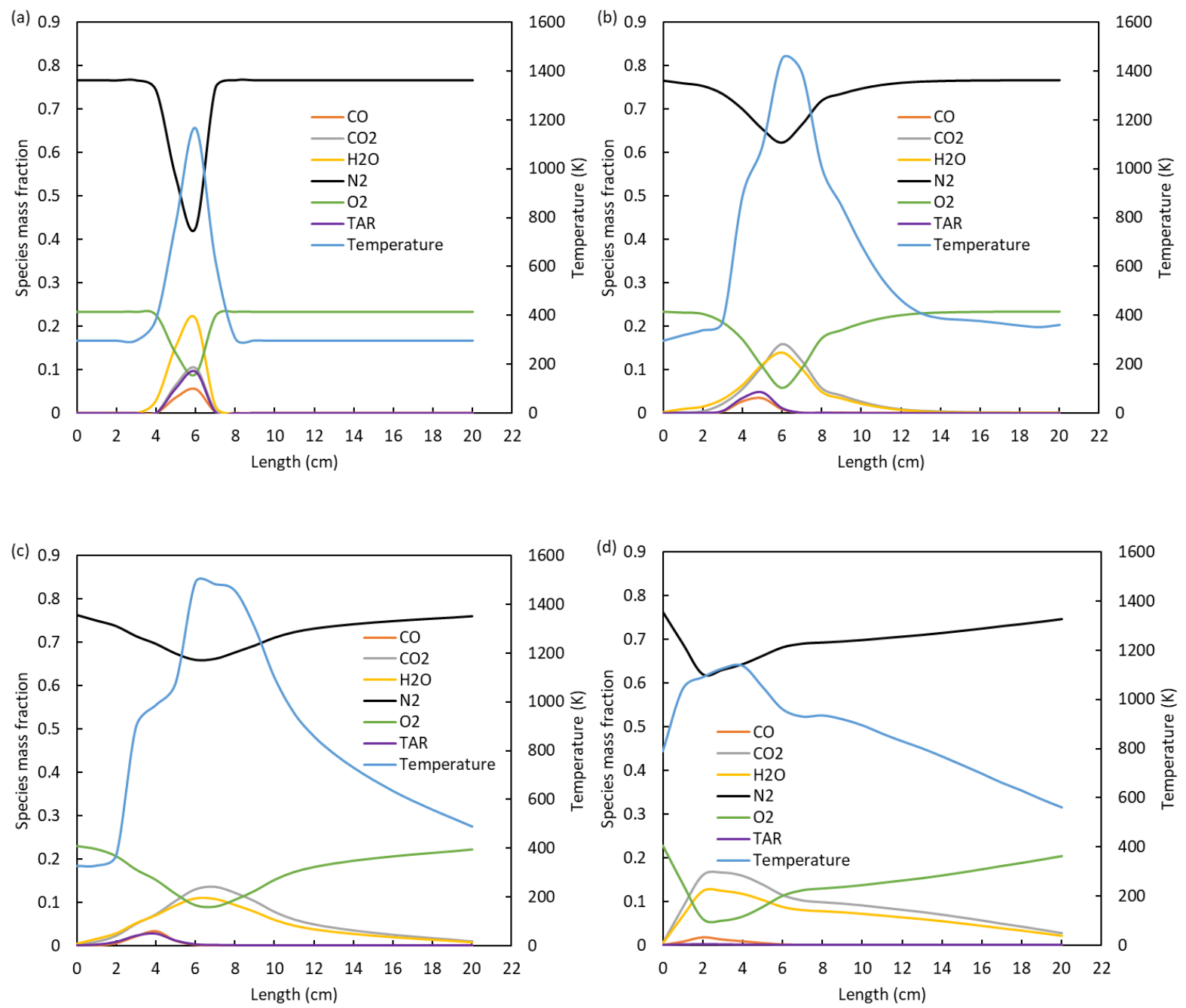

Figure 5.8: Predicted species and temperatures profiles along axial length of the reactor for wood combustion in $21 \% \mathrm{O}_{2} / 79 \% \mathrm{~N}_{2}$ mixture at different times: (a) $200 \mathrm{~s}$, (b) $300 \mathrm{~s}$ (c) $400 \mathrm{~s}$ and (d) $1000 \mathrm{~s}$. 
Figs 5.8 and 5.9 show that the flame front moves faster in $\mathrm{N}_{2}$ environment than in $\mathrm{CO}_{2}$ environment. This is associated to the higher heat capacity of $\mathrm{CO}_{2}$ and low $\mathrm{O}_{2}$ diffusivity in it. These two effects have negative impact on heating rate of the particle and consequently decreases the flame front movement.
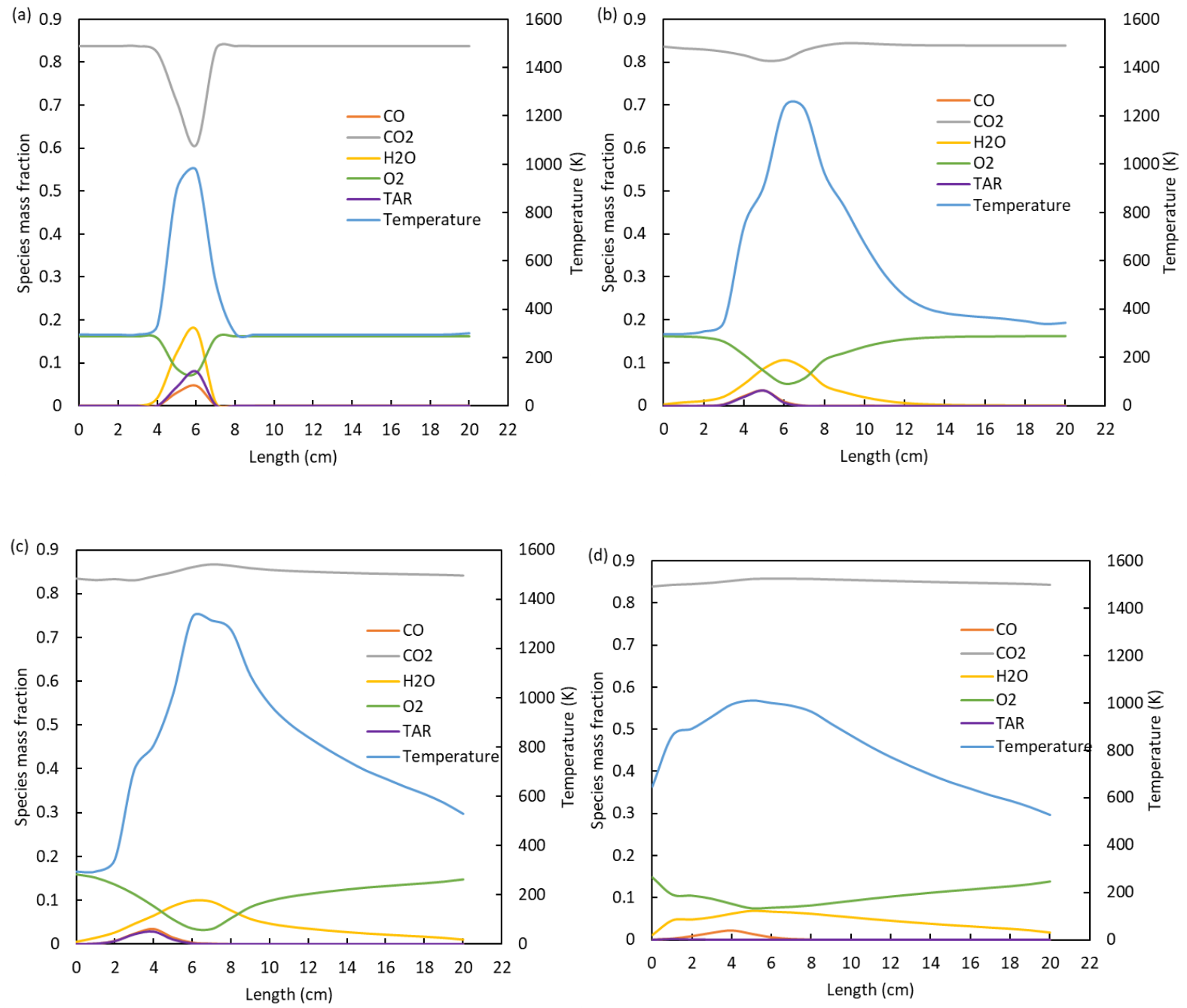

Figure 5.9: Predicted species and temperatures profiles along axial length of the reactor for wood combustion in $21 \% \mathrm{O}_{2} / 79 \% \mathrm{CO}_{2}$ mixture at different times: (a) $300 \mathrm{~s}$, (b) $450 \mathrm{~s}$ (c) $600 \mathrm{~s}$ and (d) $1100 \mathrm{~s}$. 
Figure 5.10 shows ignition time predicted by the model for fixed bed combustion of wood in various $\mathrm{O}_{2} / \mathrm{N}_{2}$ and $\mathrm{O}_{2} / \mathrm{CO}_{2}$ mixtures. In both mixtures, ignition time is inversely proportional to the $\mathrm{O}_{2}$ concentration. Under the same $\mathrm{O}_{2}$ concentration, ignition time is higher in $\mathrm{CO}_{2}$ environment than in a $\mathrm{N}_{2}$ environment. $\mathrm{CO}_{2}$ environment has low heating rates due to its higher heat capacity and low $\mathrm{O}_{2}$ diffusivity. Therefore, it takes a longer time for the particle to release enough volatiles for ignition. The effect of bed porosity on ignition time is shown in Fig. 5.11. As bed porosity is increased ignition time decreases. However, beyond a porosity of 0.68 , ignition time increases with increase in bed porosity. As bed porosity increases, more void spaces are available in the bed. Hence, there is excess $\mathrm{O}_{2}$ in the bed. Therefore, there is quick oxidation of volatiles released from the particle, which decreases the ignition time. But beyond a porosity of 0.68 , flame quenching due to excess $\mathrm{CO}_{2}$ occurs and causes an increase in ignition time.

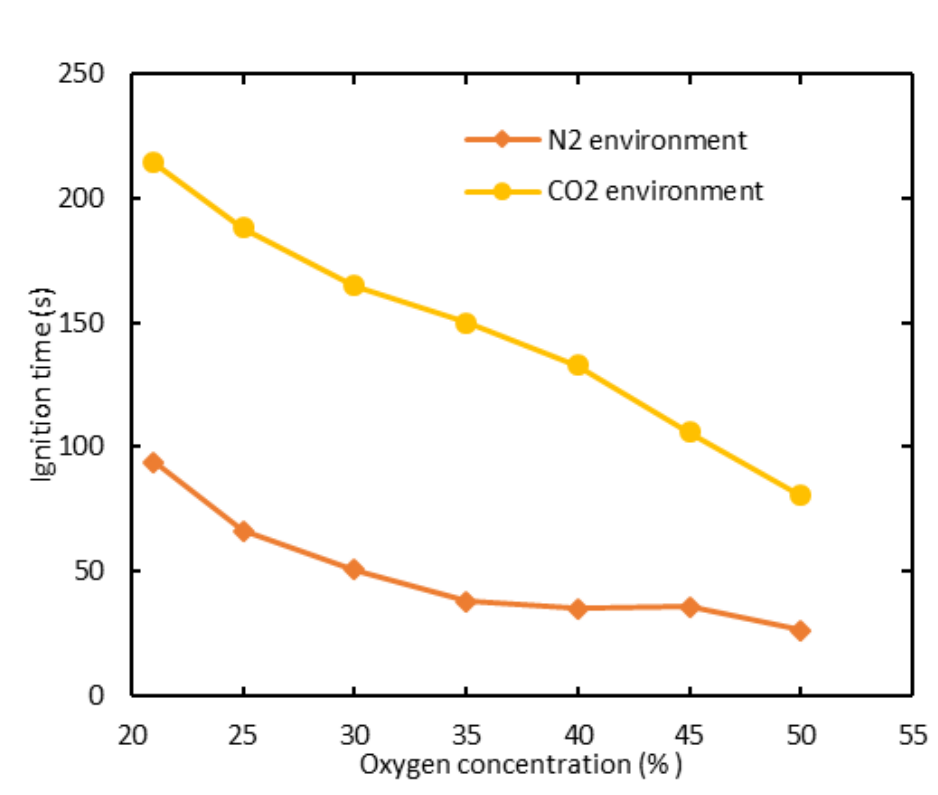

Figure 5.10: Predicted ignition time for fixed bed combustion of wood in $\mathrm{N}_{2}$ and $\mathrm{CO}_{2}$ environments. 


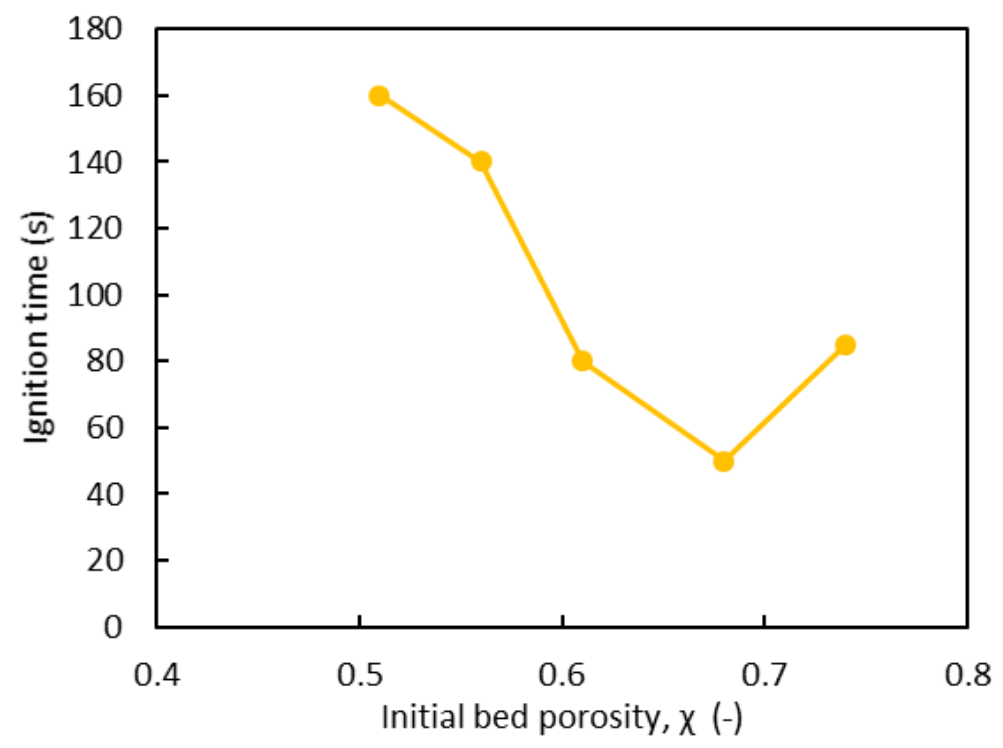

Figure 5.11: Predicted ignition time for wood combustion under oxy-fuel condition for different initial bed porosity.

The flame front propagation speed predicted by the model for fixed bed combustion of wood in various $\mathrm{O}_{2} / \mathrm{N}_{2}$ and $\mathrm{O}_{2} / \mathrm{CO}_{2}$ mixtures are shown in Fig. 5.12. In both cases, the flame front propagation speed increases with increase in $\mathrm{O}_{2}$ concentration. Under the same $\mathrm{O}_{2}$ concentration, the flame front propagation speed is higher in a $\mathrm{N}_{2}$ environment than in a $\mathrm{CO}_{2}$ environment. This is associated to the retarded ignition time in $\mathrm{CO}_{2}$ environment as noted in Fig. 5.10. In addition, the lower heating rates of the particles in $\mathrm{CO}_{2}$ environment contribute to reduction in its flame speed. Fig. 5.13 presents numerical results of predicted flame front propagation speed with respect to bed porosity. The graph shows that the flame front propagation speed increases as bed porosity is increased up to an optimum point where it starts to decrease. The optimum point occurs at $\chi=0.61$ in $21 \% \mathrm{O}_{2} / 79 \% \mathrm{~N}_{2}$ mixture and at $\chi=0.71$ in $21 \% \mathrm{O}_{2} / 79 \% \mathrm{CO}_{2}$ mixture. 


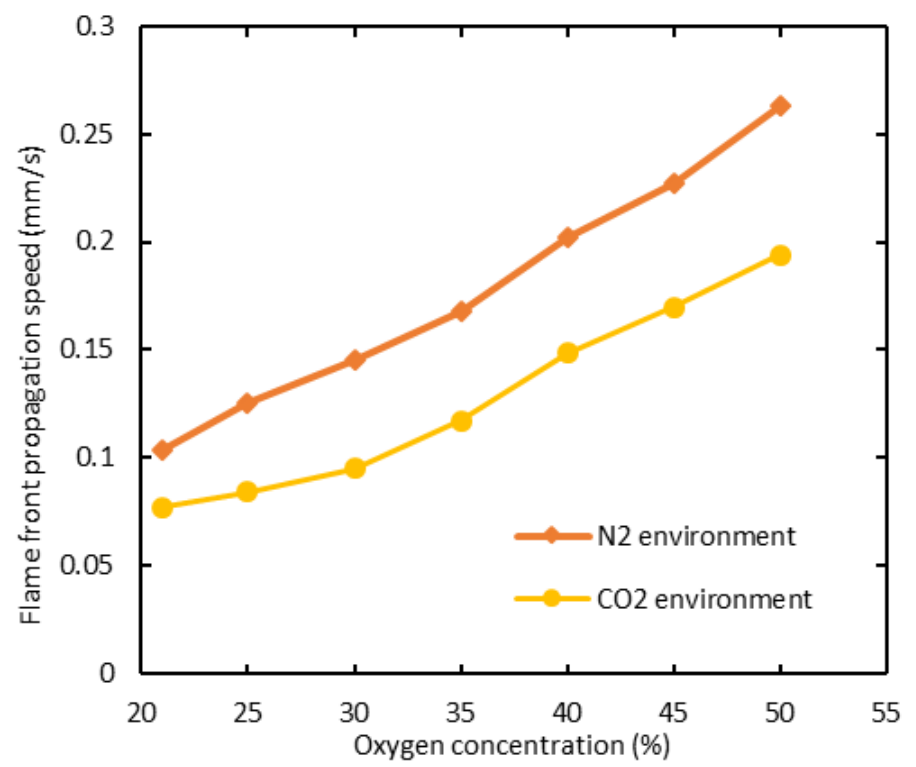

Figure 5.12: Predicted flame front propagation speed for fixed bed combustion of wood in $\mathrm{N}_{2}$ and $\mathrm{CO}_{2}$ environments.

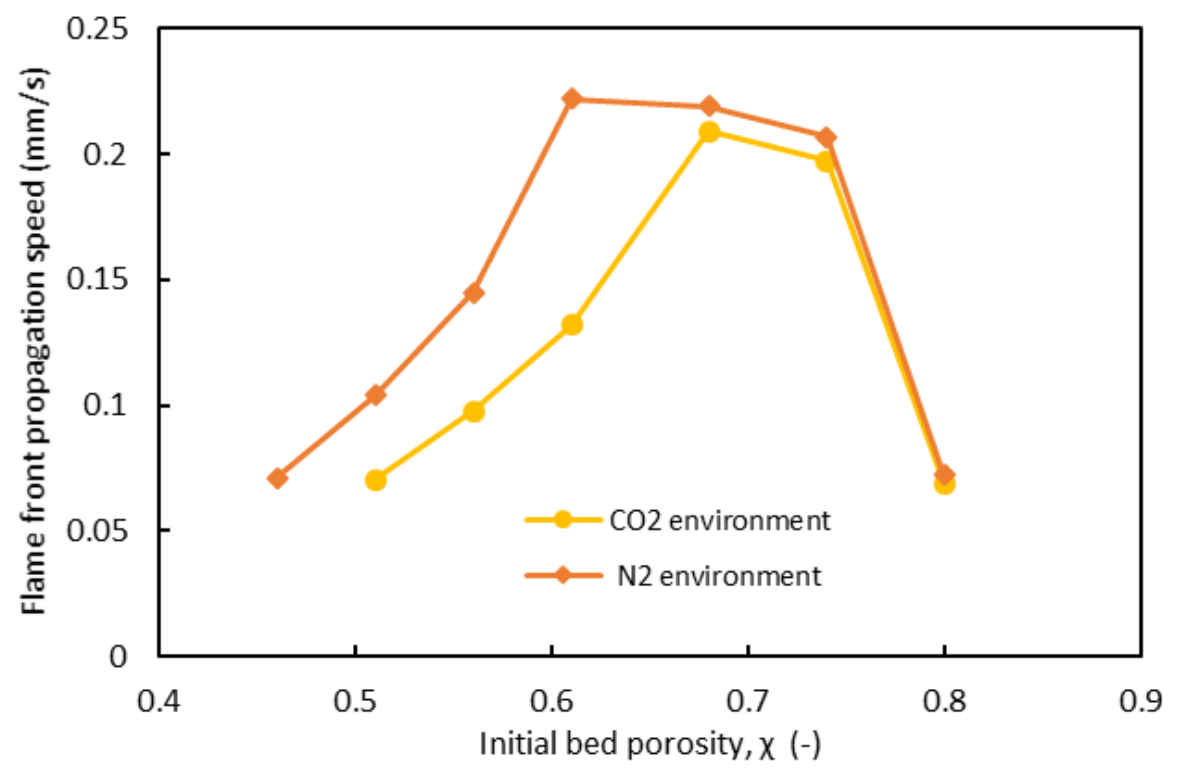

Figure 5.13: Measured and predicted flame front propagation speed for wood combustion in $\mathrm{N}_{2}$ and $\mathrm{CO}_{2}$ environments for different initial bed porosity. 


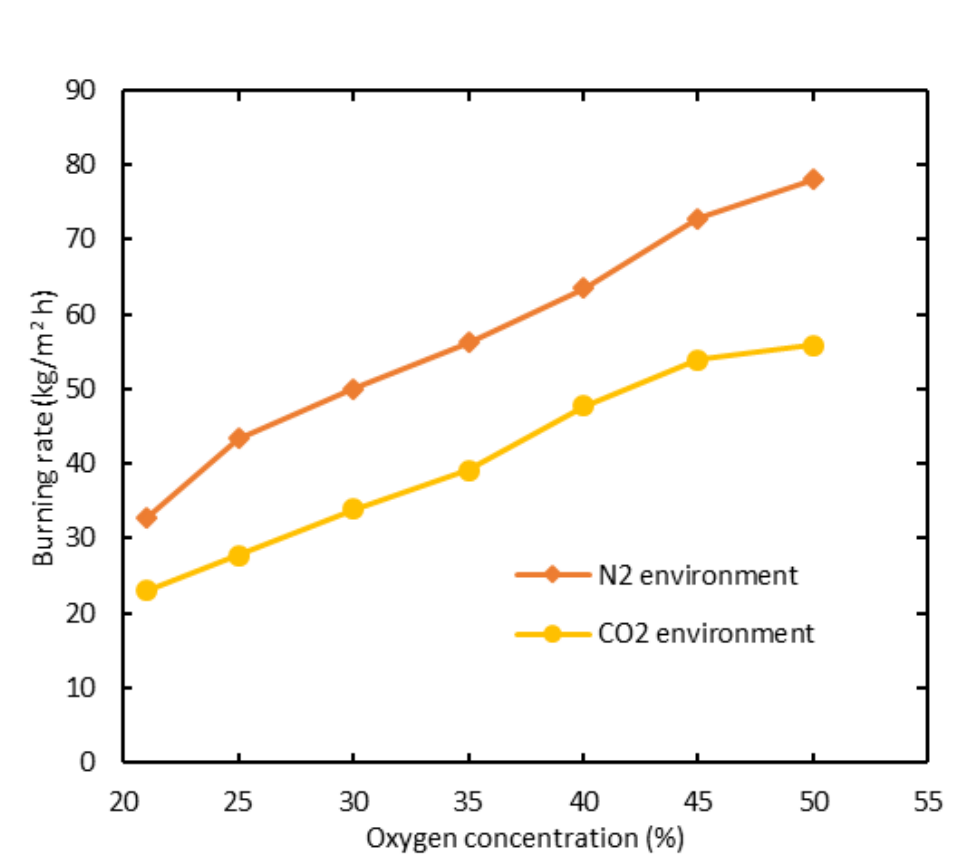

Figure 5.14: Predicted burning rates for fixed bed combustion of wood in $\mathrm{N}_{2}$ and $\mathrm{CO}_{2}$ environments.

The burning rates predicted by the model for fixed bed combustion of wood in various $\mathrm{O}_{2} / \mathrm{N}_{2}$ and $\mathrm{O}_{2} / \mathrm{CO}_{2}$ mixtures are shown in Fig. 5.14. The burning rates are directly proportional to $\mathrm{O}_{2}$ concentration. Under the same $\mathrm{O}_{2}$ concentration, the burning rate is higher in a $\mathrm{N}_{2}$ environment than in a $\mathrm{CO}_{2}$ environment. The burning rate reduction observed in $\mathrm{CO}_{2}$ environment could be attributed to its lower thermal diffusivity as compared to that of $\mathrm{N}_{2}$, (Suda et al., 2007). Furthermore, $\mathrm{CO}_{2}$ absorb radiative heat more than $\mathrm{N}_{2}$. The overall impact of these thermal properties of $\mathrm{CO}_{2}$ gas is a decrease in burning rate. 


\section{CHAPTER SIX}

\section{CFD-DEM MODEL VALIDATION, RESULTS AND DISCUSSIONS}

\subsection{Introduction}

This chapter presents CFD-DEM model validation results and discussions on the experimental and numerical study of wood conversion in a fixed bed under oxy-fuel environment. In the first section, CFD-DEM method and code validation are presented. Temperature distribution and species generation in the bed are discussed. The next section presents an investigation of wood combustion under oxy-fuel combustion environment using CFD-DEM numerical method. Effects of $\mathrm{CO}_{2}$ combustion environment on mass loss history, flame propagation speed, flame fronts positions and flame structures are discussed. Results of the influence of packing of fuel particle and bed porosity on combustion of wood in a fixed bed under oxy-fuel environment are then presented and discussed. Temperature history, ignition time, wood and char conversion rates and reaction zone thickness are discussed in detail. The last section presents the role of various $\mathrm{CO}_{2}$ effects on burning rate. The overall and individual contribution of various $\mathrm{CO}_{2}$ effects on wood conversion processes are discussed.

\subsection{CFD-DEM Method and Code Validation}

In this section, numerical simulation of wood combustion in a laboratory-scaled fixed bed under air-fuel condition is presented. The main aim was to validate CFD-DEM approach in predicting temperature distribution and species generation in combustion of wood in a fixed bed.

\subsubsection{Temperature Distribution}

The model results were validated by comparing predicted and measured temperature at corresponding positions in the fuel bed. Shown in Fig. 6.1 is the temperature history at $5 \mathrm{~cm}$ from bed bottom. A good agreement between predicted and measured temperature values is 
achieved. The graph shows that the temperature profile has two peaks; the first peak is about $1200 \mathrm{~K}$ while the second peak is about $1400 \mathrm{~K}$. As the flame front passes the position where measurement is done, temperature rises rapidly up to the first peak. Then it gradually decreases to about $900 \mathrm{~K}$ where it starts to rise again. This phase of combustion is characterized by both exothermic and endothermic processes. Exothermic reactions of the volatiles increase the temperature while drying and pyrolysis which are endothermic processes decrease the temperature. The second part of the graph where temperature rises signifies the end of endothermic processes. The volatiles transported from lower part of the bed burn in this phase. The last regime where temperature decrease is characterized by char gasification and oxidation. Whereas char oxidation increases the temperature, char gasification with $\mathrm{H}_{2} \mathrm{O}$ and $\mathrm{CO}_{2}$ decreases the temperature. Overall decrease in temperature indicates that gasification is the dominant process in this regime.

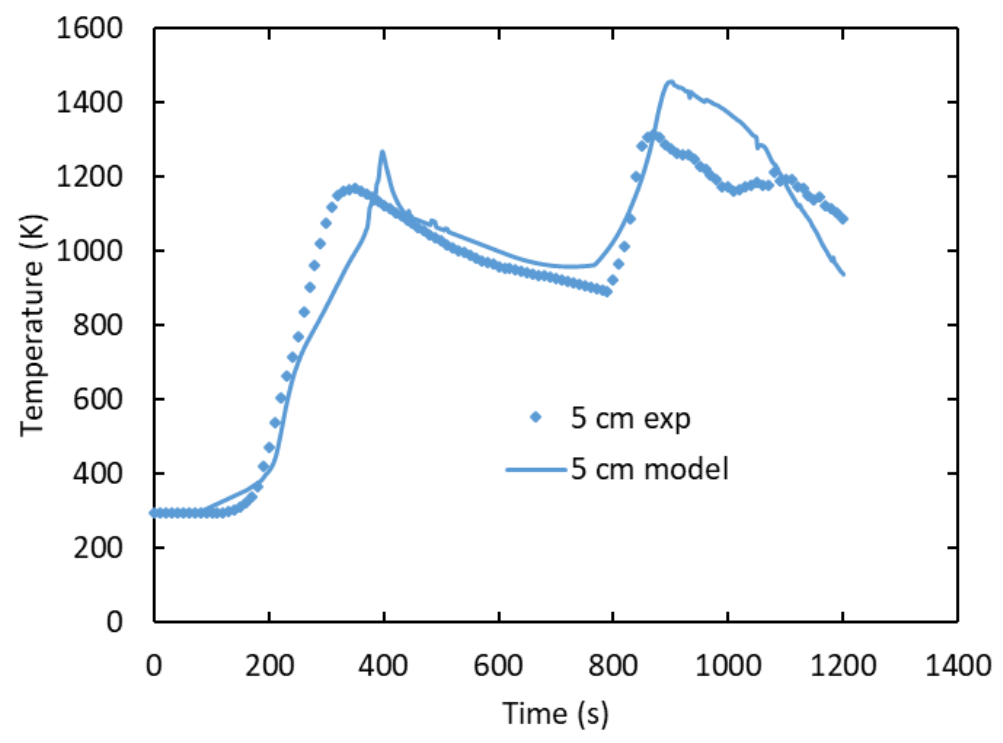

Figure 6.1: Measured and predicted temperature profiles at $5 \mathrm{~cm}$ from fuel bottom for wood combustion at $21 \% \mathrm{O}_{2} / 79 \% \mathrm{~N}_{2}$. 
Presented in Fig. 6.2 are the gas-phase and particle surface temperatures at different times. The figures clearly reveal the movement of reaction front from top to bottom as combustion proceeds. Temperature distribution at the same cross section is non-uniform. Some particles have higher temperature than others located within the same height. Uneven distribution of temperature in the same height could be attributed to random packing in the bed, which causes variation of flow field at various points in the same cross section. This affects the conversion process of the particle in terms of the associated heat and mass transfer.

Initially, the bed is ignited at the top. During ignition, heat is absorbed by the particles in drying and pyrolysis which occur simultaneously. The bed temperature does not increase significantly as illustrated in Figs. 6.2(a) and 6.2(b). Once pyrolysis products are released, they react with $\mathrm{O}_{2}$ and release more heat which increases the temperature, as shown in Fig. 6.2(c). Heat spreads to other particles by radiation, convection and conduction. As reaction front moves downward, more pyrolysis products are released. These products are not completely combusted at their point of production. Some are transported downstream (freeboard region) where they react and generate more heat which significantly increases the temperature, as shown in Figs. 6.2(d) and $6.2(\mathrm{e})$.

Movement of the reaction front from top to bottom results in devolatilization of all particles in fuel bed. As a result, the fuel bed slightly shrinks as shown in Fig. 6.2(f). The remaining biomass is now pure char which undergoes heterogeneous reactions with $\mathrm{O}_{2}, \mathrm{H}_{2} \mathrm{O}$ and $\mathrm{CO}_{2}$. The overall temperature decreases because char reactions with $\mathrm{H}_{2} \mathrm{O}$ and $\mathrm{CO}_{2}$ are dominant in this phase and they are endothermic. It is also noted that in the vicinity of the grate, temperatures are lower than in the other region of the bed. The cause of this is convective cooling associated with incoming cold air. 

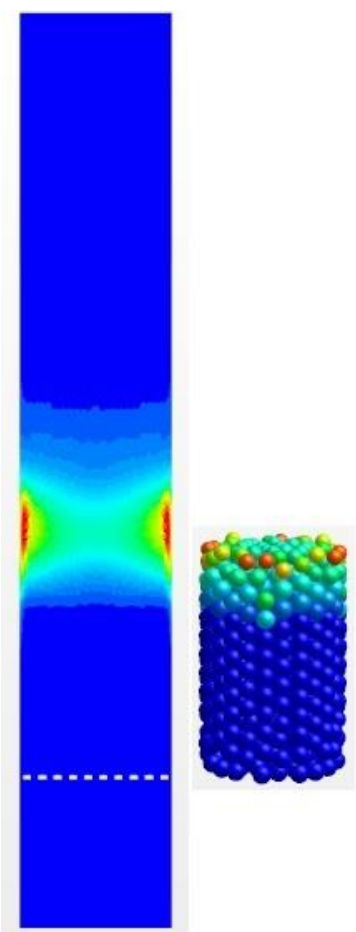

(a) $\mathrm{t}=100 \mathrm{~s}$

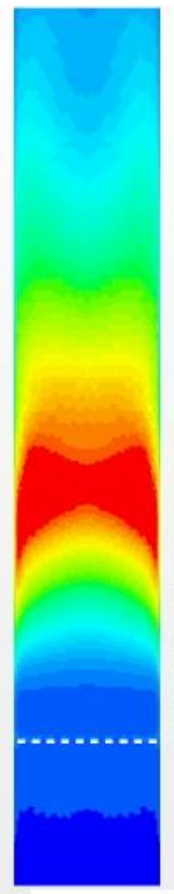

(d) $\mathrm{t}=400 \mathrm{~s}$
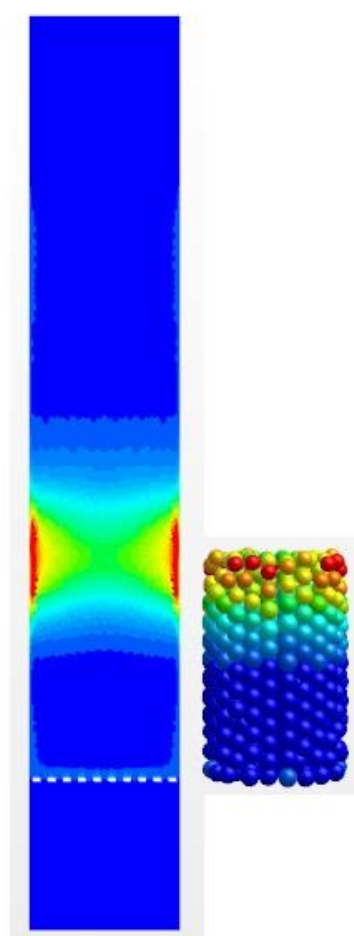

(b) $t=200 \mathrm{~s}$

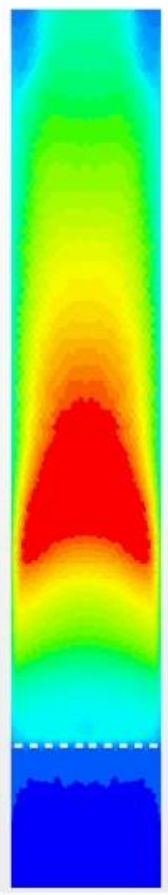

(e) $t=750 \mathrm{~s}$

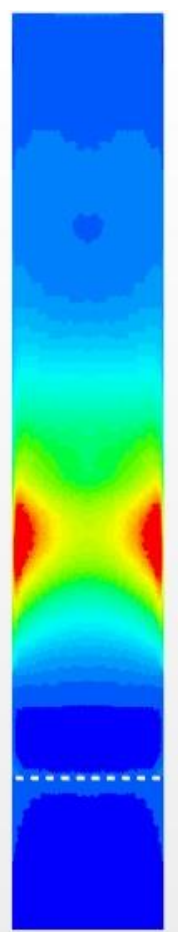

Temperature $(K)$

- 1500.0

1259.0

1018.0

777.00

536.00

(c) $\mathrm{t}=300 \mathrm{~s}$

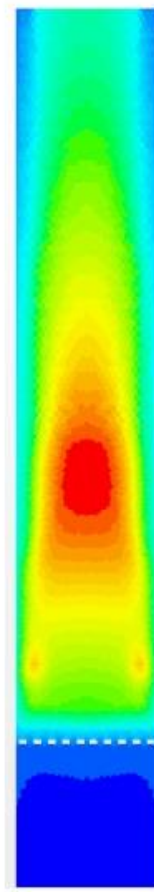

Temperature $(K)$

1500.0

1259.0

1018.0

777.00

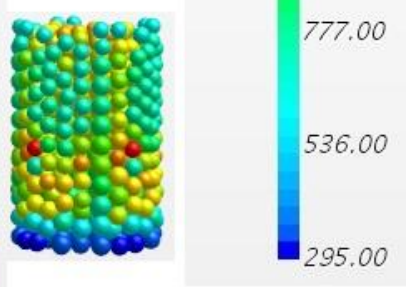

(f) $\mathrm{t}=1000 \mathrm{~s}$

Figure 6.2: Gas-phase and particle surface temperature distribution in the wood fuel bed burning at $21 \% \mathrm{O}_{2} / 79 \% \mathrm{~N}_{2}$ at different times. 


\subsubsection{Major Species Generation}

Illustrated in Figs. 6.3 and 6.4 are the mass fraction distribution of the major combustible species of pyrolysis: tar and CO. Likewise to temperature distribution, the species mass fraction distribution at a given cross section is also non-uniform. Nonetheless, the flame front propagation is clearly depicted. Significant amount of tar and CO are produced in fuel bed from ignition up to about $750 \mathrm{~s}$, as shown in Figs. 6.3 and 6.4. During this period, devolatilization is the dominant process. At 1000 s, Figs. 6.3 and 6.4, traces of the volatiles are noticeable in the bed. This indicates that at this time devolatilization is complete and the bed is undergoing char combustion.

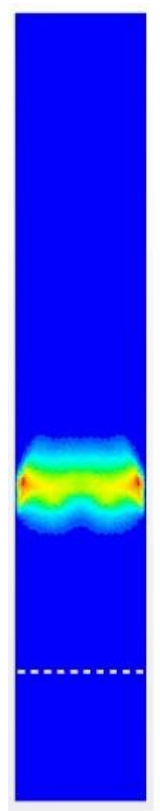

$100 \mathrm{~s}$

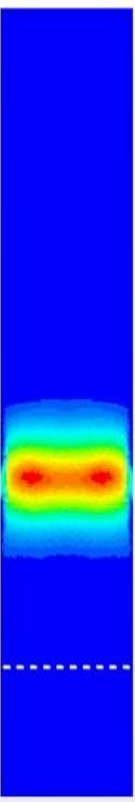

$200 \mathrm{~s}$

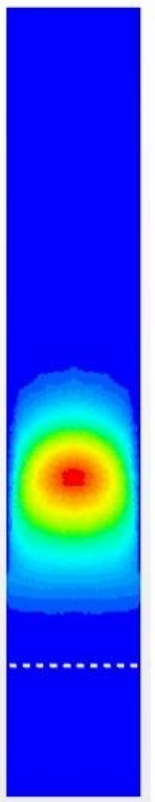

$300 \mathrm{~s}$

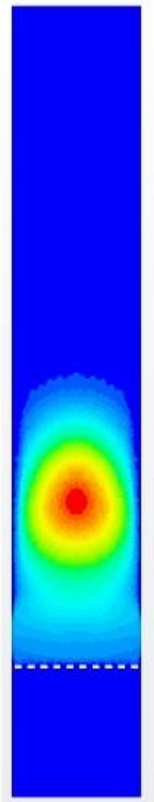

$400 \mathrm{~s}$

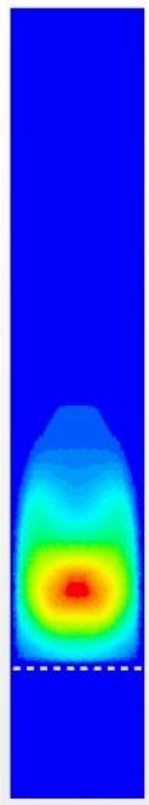

$750 \mathrm{~s}$

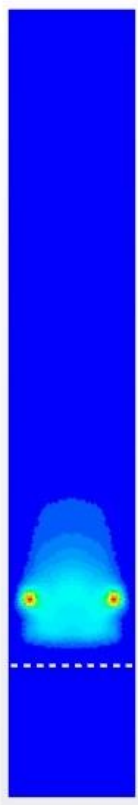

Mass Fraction of Tar

0.11335

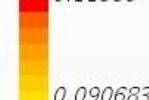

0.090683

0.068013

0.045342

0.022671

0.00000

Figure 6.3: Tar mass fraction distribution in the wood fuel bed burning at $21 \% \mathrm{O}_{2} / 79 \% \mathrm{~N}_{2}$ at different times.

Volatiles released from the bed burn within or outside the bed. As shown in Fig. 6.5, for the tested flow rate oxidant is high enough to oxidize all the volatiles. As flame front moves 
downward, the amount of tar and $\mathrm{CO}$ released at its position decreases. This could be attributed to non-uniformity of flame front movement. Some particles at the same level get heated and pyrolyzed faster than others.

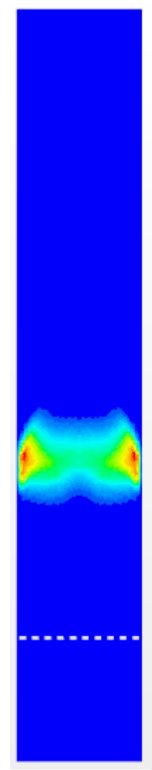

$100 \mathrm{~s}$

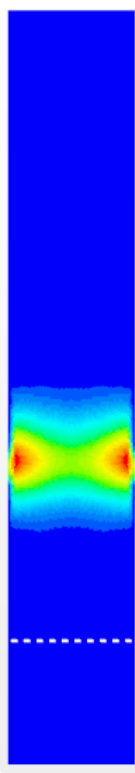

$200 \mathrm{~s}$

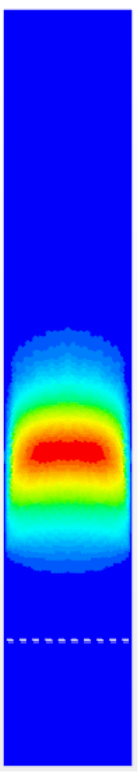

$300 \mathrm{~s}$

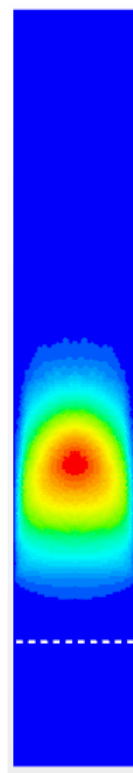

$400 \mathrm{~s}$

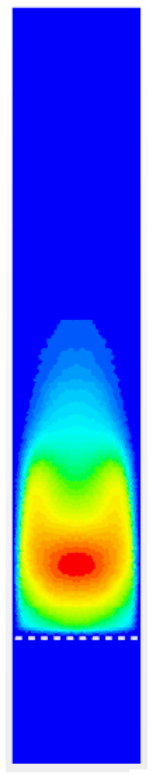

$750 \mathrm{~s}$

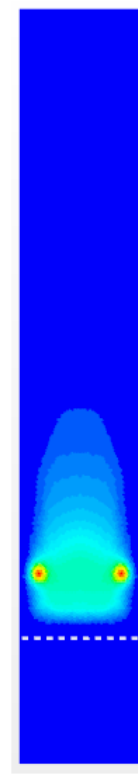

Mass Fraction of $\mathrm{CO}$

0.080076

0.064061

0.048046

0.032030

0.016015

$1000 \mathrm{~s}$

Figure 6.4: $\mathrm{CO}$ mass fraction distribution in the wood fuel bed burning at $21 \% \mathrm{O}_{2} / 79 \% \mathrm{~N}_{2}$ at different times.

Shown in Fig. 6.6 is water vapour $\left(\mathrm{H}_{2} \mathrm{O}\right)$ mass fraction distribution in fuel bed. $\mathrm{H}_{2} \mathrm{O}$ is a gaseous product arising from particle evaporation. It is also one of the pyrolysis product. In addition, $\mathrm{H}_{2} \mathrm{O}$ in the bed is due to oxidation of $\mathrm{CH}_{4}$ and $\mathrm{H}_{2}$. During initial stages of combustion, for instance ignition up to $300 \mathrm{~s}$, most of $\mathrm{H}_{2} \mathrm{O}$ is confined to fuel bed. This is because during this period $\mathrm{H}_{2} \mathrm{O}$ is mostly from particle evaporation and pyrolysis. As combustion proceeds, e.g. from $400 \mathrm{~s}$ to $1000 \mathrm{~s}, \mathrm{H}_{2} \mathrm{O}$ generated in fuel bed is spread to freeboard region by convection. It is important to note that at this time, all the aforementioned sources participate in its production making it more pronounced than earlier stage. $\mathrm{H}_{2} \mathrm{O}$ together with $\mathrm{CO}_{2}$ are the main products of 
combustion that radiate heat. As a result, its effects on temperature distribution is seen in Fig.

6.2 .

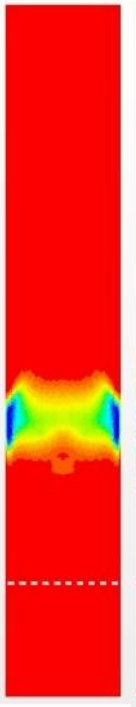

$100 \mathrm{~s}$

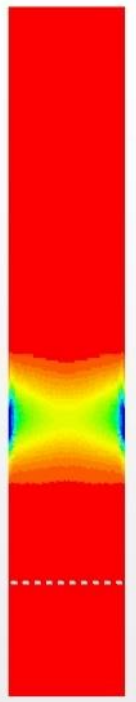

$200 \mathrm{~s}$

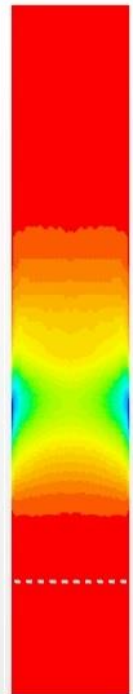

$300 \mathrm{~s}$

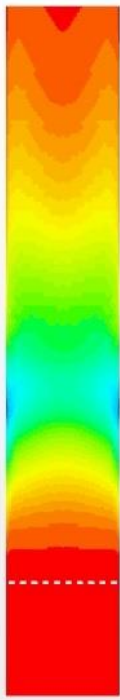

$400 \mathrm{~s}$

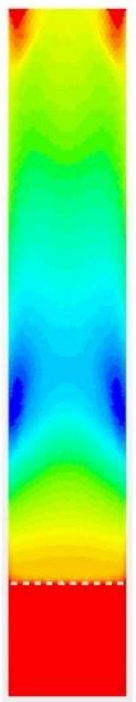

$750 \mathrm{~s} \quad 1000 \mathrm{~s}$
Mass Fraction of $\mathrm{O} 2$

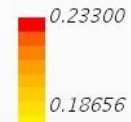

0.14012

0.093677

0.047236

0.00079485

Figure 6.5: $\mathrm{O}_{2}$ mass fraction distribution in the wood fuel bed burning at $21 \% \mathrm{O}_{2} / 79 \% \mathrm{~N}_{2}$ at different times.

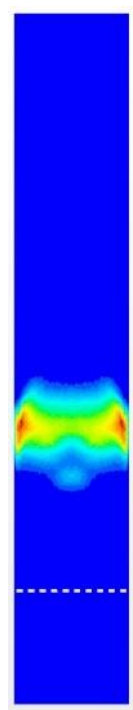

$100 \mathrm{~s}$

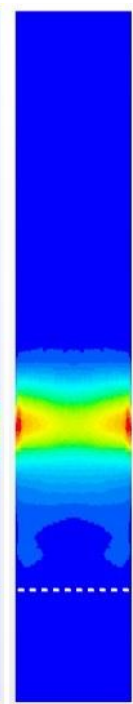

$200 \mathrm{~s}$

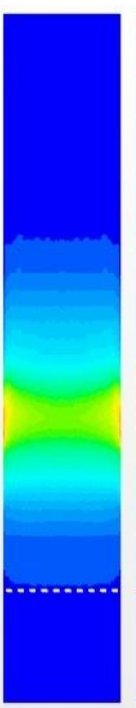

$300 \mathrm{~s}$

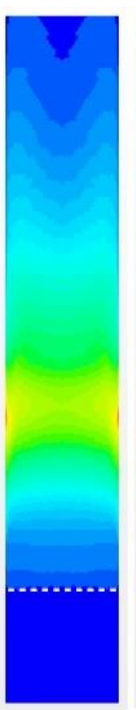

$400 \mathrm{~s}$

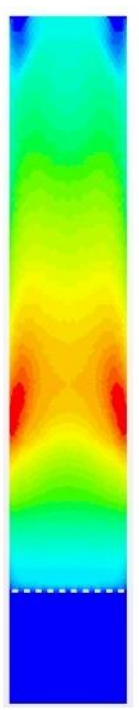

$750 \mathrm{~s} \quad 1000 \mathrm{~s}$
Mass Fraction of $\mathrm{H} 2 \mathrm{O}$

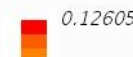

0.10084

0.075631

0.050421

0.025210

$2.8359 e-08$

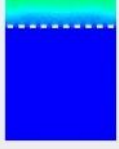

Figure 6.6: $\mathrm{H}_{2} \mathrm{O}$ mass fraction distribution in the wood fuel bed burning at $21 \% \mathrm{O}_{2} / 79 \% \mathrm{~N}_{2}$ at different times. 
Presented in Fig. 6.7 is mass fraction distribution of $\mathrm{CO}_{2}$ in the burner. $\mathrm{CO}_{2}$ is a product which arises from pyrolysis as well as oxidation of $\mathrm{CO}, \mathrm{CH}_{4}$ and char. Its production is also contributed to by tar cracking reactions. During initial stage of combustion, $100 \mathrm{~s}$ to $300 \mathrm{~s}$, it is observed that $\mathrm{CO}_{2}$ production is minimal and restricted to the fuel bed. $\mathrm{CO}_{2}$ generation is more pronounced in the last stage of combustion, $750 \mathrm{~s}$ and $1000 \mathrm{~s}$. This is char combustion stage where char is oxidized into $\mathrm{CO}$ and $\mathrm{CO}_{2}$ which increases its amount in the burner.

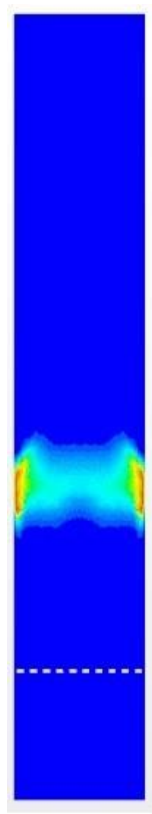

$100 \mathrm{~s}$

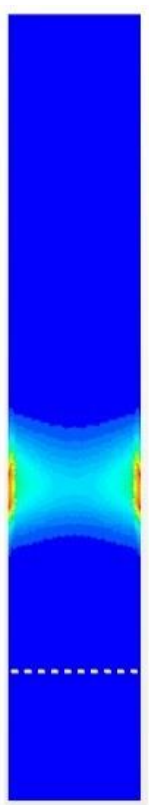

$200 \mathrm{~s}$

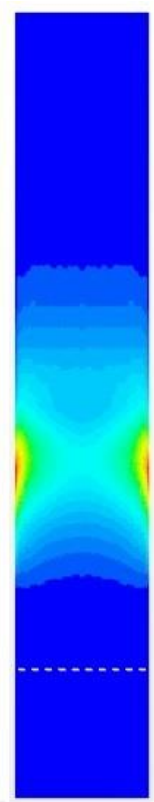

$300 \mathrm{~s}$

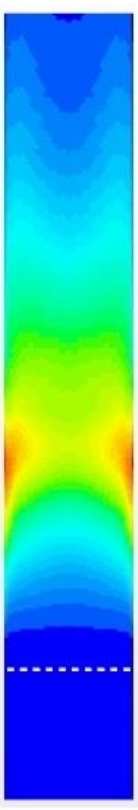

$400 \mathrm{~s}$

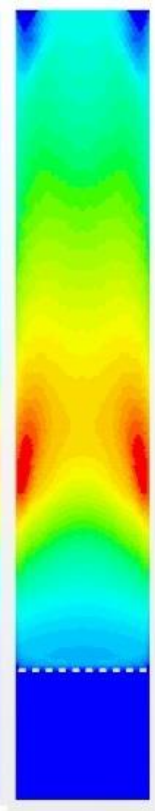

$750 \mathrm{~s} \quad 1000 \mathrm{~s}$

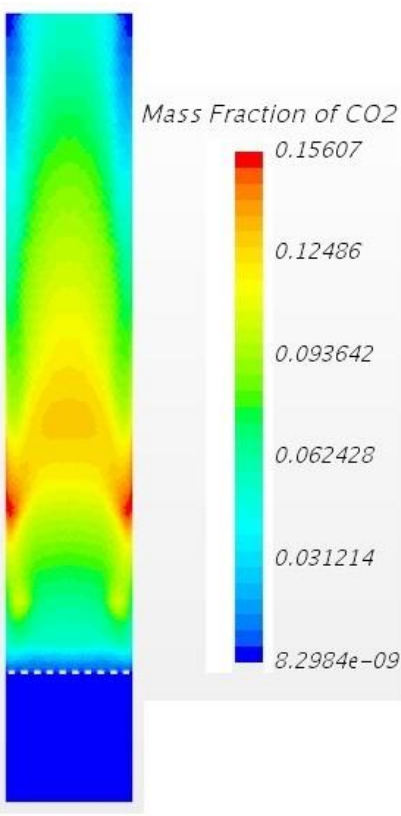

Figure 6.7: $\mathrm{CO}_{2}$ mass fraction distribution in the wood fuel bed burning at $21 \% \mathrm{O}_{2} / 79 \% \mathrm{~N}_{2}$ at different times.

Flame structures at different positions from fuel bed bottom are presented in Figs. 6.8. The graphs show that in the freeboard region flame structures at different positions have similar profiles but differ in magnitude. Since the fixed bed that was tested was operated in batch mode under unsteady conditions, amount of heat released changed with respect to time. At $10 \mathrm{~cm}$, intense heat is released between $170 \mathrm{~s}$ and $600 \mathrm{~s}$, while at $15 \mathrm{~cm}$ it is at $200 \mathrm{~s}$ to $600 \mathrm{~s}$. These 
periods fall within devolatilization stage where volatiles transported to these positions react and generate heat. Temperature then decreases gradually until the end of combustion. During this time, heat present in these positions is by convection and radiation from fuel bed.

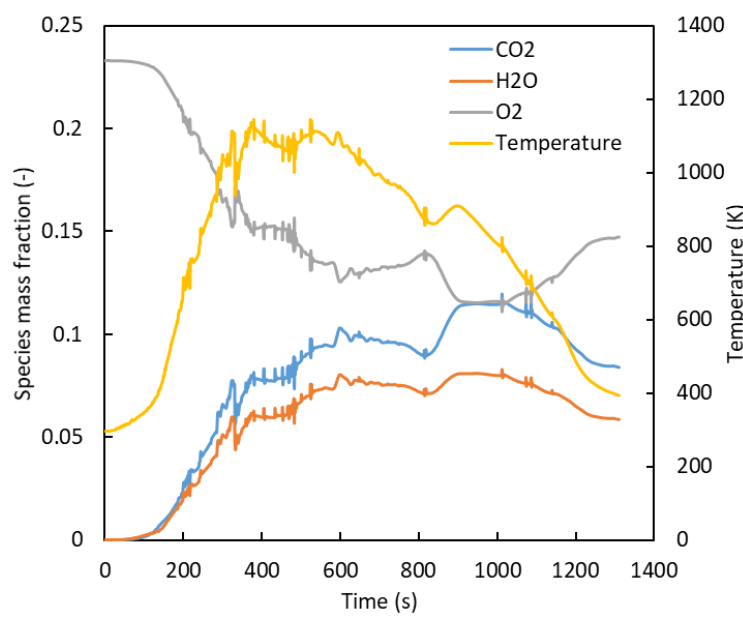

(a) $10 \mathrm{~cm}$

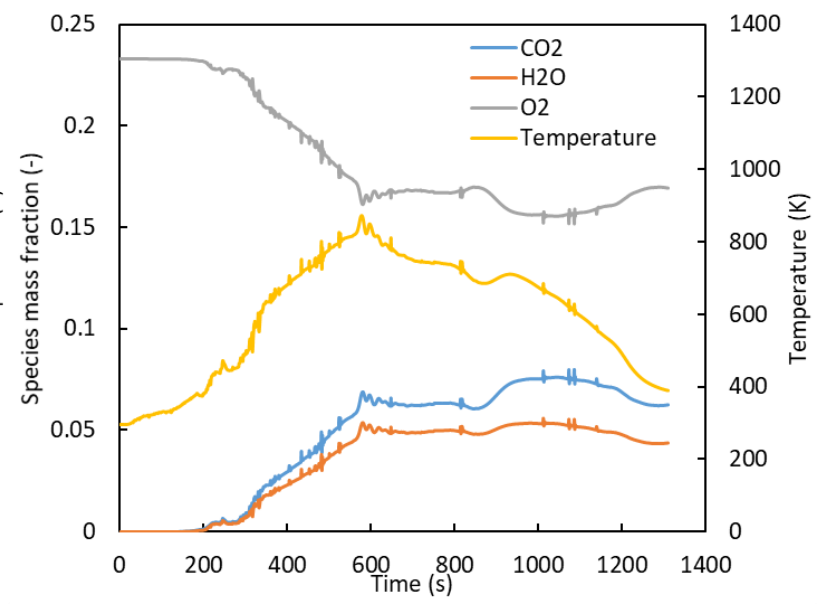

(b) $15 \mathrm{~cm}$

Figure 6.8: Major species and temperatures profiles at different position from fuel bed bottom for wood combustion at $21 \% \mathrm{O}_{2} / 79 \% \mathrm{~N}_{2}$.

In summary, this section presented modeling of fixed bed combustion of wood using CFDDEM approach. The modeling results were validated with measurement done in a laboratoryscaled fixed bed. A good agreement between model and experimental results were achieved. It was established that temperature profile at a given position in the bed has two peaks; the first peak is about $1200 \mathrm{~K}$ while the second peak is about $1400 \mathrm{~K}$. Temperature distribution at the same cross section is non-uniform. Some particles have higher temperature than others located within the same height. Likewise, species mass fraction distribution at a given cross section is also non-uniform. Nonetheless, the flame front propagation is clearly depicted. In freeboard region, flame structures at different positions have similar profiles but differ in magnitude. Therefore, it was proven that CFD-DEM is a good tool in analysis of fixed bed furnace. 


\subsection{Flame Structure of Fixed-Bed Wood Combustion under Oxy-Fuel Conditions}

This section presents an investigation of wood combustion in a laboratory-scaled fixed bed with an aim of establishing the effect of $\mathrm{CO}_{2}$ environment on flame propagation speed and flame structures. Results show that flame front propagation speed in oxy-fuel atmosphere reduced to $78 \%$ of that of the air-fuel condition with similar $\mathrm{O}_{2}$ concentration. This is attributed to the transport and thermodynamics properties of $\mathrm{CO}_{2}$ gas as well as its chemical effects. For oxyfuel conditions, propagation speed increased with increase in $\mathrm{O}_{2}$ concentration. The CFD-DEM model agrees very well with experimental values for mass loss, propagation speed and flame front positions. However, peak temperatures are poorly predicted at lower oxygen concentrations. The accuracy of temperature prediction improves at higher oxygen concentrations. During initial and devolatilization stage, mass fraction of tar predicted in $\mathrm{CO}_{2}$ environment are smaller than in $\mathrm{N}_{2}$ environment, while the amount of $\mathrm{CO}$ predicted is almost equal in both environments. However, during char combustion stage a high amount of $\mathrm{CO}$ is observed in oxy-fuel conditions.

\subsubsection{Mass Loss History}

Validity of the model is checked by comparing mass loss history, peak temperatures and flame propagation speed obtained from simulations to corresponding experimental data. Shown in Fig. 6.9 is the mass loss history for wood combustion in $21 \% \mathrm{O}_{2}$ concentration under both $\mathrm{N}_{2}$ and $\mathrm{CO}_{2}$. The model agrees very well with experimental values. The curve for oxy-fuel condition is less steep with a longer devolatilization stage when compared with $\mathrm{N}_{2}$ atmosphere. A slightly long char stage is also observed in $\mathrm{CO}_{2}$ atmosphere. In overall, combustion of the same amount of wood takes a longer time for oxy-fuel condition than for air-fuel condition. This suggest a slow fuel consumption and burning rate in $\mathrm{CO}_{2}$ atmosphere. 


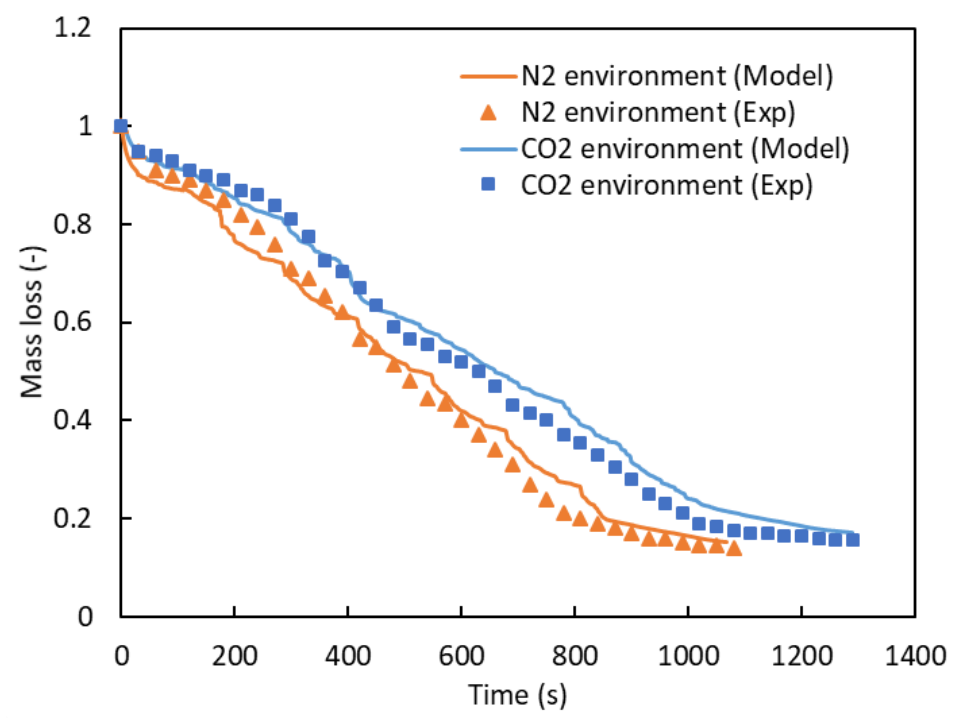

Figure 6.9: Mass loss history for wood combustion in fixed bed at $21 \% \mathrm{O}_{2} / 79 \% \mathrm{~N}_{2}$ and $21 \%$ $\mathrm{O}_{2} / 79 \% \mathrm{CO}_{2}$ mixtures.

Presented in Figs 6.10, 6.11 and 6.12 are temperature maps in the fuel bed at different times for different combustion atmospheres. The simulated and measured peak temperatures attained in the bed are compared in Fig. 6.13. Temperatures are poorly predicted at lower oxygen concentrations. The accuracy of prediction improves at higher oxygen concentrations. Temperatures corrected for radiation losses are also plotted in Fig. 6.13. Indeed, their agreement with predicted values are better than those of uncorrected values. Consequently, this emphasize the importance of considering radiation losses when validating a model.

It is important to note that after ignition, different conversion processes such as drying, devolatilization, char combustion and homogenous reactions takes place simultaneously at various heights of the bed. Since some processes are endothermic and others are exothermic, the temperatures at various regions are strongly dependent on the dominant process as discussed below. In the model used in this study, gaseous species released from biomass, depending on availability of oxidative species, either react within fuel bed or are transported to freeboard 
region where they react and produce heat. For all the cases studied, it is observed that during initial stages of combustion, freeboard temperatures are almost equal to bed temperatures. For $21 \% \mathrm{O}_{2}$ concentration, the period extended up to 300 s, Fig. 6.10, and 450 s, Fig. 6.11, for $\mathrm{N}_{2}$ and $\mathrm{CO}_{2}$ environments, respectively. As $\mathrm{O}_{2}$ concentration is increased in oxy-fuel condition, the period reduces from $450 \mathrm{~s}$ to $300 \mathrm{~s}$, Fig. 6.12. During this stage, heat release by homogeneous reactions is absorbed by downstream particles which are still undergoing devolatilization. At the same time, immediate upstream particles take up heat for drying.

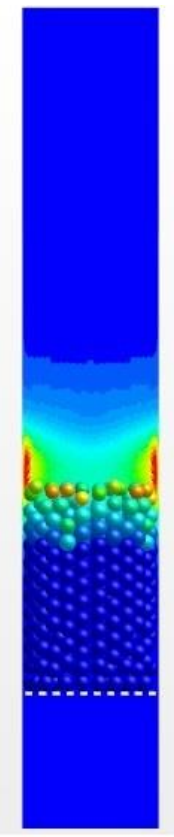

$100 \mathrm{~s}$

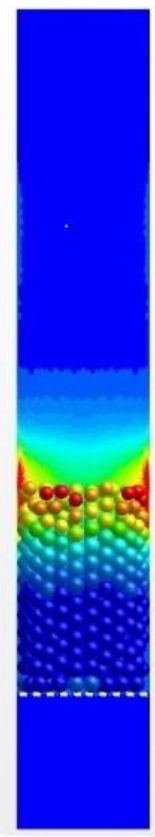

$200 \mathrm{~s}$

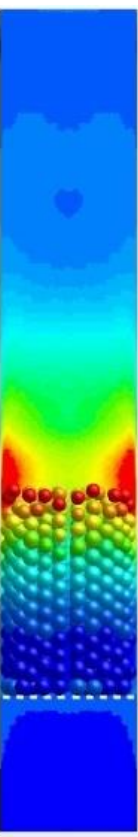

300 s

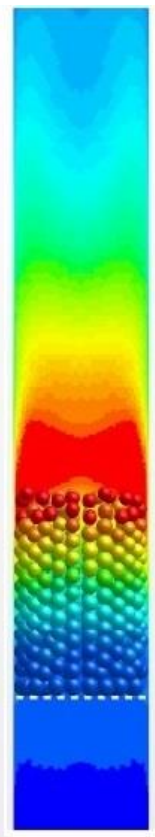

$400 \mathrm{~s}$

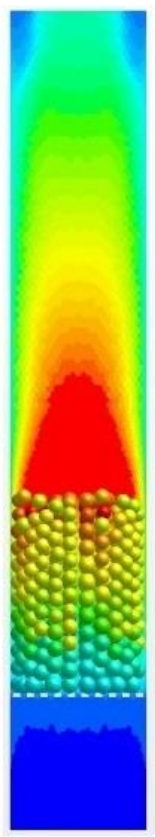

$750 \mathrm{~s}$

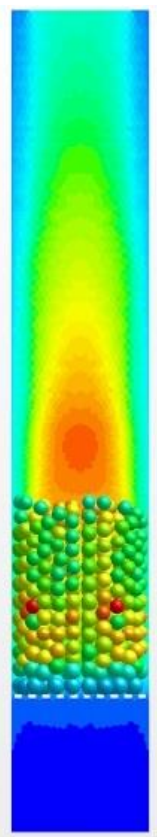

$1000 \mathrm{~s}$

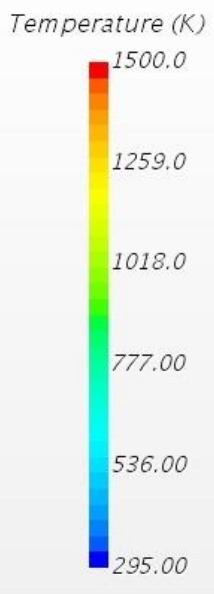

Figure 6.10: Temperature distribution in the wood fuel bed burning at $21 \% \quad \mathrm{O}_{2} / 79 \% \mathrm{~N}_{2}$ at different times.

As combustion progresses downward which is clearly depicted by propagation of reaction front, for example, between $400-750$ s, in Figs 6.10, 6.12, and 600 - 950 s, in Fig. 6.11, more volatiles are released. During this period, freeboard temperatures are higher than bed temperatures. At this time, particles adjacent to freeboard have probably completely undergone endothermic 
processes (drying and devolatilization). In addition, these particles are in char combustion stage which releases more heat. Heat released from homogeneous reaction and char combustion is transported from bed to freeboard by convection of combustion products which are dominated by $\mathrm{H}_{2} \mathrm{O}$ and $\mathrm{CO}_{2}$.

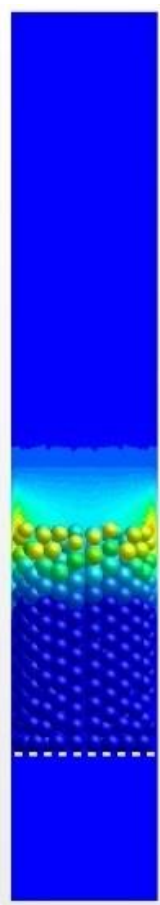

$200 \mathrm{~s}$

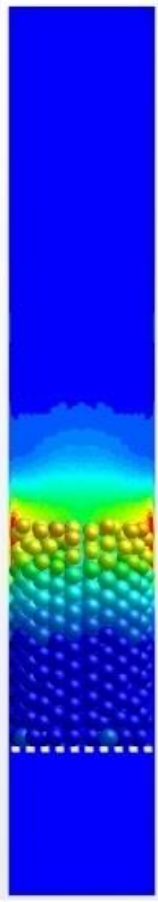

$300 \mathrm{~s}$

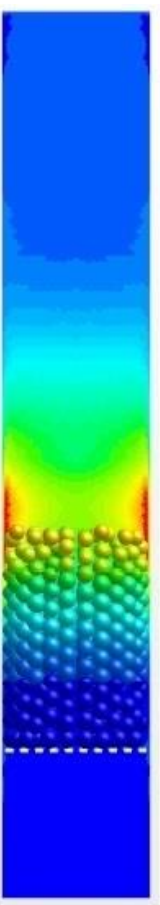

$450 \mathrm{~s}$

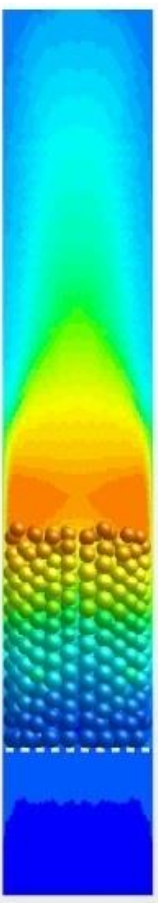

$600 \mathrm{~s}$

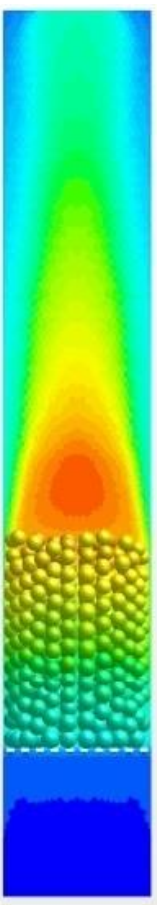

$950 \mathrm{~s}$

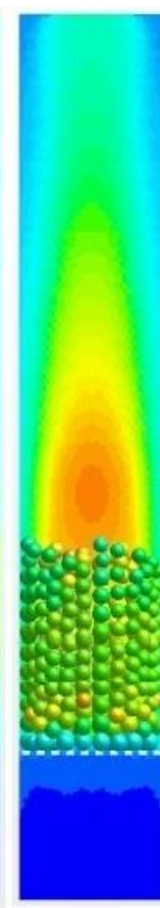

$1100 \mathrm{~s}$
Temperature $(K)$

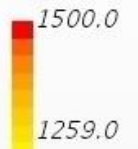

1018.0

777.00

536.00

295.00

Figure 6.11: Temperature distribution in the wood fuel bed burning at $21 \% \mathrm{O}_{2} / 79 \% \mathrm{CO}_{2}$ at different times.

After some time, reaction front reaches the bottom of the reactor and, at this point, all volatiles have been released. After this point, combustion in the bed is dominated by char combustion, for example, at $1000 \mathrm{~s}$ of Figs 6.10, 6.12 and $1100 \mathrm{~s}$ in Fig. 6.11. Freeboard temperatures decrease during this period. This is because homogeneous reactions which release intense heat is almost complete. 


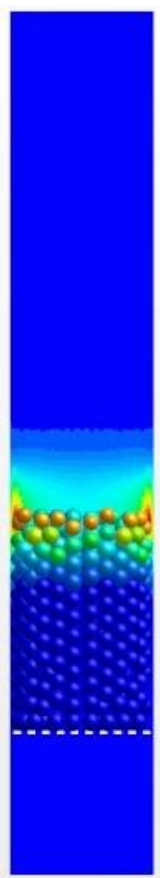

$100 \mathrm{~s}$

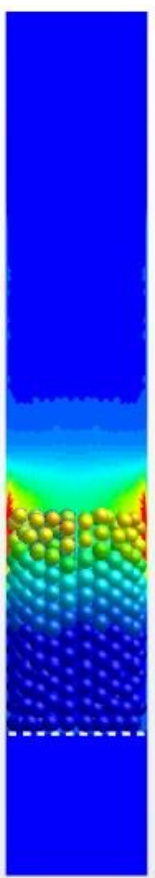

$200 \mathrm{~s}$

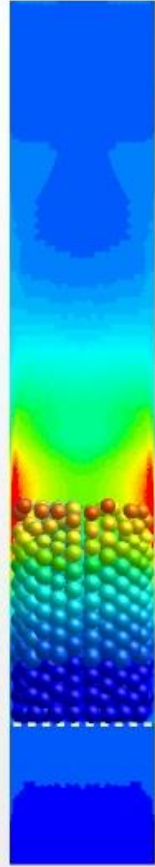

$300 \mathrm{~s}$

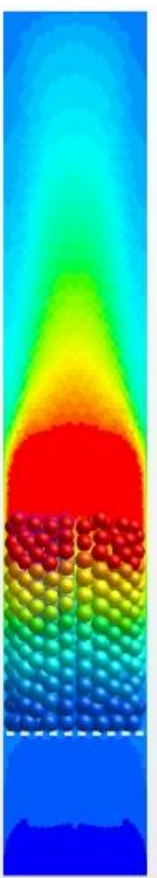

$400 \mathrm{~s}$

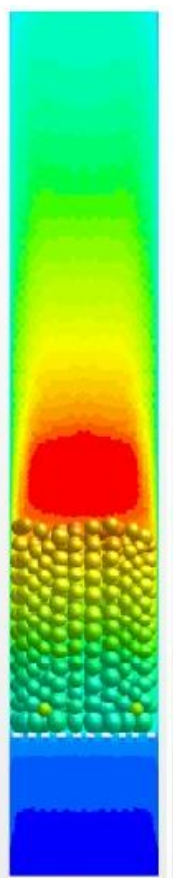

$750 \mathrm{~s}$

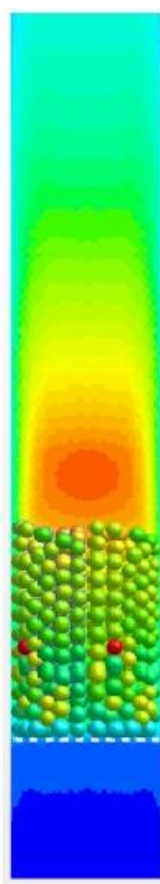

Temperature $(K)$

1500.0

1259.0

1018.0

777.00

536.00

295.00

Figure 6.12: Temperature distribution in the wood fuel bed burning at $30 \% \mathrm{O}_{2} / 70 \% \mathrm{CO}_{2}$ at different times.

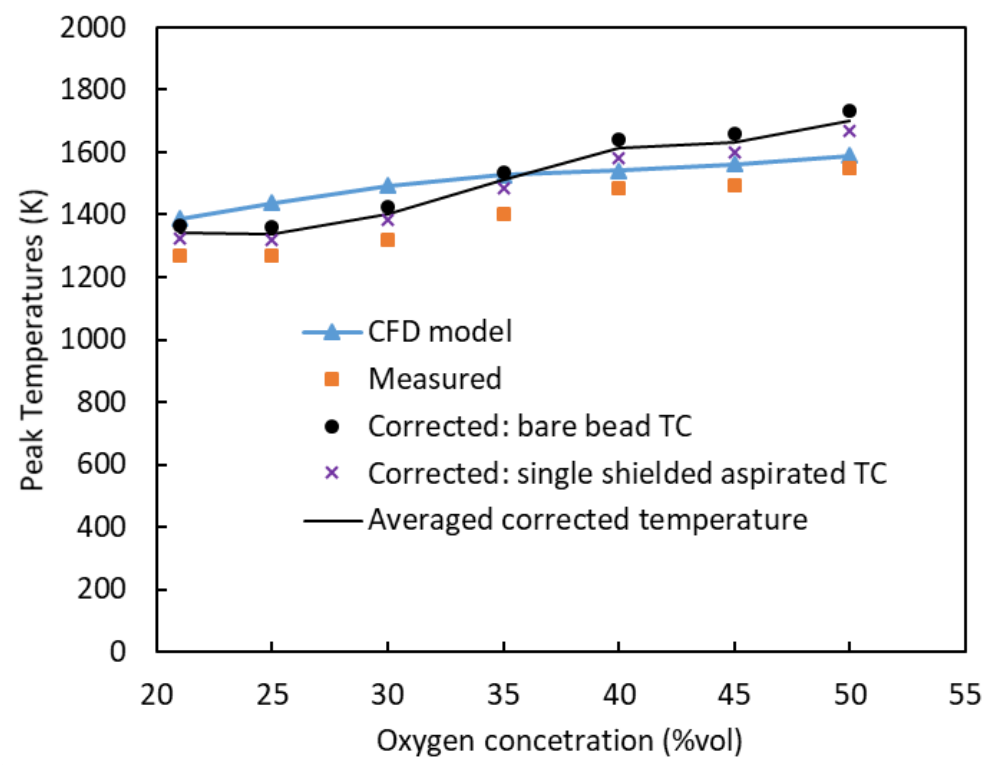

Figure 6.13: Predicted and measured peak temperatures in the wood fuel bed burning at different $\mathrm{CO}_{2}$ atmospheres. 
Even though the temperature distribution in fuel bed under both conditions exhibit the same behavior, the magnitudes are different. At $21 \% \quad \mathrm{O}_{2}$ concentration, air-fuel has a peak temperature of $1497 \mathrm{~K}$ while oxy-fuel has $1388 \mathrm{~K}$. As shown in Fig. 6.13, as $\mathrm{O}_{2}$ concentration is increased, temperature also increases. A value of temperature close to that of $21 \% \mathrm{O}_{2} / 79 \%$ $\mathrm{N}_{2}$ mixture is achieved at around $30 \% \mathrm{O}_{2} / 70 \% \mathrm{CO}_{2}$ mixture. Low values of temperatures in oxy-fuel conditions are associated with higher specific heat capacity of $\mathrm{CO}_{2}$ gas than that of $\mathrm{N}_{2}$ gas. This applies for all the temperatures above $650 \mathrm{~K}$ where specific heat capacity of $\mathrm{CO}_{2}$ gas is higher than that of $\mathrm{N}_{2}$ gas.

\subsubsection{Flame Front Propagation Speed}

The flame front propagation speed is estimated from distance and time data of temperature measuring points (Sakthivadivel \& Iniyan, 2018). For both experiment and model, flame front passes through a point when there is an abrupt increase in temperature from ambient value to a peak value (Ryu et al., 2006). The exact position of predicted and measured reaction front for wood combustion in $21 \% \mathrm{O}_{2}$ concentration under both $\mathrm{N}_{2}$ and $\mathrm{CO}_{2}$ is shown in Fig. 6.14. For air-fuel conditions at $21 \% \mathrm{O}_{2}$ concentration, a higher value of flame speed is observed. In general, propagation speed for air-fuel condition reported in literature (Dasappa \& Paul, 2001; Yang, Ryu, Khor, Yates, et al., 2005), are higher than those observed in oxy-fuel conditions of the current study. However direct comparison cannot be done because flame front propagation speed is dependent on several factors such as air mass flux, fuel properties, particles size, reactor operation mode, et cetera. Flame front speed have been shown (Dasappa \& Paul, 2001; Mahapatra et al., 2016; Ryu et al., 2006; Sakthivadivel \& Iniyan, 2018) to increase with increase in air mass flux up to a peak point where it starts to decrease. Mahapatra et al. (2016) reported a peak value of $0.089 \mathrm{~mm} / \mathrm{s}$ for air flow rate of $0.132 \mathrm{~kg} / \mathrm{m}^{2} / \mathrm{s}$ and casuarina wood as 
fuel. While studying char combustion in a packed bed, Dasappa \& Paul (2001) reported a peak value of $0.30 \mathrm{~mm} / \mathrm{s}$ for air mass flux of $0.1 \mathrm{~kg} / \mathrm{m}^{2} / \mathrm{s}$. Yang, Ryu, Khor, Yates, et al. (2005) showed that flame speed decreased from $0.24 \mathrm{~mm} / \mathrm{s}$ for $10 \mathrm{~mm}$ sized particles to $0.21 \mathrm{~mm} / \mathrm{s}$ for $35 \mathrm{~mm}$ sized particles. In a recent study, Sakthivadivel \& Iniyan (2018) obtained a flame speed of about $0.05-0.07 \mathrm{~mm} / \mathrm{s}$ for different fuels tested in air-fuel environment.

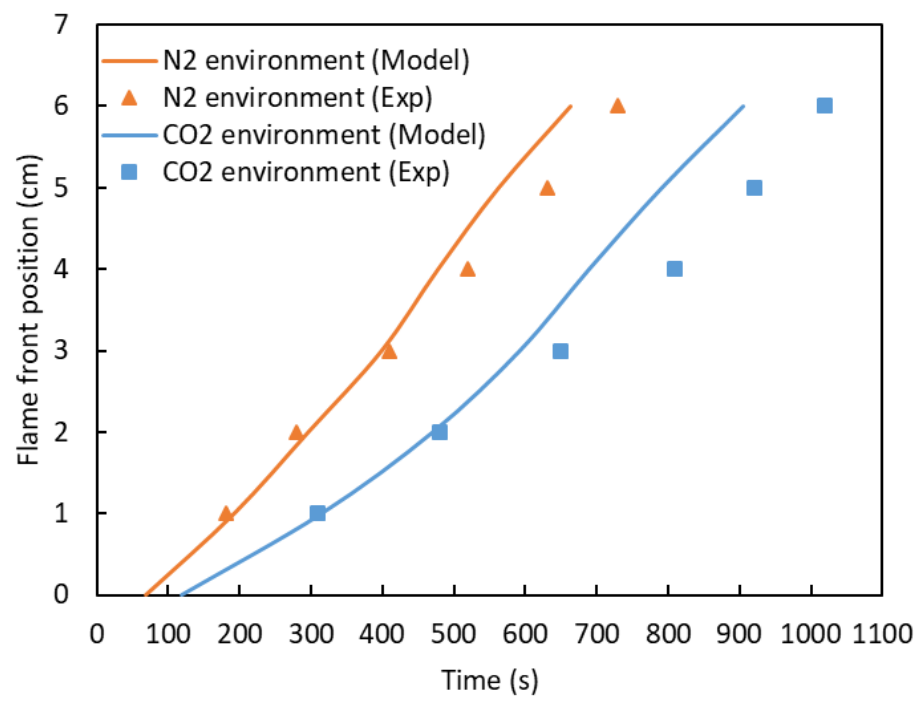

Figure 6.14: Predicted and measured flame front position for wood combustion in fixed bed at $21 \% \mathrm{O}_{2} / 79 \% \mathrm{~N}_{2}$ and $21 \% \mathrm{O}_{2} / 79 \% \mathrm{CO}_{2}$ mixtures. Fuel bed top is taken as datum.

In order to have a proper comparison, investigation of flame propagation speed for the same wood fuel with the same particle size burning in air-fuel conditions was conducted. Fig. 6.14 shows that the gradient (propagation speed) is steeper in $\mathrm{N}_{2}$ environment than in $\mathrm{CO}_{2}$ environment. Indeed, it is observed that flame speed in oxy-fuel atmosphere reduced to $76 \%$ (model) and $78 \%$ (experiment) of that of the air-fuel condition with similar $\mathrm{O}_{2}$ concentration. It is also noted that ignition delay is longer in $\mathrm{CO}_{2}$ environment. Reduction in speed could be attributed to transport and thermodynamic properties of $\mathrm{CO}_{2}$ gas and chemical effects associated with it. The chemical reactions involving consumption of $\mathrm{CO}_{2}$ include reverse water 
gas shift reaction $\mathrm{R}(14)$ and Bourdouard reaction $\mathrm{R}(16)$. The reaction rates of both reactions are several orders of magnitude smaller than those of homogeneous reactions $R(6)-R(13)$. Therefore, their contribution to flame speed is quite small. On the other hand, $\mathrm{CO}_{2}$ gas has a higher specific heat capacity than $\mathrm{N}_{2}$ gas (1.5 times higher than that of $\mathrm{N}_{2}$ ). In addition, $\mathrm{CO}_{2}$ is a heavy gas and $\mathrm{O}_{2}$ diffusivity in it is lower. Consequently, the overall effect is reduction of temperature and heating rates of fuel particles. Thus a reduced flame speed is observed in $\mathrm{CO}_{2}$ environment. It is also noted that mass fraction of combustible volatiles released in $\mathrm{CO}_{2}$ environment are smaller. This also contribute to reduction in flame speed and is discussed in subsequent paragraphs.

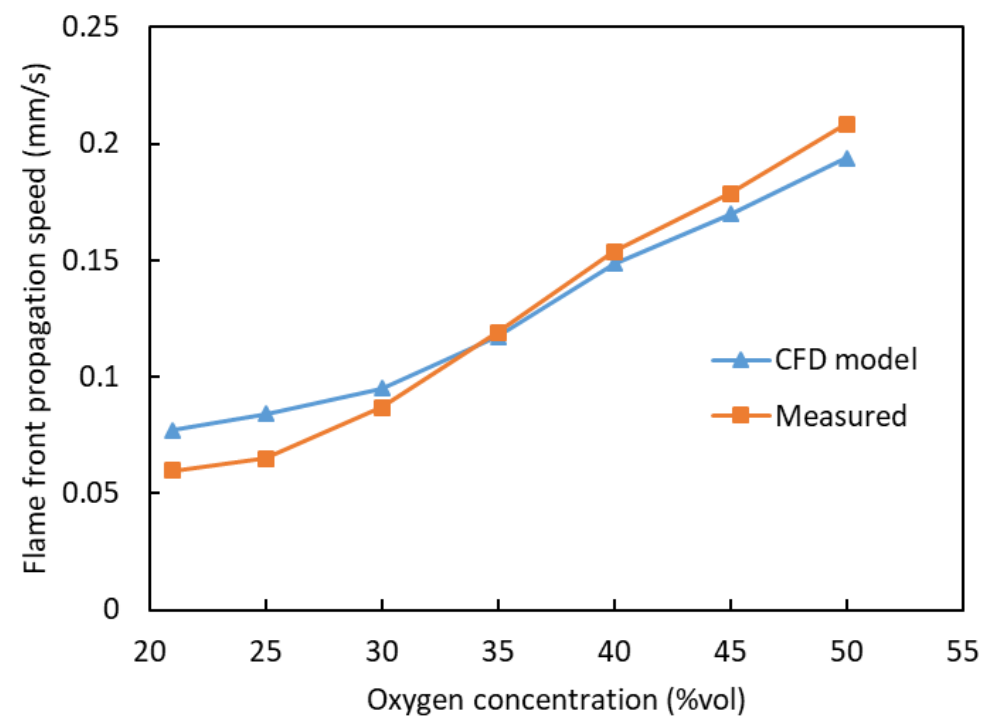

Figure 6.15: Predicted and measured flame front propagation speed in the wood fuel bed burning at different $\mathrm{CO}_{2}$ atmospheres.

Shown in Fig. 6.15 are plots of flame front propagation speed in fuel bed operated at different oxy-fuel conditions. The curves show good agreement between the predicted and measured values. Flame speed increased from $0.06 \mathrm{~mm} / \mathrm{s}$ at $21 \% \mathrm{O}_{2} / 79 \% \mathrm{CO}_{2}$ to $0.21 \mathrm{~mm} / \mathrm{s}$ at $50 \%$ $\mathrm{O}_{2} / 50 \% \mathrm{CO}_{2}$. As $\mathrm{O}_{2}$ concentration is increased, gas mixture properties also change. This means 
a reduced portion of $\mathrm{CO}_{2}$ in which $\mathrm{O}_{2}$ diffusivity is improved. As a result, an increase in temperature is seen (Fig. 6.13) and also heating rates of particles is increased. Hence, the flame speed also increases.

\subsubsection{Species Generation under Oxy-Fuel Conditions}

Presented in Figs 6.16-6.19 are the flames structures of wood combustion in both environments at different combustion stages. The main species mass fraction and temperature profiles at a given time are plotted against axial length of the reactor. Fig. 6.16 illustrates flame structures in oxy-fuel and air-fuel conditions when reaction front is at $5 \mathrm{~cm}$ from the bottom of reactor. Because each case has a different flame speed it occurs at different times: at $200 \mathrm{~s}$ in $79 \% \mathrm{~N}_{2}$, Fig. 6.16(a); and 70\% $\mathrm{CO}_{2}$, Fig. 6.16(c); and at $300 \mathrm{~s}$ in $79 \% \mathrm{CO}_{2}$, Fig. 6.16(b). In all the cases, reaction zone covers a region of depth between $4 \mathrm{~cm}$ to $7 \mathrm{~cm}$. The particles within this region are mainly undergoing drying and pyrolysis. Homogeneous reactions of pyrolysis products, tar, $\mathrm{CO}, \mathrm{CH}_{4}, \mathrm{H}_{2}$, with $\mathrm{O}_{2}$ are exothermic. It is observed that gaseous species react within the fuel bed and are also transported to freeboard region. Some of the heat released is absorbed by particles because pyrolysis is an endothermic reaction while the remaining amount is convected to freeboard region. Although the flame structures depict similar profiles, the magnitude of species and temperature are different. Highest amounts of tar and steam are observed in $79 \%$ $\mathrm{N}_{2}$ environment while lowest amounts of these species are seen in $79 \% \mathrm{CO}_{2}$ environment. The amount of $\mathrm{CO}$ is almost equal in all the 3 cases. The high amount of tar and steam in $79 \% \mathrm{~N}_{2}$ environment is attributed to high temperature which enhance pyrolysis process. Low amount of tar in oxy-fuel condition affirms the influence on flame propagation speed. 

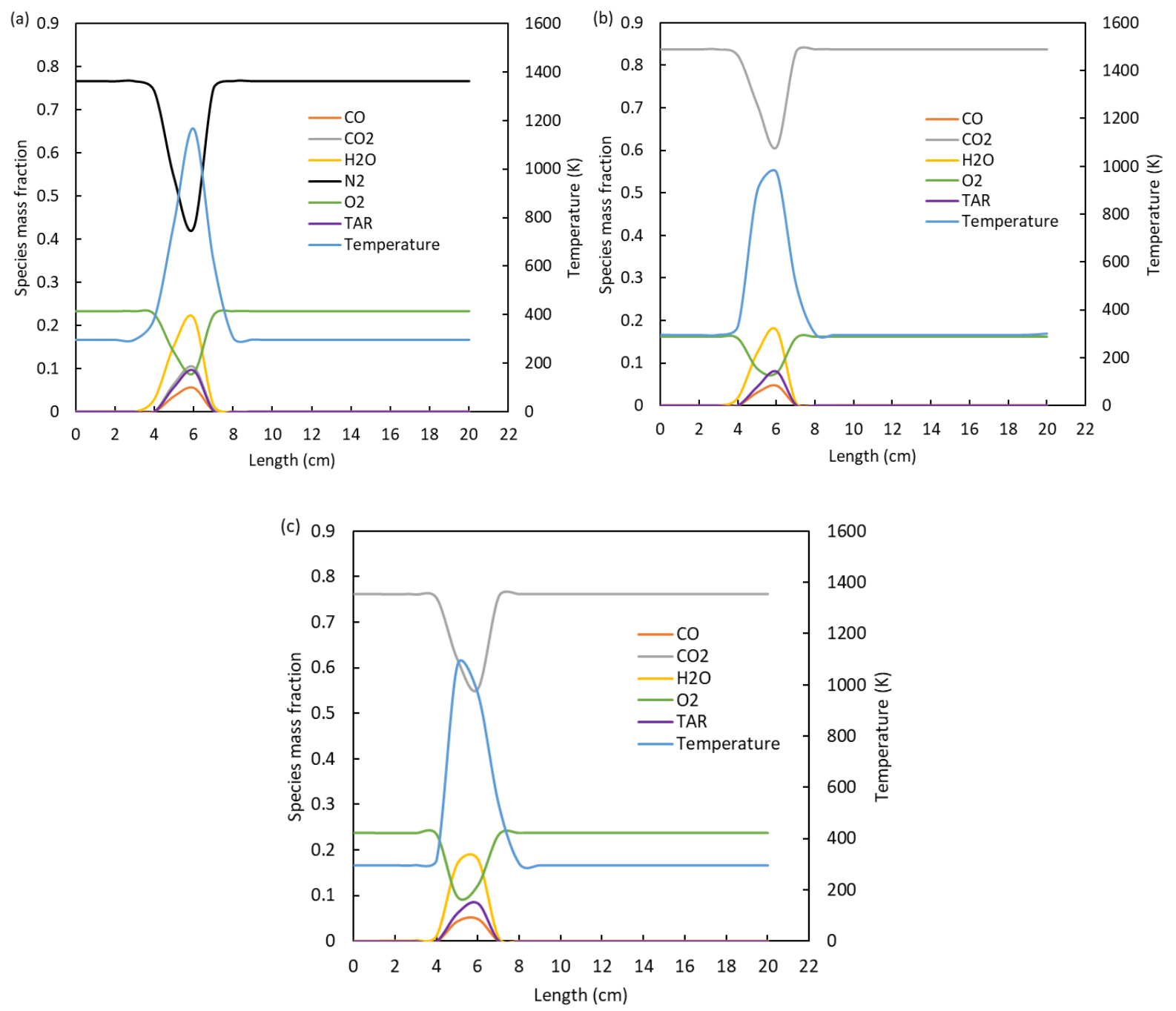

Figure 6.16: Species and temperatures profiles along axial length of the reactor for wood combustion in $\mathrm{O}_{2} / \mathrm{N}_{2}$ and $\mathrm{O}_{2} / \mathrm{CO}_{2}$ mixtures when reaction front is at $5 \mathrm{~cm}$ from fuel bottom: (a) $79 \% \mathrm{~N}_{2}$ at $200 \mathrm{~s},\left(\right.$ b) $79 \% \mathrm{CO}_{2}$ at $300 \mathrm{~s}$ and (c) $70 \% \mathrm{CO}_{2}$ at $200 \mathrm{~s}$.

As the flame front propagates downward, the positions of the peak values of species also change, Figs. 6.17 and 6.18. The position where peak temperatures occur, however, remain just approximately at the fixed bed top. This is because particles in this region have completed pyrolysis process and no longer absorb heat released by homogeneous reactions. Furthermore, at this stage, the heat transfer through convection is high enough to raise the exit temperature. 

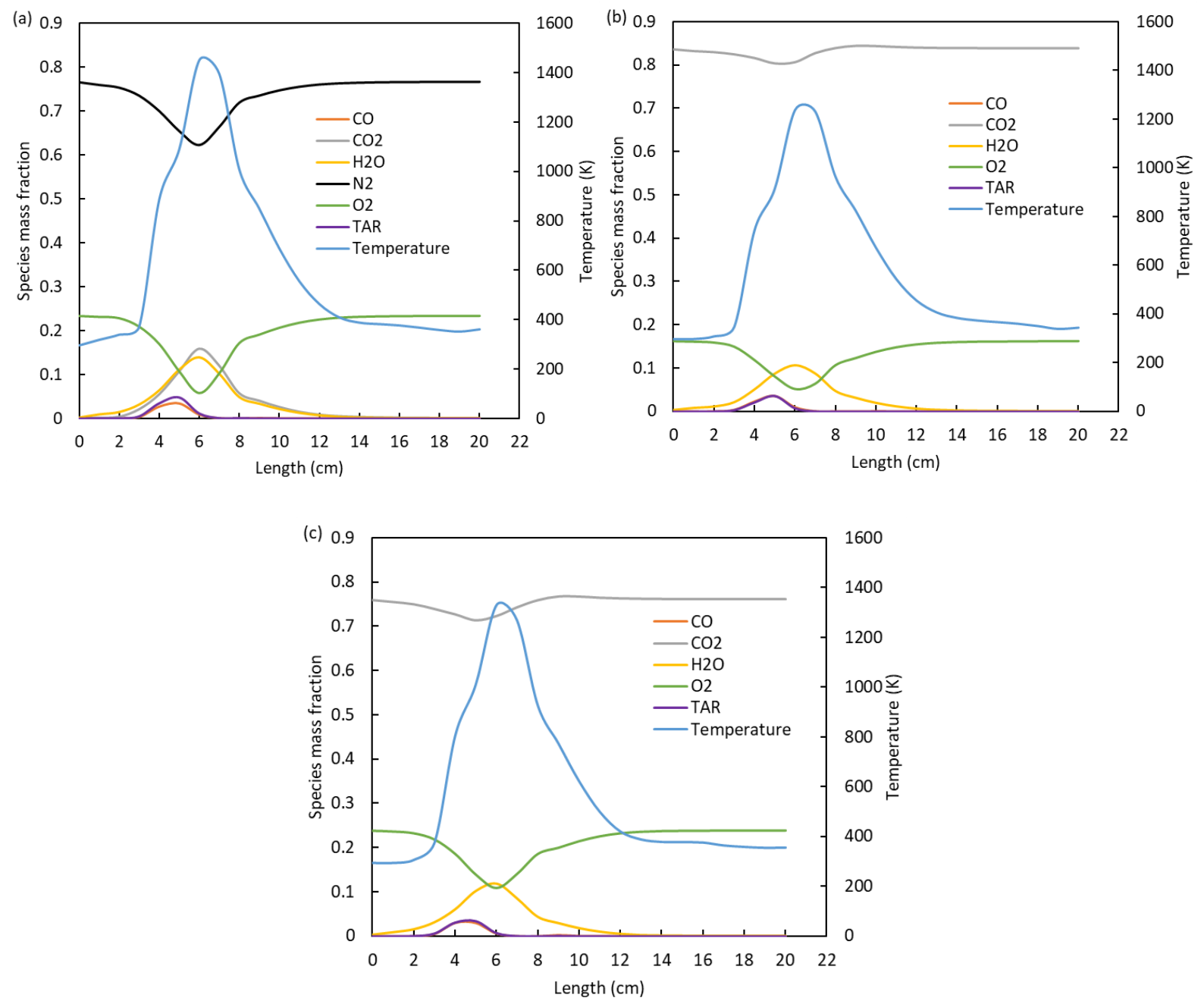

Figure 6.17: Species and temperatures profiles along axial length of the reactor for wood combustion in $\mathrm{O}_{2} / \mathrm{N}_{2}$ and $\mathrm{O}_{2} / \mathrm{CO}_{2}$ mixtures when reaction front is at $4 \mathrm{~cm}$ from fuel bottom(a) $79 \% \mathrm{~N}_{2}$ at $300 \mathrm{~s}$, (b) $79 \% \mathrm{CO}_{2}$ at $450 \mathrm{~s}$ and (c) $70 \% \mathrm{CO}_{2}$ at $300 \mathrm{~s}$.

Very low amounts of tar and $\mathrm{CO}$ and high amounts of $\mathrm{CO}_{2}$ and $\mathrm{H}_{2} \mathrm{O}$ in this region reflect an increase in consumption rate of volatiles. For oxy-fuel cases, the amount of $\mathrm{CO}_{2}$ from combustion adds to the supplied amount and hence dominates the combustion products, Figs 6.17(b) and 6.17(c). Just like in the initial stage, flame front in $\mathrm{CO}_{2}$ environment arrives at 4 cm, Fig. 6.17(b), and $3 \mathrm{~cm}$, Fig. 6.18(b), later than in air-fuel condition. For the flow condition 
tested, tar and $\mathrm{CO}$ are completely consumed within the fuel bed. As seen in the figures, $\mathrm{O}_{2}$ is sufficient for complete oxidation of these species. The amount of tar and $\mathrm{CO}$ at reaction front decreases as it moves downward, Fig. 6.18. As shown in Figs 6.18(a)-(c), the mass fraction of these species are almost equal in the three cases.
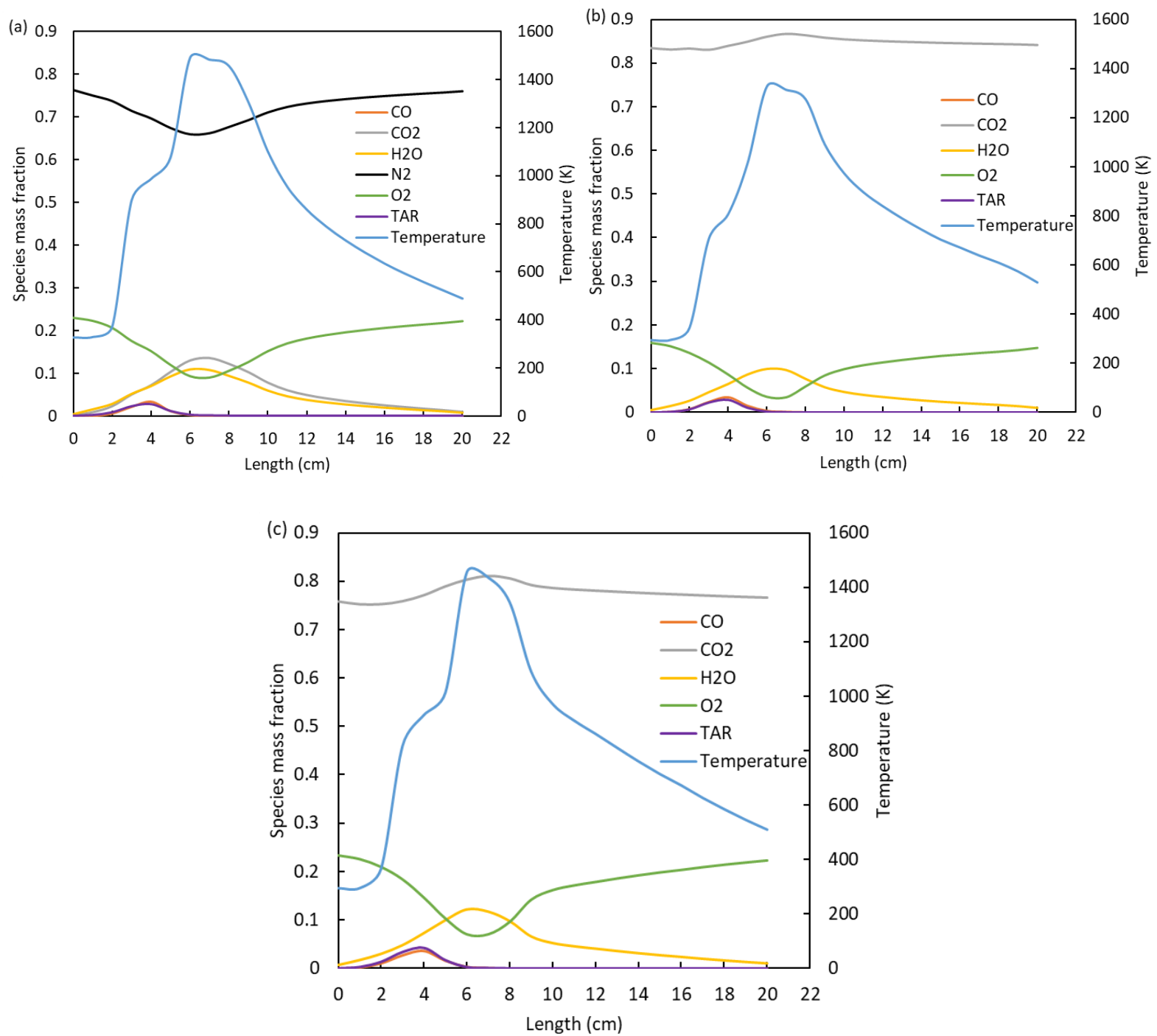

Figure 6.18: Species and temperatures profiles along axial length of the reactor for wood combustion in $\mathrm{O}_{2} / \mathrm{N}_{2}$ and $\mathrm{O}_{2} / \mathrm{CO}_{2}$ mixtures when reaction front is at $3 \mathrm{~cm}$ from fuel bottom: (a) $79 \% \mathrm{~N}_{2}$ at $400 \mathrm{~s}$, (b) $79 \% \mathrm{CO}_{2}$ at $600 \mathrm{~s}$ and (c) $70 \% \mathrm{CO}_{2}$ at $400 \mathrm{~s}$. 

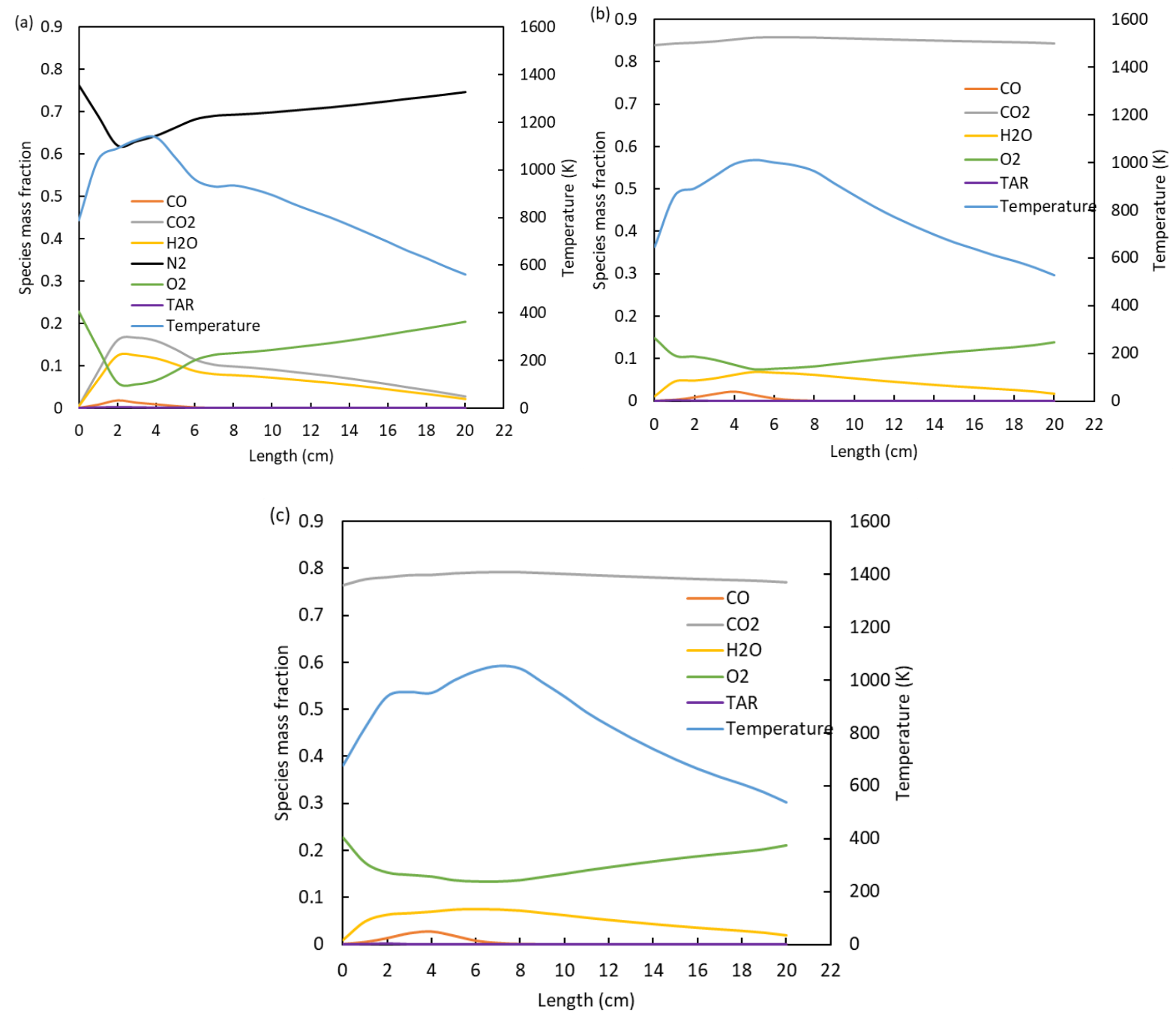

Figure 6.19: Species and temperatures profiles along axial length of the reactor for wood combustion in $\mathrm{O}_{2} / \mathrm{N}_{2}$ and $\mathrm{O}_{2} / \mathrm{CO}_{2}$ mixtures during char combustion stage: (a) $79 \% \mathrm{~N}_{2}$ at 1000 s, (b) $79 \% \mathrm{CO}_{2}$ at $1100 \mathrm{~s}$ and (c) $70 \% \mathrm{CO}_{2}$ at $1000 \mathrm{~s}$.

After the flame front reaches the bottom of the bed, the fuel bed is completely in char combustion stage. Major species generation and temperature profiles during this stage, for each of the three cases, are shown in Fig. 6.19. Absence of tar indicates that devolatilization stage has ended. As in the previous combustion stages, it is also noted that this stage occurs at a later time in $\mathrm{CO}_{2}$ environment than in $\mathrm{N}_{2}$ environment. Temperatures in the bed are relatively lower 
than in the previous combustion stages. As expected, temperatures in oxy-fuel conditions, Figs 6.19(b) and (c), are lower than that in air-fuel case, Fig. 6.19(a). Low temperatures in all cases are attributed to absence of homogeneous reactions of volatiles which reduces rate of heat release. The only heat release is in char and $\mathrm{CO}$ oxidation. In addition, char gasification with $\mathrm{CO}_{2}$ and $\mathrm{H}_{2} \mathrm{O}$ is an endothermic reaction. Moreover, heat is lost by convective heat transfer to freeboard region. Because of cold air inlet, cooling effect results in relatively low temperatures in the grate. For char combustion stage, char is converted to $\mathrm{CO}$ and $\mathrm{CO}_{2}$. A high amount of $\mathrm{CO}$ is observed in oxy-fuel condition which is as a result of gasification of char in the $\mathrm{CO}_{2}$ environment.

In this section, a comprehensive study of the effect of $\mathrm{CO}_{2}$ combustion atmosphere on flame propagation speed and flame structures in wood combustion in a laboratory-scaled fixed bed operated under counter-current mode was presented in this section. CFD-DEM approach was used to simulate wood conversion in a packed bed and the results compared to experimental data. Computational results agree very well with experimental values except temperature which showed poor prediction at low $\mathrm{O}_{2}$ concentration. For mass loss history and flame propagation speed, the deviation of most of the model data from experimental data were less than $10 \%$. The agreement of temperatures corrected for radiation losses with predicted values are better than those of uncorrected values. Hence, it was established that prediction accuracy of CFD-DEM is not the same in different $\mathrm{O}_{2} / \mathrm{CO}_{2}$ mixtures. Furthermore, it was observed that flame speed in oxy-fuel atmosphere reduced to $78 \%$ of that of the air-fuel condition with same $\mathrm{O}_{2}$ concentration. This was determined both by experiment and through computation. Reduced flame speed was attributed to a higher heat capacity of $\mathrm{CO}_{2}$ and lower $\mathrm{O}_{2}$ diffusivity in $\mathrm{CO}_{2}$ whose overall effect is reduction of temperature and heating rates of fuel particles. Low mass 
fraction of combustible volatiles predicted in the $\mathrm{CO}_{2}$ environment also contribute to a reduced flame speed. Flame structures have similar profiles but differ in value of temperature and species quantities. As expected, temperatures in the $\mathrm{CO}_{2}$ environments were lower than those in the $\mathrm{N}_{2}$ environments. During initial stages of combustion, the amount of tar and steam is observed to be highest in $79 \% \mathrm{~N}_{2}$ environment and lowest in $79 \% \mathrm{CO}_{2}$ environment, as shown in Fig. 6.16. The amount of $\mathrm{CO}$ was almost equal in both environments during pyrolysis, $Y_{C O} \approx$ 0.05 as shown in Fig. 6.16, but high amounts were predicted in oxy-fuel environments during char combustion stage, as shown in Fig. 6.19.

\subsection{Particle Packing Density}

Presented in this section is an investigation of the impact of particle packing density on fixed bed combustion of wood in an oxy-fuel burning environment. The packing density, which determines the region porosity, is influenced by fuels' geometry. Size and shape were determined directly from fuel particles and used to evaluate the particle sphericity which is an input in the computational model. Euler-Lagrange method was used to model conversion of wood in a fixed bed. A comprehensive analysis of wood conversion in terms of temperature profiles, gas species generation and conversion rates in the entire possible operation range of bed porosity were investigated. Furthermore, the computational model was validated by performing experiments in a fixed bed using wood of different shapes and sizes, viz., fixed bed of different porosity. It was established that the packing density affects combustion process in an oxy-fuel environment by changing the burning conditions and limits. The operational range with respect to porosity was decreased in an oxy-fuel burning condition due to higher quenching effects of $\mathrm{CO}_{2}$. Furthermore, the study revealed that there is an optimum packing density, $\chi=$ 0.71 , beyond which the efficiency falls due to the onset of quenching in the spaces. 


\subsubsection{Temperature History}

The CFD-DEM model results were validated by data obtained from experiment. Fig. 6.20 presents a validation of temperatures at various heights in the bed for different fuel particle types. In general, deviations of $10 \%$ or less between the model and measured data indicate a good agreement. Particle type WC, WCSD2 have two distinct temperature peaks, Figs 6.20(a)(b), while particle type WCSD1 and SD1 have a single temperature peak, Figs 6.20(d) and (e). Particle type SD2 is a transition case with a distinct first temperature peak and the temperature plateaus off in the second peak, Fig. 6.20(c). The first peak is attained during ignition front propagation phase while the second peak is attained during char oxidation phase (Khor et al., 2007). Figs 6.20(a)-(b) indicate that less porous beds have substantial amount of char remaining in the bed after devolatilization. The char combustion phase peak temperatures for these fuel particle types are higher than ignition front propagation phase peak temperatures. In particle type SD2, some of the char produced are oxidized in the first peak region leading to a higher flame temperature being attained. Subsequently, its second peak region has a low temperature value. In case of porous beds, Figs 6.20(d) and (e), they have a single peak temperature point with relatively higher values than those for the first peaks of the less porous beds. It is also observed that in all the fuel particles investigated the bed temperatures are relatively less than those for air-fuel environment in comparable burning conditions as discussed in section 6.5. Temperature in a $\mathrm{O}_{2} / \mathrm{CO}_{2}$ mixture is reduced by its higher heat capacity.

\subsubsection{Ignition Time}

Presented in Fig. 6.21 is the ignition time for the different fuel particles. Bed ignition time was considered to be the time in which the reaction front takes to starts at the top surface of the bed. Ignition time decreases with increase in initial bed porosity. For the entire range, the 

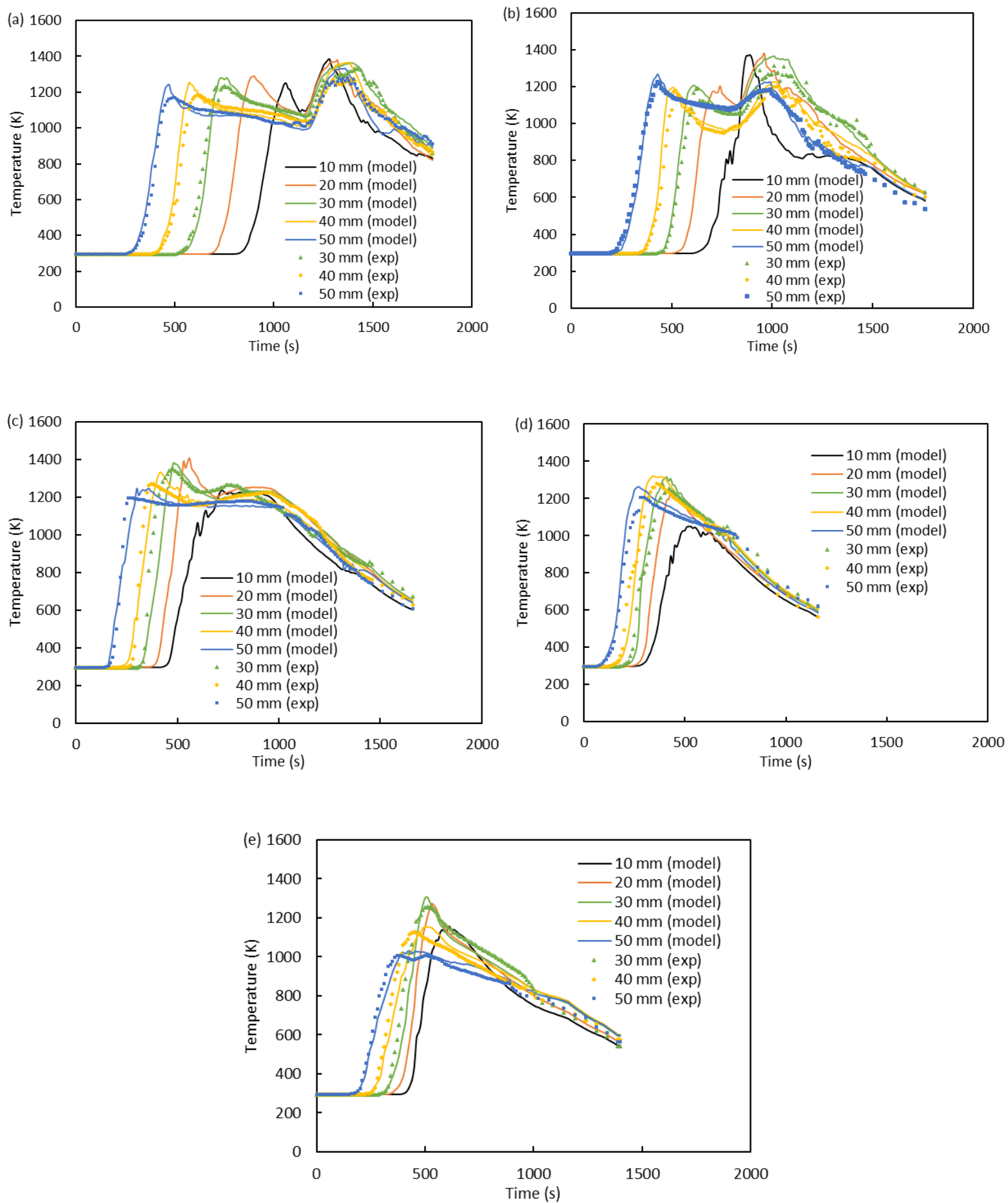

Figure 6.20: Measured and predicted temperature profiles at various heights above the grate for particle types (a) WC $(\chi=0.51)$, (b) WCSD2 $(\chi=0.56)$, (c) SD2 $(\chi=0.61)$, (d) WCSD1 ( $\chi=$ $0.68)$ and (e) SD1 $(\chi=0.74)$. 
ignition time values are higher than those reported for wood combustion under $\mathrm{N}_{2}$ environment in the same conditions, as seen later in section 6.5. Higher ignition time in $\mathrm{CO}_{2}$ environment could be due to its decreased flame temperature and heating rates. Furthermore, chemical reactions of $\mathrm{CO}_{2}$ through reactions $\mathrm{R}(14)$ and gasification of char, $\mathrm{R}(16)$, contribute to retardation of ignition time. Reaction $\mathrm{R}(16)$ is endothermic and results in decreasing the amount of heat in the bed. Consequently, it increases the ignition time delay in the fuels.

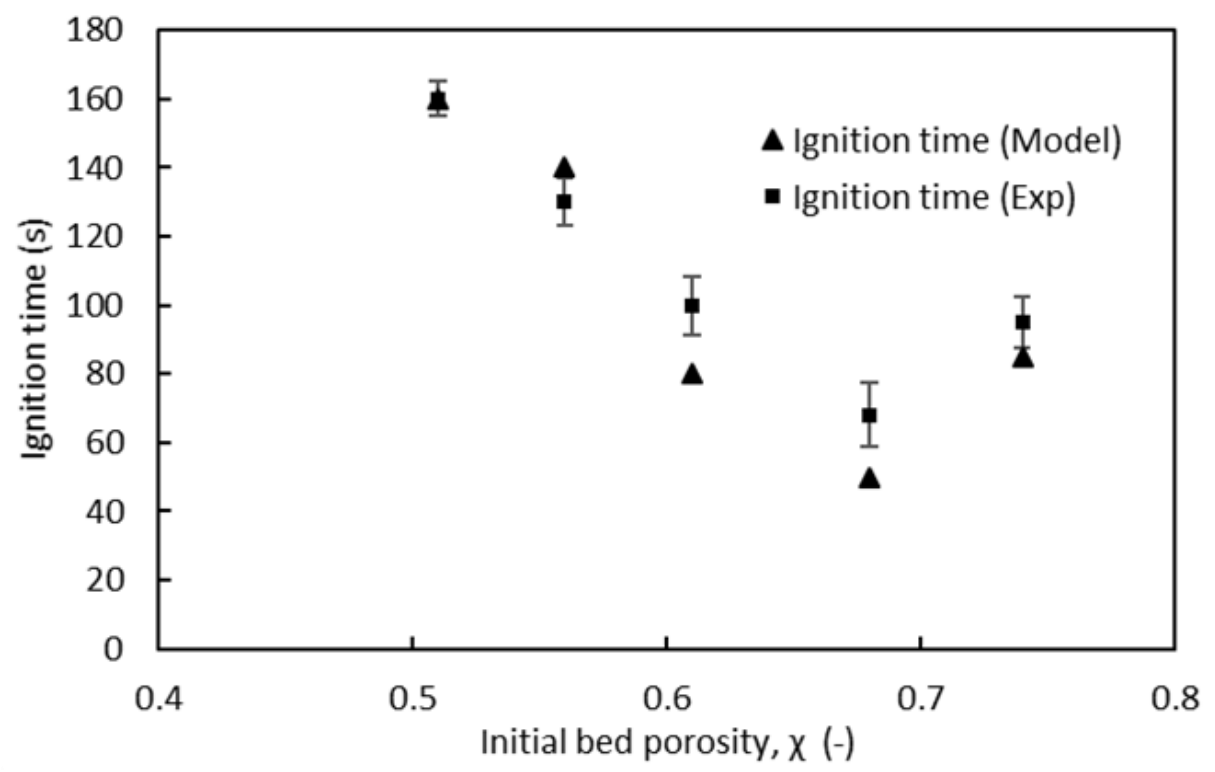

Figure 6.21: Measured and predicted ignition time for wood combustion under oxy-fuel condition for different initial bed porosity. Error bars are the standard deviations.

The impact of porosity on air to fuel stoichiometry and flame front propagation speed is presented in Fig. 6.22. The values are compared to those obtained in $\mathrm{N}_{2}$ environment under similar operating conditions. The equivalence ratio presented are the averaged values based on the total combustion time, fuel chemical composition and air flow rates. The actual equivalence ratio varies at different combustion stages as noted later in the analysis of gas species generation in the bed: It is higher during pyrolysis phase and lower during char consumption phase. For 
both cases, flame front propagation speed increases with increases in bed porosity. It is correspondingly lower in $\mathrm{CO}_{2}$ environment.

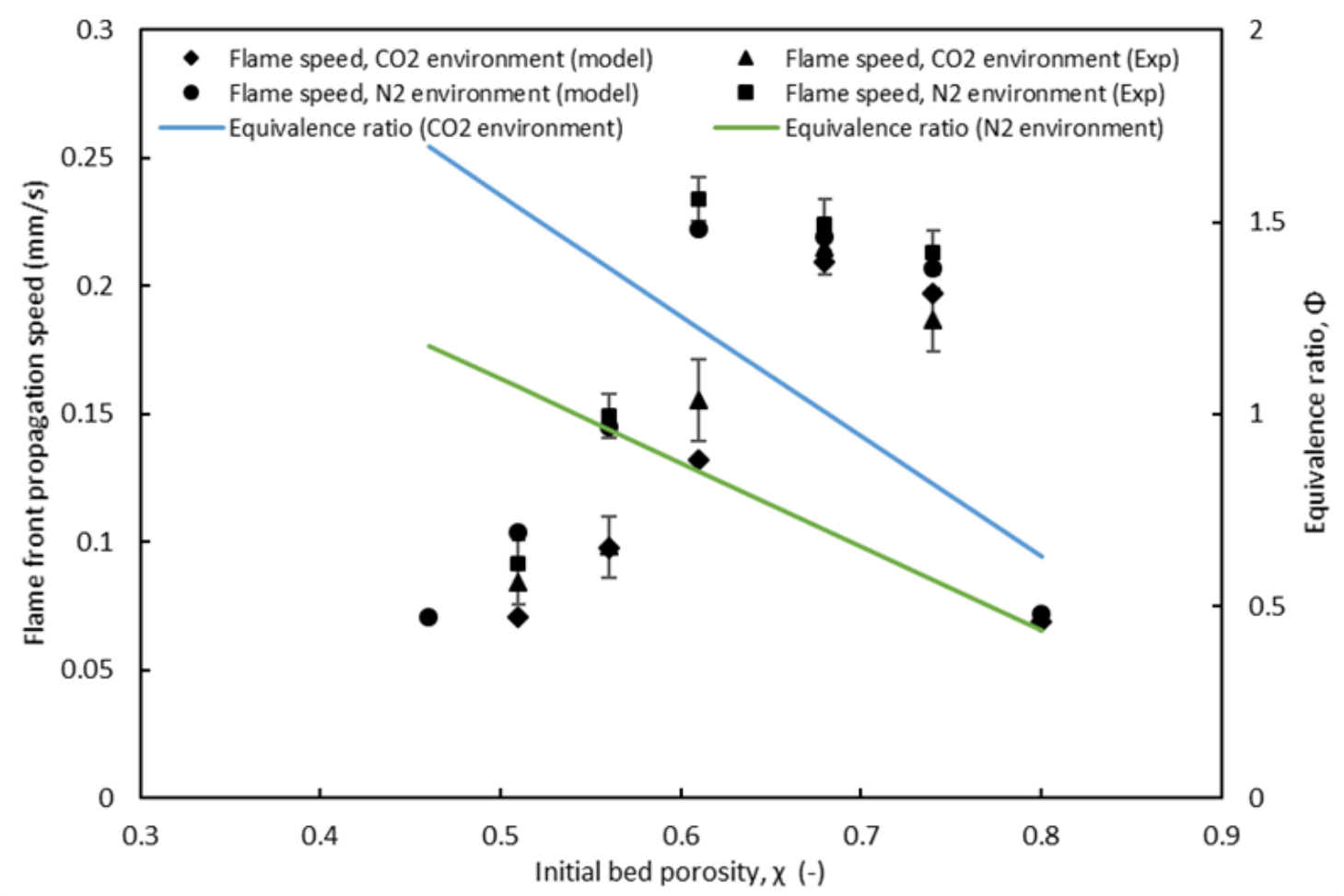

Figure 6.22: Measured and predicted flame front propagation speed for wood combustion in $\mathrm{N}_{2}$ and $\mathrm{CO}_{2}$ environments for different initial bed porosity. Error bars are the standard deviations.

Figure 6.22 also shows that as bed porosity is increased the burning condition is shifted from fuel-rich to fuel-lean side. Under the same air flow rate and $\mathrm{O}_{2}$ volumetric concentration, this shift is more toward the porous region in a $\mathrm{O}_{2} / \mathrm{CO}_{2}$ mixture than in a $\mathrm{O}_{2} / \mathrm{N}_{2}$ mixture as a result of differences in molecular weight. Furthermore, as noted in the flame front propagation speed, the operational range with respect to porosity is narrowed in $\mathrm{CO}_{2}$ environment. This is due to its high heat capacity which causes earlier quenching effects than in $\mathrm{N}_{2}$ environment. 


\subsubsection{Wood Conversion and Char Formation Rates}

Drying, pyrolysis, homogeneous reactions and char conversion in the bed occurs simultaneously. Overlapping of these processes depends on the burning conditions. Dry wood particles with the same amount of mass initially located at $4 \mathrm{~cm}$ from the grate for different particle types were tracked in order to monitor their conversion progression. Fig. 6.23(a) presents the conversion of these particles in the bed with respect to time. The mass of dry wood remains constant until the onset of pyrolysis. Amongst the cases investigated, the onset of pyrolysis in particle type WCSD1 occurred at $180 \mathrm{~s}$, which is earlier than any other particle. Pyrolysis in particle type WC started to occur at $390 \mathrm{~s}$ and took longer a time to complete, 1110 s. This indicate that as porosity of the bed is increased, pyrolysis process takes a shorter time. Though it is observed that there is an optimum point at which pyrolysis times begins to increase even with increase in porosity. This optimum point occurs when porosity is about 0.71 . This is as a result of combustion conditions becoming too lean and the flame starts to be quenched by excess $\mathrm{CO}_{2}$ through convection cooling.
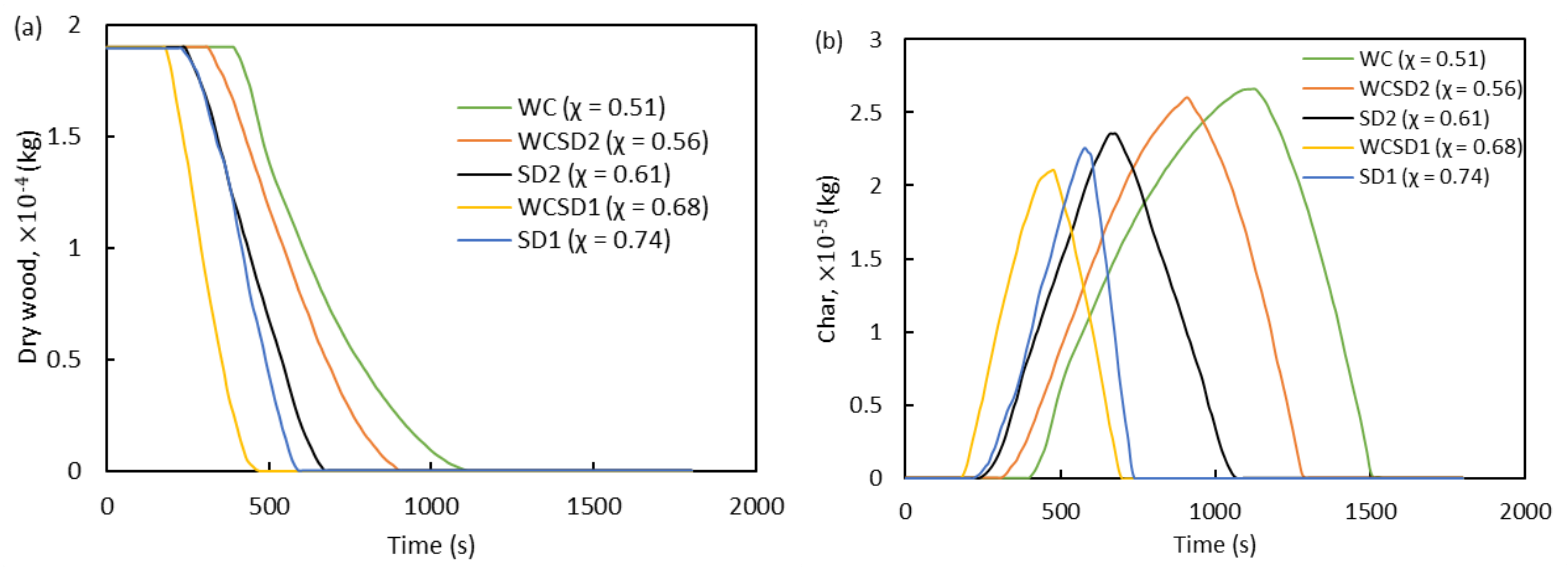

Figure 6.23: Predicted (a) wood conversion and (b) char formation of the particles with the same amount of mass initially located at $4 \mathrm{~cm}$ from the grate for different fuel particle types. 
The amount of char produced in the bed decreases with increase in porosity, Fig. 6.23(b). Higher amount of char in less porous bed indeed confirms the second peak temperatures attained in these particle types seen in Figs 6.20(a)-(b), which arise from combustion of char that is left in the bed after devolatilization. Char, which is in essence carbon, is produced and consumed within a shorter period of time as bed porosity increases. The amount of char presented in Fig. 6.23(b) is the net amount at a given time for particle tracked. Char is produced from pyrolysis of dry wood through reaction $\mathrm{R}(4)$. Once it is produced, it is consumed through reactions $\mathrm{R}(15)-\mathrm{R}(17)$ depending on bed temperature and availability of $\mathrm{O}_{2}, \mathrm{CO}_{2}$ and $\mathrm{H}_{2} \mathrm{O}$.

The actual rates for conversion of dry wood particles are presented in Fig. 6.24(a). Particle type WCSD1 and WC attained the fastest and slowest pyrolysis rate of 4.78 and $2.13 \mathrm{~kg} \mathrm{~m}^{-3} \mathrm{~s}^{-1}$, respectively. The trend of influence of porosity is similar to what was observed before; pyrolysis rate increases with increase in porosity up to the optimum point, 0.71 , where it starts to decrease. As porosity is increased, there is a quick release of volatiles. Oxidation of combustible volatiles through reaction $\mathrm{R}(6)-\mathrm{R}(10)$ releases intense heat which increases the conversion rate. Since the conversion processes are fast, ignition is quick and flame propagation is also fast as noted in Figs 6.21 and 6.22, respectively. In low porosity beds, volatiles are slowly released, heating rate is low and consequently, a slow conversion rate. Subsequently, low porosity beds have higher ignition time and low flame front propagation speed. Net char formation and consumption for the particles with respect to time are presented in Fig. 6.24(b). Just like wood pyrolysis rate, net char formation rates, positive values, increases as porosity is increased up to an optimum value, then it starts to decrease. However, the net consumption rates, negative values, have no optimum value. Particle type WC, WCSD2 and SD2 attained almost the same peak consumption rates. Char consumption rate is directly proportional to the 
char specific surface area, $S_{a, c h a r}$ as indicated in reactions $\mathrm{R}(15)-\mathrm{R}(17)$. Thus, the high specific surface area for char in porous bed increases their consumption.
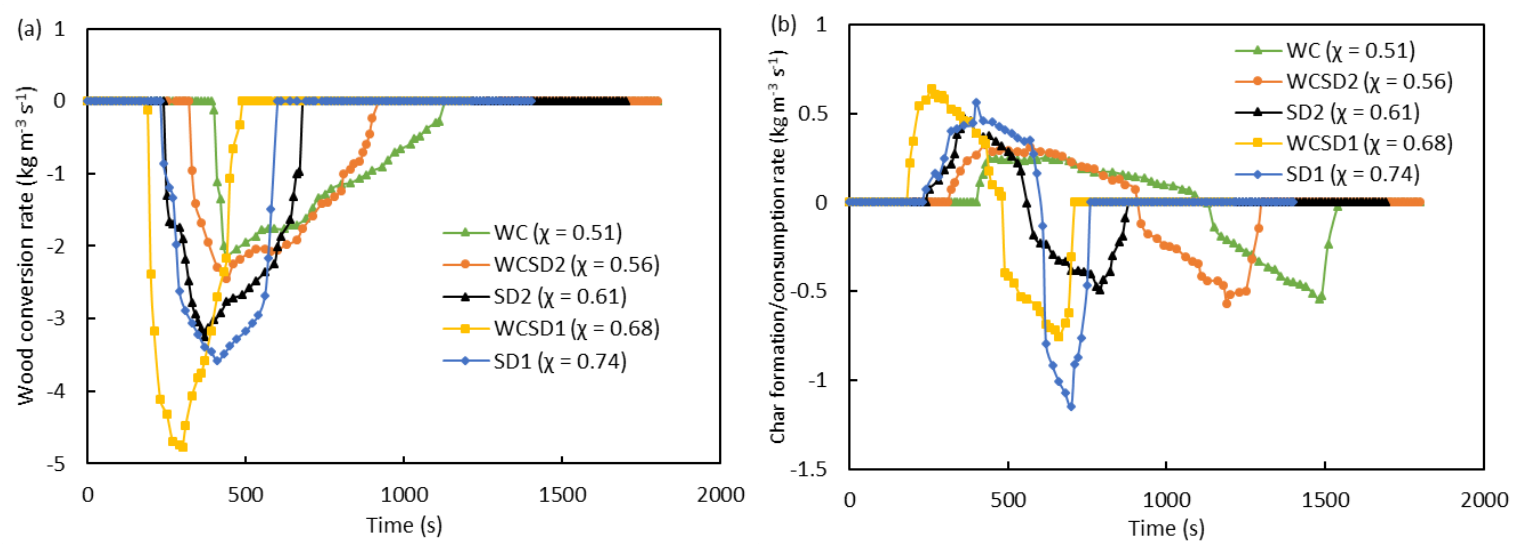

Figure 6.24: Predicted rate of (a) wood conversion and (b) char formation of the particles with the same amount of mass initially located at $4 \mathrm{~cm}$ from the grate for different fuel particle types.

\subsubsection{Flames Structures}

Gas species concentration and temperature predicted during entire conversion of wood at a particular height is shown in Fig. 6.25. The values presented are taken at $4 \mathrm{~cm}$ from the grate for different particle types. The figures clearly depict the three distinct stages of wood combustion; drying, pyrolysis and char consumption. In all the cases, drying starts when the temperature reaches about $50{ }^{\circ} \mathrm{C}$, as evident in the drying front which is always slightly ahead of the ignition front. The decrease in $\mathrm{CO}_{2}$ mole fraction at the onset of drying is due to introduction of water vapour in the bed and should not be viewed as a consumption. The absolute amount of $\mathrm{CO}_{2}$ only changes in the reaction zone as it is a product of oxidation of char and volatiles which contain carbon in their molecular structure. Alternatively, its amount may change through its participation in gasification of char, through reaction $\mathrm{R}(16)$ and in the forward and backward reactions of $\mathrm{H}_{2} \mathrm{O}$ and $\mathrm{CO}$, in $\mathrm{R}(13)$ and $\mathrm{R}(14)$. 

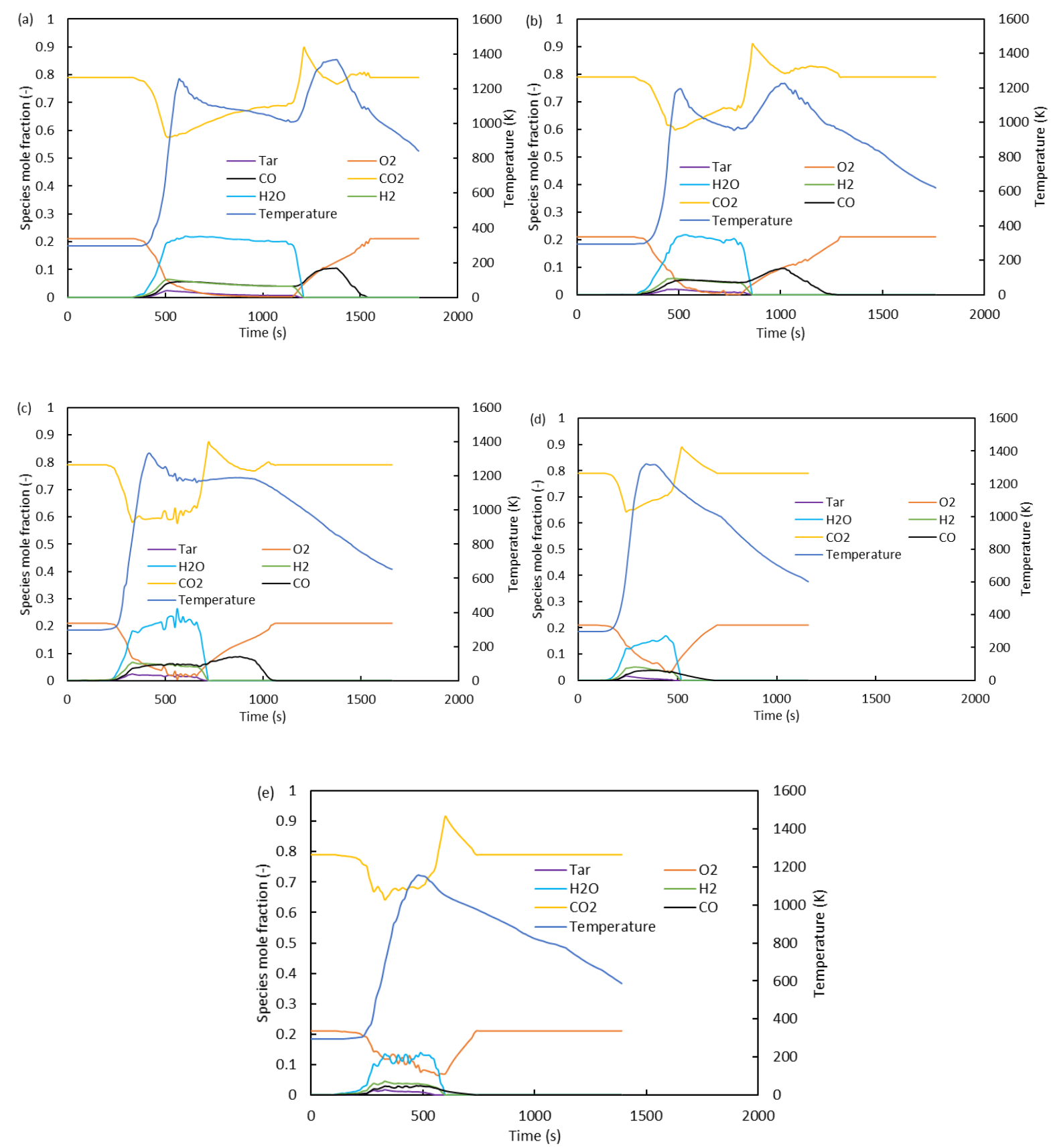

Figure 6.25: Predicted species concentration and temperature during entire combustion time taken at $4 \mathrm{~cm}$ from the grate for particle types (a) WC $(\chi=0.51)$, (b) WCSD2 $(\chi=0.56)$, (c) $\operatorname{SD} 2(\chi=0.61),(d) \operatorname{WCSD} 1(\chi=0.68)$ and (e) SD1 $(\chi=0.74)$.

During pyrolysis, particles at a local point absorb heat energy from oxidation of volatiles released by adjacent particles located in the upper side through radiation and conduction. Once 
the particle attains devolatilization temperature, then the volatiles are rapidly released. Combustible volatiles, are oxidized through reactions $\mathrm{R}(5)-\mathrm{R}(10)$ releasing intense heat which rapidly increases the temperature to the first peak point, as seen in Fig. 6.25 for all the cases. During this period, $\mathrm{O}_{2}$ decreases gradually but does not go to zero immediately. Under the same oxidizer mixture mass flux as used in this study, the extent to which $\mathrm{O}_{2}$ concentration falls depends on the bed porosity. For particle type WC and WCSD2, Figs 6.25(a) and (b), as pyrolysis progresses downward, the volatiles release at the lower part of the bed consume all the $\mathrm{O}_{2}$. Consequently, $\mathrm{O}_{2}$ is not able to reach the upper region. Since the wood fuels in this region are still undergoing pyrolysis, which is endothermic, the local temperature decreases. During this time, volatiles in upper region are not oxidized and their concentration remains almost constant. Similarly, char produced is not oxidized during this time. For this particle types, during devolatilization time, char is only consumed by gasification $\mathrm{H}_{2} \mathrm{O}$ and $\mathrm{CO}_{2}$. As a result, the amount of char is higher than for SD1, SD2 and WCSD1, as observed in Fig. 6.23(b).

Once the entire bed is completely pyrolyzed, volatiles in the lower region are the first to be completely oxidized since $\mathrm{O}_{2}$ is supplied from the bottom. This is evident in the steep increase in temperature of thermocouple located close to grate, Figs 6.20(a) and (b). After complete oxidation of volatiles in the lower region of the bed, excess $\mathrm{O}_{2}$ is convected upward. The volatiles remaining in the bed are oxidized progressively from bottom to the top, as depicted in steep temperature rise at the end of devolatilization stage in Figs 6.20(a) and (b). At a given height, $\mathrm{CO}_{2}$ concentration sharply increases at the end of devolatilization stage. This is partly due to oxidation of $\mathrm{CH}_{4}, \mathrm{CO}$ and tar. Its increase is also caused by depletion of other species through complete oxidation. Complete oxidation of volatiles end at $1200 \mathrm{~s}$ and $860 \mathrm{~s}$ for particle type WC and WCSD2, respectively, Figs 6.25(a) and (b). After this point, there is excess $\mathrm{O}_{2}$ in 
the bed and char oxidation through reaction $\mathrm{R}(15)$ starts. Concurrently, char is consumed by $\mathrm{CO}_{2}$ through Boudouard reaction $\mathrm{R}(16)$. In overall, the amount of $\mathrm{CO}_{2}$ decreases while that of $\mathrm{CO}$ increases. Finally, $\mathrm{CO}$ is completely oxidized to $\mathrm{CO}_{2}$ toward the end of char combustion.

Pyrolysis and char consumption in particle types SD2, WCSD1 and SD1 proceed in almost a similar way. They all operate under lean conditions throughout conversion process as depicted by excess $\mathrm{O}_{2}$ in their reaction zones, Figs 6.25(c)-(e). As a result, oxidation of volatiles continues in the upper part of the bed as pyrolysis progresses downwards. This is evident in the low concentration of tar, $\mathrm{CH}_{4}, \mathrm{H}_{2}$ and $\mathrm{CO}$ in these particles as compared to those of particle types WC and WCSD2. In addition, char is oxidized concurrently with volatiles. This explains the high temperatures in the first peak of the porous fuels seen in Figs 6.20(c)-(e). The low amount of char in the porous bed noted in Fig. 6.23(b) is also accounted for by this fact. For particle types SD1 and WCSD1, the heat release from oxidation of the char remaining in the bed after complete devolatilization is not sufficient to raise the temperature to a second peak, Figs 6.25(d) and (e). However, particle type SD2 still has a substantial amount of char whose oxidation is sufficient to increase the temperature to a second peak. Though it is not as high as for particle types WCSD2 and WC1.

Flame structures along axial length of the bed for different particle types when the reaction front is at $4 \mathrm{~cm}$ from the grate are presented in Fig. 6.26. The graphs clearly illustrate the thickness of the reaction front for various fuel particles. Thickness of the reaction front was considered to be the axial length in the bed in which the temperature changes from ambient value to maximum as flame front passes (Yang et al., 2003). It is affected by several factors which include burning rates, flame front propagation speed and fuel particle size. In general, it was observed that reaction front thickness increases as porosity increases; the lowest and 
highest values being $21 \mathrm{~mm}$ and $35 \mathrm{~mm}$ for particle types WC and SD1, respectively. Thin reaction front indicates that the particles at a given height burn uniformly. For this case, higher amounts of volatiles are present at a given height, Figs 6.26(a)-(c). On the other hand, a thicker reaction front as seen in Figs 6.26(d) and (e) is associated with a high flame front propagation speed, high burning rates and fast pyrolysis. In this case, fuel particles at a lower region start releasing small amount of volatiles which are immediately oxidized. Consequently, the amounts of volatiles are not as high as for cases with thin reaction front thickness. Furthermore, radiation energy in less porous beds have short penetration into fuel particles in unreacted region. Therefore, their flame front propagation moves slowly as seen in Fig. 6.22, and the reaction zone is thin. This is opposite to porous bed which allows deep penetration of radiation energy to unreacted particles in the lower part of the bed making them to have high flame front propagation speed and a thicker reaction zone.

Volatiles released when the reaction front is at $4 \mathrm{~cm}$ from the grate, for all the cases, are not completely oxidized in the fuel bed, Fig. 6.26. Unreacted volatiles do not stay in the bed but instead, they are transported to freeboard region, height above $6 \mathrm{~cm}$, where they are reacted as indicated by their decreasing levels. Unlike in the bed region, there are no endothermic processes, pyrolysis and gasification, in freeboard region. Therefore, oxidation of volatiles results in higher freeboard temperature in all the cases. It is noted that for fuels with thick reaction zone thickness, Figs 6.26(c)-(e), $\mathrm{H}_{2}$ is the dominant volatile in the low temperature region of about 300 to $800 \mathrm{~K}$. A high amount of $\mathrm{H}_{2}$ in these fuels is as a result of reaction $\mathrm{R}(13)$. This is supported by low amount of $\mathrm{CO}$ in this region. Furthermore, this reaction has been reported to have better prediction and works well in fuel lean conditions under which these fuels were operated (Andersen et al., 2009; Jones \& Lindstedt, 1988). 

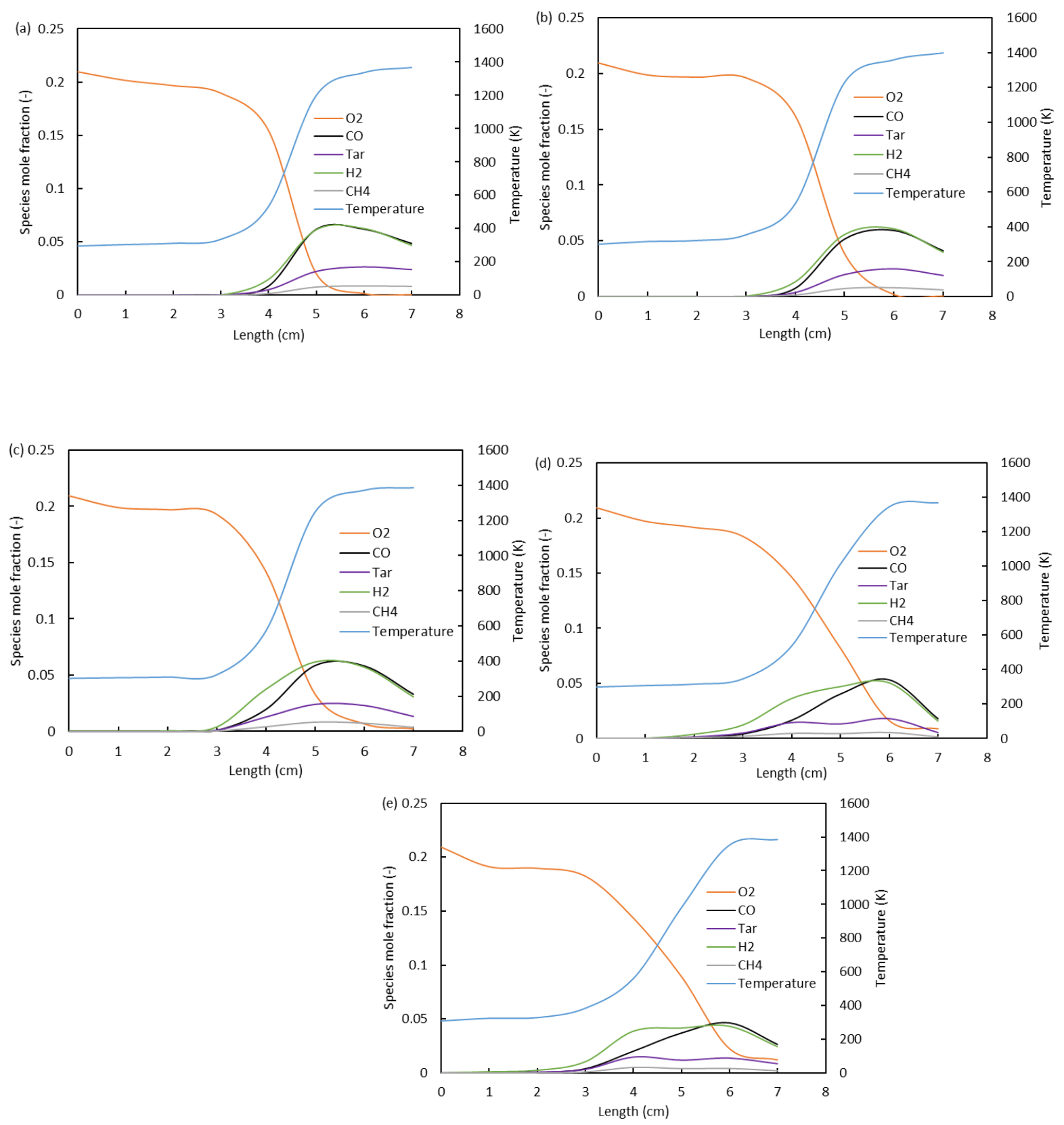

Figure 6.26: Predicted major species concentration and temperature along axial length of the bed for particle types (a) WC $(\chi=0.51)$, (b) WCSD2 $(\chi=0.56)$, (c) SD2 $(\chi=0.61)$, (d) WCSD1 $(\chi=0.68)$ and (e) SD1 $(\chi=0.74)$ when the reaction front is at $4 \mathrm{~cm}$ from the grate.

Presented in Fig. 6.27 is the predicted peak values of major combustible species concentration at fuel bed top for different fuel types during entire combustion time. It is important to determine the amount of volatiles that exit the top of the fuel bed as it indicates the extent to which they 
are oxidized inside the bed. A secondary air supply is required for cases where a large amount of combustible volatile is exiting the top of the bed. The air is supplied at the freeboard region for complete oxidation of these volatiles. Alternatively, a proper mixing

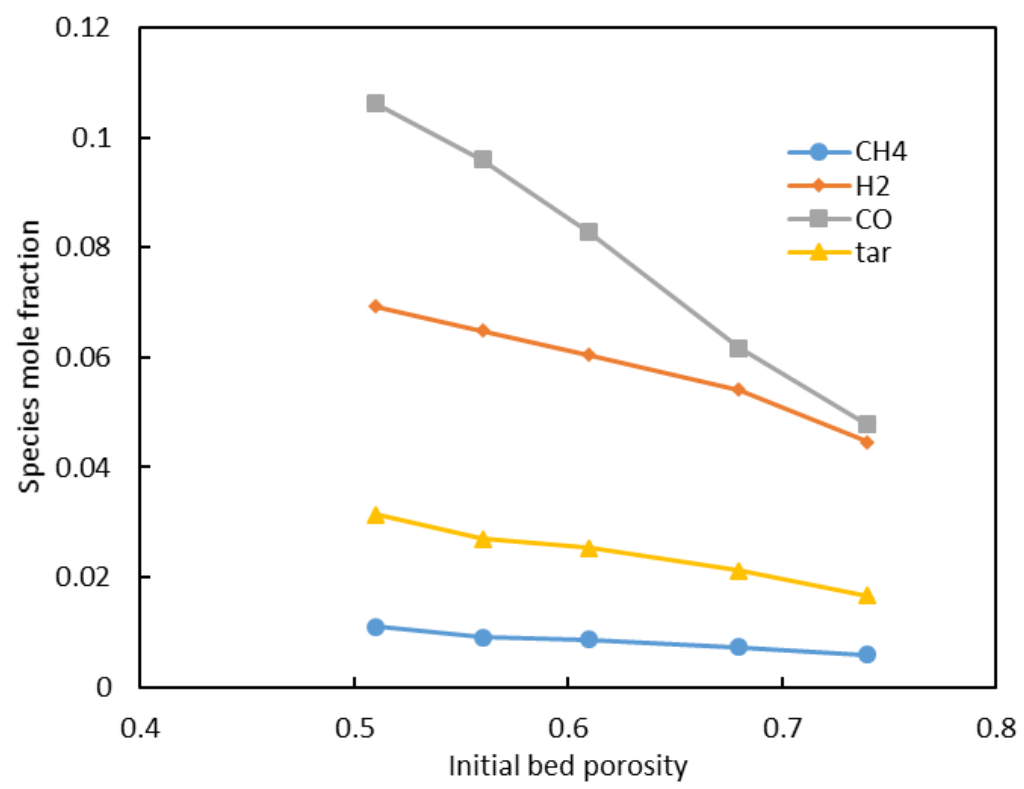

Figure 6.27: Predicted peak values of major combustible species concentration at fuel bed top for different fuel types during entire combustion time.

of these volatiles and the air is required in the freeboard region for complete combustion. Peak values of temperature and the major combustible species mole fraction along the axial length of the fixed bed for different fuel types burning under oxy-fuel condition are presented in Table E.1-E.5 in Appendix E.1. The tables show that the amount of $\mathrm{CH}_{4}, \mathrm{H}_{2}, \mathrm{CO}$ and tar decrease as initial bed porosity is increased. The amount in the top of the fuel bed were in the range of $0.006-0.011,0.045-0.069,0.048-0.106$ and $0.0167-0.0313$ for $\mathrm{CH}_{4}, \mathrm{H}_{2}, \mathrm{CO}$ and tar, respectively. The decrease is high for $\mathrm{CO}$ while it is low for $\mathrm{CH}_{4}, \mathrm{H}_{2}$ and tar. $\mathrm{CH}_{4}, \mathrm{H}_{2}$ and tar are produced solely from devolatilization of dry wood while $\mathrm{CO}$ is a product of both 
devolatilization, oxidation of tar through reaction $\mathrm{R}(9)$ and char gasification with $\mathrm{CO}_{2}$ through reaction $\mathrm{R}(16)$. Therefore, the behaviour of the former three species in the bed are expected to follow a similar trend. As noted earlier, less porous bed operates under fuel-rich conditions and therefore have high amount of unburned hydrocarbons. On the other hand, a porous bed operates under fuel-lean condition and subsequently have low amount of unburnt volatiles. For the operation conditions presented in this study, a well-designed combustion chamber with a secondary air supply is required in order to complete the oxidation of unburnt hydrocarbon.

In this section, CFD-DEM model was used to comprehensively study the influence of particle packing density and bed porosity on wood conversion in the fixed bed in the entire possible operation range. The model was validated in the initial bed porosity range of 0.50 0.75. A good agreement was achieved between the model and experiment with most points having deviations which were less than $10 \%$. It was established that porous bed shift combustion stoichiometry towards fuel-lean conditions, which is more in $\mathrm{CO}_{2}$ environment than in $\mathrm{N}_{2}$ environment. Less porous bed operates in fuel-rich conditions. Consequently, their conversion rates are slow. As a result, they have high ignition time, slow flame front propagation speed and thin reaction zone thickness. In addition, char amount is not oxidized during pyrolysis stage due to $\mathrm{O}_{2}$ deficit. A substantial amount of char is oxidized in the char combustion stage leading to two peak temperature points. On the other hand, for very porous beds, char and volatiles are concurrently oxidized during pyrolysis stage due to excess $\mathrm{O}_{2}$. Therefore, they have a single peak temperature point with relatively higher values than those for the first peaks of the less porous bed. They also have fast conversion processes, which quicken ignition, increase flame front propagation and thicken reaction zones. Furthermore, it 
was established that the operation range is narrower in $\mathrm{CO}_{2}$ environment than in $\mathrm{N}_{2}$ environment.

\subsection{Chemical, Thermal and Dilution Effects of Carbon Dioxide}

This section presents an experimental and numerical modeling of eucalyptus wood combustion under oxy-fuel conditions using a fixed bed reactor. The main objective was to isolate the role of various carbon dioxide effects on the burning rate. Wood combustion was numerically simulated under four different mixtures of $\mathrm{O}_{2}$ and $\mathrm{Ar} / \mathrm{CO}_{2} / \mathrm{N}_{2}: 21 \% \quad \mathrm{O}_{2} / 79 \% \mathrm{~N}_{2} ; 21 \% \mathrm{O}_{2} / 22.5 \% \mathrm{CO}_{2} / 56.5 \%$ Ar; $40 \% \mathrm{O}_{2} / 60 \% \mathrm{CO}_{2}$; and $40 \% \mathrm{O}_{2} / 47 \% \mathrm{CO}_{2} / 13 \%$ Ar. The first three mixtures were designed to have the same peak temperatures in order to isolate chemical and dilution effects of $\mathrm{CO}_{2}$. This was achieved by substituting some percentage of $\mathrm{CO}_{2}$ with $\mathrm{Ar}$ in $\mathrm{O}_{2} / \mathrm{CO}_{2}$ mixture while maintaining a constant concentration of $\mathrm{O}_{2}$. The fourth mixture had a higher peak temperature which was meant to isolate the thermal effect of $\mathrm{CO}_{2}$. The accuracy of model data was good with deviation of most points from measured values being within $10 \%$. It was found that ignition time in $\mathrm{CO}_{2}$ environment decreases gradually as $\mathrm{O}_{2}$ concentration is increased. On the other hand, burning rate and flame front speed increase as $\mathrm{O}_{2}$ concentration is increased. Furthermore, it was established that dilution effect is the most influential parameter on the burning rate of wood combustion in an oxy-fuel system.

\subsubsection{Overall Effect of $\mathrm{CO}_{2}$ on Wood Conversion Processes}

The overall contribution of the various effects of $\mathrm{CO}_{2}$, namely, chemical, thermal and oxygen concentration are evaluated through CFD-DEM modeling. The model results are validated by comparing them with experimental values. Shown in Fig. 6.28 are measured and predicted temperature profiles at $5 \mathrm{~cm}$ from bed bottom for air-fuel and oxy-fuel environments both at $21 \%$ 
$\mathrm{O}_{2}$ concentration. The accuracy of model data was good with deviation of most points from measured values being within $10 \%$.

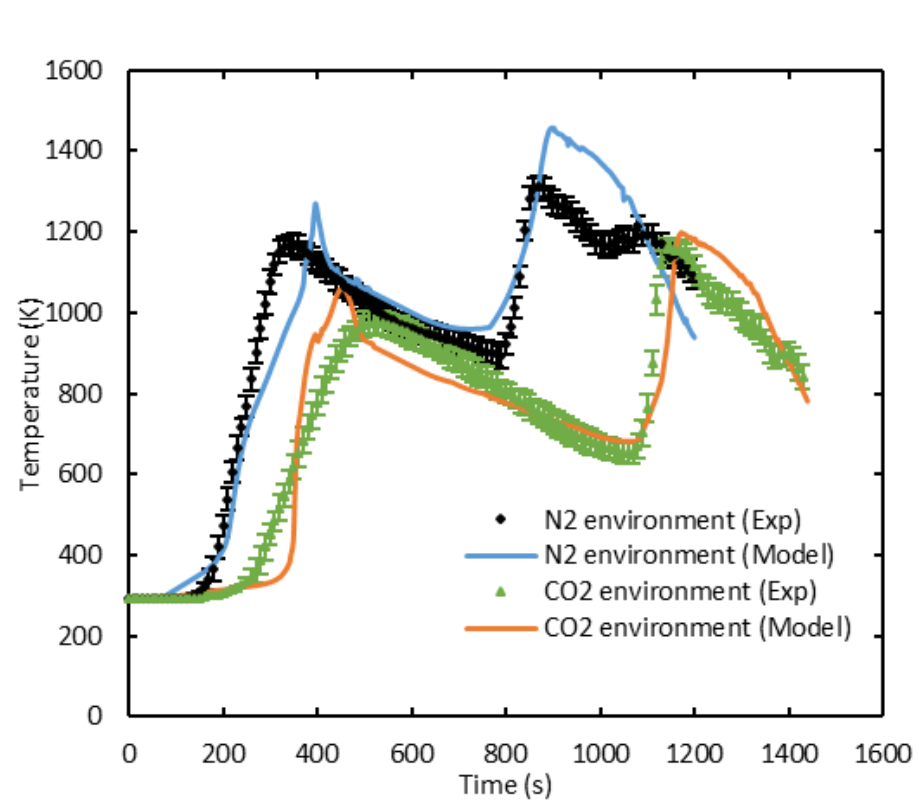

Figure 6.28: Measured and predicted temperature profiles at $5 \mathrm{~cm}$ from the bed bottom for wood combustion in $21 \% \mathrm{O}_{2} / 79 \% \mathrm{~N}_{2}$ and $21 \% \mathrm{O}_{2} / 79 \% \mathrm{CO}_{2}$ mixtures.

Figure 6.28 show that the temperature profile at any given height in both $\mathrm{N}_{2}$ and $\mathrm{CO}_{2}$ environments exhibit similar behavior. They all have two peaks. When the flame front reaches an ignition point, the temperature rises rapidly up to the first peak. Then it decreases gradually to another point and finally rises to the second peak. Combustible pyrolysis products such as $\mathrm{CH}_{4}, \operatorname{tar}, \mathrm{H}_{2}$ and $\mathrm{CO}$ are oxidized through exothermic reactions which generate heat and subsequently increases the temperature. The exothermic reactions occur concurrently with pyrolysis and drying of wood particles which are endothermic reactions and cause decrease in temperature after the first peak. When pyrolysis and drying processes are completed, exothermic reactions dominate and temperature rises again to the second peak. After the second peak, the temperature gradually decreases until the end of combustion. During this phase, a wood particle has completely been 
devolatilized leaving a pure char that undergo oxidation and gasification with $\mathrm{H}_{2} \mathrm{O}$ and $\mathrm{CO}_{2}$. It is deduced that gasification process which is endothermic is more pronounced than exothermic process (oxidation), hence the temperature decrease.

Figure 6.28 also shows that at corresponding height, air-fuel peak temperature is higher than oxyfuel temperature by about $200 \mathrm{~K}$. This is as a result of combination of both chemical and thermal effect. Lower temperatures are seen in oxy-fuel environment because $\mathrm{CO}_{2}$ has higher heat capacity than $\mathrm{N}_{2}$. Furthermore, chemical effect through endothermic reaction of $\mathrm{CO}_{2}$ with char contribute in lowering the temperature of oxy-fuel environment.

Presented in Fig. 6.29 are predicted temperature profiles at $5 \mathrm{~cm}$ from the bed bottom for wood combustion in different combustion atmospheres. It is observed that peak temperature occurrence time comes much earlier in $\mathrm{N}_{2}$ atmosphere than in $\mathrm{CO}_{2}$ atmosphere. This is an indication that combustion rate is slower in $\mathrm{CO}_{2}$ environment. For oxy-fuel combustion, peak temperature value is directly proportional to $\mathrm{O}_{2}$ concentration. In addition, its occurrence time increases as $\mathrm{O}_{2}$ concentration is decreased. Peak temperature of oxy-fuel atmosphere which is equivalent to that of standard air-fuel condition occur at about $40 \% \mathrm{O}_{2}$ concentration. However, its occurrence time is slightly earlier than in air-fuel condition. This is attributed to higher $\mathrm{O}_{2}$ concentration which enhance oxidation reactions of volatiles that releases more heat and increases flame speed.

The time taken for the reaction front to start at the top surface of the fuel bed was defined as ignition time. Presented in Fig. 6.30 is ignition time for wood combustion in both oxy-fuel and air-fuel environments. The graph shows that at any given oxygen concentration, ignition time in oxy-fuel environment is almost twice that of corresponding air-fuel condition. Retarded ignition in $\mathrm{CO}_{2}$ environment could be attributed to its high specific heat capacity and low $\mathrm{O}_{2}$ diffusivity in it. In both cases, ignition time gradually decreases as oxygen concentration is increased. 


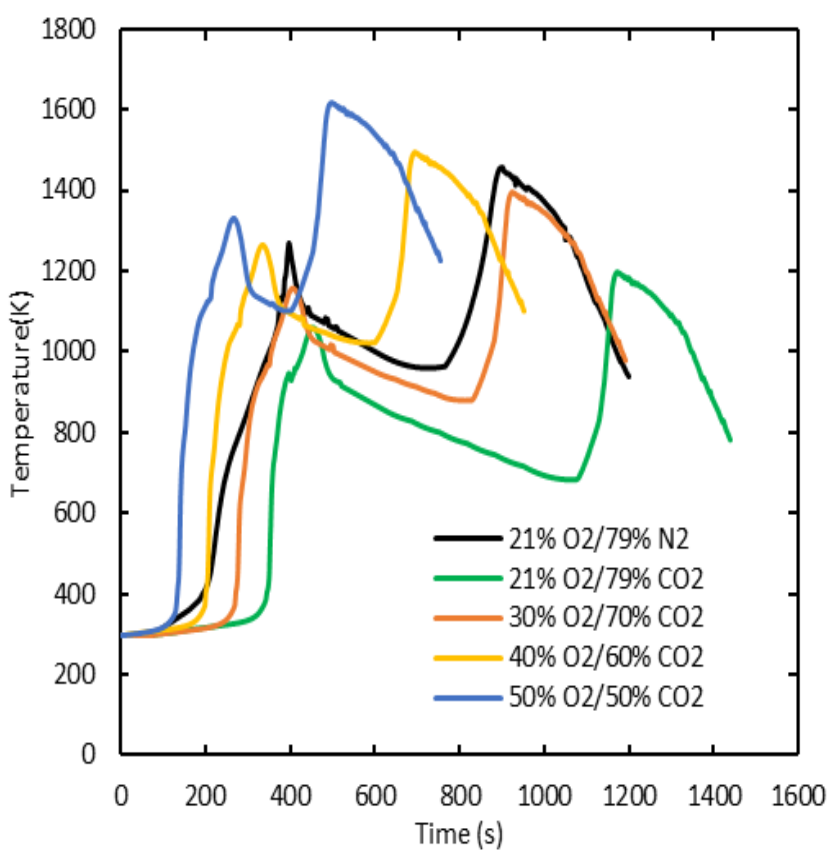

Figure 6.29: Predicted temperature profiles at $5 \mathrm{~cm}$ from the bed bottom for wood combustion in different combustion atmospheres.

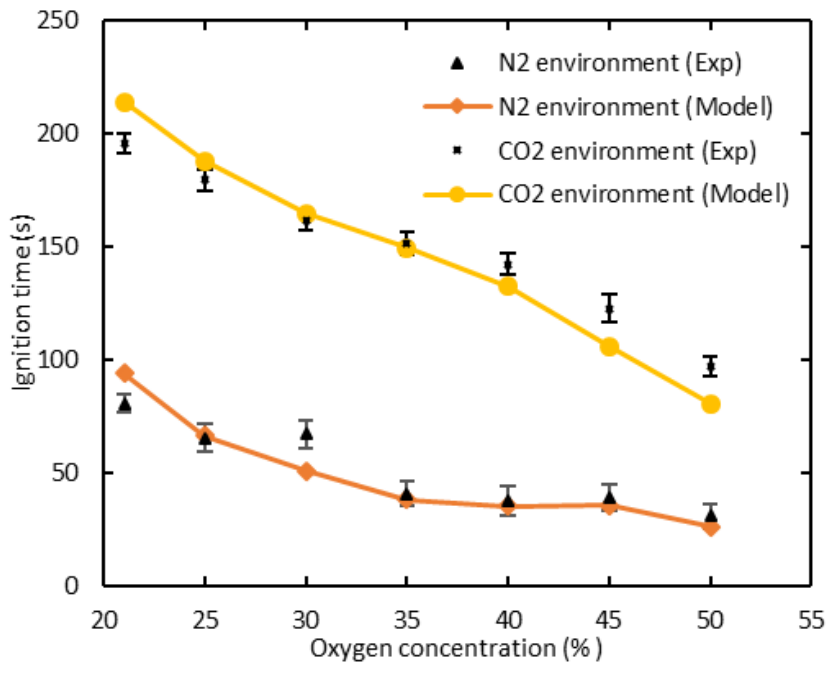

Figure 6.30: Measured and predicted ignition time for fixed bed combustion of wood in $\mathrm{N}_{2}$ and $\mathrm{CO}_{2}$ environments.

A comparison of burning rates for wood combustion in $\mathrm{N}_{2}$ and $\mathrm{CO}_{2}$ burning conditions are 
presented in Fig. 6.31. At the same $\mathrm{O}_{2}$ concentration, the burning rate in $\mathrm{CO}_{2}$ burning atmosphere is less than in $\mathrm{N}_{2}$ burning atmosphere. The burning rate of wood particles in oxy-fuel condition is lowered by the aforementioned $\mathrm{CO}_{2}$ effects, which contribute differently as would be discussed later. Thermal diffusivity of $\mathrm{CO}_{2}$ is less than that of $\mathrm{N}_{2}$ by about $35 \%$ (Suda et al., 2007). In addition, $\mathrm{CO}_{2}$ absorbs radiative heat more than $\mathrm{N}_{2}$. The overall effects of these thermal properties of $\mathrm{CO}_{2}$ is a decrease in burning rate as seen in Fig. 6.31. Furthermore, the burning rate in oxy-fuel environment is also decreased by chemical effect of $\mathrm{CO}_{2}$ through Bourdouard reaction $\mathrm{R}(16)$, which is endothermic. On the other hand, the role played by dilution is clearly demonstrated in Fig. 6.31. In both cases, burning rate is directly proportional to $\mathrm{O}_{2}$ concentration. More $\mathrm{O}_{2}$ concentration enhances oxidation of combustible pyrolysis products and char, hence releasing more heat and increasing the burning rates.

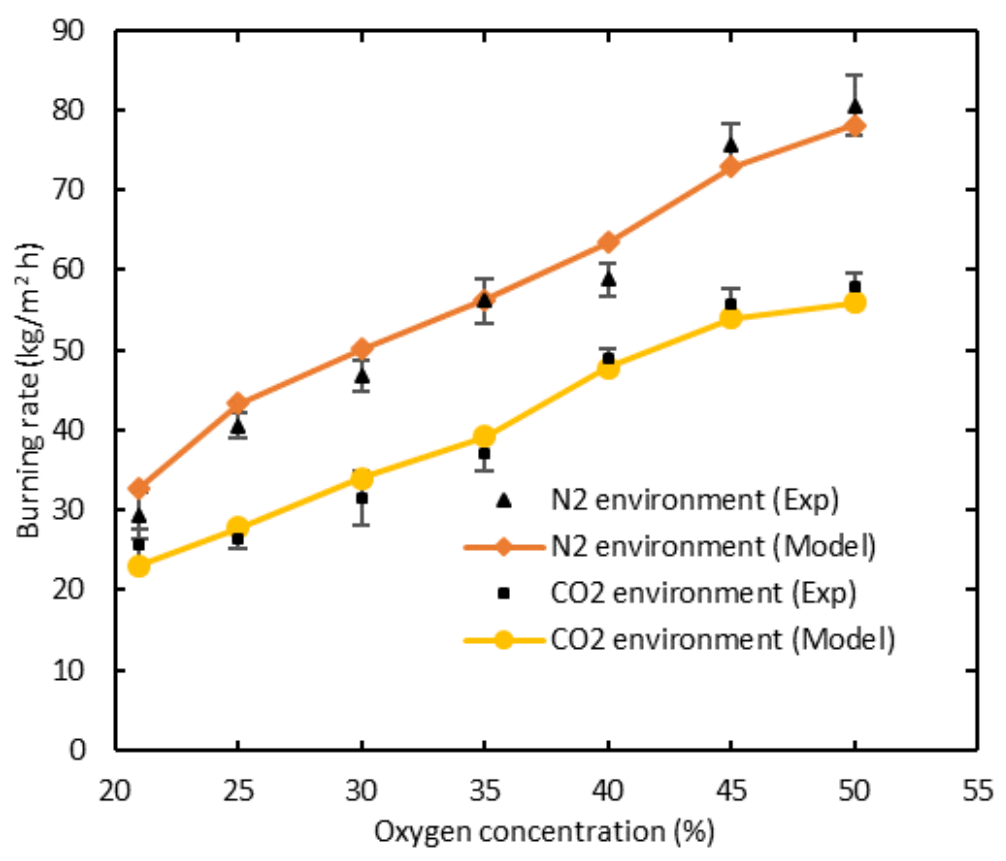

Figure 6.31: Measured and predicted burning rates for fixed bed combustion of wood in $\mathrm{N}_{2}$ and $\mathrm{CO}_{2}$ environments. 


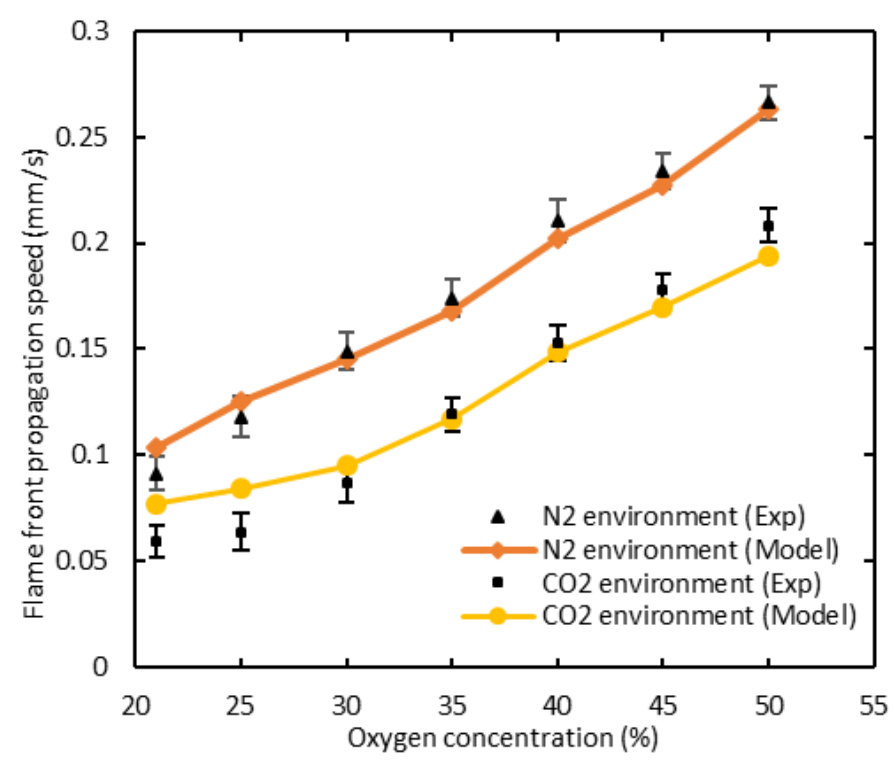

Figure 6.32: Measured and predicted flame front propagation speed for fixed bed combustion of wood in $\mathrm{N}_{2}$ and $\mathrm{CO}_{2}$ environments.

Illustrated in Fig. 6.32 is the flame front propagation speed for wood combustion in oxy-fuel and air-fuel burning atmospheres. It is observed that for all oxygen concentration, $\mathrm{CO}_{2}$ burning atmosphere had lower propagation speed as compared to $\mathrm{N}_{2}$ burning atmosphere. Furthermore, as oxygen concentration increases flame propagation speed also increases. Flame speed is directly linked to the burning rate. Therefore, the factors which reduce the burning rates in oxy-fuel environment as discussed in the preceding paragraph are also responsible for the reduced flame speed.

The species and temperature profiles along axial length of the fixed bed when the flame front is at $4 \mathrm{~cm}$ from the grate for $21 \% \mathrm{O}_{2} / 79 \% \mathrm{CO}_{2}, 30 \% \mathrm{O}_{2} / 70 \% \mathrm{CO}_{2}, 40 \% \mathrm{O}_{2} / 60 \% \mathrm{CO}_{2}$ and $50 \% \mathrm{O}_{2} / 50 \%$ $\mathrm{CO}_{2}$ are presented in Figs 6.33 and 6.34. The flame structures are similar in profile but differ in magnitude. The flame front for the mixture with high $\mathrm{O}_{2}$ concentration, $50 \%$, reaches $4 \mathrm{~cm}$ plane at $191 \mathrm{~s}$, which is earlier than those for $40 \%, 30 \%$ and $21 \%$ that reached the plane at $275 \mathrm{~s}, 360 \mathrm{~s}$ 
and $482 \mathrm{~s}$, respectively. This is because flame speed increases as $\mathrm{O}_{2}$ concentration is increased. As shown in Figs 6.33, 6.34 and Table 6.1, the amount of tar and $\mathrm{CH}_{4}$ are high at the reaction zone of $21 \% \mathrm{O}_{2}$ concentration mixture and decreases gradually for $30 \%, 40 \%$ and $50 \% \mathrm{O}_{2}$ concentration mixtures; comparison of species when the flame front is at $4 \mathrm{~cm}$ is shown in Figs E.13-E.15 in Appendix E.2. The same behavior is observed in the concentration of $\operatorname{tar}$ and $\mathrm{CH}_{4}$ in

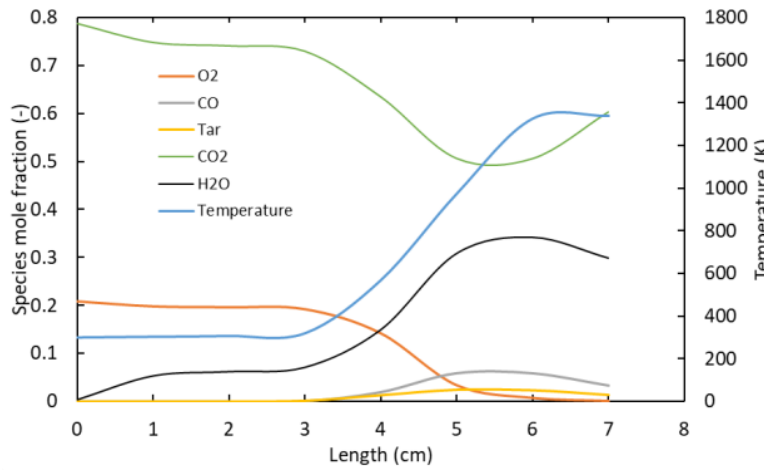

(a)

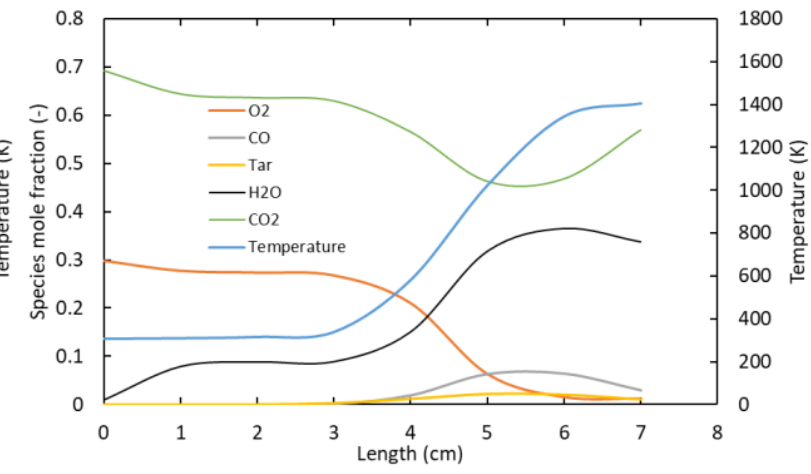

(b)

Figure 6.33: Species and temperature profiles along axial length of the bed when the flame front is at $4 \mathrm{~cm}$ from the grate for (a) $21 \% \mathrm{O}_{2} / 79 \% \mathrm{CO}_{2}$ and (b) $30 \% \mathrm{O}_{2} / 70 \% \mathrm{CO}_{2}$.

these $\mathrm{O}_{2} / \mathrm{CO}_{2}$ mixtures when the reaction front is at $3 \mathrm{~cm}, 2 \mathrm{~cm}$ and $1 \mathrm{~cm}$ from the grate as illustrated in Figs E.16-E.24. The graphs show that the mixture with $21 \% \mathrm{O}_{2}$ concentration is operating under fuel rich conditions and does not have enough $\mathrm{O}_{2}$ to oxidize these species through reactions $\mathrm{R}(7)$ and $\mathrm{R}(9)$. On the other hand, the graphs show that the mixtures with $30 \%, 40 \%$ and $50 \% \mathrm{O}_{2}$ concentration are operating under fuel lean conditions and have excess $\mathrm{O}_{2}$ in their reaction zones. Thus reduced amount of tar and $\mathrm{CH}_{4}$ are observed in these mixtures as compared to those of $21 \% \mathrm{O}_{2}$ concentration mixture. Consequently, since these reactions are exothermic, a high amount of heat is released as $\mathrm{O}_{2}$ concentration is increased. This is seen in the peak temperatures attained by these mixtures, Fig. 6.29. The high amount of heat released increases the heating rates for the particles in the bed and explains the higher flame front propagation speed and burning rates 
for high $\mathrm{O}_{2}$ concentration mixtures. High heat energy also accelerates the ignition of the particles for mixtures with high $\mathrm{O}_{2}$ concentration.

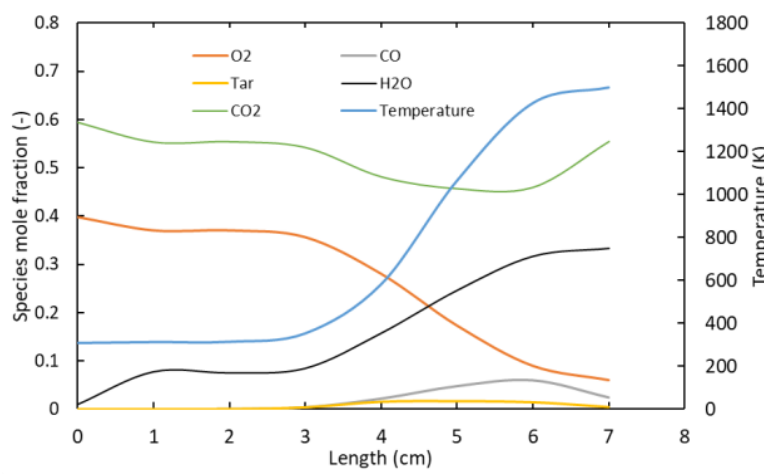

(a)

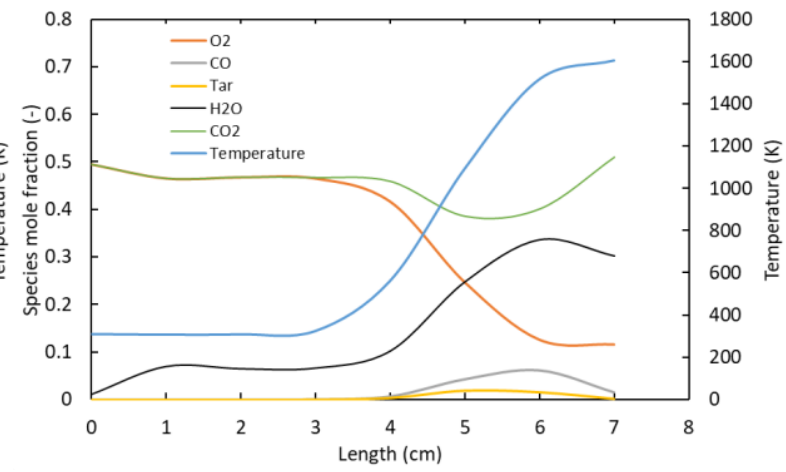

(b)

Figure 6.34: Species and temperature profiles along axial length of the bed when the flame front is at $4 \mathrm{~cm}$ from the grate for (a) $40 \% \mathrm{O}_{2} / 60 \% \mathrm{CO}_{2}$ and (b) $50 \% \mathrm{O}_{2} / 50 \% \mathrm{CO}_{2}$.

Figures 6.33, 6.34 and Table 6.1 show that the amount of $\mathrm{CO}$ is highest in the reaction zone of the mixture with $30 \% \mathrm{O}_{2}$ concentration, comparison is shown in Appendix E.2. Peak values of temperature and the major combustible species mole fraction along the axial length of the fixed bed for wood combustion burning under oxy-fuel condition of different $\mathrm{O}_{2} / \mathrm{CO}_{2}$ mixtures are presented in Table E.6-E.9 in Appendix E.2. The mixtures with $21 \%, 40 \%$ and $50 \% \mathrm{O}_{2}$ concentration have almost the same amount of $\mathrm{CO}$ in their reaction zone. Unlike tar and $\mathrm{CH}_{4}$ whose sole source is devolatilization of the wood particles, $\mathrm{CO}$ is produced from devolatilization process, oxidation of tar through reaction $\mathrm{R}(9)$ and char gasification with $\mathrm{CO}_{2}$ through reaction $\mathrm{R}(16)$. $\mathrm{CO}$ is consumed by oxidation reaction $\mathrm{R}(6)$. For a mixture with high $\mathrm{O}_{2}$ concentration, excess $\mathrm{O}_{2}$ brings an antagonistic effect to the amount of $\mathrm{CO}$ where there is a tendency for high consumption through oxidation reaction $\mathrm{R}(6)$ and high production by oxidation of tar through reaction $\mathrm{R}(9)$ as compared to that of a mixture with low $\mathrm{O}_{2}$ concentration. However, for mixtures with high $\mathrm{O}_{2}$ concentration, the production of $\mathrm{CO}$ through 
char gasification could be less than that of low $\mathrm{O}_{2}$ concentration mixture because of low amount of $\mathrm{CO}_{2}$. The overall effect of these reactions is that there is an increase in $\mathrm{CO}$ production as $\mathrm{O}_{2}$ concentration is increased up to a peak point then it starts to decrease.

Burning rate, ignition of fuel particles and flame front propagation speed are all influenced by thermal behavior of the bed. Apart from heat of combustion through chemical reactions discussed in the preceding paragraphs, flame temperature at a given point is also determined by heat flux in the form of conduction, convection and radiation. Heat flux distribution in the fixed bed is mostly by radiation. $\mathrm{H}_{2} \mathrm{O}$ and $\mathrm{CO}_{2}$ are the main products of combustion that participate in radiation. The presence of high amount of $\mathrm{CO}_{2}$ in an oxy-fuel environment makes it more emissive than air-fuel environment. As depicted by the flame temperatures in Figs. 6.29 and 6.34, a high amount of heat energy is released in the fuel bed with a high $\mathrm{O}_{2}$ concentration mixture. In this study, the heat energy contribution from different sources have not been separated. Therefore, an increase in heat energy cannot be explicitly linked to a particular source. Though, in the region of intense combustion, heat contributed by combustion is more dominant; the contribution by radiation heat flux is only 10-15\% (Lallemant et al., 1996).

Table 6.1: Peak values of major combustible species and temperature profiles for wood combustion under oxy-fuel environment for different $\mathrm{O}_{2} / \mathrm{CO}_{2}$ mixtures when the flame front is at $4 \mathrm{~cm}$ from the grate.

\begin{tabular}{|c|c|c|c|c|}
\hline \multirow{2}{*}{$\begin{array}{l}\text { Temperature/ } \\
\text { species mole } \\
\text { fraction (-) }\end{array}$} & \multicolumn{4}{|c|}{$\mathrm{O}_{2} / \mathrm{CO}_{2}$ mixture } \\
\hline & $21 \% \mathrm{O}_{2}$ & $30 \% \mathrm{O}_{2}$ & $40 \% \mathrm{O}_{2}$ & $50 \% \mathrm{O}_{2}$ \\
\hline $\begin{array}{l}\text { Temperature } \\
\text { (K) }\end{array}$ & 1338 & 1406 & 1499 & 1605 \\
\hline Tar & 0.02427 & 0.02164 & 0.01605 & 0.01837 \\
\hline $\mathrm{CO}$ & 0.05839 & 0.06488 & 0.06013 & 0.06124 \\
\hline $\mathrm{CH}_{4}$ & 0.00819 & 0.00769 & 0.00542 & 0.00684 \\
\hline
\end{tabular}




\subsubsection{Isolation of $\mathrm{CO}_{2}$ Effects on Wood Conversion Processes}

Wood combustion in four different mixtures of $\mathrm{O}_{2}$ and $\mathrm{Ar} / \mathrm{CO}_{2} / \mathrm{N}_{2}$ were numerically simulated so as to separate the various effects of $\mathrm{CO}_{2}$ on burning rate of wood. For all the cases, temperature profiles at $5 \mathrm{~cm}$ from fuel bed was considered. A method of adjusting the flame temperature using Ar, which was initially proposed by Du et al. (2009) and previously used by other researchers (AlQurashi et al. 2011; Zhou et al. 2016), was implemented in this study. The four mixtures are denoted by letters $\mathrm{A}, \mathrm{B}, \mathrm{C}$ and and $\mathrm{D}$ and their composition were: $21 \% \mathrm{O}_{2} / 79 \% \mathrm{~N}_{2} ; 21 \% \mathrm{O}_{2} / 22.5 \%$ $\mathrm{CO}_{2} / 56.5 \% \mathrm{Ar} ; 40 \% \mathrm{O}_{2} / 60 \% \mathrm{CO}_{2} ;$ and $40 \% \mathrm{O}_{2} / 47 \% \mathrm{CO}_{2} / 13 \%$ Ar, respectively. Furthermore, other properties of the different mixtures such as mass fraction of the constituents, combined heat capacity and oxygen diffusion coefficient are provided in Table 6.2. These properties were evaluated and compared at room temperature (298 K), ignition temperature (500 K) and flame temperature $(1400 \mathrm{~K})$. Combustion of wood in mixtures A, B and C were designed to have the same peak temperatures, as shown in Fig. 6.35. A high amount of Ar in mixture B was to increase the peak temperature which is low when $\mathrm{CO}_{2}$ alone is used as a diluent. As shown in Table 6.2, this mixture has a lower specific heat capacity. This enabled the mixture to have the same peak temperature as that of mixture $\mathrm{A}$ and $\mathrm{C}$. The peak temperature of wood combustion in mixture $\mathrm{D}$ was higher than for the other three by $167 \mathrm{~K}$.

The burning rates of wood combustion in the four mixtures were evaluated and presented in Fig. 6.36. Burning rate in mixture A was used as a datum. The difference in burning rates of combustion in mixture $\mathrm{A}$ and $\mathrm{B}$ is due to chemical effect because they have the same oxygen concentration and temperature values. Since temperature is the only similar parameter for combustion in mixture A and $\mathrm{C}$, then the difference in their burning rate is due to a combination of oxygen concentration and chemical effect. Oxygen concentration effect is achieved when oxygen concentration is increased to $40 \%$ while maintaining the same temperature in $\mathrm{CO}_{2}$ environment - combustion in 
mixture $\mathrm{B}$ and C. Finally, the difference in burning rates for combustion in mixture $\mathrm{C}$ and $\mathrm{D}$ is due to thermal effect since they have the same oxygen concentration but different temperature values. Table 6.2: Composition, combined heat capacity and $\mathrm{O}_{2}$ diffusion coefficient of the four mixtures at different temperatures.

\begin{tabular}{|c|c|c|c|c|c|}
\hline \multirow{2}{*}{ Properties } & & \multicolumn{4}{|c|}{ Gas mixtures } \\
\hline & & $\mathrm{A}$ & B & $\mathrm{C}$ & $\mathrm{D}$ \\
\hline \multirow{4}{*}{$\begin{array}{l}\text { Mass fraction of the } \\
\text { components [-] }\end{array}$} & $\mathrm{Ar}$ & 0.000 & 0.576 & 0.000 & 0.134 \\
\hline & $\mathrm{O}_{2}$ & 0.233 & 0.171 & 0.327 & 0.331 \\
\hline & $\mathrm{N}_{2}$ & 0.767 & 0.000 & 0.000 & 0.000 \\
\hline & $\mathrm{CO}_{2}$ & 0.000 & 0.253 & 0.673 & 0.535 \\
\hline \multirow{3}{*}{$c_{p}$ for the mixture $[\mathrm{kJ} / \mathrm{kg} \mathrm{K}]$} & At $298 \mathrm{~K}$ & 1.005 & 0.67 & 0.868 & 0.825 \\
\hline & At $500 \mathrm{~K}$ & 1.03 & 0.725 & 1.006 & 0.939 \\
\hline & At $1400 \mathrm{~K}$ & 1.209 & 0.826 & 1.255 & 1.147 \\
\hline \multirow{3}{*}{$\begin{array}{l}\mathrm{O}_{2} \text { diffusion coefficient in the } \\
\text { mixture }\left(\mathrm{cm}^{2} / \mathrm{s}\right)\end{array}$} & At $298 \mathrm{~K}$ & 0.209 & 0.184 & 0.156 & 0.164 \\
\hline & At $500 \mathrm{~K}$ & 0.513 & 0.462 & 0.398 & 0.415 \\
\hline & At $1400 \mathrm{~K}$ & 2.888 & 2.642 & 2.31 & 2.401 \\
\hline
\end{tabular}

Individual contribution of $\mathrm{CO}_{2}$ effects on burning rates of wood combustion is presented in Fig. 6.37. It was established that chemical, thermal and oxygen concentration influenced burning rate of wood by $5 \%, 9 \%$ and $86 \%$, respectively. It is evident that oxygen concentration is the most influential parameter on the burning rate. As oxygen concentration is increased, oxidation of char and combustible pyrolysis products are also enhanced. Therefore, more heat is generated and fuel burning rate is significantly improved. The influence of thermal and chemical are not very significant. Thermal effect is only $9 \%$ and translate to a temperature change of $167 \mathrm{~K}$. Chemical effect on the burning rate is quite small because the rate of the chemical reactions involving $\mathrm{CO}_{2}$ consumption ( $\mathrm{R}(14)$ and $\mathrm{R}(16))$ are far much less compared to the rate of $(\mathrm{R}(6)$ and $\mathrm{R}(13))$. 


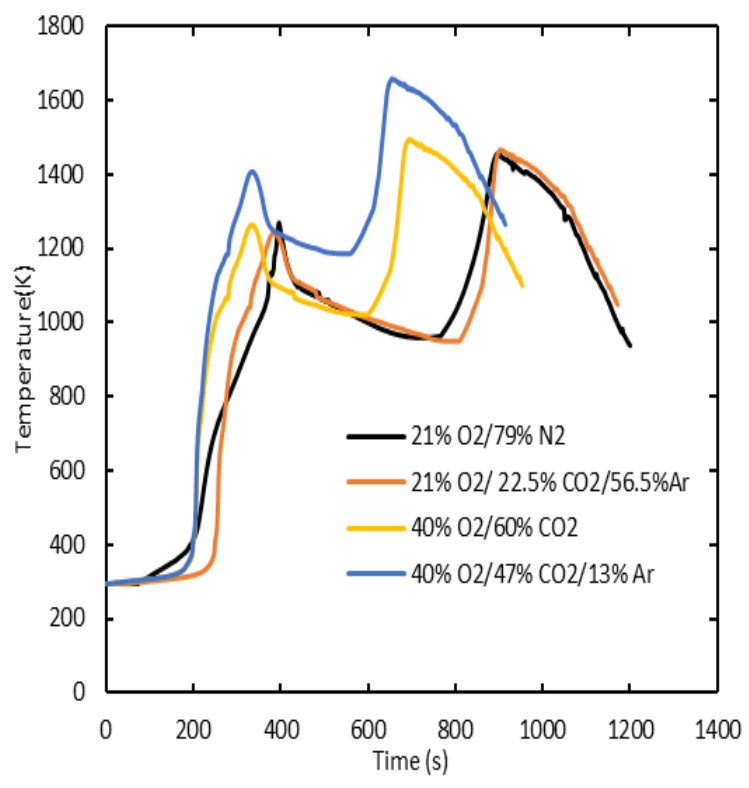

Figure 6.35: Predicted temperature profiles at $5 \mathrm{~cm}$ from the bed bottom for wood combustion in four combustion environments.

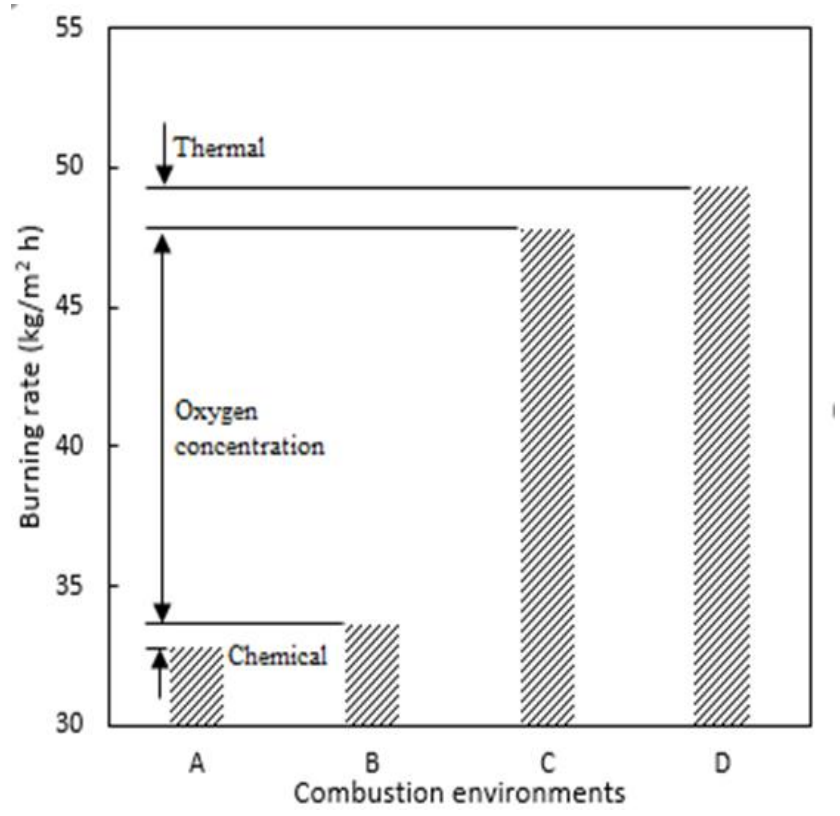

Figure 6.36: Predicted separate effects of $\mathrm{CO}_{2}$ on burning rates for wood combustion in four combustion environments. 


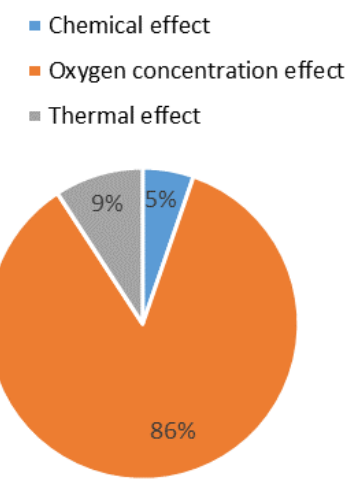

Figure 6.37: Predicted contributions of separate effects of $\mathrm{CO}_{2}$ on burning rates for wood combustion in four combustion environments.

The overall and separate effects of $\mathrm{CO}_{2}$ burning atmosphere on the combustion properties of wood burning in a fixed bed were investigated through numerical modeling. Modeling was validated by comparison with measured data. It was established that the dilution effect is the most influential parameter on the burning rate of wood combustion in an oxy-fuel system. The influence of thermal and chemical are not very significant. The peak temperature of oxy-fuel atmosphere which is equivalent to that of standard air-fuel condition occur at a higher $\mathrm{O}_{2}$ concentration. However, its occurrence time is slightly earlier than in air-fuel condition. At any given oxygen concentration, ignition time in oxy-fuel is almost twice that of corresponding air-fuel condition. In both cases, ignition time gradually decreases as oxygen concentration is increased. At the same oxygen concentration, burning rate and flame propagation speed in $\mathrm{CO}_{2}$ combustion environment was less than in $\mathrm{N}_{2}$ combustion environment. 


\section{CHAPTER SEVEN \\ CONCLUSIONS}

\subsection{Introduction}

Presented in this chapter is a summary of the main findings of this study. The findings covered three major areas considered in this work; flame propagation speed under oxy-fuel conditions, particle packing density and separate effects of $\mathrm{CO}_{2}$ in oxy-fuel combustion. In addition, conclusions arising out of the study are also discussed.

\subsection{Summary}

The main findings of this study is summarized as follows:

- CFD-DEM model agreed very well with experimental values for mass loss, propagation speed, flame front positions, burning rate and ignition time.

- Flame front propagation speed in oxy-fuel atmosphere reduced to $78 \%$ of that of the air-fuel condition with similar $\mathrm{O}_{2}$ concentration.

- Under the same $\mathrm{O}_{2}$ concentration, peak temperature and burning rate are reduced while ignition time is increased in an oxy-fuel environment as compared to air-fuel environment.

- For oxy-fuel combustion, peak temperature value, burning rate and propagation speed increases while ignition time reduces as $\mathrm{O}_{2}$ concentration is increased.

- The packing density affects the combustion process in an oxy-fuel environment by changing the burning conditions and flammability limits. As bed porosity is increased, the combustion condition is shifted from fuel-rich to fuel-lean side and this increases the conversion rate, reduces the ignition time, increases the flame front propagation speed and thicken the reaction zones. 
- There is an optimum packing density, $\chi=0.71$, beyond which the efficiency falls off due to the onset of quenching in the spaces.

- Dilution effect of $\mathrm{CO}_{2}$ is the most influential parameter on the burning rate of wood combustion in an oxy-fuel environment. The influence of thermal and chemical are not very significant.

\subsection{Conclusions}

Modeling and experimental work on oxy-fuel combustion of biomass in a laboratory fixed bed reactor has been investigated in this thesis. The focus was on flame propagation speed under oxy-fuel conditions, particle packing density and separate effects of $\mathrm{CO}_{2}$ in oxy-fuel combustion. In all the cases, CFD-DEM approach was used to simulate wood conversion in a fixed bed and the results compared to experimental data. A good agreement between model and experimental results were achieved in all the cases studied.

First, the effect of $\mathrm{CO}_{2}$ environment on flame propagation speed and flame structures were investigated. Computational results agree very well with experimental values except temperature which showed poor prediction at low $\mathrm{O}_{2}$ concentration. The agreement of temperatures corrected for radiation losses with predicted values are better than those of uncorrected values. Hence, it was established that prediction accuracy of CFD-DEM is not the same in different $\mathrm{O}_{2} / \mathrm{CO}_{2}$ mixtures. Furthermore, it was observed that flame speed in oxy-fuel atmosphere reduced to $78 \%$ of that of the air-fuel condition with same $\mathrm{O}_{2}$ concentration. This was determined both by experiment and through computation. Reduced flame speed was attributed to a higher heat capacity of $\mathrm{CO}_{2}$ and lower $\mathrm{O}_{2}$ diffusivity in $\mathrm{CO}_{2}$ whose overall effect is reduction of temperature and heating rates of fuel particles. Low mass fraction of combustible volatiles predicted in the $\mathrm{CO}_{2}$ environment also contribute to a reduced flame speed. Flame 
structures have similar profiles but differ in value of temperature and species quantities. Temperatures in the $\mathrm{CO}_{2}$ environments were lower than those in the $\mathrm{N}_{2}$ environments. During initial stages of combustion, the amount of tar and steam is observed to be highest in $79 \% \mathrm{~N}_{2}$ environment and lowest in $79 \% \mathrm{CO}_{2}$ environment. The amount of $\mathrm{CO}$ was almost equal in both environments during pyrolysis but high amount was predicted in oxy-fuel environments during char combustion stage.

Second, CFD-DEM model was used to comprehensively study the influence of particle packing density and bed porosity on wood conversion in the fixed bed in the entire possible operation range. The model was validated in the initial bed porosity range of $0.50-0.75$. A good agreement was achieved between the model and experiment with most points having deviations which were less than $10 \%$. It was established that the packing density affects the combustion process in an oxy-fuel environment by changing the burning conditions and flammability limits. As bed porosity is increased, the combustion condition is shifted from fuel-rich to fuel-lean side and this increases the conversion rate, reduces the ignition time, increases the flame front propagation speed and thicken the reaction zones. In addition, as bed porosity is increased, volatiles and char are concurrently oxidized during pyrolysis stage leading to a single temperature peak. On contrary, less porous bed has two distinct temperature peaks since volatiles and char are oxidized sequentially due to $\mathrm{O}_{2}$ deficit. It was also found out that there is an optimum packing density, $\chi=0.71$, beyond which the efficiency falls off due to the onset of quenching in the spaces. Furthermore, the operational range with respect to porosity was decreased in an oxy-fuel burning condition due to higher quenching effects of $\mathrm{CO}_{2}$.

Finally, the overall and separate effect of $\mathrm{CO}_{2}$ environment on the combustion properties of wood burning in a fixed bed were investigated through numerical modeling. It was established 
that the peak temperature of oxy-fuel atmosphere which is equivalent to air-fuel at $21 \% \mathrm{O} 2$ concentration occur at about $40 \% \mathrm{O}_{2}$ concentration. Its occurrence time is slightly earlier than that of $21 \% \mathrm{O}_{2} / 79 \% \mathrm{~N}_{2}$ atmosphere. At any given oxygen concentration, ignition time in oxyfuel is almost twice that of corresponding air-fuel condition. In both cases, ignition time gradually decreases as oxygen concentration is increased. At the same oxygen concentration, burning rate and flame propagation speed in $\mathrm{CO}_{2}$ combustion environment was less than in $\mathrm{N}_{2}$ combustion environment. Chemical, thermal and oxygen concentration influenced burning rate of wood by $5 \%, 9 \%$ and $86 \%$, respectively.

\subsection{Significance of the Study}

This study deals with experimental and numerical simulation of fixed bed combustion of wood under oxy-fuel environment. Oxy-fuel combustion considered in this research work is significant because it is a clean energy technology where $\mathrm{CO}_{2}$ is captured through recycling of flue gas, and at the same time nitrogen oxides $\left(\mathrm{NO}_{\mathrm{x}}\right)$ emissions are reduced. Fixed bed combustion technology that is also considered in this study is relevant in industrial application, particularly for power plants that generate up to $40 \mathrm{MW}_{\text {th. }}$. The fixed bed technique is favourable because of its simplicity. The mechanisms through which $\mathrm{CO}_{2}$ affects fundamental combustion properties of wood burning in a fixed bed are investigated in this research work. An understanding of these mechanisms is important because it helps in design of optimized oxyfuel burners. Furthermore, the combustion properties investigated in this study, viz., temperature profiles, ignition time, burning rate, flame propagation speed and species evolution in the bed are the main parameters to consider when designing a new burner. Therefore, the findings from this work are important and may be useful when designing burners which operate under oxy-fuel combustion conditions. The study revealed that the packing density affects 
combustion process in an oxy-fuel environment by changing the burning conditions and flammability limits. The study also revealed that there is an optimum packing density beyond which the efficiency falls due to the onset of quenching in the spaces. These findings are meaningful, relevant and appealing to audience in energy sector, biomass conversion, fuel sector, power plant and scientific community at large. 


\section{CHAPTER EIGHT OUTLOOK FOR FUTURE WORK}

In practice, shrinking or local collapse is a possible problem during combustion of biomass fuels. In this thesis, the experimental set up did not have a provision for measuring, monitoring and visualizing the volume change in bed layers. Combustion chamber was not made of a transparent material. Therefore, it was not possible to observe or measure shrinkage. A shrinkage model from literature was implemented in our computational work. Hence, there is need to carry out an experimental study which consider shrinkage in the fuel bed. In this study, particle packing density was analyzed by considering initial arrangement of particles in the bed. However, in practice, the packing density and porosity changes as combustion proceeds. Channeling in the bed could also arise as combustion takes place. These were not considered in this work. Hence, there is also need to consider them in a future study. In this study, CFD-DEM model slightly over predicted temperature of wood combustion under oxy-fuel conditions at low $\mathrm{O}_{2}$ concentration. This could be attributed mainly to the kinetic model and the heat transfer model that were implemented in this study. Chemical kinetic model for gas-phase used in this study is a skeletal mechanism that had a few reactions as presented in Table 3.4. The model consisted of oxidation reactions of the products of devolatilization, i.e., $\mathrm{H}_{2}, \mathrm{CH}_{4}$, tar and $\mathrm{CO}$. Furthermore, it had dominant reaction pathway $\mathrm{R}(10)$, which is important in an oxy-fuel environment. The skeletal mechanism used in this thesis was necessary due to high demand for computation power required in three dimensional modelling. Though there was a good agreement between the model results and experimental data, better prediction could be achieved by incorporating a full chemical kinetic mechanism for hydrocarbon combustion. Combustion properties of the fixed bed such as burning rate, ignition of fuel particles and flame front propagation speed are all influenced by thermal behavior of the bed. Flame temperature 
at a given point is determined by heat of combustion through chemical reactions and heat flux distribution in the bed which is mostly by radiation. The presence of high amount of $\mathrm{CO}_{2}$ in an oxy-fuel environment makes it more emissive than air-fuel environment. A radiation model which take into consideration this fact should be implemented when modeling wood combustion in an oxy-fuel environment. In this work unmodified WSGGM was used to account for heat transfer by radiation. This model was initially developed for air-fuel environment. There are studies which show that the impact of modifying WSGGM for application in oxyfuel condition is negligible in small scale reactors. While it has been noted that modified WSGGM model has significant improvement on the accuracy when considering large scale reactors, the effect on small scale reactors is minimal. This is because evaluation of gaseous radiative properties using non-gray method employed in modified WSGGM has an inherent potential of improving the accuracy of oxy-fuel combustion models but the degree of improvement depends on the scale or the beam length of the furnace under study. For small scale reactors operating under oxy-fuel conditions, unmodified WSGGM can be used to predict combustion with good accuracy. The reactor used in this study is small, therefore, unmodified WSGGM was implemented with an expectation that it would not significantly affects the results. Other radiation models could be implemented to test their suitability in modeling oxyfuel environment in small combustion devices. Furthermore, in this study, the heat energy contribution from different sources have not been separated. A detail analysis of heat transfer in the bed could be investigated in a future study.

In this thesis, ash inhibition model was not considered. During the late stage of char combustion ash is produced as one of the products. Mineral matter present in ash act as catalyst in char consumption. This effect is significant at low temperatures. However, at high temperatures 
where heat and mass transfer is significant, ash inhibit char consumption. Ash inhibit char combustion by forming an outer inorganic layer which prevent $\mathrm{O}_{2}$ from reaching the reacting surface. In addition, the effective surface area is reduced since some part of the particle volume is occupied by ash. Consequently, char oxidation and gasification given by reactions $\mathrm{R}(15)$ to $\mathrm{R}(17)$ are not accurately predicted as their reaction rates are expressed in terms of external area. All these ash effects have not been considered in the model used in this study. Therefore, there is a need for consideration of these effects in a future study in order to improve the accuracy of the model.

Validity of the model was checked by comparing mass loss history and temperatures obtained from simulations to corresponding experimental data. Other combustion properties such as flame speed, ignition time, burning rates were determined using mass loss and temperature measurement. The model was used to quantify combustion properties though analysis of wood conversion into char and volatiles and their consumption rates in the bed under different oxidizer concentration and initial bed porosity. The model flame structures in terms of distribution of main gas species along the axial length of the reactor at a given time were used to analyze oxy-fuel combustion conditions. Furthermore, their time histories were also used. The volatiles that were considered in the model used in this work include $\mathrm{CO}, \mathrm{H}_{2}, \mathrm{CH}_{4}$, tar, $\mathrm{H}_{2} \mathrm{O}$ and $\mathrm{CO}_{2}$. These volatiles are generated from drying and pyrolysis of wood. These are endothermic reactions which absorb heat and reduce bed temperature. On the other hand, combustible pyrolysis product such as $\mathrm{CH}_{4}$, tar, $\mathrm{H}_{2}$ and $\mathrm{CO}$ are oxidized through exothermic reaction which generate heat and subsequently increases the temperature. Thus, a well predicted temperature indicates that the amount of volatiles released in the bed are also correctly 
approximated by the model. Despite this assumption, there is need for measurement of the volatiles in order to ensure the validity of the model.

Finally, the presence of $\mathrm{CO}_{2}$ in oxidizer alters gas properties such as density, heat capacity, diffusivity and gas emissivity with consequences on fuel reactivity, flame temperature and emissions. As a result, particulate matter and soot formation in an oxy-fuel environment are not the same as in air-fuel environment. Furthermore, since $\mathrm{N}_{2}$ is replaced by $\mathrm{CO}_{2}$, formation of nitrogen oxides $\left(\mathrm{NO}_{\mathrm{x}}\right)$ is expected to be minimal in an oxy-fuel environment. Indeed, in such environment, $\mathrm{NO}_{\mathrm{x}}$ is only formed through fuel-bound route. Pollutant formation in a fixed bed combustion under oxy-fuel environment is an important aspect which need to be addressed in a future study. 


\section{REFERENCES}

Abrego, J., Atienza-Martínez, M., Plou, F., \& Arauzo, J. (2019). Heat requirement for fixed bed pyrolysis of beechwood chips. Energy, 178, 145-157.

https://doi.org/10.1016/j.energy.2019.04.078

Al-Qurashi, K., Lueking, A. D., \& Boehman, A. L. (2011). The deconvolution of the thermal, dilution, and chemical effects of exhaust gas recirculation (EGR) on the reactivity of engine and flame soot. Combustion and Flame, 158(9), 1696-1704.

https://doi.org/10.1016/j.combustflame.2011.02.006

Álvarez, L., Yin, C., Riaza, J., Pevida, C., Pis, J. J., \& Rubiera, F. (2014). Biomass co-firing under oxy-fuel conditions: A computational fluid dynamics modelling study and experimental validation. Fuel Processing Technology, 120, 22-33.

https://doi.org/10.1016/j.fuproc.2013.12.005

Andersen, J., Jensen, P. A., Meyer, K. E., Hvid, S. L., \& Glarborg, P. (2009). Experimental and numerical investigation of gas-phase freeboard combustion. Part 1: Main combustion process. Energy and Fuels, 23(12), 5773-5782. https://doi.org/10.1021/ef900752a

Andersson, K., \& Johnsson, F. (2007). Flame and radiation characteristics of gas-fired $\mathrm{O}_{2} / \mathrm{CO}_{2}$ combustion. Fuel, 86(5-6), 656-668. https://doi.org/10.1016/j.fuel.2006.08.013

Antal, M. J., \& Varhegyi, G. (1995). Cellulose pyrolysis kinetics: the current state of knowledge. Ind Eng Chem Res, 34, 703-717.

Anthony, D. B., Howard, J. B., Hottel, H. C., \& Meissner, H. P. (1976). Rapid devolatilization and hydrogasification of bituminous coal. Fuel, 55(2), 121-128. https://doi.org/10.1016/0016-2361(76)90008-9 
Balat, M., Balat, M., Kirtay, E., \& Balat, H. (2009a). Main routes for the thermo-conversion of biomass into fuels and chemicals. Part 1: Pyrolysis systems. Energy Conversion and Management, 50(12), 3147-3157. https://doi.org/10.1016/J.ENCONMAN.2009.08.014

Balat, M., Balat, M., Kırtay, E., \& Balat, H. (2009b). Main routes for the thermo-conversion of biomass into fuels and chemicals. Part 2: Gasification systems. Energy Conversion and Management, 50(12), 3158-3168. https://doi.org/10.1016/J.ENCONMAN.2009.08.013

Bautista, J. R., Russel, W. B., \& Seville, D. A. (1986). Time-resolved pyrolysis product distributions of softening coals. Industrial and Engineering Chemistry Fundamentals, 25(4), 536-544. https://doi.org/10.1021/i100024a013

Bejarano, P. A., \& Levendis, Y. A. (2008). Single-coal-particle combustion in $\mathrm{O}_{2} / \mathrm{N}_{2}$ and $\mathrm{O}_{2} / \mathrm{CO}_{2}$ environments. Combustion and Flame, 153(1-2), 270-287. https://doi.org/10.1016/J.COMBUSTFLAME.2007.10.022

Bitra, V. S. P., Womac, A. R., Chevanan, N., Miu, P. I., Igathinathane, C., Sokhansanj, S., \& Smith, D. R. (2009). Direct mechanical energy measures of hammer mill comminution of switchgrass, wheat straw, and corn stover and analysis of their particle size distributions. Powder Technology, 193(1), 32-45. https://doi.org/10.1016/J.POWTEC.2009.02.010

Blevins, L. G., \& Pitts, W. M. (1999). Modeling of bare and aspirated thermocouples in compartment fires. Fire Safety Journal, 33, 239-259.

Borrego, A. G., \& Alvarez, D. (2007). Comparison of chars obtained under oxy-fuel and conventional pulverized coal combustion atmospheres. Energy \& Fuels, 21, 3171-3179. 
Borrego, A. G., Garavaglia, L., \& Kalkreuth, W. D. (2009). Characteristics of high heating rate biomass chars prepared under $\mathrm{N}_{2}$ and $\mathrm{CO}_{2}$ atmospheres. International Journal of Coal Geology, 77(3-4), 409-415. https://doi.org/10.1016/J.COAL.2008.06.004

Branca, C., Giudicianni, P., \& Di Blasi, C. (2003). GC/MS characterization of liquids generated from low-temperature pyrolysis of wood. Ind Eng Chem Res, 42, 3190-3202.

Brezáni, I., \& Zeleňák, F. (2010). Improving the effectivity of work with Rosin-Rammler diagram by using MATLAB R GUI tool. Acta Montanistica Slovaca, 15, 152-157.

Brix, J., Jensen, P. A., \& Jensen, A. D. (2010). Coal devolatilization and char conversion under suspension fired conditions in $\mathrm{O}_{2} / \mathrm{N}_{2}$ and $\mathrm{O}_{2} / \mathrm{CO}_{2}$ atmospheres. Fuel, 89(11), 3373-3380. https://doi.org/10.1016/J.FUEL.2010.03.019

Brohez, S., Delvosalle, C., \& Marlair, G. (2004). A two-thermocouples probe for radiation corrections of measured temperatures in compartment fires. Fire Safety Journal, 39(5), 399-411. https://doi.org/10.1016/J.FIRESAF.2004.03.002

Burcat, A., \& Ruscic, B. (2005). Third millennium ideal gas and condensed phase thermo chemical database for combustion with updates from active thermochemical tables. In Argonne National Laboratory Report No. ANL-05/20 TAE 960. Chicago.

Caballero, J. A., Conesa, J. A., Font, R., \& Marcilla, A. (1997). Pyrolysis kinetics of almond shells and olive stones considering their organic fractions. J Anal Appl Pyrol, 42, 159175.

CD-Adapco. (2017). STAR CCM+ Version 11.04. www.Cd-Adapco.Com.

Cetin, E., Moghtaderi, B., Gupta, R., \& Wall, T. F. (2004). Influence of pyrolysis conditions 
on the structure and gasification reactivity of biomass chars. Fuel, 83(16), 2139-2150. https://doi.org/10.1016/J.FUEL.2004.05.008

Ceylan, İ., Aktaş, M., \& Doğan, H. (2007). Mathematical modeling of drying characteristics of tropical fruits. Applied Thermal Engineering, 27(11-12), 1931-1936. https://doi.org/10.1016/J.APPLTHERMALENG.2006.12.020

Chen, L. (2013). Computational fluid dynamics simulations of oxy-coal combustion for carbon capture at atmosphere and elevated pressures. PhD Thesis, Department of Mechanical Engineering, Massachusetts Institute of Technology.

Chen, L., Yong, S. Z., \& Ghoniem, A. F. (2012). Oxy-fuel combustion of pulverized coal: Characterization, fundamentals, stabilization and CFD modeling. Progress in Energy and Combustion Science, 38(2), 156-214. https://doi.org/10.1016/J.PECS.2011.09.003

Chen, W., Annamalai, K., Ansley, R. J., \& Mirik, M. (2012). Updraft fixed bed gasification of mesquite and juniper wood samples. Energy, 41, 454-461. https://doi.org/10.1016/j.energy.2012.02.052

Chen, Y., \& Sheng, C. (2016). Modeling of a single char particle burning in oxygen-enriched $\mathrm{O}_{2} / \mathrm{N}_{2}$ and $\mathrm{O}_{2} / \mathrm{CO}_{2}$ environment with single film model. Fuel, 184, 905-914. https://doi.org/10.1016/j.fuel.2016.05.003

Chen, Z., Wu, W., \& Agarwal, P. K. (2000). Steam-drying of coal. Part 1. Modeling the behavior of a single particle. Fuel, 79(8), 961-974. https://doi.org/10.1016/S00162361(99)00217-3

Chui, E. H., Majeski, A. J., Douglas, M. A., Tan, Y., \& Thambimuthu, K. V. (2004). 
Numerical investigation of oxy-coal burner and combustor design concepts. Energy, 29, $1285-1296$.

Collazo, J., Porteiro, J., Patiño, D., \& Granada, E. (2012). Numerical modeling of the combustion of densified wood under fixed-bed conditions. Fuel, 93, 149-159. https://doi.org/10.1016/j.fuel.2011.09.044

Comiti, J., \& Renaud, M. (1991). Liquid-solid mass transfer in packed beds of parallelepipedal particles: energetic correlation. Chemical Engineering Science, 46(1), 143-154. https://doi.org/10.1016/0009-2509(91)80124-H

Cooper, J., \& Hallett, W. L. H. (2000). A numerical model for packed-bed combustion of char particles. Chemical Engineering Science, 55(20), 4451-4460. https://doi.org/10.1016/S0009-2509(00)00097-X

Costa, M., Massarotti, N., Indrizzi, V., Rajh, B., Yin, C., \& Samec, N. (2014). Engineering bed models for solid fuel conversion process in grate-fired boilers. Energy, 77, 244-253. https://doi.org/10.1016/j.energy.2014.07.067

Croiset, E., Thambimuthu, K., \& Palmer, A. (2000). Coal combustion in $0_{2} / \mathrm{CO}_{2}$ mixtures compared with air. The Canadian Journal of Chemical Engineering, 78, 402-407.

Dasappa, S., \& Paul, P. J. (2001). Gasification of char particles in packed beds: Analysis and results. International Journal of Energy Research, 25(12), 1053-1072. https://doi.org/10.1002/er.740

Di Blasi, C., Branca, C., Santoro, A., \& Gonzalez Hernandez, E. (2001). Pyrolytic behavior and products of some wood varieties. Combustion and Flame, 124, 165-177. 
Di Blasi, C. (2000). Dynamic behaviour of stratified downdraft gasifiers. Chemical Engineering Science, 55(15), 2931-2944. https://doi.org/10.1016/S0009-2509(99)00562$\mathrm{X}$

Di Blasi, C. (2008). Modeling chemical and physical processes of wood and biomass pyrolysis. Progress in Energy and Combustion Science, 34(1), 47-90. https://doi.org/10.1016/j.pecs.2006.12.001

Djamarani, K., \& Clark, I. M. (1997). Characterization of particle size based on fine and coarse fractions. Powder Technology, 93(2), 101-108. https://doi.org/10.1016/S00325910(97)03233-6

Domenichini, R., Gasparini, F., Cotone, P., \& Santos, S. (2011). Techno-economic evaluation of biomass fired or co-fired power plants with post combustion $\mathrm{CO}_{2}$ capture. Energy Procedia, 4, 1851-1860. https://doi.org/10.1016/j.egypro.2011.02.063

Dosanjh, S. S., Pagni, P. J., \& Fernandez-Pello, A. C. (1987). Forced cocurrent smoldering combustion. Combustion and Flame, 68(2), 131-142. https://doi.org/10.1016/00102180(87)90052-6

Du, D. X., Axelbaum, R. L., \& Law, C. K. (1991). The influence of carbon dioxide and oxygen as additives on soot formation in diffusion flames. Symposium (International) on Combustion, 23(1), 1501-1507. https://doi.org/10.1016/S0082-0784(06)80419-4

Echekki, T., \& Mastorakos, E. (2011). Turbulent combustion modeling: Advances, new trends and perspective. In T. Echekki \& E. Mastorakos (Eds.), Springer. https://doi.org/10.1016/S0360-1285(01)00017-X 
Essenhigh, R. H., Misra, M. K., \& Shaw, D. W. (1989). Ignition of coal particles: A review. Combustion and Flame, 77(1), 3-30. https://doi.org/10.1016/0010-2180(89)90101-6

Evans, D. D., \& Emmons, H. W. (1977). Combustion of wood charcoal. Fire Safety Journal, 1(1), 57-66. https://doi.org/10.1016/0379-7112(77)90008-X

Evans, R. J., \& Milne, T. A. (1997). Chemistry of tar formation and maturation in the thermochemical conversion of biomass. In A. V Bridgwater \& D. G. B. Boocock (Eds.), Developments in thermochemical biomass conversion (pp. 803-816). London: Blackie Academic \& Professional.

Farrow, T. S., Sun, C., \& Snape, C. E. (2013). Impact of biomass char on coal char burn-out under air and oxy-fuel conditions. Fuel, 114, 128-134. https://doi.org/10.1016/j.fuel.2012.07.073

Fatehi, M., \& Kaviany, M. (1994). Adiabatic reverse combustion in a packed bed. Combustion and Flame, 99(1), 1-17. https://doi.org/10.1016/0010-2180(94)90078-7

Fiveland, W. A. (1984). Discrete-ordinates solutions of the radiative transport equation for rectangular enclosures. Journal of Heat Transfer, 106(4), 699-706. https://doi.org/doi:10.1115/1.3246741

Fiveland, W. A. (1988). Three-dimensional radiative heat-transfer solutions by the discreteordinates method. Journal of Thermophysics and Heat Transfer, 2(4), 309-316. https://doi.org/10.2514/3.105

Geier, M., Shaddix, C. R., Davis, K. A., \& Shim, H.-S. (2012). On the use of single-film models to describe the oxy-fuel combustion of pulverized coal char. Applied Energy, 93, 
675-679. https://doi.org/10.1016/J.APENERGY.2011.12.097

Gibbins-Matham, J., \& Kandiyoti, R. (1988). Coal pyrolysis yields from fast and slow heating in a wire-mesh apparatus with a gas sweep. Energy and Fuels, 2(4), 505-511. https://doi.org/10.1021/ef00010a017

Gil, M. V., Riaza, J., Álvarez, L., Pevida, C., Pis, J. J., \& Rubiera, F. (2012a). Kinetic models for the oxy-fuel combustion of coal and coal/biomass blend chars obtained in $\mathrm{N}_{2}$ and $\mathrm{CO}_{2}$ atmospheres. Energy, 48(1), 510-518. https://doi.org/10.1016/j.energy.2012.10.033

Gil, M. V., Riaza, J., Álvarez, L., Pevida, C., Pis, J. J., \& Rubiera, F. (2012b). Oxy-fuel combustion kinetics and morphology of coal chars obtained in $\mathrm{N}_{2}$ and $\mathrm{CO}_{2}$ atmospheres in an entrained flow reactor. Applied Energy, 91(1), 67-74. https://doi.org/10.1016/J.APENERGY.2011.09.017

Gil, M. V., Riaza, J., Álvarez, L., Pevida, C., \& Rubiera, F. (2015). Biomass devolatilization at high temperature under $\mathrm{N}_{2}$ and $\mathrm{CO}_{2}$ : Char morphology and reactivity. Energy, 91, 655-662. https://doi.org/10.1016/j.energy.2015.08.074

Glarborg, P., \& Bentzen, L. L. B. (2008). Chemical effects of a high $\mathrm{CO}_{2}$ concentration in oxy-fuel combustion of methane. Energy and Fuels, 22(1), 291-296. https://doi.org/10.1021/ef7005854

Glaser, M. B., \& Thodos, G. (1958). Heat and momentum transfer in the flow of gases through packed beds. AIChE Journal, 4(1), 63-68. https://doi.org/10.1002/aic.690040113

Goh, Y. R., Lim, C. N., Chan, K. H., Zakaria, R., Reynolds, G., Yang, Y. B., ... Swithenbank, 
J. (1999). Mixing, modelling and measurements of incinerator bed combustion. Second International Symposium on Incineration and Flue Gas Treatment Technology, Sheffield, UK; 4-6 July 1999.

Gómez, M. A., Porteiro, J., de la Cuesta, D., Patiño, D., \& Míguez, J. L. (2016). Numerical simulation of the combustion process of a pellet-drop-feed boiler. Fuel, 184, 987-999. https://doi.org/10.1016/j.fuel.2015.11.082

Gómez, M. A., Porteiro, J., Patiño, D., \& Míguez, J. L. (2014). CFD modelling of thermal conversion and packed bed compaction in biomass combustion. Fuel, 117(PART A), 716-732. https://doi.org/10.1016/j.fuel.2013.08.078

Gonzalo-Tirado, C., \& Jiménez, S. (2015). Accuracy of the single-film model in the prediction of coal char conversion rates under oxy-fuel and conventional combustion conditions. Proceedings of the Combustion Institute, 35(2), 2331-2338. https://doi.org/10.1016/J.PROCI.2014.06.092

Gort, R., \& Brouwers, J. J. H. (2001). Theoretical analysis of the propagation of a reaction front in a packed bed. Combustion and Flame, 124(1-2), 1-13. https://doi.org/10.1016/S0010-2180(00)00149-8

Gubba, S. R., Ma, L., Pourkashanian, M., \& Williams, A. (2011). Influence of particle shape and internal thermal gradients of biomass particles on pulverised coal/biomass co-fired flames. Fuel Processing Technology, 92, 2185-2195.

https://doi.org/10.1016/j.fuproc.2011.07.003

Guo, F., Li, X., Wang, Y., Liu, Y., Li, T., \& Guo, C. (2017). Characterization of Zhundong lignite and biomass co-pyrolysis in a thermogravimetric analyzer and a fixed bed reactor. 
Energy, 141, 2154-2163. https://doi.org/10.1016/j.energy.2017.11.141

Ha, M. Y., \& Choi, B. R. (1994). A numerical study on the combustion of a single carbon particle entrained in a steady flow. Combustion and Flame, 97, 1-16.

Hanaoka, T., Sakanishi, K., \& Okumura, Y. (2012). The effect of $\mathrm{N}_{2} / \mathrm{CO}_{2} / \mathrm{O}_{2}$ content and pressure on characteristics and $\mathrm{CO}_{2}$ gasification behavior of biomass-derived char. Fuel Processing Technology, 104, 287-294. https://doi.org/10.1016/j.fuproc.2012.05.024

Haseli, Y., Oijen, J. A. Van, \& Goey, L. P. H. De. (2011). Bioresource Technology A detailed one-dimensional model of combustion of a woody biomass particle. Bioresource Technology, 102(20), 9772-9782.

Haugen, N. E. L., Mitchell, R. E., \& Tilghman, M. B. (2015). A comprehensive model for char particle conversion in environments containing $\mathrm{O}_{2}$ and $\mathrm{CO}_{2}$. Combustion and Flame, 162(4), 1455-1463. https://doi.org/10.1016/j.combustflame.2014.11.015

Haynes, B. S., \& Wagner, H. G. (1981). Soot formation. Progress in Energy and Combustion Science, 7(4), 229-273. https://doi.org/10.1016/0360-1285(81)90001-0

He, F., \& Behrendt, F. (2011). A new method for simulating the combustion of a large biomass particle - A combination of a volume reaction model and front reaction approximation. Combustion and Flame, 158(12), 2500-2511. https://doi.org/10.1016/j.combustflame.2011.04.016

Henriksen, U., Hindsgaul, C., Qvale, B., Fjellerup, J., \& Jensen, A. D. (2006). Investigation of the anisotropic behavior of wood char particles during gasification. Energy \& Fuels, 20(5), 2233-2238. https://doi.org/10.1021/ef060140f 
Hermansson, S., \& Thunman, H. (2011). CFD modelling of bed shrinkage and channelling in fixed-bed combustion. Combustion and Flame, 158(5), 988-999. https://doi.org/10.1016/J.COMBUSTFLAME.2011.01.022

Heuer, S., Senneca, O., Wütscher, A., Düdder, H., Schiemann, M., Muhler, M., \& Scherer, V. (2016). Effects of oxy-fuel conditions on the products of pyrolysis in a drop tube reactor. Fuel Processing Technology, 150, 41-49. https://doi.org/10.1016/J.FUPROC.2016.04.034

Horttanainen, M., Saastamoinen, J., \& Sarkomaa, P. (2002). Operational limits of ignition front propagation against airflow in packed beds of different wood fuels. Energy and Fuels, 16(3), 676-686. https://doi.org/10.1021/ef010209d

Howard, J. B., \& Essenhigh, R. H. (1967a). Mechanism of solid-partical combustion with simultaneous gas-phase volatiles combustion. Symposium (International) on Combustion, 11(1), 399-408. https://doi.org/10.1016/S0082-0784(67)80164-4

Howard, J. B., \& Essenhigh, R. H. (1967b). Pyrolysis of coal particles. Industrial \& Engineering Chemistry Process Design and Development, 6, 74-84. https://doi.org/10.1021/i260021a013

Huff, E. R. (1985). Effect of size, shape, density, moisture and furnace wall temperature on burning times of wood pieces. Fundamentals of Thermochemical Biomass Conversion, Elsevier, 761-775.

IEA. (2016). World Energy Outlook 2016: Executive Summary. World Energy Outlook, 1-8. https://doi.org/http://www.iea.org/publications/freepublications/publication/WEB_World EnergyOutlook2015ExecutiveSummaryEnglishFinal.pdf 
Incropera, F. P., DeWitt, D. P., Bergman, T. L., \& Lavine, A. S. (2006). Fundamentals of heat and mass transfer (Sixth). John Wiley \& Sons.

Irfan, M. F., Arami-Niya, A., Chakrabarti, M. H., Wan Daud, W. M. A., \& Usman, M. R. (2012). Kinetics of gasification of coal, biomass and their blends in air $\left(\mathrm{N}_{2} / \mathrm{O}_{2}\right)$ and different oxy-fuel $\left(\mathrm{O}_{2} / \mathrm{CO}_{2}\right)$ atmospheres. Energy, 37(1), 665-672. https://doi.org/10.1016/j.energy.2011.10.032

Issa, R. I., Gosman, A. D., \& Watkins, A. P. (1986). The computation of compressible and incompressible recirculating flows by a non-iterative implicit scheme. Journal of Computational Physics, 62(1), 66-82. https://doi.org/10.1016/0021-9991(86)90100-2

Jiménez, S., \& Ballester, J. (2005). Influence of operating conditions and the role of sulfur in the formation of aerosols from biomass combustion. Combustion and Flame, 140, 346358. https://doi.org/10.1016/j.combustflame.2004.12.004

Johansson, R., Andersson, K., Leckner, B., \& Thunman, H. (2010). Models for gaseous radiative heat transfer applied to oxy-fuel conditions in boilers. International Journal of Heat and Mass Transfer, 53(1-3), 220-230.

https://doi.org/10.1016/J.IJHEATMASSTRANSFER.2009.09.039

Johansson, R., Thunman, H., \& Leckner, B. (2007). Influence of intraparticle gradients in modeling of fixed bed combustion. Combustion and Flame, 149(1-2), 49-62. https://doi.org/10.1016/j.combustflame.2006.12.009

Jones, W. P., \& Launder, B. E. (1972). The prediction of laminarization with a two-equation model of turbulence. International Journal of Heat and Mass Transfer, 15(2), 301-314. https://doi.org/10.1016/0017-9310(72)90076-2 
Jones, W. P., \& Lindstedt, R. P. (1988). Global reaction schemes for hydrocarbon combustion. Combustion and Flame, 73(3), 233-249. https://doi.org/10.1016/00102180(88)90021-1

Ju, Y., Masuya, G., \& Ronney, P. D. (1998). Effects of radiative emission and absorption on the propagation and extinction of premixed gas flames. Symposium (International) on Combustion, 27(2), 2619-2626. https://doi.org/10.1016/S0082-0784(98)80116-1

Kangwanpongpan, T. (2013). Contribution to CFD modeling of lignite oxy-fuel combustion with special focus on radiation properties. Doctor of Philosophy at Brandenburg University, Cottubus, Germany, 295.

Khare, S., Wall, T. F., Farida, A. Z., Liu, Y., Moghtaderi, B., \& Gupta, R. P. (2008). Factors influencing the ignition of flames from air-fired swirl pf burners retrofitted to oxy-fuel. Fuel, 87, 1042-1049.

Khatami, R., Stivers, C., Joshi, K., Levendis, Y. A., \& Sarofim, A. F. (2012). Combustion behavior of single particles from three different coal ranks and from sugar cane bagasse in $\mathrm{O}_{2} / \mathrm{N}_{2}$ and $\mathrm{O}_{2} / \mathrm{CO}_{2}$ atmospheres. Combustion and Flame, 159(3), 1253-1271. https://doi.org/10.1016/J.COMBUSTFLAME.2011.09.009

Khodaei, H., Al-Abdeli, Y. M., Guzzomi, F., \& Yeoh, G. H. (2015). An overview of processes and considerations in the modelling of fixed-bed biomass combustion. Energy, 88, 946-972. https://doi.org/10.1016/j.energy.2015.05.099

Khor, A., Ryu, C., Yang, Y. Bin, Sharifi, V. N., \& Swithenbank, J. (2007). Straw combustion in a fixed bed combustor. Fuel, 86(1-2), 152-160. https://doi.org/10.1016/j.fuel.2006.07.006 
Kiga, T., Takano, S., Kimura, N., Omata, K., Okawa, M., Mori, T., \& Kato, M. (1997). Characteristics of pulverized-coal combustion in the system of oxygen/recycled flue gas combustion. Energy Conversion and Management, 38, S129-S134. https://doi.org/10.1016/S0196-8904(96)00258-0

Kijo-Kleczkowska, A., Środa, K., Kosowska-Golachowska, M., Musiał, T., \& Wolski, K. (2016). Combustion of pelleted sewage sludge with reference to coal and biomass. Fuel, 170, 141-160. https://doi.org/10.1016/J.FUEL.2015.12.026

Kimura, N., Omata, K., Kiga, T., Takano, S., \& Shikisima, S. (1995). The characteristics of pulverized coal combustion in $\mathrm{O}_{2} / \mathrm{CO}_{2}$ mixtures for $\mathrm{CO}_{2}$ recovery. Energy Conversion and Management, 36(6-9), 805-808. https://doi.org/10.1016/0196-8904(95)00126-X

Kinoshita, C. M., Wang, Y., \& Zhou, J. (1994). Tar formation under different biomass gasification conditions. J Anal Appl Pyrol, 29, 169-181.

Klason, T., Bai, X. S., Bahador, M., Nilsson, T. K., \& Sundén, B. (2008). Investigation of radiative heat transfer in fixed bed biomass furnaces. Fuel, 87(10-11), 2141-2153. https://doi.org/10.1016/J.FUEL.2007.11.016

Knaus, H., Richter, S., Unterberger, S., Schnell, U., Maier, H., \& Hein, K. R. G. (2000). On the application of different turbulence models for the computation of fluid flow and combustion processes in small scale wood heaters. Experimental Thermal and Fluid Science, 21(1-3), 99-108. https://doi.org/10.1016/S0894-1777(99)00059-X

Ko, G. H., Sanchez, D. M., Peters, W. A., \& Howard, J. B. (1989). Correlations for effects of coal type and pressure on tar yields from rapid devolatilization. Symposium (International) on Combustion, 22(1), 115-124. https://doi.org/10.1016/S0082- 
0784(89)80017-7

La Villetta, M., Costa, M., \& Massarotti, N. (2017). Modelling approaches to biomass gasification: A review with emphasis on the stoichiometric method. Renewable and Sustainable Energy Reviews, 74(January), 71-88.

https://doi.org/10.1016/j.rser.2017.02.027

Lallemant, N., Sayre, A., \& Weber, R. (1996). Evaluation of emissivity correlations for $\mathrm{H}_{2} \mathrm{O}-$ $\mathrm{CO}_{2}-\mathrm{N}_{2} /$ air mixtures and coupling with solution methods of the radiative transfer equation. Progress in Energy and Combustion Science, 22(6), 543-574. https://doi.org/https://doi.org/10.1016/S0360-1285(96)00010-X

Lapuerta, M., Hernández, J. J., Pazo, A., \& López, J. (2008). Gasification and co-gasification of biomass wastes: Effect of the biomass origin and the gasifier operating conditions. Fuel Processing Technology, 89(9), 828-837. https://doi.org/10.1016/J.FUPROC.2008.02.001

Larfeldt, J., Leckner, B., \& Melaaen, M. C. (2000). Modelling and measurements of the pyrolysis of large wood particles. Fuel, 79(13), 1637-1643. https://doi.org/10.1016/S0016-2361(00)00007-7

Launder, B. E., \& Sharma, B. I. (1974). Application of the energy-dissipation model of turbulence to the calculation of flow near a spinning disc. Letters in Heat and Mass Transfer, 1(2), 131-137. https://doi.org/10.1016/0094-4548(74)90150-7

Lee, J. C., Yetter, R. A., \& Dryer, F. L. (1995). Transient numerical modeling of carbon particle ignition and oxidation. Combustion and Flame, 101(4), 387-398. https://doi.org/10.1016/0010-2180(94)00207-9 
Levendis, Y. A., Joshi, K., Khatami, R., \& Sarofim, A. F. (2011). Combustion behavior in air of single particles from three different coal ranks and from sugarcane bagasse. Combustion and Flame, 158(3), 452-465. https://doi.org/10.1016/J.COMBUSTFLAME.2010.09.007

Li, X., Rathnam, R. K., Yu, J., Wang, Q., Wall, T., \& Meesri, C. (2010). Pyrolysis and combustion characteristics of an indonesian low-rank coal under $\mathrm{O}_{2} / \mathrm{N}_{2}$ and $\mathrm{O}_{2} / \mathrm{CO}_{2}$ conditions. Energy and Fuels, 24(1), 160-164. https://doi.org/10.1021/ef900533d

Lienhard IV, J. H., \& Lienhard V, J. H. (2003). A heat transfer textbook (Third). Cambridge, Massachusetts, U.S.A: Phlogiston Press.

Liu, F., Guo, H., \& Smallwood, G. J. (2003). The chemical effect of $\mathrm{CO}_{2}$ replacement of $\mathrm{N}_{2}$ in air on the burning velocity of $\mathrm{CH}_{4}$ and $\mathrm{H}_{2}$ premixed flames. Combustion and Flame, 133(4), 495-497. https://doi.org/10.1016/S0010-2180(03)00019-1

Liu, F., Guo, H., Smallwood, G. J., \& Gülder, Ö. L. (2001). The chemical effects of carbon dioxide as an additive in an ethylene diffusion flame: Implications for soot and $\mathrm{NO}_{\mathrm{x}}$ formation. Combustion and Flame, 125(1-2), 778-787. https://doi.org/10.1016/S00102180(00)00241-8

Liu, H., Zailani, R., \& Gibbs, B. M. (2005a). Comparisons of pulverized coal combustion in air and in mixtures of $\mathrm{O}_{2} / \mathrm{CO}_{2}$. Fuel, 84(7-8), 833-840. https://doi.org/10.1016/J.FUEL.2004.11.018

Liu, H., Zailani, R., \& Gibbs, B. M. (2005b). Pulverized coal combustion in air and in $\mathrm{O}_{2} / \mathrm{CO}_{2}$ mixtures with $\mathrm{NO}_{\mathrm{x}}$ recycle. Fuel, 84(16), 2109-2115. https://doi.org/10.1016/J.FUEL.2005.04.028 
Liu, Y., Geier, M., Molina, A., \& Shaddix, C. R. (2011). Pulverized coal stream ignition delay under conventional and oxy-fuel combustion conditions. International Journal of Greenhouse Gas Control, 5, S36-S46. https://doi.org/10.1016/J.IJGGC.2011.05.028

Loo, S. van, \& Koppejan, J. (Eds.). (2008). The handbook of biomass combustion and cofiring. London: Earthscan.

Lu, H., Ip, E., Scott, J., Foster, P., Vickers, M., \& Baxter, L. L. (2010). Effects of particle shape and size on devolatilization of biomass particle. Fuel, 89(5), 1156-1168. https://doi.org/10.1016/J.FUEL.2008.10.023

Maffei, T., Khatami, R., Pierucci, S., Faravelli, T., Ranzi, E., \& Levendis, Y. A. (2013). Experimental and modeling study of single coal particle combustion in $\mathrm{O}_{2} / \mathrm{N}_{2}$ and oxyfuel $\left(\mathrm{O}_{2} / \mathrm{CO}_{2}\right)$ atmospheres. Combustion and Flame, 160(11), 2559-2572. https://doi.org/10.1016/j.combustflame.2013.06.002

Mahapatra, S. (2016). Experiments and analysis on wood gasification in an open top downdraft gasifier. PhD Thesis, Faculty of Engineering, Centre for Sustainable Technologies, Indian Institute of Science Bangalore, India.

Mahapatra, S., Kumar, S., \& Dasappa, S. (2016). Gasification of wood particles in a cocurrent packed bed: Experiments and model analysis. Fuel Processing Technology, 145, 76-89. https://doi.org/10.1016/j.fuproc.2016.01.032

Mahmoudi, A. H., Hoffmann, F., Markovic, M., Peters, B., \& Brem, G. (2016). Numerical modeling of self-heating and self-ignition in a packed-bed of biomass using XDEM. Combustion and Flame, 163, 358-369. https://doi.org/10.1016/j.combustflame.2015.10.010 
Mahmoudi, A. H., Hoffmann, F., \& Peters, B. (2016). Semi-resolved modeling of heat-up, drying and pyrolysis of biomass solid particles as a new feature in XDEM. Applied Thermal Engineering, 93, 1091-1104.

https://doi.org/10.1016/j.applthermaleng.2015.10.033

Mahmoudi, A. H., Markovic, M., Peters, B., \& Brem, G. (2015). An experimental and numerical study of wood combustion in a fixed bed using Euler-Lagrange approach (XDEM). Fuel, 150, 573-582. https://doi.org/10.1016/j.fuel.2015.02.008

Malinin, D. R., \& Yoe, J. H. (1961). Development of the laws of colorimetry: A historical sketch. J. Chem. Educ., 38(3), 129-131. https://doi.org/https://doi.org/10.1021/ed038p129

Martínez, J. D., Mahkamov, K., Andrade, R. V., \& Silva Lora, E. E. (2012). Syngas production in downdraft biomass gasifiers and its application using internal combustion engines. Renewable Energy, 38(1), 1-9. https://doi.org/10.1016/J.RENENE.2011.07.035

Masri, A. R., Dibble, R. W., \& Barlow, R. S. (1992). Chemical kinetic effects in nonpremixed flames of $\mathrm{H}_{2} / \mathrm{CO}_{2}$ fuel. Combustion and Flame, 91(3-4), 285-309. https://doi.org/10.1016/0010-2180(92)90059-X

Mathekga, H. I., Oboirien, B. O., \& North, B. C. (2016). A review of oxy-fuel combustion in fluidized bed reactors. International Journal of Energy Research, 40, 878-902. https://doi.org/10.1002/er

McLintock, I. S. (1968). The effect of various diluents on soot production in laminar ethylene diffusion flames. Combustion and Flame, 12(3), 217-225. https://doi.org/10.1016/00102180(68)90018-7 
Mehrabian, R. (2013). CFD simulation of the thermal conversion of solid biomass in packed bed furnaces. PhD Thesis, the Institute for Process and Particle Engineering, Graz University of Technology.

Mehrabian, R., Shiehnejadhesar, A., Scharler, R., \& Obernberger, I. (2014). Multi-physics modelling of packed bed biomass combustion. Fuel, 122, 164-178. https://doi.org/10.1016/j.fuel.2014.01.027

Meier, D., Oasmaa, A., \& Peacocke, G. V. C. (1997). Properties of fast pyrolysis liquids: status of test methods. In A. V. Bridgwater \& D. G. B. Boocock (Eds.), Developments in thermochemical biomass conversion (pp. 391-408). London: Blackie Academic \& Professional.

Melgar, A., Pérez, J. F., Laget, H., \& Horillo, A. (2007). Thermochemical equilibrium modelling of a gasifying process. Energy Conversion and Management, 48(1), 59-67. https://doi.org/10.1016/J.ENCONMAN.2006.05.004

Meng, X., Sun, R., Ismail, T. M., Zhou, W., Ren, X., \& Zhang, R. (2018). Parametric studies on corn straw combustion characteristics in a fixed bed: Ash and moisture content. Energy, 158, 192-203. https://doi.org/10.1016/j.energy.2018.06.060

Mitchell, R. E., Kee, R. J., Glarborg, P., \& Coltrin, M. E. (1991). The effect of CO conversion in the boundary layers surrounding pulverized-coal char particles. Symposium (International) on Combustion, 23(1), 1169-1176. https://doi.org/10.1016/S00820784(06)80377-2

Molina, A., \& Shaddix, C. R. (2007). Ignition and devolatilization of pulverized bituminous coal particles during oxygen/carbon dioxide coal combustion. Proceedings of the 
Combustion Institute, 31, 1905-1912. https://doi.org/10.1016/j.proci.2006.08.102

Morf, P., Hasler, P., \& Nussbaumer, T. (2002). Mechanisms and kinetics of homogeneous secondary reactions of tar from continuous pyrolysis of wood chips. Fuel, 81, 843-853.

Nakayama, S., Noguchi, Y., Kiga, T., Miyamae, S., Maeda, U., Kawai, M., ... Makino, H. (1992). Pulverized coal combustion in $\mathrm{O}_{2} / \mathrm{CO}_{2}$ mixtures on a power plant for $\mathrm{CO}_{2}$ recovery. Energy Conversion and Management, 33(5-8), 379-386. https://doi.org/10.1016/0196-8904(92)90034-T

Naredi, P., \& Pisupati, S. (2011). Effect of $\mathrm{CO}_{2}$ during coal pyrolysis and char burnout in oxy-coal combustion. Energy and Fuels, 25(6), 2452-2459. https://doi.org/10.1021/ef200197w

Niu, S., Han, K., \& Lu, C. (2011). Characteristic of coal combustion in oxygen/carbon dioxide atmosphere and nitric oxide release during this process. Energy Conversion and Management, 52(1), 532-537. https://doi.org/10.1016/J.ENCONMAN.2010.07.028

Nozaki, T., Takano, S., Kiga, T., Omata, K., \& Kimura, N. (1997). Analysis of the flame formed during oxidation of pulverized coal by an $\mathrm{O}_{2} / \mathrm{CO}_{2}$ mixture. Energy, 22(2-3), 199-205. https://doi.org/10.1016/S0360-5442(96)00143-0

Padban, N., Wang, W., Ye, Z., Bjerle, I., \& Odenbrand, I. (2000). Tar formation in pressurized fluidized bed air gasification of woody biomass. Energy \& Fuels, 14, 603611.

Park, R. M., Carroll, R. M., Bliss, P., Burns, G. W., Desmaris, R. R., Hall, F. B., ... Wang, T. P. (1993). MNL12-4TH - Manual on the Use of Thermocouples in Temperature 
Measurement : 4th Edition (Fourth Edi). https://doi.org/https://doi.org/10.1520/MNL124TH-EB

Park, S., Kim, J. A., Ryu, C., Yang, W., Kim, Y. J., \& Seo, S. (2012). Effects of gas and particle emissions on wall radiative heat flux in oxy-fuel combustion. Journal of Mechanical Science and Technology, 26(5), 1633-1641. https://doi.org/10.1007/s12206012-0324-8

Pattanotai, T., Watanabe, H., \& Okazaki, K. (2015). Effects of particle aspect ratio on pyrolysis and gasification of anisotropic wood cylinder. Fuel, 150, 162-168. https://doi.org/10.1016/J.FUEL.2015.02.017

Payne, R., Chen, S. L., Wolsky, A. M., \& Richter, W. F. (1989). CO 2 recovery via coal combustion in mixtures of oxygen and recycled flue gas. Combustion Science and Technology, 67(1-3), 1-16. https://doi.org/10.1080/00102208908924058

Peleg, M. (1996). Determination of the parameters of the Rosin-Rammler and beta distributions from their mode and variance using equation-solving software. Powder Technology, 87(2), 181-184. https://doi.org/10.1016/0032-5910(95)03073-5

Pérez, J. F., Melgar, A., \& Tinaut, F. V. (2014). Modeling of fixed bed downdraft biomass gasification: Application on lab-scale and industrial reactors. International Journal of Energy Research, 38, 319-338. https://doi.org/10.1002/er

Peters, B. (2002). Measurements and application of a discrete particle model (DPM) to simulate combustion of a packed bed of individual fuel particles conversion of particles. Combustion and Flame, 146, 132-146. 
Piskorz, J., Majerski, P., Radlein, D., Scott, D. S., \& Bridgwater, A. V. (1998). Fast pyrolysis of sweet sorghum and sweet sorghum bagasse. J Anal Appl Pyrol, 46, 15-29.

Plis, P., \& Wilk, R. K. (2011). Theoretical and experimental investigation of biomass gasification process in a fixed bed gasifier. Energy, 36, 3838-3845. https://doi.org/10.1016/j.energy.2010.08.039

Pohlmann, J. G., Osório, E., Vilela, A. C. F., Diez, M. A., \& Borrego, A. G. (2017). Pulverized combustion under conventional $\left(\mathrm{O}_{2} / \mathrm{N}_{2}\right)$ and oxy-fuel $\left(\mathrm{O}_{2} / \mathrm{CO}_{2}\right)$ conditions of biomasses treated at different temperatures. Fuel Processing Technology, 155, 174-182. https://doi.org/10.1016/j.fuproc.2016.05.025

Pohlmann, J. G., Vilela, A. C. F., \& Borrego, A. G. (2010). Reactivity to $\mathrm{CO}_{2}$ of chars prepared in $\mathrm{O}_{2} / \mathrm{N}_{2}$ and $\mathrm{O}_{2} / \mathrm{CO}_{2}$ mixtures for pulverized coal injection (PCI) in blast furnace in relation to char petrographic characteristics. International Journal of Coal Geology, 84(3-4), 293-300. https://doi.org/10.1016/J.COAL.2010.10.008

Ponzio, A., Senthoorselvan, S., Yang, W., Blasiak, W., \& Eriksson, O. (2008). Ignition of single coal particles in high-temperature oxidizers with various oxygen concentrations. Fuel, 87(6), 974-987. https://doi.org/10.1016/J.FUEL.2007.06.027

Porteiro, J., Granada, E., Collazo, J., Patiño, D., \& Morán, J. C. (2007). A model for the combustion of large particles of densified wood. Energy \& Fuels, 21(6), 3151-3159. https://doi.org/10.1021/ef0701891

Porteiro, J., Patiño, D., Collazo, J., Granada, E., Moran, J., \& Miguez, J. L. (2010). Experimental analysis of the ignition front propagation of several biomass fuels in a fixed-bed combustor. Fuel, 89(1), 26-35. https://doi.org/10.1016/J.FUEL.2009.01.024 
Pyle, D. L., \& Zaror, C. A. (1984). Heat transfer and kinetics in the low temperature pyrolysis of solids. Chem Eng Sci, 19, 147-158.

Rashidian, B., Al-Abdeli, Y. M., Yeoh, G. H., Patiño, D., \& Guzzomi, F. (2017). Methodologies for processing fixed bed combustor data. Combustion Science and Technology, 189(1), 79-102. https://doi.org/10.1080/00102202.2016.1193497

Rathnam, R. K., Elliott, L. K., Wall, T. F., Liu, Y., \& Moghtaderi, B. (2009). Differences in reactivity of pulverised coal in air $\left(\mathrm{O}_{2} / \mathrm{N}_{2}\right)$ and oxy-fuel $\left(\mathrm{O}_{2} / \mathrm{CO}_{2}\right)$ conditions. Fuel Processing Technology, 90(6), 797-802. https://doi.org/10.1016/J.FUPROC.2009.02.009

Riaza, J., Álvarez, L., Gil, M. V., Pevida, C., Pis, J. J., \& Rubiera, F. (2011). Effect of oxyfuel combustion with steam addition on coal ignition and burnout in an entrained flow reactor. Energy, 36(8), 5314-5319. https://doi.org/10.1016/J.ENERGY.2011.06.039

Riaza, J., Gil, M. V., Álvarez, L., Pevida, C., Pis, J. J., \& Rubiera, F. (2012). Oxy-fuel combustion of coal and biomass blends. Energy, 41(1), 429-435. https://doi.org/10.1016/J.ENERGY.2012.02.057

Riaza, Juan, Khatami, R., Levendis, Y. A., Álvarez, L., Gil, M. V., Pevida, C., ... Pis, J. J. (2014). Combustion of single biomass particles in air and in oxy-fuel conditions. Biomass and Bioenergy, 64, 162-174. https://doi.org/10.1016/j.biombioe.2014.03.018

Roberts, I. L., Coney, J. E. R., \& Gibbs, B. M. (2011). Estimation of radiation losses from sheathed thermocouples. Applied Thermal Engineering, 31(14-15), 2262-2269. https://doi.org/10.1016/j.applthermaleng.2011.03.020

Rönnbäck, M., Axell, M., Gustavsson, L., Thunman, H., \& Lecher, B. (2008). Combustion 
processes in a biomass fuel bed-experimental results. Progress in Thermochemical Biomass Conversion, 743-757. https://doi.org/10.1002/9780470694954.ch59

Ruan, J., Kobayashi, H., Niioka, T., \& Ju, Y. (2001). Combined effects of nongray radiation and pressure on premixed $\mathrm{CH}_{4} / \mathrm{O}_{2} / \mathrm{CO}_{2}$ flames. Combustion and Flame, 124(1-2), 225230. https://doi.org/10.1016/S0010-2180(00)00198-X

Ruiz Celma, A., Rojas, S., \& Lopez-Rodríguez, F. (2008). Mathematical modelling of thinlayer infrared drying of wet olive husk. Chemical Engineering and Processing: Process Intensification, 47(9-10), 1810-1818. https://doi.org/10.1016/J.CEP.2007.10.003

Ryan, J. S., \& Hallett, W. L. H. (2002). Packed bed combustion of char particles: Experiments and an ash model. Chemical Engineering Science, 57(18), 3873-3882. https://doi.org/10.1016/S0009-2509(02)00235-X

Ryu, C., Yang, Y. Bin, Khor, A., Yates, N. E., Sharifi, V. N., \& Swithenbank, J. (2006). Effect of fuel properties on biomass combustion: Part I. Experiments - fuel type, equivalence ratio and particle size. Fuel, 85, 1039-1046. https://doi.org/10.1016/j.fuel.2005.09.019

Saastamoinen, J. J., \& Taipale, R. (2000). Propagation of the ignition front in beds of wood particles. Combustion and Flame, 123, 214-226.

Sakthivadivel, D., \& Iniyan, S. (2018). Characterization, density and size effects of fuels in an advanced micro-gasifier stove. Biofuels. https://doi.org/10.1080/17597269.2018.1426163

Sander, A. (2007). Thin-layer drying of porous materials: Selection of the appropriate 
mathematical model and relationships between thin-layer models parameters. Chemical Engineering and Processing: Process Intensification, 46(12), 1324-1331. https://doi.org/10.1016/J.CEP.2006.11.001

Scheffknecht, G., Al-Makhadmeh, L., Schnell, U., \& Maier, J. (2011). Oxy-fuel coal combustion - A review of the current state-of-the-art. International Journal of Greenhouse Gas Control, 5(SUPPL. 1), 16-35. https://doi.org/10.1016/j.ijggc.2011.05.020

Schug, K. P., Manheimer-Timnat, Y., Yaccarinc, P., \& Glassman, I. (1980). Sooting behavior of gaseous hydrocarbon diffusion flames and the influence of additives. Combustion Science and Technology, 22(5-6), 235-250. https://doi.org/10.1080/00102208008952387

Scott, D. S., Piskorz, J., Bergougnou, M. A., Graham, R., \& Overend, R. P. (1988). The role of temperature in the fast pyrolysis of cellulose and wood. Ind Eng Chem Res, 27, 8-15.

Serio, M. A., Hamblen, D. G., Markham, J. R., \& Solomon, P. R. (1987). Kinetics of volatile product evolution in coal pyrolysis: Experiment and theory. Energy and Fuels, 1(2), 138-152. https://doi.org/10.1021/ef00002a002

Shaddix, C. R., \& Molina, A. (2009). Particle imaging of ignition and devolatilization of pulverized coal during oxy-fuel combustion. Proceedings of the Combustion Institute, 32(2), 2091-2098. https://doi.org/10.1016/J.PROCI.2008.06.157

Shafizadeh, F. (1985). Pyrolytic reactions and products of biomass. In R. P. Overend, T. A. Milne, \& L. K. Mudge (Eds.), Fundamentals of biomass thermochemical conversion (pp. 183-217.). London: Elsevier. 
Shan, F., Lin, Q., Zhou, K., Wu, Y., Fu, W., Zhang, P., ... Yi, B. (2017). An experimental study of ignition and combustion of single biomass pellets in air and oxy-fuel. Fuel, 188, 277-284. https://doi.org/10.1016/j.fuel.2016.09.069

Shin, D., \& Choi, S. (2000). The combustion of simulated waste particles in a fixed bed. Combustion and Flame, 121(1-2), 167-180. https://doi.org/10.1016/S00102180(99)00124-8

Shur, M. L., Spalart, P. R., Strelets, M. K., \& Travin, A. K. (2008). A hybrid RANS-LES approach with delayed-DES and wall-modelled LES capabilities. International Journal of Heat and Fluid Flow, 29(6), 1638-1649.

https://doi.org/10.1016/J.IJHEATFLUIDFLOW.2008.07.001

Smart, J. P., O’Nions, P., \& Riley, G. S. (2010). Radiation and convective heat transfer, and burnout in oxy-coal combustion. Fuel, 89(9), 2468-2476. https://doi.org/10.1016/J.FUEL.2010.03.048

Smart, J. P., O’Nions, P., Riley, G. S., \& Jamieson, E. (2009). Radiation and convection heat transfer in oxyfuel combustion. 1st IEA Oxyfuel Combustion Conference, Cottbus., 2009.

Smith, G. P., Golden, D. M., Frenklach, M., Moriarty, N. W., Eiteneer, B., Goldenberg, M., ... Qin, Z. (1999). GRI-Mech 3.0. Retrieved July 13, 2018, from http://combustion.berkeley.edu/gri-mech/version30/text30.html

Smith, T. F., Shen, Z. F., \& Friedman, J. N. (1982). Evaluation of coefficients for the weighted sum of gray gases model. Journal of Heat Transfer, 104(4), 602-608. https://doi.org/10.1115/1.3245174 
Suda, T., Masuko, K., Sato, J., Yamamoto, A., \& Okazaki, K. (2007). Effect of carbon dioxide on flame propagation of pulverized coal clouds in $\mathrm{CO}_{2} / \mathrm{O}_{2}$ combustion. Fuel, 86(12-13), 2008-2015. https://doi.org/10.1016/j.fuel.2006.11.038

Suuberg, E. M., Peters, W. A., \& Howard, J. B. (1980). Product compositions in rapid hydropyrolysis of coal. Fuel, 59(6), 405-412. https://doi.org/10.1016/00162361(80)90193-3

Tan, Y., Croiset, E., Douglas, M. A., \& Thambimuthu, K. V. (2006). Combustion characteristics of coal in a mixture of oxygen and recycled flue gas. Fuel, 85(4), 507512. https://doi.org/10.1016/J.FUEL.2005.08.010

The British Standards Institution. (2010). BS EN 15149-2:2010: Solid biofuels. Determination of particle size distribution. Vibrating screen method using sieve apertures of 3,15 $\mathrm{mm}$ and below. The British Standards Institution.

Thunman, H., Leckner, B., Niklasson, F., \& Johnsson, F. (2002). Combustion of wood particles - A particle model for Eulerian calculations. Combustion and Flame, 129(1-2), 30-46. https://doi.org/10.1016/S0010-2180(01)00371-6

Thunman, Henrik, \& Leckner, B. (2005). Influence of size and density of fuel on combustion in a packed bed. Proceedings of the Combustion Institute, 30(2), 2939-2946. https://doi.org/10.1016/J.PROCI.2004.07.010

Tinaut, F. V., Melgar, A., Pérez, J. F., \& Horrillo, A. (2008). Effect of biomass particle size and air superficial velocity on the gasification process in a downdraft fixed bed gasifier. An experimental and modelling study. Fuel Processing Technology, 89(11), 1076-1089. https://doi.org/10.1016/J.FUPROC.2008.04.010 
Toftegaard, M. B., Brix, J., Jensen, P. A., Glarborg, P., \& Jensen, A. D. (2010). Oxy-fuel combustion of solid fuels. Progress in Energy and Combustion Science, 36(5), 581-625. https://doi.org/10.1016/J.PECS.2010.02.001

Tolvanen, H., \& Raiko, R. (2014). An experimental study and numerical modeling of combusting two coal chars in a drop-tube reactor: A comparison between $\mathrm{N}_{2} / \mathrm{O}_{2}, \mathrm{CO}_{2} / \mathrm{O}_{2}$, and $\mathrm{N}_{2} / \mathrm{CO}_{2} / \mathrm{O}_{2}$ atmospheres. Fuel, 124, 190-201. https://doi.org/10.1016/J.FUEL.2014.01.103

Toporov, D., Bocian, P., Heil, P., Kellermann, A., Stadler, H., Tschunko, S., \& Al., E. (2008). Detailed investigation of a pulverized fuel swirl flame in $\mathrm{CO}_{2} / \mathrm{O}_{2}$ atmosphere. Combustion and Flame, 155, 605-618.

Topuz, A., Gur, M., \& Gul, M. Z. (2004). An experimental and numerical study of fluidized bed drying of hazelnuts. Applied Thermal Engineering, 24(10), 1535-1547. https://doi.org/10.1016/J.APPLTHERMALENG.2003.11.020

Trudel, É., \& Hallett, W. (2017). Pressure drop in packed beds of angular parallelepipeds, including the effects of particle interference. Chemical Engineering Science, 162, 209217. https://doi.org/10.1016/J.CES.2017.01.004

Trudel, É., Hallett, W. L. H., Wiens, E., Neil, J. D. O., Busigin, M. K., \& Berdusco, D. (2018). Fuel particle shape effects in the packed bed combustion of wood. Combustion and Flame, 198, 100-111. https://doi.org/10.1016/j.combustflame.2018.09.006

van Kuijk, H. A. J. A. (2008). Grate furnace combustion: A submodel for the solid fuel layer. PhD Thesis, Technische Universiteit Eindhoven. https://doi.org/10.1615/intjmultcompeng.v6.i1.90 
Varhegyi, G., Gronli, M. G., \& Di Blasi, C. (2004). Effects of sample origin, extraction and hot water washing on the devolatilization kinetics of chestnut wood. Ind Eng Chem Res, 43, 2356-2367.

Varhegyi, G., Szabo, P., \& Antal, M. J. (1994). Reaction kinetics of the thermal decomposition of cellulose and hemicellulose in biomass materials. In A. V. Bridgwater (Ed.), Advances in thermochemical biomass conversion (pp. 760-771). London: Blackie Academic \& Professional.

Varunkumar, S. (2012). Packed bed gasification - combustion in biomass based domestic stoves and combustion systems. PhD Thesis, Faculty of Engineering, Department of Aerospace Engineering Indian Institute of Science Bangalore - 560012 (INDIA).

Villermaux, J., Antoine, B., Lede, J., \& Soulignac, F. (1986). A new model for thermal volatilization of solid particles undergoing fast pyrolysis. Chemical Engineering Science, 41(1), 151-157. https://doi.org/10.1016/0009-2509(86)85208-3

Wang, C., Zhang, X., Liu, Y., \& Che, D. (2012). Pyrolysis and combustion characteristics of coals in oxyfuel combustion. Applied Energy, 97, 264-273. https://doi.org/10.1016/J.APENERGY.2012.02.011

Wang, G., Zander, R., \& Costa, M. (2014). Oxy-fuel combustion characteristics of pulverized coal in a drop tube furnace. Fuel, 115, 452-460. https://doi.org/10.1016/j.fuel.2013.07.063

Wang, H. H. (2007). Kinetic analysis of dehydration of a bituminous coal using the TGA technique. Energy and Fuels, 21(6), 3070-3075. https://doi.org/10.1021/ef070170y 
Wehinger, G. D. (2016). Particle-resolved CFD simulations of catalytic flow reactors. $P h D$ Thesis, Technischen Universität Berlin.

Westbrook, C. K., \& Dryer, F. L. (1981). Simplified reaction mechanisms for the oxidation of hydrocarbon fuels in flames. Combustion Science and Technology, 27, 31-43.

Westbrook, C. K., \& Dryer, F. L. (1984). Chemical kinetic modeling of hydrocarbon combustion. Progress in Energy and Combustion Science, 10(1), 1-57. https://doi.org/10.1016/0360-1285(84)90118-7

Whitaker, S. (1972). Forced convection heat transfer correlations for flow in pipes, past flat plates, single cylinders, single spheres, and for flow in packed beds and tube bundles. AIChE Journal, 18(2), 361-371. https://doi.org/10.1002/aic.690180219

Wijayanta, A. T., Saiful Alam, M., Nakaso, K., Fukai, J., \& Shimizu, M. (2012). Optimized combustion of biomass volatiles by varying $\mathrm{O}_{2}$ and $\mathrm{CO}_{2}$ levels: A numerical simulation using a highly detailed soot formation reaction mechanism. Bioresource Technology, 110, 645-651. https://doi.org/10.1016/j.biortech.2012.01.068

Williams, O., Newbolt, G., Eastwick, C., Kingman, S., Giddings, D., Lormor, S., \& Lester, E. (2016). Influence of mill type on densified biomass comminution. Applied Energy, 182, 219-231. https://doi.org/10.1016/j.apenergy.2016.08.111

Wurzenberger, J. C., Wallner, S., Raupenstrauch, H., \& Khinast, J. G. (2002). Thermal conversion of biomass: Comprehensive reactor and particle modeling. AIChE Journal, 48(10), 2398-2411. https://doi.org/10.1002/aic.690481029

Yahaya, A. Z., Somalu, M. R., Muchtar, A., Sulaiman, S. A., \& Daud, W. R. W. (2019). 
Effect of particle size and temperature on gasification performance of coconut and palm kernel shells in downdraft fixed-bed reactor. Energy, 175, 931-940. https://doi.org/10.1016/j.energy.2019.03.138

Yang, Y. B., Ryu, C., Khor, A., Yates, N. E., Sharifi, V. N., \& Swithenbank, J. (2005). Effect of fuel properties on biomass combustion. Part II. Modelling approach -identification of the controlling factors. Fuel, 84(16), 2116-2130. https://doi.org/10.1016/J.FUEL.2005.04.023

Yang, Y.B., Ryu, C., Sharifi, V. N., \& Swithenbank, J. (2006). Effect of model and operating parameters on air gasification of char. Energy \& Fuels 2006, 20, 1698-1708. https://doi.org/10.1016/S0009

Yang, Y.B., Sharifi, V. N., \& Swithenbank, J. (2004). Effect of air flow rate and fuel moisture on the burning behaviours of biomass and simulated municipal solid wastes in packed beds. Fuel, 83(11-12), 1553-1562. https://doi.org/10.1016/J.FUEL.2004.01.016

Yang, Y. B., Goh, Y. R., Zakaria, R., Nasserzadeh, V., \& Swithenbank, J. (2002). Mathematical modelling of MSW incineration on a travelling bed. Waste Management, 22(4), 369-380. https://doi.org/10.1016/S0956-053X(02)00019-3

Yang, Y. B., Ryu, C., Khor, A., Sharifi, V. N., \& Swithenbank, J. (2005). Fuel size effect on pinewood combustion in a packed bed. Fuel, 84(16), 2026-2038. https://doi.org/10.1016/j.fuel.2005.04.022

Yang, Y. B., Yamauchi, H., Nasserzadeh, V., \& Swithenbank, J. (2003). Effects of fuel devolatilisation on the combustion of wood chips and incineration of simulated municipal solid wastes in a packed bed. Fuel, 82(18), 2205-2221. 
https://doi.org/10.1016/S0016-2361(03)00145-5

Yin, C. (2012). nongray-gas effects in modeling of large-scale oxy-fuel combustion processes. Energy \& Fuels, 26, 3349-3356.

Yin, C., Johansen, L. C. R., Rosendahl, L. A., \& Kær, S. K. (2010). New weighted sum of gray gases model applicable to computational fluid dynamics (CFD) modeling of oxyfuel combustion: Derivation, validation, and implementation. Energy \& Fuels, 24(12), 6275-6282. https://doi.org/10.1021/ef101211p

Yuzbasi, N. S., \& Selçuk, N. (2011). Air and oxy-fuel combustion characteristics of biomass/lignite blends in TGA-FTIR. Fuel Processing Technology, 92(5), 1101-1108. https://doi.org/10.1016/J.FUPROC.2011.01.005

Zakaria, R., Goh, Y., Yang, Y., Lim, C., Goodfellow, J., Chan, K., ... Swithenbank, J. (2000). Reduction of NOx emission from the burning bed in a municipal solid waste incinerator. Fifth European Conference on Industrial Furnaces and Boilers, Espinho-PortoPortugal; 11-14 April 2000.

Zhou, H., Jensen, A. D., Glarborg, P., Jensen, P. A., \& Kavaliauskas, A. (2005). Numerical modeling of straw combustion in a fixed bed. Fuel, 84(4), 389-403. https://doi.org/10.1016/J.FUEL.2004.09.020

Zhou, K., Lin, Q., Hu, H., Hu, H., \& Song, L. (2016). The ignition characteristics and combustion processes of the single coal slime particle under different hot-coflow conditions in $\mathrm{N}_{2} / \mathrm{O}_{2}$ atmosphere. Energy, 136, 173-184.

https://doi.org/10.1016/j.energy.2016.02.038 
Zhou, Y., Jin, X., \& Jin, Q. (2016). Numerical investigation on separate physicochemical effects of carbon dioxide on coal char combustion in $\mathrm{O}_{2} / \mathrm{CO}_{2}$ environments. Combustion and Flame, 167, 52-59. https://doi.org/10.1016/j.combustflame.2016.02.028

Zhu, D. L., Egolfopoulos, F. N., \& Law, C. K. (1989). Experimental and numerical determination of laminar flame speeds of methane/( $\left.\mathrm{Ar}, \mathrm{N}_{2}, \mathrm{CO}_{2}\right)$-air mixtures as function of stoichiometry, pressure, and flame temperature. Symposium (International) on Combustion, 22(1), 1537-1545. https://doi.org/10.1016/S0082-0784(89)80164-X 


\section{APPENDIX A}

\section{ROSIN-RAMMLER DISTRIBUTION FUNCTION}

Rosin-Rammler distribution function, Eq. (A.1), was originally developed for characterization of powdered coal (Williams et al., 2016). However, it has found application in many materials, (Djamarani \& Clark, 1997) including biomass particles (Bitra et al., 2009; Gil et al., 2012b). It is a good method for particles obtained through comminution; various types of crushing, grinding and milling.

$$
R_{R}(d)=100\left(\exp \left(-\frac{d}{\bar{d}}\right)^{n_{R}}\right)
$$

where $d$ is the particle diameter or mesh size, $\bar{d}$ is the characteristic size, $n_{R}$ is the parameter of Rosin-Rammler distribution and $R_{R}$ is the percentage of accumulated oversize mass. $n_{R}$ was determined according to Brezáni and Zeleňák (2010).

Even though parameter $n_{R}$ and $\bar{d}$ can be obtained using an equation fitting software, it is alternatively obtained using linear regression of data plotted in Rosin-Rammler diagram (Brezáni \& Zeleňák, 2010). The later was implemented in this thesis.

Logarithm of $\mathrm{Eq}(A .1)$ is taken twice and rearranged to give the following expression:

$$
\log \left(\log \left(\frac{100}{R_{R}(d)}\right)\right)=n_{R} \cdot \log d-n_{R} \cdot \log \bar{d}+\log (\log e) .
$$

For any material, parameter $n_{R}$ and $\bar{d}$ are constant, therefore from Eq. (A.2),

$$
\log (\log e)-n_{R} \cdot \log \bar{d}=\text { const }
$$

Hence, Eq. (A.2) may be expressed as follows: 


$$
\log \left(\log \left(\frac{100}{R_{R}(d)}\right)\right)=n_{R} \cdot \log d+\text { const }
$$

A plot of $\log \left(\log \left(\frac{100}{R(d)}\right)\right)$ against $\log d$ is a straight line, and is refers to Rosin-Rammler (RR) diagram, Peleg (1996).

Characteristic size, $\bar{d}$, of a give material is obtained by classifying it on a mesh $d=\bar{d}$. Using this in Eq. (A.1), then the percentage of oversize material is given as $R_{R}(d)=36.79 \%$. Consequently, characteristic size is obtained as follows:

$$
\bar{d}=10^{\log _{10}\left(\log _{10}(100 / 36.79)\right)-\text { const }} \text {. }
$$

And $n$ is the gradient of the plotted line given as follows:

$$
n_{R}=\frac{\log \left(\log \frac{100}{R_{R}\left(d_{2}\right)}\right)-\log \left(\log \frac{100}{R_{R}\left(d_{1}\right)}\right)}{\log d_{2}-\log d_{1}},
$$

where $\left[d_{1}, R_{R}\left(d_{1}\right)\right]$ and $\left[d_{2}, R_{R}\left(d_{2}\right)\right]$ are random data points on the best fitted line.

Table A.1: Particle size distribution of wood particles samples.

\begin{tabular}{cccccc}
\hline \multicolumn{2}{c}{ Sawdust 1 (SD1) } & \multicolumn{2}{c}{ Sawdust 2 (SD2) } & \multicolumn{2}{c}{ Wood chips (WC) } \\
$\begin{array}{c}\text { Mesh size } \\
(\mathrm{mm})\end{array}$ & $\begin{array}{c}\text { Mass } \\
\text { Retained }(\%)\end{array}$ & $\begin{array}{c}\text { Mesh size } \\
(\mathrm{mm})\end{array}$ & $\begin{array}{c}\text { Mass } \\
\text { Retained }(\%)\end{array}$ & $\begin{array}{c}\text { Mesh size } \\
(\mathrm{mm})\end{array}$ & $\begin{array}{c}\text { Mass } \\
\text { Retained }(\%)\end{array}$ \\
\hline 0.5 & 95 & 2.2 & 92 & 4.5 & 65 \\
0.71 & 80 & 2.5 & 81 & 5 & 45 \\
1 & 65 & 2.8 & 72 & 5.6 & 32 \\
1.25 & 42 & 3.15 & 35 & 6.3 & 20 \\
1.4 & 15 & 3.55 & 12 & 7.1 & 7 \\
\hline
\end{tabular}

Presented on Table A.1 are data for the particles size distribution of the wood used in this study. The size distribution was obtained using Fritsch vibratory sieve shaker. The RR diagram for fuel sample SD1 is shown in Fig. A.1. From this graph, parameter $n_{R}$ and $\bar{d}$ were calculated as 
3.212 and $1.23 \mathrm{~mm}$, respectively. Similarly, these parameters were calculated for all the fuel samples and presented in Table A.2.

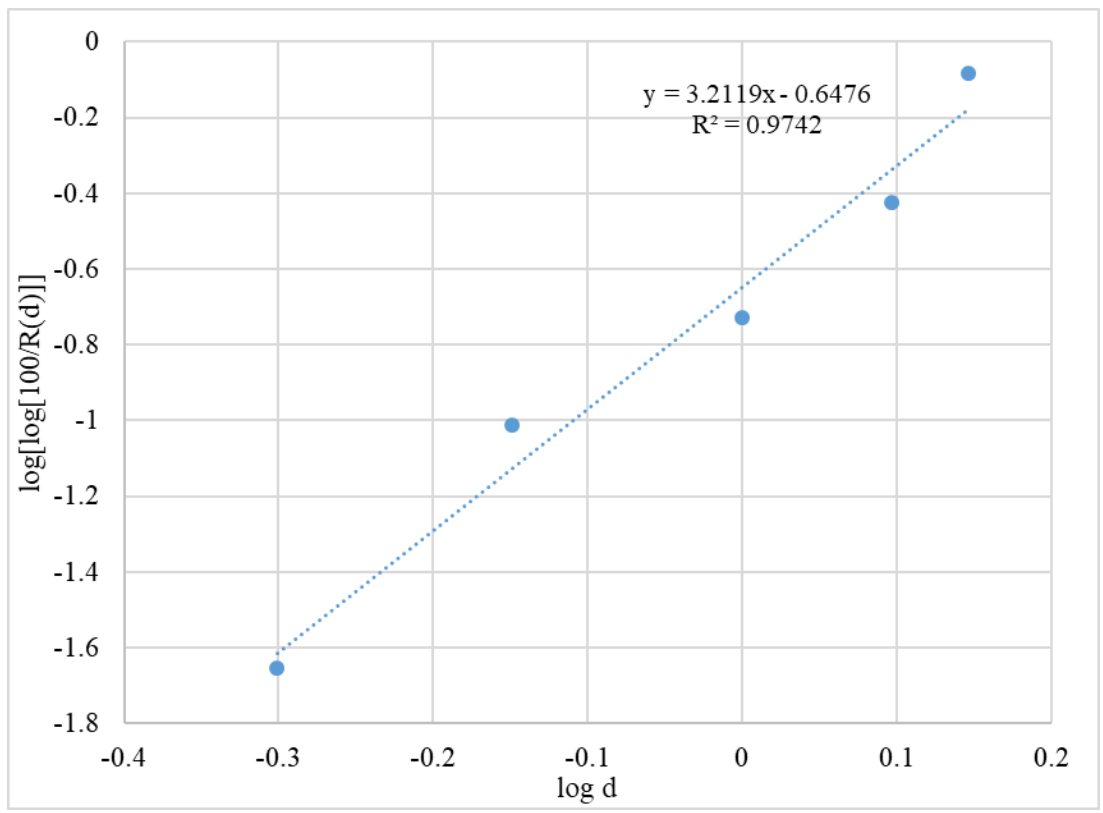

Figure A.1: RR diagram for fuel sample SD1.

Table A.2: Characteristic size of different fuel samples.

\begin{tabular}{cccc}
\hline Parameter & $\begin{array}{c}\text { Sawdust 1 } \\
\text { (SD1) }\end{array}$ & $\begin{array}{c}\text { Sawdust 2 } \\
\text { (SD2) }\end{array}$ & $\begin{array}{c}\text { Wood chips } \\
\text { (WC) }\end{array}$ \\
\hline $\bar{d}$ & 1.227 & 3.183 & 5.474 \\
$n$ & 3.212 & 6.801 & 3.789 \\
$\mathrm{R}^{2}$ & 0.974 & 0.988 & 0.985 \\
\hline
\end{tabular}




\section{APPENDIX B \\ TEMPERATURE MEASUREMENT APPARATUS}

Temperature of combustion zone were measured using type K class 2 thermocouple (range of -200 to $+1372{ }^{\circ} \mathrm{C}$ ) which were coupled to a data acquisition system comprising of MAX31850 cold-junction compensated, 1-wire thermocouple-to-digital converter, Arduino program code and a computer, as shown in Fig. B.1.

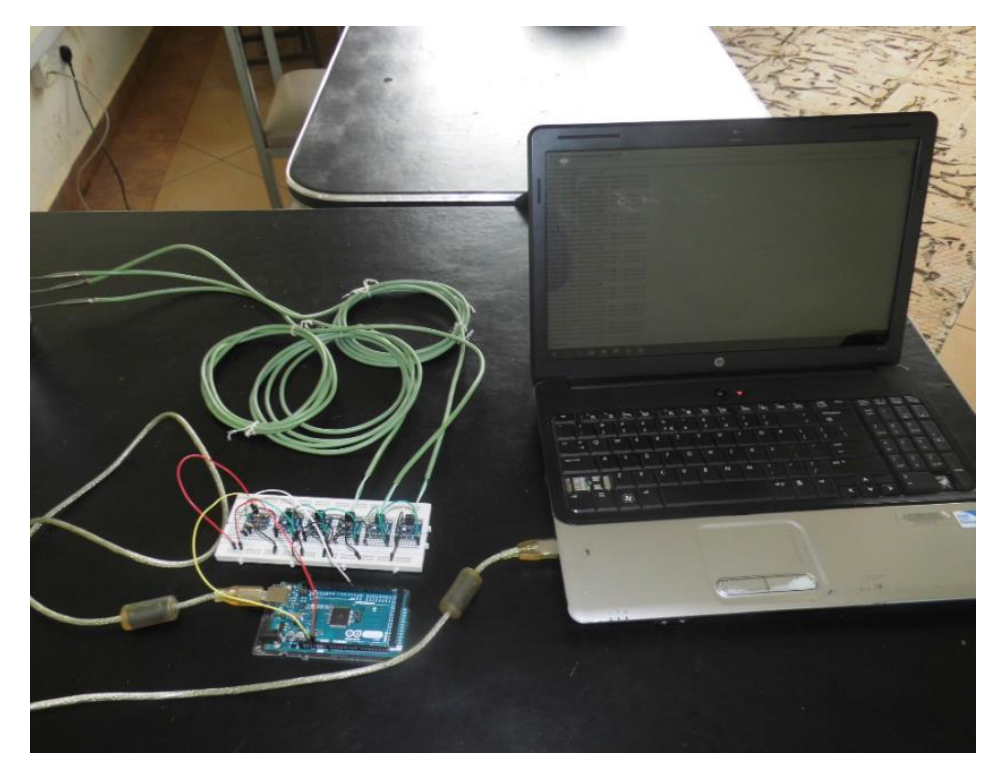

Figure B.1: Temperature data acquisition system.

The uncertainty analysis of the whole system was estimated using model Eq. (B.1). In this analysis, main errors were only considered.

$$
T_{D}=T_{M}+\delta E_{S}+\delta E_{C}+C_{S} \delta T_{R}+\delta E_{V C}+\delta E_{P}+\delta E_{A}
$$

where $T_{D}$ is the display temperature, $T_{M}$ is the temperature at measuring point, $\delta E_{S}$ is the deviation of the sensor, $\delta E_{C}$ is the error due to insufficient temperature conditioning, $C_{S}$ is the sensor sensitivity, $\delta T_{R}$ is the reference point temperature change, $\delta E_{V C}$ is the voltage change due to compensation cable, $\delta E_{P}$ is the error due to processing and linearization in electronic device and $\delta E_{A}$ is the error due to component aging (long term drift). 


\section{B.1 Determination of Individual Uncertainty Components}

Individual uncertainty components were estimated using European standards and/or manufacturers datasheet.

1. Deviation of the sensor $\left(\delta E_{S}\right)-$ Specified according to European standards DIN EN 60584. For type K class 2 thermocouple, DIN EN 60584 requires that $\delta E_{S}=0.0075$. $|t|$

2. Error due to insufficient temperature conditioning $\left(\delta E_{C}\right)$ - It was assumed that measurement was stable. Therefore, this uncertainty was neglected.

3. Error due to reference point temperature change $\left(C_{S} \delta T_{R}\right)$ - Cold junction accuracy according to the datasheet of MAX31850 thermocouple converter is given as $\pm 2{ }^{\circ} \mathrm{C}$

4. Voltage change due to compensation cable $\left(\delta E_{V C}\right)$ - Compensation cable had a tolerance of $\pm 2.5^{\circ} \mathrm{C}$.

5. Error due to processing and linearization in electronic device $\left(\delta E_{P}\right)-$ According to the datasheet of MAX31850 thermocouple converter, this error was specified as follows:

a. $\delta E_{P}= \pm 2^{\circ} \mathrm{C}$ for temperature range -200 to $+700{ }^{\circ} \mathrm{C}$

b. $\delta E_{P}= \pm 4^{\circ} \mathrm{C}$ for temperature range +700 to $+1372{ }^{\circ} \mathrm{C}$

6. Error due to component aging $\left(\delta E_{A}\right)$ - According to the datasheet of MAX31850 thermocouple converter, this error was specified as $\pm 0.24{ }^{\circ} \mathrm{C}$.

A simple measurement uncertainty (68.3\% confidence interval), $\delta_{S U}$ was first calculated. This was achieved by dividing individual uncertainty components by $\sqrt{3}$ (assuming a rectangle distribution) and then added geometrically as shown by Eq. (B.2).

$$
\delta_{S U}=\sqrt{\left(\frac{\delta E_{S}}{\sqrt{3}}\right)^{2}+\left(\frac{C_{S} \delta T_{R}}{\sqrt{3}}\right)^{2}+\left(\frac{\delta E_{V C}}{\sqrt{3}}\right)^{2}+\left(\frac{\delta E_{P}}{\sqrt{3}}\right)^{2}+\left(\frac{\delta E_{A}}{\sqrt{3}}\right)^{2}},
$$


Total measurement uncertainty, $\delta_{T U}$ with a confidence interval of $95 \%$ was calculated by multiplying simple measurement uncertainty by $2\left(\delta_{T U}=2 \times \delta_{S U}\right)$. The results for the whole thermocouple measurement range are tabulated in Table B.1.

Table B.1: Uncertainty analysis of temperature measurement apparatus.

\begin{tabular}{|c|c|c|c|c|c|c|c|}
\hline \multirow{2}{*}{$\begin{array}{c}\text { Temperature } \\
\left({ }^{\circ} \mathrm{C}\right)\end{array}$} & \multicolumn{5}{|c|}{ Individual Uncertainty Contribution $\left({ }^{\circ} \mathrm{C}\right)$} & \multirow{2}{*}{$\begin{array}{c}\text { Simple } \\
\text { measurement } \\
\text { uncertainty } \\
\left({ }^{\circ} \mathrm{C}\right)\end{array}$} & \multirow{2}{*}{$\begin{array}{c}\text { Total } \\
\text { measurement } \\
\text { uncertainty } \\
\left({ }^{\circ} \mathrm{C}\right)\end{array}$} \\
\hline & $\frac{\delta E_{S}}{\sqrt{3}}$ & $\frac{C_{S} \delta T_{R}}{\sqrt{3}}$ & $\frac{\delta E_{V C}}{\sqrt{3}}$ & $\frac{\delta E_{P}}{\sqrt{3}}$ & $\frac{\delta E_{A}}{\sqrt{3}}$ & & \\
\hline 0 & 0.000 & 1.155 & 1.443 & 1.155 & 0.139 & 2.184 & 4.368 \\
\hline 10 & 0.043 & 1.155 & 1.443 & 1.155 & 0.139 & 2.184 & 4.369 \\
\hline 20 & 0.087 & 1.155 & 1.443 & 1.155 & 0.139 & 2.186 & 4.371 \\
\hline 30 & 0.130 & 1.155 & 1.443 & 1.155 & 0.139 & 2.188 & 4.375 \\
\hline 40 & 0.173 & 1.155 & 1.443 & 1.155 & 0.139 & 2.191 & 4.381 \\
\hline 50 & 0.217 & 1.155 & 1.443 & 1.155 & 0.139 & 2.195 & 4.389 \\
\hline 60 & 0.260 & 1.155 & 1.443 & 1.155 & 0.139 & 2.199 & 4.398 \\
\hline 70 & 0.303 & 1.155 & 1.443 & 1.155 & 0.139 & 2.205 & 4.410 \\
\hline 80 & 0.346 & 1.155 & 1.443 & 1.155 & 0.139 & 2.211 & 4.422 \\
\hline 90 & 0.390 & 1.155 & 1.443 & 1.155 & 0.139 & 2.218 & 4.437 \\
\hline 100 & 0.433 & 1.155 & 1.443 & 1.155 & 0.139 & 2.226 & 4.453 \\
\hline 110 & 0.476 & 1.155 & 1.443 & 1.155 & 0.139 & 2.235 & 4.470 \\
\hline 120 & 0.520 & 1.155 & 1.443 & 1.155 & 0.139 & 2.245 & 4.490 \\
\hline 130 & 0.563 & 1.155 & 1.443 & 1.155 & 0.139 & 2.255 & 4.510 \\
\hline 140 & 0.606 & 1.155 & 1.443 & 1.155 & 0.139 & 2.266 & 4.533 \\
\hline 150 & 0.650 & 1.155 & 1.443 & 1.155 & 0.139 & 2.278 & 4.557 \\
\hline 160 & 0.693 & 1.155 & 1.443 & 1.155 & 0.139 & 2.291 & 4.582 \\
\hline 170 & 0.736 & 1.155 & 1.443 & 1.155 & 0.139 & 2.305 & 4.609 \\
\hline 180 & 0.779 & 1.155 & 1.443 & 1.155 & 0.139 & 2.319 & 4.638 \\
\hline 190 & 0.823 & 1.155 & 1.443 & 1.155 & 0.139 & 2.334 & 4.667 \\
\hline 200 & 0.866 & 1.155 & 1.443 & 1.155 & 0.139 & 2.349 & 4.699 \\
\hline 210 & 0.909 & 1.155 & 1.443 & 1.155 & 0.139 & 2.366 & 4.731 \\
\hline 220 & 0.953 & 1.155 & 1.443 & 1.155 & 0.139 & 2.383 & 4.765 \\
\hline 230 & 0.996 & 1.155 & 1.443 & 1.155 & 0.139 & 2.400 & 4.800 \\
\hline 240 & 1.039 & 1.155 & 1.443 & 1.155 & 0.139 & 2.419 & 4.837 \\
\hline 250 & 1.083 & 1.155 & 1.443 & 1.155 & 0.139 & 2.437 & 4.875 \\
\hline 260 & 1.126 & 1.155 & 1.443 & 1.155 & 0.139 & 2.457 & 4.914 \\
\hline 270 & 1.169 & 1.155 & 1.443 & 1.155 & 0.139 & 2.477 & 4.954 \\
\hline
\end{tabular}




\begin{tabular}{|c|c|c|c|c|c|c|c|}
\hline 280 & 1.212 & 1.155 & 1.443 & 1.155 & 0.139 & 2.498 & 4.996 \\
\hline 290 & 1.256 & 1.155 & 1.443 & 1.155 & 0.139 & 2.519 & 5.038 \\
\hline 300 & 1.299 & 1.155 & 1.443 & 1.155 & 0.139 & 2.541 & 5.082 \\
\hline 310 & 1.342 & 1.155 & 1.443 & 1.155 & 0.139 & 2.563 & 5.127 \\
\hline 320 & 1.386 & 1.155 & 1.443 & 1.155 & 0.139 & 2.586 & 5.173 \\
\hline 330 & 1.429 & 1.155 & 1.443 & 1.155 & 0.139 & 2.610 & 5.220 \\
\hline 340 & 1.472 & 1.155 & 1.443 & 1.155 & 0.139 & 2.634 & 5.268 \\
\hline 350 & 1.516 & 1.155 & 1.443 & 1.155 & 0.139 & 2.658 & 5.316 \\
\hline 360 & 1.559 & 1.155 & 1.443 & 1.155 & 0.139 & 2.683 & 5.366 \\
\hline 370 & 1.602 & 1.155 & 1.443 & 1.155 & 0.139 & 2.709 & 5.417 \\
\hline 380 & 1.645 & 1.155 & 1.443 & 1.155 & 0.139 & 2.734 & 5.469 \\
\hline 390 & 1.689 & 1.155 & 1.443 & 1.155 & 0.139 & 2.761 & 5.521 \\
\hline 400 & 1.732 & 1.155 & 1.443 & 1.155 & 0.139 & 2.787 & 5.575 \\
\hline 410 & 1.775 & 1.155 & 1.443 & 1.155 & 0.139 & 2.814 & 5.629 \\
\hline 420 & 1.819 & 1.155 & 1.443 & 1.155 & 0.139 & 2.842 & 5.684 \\
\hline 430 & 1.862 & 1.155 & 1.443 & 1.155 & 0.139 & 2.870 & 5.740 \\
\hline 440 & 1.905 & 1.155 & 1.443 & 1.155 & 0.139 & 2.898 & 5.796 \\
\hline 450 & 1.949 & 1.155 & 1.443 & 1.155 & 0.139 & 2.927 & 5.854 \\
\hline 460 & 1.992 & 1.155 & 1.443 & 1.155 & 0.139 & 2.956 & 5.912 \\
\hline 470 & 2.035 & 1.155 & 1.443 & 1.155 & 0.139 & 2.985 & 5.970 \\
\hline 480 & 2.078 & 1.155 & 1.443 & 1.155 & 0.139 & 3.015 & 6.030 \\
\hline 490 & 2.122 & 1.155 & 1.443 & 1.155 & 0.139 & 3.045 & 6.090 \\
\hline 500 & 2.165 & 1.155 & 1.443 & 1.155 & 0.139 & 3.075 & 6.150 \\
\hline 510 & 2.208 & 1.155 & 1.443 & 1.155 & 0.139 & 3.106 & 6.212 \\
\hline 520 & 2.252 & 1.155 & 1.443 & 1.155 & 0.139 & 3.137 & 6.273 \\
\hline 530 & 2.295 & 1.155 & 1.443 & 1.155 & 0.139 & 3.168 & 6.336 \\
\hline 540 & 2.338 & 1.155 & 1.443 & 1.155 & 0.139 & 3.199 & 6.399 \\
\hline 550 & 2.382 & 1.155 & 1.443 & 1.155 & 0.139 & 3.231 & 6.463 \\
\hline 560 & 2.425 & 1.155 & 1.443 & 1.155 & 0.139 & 3.263 & 6.527 \\
\hline 570 & 2.468 & 1.155 & 1.443 & 1.155 & 0.139 & 3.296 & 6.591 \\
\hline 580 & 2.511 & 1.155 & 1.443 & 1.155 & 0.139 & 3.328 & 6.656 \\
\hline 590 & 2.555 & 1.155 & 1.443 & 1.155 & 0.139 & 3.361 & 6.722 \\
\hline 600 & 2.598 & 1.155 & 1.443 & 1.155 & 0.139 & 3.394 & 6.788 \\
\hline 610 & 2.641 & 1.155 & 1.443 & 1.155 & 0.139 & 3.427 & 6.855 \\
\hline 620 & 2.685 & 1.155 & 1.443 & 1.155 & 0.139 & 3.461 & 6.921 \\
\hline 630 & 2.728 & 1.155 & 1.443 & 1.155 & 0.139 & 3.494 & 6.989 \\
\hline 640 & 2.771 & 1.155 & 1.443 & 1.155 & 0.139 & 3.528 & 7.057 \\
\hline 650 & 2.815 & 1.155 & 1.443 & 1.155 & 0.139 & 3.562 & 7.125 \\
\hline 660 & 2.858 & 1.155 & 1.443 & 1.155 & 0.139 & 3.597 & 7.194 \\
\hline 670 & 2.901 & 1.155 & 1.443 & 1.155 & 0.139 & 3.631 & 7.263 \\
\hline 680 & 2.944 & 1.155 & 1.443 & 1.155 & 0.139 & 3.666 & 7.332 \\
\hline
\end{tabular}




\begin{tabular}{|c|c|c|c|c|c|c|c|}
\hline 690 & 2.988 & 1.155 & 1.443 & 1.155 & 0.139 & 3.701 & 7.402 \\
\hline 700 & 3.031 & 1.155 & 1.443 & 1.155 & 0.139 & 3.736 & 7.472 \\
\hline 710 & 3.074 & 1.155 & 1.443 & 2.309 & 0.139 & 4.269 & 8.537 \\
\hline 720 & 3.118 & 1.155 & 1.443 & 2.309 & 0.139 & 4.300 & 8.600 \\
\hline 730 & 3.161 & 1.155 & 1.443 & 2.309 & 0.139 & 4.331 & 8.663 \\
\hline 740 & 3.204 & 1.155 & 1.443 & 2.309 & 0.139 & 4.363 & 8.726 \\
\hline 750 & 3.248 & 1.155 & 1.443 & 2.309 & 0.139 & 4.395 & 8.790 \\
\hline 760 & 3.291 & 1.155 & 1.443 & 2.309 & 0.139 & 4.427 & 8.854 \\
\hline 770 & 3.334 & 1.155 & 1.443 & 2.309 & 0.139 & 4.459 & 8.919 \\
\hline 780 & 3.377 & 1.155 & 1.443 & 2.309 & 0.139 & 4.492 & 8.984 \\
\hline 790 & 3.421 & 1.155 & 1.443 & 2.309 & 0.139 & 4.524 & 9.049 \\
\hline 800 & 3.464 & 1.155 & 1.443 & 2.309 & 0.139 & 4.557 & 9.115 \\
\hline 810 & 3.507 & 1.155 & 1.443 & 2.309 & 0.139 & 4.590 & 9.181 \\
\hline 820 & 3.551 & 1.155 & 1.443 & 2.309 & 0.139 & 4.623 & 9.247 \\
\hline 830 & 3.594 & 1.155 & 1.443 & 2.309 & 0.139 & 4.657 & 9.314 \\
\hline 840 & 3.637 & 1.155 & 1.443 & 2.309 & 0.139 & 4.690 & 9.381 \\
\hline 850 & 3.681 & 1.155 & 1.443 & 2.309 & 0.139 & 4.724 & 9.448 \\
\hline 860 & 3.724 & 1.155 & 1.443 & 2.309 & 0.139 & 4.758 & 9.516 \\
\hline 870 & 3.767 & 1.155 & 1.443 & 2.309 & 0.139 & 4.792 & 9.584 \\
\hline 880 & 3.811 & 1.155 & 1.443 & 2.309 & 0.139 & 4.826 & 9.652 \\
\hline 890 & 3.854 & 1.155 & 1.443 & 2.309 & 0.139 & 4.860 & 9.720 \\
\hline 900 & 3.897 & 1.155 & 1.443 & 2.309 & 0.139 & 4.895 & 9.789 \\
\hline 910 & 3.940 & 1.155 & 1.443 & 2.309 & 0.139 & 4.929 & 9.858 \\
\hline 920 & 3.984 & 1.155 & 1.443 & 2.309 & 0.139 & 4.964 & 9.928 \\
\hline 930 & 4.027 & 1.155 & 1.443 & 2.309 & 0.139 & 4.999 & 9.997 \\
\hline 940 & 4.070 & 1.155 & 1.443 & 2.309 & 0.139 & 5.034 & 10.067 \\
\hline 950 & 4.114 & 1.155 & 1.443 & 2.309 & 0.139 & 5.069 & 10.137 \\
\hline 960 & 4.157 & 1.155 & 1.443 & 2.309 & 0.139 & 5.104 & 10.208 \\
\hline 970 & 4.200 & 1.155 & 1.443 & 2.309 & 0.139 & 5.139 & 10.278 \\
\hline 980 & 4.244 & 1.155 & 1.443 & 2.309 & 0.139 & 5.175 & 10.349 \\
\hline 990 & 4.287 & 1.155 & 1.443 & 2.309 & 0.139 & 5.210 & 10.420 \\
\hline 1000 & 4.330 & 1.155 & 1.443 & 2.309 & 0.139 & 5.246 & 10.492 \\
\hline 1010 & 4.373 & 1.155 & 1.443 & 2.309 & 0.139 & 5.282 & 10.563 \\
\hline 1020 & 4.417 & 1.155 & 1.443 & 2.309 & 0.139 & 5.318 & 10.635 \\
\hline 1030 & 4.460 & 1.155 & 1.443 & 2.309 & 0.139 & 5.354 & 10.707 \\
\hline 1040 & 4.503 & 1.155 & 1.443 & 2.309 & 0.139 & 5.390 & 10.779 \\
\hline 1050 & 4.547 & 1.155 & 1.443 & 2.309 & 0.139 & 5.426 & 10.852 \\
\hline 1060 & 4.590 & 1.155 & 1.443 & 2.309 & 0.139 & 5.462 & 10.925 \\
\hline 1070 & 4.633 & 1.155 & 1.443 & 2.309 & 0.139 & 5.499 & 10.997 \\
\hline 1080 & 4.677 & 1.155 & 1.443 & 2.309 & 0.139 & 5.535 & 11.071 \\
\hline 1090 & 4.720 & 1.155 & 1.443 & 2.309 & 0.139 & 5.572 & 11.144 \\
\hline
\end{tabular}




\begin{tabular}{|c|c|c|c|c|c|c|c|}
\hline 1100 & 4.763 & 1.155 & 1.443 & 2.309 & 0.139 & 5.609 & 11.217 \\
\hline 1110 & 4.806 & 1.155 & 1.443 & 2.309 & 0.139 & 5.645 & 11.291 \\
\hline 1120 & 4.850 & 1.155 & 1.443 & 2.309 & 0.139 & 5.682 & 11.365 \\
\hline 1130 & 4.893 & 1.155 & 1.443 & 2.309 & 0.139 & 5.719 & 11.439 \\
\hline 1140 & 4.936 & 1.155 & 1.443 & 2.309 & 0.139 & 5.756 & 11.513 \\
\hline 1150 & 4.980 & 1.155 & 1.443 & 2.309 & 0.139 & 5.794 & 11.587 \\
\hline 1160 & 5.023 & 1.155 & 1.443 & 2.309 & 0.139 & 5.831 & 11.662 \\
\hline 1170 & 5.066 & 1.155 & 1.443 & 2.309 & 0.139 & 5.868 & 11.736 \\
\hline 1180 & 5.110 & 1.155 & 1.443 & 2.309 & 0.139 & 5.906 & 11.811 \\
\hline 1190 & 5.153 & 1.155 & 1.443 & 2.309 & 0.139 & 5.943 & 11.886 \\
\hline 1200 & 5.196 & 1.155 & 1.443 & 2.309 & 0.139 & 5.981 & 11.961 \\
\hline 1210 & 5.239 & 1.155 & 1.443 & 2.309 & 0.139 & 6.018 & 12.037 \\
\hline 1220 & 5.283 & 1.155 & 1.443 & 2.309 & 0.139 & 6.056 & 12.112 \\
\hline 1230 & 5.326 & 1.155 & 1.443 & 2.309 & 0.139 & 6.094 & 12.188 \\
\hline 1240 & 5.369 & 1.155 & 1.443 & 2.309 & 0.139 & 6.132 & 12.264 \\
\hline 1250 & 5.413 & 1.155 & 1.443 & 2.309 & 0.139 & 6.170 & 12.340 \\
\hline 1260 & 5.456 & 1.155 & 1.443 & 2.309 & 0.139 & 6.208 & 12.416 \\
\hline 1270 & 5.499 & 1.155 & 1.443 & 2.309 & 0.139 & 6.246 & 12.492 \\
\hline 1280 & 5.543 & 1.155 & 1.443 & 2.309 & 0.139 & 6.284 & 12.568 \\
\hline 1290 & 5.586 & 1.155 & 1.443 & 2.309 & 0.139 & 6.322 & 12.645 \\
\hline 1300 & 5.629 & 1.155 & 1.443 & 2.309 & 0.139 & 6.361 & 12.721 \\
\hline 1310 & 5.672 & 1.155 & 1.443 & 2.309 & 0.139 & 6.399 & 12.798 \\
\hline 1320 & 5.716 & 1.155 & 1.443 & 2.309 & 0.139 & 6.437 & 12.875 \\
\hline 1330 & 5.759 & 1.155 & 1.443 & 2.309 & 0.139 & 6.476 & 12.952 \\
\hline 1340 & 5.802 & 1.155 & 1.443 & 2.309 & 0.139 & 6.514 & 13.029 \\
\hline 1350 & 5.846 & 1.155 & 1.443 & 2.309 & 0.139 & 6.553 & 13.106 \\
\hline 1360 & 5.889 & 1.155 & 1.443 & 2.309 & 0.139 & 6.592 & 13.183 \\
\hline 1370 & 5.932 & 1.155 & 1.443 & 2.309 & 0.139 & 6.630 & 13.261 \\
\hline
\end{tabular}

\section{B.2 Calibration of Thermocouple Data Acquisition System}

The total measurement uncertainty estimated and provided in Table B.1 was checked by calibrating thermocouple data acquisition system at $22{ }^{\circ} \mathrm{C}$ in a water bath thermostat. Measurements for each thermocouple was repeated 40 times under the same conditions. Calibration data is provided in Table B.2. Standard deviation for both the estimated uncertainty and calibration data are within the same range. 
Table B.2: Calibration of thermocouple data acquisition system.

\begin{tabular}{|c|c|c|c|c|c|c|}
\hline Tests & $\begin{array}{c}\text { Reference } \\
\text { Temperature } \\
\left({ }^{\circ} \mathrm{C}\right)\end{array}$ & $\begin{array}{l}\text { Thermocou } \\
\text { ple } 1\left({ }^{\circ} \mathrm{C}\right)\end{array}$ & $\begin{array}{l}\text { Thermocou } \\
\text { ple } 2\left({ }^{\circ} \mathrm{C}\right)\end{array}$ & $\begin{array}{c}\text { Thermocou } \\
\text { ple } 3\left({ }^{\circ} \mathrm{C}\right)\end{array}$ & $\begin{array}{c}\text { Thermocou } \\
\text { ple } 4\left({ }^{\circ} \mathrm{C}\right)\end{array}$ & $\begin{array}{c}\text { Thermocou } \\
\text { ple } 5\left({ }^{\circ} \mathrm{C}\right)\end{array}$ \\
\hline 1 & 22.00 & 23.25 & 25.25 & 22.75 & 24.25 & 24.75 \\
\hline 2 & 22.00 & 23.00 & 24.75 & 21.50 & 26.25 & 26.00 \\
\hline 3 & 22.00 & 24.50 & 24.25 & 21.75 & 27.00 & 26.25 \\
\hline 4 & 22.00 & 26.75 & 18.25 & 24.75 & 23.00 & 27.00 \\
\hline 5 & 22.00 & 22.50 & 23.00 & 27.25 & 23.25 & 24.50 \\
\hline 6 & 22.00 & 20.25 & 23.75 & 26.50 & 24.50 & 21.00 \\
\hline 7 & 22.00 & 25.75 & 20.75 & 24.50 & 21.25 & 20.00 \\
\hline 8 & 22.00 & 20.00 & 21.75 & 20.25 & 20.25 & 22.75 \\
\hline 9 & 22.00 & 19.50 & 21.75 & 21.75 & 24.25 & 19.75 \\
\hline 10 & 22.00 & 22.75 & 26.50 & 20.25 & 19.25 & 20.75 \\
\hline 11 & 22.00 & 23.25 & 24.50 & 25.75 & 18.25 & 20.50 \\
\hline 12 & 22.00 & 22.75 & 25.75 & 19.25 & 20.75 & 21.50 \\
\hline 13 & 22.00 & 21.75 & 22.00 & 22.75 & 21.50 & 22.00 \\
\hline 14 & 22.00 & 21.75 & 22.50 & 20.75 & 22.00 & 20.50 \\
\hline 15 & 22.00 & 22.25 & 23.00 & 25.25 & 23.75 & 24.50 \\
\hline 16 & 22.00 & 18.75 & 25.50 & 23.75 & 24.50 & 23.50 \\
\hline 17 & 22.00 & 24.50 & 26.00 & 24.75 & 20.50 & 24.50 \\
\hline 18 & 22.00 & 24.75 & 19.25 & 21.75 & 26.50 & 21.75 \\
\hline 19 & 22.00 & 21.75 & 20.00 & 22.50 & 22.50 & 20.50 \\
\hline 20 & 22.00 & 25.00 & 21.75 & 20.75 & 22.75 & 22.75 \\
\hline 21 & 22.00 & 23.75 & 20.75 & 20.00 & 24.50 & 25.50 \\
\hline 22 & 22.00 & 20.75 & 21.25 & 24.00 & 24.75 & 25.75 \\
\hline 23 & 22.00 & 20.50 & 23.75 & 25.50 & 20.25 & 26.50 \\
\hline 24 & 22.00 & 27.25 & 24.50 & 22.00 & 23.50 & 27.50 \\
\hline 25 & 22.00 & 25.25 & 22.75 & 26.75 & 23.00 & 20.25 \\
\hline 26 & 22.00 & 20.50 & 24.75 & 25.75 & 24.75 & 23.50 \\
\hline 27 & 22.00 & 24.25 & 20.25 & 25.25 & 25.50 & 24.50 \\
\hline 28 & 22.00 & 25.75 & 25.75 & 20.50 & 26.75 & 24.75 \\
\hline 29 & 22.00 & 23.25 & 24.50 & 21.75 & 25.50 & 25.75 \\
\hline 30 & 22.00 & 22.75 & 22.25 & 24.50 & 25.75 & 25.75 \\
\hline 31 & 22.00 & 23.00 & 20.50 & 25.50 & 20.25 & 21.75 \\
\hline 32 & 22.00 & 24.50 & 26.25 & 26.00 & 21.50 & 24.75 \\
\hline 33 & 22.00 & 26.75 & 25.50 & 24.75 & 22.75 & 25.50 \\
\hline 34 & 22.00 & 21.75 & 25.25 & 22.00 & 21.75 & 23.25 \\
\hline 35 & 22.00 & 21.50 & 23.25 & 23.75 & 25.50 & 22.75 \\
\hline 36 & 22.00 & 26.00 & 19.75 & 25.50 & 20.75 & 23.50 \\
\hline 37 & 22.00 & 20.50 & 21.75 & 26.25 & 23.00 & 20.75 \\
\hline
\end{tabular}




\begin{tabular}{|c|c|c|c|c|c|c|}
38 & 22.00 & 22.75 & 24.25 & 25.25 & 26.25 & 24.75 \\
\hline 39 & 22.00 & 23.50 & 26.75 & 25.75 & 25.75 & 24.25 \\
\hline 40 & 22.00 & 23.50 & 24.75 & 26.00 & 24.75 & 23.75 \\
\hline Mean & & $\mathbf{2 3 . 0 6}$ & $\mathbf{2 3 . 2 2}$ & $\mathbf{2 3 . 6 3}$ & $\mathbf{2 3 . 3 2}$ & $\mathbf{2 3 . 4 9}$ \\
\hline Std.dev & & $\mathbf{2 . 0 7 4}$ & $\mathbf{2 . 1 9 8}$ & $\mathbf{2 . 2 0 7}$ & $\mathbf{2 . 2 3 3}$ & $\mathbf{2 . 1 4 8}$ \\
\hline
\end{tabular}




\section{APPENDIX C \\ RADIATION LOSS CORRECTION}

Temperature measured by thermocouple may differ significantly from the true gas temperature because of radiation heat loss from the thermocouple surface to the cooler surrounding walls. Error due to radiation loss was corrected according to the methodology developed by Blevins \& Pitts (1999) and have been applied by other researchers (Brohez et al., 2004; Rashidian et al., 2017; Roberts et al., 2013). In this method, maximum and minimum measurement error which occur when using bare bead and single shielded aspirated thermocouple (TC), respectively, are used to estimate the error in sheathed thermocouple with the same bead size. A description of model equations for bare-bead and single-shielded thermocouple are given in the following subsections.

\section{C.1 Model Equations for Bare-Bead Thermocouple}

A representation of the heat transfers in a bare-bead thermocouple is shown in Fig. C.1 (Blevins $\&$ Pitts, 1999). Heat transfers are through radiation and convection. The energy balance on the bead is given by the following expression:

$$
h_{b g}\left(T_{g}-T_{b}\right)=\varepsilon_{b} \sigma\left(T_{b}^{4}-T_{\infty}^{4}\right)
$$

where $h_{b g}$ is the heat transfer coefficient between external gas flow and bare thermocouple bead, $T_{b}, T_{g}$, and $T_{\infty}$ are thermocouple bead temperature, gas temperature and average effective temperature of surrounding, respectively, $\varepsilon_{b}$ is the thermocouple bead emissivity and $\sigma$ is the Stefan-Boltzmann constant.

$h_{b g}$ is evaluated from the following correlation: 


$$
h_{b g}=N u_{d} \frac{\lambda_{g}}{D_{b}}
$$

where $D_{b}$ is the bead diameter, $\lambda_{g}$ is gas thermal conductivity and $N u_{d}$ is Nusselt number. $N u_{d}$ is estimated using Whitaker's correlation for external flow over a sphere (Whitaker, 1972) given by Eq. (C.3).
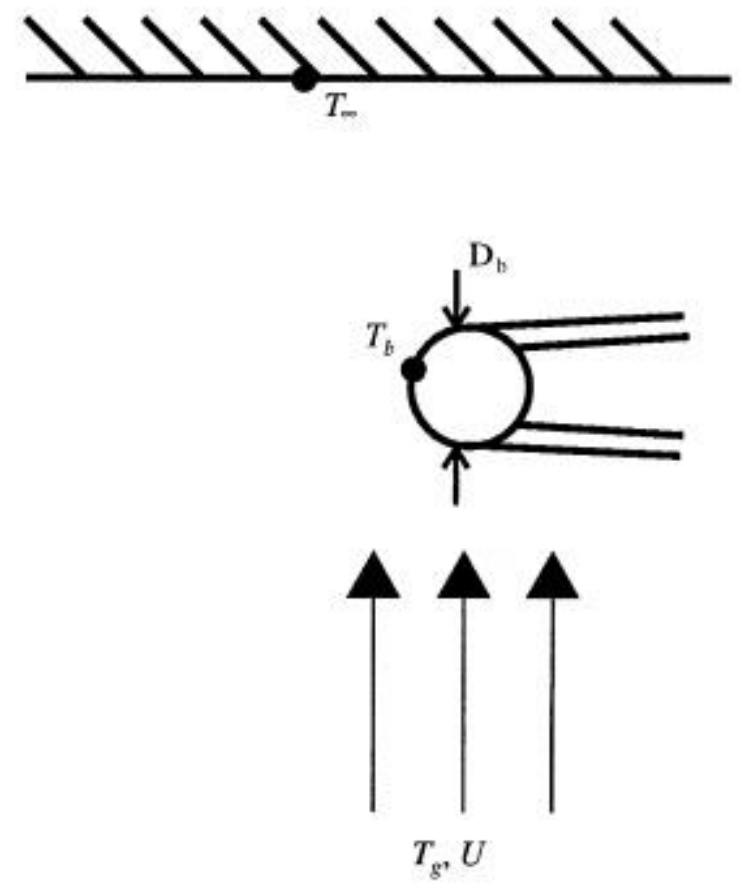

Figure C.1: Heat transfers in a bare-bead thermocouple.

$$
N u_{d}=2+\left(0.4 R e^{0.5}+0.06 R e^{2 / 3}\right) \operatorname{Pr}^{0.4} \quad 3.5 \leq R e \leq 7.6 \times 10^{4}
$$

and

$$
\lambda_{g}=\frac{\mu_{g} c_{p}}{P r}
$$


where $R e$ is Reynolds number, $P r$ is Prandtl number, $c_{p}$ specific heat capacity and $\mu_{g}$ is dynamic viscosity of gas.

Therefore, in order to correct a temperature measured by bare-bead thermocouple for radiation loss, raw temperature (measured) and surrounding temperature are required.

\section{C.2 Model Equations for Single-Shielded Thermocouple}

A representation of the heat transfers in a single-shielded aspirated thermocouple is shown in Fig. C.2 (Blevins \& Pitts, 1999). Heat transfers are also through radiation and convection. The energy balance on the bead is given as follows:
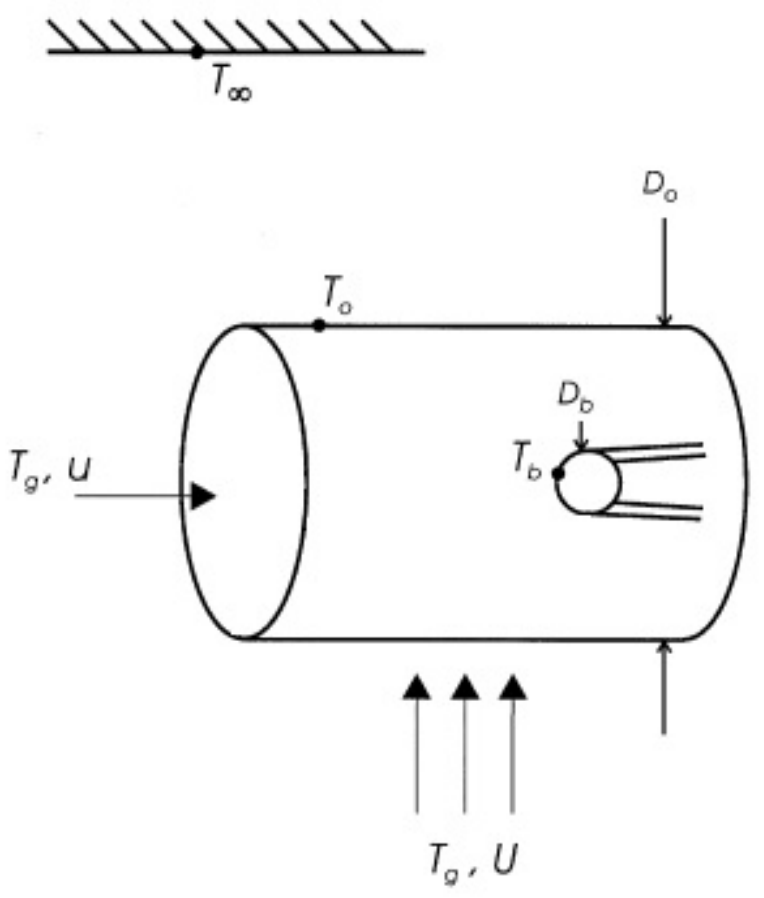

Figure C.2: Heat transfers in a single-shielded aspirated thermocouple.

$$
h_{a b}\left(T_{g}-T_{b}\right)=\varepsilon_{b} \sigma\left(T_{b}^{4}-T_{0}^{4}\right),
$$

and on the shield 


$$
h_{a s}\left(T_{g}-T_{0}\right)+h_{g s}\left(T_{g}-T_{0}\right)=-\varepsilon_{b} \sigma\left(\frac{A_{b}}{A_{0}}\right)\left(T_{b}^{4}-T_{0}^{4}\right)+\varepsilon_{0} \sigma\left(T_{0}^{4}-T_{\infty}^{4}\right),
$$

where $A_{b}$ and $A_{0}$ are the surface area of thermocouple bead and outermost shield, respectively, $h_{a b}$ is the heat transfer coefficient between aspirating gas flow and bare thermocouple bead, $h_{a s}$ is the heat transfer coefficient between aspirating gas flow and shield, $h_{g s}$ is the heat transfer coefficient between external gas flow and shield, $T_{0}$ is the outermost shield temperature and $\varepsilon_{0}$ is the outermost shield emissivity.

$h_{a b}$ is calculated in the same way as for bare-bead thermocouple using Eqs. (C.2-C.4). $h_{a s}$ and $h_{g s}$ are calculated using correlation for a cylinder in crossflow (Rashidian et al., 2017), as shown in the following expressions:

$$
\begin{array}{cc}
N u_{d}=0.989 R e^{0.330} \operatorname{Pr}^{1 / 3} & 0.4 \leq R e \leq 4 \\
N u_{d}=0.911 R e^{0.385} \operatorname{Pr}^{1 / 3} & 4 \leq R e \leq 40 \\
N u_{d}=0.683 R e^{0.466} \operatorname{Pr}^{1 / 3} & 40 \leq R e \leq 4000 \\
N u_{d}=0.193 R e^{0.618} \operatorname{Pr}^{1 / 3} & 4000 \leq R e \leq 40000
\end{array}
$$

Thus, in order to correct a temperature measured by single-shielded aspirated thermocouple for radiation loss, raw temperature (measured) and surrounding temperature are also required. 


\section{APPENDIX D \\ NUMERICAL MODELLING TECHNIQUES}

\section{D.1 Radiation Model Formulation}

When radiation passes through a medium, the intervening material absorbs and increments its radiant intensity $I$ in the $\Omega$ direction. This process is governed by Radiative Transfer Equation (RTE). For a specific wavelength, $\lambda$, the equation is expressed as follows (Fiveland, 1988; Incropera et al., 2006):

$$
\frac{d I_{\lambda}}{d s}=-\beta_{\lambda} I_{\lambda}+k_{a \lambda} I_{b \lambda}+\frac{k_{s \lambda}}{4 \pi} \int_{4 \pi} I_{\lambda}(\Omega) d \Omega+k_{p a \lambda} I_{p b \lambda}+\frac{k_{p s \lambda}}{4 \pi} \int_{4 \pi} I_{\lambda}(\Omega) d \Omega,
$$

where $I_{\lambda}$ is the radiative intensity at wavelength $\lambda, \beta_{\lambda}$ is the extinction coefficient, which is defined as follows:

$$
\beta_{\lambda}=k_{a \lambda}+k_{s \lambda}+k_{p a \lambda}+k_{p s \lambda}
$$

$k_{a \lambda}$ is the absorption coefficient at wavelength $\lambda, k_{s \lambda}$ scattering coefficient at wavelength $\lambda$, $k_{p a \lambda}$ particle absorption coefficient at wavelength $\lambda, k_{\text {pa }}$ particle scattering coefficient at wavelength $\lambda, I_{b \lambda}$ is the black body intensity at wavelength $\lambda, \Omega$ is the solid angle and $s$ is the distance in $\Omega$ direction. The black body intensity at wavelength $\lambda$ is expressed by Eq. (D.3):

$$
I_{b \lambda}=\frac{2 C_{R}}{n^{2} \lambda^{5}\left(\exp \left(C_{R 2} / n \lambda T\right)-1\right)},
$$

and $C_{R}=0.595522 \times 10^{-16} \mathrm{~W} \mathrm{~m}^{2} / \mathrm{s}$ and $C_{R 2}=0.01439 \mathrm{~m} \mathrm{~K}$. The in-scattering component is assumed to be isotropic. When the medium has several components, the absorption coefficient $k_{a \lambda}$ is expressed by Eq. (D.4):

$$
k_{a \lambda}=\sum_{i} k_{a \lambda i}
$$


where $i$ represent the participating media, such as, fuel particles, $\mathrm{CO}_{2}, \mathrm{H}_{2} \mathrm{O}$, or soot.

A gray gas medium is the one whose optical properties such as absorptivity, reflectivity, scattering coefficient and refractive index do not depend on wavelength. For a gray medium, Eq. (3.29) is integrated over entire spectrum to produce a wavelength independent equation.

The particle radiation is valid for both gray and multiband radiation for continuous media. However, for the case of multiband radiation, the particle properties are still gray. The surface and continuum properties can be spectral, but the particle properties are gray. Particle scattering is isotropic.

The boundary condition that is applied to the RTE Eq. (D.1) for each wavelength $\lambda$ is expressed by Eq. (D.5):

$$
I_{\lambda}(\mathbf{s})=\epsilon_{w \lambda} I_{b \lambda}+\frac{\rho_{w \lambda}^{d}}{\pi_{e f f}} \int_{\mathbf{n} \cdot \mathbf{s}^{\prime}<0} I_{\lambda}\left(s^{\prime}\right)\left|\mathbf{n} \cdot \mathbf{s}^{\prime}\right| d \Omega+\rho_{w \lambda}^{s} I_{\lambda}\left(\mathbf{s}^{\mathbf{s}}\right)+\tau_{w \lambda}\left(\mathbf{s}^{\mathbf{i}}\right) I_{\lambda}\left(\mathbf{s}^{\mathbf{i}}\right),
$$

where $\epsilon_{w \lambda}$ is the diffuse emissivity, $\rho_{w \lambda}^{d}$ is the diffuse reflectivity, $\pi_{e f f}=\sum_{s_{\mathbf{i}} \cdot \mathbf{n}_{\mathbf{i}}} w_{i}\left(\mathbf{s}_{\mathbf{i}} \cdot \mathbf{n}_{\mathbf{i}}\right)$ is the half moment for the ordinate set chosen, $\rho_{w \lambda}^{s}$ is the specular reflectivity, $\tau_{w \lambda}$ is the transmissivity. Only interfaces can be partially transmissive; all other external boundaries are modeled as opaque. $\mathbf{s}^{\mathbf{s}}=\mathbf{s}-2(\mathbf{s} \cdot \mathbf{n}) \mathbf{n}, \mathbf{s}^{\mathbf{i}}$ is the incoming ray direction as determined by the laws of refraction or Snell's law, $\mathbf{n}$ is the surface normal.

The radiant heat flux for a particular direction, $q_{r}$ is obtained by integrating Eq. (D.5) for all the solid angles and the entire spectrum as follows:

$$
q_{r}(r)=\int_{0}^{\infty} \int_{4 \pi} I_{\lambda}(s) s d \Omega d \lambda .
$$


Equation (D.6) enables energy to be exchanged between radiant energy field and fluid. This is achieved by incorporating the divergence of heat flux Eq. (D.6) into gas phase energy equation. The divergence of Eq. (D.6) is evaluated as follows (CD-Adapco, 2017; Incropera et al., 2006):

$$
\nabla \cdot q_{r}=\int_{0}^{\infty} k_{a \lambda}\left(4 \pi I_{b \lambda}-\int_{4 \pi} I_{\lambda} d \Omega\right) d \lambda
$$

Similarly, the divergence of the heat flux for particle is expressed as follows:

$$
\nabla \cdot q_{p r}=\int_{0}^{\infty} k_{p a \lambda}\left(4 \pi I_{p b \lambda}-\int_{4 \pi} I_{\lambda} d \Omega\right) d \lambda,
$$

DOM solves RTE equation for a given direction. The radiation field is divided into discrete solid angles, which are measured in steradian [sr], as shown in Fig. D.1. One steradian is a solid angle whose area at the sphere surface is equal to the square of radius and subtended at spheres's centre. Therefore, a whole sphere has a solid angle of $4 \pi \mathrm{sr}$.

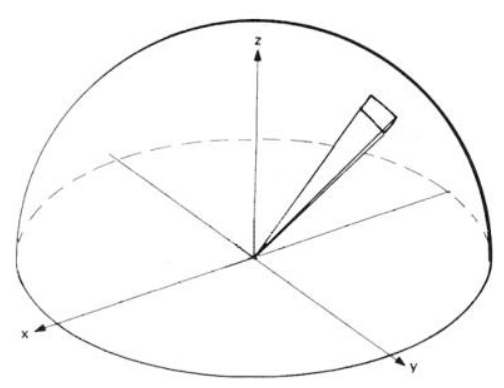

Figure D.1: Illustration of a discrete solid angle used for DOM solution.

DOM requires specification of the number of solid angles or ordinates into which the sphere surrounding any given point is divided. The accuracy of the solution is improved by using a large number of solid angles or ordinates. More details about this method can be found in 
Fiveland (1984) and Klason et al. (2008). Based on this method, Eq. (D.1) is discretized as follows:

$$
s_{i} \cdot \nabla I_{i \Delta \lambda}=-\beta_{\Delta \lambda} I_{i \Delta \lambda}+k_{a \Delta \lambda} I_{b \Delta \lambda}+\frac{k_{s \Delta \lambda}}{4 \pi} \sum_{j=1}^{n} w_{j} I_{j \Delta \lambda}+\bar{k}_{p a \Delta \lambda} I_{p b \Delta \lambda}+\frac{\bar{k}_{p s \Delta \lambda}}{4 \pi} \sum_{j=1}^{n} w_{j} I_{j \Delta \lambda},
$$

where $\Delta \lambda$ is a wavelength band from $\lambda_{m}$ to $\lambda_{n}, w_{j}$ is the quadrature weights that is a function of the chosen ordinates, $n$ is the number of ordinates, $\bar{k}_{p a \Delta \lambda}$ and $\bar{k}_{p s \Delta \lambda}$ are equivalent particle absorption and scattering coefficients, respectively.

The black body emission in the wavelength band $\lambda_{m}$ to $\lambda_{n}$ is expressed by Eq. (D.10):

$$
I_{b \Delta \lambda}=\int_{0}^{\lambda_{n}} I_{b \lambda} d \lambda-\int_{0}^{\lambda_{m}} I_{b \lambda} d \lambda
$$

The equivalent particle absorption and scattering coefficients are expressed by Eqs. (D.11) and (D.12), respectively.

$$
\begin{aligned}
\bar{k}_{p a \Delta \lambda} & =\sum_{i} Q_{a, i} N_{i} \frac{\pi d_{i}^{2}}{4}, \\
\bar{k}_{p s \Delta \lambda} & =\sum_{i} Q_{s, i} N_{i} \frac{\pi d_{i}^{2}}{4}
\end{aligned}
$$

where $i$ indicates the parcel index number, $N_{i}$ is the particle number density, $Q_{a, i}$ is the particle absorption efficiency and $Q_{s, i}$ is the particle absorption efficiency.

RTE equation is set and solved for each direction. Therefore, for a radiation field, the number of equations to be computed is equal to the number of ordinates. The resulting algebraic equations are solved using appropriate techniques as applied in other transport equations. It is 
important to evaluate boundary conditions at the wall. Thus, after angular discretization, the boundary conditions given by Eq. (D.5) take the following form:

$$
I_{i \Delta \lambda, w}=\epsilon_{w \Delta \lambda} I_{b \Delta \lambda}+\frac{\rho_{w \Delta \lambda}^{d}}{\pi_{e f f}} \sum_{\mathbf{n} \cdot \mathbf{s}^{\prime}<0} I_{j \Delta \lambda}\left|\mathbf{n} \cdot \mathbf{s}^{\prime}{ }_{j}\right|_{w}+f \rho_{w \Delta \lambda}^{s} I_{\Delta \lambda}\left(\mathbf{s}^{\mathbf{s}}\right)+\tau_{w \Delta \lambda} I_{i \Delta \lambda}
$$

Beside the other symbols defined before, $f$ is the correction factor that is used when the direction of specular reflection is not aligned with any discrete ordinate direction. The diffuse reflection term represents summation over incident ordinate directions.

Convergence of solution is determined using the usual way of the normalized difference in the incident energy from successive space-angle sweeps. This is set by specifying an appropriate convergence tolerance on the solver.

Radiation energy is exchanged with fluid medium through a source term in the gas phase energy Eq. (4.5). The coupling is through Eq. (D.7) whose discretized form for a particular cell is expressed by Eq. (D.14):

$$
-\nabla \cdot q_{r}=\sum_{\lambda} k_{a \Delta \lambda}\left(\sum_{j=1}^{n} w_{j} I_{j \Delta \lambda}-4 \pi I_{b \Delta \lambda}\right)
$$

The net absorption rate of radiative energy by all particles within a given cell is expressed by Eq. (D.15):

$$
-\nabla \cdot q_{p r}=\sum_{\lambda} \bar{k}_{p a \Delta \lambda}\left(\sum_{j=1}^{n} w_{j} I_{j \Delta \lambda}-4 \pi I_{p b \Delta \lambda}\right)
$$

At convergence, Eqs. (D.15) exactly balances the net radiative energy that all particles absorb. 


\section{D.2 Finite Volume Discretization for Continuous Phase}

In this technique, the computation domain is divided into a finite number of small control volumes which are equivalent to the cell in a computational grid. Integral transport equations in their discrete form are applied at each control volume, $V$.

The integral form of a general transport equation of a scalar quantity, $\phi$, in a continuum is given by Eq. (D.16):

$$
\frac{d}{d t} \int_{V} \rho \chi \phi \mathrm{dV}+\int_{A} \rho \phi\left(\mathbf{v}-\mathbf{v}_{\mathbf{g g}}\right) \cdot \mathrm{d} \mathbf{a}=\int_{A} \Gamma \nabla \phi \cdot \mathrm{d} \mathbf{a}+\int_{V} S_{\phi} d V,
$$

The discrete form of Eq. (D.16) applied to a cell-centered control volume for cell-0 is expressed by Eq. (D.17):

$$
\frac{d}{d t}(\rho \chi \phi V)_{0}+\sum_{f}[\rho \phi(\mathbf{v} \cdot \mathbf{a}-G)]_{f}=\sum_{f}(\Gamma \nabla \phi \cdot \mathbf{a})_{f}+\left(S_{\phi} V\right)_{0}
$$

where, $\mathbf{a}$ is the face area vector, A is the face area, subscript $f$ is the face quantity, $G$ is the grid flux, $\mathbf{v}$ is the velocity $\mathbf{v}_{\mathbf{g g}}$ is the grid velocity, subscript 0 is the cell- 0 quantity and $\Gamma$ is the diffusion coefficient. $G$ is computed from the mesh motion as $G_{f}=\mathbf{v}_{\mathbf{g g}} \cdot \boldsymbol{a}_{f}$.

The different terms in Eq. (D.17), namely, transient term, convective flux, diffusion flux and source term are discretized using different techniques.

The transient term is discretized using first-order or second-order temporal discretization scheme. The first-order scheme is Euler implicit scheme which consider the current time level $(n+1)$ and the previous time level n, expressed by Eq. (D.18):

$$
\frac{d}{d t}(\rho \chi \phi V)_{0}=\frac{(\rho \chi \phi V)_{0}{ }^{n+1}-(\rho \chi \phi V)_{0}{ }^{n}}{\Delta t} .
$$


The second order temporal scheme uses solutions at three time levels; current time level (n + 1) and two previous time levels, $n$ and ( $n-1)$. It is expressed by Eq. (D.19):

$$
\frac{d}{d t}(\rho \chi \phi V)_{0}=\frac{\left(\gamma^{2}-1\right)\left[(\rho \chi \phi V)_{0}{ }^{n+1}-(\rho \chi \phi V)_{0}{ }^{n}\right]+\left[(\rho \chi \phi V)_{0}{ }^{n-1}-(\rho \chi \phi V)_{0}{ }^{n}\right]}{\gamma(\gamma-1) \Delta t^{n+1}}
$$

and

$$
\gamma=1+\frac{\Delta t^{n+1}}{\Delta t^{n}}, \quad \Delta t^{n+1}=t^{n+1}-t^{n}, \quad \Delta t^{n}=t^{n}-t^{n-1}
$$

On the first time step of a second order temporal scheme, a first order discretization scheme is used since only two time levels are available.

The convective flux at a face is discretized as follows:

$$
[\rho \phi(\mathbf{v} \cdot \mathbf{a}-G)]_{f}=(\dot{m} \phi)_{f}=\dot{m}_{f} \phi_{f}
$$

where $\dot{m}_{f}$ is the mass flow rate at the face. In STAR CCM+, the face value of the scalar $\phi_{f}$ is computed from cell value using different schemes. In this work first-order upwind, second order upwind and central differencing scheme have been applied for different scenarios.

In case of first-order upwind scheme, the convective flux is calculated as follows:

$$
(\dot{m} \phi)_{f}= \begin{cases}\dot{m}_{f} \phi_{0} & \text { for } \dot{m}_{f} \geq 0 \\ \dot{m}_{f} \phi_{1} & \text { for } \dot{m}_{f}<0\end{cases}
$$

This scheme is less accurate because it introduces a dissipative error which help the solution in convergence. It is used to obtain initial solution before switching to more accurate schemes.

In case of second-order upwind scheme, the convective flux is calculated as follows: 


$$
(\dot{m} \phi)_{f}= \begin{cases}\dot{m}_{f} \phi_{f, 0} & \text { for } \dot{m}_{f} \geq 0 \\ \dot{m}_{f} \phi_{f, 1} & \text { for } \dot{m}_{f}<0\end{cases}
$$

where the face values $\phi_{f, 0}$ and $\phi_{f, 1}$ are linearly interpolated from the cell values on either side of the face as expressed by Eqs. (D.24) and (D.25), respectively.

$$
\begin{aligned}
& \phi_{f, 0}=\phi_{0}+\mathbf{s}_{0} \cdot(\Delta \phi)_{r, 0}, \\
& \phi_{f, 1}=\phi_{1}+\mathbf{s}_{1} \cdot(\Delta \phi)_{r, 1},
\end{aligned}
$$

where $\mathbf{s}$ is the vector between cell face and cell centroid, $\mathbf{x}$ is the position vector and $\mathbf{s}_{0}=\mathbf{x}_{f}$ $\mathbf{x}_{0}, \mathbf{s}_{1}=\mathbf{x}_{f}-\mathbf{x}_{1}$ while $(\Delta \phi)_{r, 0}$ and $(\Delta \phi)_{r, 1}$ are the limited reconstruction gradients in cells 0 and 1, respectively. This scheme has a second-order accuracy. Despite introduction of dissipation errors through reconstruction gradients, it is still more accurate than first-order scheme. However, it has a poorer convergence.

And in case of central differencing scheme, the convective flux is calculated as follows:

$$
(\dot{m} \phi)_{f}=\dot{m}_{f}\left(\omega_{f} \phi_{0}+\left(1-\omega_{f}\right) \phi_{1}\right) .
$$

where $\omega_{f}$ is the geometric weighting factor related to mesh stretching. For uniform mesh $\omega_{f}$ would have a value of 0.5 . It is second-order accurate. However, it is prone to dispersive error which is problematic to positive definite quantities such as temperature and turbulent kinetic energy.

In diffusion term, the interior face gradient $\left(\nabla \phi_{f}\right)$ is computed from cell values $\phi_{0}$ and $\phi_{1}$ through the following expression:

$$
\nabla \phi_{f}=\left(\phi_{1}-\phi_{0}\right) \vec{\alpha}+\overline{\nabla \phi}-(\overline{\nabla \phi} \cdot \mathbf{d s}) \vec{\alpha},
$$

where 


$$
\vec{\alpha}=\frac{\mathbf{a}}{\mathbf{a} \cdot \mathbf{d s}}, \quad \mathbf{d s}=\mathbf{x}_{\mathbf{1}}-\mathbf{x}_{0} \text { and } \overline{\nabla \phi}=\frac{\nabla \phi_{0}+\nabla \phi_{1}}{2}
$$

The second-order accurate expression for diffusion flux at an interior face, $D_{f}$ is subsequently represented by Eq. (D.28):

$$
D_{f}=\Gamma_{f} \nabla \phi_{f} \cdot \mathbf{a}=\Gamma_{f}\left(\phi_{1}-\phi_{0}\right) \vec{\alpha} \cdot \mathbf{a}+\overline{\nabla \phi} \cdot \mathbf{a}-(\overline{\nabla \phi} \cdot \mathbf{d} \mathbf{s}) \vec{\alpha} \cdot \mathbf{a},
$$

where $\Gamma_{f}$ is a suitable average value of the cell values.

The second and third terms in Eq. (D.28) represent the secondary gradient contribution. They are essential for maintaining accuracy on non-orthogonal meshes. The formulation of the diffusion flux at the face assumes that the centroids of cells 0 and 1 lie on opposing sides of the face, as illustrated by Fig. D.2. It is further assumed that their location is consistent with the convention that the face area vector points out of cell 0 . None-physical solutions are avoided by using mesh for which the angle between a and ds should be less than 90 degrees. In STAR $\mathrm{CCM}+$ software, this is ensured by checking mesh skewness angle which is computed and stored in the adjacent cell. The value that is stored in each cell represents the largest skewness angle for each face of the cell.

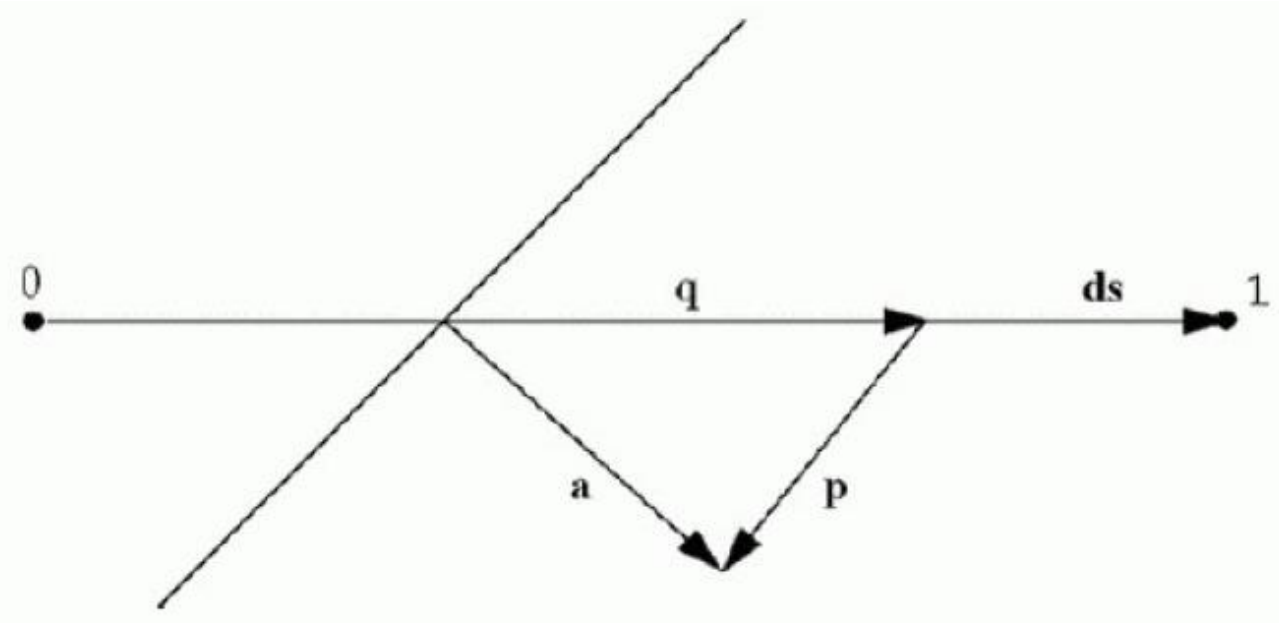

Figure D.2: Discretization of diffusion flux at an interior face. 
Similarly, the second-order accurate expression for diffusion flux at a boundary face, $D_{f}$ is subsequently represented by Eq. (D.29):

$$
D_{f}=\Gamma_{f} \nabla \phi_{f} \cdot \mathbf{a}=\Gamma_{f}\left(\phi_{f}-\phi_{0}\right) \vec{\alpha} \cdot \mathbf{a}+\nabla \phi \cdot \mathbf{a}-(\nabla \phi \cdot \mathbf{d s}) \vec{\alpha} \cdot \mathbf{a},
$$

where $\mathbf{d s}=\mathbf{x}_{f}-\mathbf{x}_{0}$.

\section{D.3 Lagrange Phase Formulation}

Solid-phase was modeled through Lagrangian multiphase approach. The Lagrangian multiphase model enables solution of any number of different phases with each being modelled in Lagrangian framework. In this framework, parcels which represent particles are tracked in the continuum. A parcel represents a localized group of dispersed phases having the same properties. A given number of particles are grouped together in a single parcel. Thus a parcel is analogous to a cell used in discretization of a continuous fluid domain. To improve prediction accuracy and a better representation of the entire population of particles, a large number of parcels should be used.

The position of each parcel, $r_{p}(t)$ with respect to the frame of reference, is tracked using equation of motion:

$$
\frac{d r_{p}}{d t}=\mathbf{v}_{p}-\mathbf{v}_{g}
$$

where $\mathbf{v}_{g}(\mathbf{x}, t)$ is the grid velocity which is evaluated at parcel mean centroid and $\mathbf{v}_{p}(t)$ is the absolute velocity of the parcel. 
The solution of equations in a Lagrangian framework implies the time-marching of ordinary differential equations (ODEs). An ODE for the position of each parcel, Eq. (D.30) is formulated in order to solve the governing equation for Lagrangian phase equations.

The conversion of wood particles in the fixed bed is unsteady. A time-step in an unsteady simulation advances the solution from time $t$ to time $t+\Delta t$. In STAR CCM+ software, a single iteration of the unsteady solver for the Lagrangian Multiphase model involves:

1. Recovering the Lagrangian Multiphase solution at time $t$.

2. Advancing the Lagrangian Multiphase solution to time $t+\Delta t$ by time-marching. A local time-step is used for each parcel. The time-step is adjusted dynamically according to the time-step controls in force.

These two steps are executed in each iteration of the unsteady solver, before the flow solver. Through two way coupling model, source terms that the Lagrangian phase models compute are stored for subsequent application in their respective transport equations in continuous phase. 


\section{APPENDIX E \\ SPECIES GENERATION AND DEPLETION IN FUEL BED}

\section{E.1 Particle Packing Density}

Figures E.1 - E.12 show comparison of species generation and depletion in the fuel bed at different bed heights for wood combustion in a fixed bed under oxy-fuel conditions and different particles packing density. Comparisons are done when the flame front is passing through $4 \mathrm{~cm}, 3 \mathrm{~cm}, 2 \mathrm{~cm}$ and $1 \mathrm{~cm}$ from fuel bed bottom, respectively.

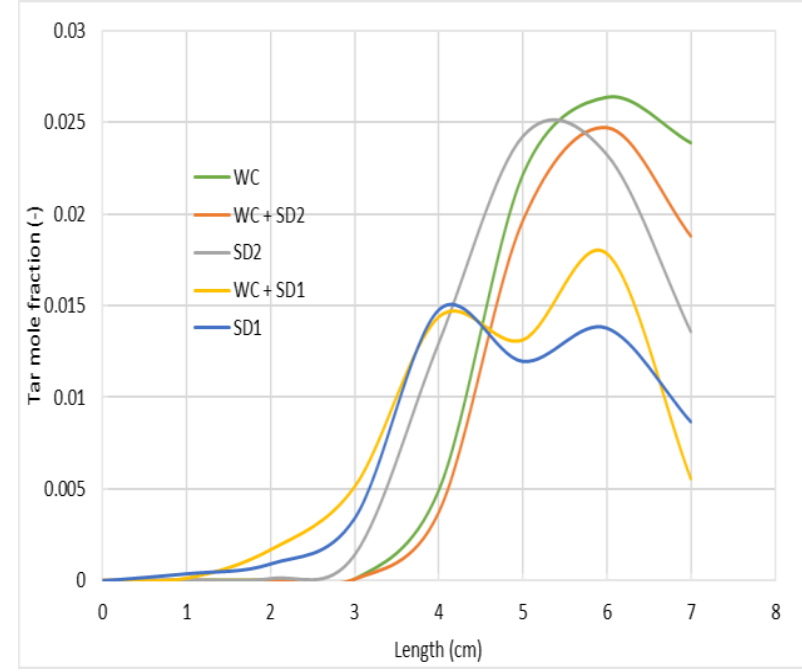

(a)

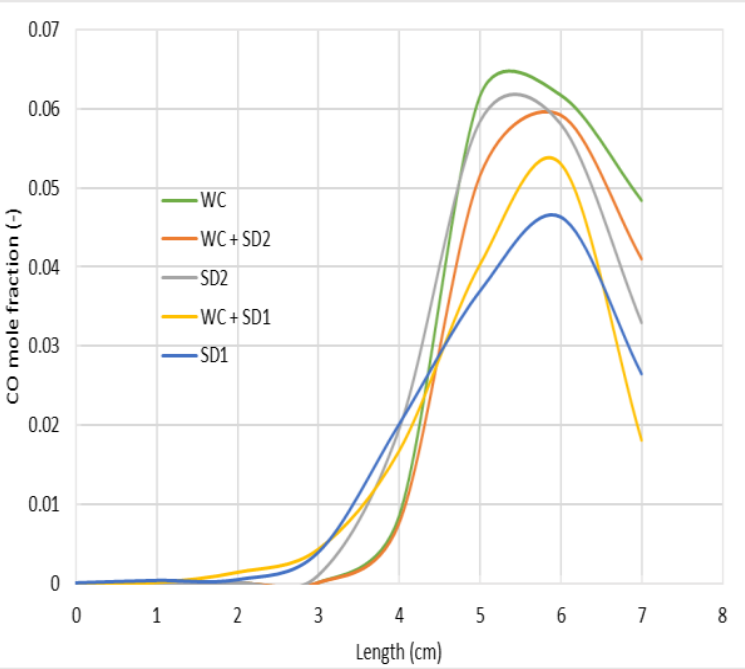

(b)

Figure E.1: Comparison of species concentration profiles along axial length of the bed for different fuel types burning under oxy-fuel condition when reaction front is at $4 \mathrm{~cm}$ from the grate: (a) Tar mole fraction (b) $\mathrm{CO}$ mole fraction. 


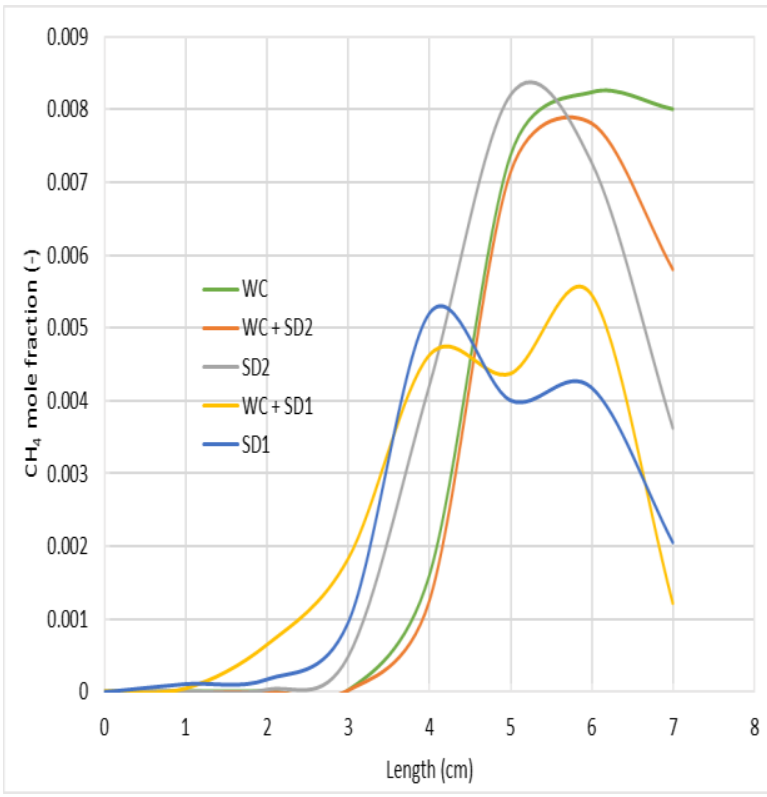

(a)

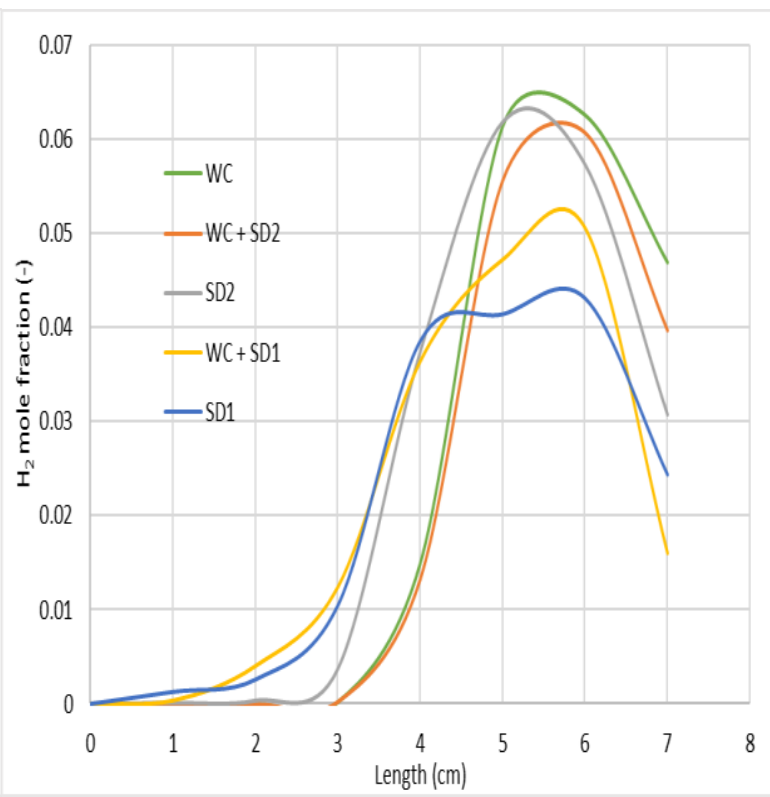

(b)

Figure E.2: Comparison of species concentration profiles along axial length of the bed for different fuel types burning under oxy-fuel condition when reaction front is at $4 \mathrm{~cm}$ from the grate: (a) $\mathrm{CH}_{4}$ mole fraction (b) $\mathrm{H}_{2}$ mole fraction.

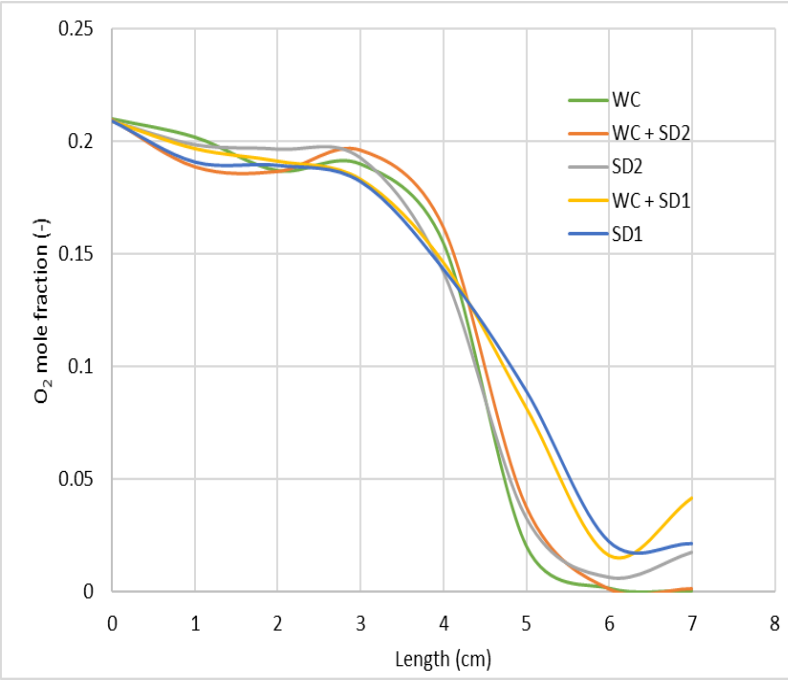

(a)

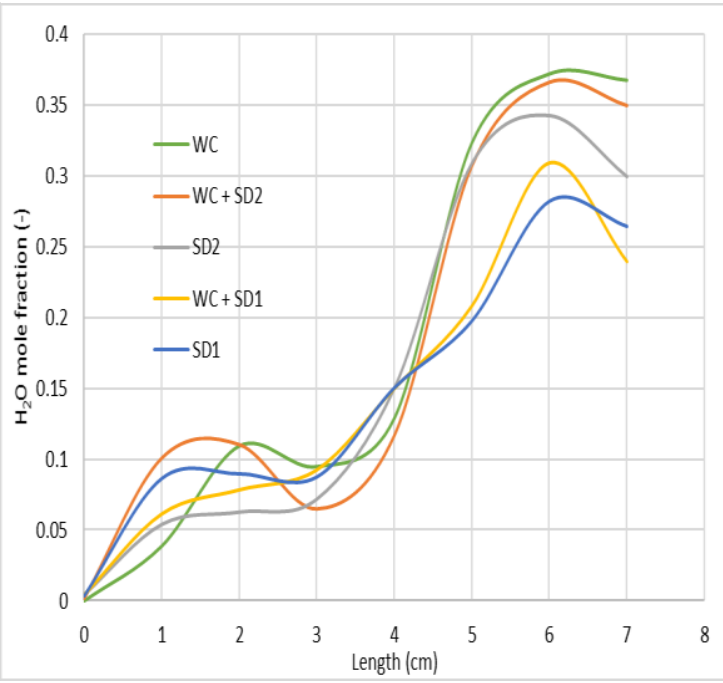

(b)

Figure E.3: Comparison of species concentration profiles along axial length of the bed for different fuel types burning under oxy-fuel condition when reaction front is at $4 \mathrm{~cm}$ from the grate: (a) $\mathrm{O}_{2}$ mole fraction (b) $\mathrm{H}_{2} \mathrm{O}$ mole fraction. 


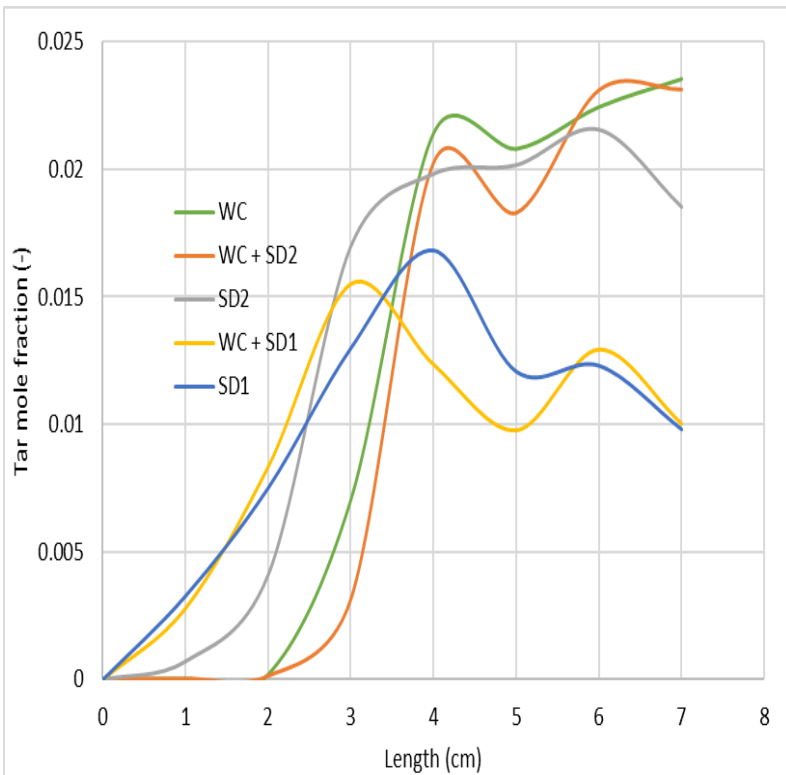

(a)

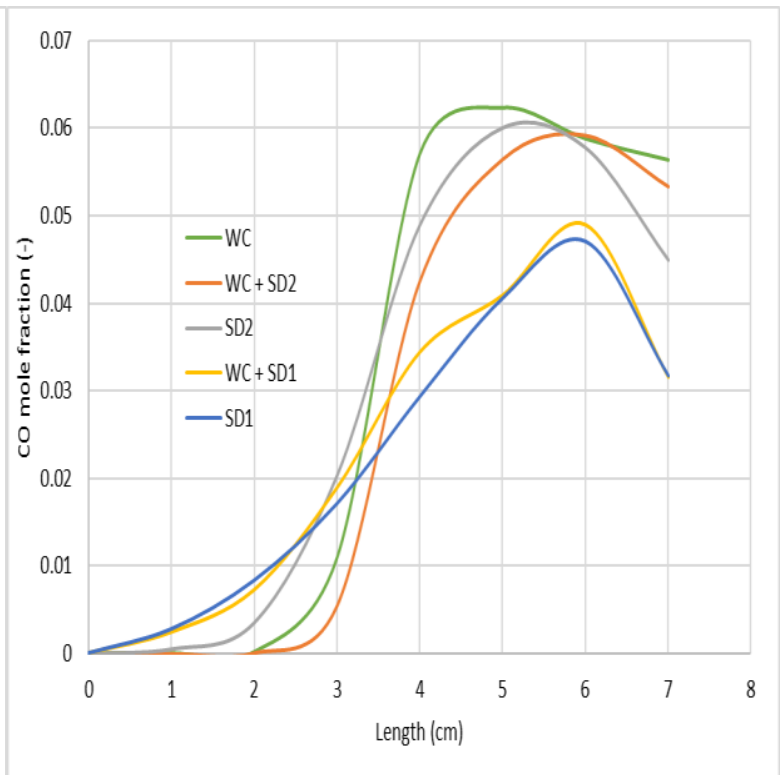

(b)

Figure E.4: Comparison of species concentration profiles along axial length of the bed for different fuel types burning under oxy-fuel condition when reaction front is at $3 \mathrm{~cm}$ from the grate: (a) Tar mole fraction (b) $\mathrm{CO}$ mole fraction.

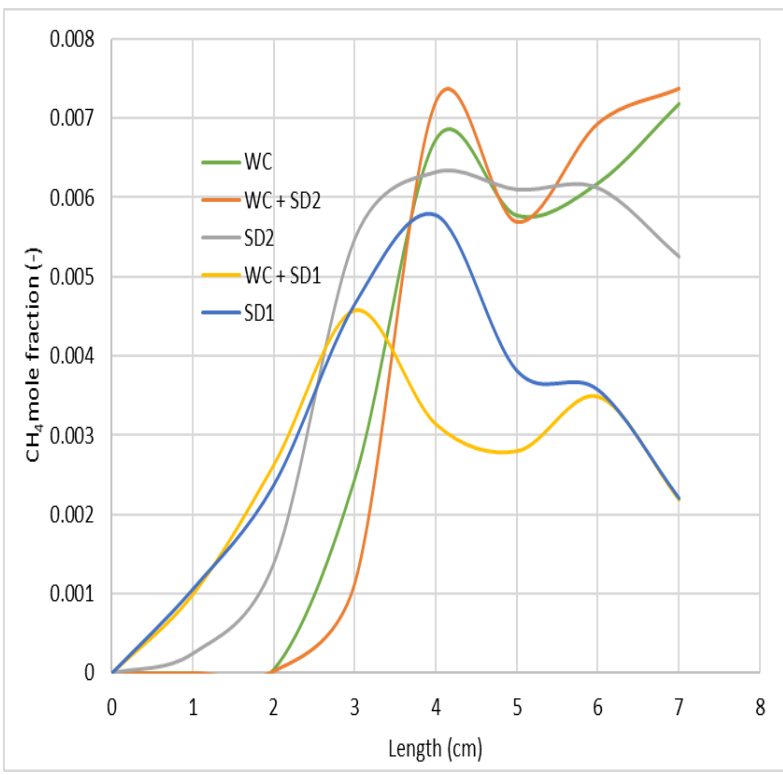

(a)

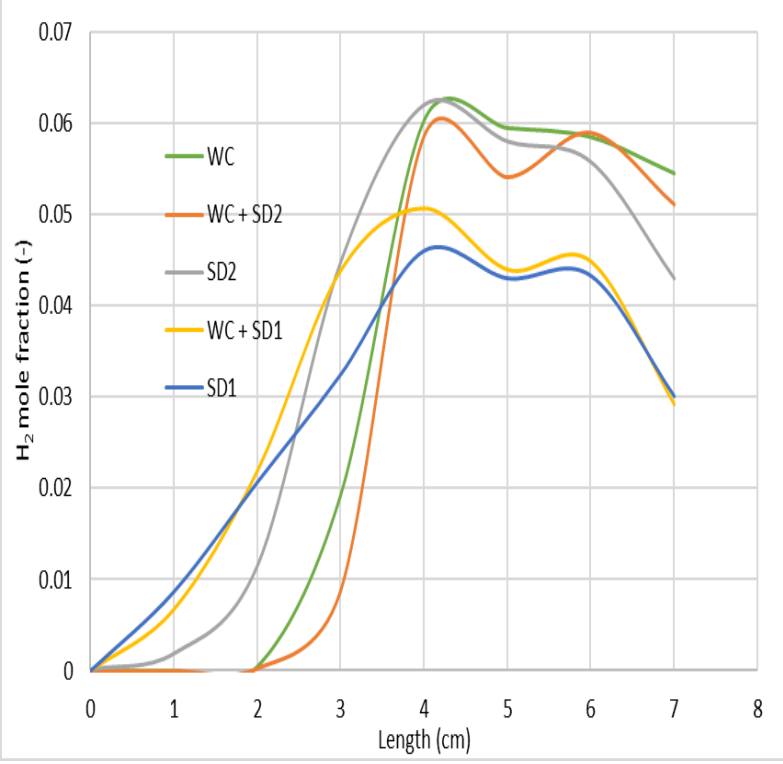

(b)

Figure E.5: Comparison of species concentration profiles along axial length of the bed for different fuel types burning under oxy-fuel condition when reaction front is at $3 \mathrm{~cm}$ from the grate: (a) $\mathrm{CH}_{4}$ mole fraction (b) $\mathrm{H}_{2}$ mole fraction. 


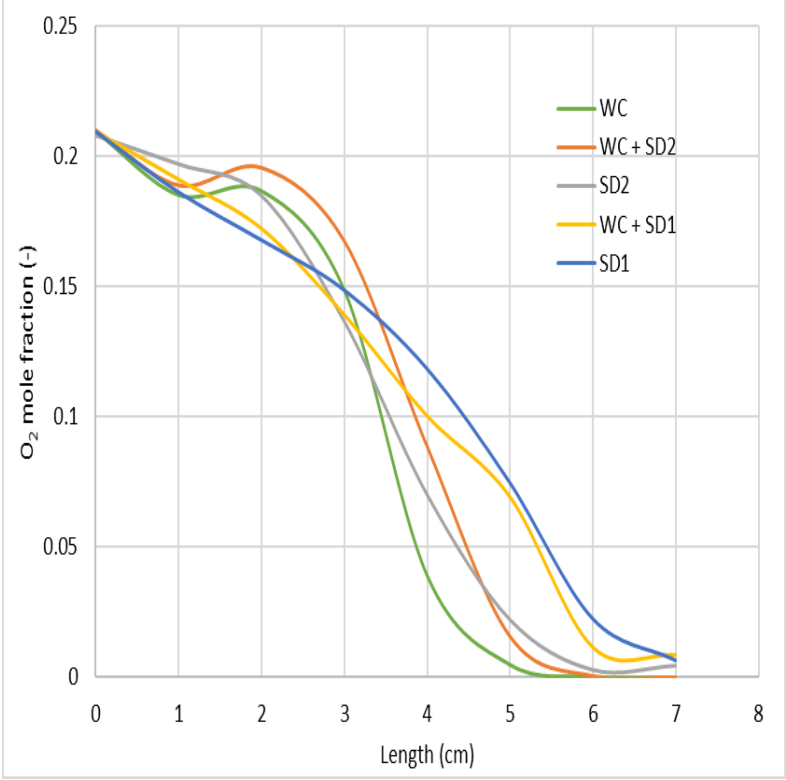

(a)

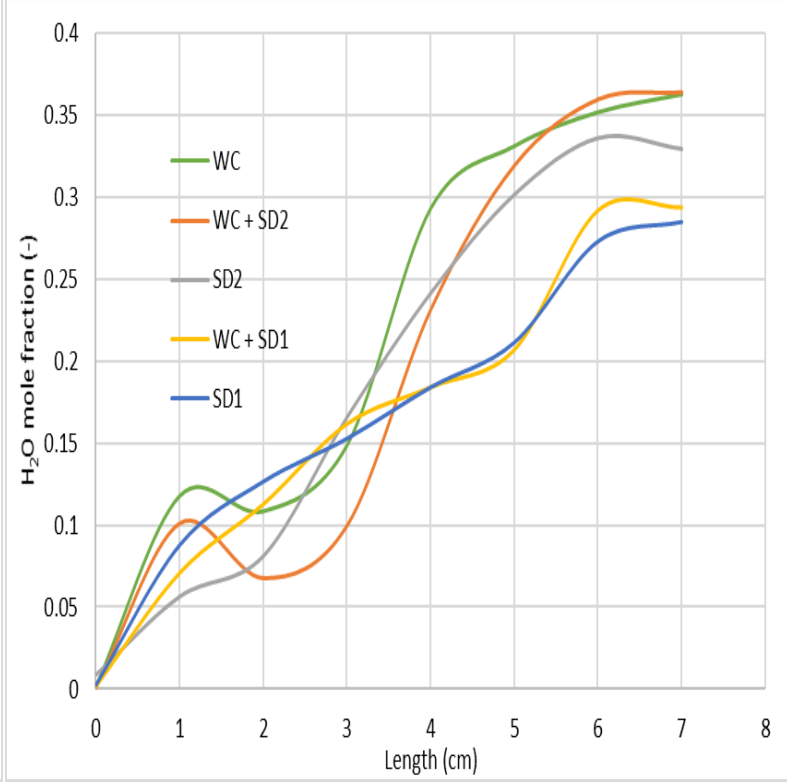

(b)

Figure E.6: Comparison of species concentration profiles along axial length of the bed for different fuel types burning under oxy-fuel condition when reaction front is at $3 \mathrm{~cm}$ from the grate: (a) $\mathrm{O}_{2}$ mole fraction (b) $\mathrm{H}_{2} \mathrm{O}$ mole fraction.

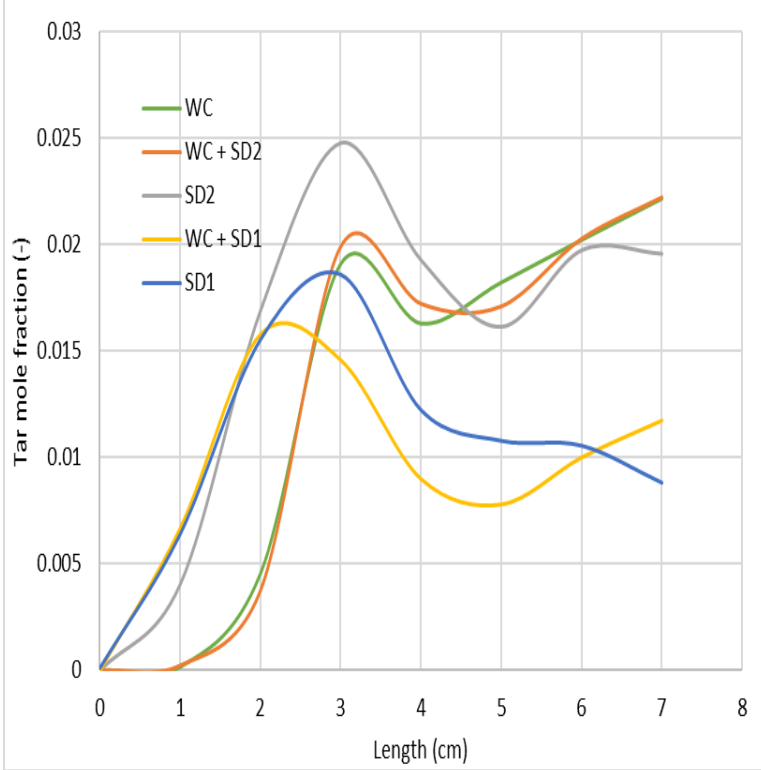

(a)

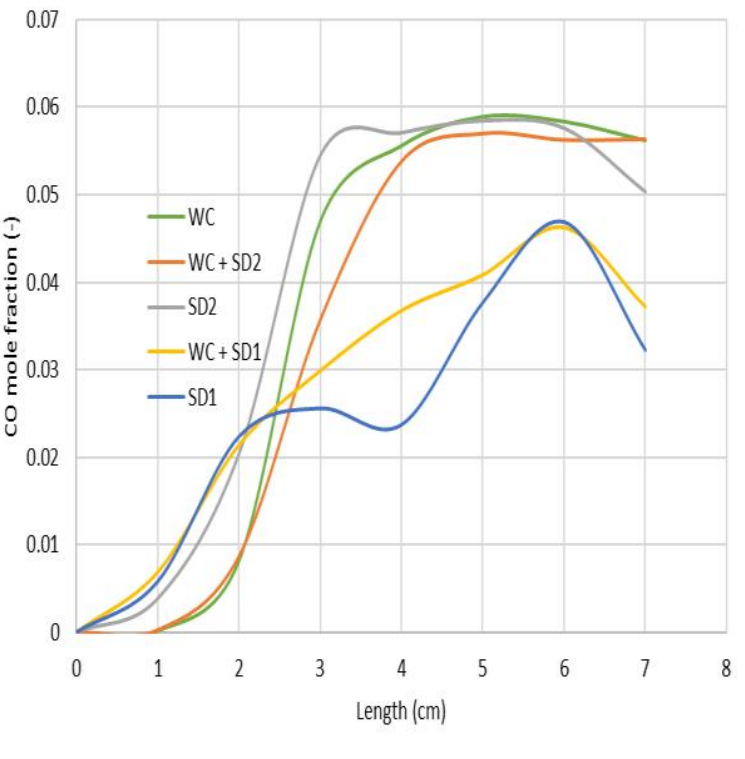

(b)

Figure E.7: Comparison of species concentration profiles along axial length of the bed for different fuel types burning under oxy-fuel condition when reaction front is at $2 \mathrm{~cm}$ from the grate: (a) Tar mole fraction (b) CO mole fraction. 


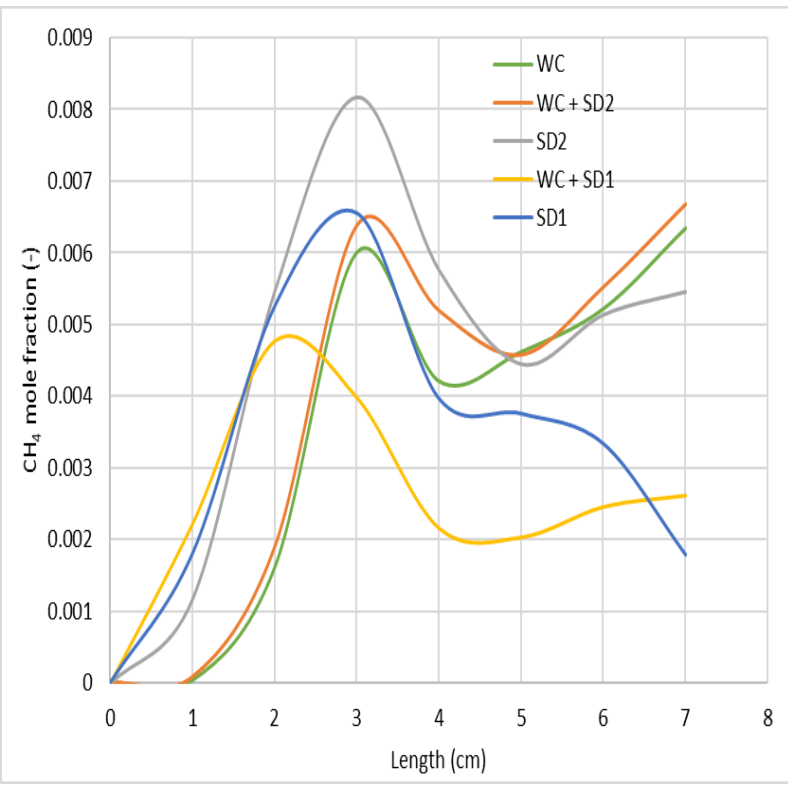

(a)

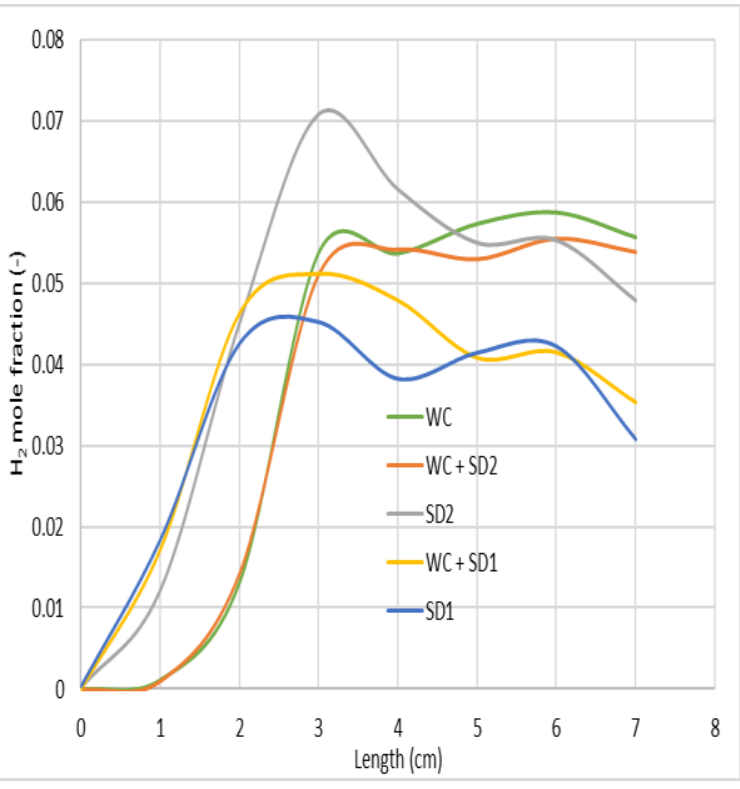

(b)

Figure E.8: Comparison of species concentration profiles along axial length of the bed for different fuel types burning under oxy-fuel condition when reaction front is at $2 \mathrm{~cm}$ from the grate: (a) $\mathrm{CH}_{4}$ mole fraction (b) $\mathrm{H}_{2}$ mole fraction.

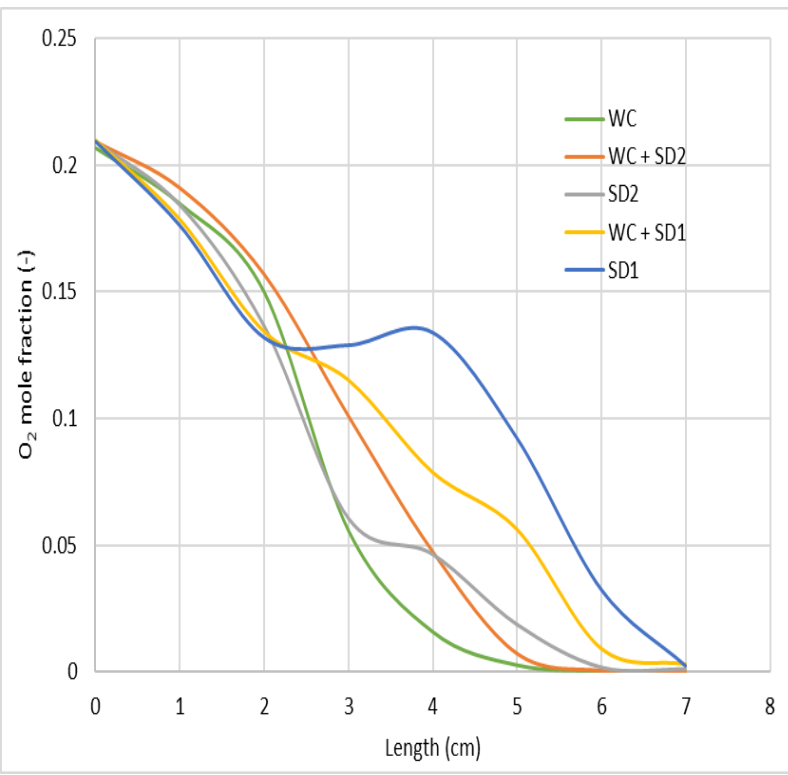

(a)

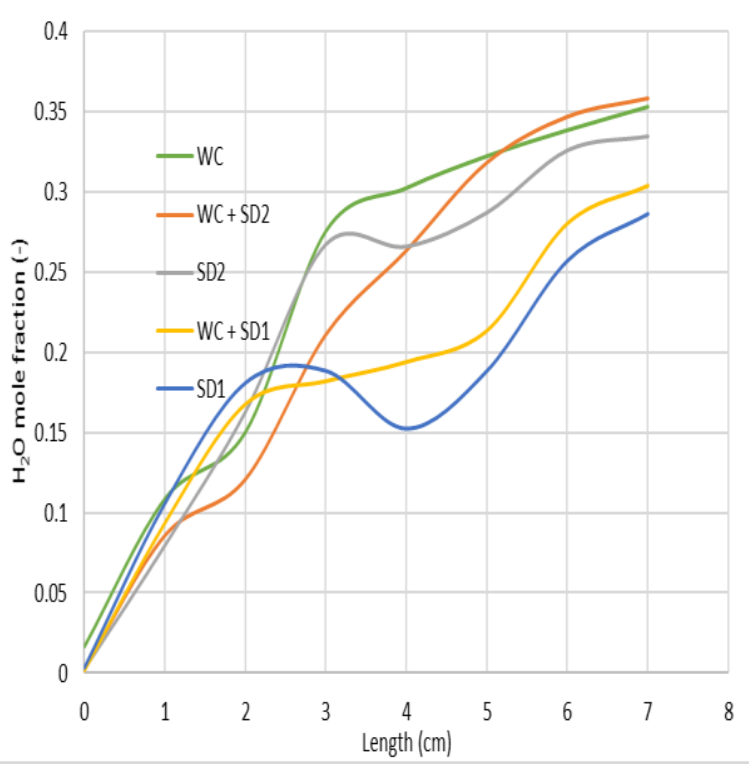

(b)

Figure E.9: Comparison of species concentration profiles along axial length of the bed for different fuel types burning under oxy-fuel condition when reaction front is at $2 \mathrm{~cm}$ from the grate: (a) $\mathrm{O}_{2}$ mole fraction (b) $\mathrm{H}_{2} \mathrm{O}$ mole fraction. 


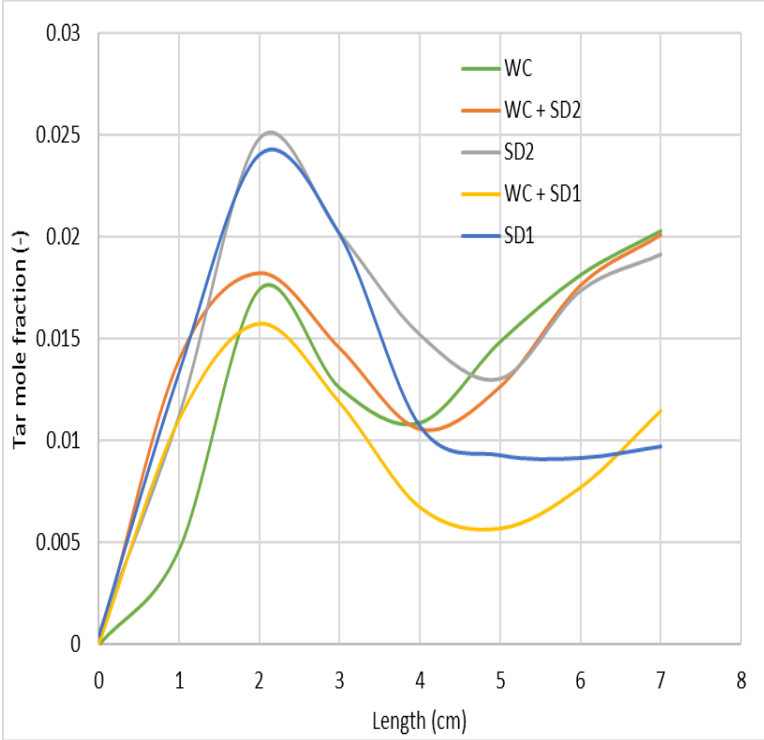

(a)

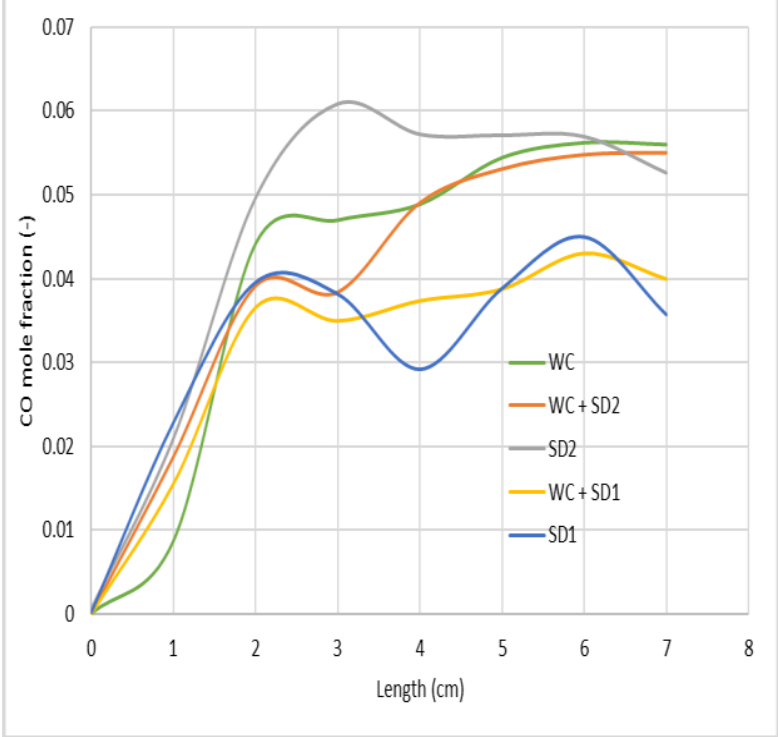

(b)

Figure E.10: Comparison of species concentration profiles along axial length of the bed for different fuel types burning under oxy-fuel condition when reaction front is at $1 \mathrm{~cm}$ from the grate: (a) Tar mole fraction (b) CO mole fraction.

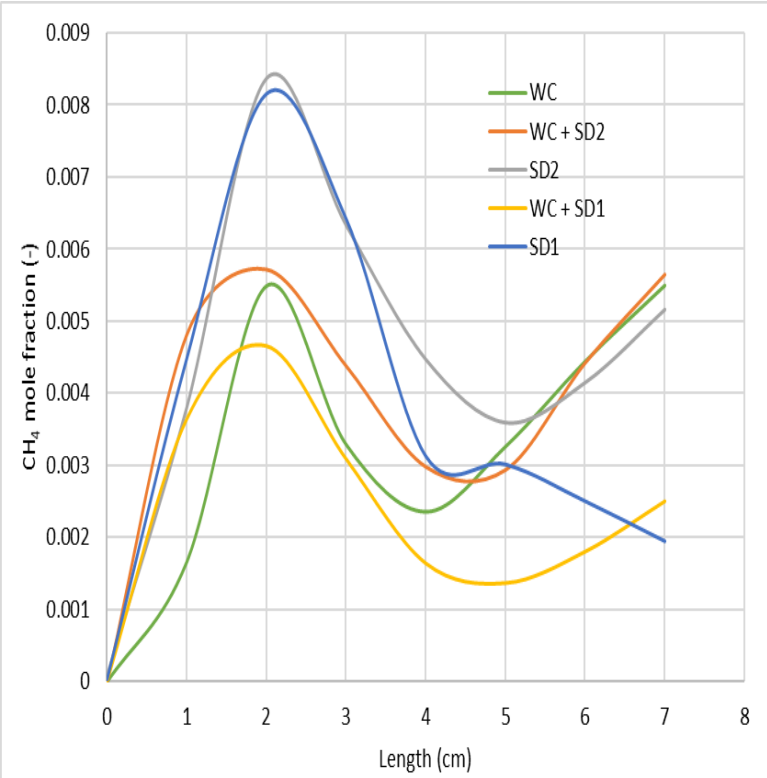

(a)

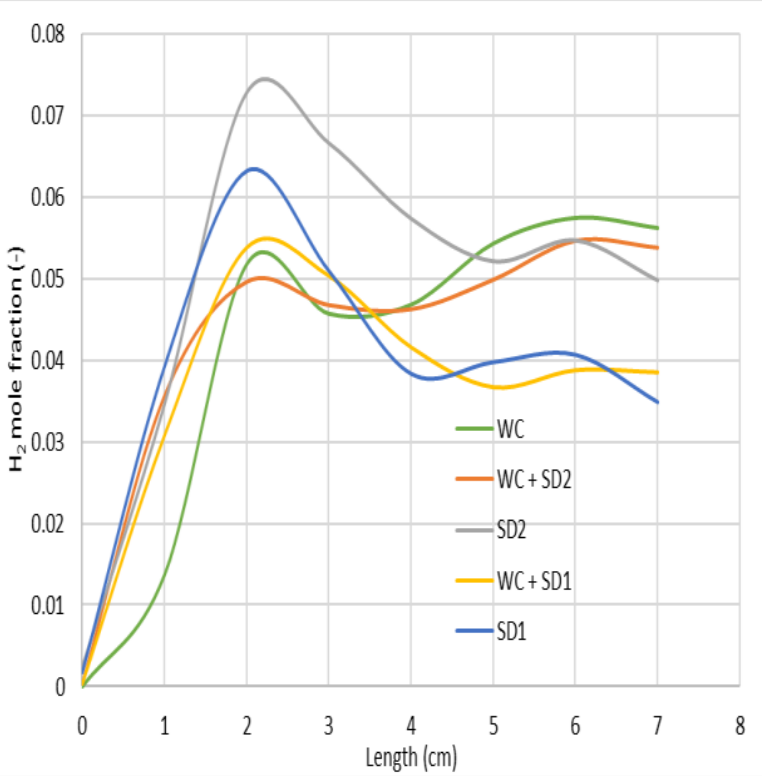

(b)

Figure E.11: Comparison of species concentration profiles along axial length of the bed for different fuel types burning under oxy-fuel condition when reaction front is at $1 \mathrm{~cm}$ from the grate: (a) $\mathrm{CH}_{4}$ mole fraction (b) $\mathrm{H}_{2}$ mole fraction. 


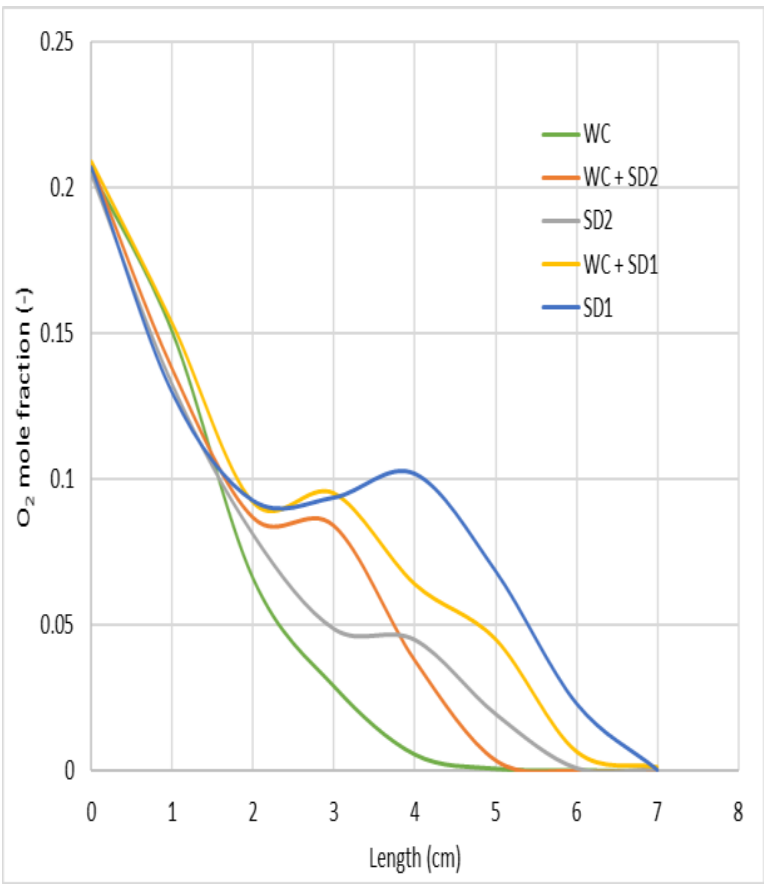

(a)

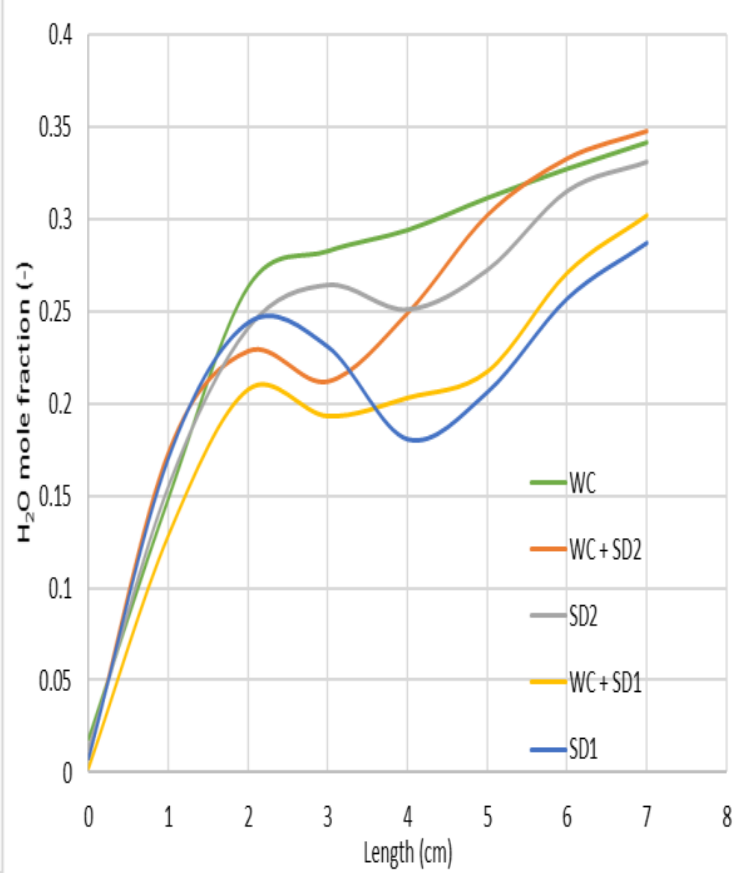

(b)

Figure E.12: Comparison of species concentration profiles along axial length of the bed for different fuel types burning under oxy-fuel condition when reaction front is at $1 \mathrm{~cm}$ from the grate: (a) $\mathrm{O}_{2}$ mole fraction (b) $\mathrm{H}_{2} \mathrm{O}$ mole fraction.

Tables E.1 - E.5 show the peak values for the major combustible species mole fraction and temperature along axial length of the bed for combustion of different types of wood in a fixed bed under oxy-fuel conditions. The tables present values for position $1 \mathrm{~cm}$ to $10 \mathrm{~cm}$ of the fixed bed measured from fuel bed bottom. 
Table E.1: Peak values of temperature and the major combustible species mole fraction along the axial length of the fixed bed for fuel type SD1 burning under oxy-fuel condition.

\begin{tabular}{lrrrrrrrrrrr}
\hline \multirow{2}{*}{$\begin{array}{c}\text { Temperature/ } \\
\text { species mole } \\
\text { fraction (-) }\end{array}$} & $1 \mathrm{~cm}$ & $2 \mathrm{~cm}$ & $3 \mathrm{~cm}$ & $4 \mathrm{~cm}$ & $5 \mathrm{~cm}$ & $6 \mathrm{~cm}$ & $7 \mathrm{~cm}$ & $8 \mathrm{~cm}$ & $9 \mathrm{~cm}$ & $10 \mathrm{~cm}$ \\
\cline { 2 - 11 } $\begin{array}{l}\text { Temperature } \\
(\mathrm{K})\end{array}$ & 1156 & 1274 & 1307 & 1157 & 1027 & 1096 & 1115 & 1027 & 913 & 678 \\
Tar & 0.0131 & 0.0156 & 0.0153 & 0.0168 & 0.0159 & 0.0166 & 0.0100 & 0.0023 & 0.0001 & 0.0000 \\
$\mathrm{CO}$ & 0.0313 & 0.0330 & 0.0386 & 0.0305 & 0.0409 & 0.0478 & 0.0371 & 0.0110 & 0.0013 & 0.0002 \\
$\mathrm{CH}_{4}$ & 0.0043 & 0.0045 & 0.0054 & 0.0058 & 0.0058 & 0.0058 & 0.0022 & 0.0004 & 0.0000 & 0.0000 \\
$\mathrm{H}_{2}$ & 0.0429 & 0.0475 & 0.0494 & 0.0460 & 0.0446 & 0.0468 & 0.0364 & 0.0100 & 0.0011 & 0.0002 \\
\hline
\end{tabular}

Table E.2: Peak values of temperature and the major combustible species mole fraction along the axial length of the fixed bed for fuel type WC + SD1 burning under oxy-fuel condition.

\begin{tabular}{lrrrrrrrrrrr}
\hline \multirow{2}{*}{$\begin{array}{c}\text { Temperature/ } \\
\text { species mole } \\
\text { fraction (-) }\end{array}$} & $1 \mathrm{~cm}$ & $2 \mathrm{~cm}$ & $3 \mathrm{~cm}$ & $4 \mathrm{~cm}$ & $5 \mathrm{~cm}$ & $6 \mathrm{~cm}$ & $7 \mathrm{~cm}$ & $8 \mathrm{~cm}$ & $9 \mathrm{~cm}$ & $10 \mathrm{~cm}$ \\
\cline { 2 - 11 } $\begin{array}{l}\text { Temperature } \\
(\mathrm{K})\end{array}$ & 1048 & 1235 & 1314 & 1319 & 1263 & 1299 & 1200 & 922 & 801 & 656 \\
$\mathrm{Tar}$ & 0.0144 & 0.0168 & 0.0158 & 0.0176 & 0.0165 & 0.0212 & 0.0118 & 0.0006 & 0.0001 & 0.0000 \\
$\mathrm{CO}$ & 0.0270 & 0.0386 & 0.0366 & 0.0377 & 0.0410 & 0.0617 & 0.0404 & 0.0040 & 0.0013 & 0.0002 \\
$\mathrm{CH}_{4}$ & 0.0050 & 0.0050 & 0.0046 & 0.0055 & 0.0060 & 0.0072 & 0.0026 & 0.0001 & 0.0000 & 0.0000 \\
$\mathrm{H}_{2}$ & 0.0396 & 0.0551 & 0.0516 & 0.0507 & 0.0504 & 0.0541 & 0.0391 & 0.0036 & 0.0012 & 0.0003 \\
\hline
\end{tabular}

Table E.3: Peak values of temperature and the major combustible species mole fraction along the axial length of the fixed bed for fuel type SD2 burning under oxy-fuel condition.

\begin{tabular}{lrrrrrrrrrrr}
\hline \multirow{2}{*}{$\begin{array}{c}\text { Temperature/ } \\
\text { species mole } \\
\text { fraction (-) }\end{array}$} & $1 \mathrm{~cm}$ & $2 \mathrm{~cm}$ & $3 \mathrm{~cm}$ & $4 \mathrm{~cm}$ & $5 \mathrm{~cm}$ & $6 \mathrm{~cm}$ & $7 \mathrm{~cm}$ & $8 \mathrm{~cm}$ & $9 \mathrm{~cm}$ & $10 \mathrm{~cm}$ \\
\cline { 2 - 12 } $\begin{array}{l}\text { Temperature } \\
(\mathrm{K})\end{array}$ & 1236 & 1409 & 1381 & 1331 & 1246 & 1275 & 1196 & 1189 & 1082 & 978 \\
Tar & 0.0205 & 0.0266 & 0.0256 & 0.0242 & 0.0259 & 0.0253 & 0.0200 & 0.0113 & 0.0016 & 0.0001 \\
$\mathrm{CO}$ & 0.0843 & 0.0842 & 0.0822 & 0.0818 & 0.0801 & 0.0827 & 0.0526 & 0.0283 & 0.0073 & 0.0009 \\
$\mathrm{CH}_{4}$ & 0.0067 & 0.0088 & 0.0085 & 0.0083 & 0.0092 & 0.0086 & 0.0055 & 0.0030 & 0.0003 & 0.0000 \\
$\mathrm{H}_{2}$ & 0.0503 & 0.0633 & 0.0607 & 0.0679 & 0.0634 & 0.0604 & 0.0497 & 0.0267 & 0.0061 & 0.0008 \\
\hline
\end{tabular}


Table E.4: Peak values of temperature and the major combustible species mole fraction along the axial length of the fixed bed for fuel type WC + SD2 burning under oxy-fuel condition.

\begin{tabular}{lrrrrrrrrrrr}
\hline \multirow{2}{*}{$\begin{array}{c}\text { Temperature/ } \\
\text { species mole } \\
\text { fraction (-) }\end{array}$} & $1 \mathrm{~cm}$ & $2 \mathrm{~cm}$ & $3 \mathrm{~cm}$ & $4 \mathrm{~cm}$ & $5 \mathrm{~cm}$ & $6 \mathrm{~cm}$ & $7 \mathrm{~cm}$ & $8 \mathrm{~cm}$ & $9 \mathrm{~cm}$ & $10 \mathrm{~cm}$ \\
\cline { 2 - 12 } $\begin{array}{l}\text { Temperature } \\
(\mathrm{K})\end{array}$ & 1370 & 1380 & 1362 & 1227 & 1267 & 1280 & 1199 & 1157 & 1042 & 1444 \\
Tar & 0.0243 & 0.0220 & 0.0208 & 0.0212 & 0.0213 & 0.0270 & 0.0233 & 0.0100 & 0.0056 & 0.0027 \\
$\mathrm{CO}$ & 0.0947 & 0.0951 & 0.0946 & 0.0956 & 0.0953 & 0.0960 & 0.0621 & 0.0402 & 0.0187 & 0.0052 \\
$\mathrm{CH}_{4}$ & 0.0078 & 0.0073 & 0.0072 & 0.0073 & 0.0075 & 0.0090 & 0.0074 & 0.0027 & 0.0011 & 0.0003 \\
$\mathrm{H}_{2}$ & 0.0589 & 0.0527 & 0.0517 & 0.0598 & 0.0579 & 0.0648 & 0.0546 & 0.0546 & 0.0296 & 0.0161 \\
\hline
\end{tabular}

Table E.5: Peak values of temperature and the major combustible species mole fraction along the axial length of the fixed bed for fuel type WC burning under oxy-fuel condition.

\begin{tabular}{lrrrrrrrrrrr}
\hline \multirow{2}{*}{$\begin{array}{c}\text { Temperature/ } \\
\text { species mole } \\
\text { fraction (-) }\end{array}$} & $1 \mathrm{~cm}$ & $2 \mathrm{~cm}$ & $3 \mathrm{~cm}$ & $4 \mathrm{~cm}$ & $5 \mathrm{~cm}$ & $6 \mathrm{~cm}$ & $7 \mathrm{~cm}$ & $8 \mathrm{~cm}$ & $9 \mathrm{~cm}$ & $10 \mathrm{~cm}$ \\
\cline { 2 - 11 } & & & & & & & & & & & \\
\hline $\begin{array}{l}\text { Temperature } \\
(\mathrm{K})\end{array}$ & 1385 & 1379 & 1364 & 1366 & 1330 & 1325 & 1298 & 1265 & 1134 & 1105 \\
Tar & 0.0259 & 0.0261 & 0.0227 & 0.0248 & 0.0226 & 0.0313 & 0.0260 & 0.0185 & 0.0174 & 0.0161 \\
$\mathrm{CO}$ & 0.1053 & 0.1047 & 0.1047 & 0.1057 & 0.1063 & 0.1062 & 0.0568 & 0.0543 & 0.0513 & 0.0481 \\
$\mathrm{CH}_{4}$ & 0.0086 & 0.0085 & 0.0078 & 0.0084 & 0.0077 & 0.0110 & 0.0087 & 0.0048 & 0.0044 & 0.0039 \\
$\mathrm{H}_{2}$ & 0.0603 & 0.0551 & 0.0554 & 0.0649 & 0.0616 & 0.0692 & 0.0564 & 0.0564 & 0.0541 & 0.0508 \\
\hline
\end{tabular}

\section{E.2 Wood Combustion in a Fixed Bed under Oxy-fuel Condition}

Figures E.13 - E.24 show comparison of species generation and depletion in the fuel bed at different bed heights for wood combustion in a fixed bed under oxy-fuel conditions for different $\mathrm{O}_{2} / \mathrm{CO}_{2}$ mixtures. Comparisons are done when the flame front is passing through $4 \mathrm{~cm}, 3 \mathrm{~cm}$, $2 \mathrm{~cm}$ and $1 \mathrm{~cm}$ from fuel bed bottom, respectively. 


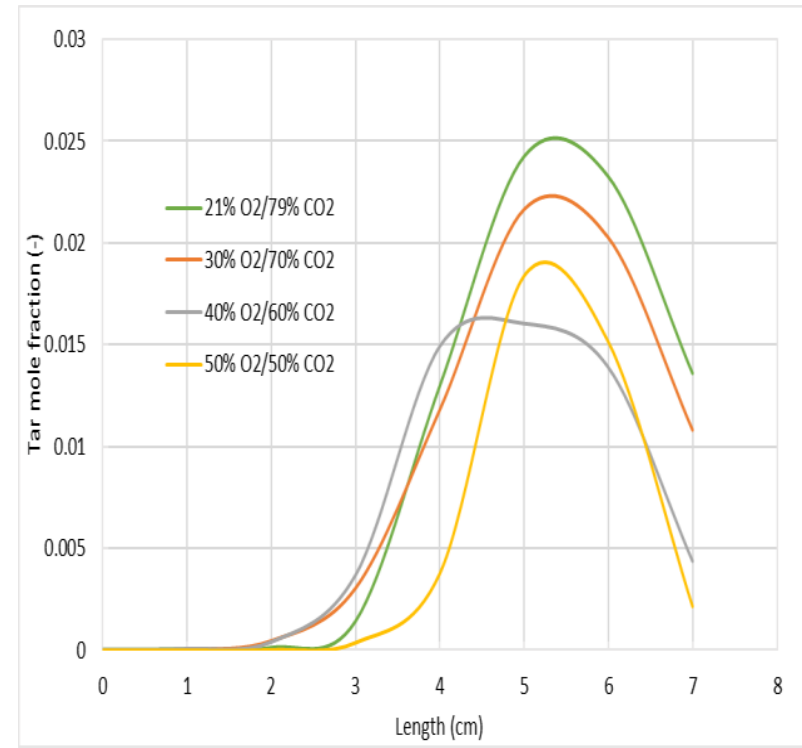

(a)

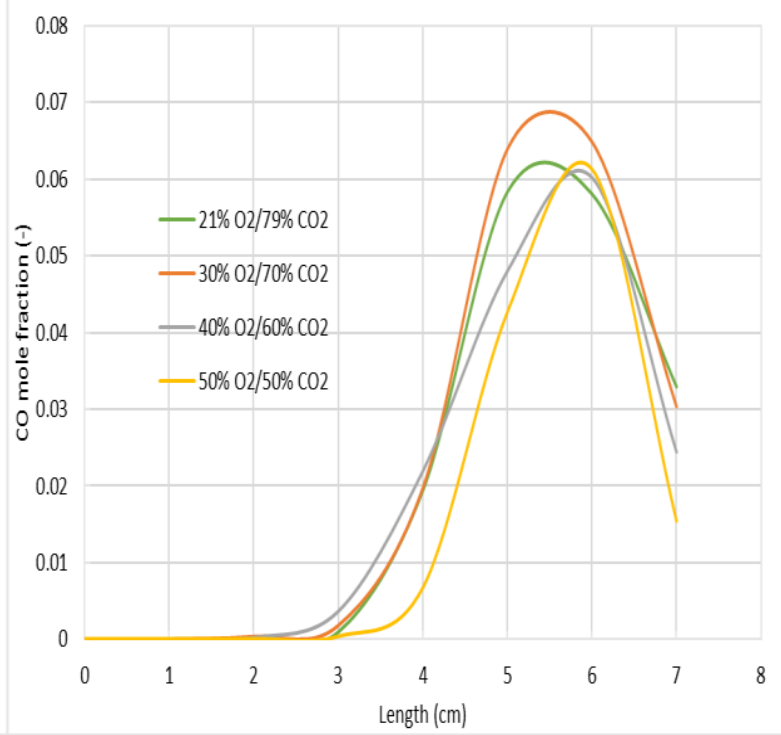

(b)

Figure E.13: Comparison of species concentration profiles along axial length of the bed burning under oxy-fuel condition for different $\mathrm{O}_{2} / \mathrm{CO}_{2}$ mixtures when reaction front is at $4 \mathrm{~cm}$ from the grate: (a) Tar mole fraction (b) $\mathrm{CO}$ mole fraction.

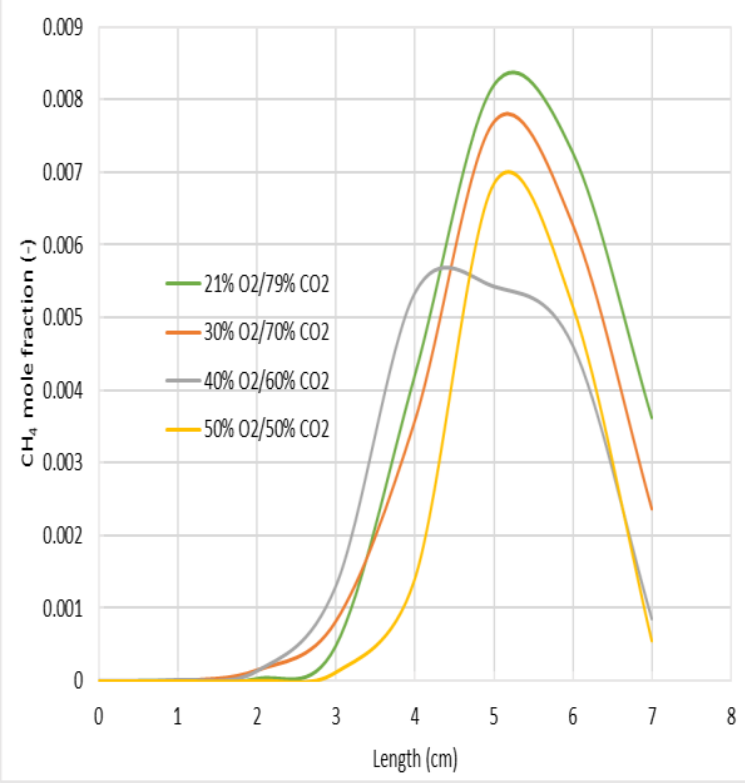

(a)

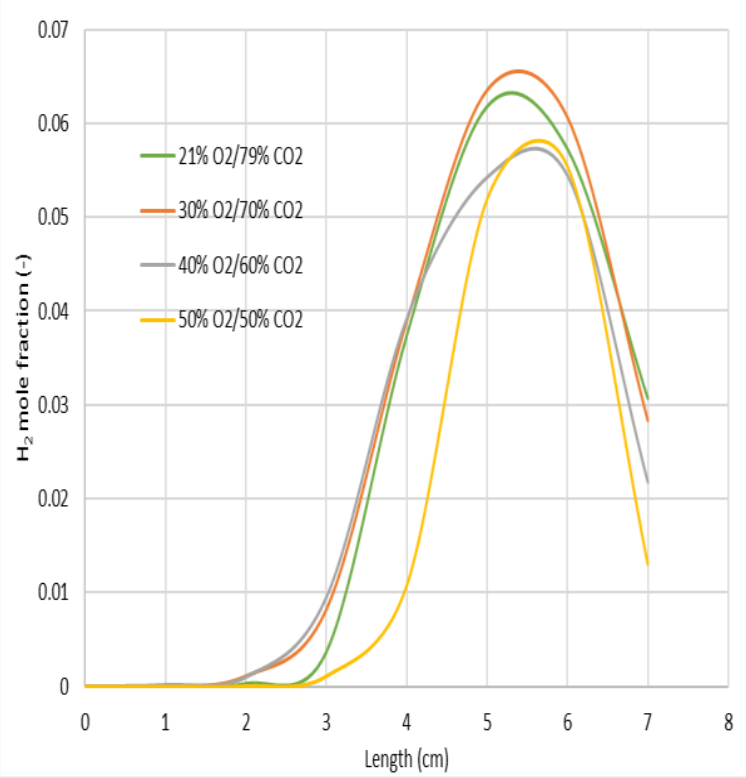

(b)

Figure E.14: Comparison of species concentration profiles along axial length of the bed burning under oxy-fuel condition for different $\mathrm{O}_{2} / \mathrm{CO}_{2}$ mixtures when reaction front is at $4 \mathrm{~cm}$ from the grate: (a) $\mathrm{CH}_{4}$ mole fraction (b) $\mathrm{H}_{2}$ mole fraction. 


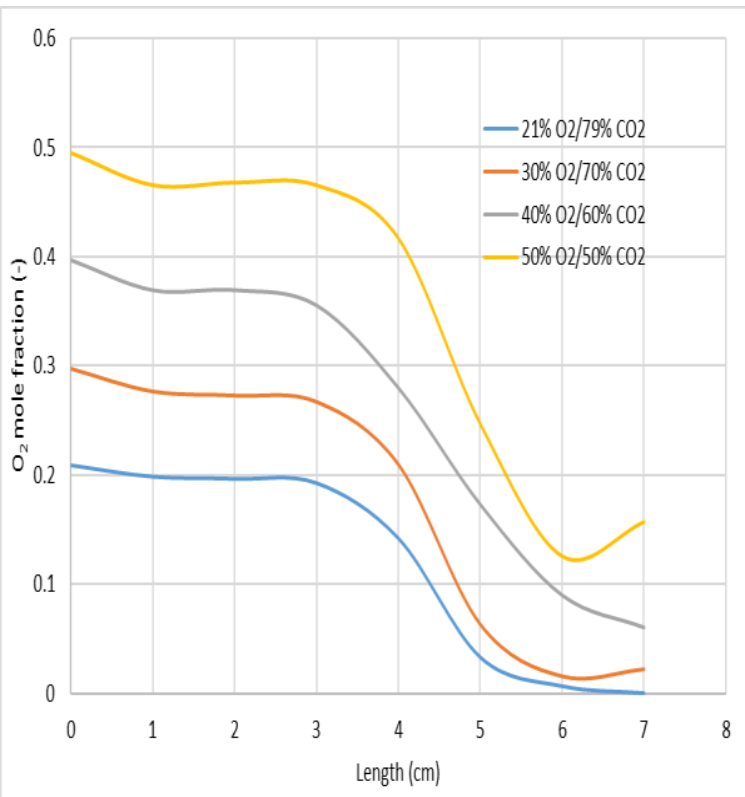

(a)

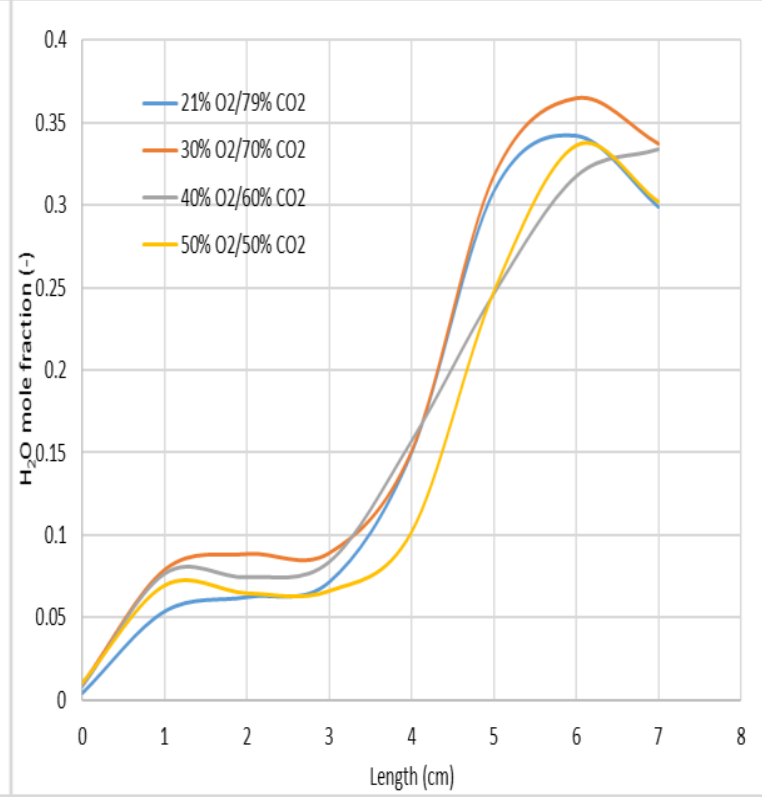

(b)

Figure E. 15: Comparison of species concentration profiles along axial length of the burning under oxy-fuel condition for different $\mathrm{O}_{2} / \mathrm{CO}_{2}$ mixtures when reaction front is at $4 \mathrm{~cm}$ from the grate: (a) $\mathrm{O}_{2}$ mole fraction (b) $\mathrm{H}_{2} \mathrm{O}$ mole fraction.

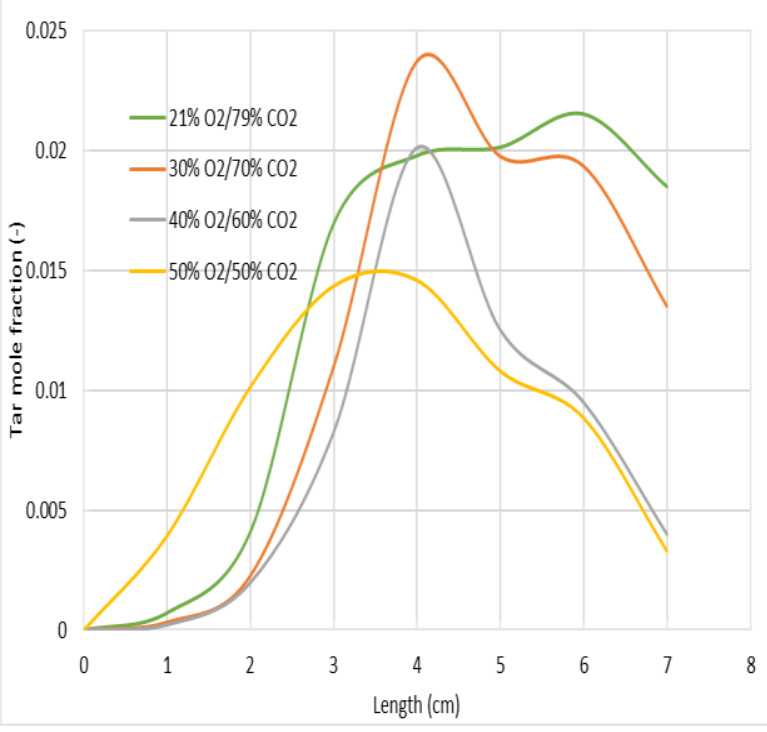

(a)

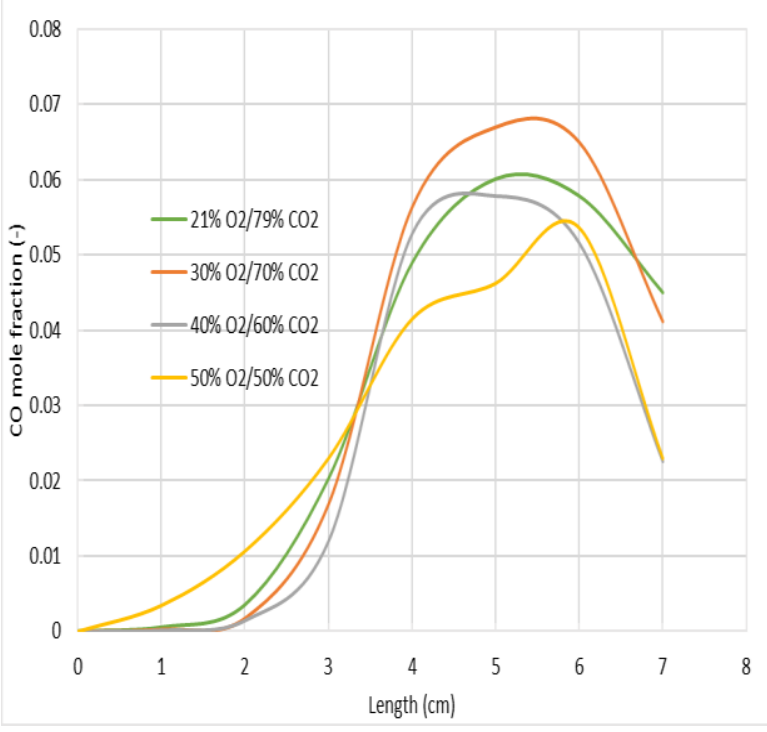

(b)

Figure E.16: Comparison of species concentration profiles along axial length of the bed burning under oxy-fuel condition for different $\mathrm{O}_{2} / \mathrm{CO}_{2}$ mixtures when reaction front is at $3 \mathrm{~cm}$ from the grate: (a) Tar mole fraction (b) $\mathrm{CO}$ mole fraction. 


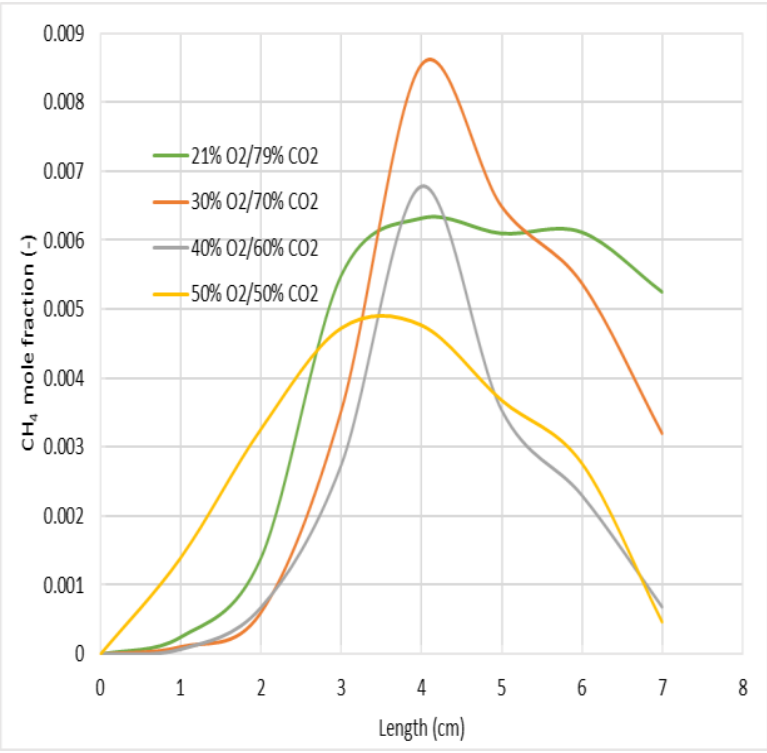

(a)

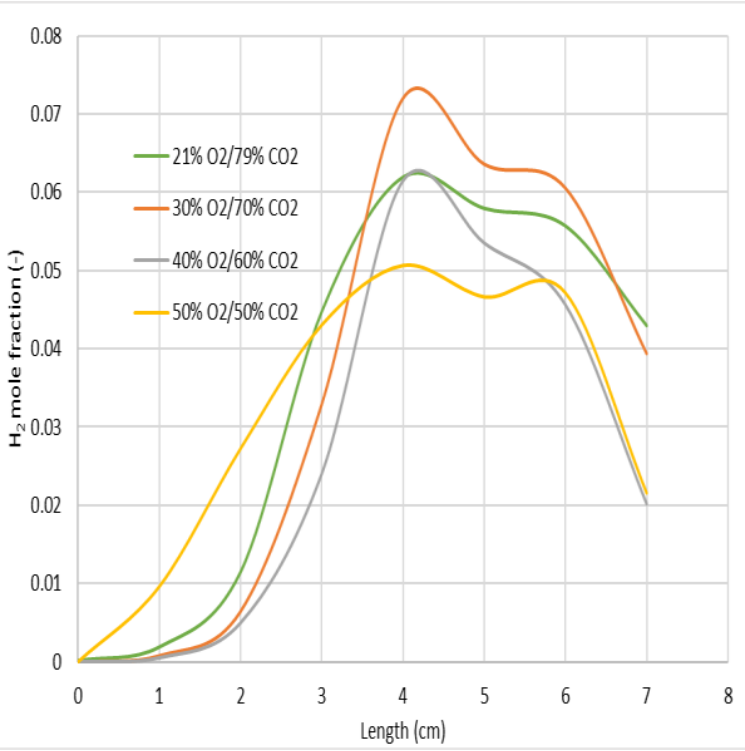

(b)

Figure E.17: Comparison of species concentration profiles along axial length of the bed burning under oxy-fuel condition for different $\mathrm{O}_{2} / \mathrm{CO}_{2}$ mixtures when reaction front is at $3 \mathrm{~cm}$ from the grate: (a) $\mathrm{CH}_{4}$ mole fraction (b) $\mathrm{H}_{2}$ mole fraction.

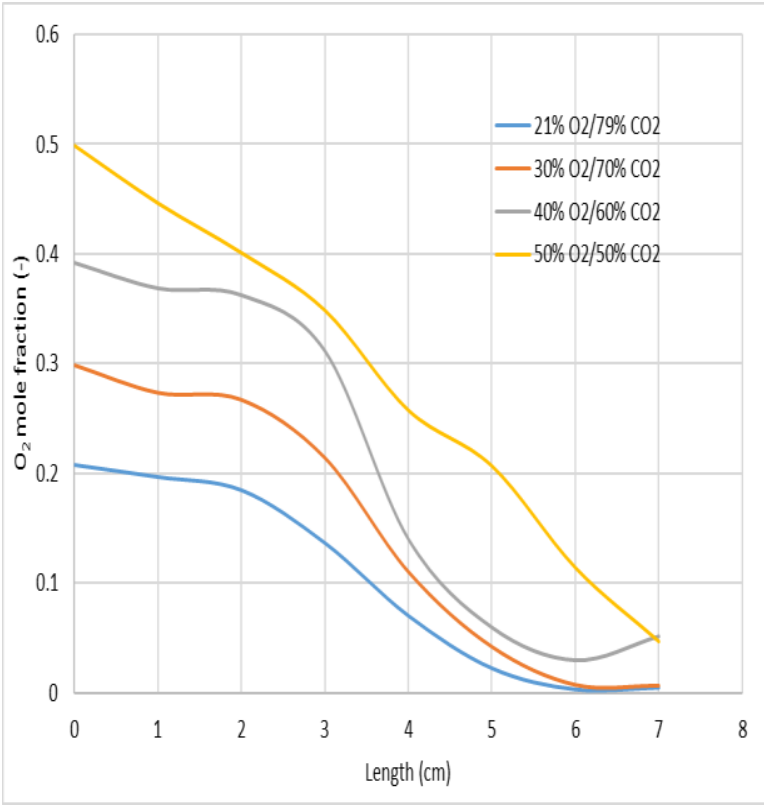

(a)

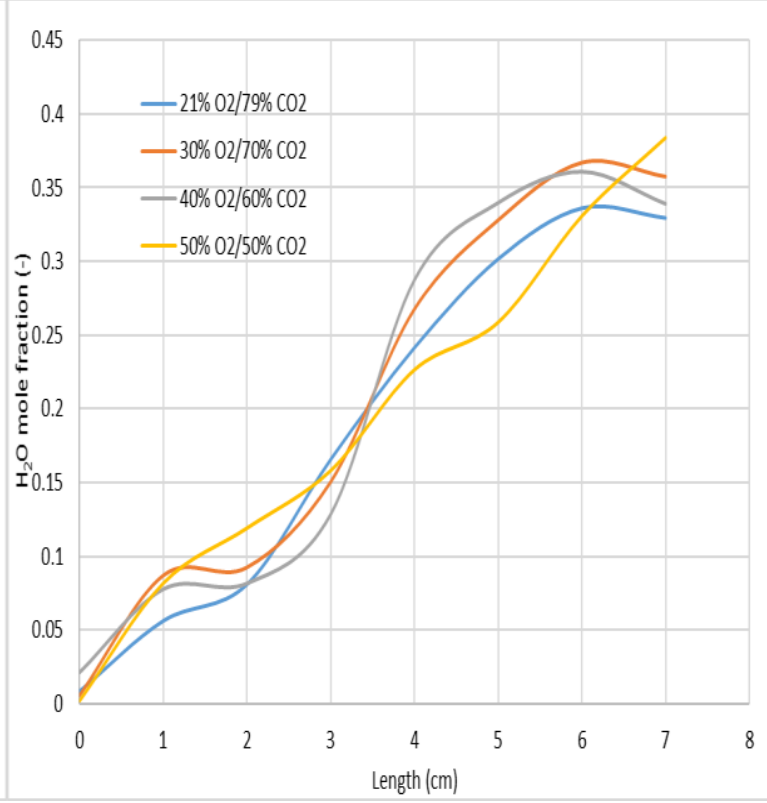

(b)

Figure E.18: Comparison of species concentration profiles along axial length of the bed burning under oxy-fuel condition for different $\mathrm{O}_{2} / \mathrm{CO}_{2}$ mixtures when reaction front is at $3 \mathrm{~cm}$ from the grate: (a) $\mathrm{O}_{2}$ mole fraction (b) $\mathrm{H}_{2} \mathrm{O}$ mole fraction. 


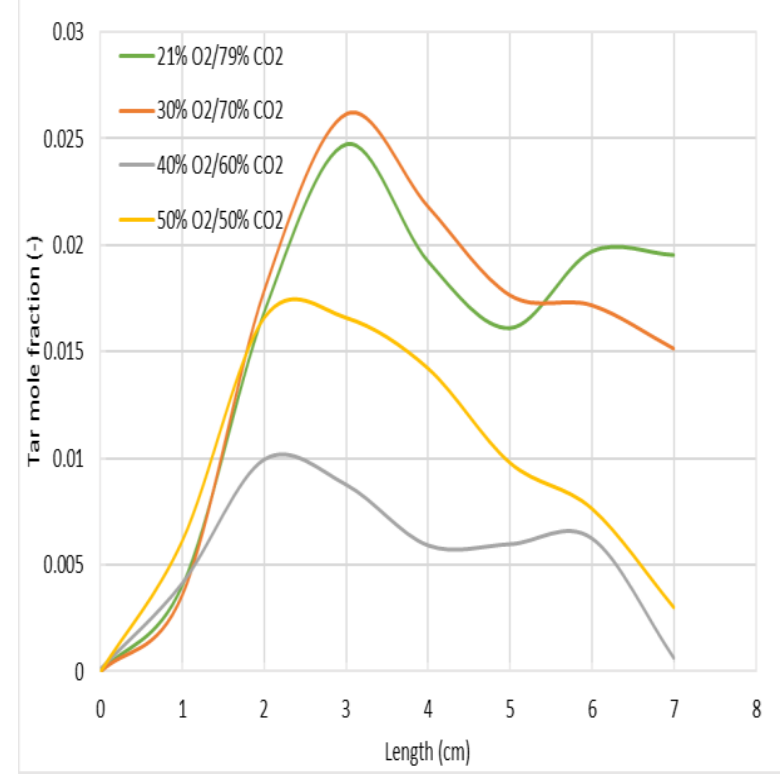

(a)

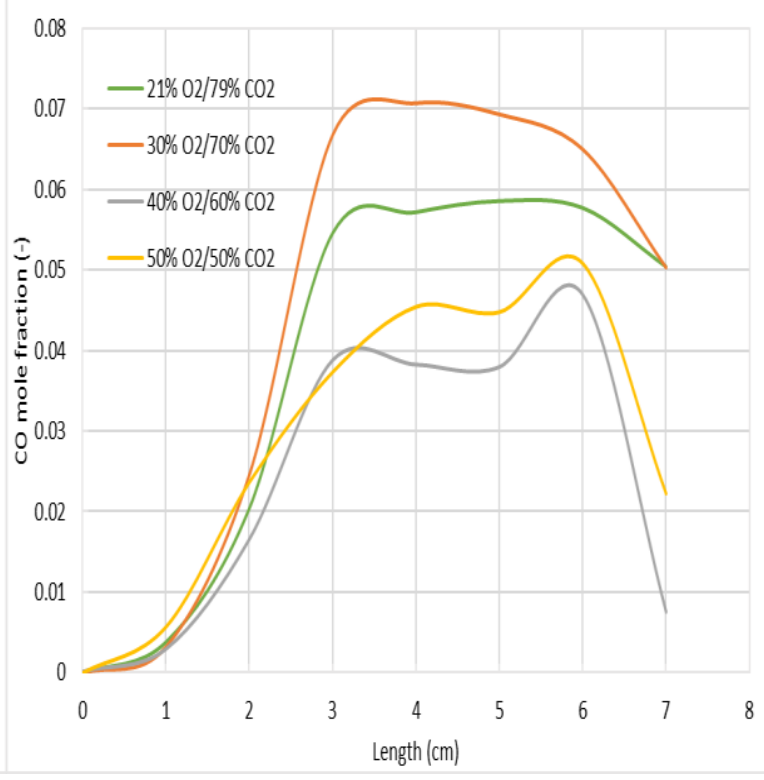

(b)

Figure E.19: Comparison of species concentration profiles along axial length of the bed burning under oxy-fuel condition for different $\mathrm{O}_{2} / \mathrm{CO}_{2}$ mixtures when reaction front is at $2 \mathrm{~cm}$ from the grate: (a) Tar mole fraction (b) $\mathrm{CO}$ mole fraction.

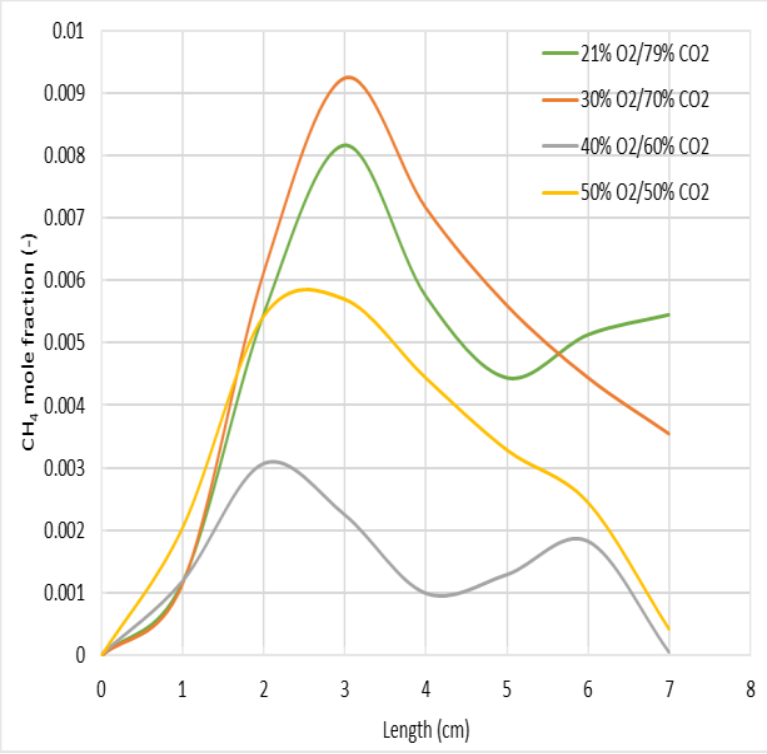

(a)

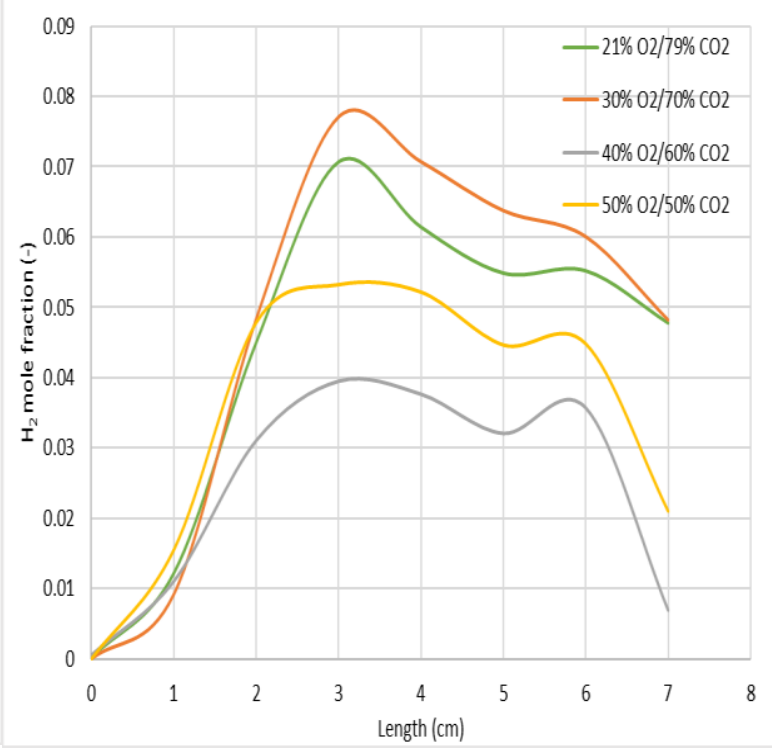

(b)

Figure E.20: Comparison of species concentration profiles along axial length of the bed burning under oxy-fuel condition for different $\mathrm{O}_{2} / \mathrm{CO}_{2}$ mixtures when reaction front is at $2 \mathrm{~cm}$ from the grate: (a) $\mathrm{CH}_{4}$ mole fraction (b) $\mathrm{H}_{2}$ mole fraction. 


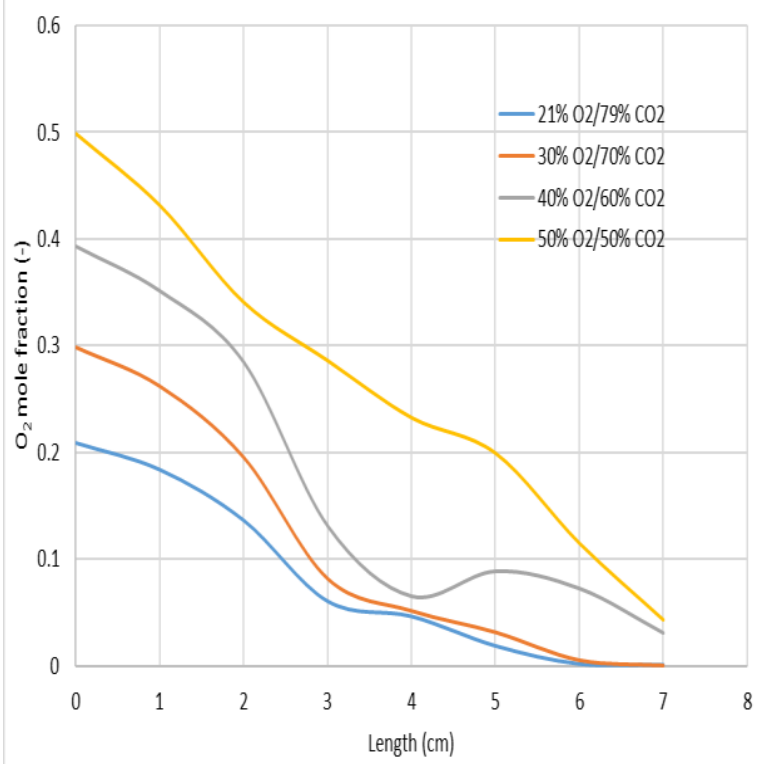

(a)

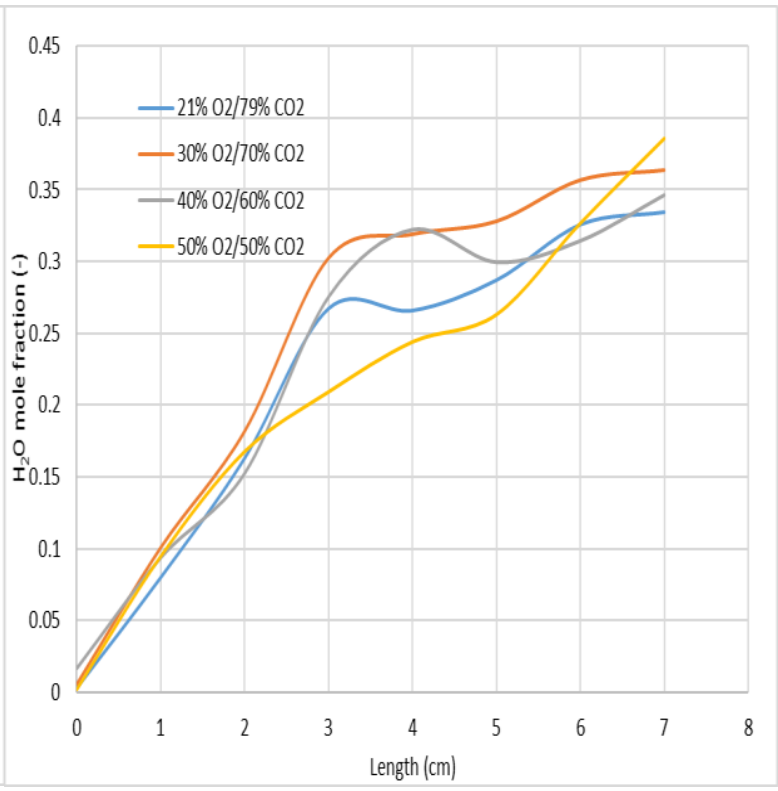

(b)

Figure E.21: Comparison of species concentration profiles along axial length of the bed burning under oxy-fuel condition for different $\mathrm{O}_{2} / \mathrm{CO}_{2}$ mixtures when reaction front is at $2 \mathrm{~cm}$ from the grate: (a) $\mathrm{O}_{2}$ mole fraction (b) $\mathrm{H}_{2} \mathrm{O}$ mole fraction.

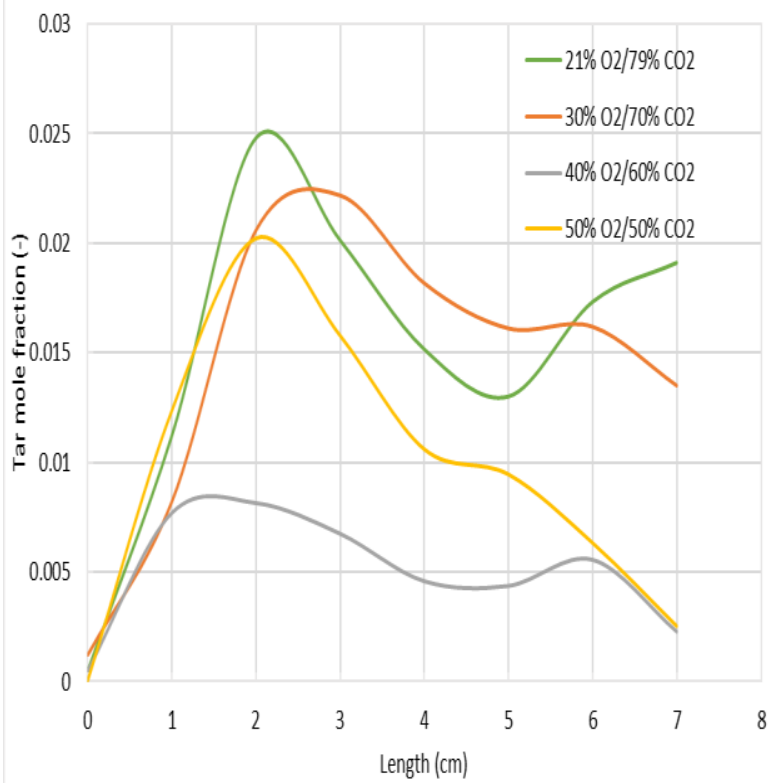

(a)

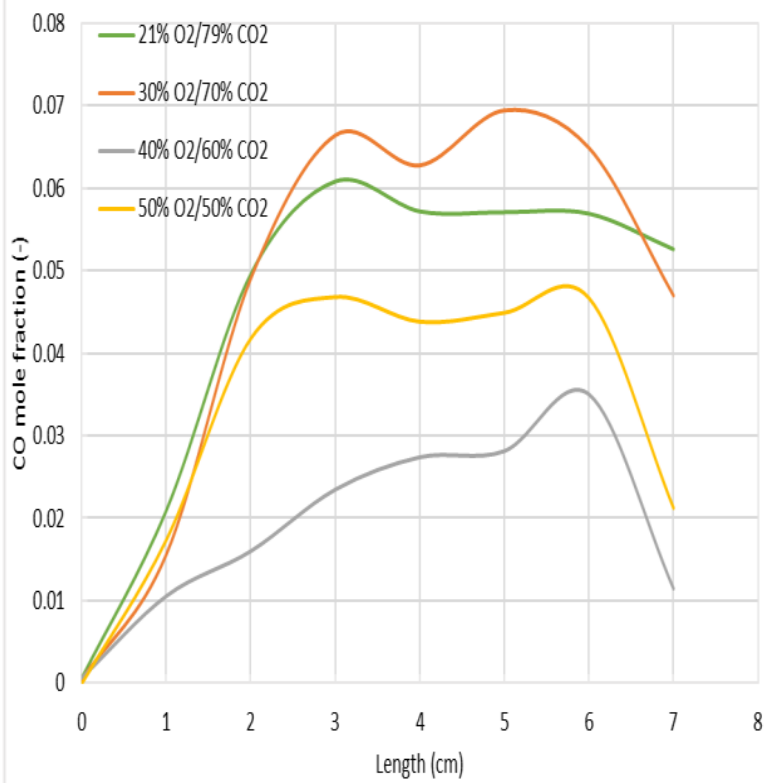

(b)

Figure E.22: Comparison of species concentration profiles along axial length of the bed burning under oxy-fuel condition for different $\mathrm{O}_{2} / \mathrm{CO}_{2}$ mixtures when reaction front is at $1 \mathrm{~cm}$ from the grate: (a) Tar mole fraction (b) $\mathrm{CO}$ mole fraction. 


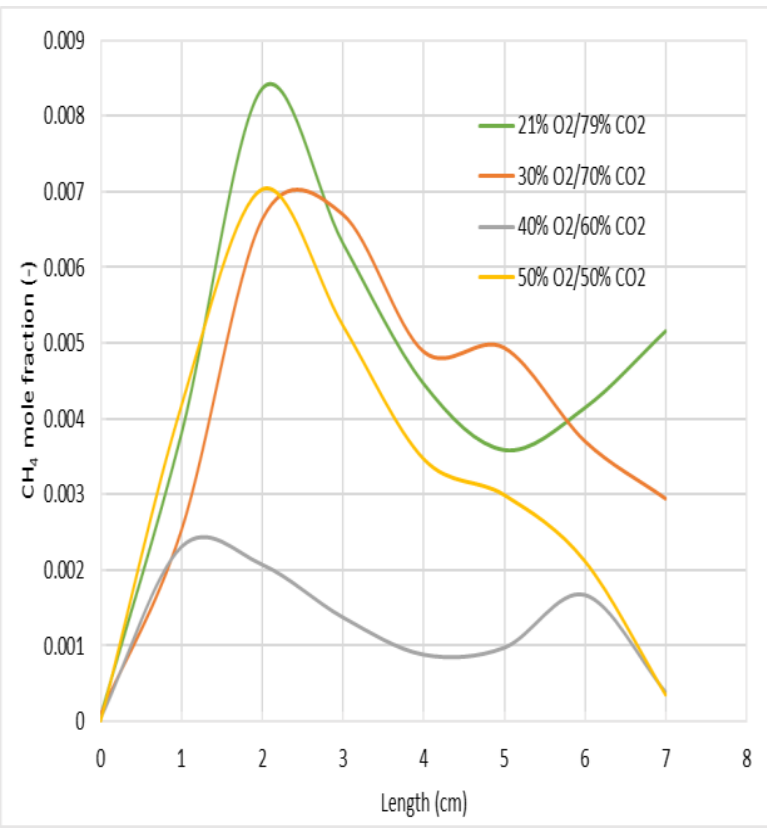

(a)

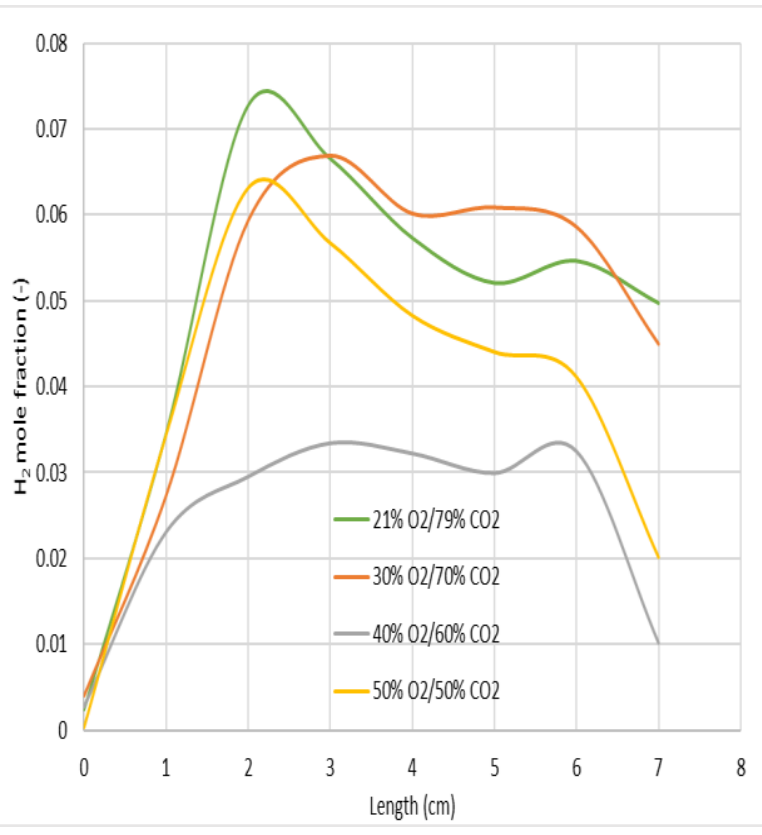

(b)

Figure E.23: Comparison of species concentration profiles along axial length of the bed burning under oxy-fuel condition for different $\mathrm{O}_{2} / \mathrm{CO}_{2}$ mixtures when reaction front is at $1 \mathrm{~cm}$ from the grate: (a) $\mathrm{CH}_{4}$ mole fraction (b) $\mathrm{H}_{2}$ mole fraction.

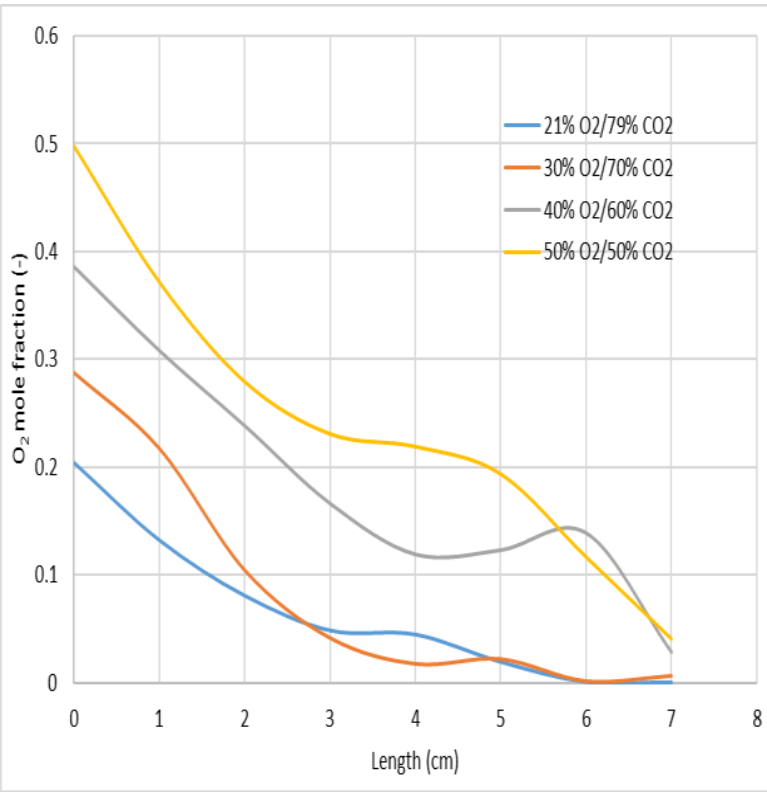

(a)

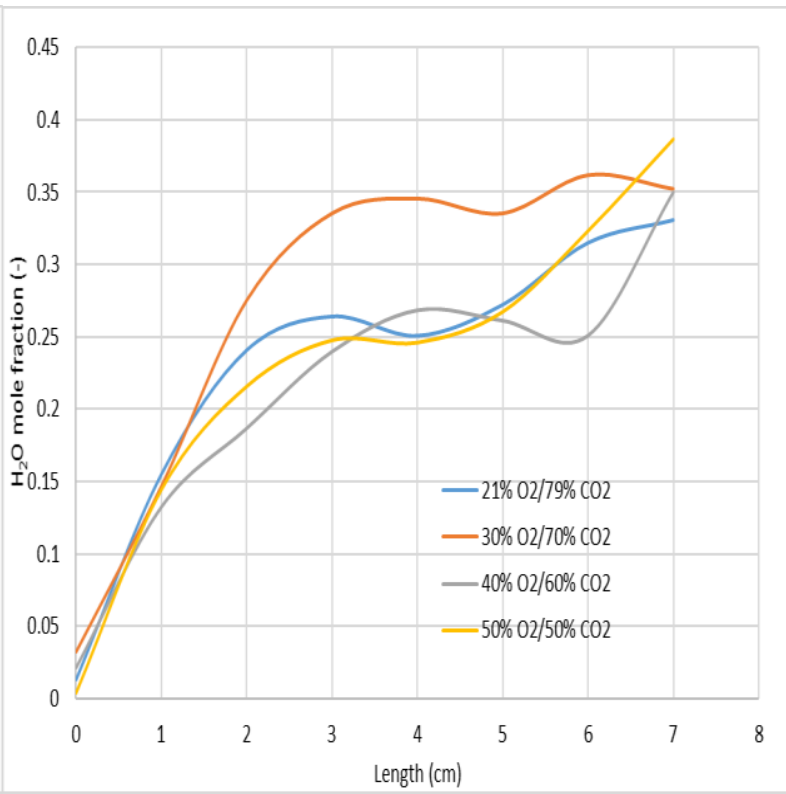

(b)

Figure E.24: Comparison of species concentration profiles along axial length of the bed burning under oxy-fuel condition for different $\mathrm{O}_{2} / \mathrm{CO}_{2}$ mixtures when reaction front is at $1 \mathrm{~cm}$ from the grate: (a) $\mathrm{O}_{2}$ mole fraction (b) $\mathrm{H}_{2} \mathrm{O}$ mole fraction. 
Tables E.6 - E.9 show the peak values for the major combustible species mole fraction and temperature along axial length of the bed for combustion of wood in a fixed bed under oxy-fuel conditions for different $\mathrm{O}_{2} / \mathrm{CO}_{2}$ mixtures. The tables present values for position $1 \mathrm{~cm}$ to $10 \mathrm{~cm}$ of the fixed bed measured from fuel bed bottom.

Table E.6: Peak values of temperature and the major combustible species mole fraction along the axial length of the fixed bed for wood combustion burning under oxy-fuel condition of $21 \% \mathrm{O}_{2} / 79 \% \mathrm{CO}_{2}$.

\begin{tabular}{lrrrrrrrrrrr}
\hline $\begin{array}{c}\text { Temperature/ } \\
\text { species mole } \\
\text { fraction (-) }\end{array}$ & $1 \mathrm{~cm}$ & $2 \mathrm{~cm}$ & $3 \mathrm{~cm}$ & $4 \mathrm{~cm}$ & $5 \mathrm{~cm}$ & $6 \mathrm{~cm}$ & $7 \mathrm{~cm}$ & $8 \mathrm{~cm}$ & $9 \mathrm{~cm}$ & $10 \mathrm{~cm}$ \\
\cline { 2 - 11 } $\begin{array}{l}\text { Temperature } \\
(\mathrm{K})\end{array}$ & 1375 & 1365 & 1346 & 1367 & 1368 & 1369 & 1388 & 1289 & 1190 & 907 \\
Tar & 0.0205 & 0.0266 & 0.0257 & 0.0242 & 0.0260 & 0.0254 & 0.0201 & 0.0113 & 0.0016 & 0.0001 \\
$\mathrm{CO}$ & 0.0444 & 0.0544 & 0.0523 & 0.0619 & 0.0603 & 0.0629 & 0.0527 & 0.0284 & 0.0073 & 0.0009 \\
$\mathrm{CH}_{4}$ & 0.0067 & 0.0088 & 0.0085 & 0.0083 & 0.0092 & 0.0086 & 0.0055 & 0.0030 & 0.0003 & 0.0000 \\
$\mathrm{H}_{2}$ & 0.0505 & 0.0635 & 0.0609 & 0.0681 & 0.0636 & 0.0606 & 0.0499 & 0.0268 & 0.0062 & 0.0008 \\
\hline
\end{tabular}

Table E.7: Peak values of temperature and the major combustible species mole fraction along the axial length of the fixed bed for wood combustion burning under oxy-fuel condition of $30 \% \mathrm{O}_{2} / 70 \% \mathrm{CO}_{2}$.

\begin{tabular}{lrrrrrrrrrrr}
\hline \multirow{2}{*}{$\begin{array}{c}\text { Temperature/ } \\
\text { species mole } \\
\text { fraction (-) }\end{array}$} & $1 \mathrm{~cm}$ & $2 \mathrm{~cm}$ & $3 \mathrm{~cm}$ & $4 \mathrm{~cm}$ & $5 \mathrm{~cm}$ & $6 \mathrm{~cm}$ & $7 \mathrm{~cm}$ & $8 \mathrm{~cm}$ & $9 \mathrm{~cm}$ & $10 \mathrm{~cm}$ \\
\cline { 2 - 12 } $\begin{array}{l}\text { Temperature } \\
(\mathrm{K})\end{array}$ & 1493 & 1493 & 1492 & 1493 & 1493 & 1493 & 1493 & 1493 & 1458 & 1446 \\
$\mathrm{Tar}$ & 0.0138 & 0.0217 & 0.0275 & 0.0244 & 0.0273 & 0.0238 & 0.0160 & 0.0083 & 0.0028 & 0.0003 \\
$\mathrm{CO}$ & 0.0706 & 0.0955 & 0.1018 & 0.1077 & 0.1018 & 0.0996 & 0.0844 & 0.0289 & 0.0162 & 0.0031 \\
$\mathrm{CH}_{4}$ & 0.0033 & 0.0076 & 0.0100 & 0.0087 & 0.0104 & 0.0084 & 0.0038 & 0.0017 & 0.0002 & 0.0000 \\
$\mathrm{H}_{2}$ & 0.0481 & 0.0606 & 0.0785 & 0.0732 & 0.0700 & 0.0639 & 0.0503 & 0.0274 & 0.0150 & 0.0028 \\
\hline
\end{tabular}


Table E.8: Peak values of temperature and the major combustible species mole fraction along the axial length of the fixed bed for wood combustion burning under oxy-fuel condition of $40 \% \mathrm{O}_{2} / 60 \% \mathrm{CO}_{2}$.

\begin{tabular}{lrrrrrrrrrrr}
\hline \multirow{2}{*}{$\begin{array}{c}\text { Temperature/ } \\
\text { species mole } \\
\text { fraction (-) }\end{array}$} & $1 \mathrm{~cm}$ & $2 \mathrm{~cm}$ & $3 \mathrm{~cm}$ & $4 \mathrm{~cm}$ & $5 \mathrm{~cm}$ & $6 \mathrm{~cm}$ & $7 \mathrm{~cm}$ & $8 \mathrm{~cm}$ & $9 \mathrm{~cm}$ & $10 \mathrm{~cm}$ \\
\cline { 2 - 12 } & & & & & & & & & & & \\
\hline $\begin{array}{l}\text { Temperature } \\
(\mathrm{K})\end{array}$ & 1035 & 1414 & 1541 & 1541 & 1541 & 1541 & 1541 & 1499 & 1295 & 1251 \\
Tar & 0.0099 & 0.0117 & 0.0131 & 0.0201 & 0.0179 & 0.0179 & 0.0044 & 0.0032 & 0.0002 & 0.0000 \\
$\mathrm{CO}$ & 0.0189 & 0.0197 & 0.0388 & 0.0528 & 0.0578 & 0.0616 & 0.0342 & 0.0296 & 0.0024 & 0.0001 \\
$\mathrm{CH}_{4}$ & 0.0032 & 0.0036 & 0.0044 & 0.0068 & 0.0063 & 0.0066 & 0.0010 & 0.0004 & 0.0000 & 0.0000 \\
$\mathrm{H}_{2}$ & 0.0099 & 0.0117 & 0.0131 & 0.0201 & 0.0179 & 0.0179 & 0.0044 & 0.0032 & 0.0002 & 0.0000 \\
\hline
\end{tabular}

Table E.9: Peak values of temperature and the major combustible species mole fraction along the axial length of the fixed bed for wood combustion burning under oxy-fuel condition of $50 \% \mathrm{O}_{2} / 50 \% \mathrm{CO}_{2}$.

\begin{tabular}{|c|c|c|c|c|c|c|c|c|c|c|}
\hline \multirow{2}{*}{$\begin{array}{c}\text { Temperature/ } \\
\text { species mole } \\
\text { fraction (-) }\end{array}$} & \multicolumn{10}{|c|}{ Peak values along axial length of the bed (Measure from the grate) } \\
\hline & $1 \mathrm{~cm}$ & $2 \mathrm{~cm}$ & $3 \mathrm{~cm}$ & $4 \mathrm{~cm}$ & $5 \mathrm{~cm}$ & $6 \mathrm{~cm}$ & $7 \mathrm{~cm}$ & $8 \mathrm{~cm}$ & $9 \mathrm{~cm}$ & $10 \mathrm{~cm}$ \\
\hline $\begin{array}{l}\text { Temperature } \\
(\mathrm{K})\end{array}$ & 1605 & 1596 & 1605 & 1605 & 1605 & 1605 & 1605 & 1605 & 1557 & 1296 \\
\hline Tar & 0.0172 & 0.0206 & 0.0167 & 0.0176 & 0.0184 & 0.0189 & 0.0036 & 0.0013 & 0.0002 & 0.0000 \\
\hline $\mathrm{CO}$ & 0.0521 & 0.0595 & 0.0529 & 0.0458 & 0.0495 & 0.0631 & 0.0238 & 0.0117 & 0.0022 & 0.0003 \\
\hline $\mathrm{CH}_{4}$ & 0.0063 & 0.0072 & 0.0057 & 0.0063 & 0.0068 & 0.0068 & 0.0007 & 0.0001 & 0.0000 & 0.0000 \\
\hline $\mathrm{H}_{2}$ & 0.0575 & 0.0669 & 0.0585 & 0.0529 & 0.0535 & 0.0606 & 0.0218 & 0.0105 & 0.0020 & 0.0003 \\
\hline
\end{tabular}




\section{APPENDIX F \\ LIST OF PUBLICATIONS FROM THIS THESIS}

\section{Journal Publications}

1. 1. Tanui J. K., Kioni P. N., Mirre T. and Nowitzki M. (2018). The effect of carbon dioxide on flame propagation speed of wood combustion in a fixed bed under oxy-fuel conditions. Fuel Processing Technology, 179, 285-295.

https://www.sciencedirect.com/science/article/pii/S0378382018304867

2. Tanui J. K., Kioni P. N., Mirre T. and Nowitzki M. (2019). Chemical, thermal and dilution effects of carbon dioxide in oxy-fuel combustion of wood in a fixed bed. Journal of Mechanical Science and Technology, 33(12), 6063-6073.

http://link.springer.com/article/10.1007/s12206-019-1150-z

3. Tanui J. K., Kioni P. N., Mirre T. and Nowitzki M. (2019). Application of CFD-DEM method in modelling of wood combustion in a fixed bed. Submitted to Bulgarian Chemical Communication.

4. Tanui J. K., Kioni P. N., Mirre T., Nowitzki M. and Karuri N. W. (2020). The influence of particle packing density on wood combustion in a fixed bed under oxyfuel conditions. Energy, 194.

https://www.sciencedirect.com/science/article/abs/pii/S0360544219325587

\section{Conference Papers}

1. Tanui J. K., Kioni P. N., Mirre T. and Nowitzki M. (2018). Cooperation with Kenya $\mathrm{PhD}$ research on numerical simulation of wood combustion in a laboratory fixed bed using CFD-DEM Approach. poster in Forschung in Wildau - innovativ und praxisnah, 2018.

2. Tanui J. K., Kioni P. N., Mirre T., Nowitzki M. and Karuri N. W. (2019). A Numerical study of volatile matter generation from wood combustion in a fixed bed under $\mathrm{O}_{2} / \mathrm{CO}_{2}$ environment. $5^{T H}$ Dekut International Conference on Science, Technology, Innovation and Entrepreneurship (STI\&E), 2019. 
Research article

\title{
The effect of carbon dioxide on flame propagation speed of wood combustion in a fixed bed under oxy-fuel conditions
}

\author{
J.K. Tanui ${ }^{\mathrm{a}, *}$, P.N. Kioni ${ }^{\mathrm{a}}$, T. Mirre ${ }^{\mathrm{b}}$, M. Nowitzki ${ }^{\mathrm{b}}$ \\ ${ }^{a}$ Department of Mechanical Engineering, Dedan Kimathi University of Technology, P.O. Box 657-10100, Nyeri, Kenya \\ ${ }^{\mathrm{b}}$ Fachbereich Ingenieur- und Naturwissenschaften, Technische Hochschule Wildau, Hochschulring 1, 15745 Wildau, Germany
}

\section{A R T I C L E I N F O}

\section{Keywords:}

Oxy-fuel

Flame front

Propagation speed

Fixed bed

Wood combustion

CFD-DEM

\begin{abstract}
A B S T R A C T
This paper presents an investigation of wood combustion in a laboratory-scale fixed bed with an aim of establishing the effect of $\mathrm{CO}_{2}$ environment on flame propagation speed and flame structures. Different oxy-fuel combustion atmospheres in which the composition of $\mathrm{O}_{2}$ in $\mathrm{CO}_{2}$ was varied from $21 \%$ to $50 \%$ by volume were tested and compared to air-fuel condition. Euler-Lagrange (Computational Fluid Dynamics - Discrete Element Method, CFD-DEM) approach which captures information of individual particle processes is used to model wood conversion in a packed bed. Results show that flame front propagation speed in oxy-fuel atmosphere reduced to $78 \%$ of that of the air-fuel condition with similar $\mathrm{O}_{2}$ concentration. For oxy-fuel conditions, propagation speed increased with increase in $\mathrm{O}_{2}$ concentration. The CFD-DEM model agrees very well with experimental values for mass loss, propagation speed and flame front positions. However, peak temperatures are poorly predicted at lower oxygen concentrations. The accuracy of temperature prediction improves at higher oxygen concentrations. During initial and devolatilization stage, mass fraction of tar predicted in $\mathrm{CO}_{2}$ environment are smaller than in $\mathrm{N}_{2}$ environment, while the amount of $\mathrm{CO}$ predicted is almost equal in both environments. However, during char combustion stage a high amount of $\mathrm{CO}$ is observed in oxy-fuel conditions.
\end{abstract}

\section{Introduction}

Biomass fuel is still the major source of energy for a significant proportion of the world population. Conventionally, biomass is burned in combustors that use air as oxidizer. The need for efficiency and reduced emissions has led to development of clean combustion technologies such as oxy-fuel combustion. In this technique, fuel is burnt in condition in which $\mathrm{CO}_{2}$ replaces $\mathrm{N}_{2}$ as the inert gas. $\mathrm{CO}_{2}$ is obtained from recycling of exhaust gas. It is a strategy of reducing or capturing $\mathrm{CO}_{2}$. This technique is applied to both gaseous, Marsh et al. [1], and solid fuels, Bhunia et al. [2] and Álvarez et al. [3]. It has been identified as the most competitive carbon capture technology for retrofitting of the existing power plants, Scheffknecht et al. [4].

Previous works on oxy-fuel combustion range from laboratory research to actual test of the power plants. Tests have been carried out in pilot scale, industrial scale and full scale power plant [4]. Large scale oxy-fuel power plants of sizes between 30 and $300 \mathrm{MW}_{\text {th }}$ have been established and installed worldwide [4]. Most of these power plants are coal-fired, but a few others use biomass or are co-fired $[5,6]$. Thus there is need for better understanding of oxy-fuel combustion in a $\mathrm{CO}_{2}$ rich environment. Shan et al. [7] study of single biomass pellet reported that $\mathrm{CO}_{2}$ environment increases ignition delay time. A similar behavior has been observed for oxy-coal combustion $[8,9]$. This was attributed to a decrease in particle surface heating rate due to decreased co-flow temperature associated with the higher specific heat capacity of $\mathrm{CO}_{2}$ than $\mathrm{N}_{2}$ and low oxygen diffusion rate in $\mathrm{CO}_{2}$. According to Molina et al. [8], other possible reasons for increased ignition delay time are suppression of radical formation by $\mathrm{CO}_{2}$ chemical effects and thermal decomposition of $\mathrm{CO}_{2}$. It has been observed that internal ignition temperature of the pellet decreases with increase in $\mathrm{O}_{2}$ concentration [7]. However, Shan et al. [7] concluded that the effect of oxidation temperature on internal ignition temperature is more than the effect of oxygen concentration.

Another observation $[7,10]$ is that volatile combustion time increases while combustion temperature decreases [10] when $\mathrm{N}_{2}$ is replaced with $\mathrm{CO}_{2}$ (21\% oxygen). Riaza et al. [10] noted that the intensity of combustion of a single biomass particle is reduced in $\mathrm{CO}_{2}$ environment with $21 \% \mathrm{O}_{2}$. As $\mathrm{O}_{2}$ is increased, combustion intensity also increases.

Oxy-fuel combustion of biomass co-firing with coal has also been studied [11-13]. Biomass and coal blends are preferred because it results in reduction of $\mathrm{CO}_{2}, \mathrm{NO}_{\mathbf{x}}$ and $\mathrm{SO}_{\mathbf{x}}$ emission when compared to a

\footnotetext{
* Corresponding author

E-mail address: josephat.tanui@dkut.ac.ke (J.K. Tanui).
} 


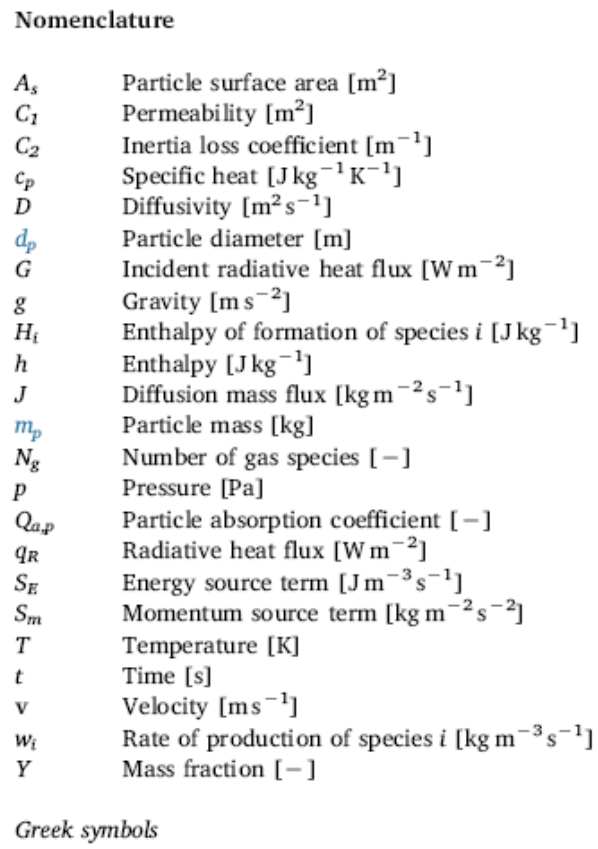

pure coal plant. In addition, alkali metals present in biomass fuel provides catalytic effects on oxidation and gasification reactions. Indeed, the catalytic effect has been found to be more pronounced under oxyfuel combustion conditions [11]. Irfan et al. [14] observed that there were improved ignition properties for coal/biomass blends in both oxyfuel and air-fuel conditions.

Pohlmann et al. [15] has studied the effects of $\mathrm{O}_{2} / \mathrm{CO}_{2}$ and $\mathrm{O}_{2} / \mathrm{N}_{2}$ environment on char reactivity and burnout of pulverized torrefied and carbonized biomass burned in a drop tube furnace. $\mathrm{CO}_{2}$ environment increases the burnout of biomass fuel. In addition, $\mathrm{CO}_{2}$ environment increases char surface area $[16,17]$. Char from $\mathrm{CO}_{2}$ devolatilization environment is small in size and has low reactivity [18, 19]. Improved char burnout in $\mathrm{CO}_{2}$ has been attributed to contribution from $\mathrm{CO}_{2}$ gasification $[15,18,20]$. Even though the burnout time is high, the release of volatile is low under the fast heating conditions in a drop tube furnace operated under oxy-fuel environment [15].

Even though different aspects of oxy-fuel combustion of biomass have been investigated, the mechanism through which $\mathrm{CO}_{2}$ environ ment affects fundamental combustion phenomena such as flame propagation speed and flame structures in a fixed bed reactor have not been reported. Flame propagation speed is one of the main parameters to consider when designing a new burner.

Flame propagation rate in biomass fixed bed gasifiers has been investigated under different operating conditions [21-26] although not in oxy-fuel environment. It is affected by various factors such as biomass fuel type, density, size, ultimate and proximate analysis and superficial velocity. Based on superficial velocity, operation regimes have been classified either as two-regime [21] or three-regime [27]. In the tworegime classification, propagation speed increases in the fuel rich regime and decreases in the fuel lean regime. On the other hand, threeregime classification has fuel rich regime, fuel lean regime and con vective cooling regime where propagation speed increases rapidly, gradually and decreases rapidly, respectively. Furthermore, the role of ash in flame propagation speed has been assessed [28]. Ash affects
Particle porosity [-]

Thermal conductivity $\left[\mathrm{W} \mathrm{m}^{-1} \mathrm{~K}^{-1}\right.$ ]

Viscosity $\left[\mathrm{kg} \mathrm{m}^{-1} \mathrm{~s}^{-1}\right]$

Density $\left[\mathrm{kg} \mathrm{m}^{-3}\right]$

Stefan-Boltzmann constant $\left[\mathrm{W} \mathrm{m}^{-2} \mathrm{~K}^{-4}\right]$

Shear stress tensor $[\mathrm{Pa}]$

Region porosity [-]

Subscripts

$0 \quad$ Initial state of the particle

e Effective

g Gas

i,g Gaseous species

$i, s \quad$ Solid-phase species

$s \quad$ Solid

Superscripts

gs Heterogeneous reaction

Operators

$\nabla \quad$ Gradient operator

$\nabla \quad$ Divergence operator radiative heat transfer to the unburnt biomass, hence affecting the flame propagation. Although numerous works on flame propagation rate of biomass combustion in fixed bed have been done, none addresses an oxy-fuel environment.

The main aim of this work is to comprehensively investigate the effects of $\mathrm{CO}_{2}$ environment on flame propagation speed and flame structures. A commercial CFD software CD-Adapco (STAR CCM+ version 11.04) [29] is used to simulate thermal conversion of wood in oxyfuel environments. Euler-Lagrange approach which captures detailed information of individual particle processes is used to model wood conversion in a packed bed. Furthermore, measurements were done in a laboratory-scaled fixed bed reactor operated under oxy-fuel conditions. CFD simulations were validated by comparing them with measured data in a laboratory set-up.

\section{Experimental set-up}

A schematic diagram and a photo of the combustion test rig used in this work are shown in the Fig. $1 \mathrm{a}$ and b, respectively. It is a laboratoryscale fixed bed, which has provision for regulating the flow of $\mathrm{O}_{2}, \mathrm{CO}_{2}$ and $\mathrm{N}_{2}$. Its internal and external radius are $20 \mathrm{~mm}$ and $40 \mathrm{~mm}$, respectively and the height is $200 \mathrm{~mm}$. It has provisions for thermocouple insertions located at $10 \mathrm{~mm}$ intervals. Internal and external parts are made of stainless steel and between them is a $20 \mathrm{~mm}$ thick refractory cement for insulation. Thermal conductivity of refractory cement is $0.34 \mathrm{~W} / \mathrm{m} \cdot \mathrm{K}$ [30]. Critical insulation radius for this material, considering typical values of convective heat transfer coefficient for air in natural convection as $10-20 \mathrm{~W} / \mathrm{m}^{2} \cdot \mathrm{K}$ [31], lies between 17 and $34 \mathrm{~mm}$. An external radius of $40 \mathrm{~mm}$ used in this reactor is, therefore, sufficient for heat insulation. Fuel bed is held by a stainless steel grate.

The reactor was operated in counter-current flame propagation mode. Top fuel was ignited initially and the flame front propagates downward into the virgin fuel. Oxidizer was supplied from the bottom. For this arrangement, there is no fuel bed movement. The fuel bed was 


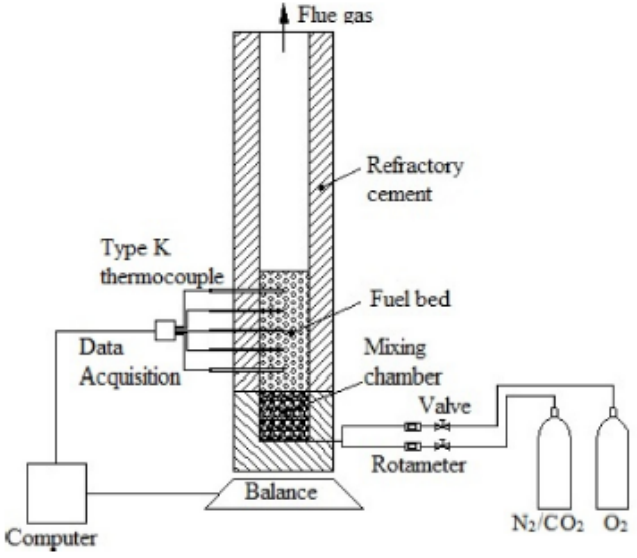

(a) Schematic diagram

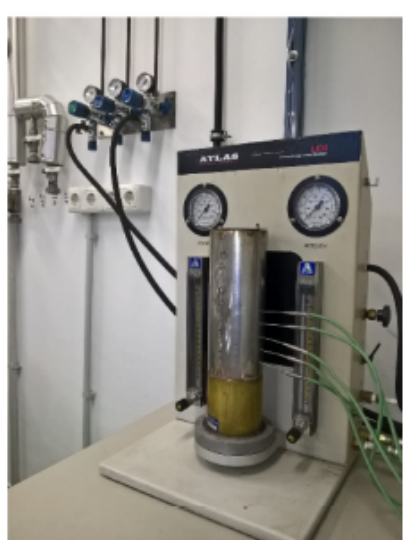

(b) Photo

Fig. 1. A schematic diagram and a photo of the combustion test rig.

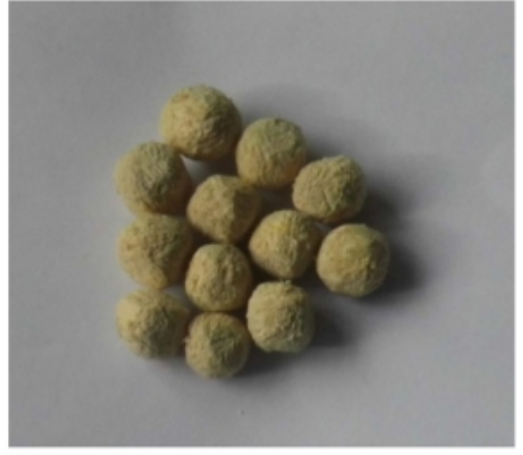

Fig. 2. A photo of processed wood fuel samples.

ignited using methane gas flame with a flow rate of $0.051 \mathrm{~m}^{3} / \mathrm{h}$. Ignition time was about $10 \mathrm{~s}$. The amount of methane used in ignition was estimated to be $94 \mathrm{mg}$ and released a total amount of heat of $4719 \mathrm{~J}$. It was expected that this amount of heat ignites a top layer of wood of about $2.26 \mathrm{~g}$, therefore, wood temperature during ignition was raised to about $1182^{\circ} \mathrm{C}$.

Oxidizer was a mixture of pure $\mathrm{O}_{2}$ and $\mathrm{N}_{2}$ or $\mathrm{CO}_{2}$ in various composition. The different gas components were supplied independently through a perforated bottom plate of a $100 \mathrm{~mm}$ long mixing chamber made of brass. The chamber was filled with $8 \mathrm{~mm}$ long hollow glass with internal diameter of $4 \mathrm{~mm}$ for settling and generating a relatively uniform flow. A constant mass flow rate of $0.1 \mathrm{~kg} / \mathrm{m}^{2} / \mathrm{s}$ was used for all the tests carried out. Gas flow rates were measured using variable area flowmeters (rotameters) in-build in Atlas LOI equipment with a tolerance of $\pm 2 \%$. During combustion, the reactor was placed on a weighting balance in order to obtain mass loss history. The weighing balance has an accuracy of $\pm 0.01 \mathrm{~g}$. Temperature in the fuel bed was monitored by five Type $\mathrm{K}$ thermocouples. Uncertainty of thermocouple data acquisition system is dependent on combustion zone temperature. For the whole range of thermocouple measurement, it is between $\pm 2.184^{\circ} \mathrm{C}$ and $\pm 6.630^{\circ} \mathrm{C}$. In addition, temperature measured by thermocouple may differ significantly from the true gas temperature because of radiation heat loss from the thermocouple surface to the cooler surrounding walls. Error due to radiation loss was corrected according to the methodology developed by Blevins and Pitts [32] and has been applied by other researchers [33]. In this method, maximum and minimum measurement error which occurs when using bare bead and single shielded aspirated thermocouple (TC), respectively, are used to estimate the error in sheathed thermocouple with the same bead size.

Measurement was made for different $\mathrm{O}_{2} / \mathrm{CO}_{2}$ mixtures which varied in composition of $\mathrm{O}_{2}$ in $\mathrm{CO}_{2}$ from $21 \%$ to $50 \%$ by volume. For comparison purposes, measurements were made for air-fuel condition. The gaseous mixtures were supplied at room temperature ( $295 \mathrm{~K}$ ). Each test was done in three replicate to check repeatability.

In this work, eucalyptus wood was combusted in the reactor. The reactor was filled with spherical wood of $5 \mathrm{~mm}$ diameter to a height of $60 \mathrm{~mm}$. A photo of processed wood fuel samples is presented in Fig. 2, while their proximate and ultimate analysis is presented in Table 1.

\section{Numerical modeling}

\subsection{Gas and solid phase dynamics}

A packed bed of solid fuel consists of particles which interact with one another in terms of heat exchange by conduction and radiation. They also interact with gas phase surrounding them in the void spaces. In addition, they undergo conversion through several processes, that is, drying, pyrolysis and char oxidation. All these processes must be accounted for in the modeling of particle combustion in a fuel bed.

In this work, all numerical simulations were carried out using a commercial CFD software CD-Adapco (STAR CCM+ version 11.04) [29]. Euler-Lagrange (CFD-DEM) approach was used to model biomass

Table 1

Proximate and ultimate analysis of fuel sample.

\begin{tabular}{|c|c|c|c|}
\hline \multicolumn{2}{|l|}{ Proximate analysis } & $(w t \%)$ & Standards \\
\hline \multicolumn{2}{|l|}{ Moisture } & 10.3 & CEN-TS 14774-2:2009 \\
\hline \multicolumn{2}{|l|}{ Volatile matter (wt $\%$ dry basis) } & 84.9 & CEN-TS 15148:2009 \\
\hline \multicolumn{2}{|c|}{ Fixed carbon (wt\% dry basis) - by difference } & 14.9 & - \\
\hline \multicolumn{2}{|l|}{ Ash (wt\% dry basis) } & 0.2 & CEN-TS 14775:2009 \\
\hline Ultimate analysis & \multicolumn{2}{|c|}{ (wt $\%$ dry basis) } & Standards \\
\hline C & \multicolumn{2}{|l|}{50.87} & CEN-TS 15104:2011 \\
\hline $\mathrm{H}$ & \multicolumn{2}{|l|}{5.73} & CEN-TS 15104:2011 \\
\hline $\mathrm{N}$ & \multicolumn{2}{|l|}{0.3} & CEN-TS 15104:2011 \\
\hline O (by difference) & \multicolumn{2}{|l|}{43.1} & - \\
\hline Gross calorific value $(\mathrm{MJ} / \mathrm{kg}$ ) & \multicolumn{2}{|l|}{19.3} & CEN-TS 14918:2009 \\
\hline
\end{tabular}


Table 2

Physical properties of wood [34].

\begin{tabular}{ll}
\hline Particle diameter, $d_{p}(\mathrm{~m})$ & 0.005 \\
Eucalyptus wood & \\
$\quad \begin{array}{l}\text { Density, } \rho\left(\mathrm{kg} / \mathrm{m}^{3}\right) \\
\text { Porosity, } \theta\end{array}$ & 1220 \\
$\quad$ Specific heat, $c_{\mathrm{p}}(\mathrm{J} / \mathrm{kgK})$ & 0.64 \\
$\quad$ Conductivity, $\lambda_{a}(\mathrm{~W} / \mathrm{mK})$ & $1500+T_{a}$ \\
Char & 0.2 \\
$\quad$ Density, $\rho\left(\mathrm{kg} / \mathrm{m}^{3}\right)$ & 250 \\
Porosity, $\theta$ & 0.85 \\
Specific heat, $c_{p}(\mathrm{~J} / \mathrm{kgK})$ & $420+2.09 T_{2}-6.85 \times 10^{-4} T_{i}^{2}$ \\
Conductivity, $\lambda_{\mathrm{a}}(\mathrm{W} / \mathrm{mK})$ & 0.1 \\
\hline
\end{tabular}

conversion in a packed bed. Solid particles and their conversion were modeled using DEM while fluid phase was modeled as a continuous phase using CFD. Detailed description of the governing equations for combustion is provided in CD-Adapco user guide [29]. Here we only discuss details of user-defined and specific sub-models subject to the following assumptions:

1. Wood fuel is considered as spherical particles which are modeled as thermally thin. Therefore, the particle is assumed to be internally homogeneous with a low Biot number. The physical properties of the wood and char used in simulations are presented in Table 2.

2. Fuel bed is considered as a porous media where the pressure loss is accounted for by Ergun equation [34]. This is incorporated as a source term in gas-phase momentum equation.

3. Gas flow in the bed is assumed to be turbulent.

4. Gas phase and solid phase interact by exchanging mass, species and energy. Heat is exchanged between solid-phase and gas-phase by convection and radiation while within solid phase is by conduction and radiation.

5. Porosity of the particle, $\theta$ is assumed to vary during bed thermal conversion as a result of local consumption of solid phase. Therefore, the particle diameter slightly shrinks producing a slight change in the bed size during entire combustion period. The porosity is modeled [29] according to Eqs. (1) and (2):

$\frac{d_{p}}{d_{p, 0}}=\left(\frac{m_{p}}{m_{p, 0}}\right)^{\alpha / 3}$

$\theta=1-\left(\frac{m_{p}}{m_{p, 0}}\right)^{1-\alpha}$

where $d_{p}$ is the particle diameter, $m_{p}$ is the particle mass, $\alpha$ is the exponent factor $(0 \leq \alpha \leq 1)$ and 0 is the initial state of the particle.

Based on these assumptions, governing equations are presented on Table 3 (gas-phase) and Table 4 (solid-phase) [29].

In this work, flow in bed and free board regions have been assumed to be turbulent based on previous research on comparable systems [35, 36]. Turbulence was accounted by standard $k-\epsilon$ model. Two-way

Table 3

Gas-phase conservation equations.

$$
\begin{aligned}
& \frac{\partial}{\partial t}\left(x_{g}\right)+\nabla \cdot\left(\rho_{g} \mathbf{v}_{g}\right)=\sum_{i, g} w_{i g}^{g} \\
& \frac{\partial}{\partial t}\left(\rho_{g} \mathbf{v}_{g}\right)+\nabla \cdot\left(\rho_{g} \mathbf{v}_{g} \mathbf{v}_{g}\right)=-\nabla p+\nabla \cdot \tau+\rho_{g} g+S_{m} \\
& \frac{\partial}{\partial t}\left(\chi \rho_{g} h_{g}\right)+\nabla \cdot\left(\rho_{g} v_{g} h_{g}\right)=\frac{\partial}{\partial t}(\chi p)+\nabla \cdot\left(\lambda_{g, e} \nabla T_{g}-\sum_{i=1}^{N_{g}} h_{i, g} J_{i, g}\right)+\nabla \cdot\left(v_{g} p\right) \\
& -\nabla \cdot\left(\tau \cdot v_{\mathrm{g}}\right)+S_{E} \\
& \frac{\partial}{\partial t}\left(\rho_{g} Y_{i, g}\right)+\nabla \cdot\left(\rho_{g} V_{g} Y_{i g}\right)=\nabla \cdot\left(\rho_{g} D \nabla Y_{i, g}\right)+w_{i, g}^{g} \\
& S_{m}=-\left(\frac{\mu}{C_{1}} v_{g}+C_{2} \rho_{g}\left|v_{g}\right| v_{g}\right) \\
& S_{E}=A_{j} h_{C}\left(T_{a}-T_{g}\right)-\Sigma_{L, g} w_{i, g}^{g} H_{L, g}+q_{R}
\end{aligned}
$$

Table 4

Solid-phase conservation equations.

$$
\begin{aligned}
& \frac{\partial}{\partial t}\left((1-\chi) \rho_{s}\right)=\sum_{i, s} w_{i, s}^{g s} \\
& \frac{\partial}{\partial t}\left((1-\chi) \rho_{s} Y_{i, s}\right)=w_{i, s}^{g s} \\
& \rho_{s} c_{p s}(1-\chi) \frac{\partial T_{p}}{\partial t}=\nabla \cdot\left(\lambda_{s, e} \nabla T_{s}\right)+A_{s} h_{c}\left(T_{g}-T_{s}\right)+\frac{A_{s}}{4} Q_{a, p}\left(G-4 \sigma T_{s}^{4}\right)+\sum_{i, s} w_{i, s}^{g s} H_{i, s}
\end{aligned}
$$

coupling model allow solid-phase to exchange mass, species and energy with the continuous phase. The interaction between solid-phase and gas-phase in terms of convective heat transfer is enabled by a source term added to solid phase energy equation, Table 4, and subtracted in gas-phase energy equation, Table 3. Heat transfer coefficient is estimated from Nusselt number which is calculated from Wakao et al. [37] correlation. Similarly, mass and species exchanged between the two phases are coupled by source terms which have same magnitude but opposite in sign; $\sum_{i, g} w_{i, g}^{g s}=-\sum_{i, s} w_{i, s}^{g s}$ and $w_{i g}^{g s}=-w_{i, s}^{g s}$ for mass and species, respectively.

The presence of high concentration of $\mathrm{H}_{2} \mathrm{O}$ and $\mathrm{CO}_{2}$ gases in an oxyfuel combustion environment alters radiative gas properties. The choice of the property model affects the accuracy of the overall radiation model. Some models use oversimplified approach, for example, gray gas model, while others use comprehensive approach, for example, wavelength dependent property models. A widely used model is Weighted-Sum-of-Gray-Gas-Model (WSGGM) which works well in an air-fuel combustion environment, Smith et al. [38]. There have been some efforts, for instance Yin et al. [39], to modify WSGGM so as to improve its accuracy in predicting radiation in an oxy-fuel combustion environment. It has been noted that modified WSGGM model has sig. nificant improvement on the accuracy when considering large scale reactors $[12,40]$. A minimal change of $<1 \%$ on temperature was noted when applied on a small scale reactor [12]. The reactor used in this study is small, therefore, unmodified WSGGM was implemented with an expectation that it would not significantly affects the results.

\subsection{Chemical kinetic model}

Biomass conversion was modeled by four sub-models, namely, drying, pyrolysis, gas-phase reactions and char oxidation models. The overall kinetic model used in this work is presented in Table 5. Drying of the wet wood was modeled by a first-order kinetic rate model, shown in reaction $R(1)$ [41].

Dry wood decomposed into primary components char, tar and gas through pyrolysis process. The kinetics of dry wood conversion into tar, char and gas is given by reactions R(2)-R(4) while the tar cracking is reaction $\mathrm{R}(5)$. The mass fractions for gas species from wood pyrolysis in reaction $R(2)$ were specified according to Mahmoudi et al. [42] and Di Blasi [43]. The components of tar cracking reaction R(5) are inert tar, $\mathrm{CO}, \mathrm{CO}_{2}, \mathrm{H}_{2}$ and $\mathrm{CH}_{4}$ whose mass fractions amounts are $0.22,0.564$, $0.111,0.017$ and 0.088 , respectively $[44,45]$.

Gas species considered in homogenous gas-phase reactions $R(6)-R$ (14) are those generated from drying $\left(\mathrm{H}_{2} \mathrm{O}\right)$, devolatilization $\left(\mathrm{CO}_{2}\right.$, $\mathrm{H}_{2} \mathrm{O}, \mathrm{CO}, \mathrm{H}_{2}, \mathrm{CH}_{4}$, tar), tar cracking and char heterogeneous reactions. Oxidation of $\mathrm{CO}, \mathrm{CH}_{4}, \mathrm{H}_{2}$ and tar are represented by reactions $\mathrm{R}(6)-\mathrm{R}$ (9). For the purpose of checking the chemical effect in oxy-fuel environment reaction $\mathrm{R}(10)$, which has been identified as dominant reaction pathway [46, 47], is incorporated into the mechanism. Important chain-branching steps of $\mathrm{H}_{2}(\mathrm{R}(11), \mathrm{R}(12))$ relevant to this reaction are included. Furthermore, the forward and reverse reactions $\mathrm{R}$ (13) and $\mathrm{R}(14)$ for $\mathrm{H}_{2} \mathrm{O}$ and $\mathrm{CO}$ have been considered [35, 41].

Char consumption is represented by heterogeneous reactions $\mathrm{R}(15)$ $\mathrm{R}(17)$. Char oxidation is given by reaction $\mathrm{R}(15)$ while its gasification by $\mathrm{CO}_{2}$ and $\mathrm{H}_{2} \mathrm{O}$ is by reactions $\mathrm{R}(16)$ and $\mathrm{R}(17)$, respectively. The parameter $\Omega$ in reaction $\mathrm{R}(15)$ control the ratio of $\mathrm{CO}_{2}$ to $\mathrm{CO}$ emitted when char is burning. It is expressed as a function of char surface 
Table 5

Biomass kinetic model.

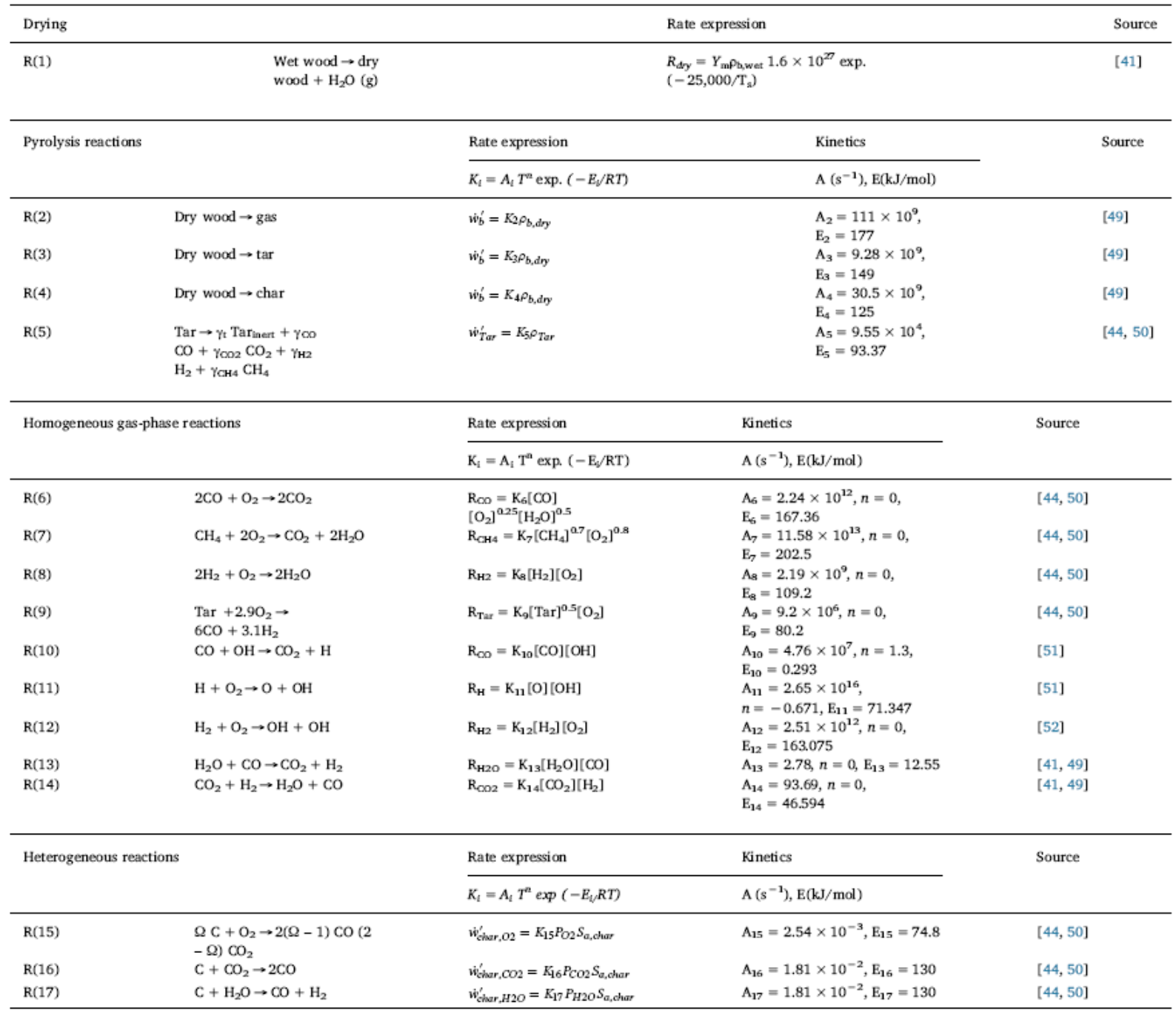

temperature $[41,48]$ :

$\Omega=\frac{2\left(1+4.3 \exp \left[-3390 / T_{\text {particle }}\right]\right)}{2+4.3 \exp \left[-3390 / T_{\text {particle }}\right]}$.

\subsection{Mesh and boundary conditions}

Computational domain representing the burner was meshed into highly-refined unstructured grids which ensured grid independent solutions. The burner was considered to have double symmetry. Therefore, a quarter of the burner with the dimensions described in section 2 was used in all simulated cases. Mesh independent test was carried out to determine appropriate number of cells. Approximately 200,000 cells made of polyhedral elements and prismatic layers near the wall were used.

Cold mixture of $\mathrm{O}_{2} / \mathrm{N}_{2}$ or $\mathrm{CO}_{2}$ at $295 \mathrm{~K}$ enters the computational domain at the inlet boundary. For all the tests, the mass flux at the inlet was $0.1 \mathrm{~kg} / \mathrm{m}^{2} / \mathrm{s}$ while mass fraction of $\mathrm{O}_{2}$ and $\mathrm{N}_{2}$ or $\mathrm{CO}_{2}$ was specified according to the case tested. Combustion products exited at the domain at the top which was modeled as outflow boundary with zero temperature and species gradients. The wall was considered stationary with no slip condition. Thermal boundary conditions at the wall were modeled as a mixture of convective and radiation heat transfer. Convective heat flux at the wall was selected with an adopted heat transfer coefficient of $10 \mathrm{~W} / \mathrm{m}^{2} \cdot \mathrm{K}$. An emissivity of 0.8 was adopted because the wall was made from stainless steel [31].

\section{Results and discussions}

The accuracy of the simulation solutions was ensured by running mesh independence tests. The prediction of temperature profiles along axial length of the reactor for oxy-fuel environment at two different times applying different computational mesh sizes are shown in Fig. 3a and b. In both cases, there was a significant change in results when mesh size was increased from 100,000 cells to 200,000 cells. But the 

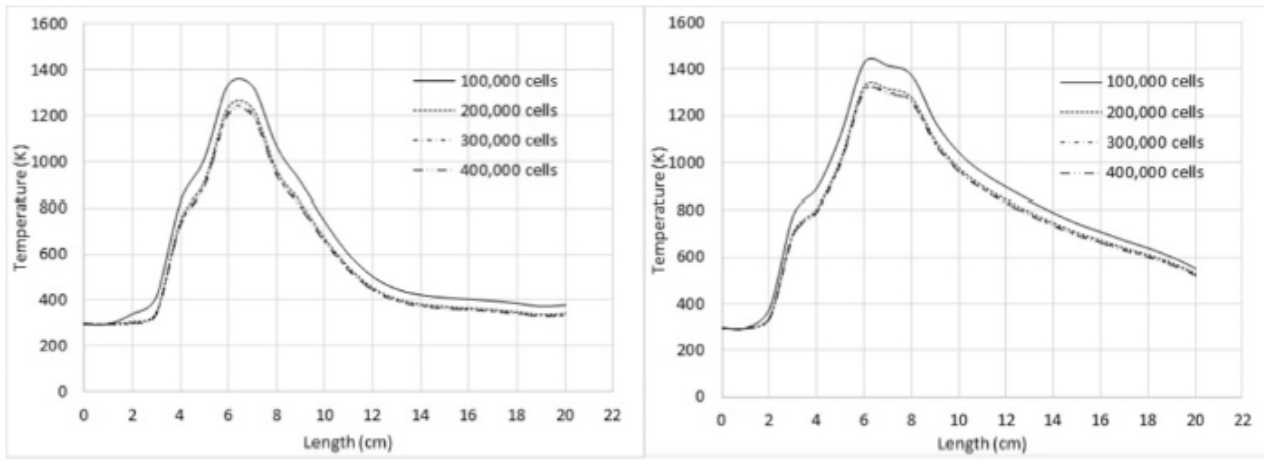

Fig. 3. Comparison of temperatures profiles along axial length of the reactor for wood combustion in $\mathrm{O}_{2} / \mathrm{CO}_{2}$ mixtures at two different times applying different computational mesh sizes.

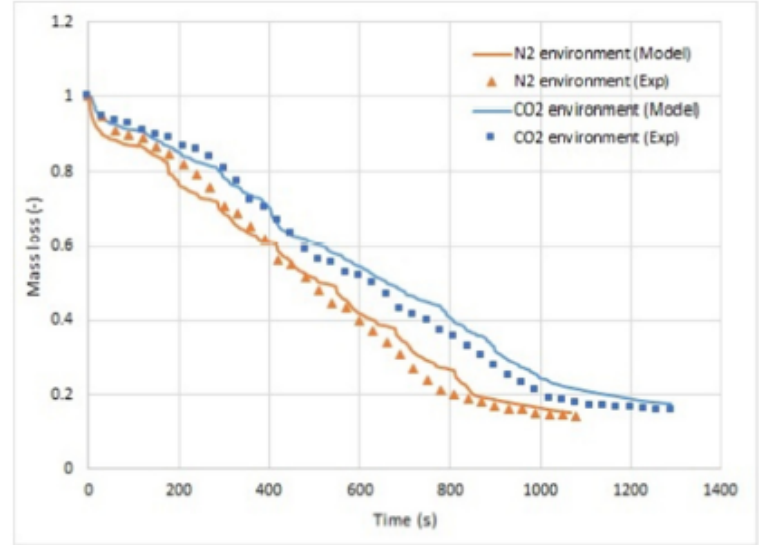

Fig. 4. Mass loss history for wood combustion in fixed bed at $21 \% \mathrm{O}_{2} / 79 \% \mathrm{~N}_{2}$ and $21 \% \mathrm{O}_{2} / 79 \% \mathrm{CO}_{2}$ mixtures.

predictions using 200,000 cells, 300,000 cells and 400,000 cells did not have much differences. Therefore, a computational mesh with 200,0000 cells was selected for all the cases computed.

Validity of the model is checked by comparing mass loss history, peak temperatures and flame propagation speed obtained from simulations to corresponding experimental data. Shown in Fig. 4 is the mass loss history for wood combustion in $21 \% \mathrm{O}_{2}$ concentration under both $\mathrm{N}_{2}$ and $\mathrm{CO}_{2}$. The model agrees very well with experimental values. The curve for oxy-fuel condition is less steep with a longer devolatilization stage when compared with $\mathrm{N}_{2}$ atmosphere. A slightly long char stage is also observed in $\mathrm{CO}_{2}$ atmosphere. In overall, combustion of the same amount of wood takes a longer time for oxy-fuel condition than for airfuel condition. This suggests a slow fuel consumption and burning rate in $\mathrm{CO}_{2}$ atmosphere.

Presented in Figs. 5, 6 and 7 are temperature maps in the fuel bed at different times for different combustion atmospheres. The simulated and measured peak temperatures attained in the bed are compared in Fig. 8. Temperatures are poorly predicted at lower oxygen concentrations. The accuracy of prediction improves at higher oxygen concentrations. Temperatures corrected for radiation losses are also plotted in Fig. 8. Indeed, their agreement with predicted values is better than those of uncorrected values. Consequently, this emphasizes the importance of considering radiation losses when validating a model.

It is important to note that after ignition, different conversion processes such as drying, devolatilization, char combustion and homogenous reactions takes place simultaneously at various height of the bed. Since some processes are endothermic and others are exothermic, the temperatures at various regions are strongly dependent on the dominant process as discussed further below. In the model used in this study, gaseous species release from biomass, depending on availability of oxidative species either react within fuel bed or are transported to freeboard region where they continue reacting and produce heat. For all the cases studied, it is observed that during initial stages of combustion, freeboard temperatures are almost equal to bed temperatures. For $21 \% \mathrm{O}_{2}$ concentration, the period extended up to $300 \mathrm{~s}$, Fig. 5, and $450 \mathrm{~s}$, Fig. 6, for $\mathrm{N}_{2}$ and $\mathrm{CO}_{2}$ environments, respectively. As $\mathrm{O}_{2}$ concentration is increased in oxy-fuel condition, the period reduces from $450 \mathrm{~s}$ to $300 \mathrm{~s}$, Fig. 7. During this stage, heat release by homogeneous reactions is absorbed by downstream particles which are still undergoing devolatilization. At the same time, immediate upstream particles take up heat for drying.

As combustion progresses downward which is clearly depicted by propagation of reaction front, e.g. between 400 and $750 \mathrm{~s}$ in Figs. 5, 7 and $600-950 \mathrm{~s}$ in Fig. 6, more volatiles are released. During this period, freeboard temperatures are higher than bed temperatures. At this time, particles adjacent to freeboard probably have completed endothermic processes (drying and devolatilization). In addition, these particles are in char combustion stage which releases more heat. Heat released from homogeneous reaction and char combustion is transported from bed to freeboard by convection of combustion products which are dominated by $\mathrm{H}_{2} \mathrm{O}$ and $\mathrm{CO}_{2}$.

After some time, reaction front reaches the bottom of the reactor and all volatiles have been released. After this point, combustion in the bed is dominated by char combustion, e.g. at 1000 s of Figs. 5, 7 and $1100 \mathrm{~s}$ in Fig. 6. Freeboard temperatures decrease during this period. This is because homogeneous reactions which release intense heat are almost complete.

Even though the temperature distribution in fuel bed under both conditions exhibits the same behavior, the magnitudes are different. At $21 \% \mathrm{O}_{2}$ concentration, air-fuel has a peak temperature of $1497 \mathrm{~K}$ while oxy-fuel has $1388 \mathrm{~K}$. As shown in Fig. 8 , as $\mathrm{O}_{2}$ concentration is increased, temperature also increases. A value of temperature close to that of $21 \% \mathrm{O}_{2} / 79 \% \mathrm{~N}_{2}$ mixture is achieved at around $30 \% \mathrm{O}_{2} / 70 \% \mathrm{CO}_{2}$ mixture. Low values of temperatures in oxy-fuel conditions are associated with higher specific heat capacity of $\mathrm{CO}_{2}$ gas than that of $\mathrm{N}_{2}$ gas. This applies for all the temperatures above $650 \mathrm{~K}$ where specific heat capacity of $\mathrm{CO}_{2}$ gas is higher than that of $\mathrm{N}_{2}$ gas.

The flame front propagation speed is estimated from distance and time data of temperature measuring points, Sakthivadivel and Iniyan [22]. For both experiment and model, flame front passes through a point when there is an abrupt increase in temperature from ambient value to a peak value, Ryu et al. [23]. The exact position of predicted and measured reaction front for wood combustion in $21 \% \mathrm{O}_{2}$ 


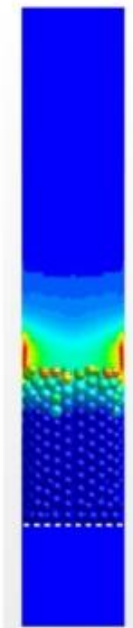

$100 \mathrm{~s}$

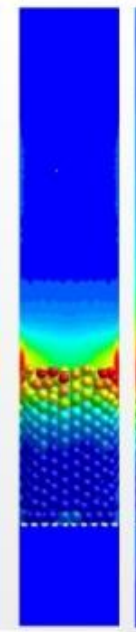

$200 \mathrm{~s}$

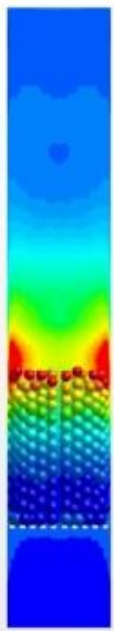

300 s

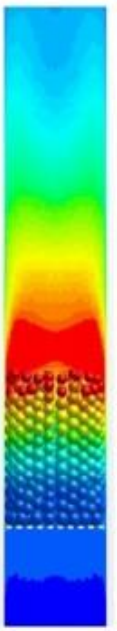

$400 \mathrm{~s}$

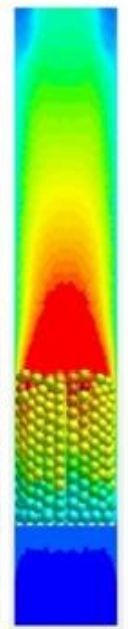

$750 \mathrm{~s}$

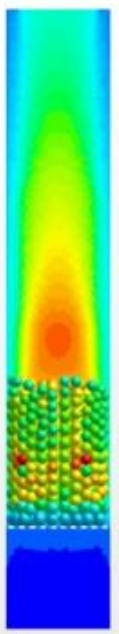

$1000 \mathrm{~s}$

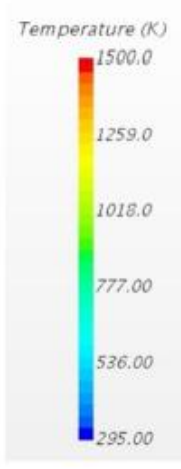

Fig. 5. Temperature distribution in the wood fuel bed burning at $21 \% \mathrm{O}_{2} / 79 \% \mathrm{~N}_{2}$ at different times. concentration under both $\mathrm{N}_{2}$ and $\mathrm{CO}_{2}$ is shown in Fig. 9. For air-fuel conditions at $21 \% \mathrm{O}_{2}$ concentration, a higher value of flame speed is observed. In general, propagation speed for air-fuel condition reported in literature $[25,26]$ is higher than those observed in oxy-fuel conditions of the current study. However direct comparison cannot be done because flame front propagation speed is dependent on several factors such as air mass flux, fuel properties, particles size, reactor operation mode, et cetera. Flame front speed have been shown [22-25] to increase with increase in air mass flux up to a peak point where it starts to decrease. Mahapatra et al. [24] reported a peak value of $0.089 \mathrm{~mm} / \mathrm{s}$ for air flow rate of $0.132 \mathrm{~kg} / \mathrm{m}^{2} / \mathrm{s}$ and casuarina wood as fuel. While studying char combustion in a packed bed, Dasappa and Paul [25] reported a peak value of $0.30 \mathrm{~mm} / \mathrm{s}$ for air mass flux of $0.1 \mathrm{~kg} / \mathrm{m}^{2} / \mathrm{s}$. Yang et al. [26] showed that flame speed decreased from $0.24 \mathrm{~mm} / \mathrm{s}$ for $10 \mathrm{~mm}$ sized particles to $0.21 \mathrm{~mm} / \mathrm{s}$ for $35 \mathrm{~mm}$ sized particles. In a recent study, Sakthivadivel and Iniyan [22] obtained a flame speed of about $0.05-0.07 \mathrm{~mm} / \mathrm{s}$ for different fuels tested in air-fuel environment.

In order to have a proper comparison, investigation of flame propagation speed for the same wood fuel with the same particle size burning in air-fuel conditions was conducted. Fig. 9 shows that the gradient (propagation speed) is steeper in $\mathrm{N}_{2}$ environment than in $\mathrm{CO}_{2}$ environment. Indeed, it is observed that flame speed in oxy-fuel atmosphere reduced to $76 \%$ (model) and $78 \%$ (experiment) of that of the air-fuel condition with similar $\mathrm{O}_{2}$ concentration. It is also noted that ignition delay is longer in $\mathrm{CO}_{2}$ environment. Reduction in speed could be attributed to transport and thermodynamic properties of $\mathrm{CO}_{2}$ gas and chemical effects associated with it. The chemical reactions involving consumption of $\mathrm{CO}_{2}$ include reverse water gas shift reaction $\mathrm{R}(14)$ and Bourdouard reaction $\mathrm{R}(16)$. The reaction rates of both reactions are several orders of magnitude smaller than those of homogeneous

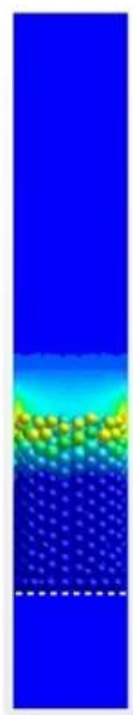

$200 \mathrm{~s}$

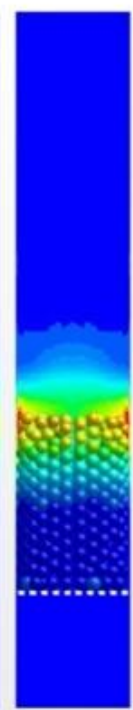

$300 \mathrm{~s}$

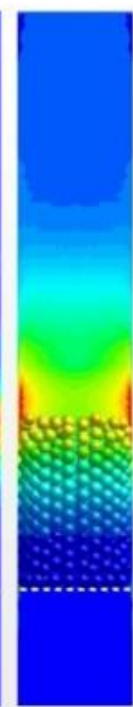

$450 \mathrm{~s}$

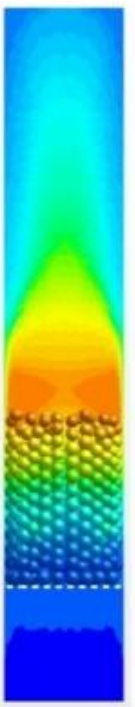

$600 \mathrm{~s}$

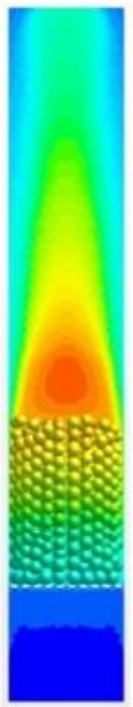

$950 \mathrm{~s}$

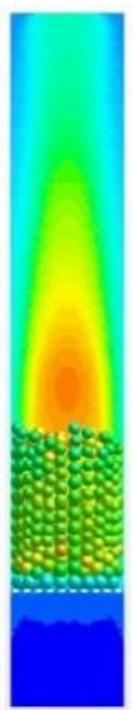

$1100 \mathrm{~s}$
Temperature (K)

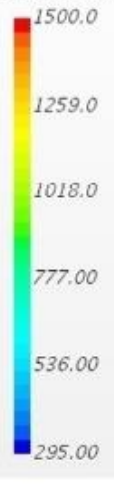

Fig. 6. Temperature distribution in the wood fuel bed burning at $21 \% \mathrm{O}_{2} / 79 \% \mathrm{CO}_{2}$ at different times. 


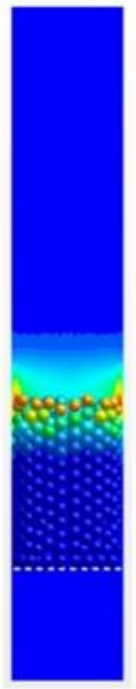

$100 \mathrm{~s}$

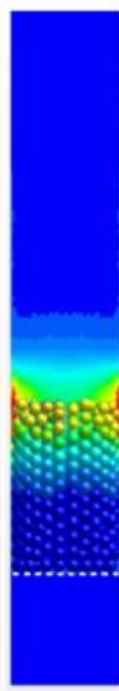

$200 \mathrm{~s}$

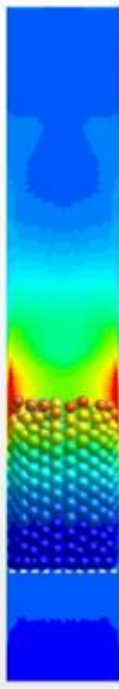

$300 \mathrm{~s}$

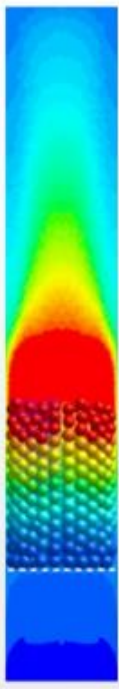

$400 \mathrm{~s}$

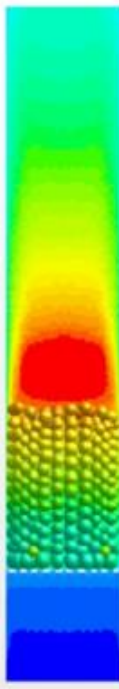

$750 \mathrm{~s}$

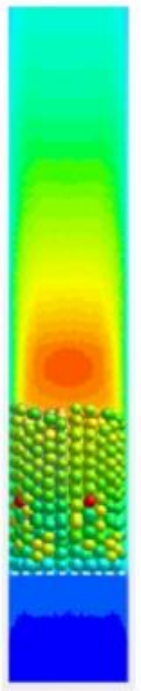

$1000 \mathrm{~s}$

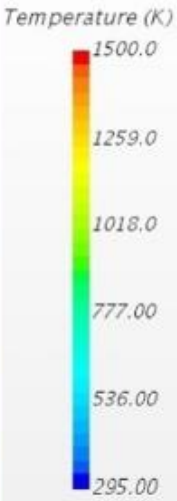

Fig. 7. Temperature distribution in the wood fuel bed burning at $30 \% \mathrm{O}_{2} / 70 \% \mathrm{CO}_{2}$ at different times.

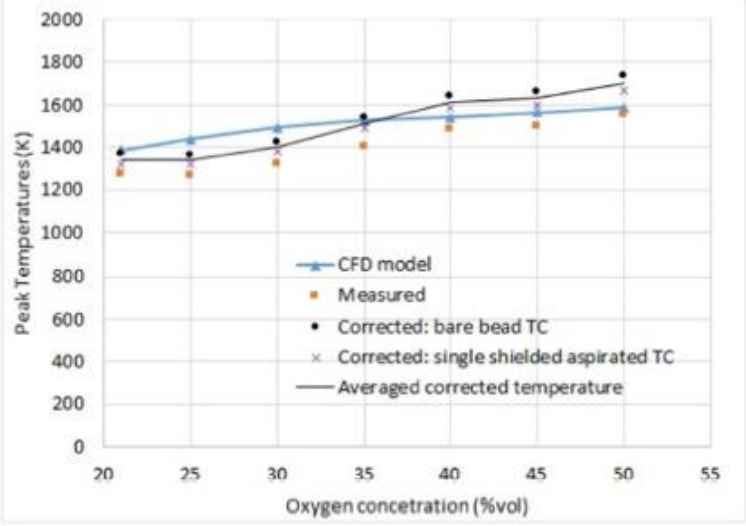

Fig. 8. Predicted and measured peak temperatures in the wood fuel bed burning at different $\mathrm{CO}_{2}$ atmospheres.

reactions $\mathrm{R}(6)-\mathrm{R}(13)$. Therefore, their contribution to flame speed is quite small. On the other hand, $\mathrm{CO}_{2}$ gas has a higher heat capacity than $\mathrm{N}_{2}$ gas (1.5 times higher than that of $\mathrm{N}_{2}$ ). In addition, $\mathrm{CO}_{2}$ is a heavy gas and $\mathrm{O}_{2}$ diffusivity in it is lower. Consequently, the overall effect is reduction of temperature and heating rates of fuel particles. Thus a reduced flame speed is observed in $\mathrm{CO}_{2}$ environment. It is also noted that mass fraction of combustible volatiles released in $\mathrm{CO}_{2}$ environment are smaller. This also contributes to reduction in flame speed and is discussed in subsequent paragraphs.

Shown in Fig. 10 are plots of flame front propagation speed in fuel bed operated at different oxy-fuel conditions. The curves show good agreement between the predicted and measured values. Flame speed increased from $0.06 \mathrm{~mm} / \mathrm{s}$ at $21 \% \mathrm{O}_{2} / 79 \% \mathrm{CO}_{2}$ to $0.21 \mathrm{~mm} / \mathrm{s}$ at $50 \% \mathrm{O}_{2}$ $50 \% \mathrm{CO}_{2}$. As $\mathrm{O}_{2}$ concentration is increased, gas mixture properties also change. This means a reduced portion of $\mathrm{CO}_{2}$ in which $\mathrm{O}_{2}$ diffusivity is improved. As a result, an increase in temperature is seen (Fig. 8) and also heating rates of particles is increased. Hence, the flame speed also increases.

Presented in Figs. 11-14 are the flames structures of wood

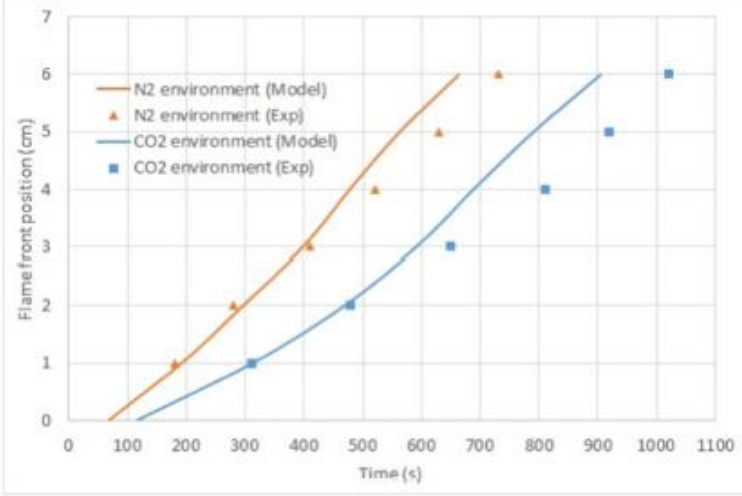

Fig. 9. Predicted and measured flame front position for wood combustion in fixed bed at $21 \% \mathrm{O}_{2} / 79 \% \mathrm{~N}_{2}$ and $21 \% \mathrm{O}_{2} / 79 \% \mathrm{CO}_{2}$ mixtures. Fuel bed top is taken as datum.

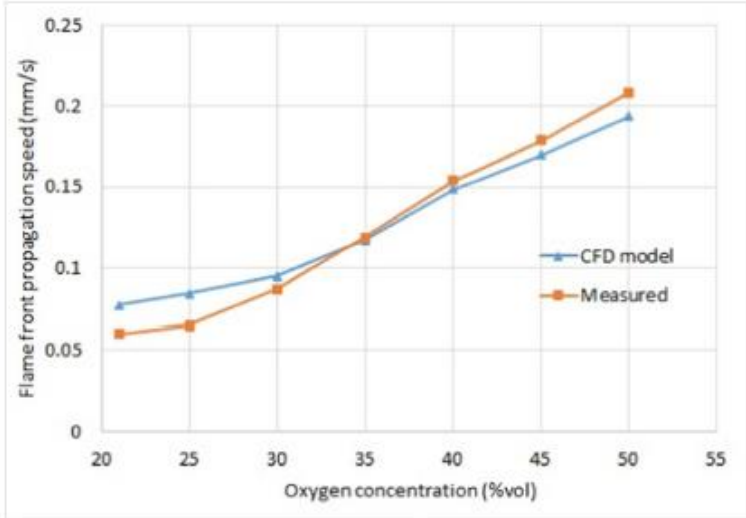

Fig. 10. Predicted and measured flame front propagation speed in the wood fuel bed burning at different $\mathrm{CO}_{2}$ atmospheres. 


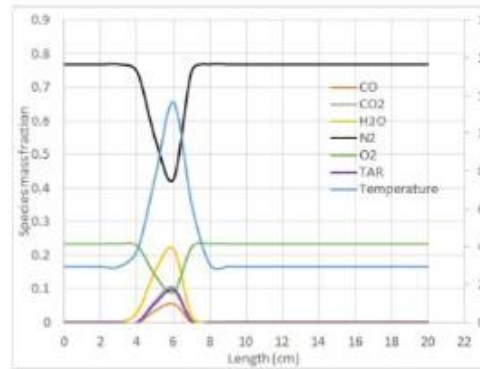

(a) $79 \% \mathrm{~N}_{2}$ at $200 \mathrm{~s}$

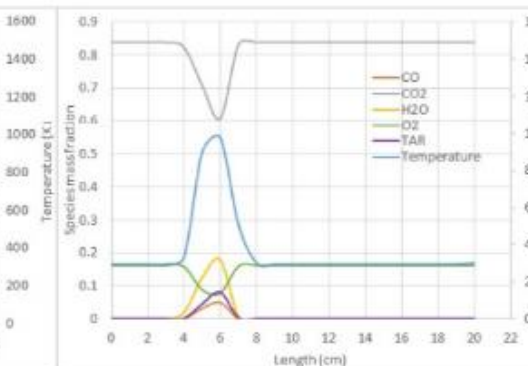

(b) $79 \% \mathrm{CO}_{2}$ at $300 \mathrm{~s}$

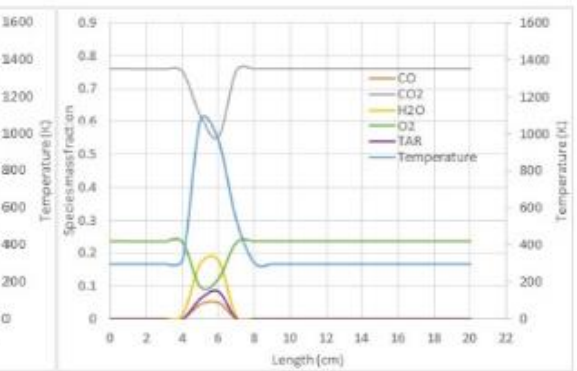

(c) $70 \% \mathrm{CO}_{2}$ at $200 \mathrm{~s}$

Fig. 11. Species and temperatures profiles along axial length of the reactor for wood combustion in $\mathrm{O}_{2} / \mathrm{N}_{2}$ and $\mathrm{O}_{2} / \mathrm{CO}_{2}$ mixtures when reaction front is at $5 \mathrm{~cm}$ from fuel bottom.

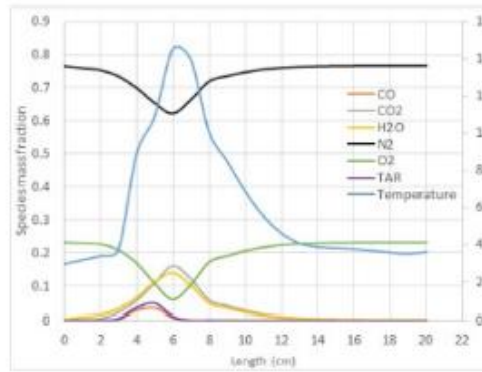

(a) $79 \% \mathrm{~N}_{2}$ at $300 \mathrm{~s}$

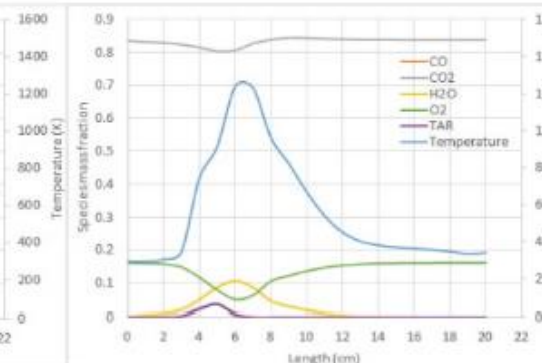

(b) $79 \% \mathrm{CO}_{2}$ at $450 \mathrm{~s}$

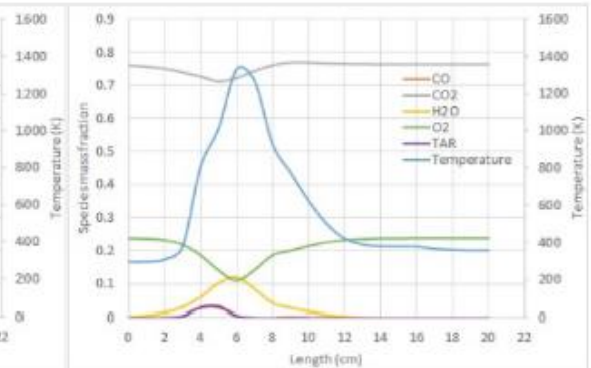

(c) $70 \% \mathrm{CO}_{2}$ at $300 \mathrm{~s}$

Fig. 12. Species and temperatures profiles along axial length of the reactor for wood combustion in $\mathrm{O}_{2} / \mathrm{N}_{2}$ and $\mathrm{O}_{2} / \mathrm{CO}_{2}$ mixtures when reaction front is at $4 \mathrm{~cm}$ from fuel bottom.

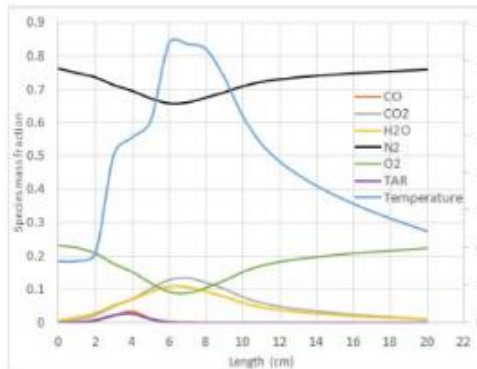

(a) $79 \% \mathrm{~N}_{2}$ at $400 \mathrm{~s}$

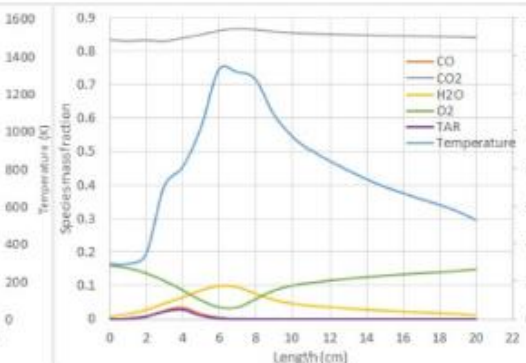

(b) $79 \% \mathrm{CO}_{2}$ at $600 \mathrm{~s}$

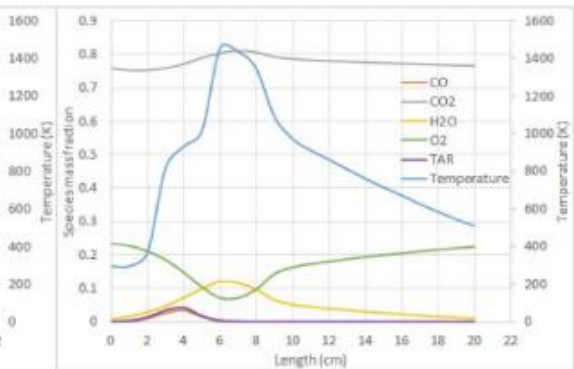

(c) $70 \% \mathrm{CO}_{2}$ at $400 \mathrm{~s}$

Fig. 13. Species and temperatures profiles along axial length of the reactor for wood combustion in $\mathrm{O}_{2} / \mathrm{N}_{2}$ and $\mathrm{O}_{2} / \mathrm{CO}_{2}$ mixtures when reaction front is at $3 \mathrm{~cm}$ from fuel bottom.

combustion in both environments at different combustion stages. The main species mass fraction and temperature profiles at a given time are plotted against axial length of the reactor. Fig. 11 illustrates flame structures in oxy-fuel and air-fuel conditions when reaction front is at $5 \mathrm{~cm}$ from the bottom of reactor. Because each case has a different flame speed it occurs at different times; at $200 \mathrm{~s}$ in $79 \% \mathrm{~N}_{2}$, Fig. $11 \mathrm{a}$, and $70 \% \mathrm{CO}_{2}$, Fig. 11c, and at $300 \mathrm{~s}$ in $79 \% \mathrm{CO}_{2}$, Fig. 11b. In all the cases, reaction zone covers a region of depth between $4 \mathrm{~cm}$ to $7 \mathrm{~cm}$. The particles within this region are mainly undergoing drying and pyrolysis. Homogeneous reactions of pyrolysis products, tar, $\mathrm{CO}, \mathrm{CH}_{4}, \mathrm{H}_{2}$, with $\mathrm{O}_{2}$ are exothermic. It is observed that gaseous species react within the fuel bed and are also transported to freeboard region. Some of the heat released is absorbed by particles because pyrolysis is an endothermic reaction while the remaining amount is convected to freeboard region. Although the flame structures depict similar profiles, the magnitude of species and temperature are different. Highest amounts of tar and steam are observed in $79 \% \mathrm{~N}_{2}$ environment while lowest amounts of these species are seen in $79 \% \mathrm{CO}_{2}$ environment. The amount of $\mathrm{CO}$ is almost equal in all the 3 cases. The high amount of tar and steam in $79 \% \mathrm{~N}_{2}$ environment is attributed to high temperature which enhances 


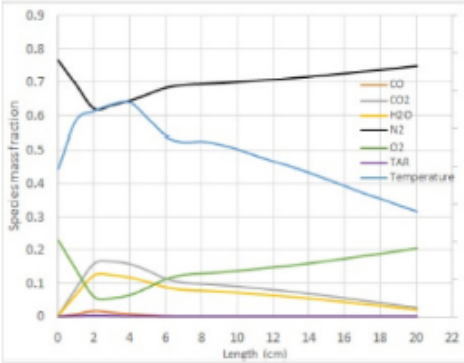

(a) $79 \% \mathrm{~N}_{2}$ at $1000 \mathrm{~s}$

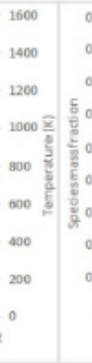

(b) $79 \% \mathrm{CO}_{2}$ at $1100 \mathrm{~s}$

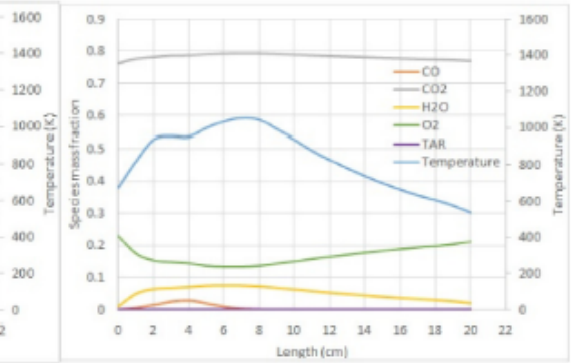

(c) $70 \% \mathrm{CO}_{2}$ at $1000 \mathrm{~s}$

Fig. 14. Species and temperatures profiles along axial length of the reactor for wood combustion in $\mathrm{O}_{2} / \mathrm{N}_{2}$ and $\mathrm{O}_{2} / \mathrm{CO}_{2}$ mixtures during char combustion stage.

pyrolysis process. Low amount of tar in oxy-fuel condition affirms the influence on flame propagation speed.

As the flame front propagates downward, the positions of the peak values of species also change, Figs. 12 and 13. The position where peak temperatures occur, however, remain just approximately at the fixed bed top. This is because particles in this region have completed pyrolysis process and no longer absorb heat released by homogeneous reactions. Furthermore, at this stage, the heat transfer through convection is high enough to raise the exit temperature. Very low amounts of tar and $\mathrm{CO}$ and high amounts of $\mathrm{CO}_{2}$ and $\mathrm{H}_{2} \mathrm{O}$ in this region reflect an increase in consumption rate of volatiles. For oxy-fuel cases, the amount of $\mathrm{CO}_{2}$ from combustion adds to the supplied amount and hence dominates the combustion products, Fig. 12b and c. Just like in the initial stage, flame front in $\mathrm{CO}_{2}$ environment arrives at $4 \mathrm{~cm}$, Fig. $12 \mathrm{~b}$, and $3 \mathrm{~cm}$, Fig. 13b, later than in air-fuel condition. For the flow condition tested, tar and $\mathrm{CO}$ are completely consumed within the fuel bed. As seen in the figures, $\mathrm{O}_{2}$ is sufficient for complete oxidation of these species. The amount of tar and $\mathrm{CO}$ at reaction front decreases as it moves downward, Fig. 13. As shown in Fig. 13a-c, the mass fraction of these species are almost equal in the three cases.

After the flame front reaches the bottom of the bed, the fuel bed is completely in char combustion stage. Major species generation and temperature profiles during this stage, for each of the three cases, are shown in Fig. 14. Absence of tar indicates that devolatilization stage has ended. As in the previous combustion stages, it is also noted that this stage occurs at a later time in $\mathrm{CO}_{2}$ environment than in $\mathrm{N}_{2}$ environment. Temperatures in the bed are relatively lower than in the previous combustion stages. As expected, temperatures in oxy-fuel conditions, Fig. 14b and c, are lower than that in air-fuel case, Fig. 14a. Low temperatures in all cases are attributed to absence of homogeneous reactions of volatiles which reduces rate of heat release. The only heat release is in char and $\mathrm{CO}$ oxidation. In addition, char gasification with $\mathrm{CO}_{2}$ and $\mathrm{H}_{2} \mathrm{O}$ is an endothermic reaction. Moreover, heat is lost by convective heat transfer to freeboard region. Because of cold air inlet, cooling effect results in relatively low temperatures in the grate. For char combustion stage, char is converted to $\mathrm{CO}$ and $\mathrm{CO}_{2}$. A high amount of $\mathrm{CO}$ is observed in oxy-fuel condition which is as a result of gasification of char in the $\mathrm{CO}_{2}$ environment.

\section{Conclusion}

A comprehensive study of the effect of $\mathrm{CO}_{2}$ combustion atmosphere on flame propagation speed and flame structures in wood combustion in a laboratory-scaled fixed bed operated under counter-current mode was presented in this paper. CFD-DEM approach was used to simulate wood conversion in a packed bed and the results compared to experimental data. Computational results agree very well with experimental values except temperature which showed poor prediction at low $\mathrm{O}_{2}$ concentration. The agreement of temperatures corrected for radiation losses with predicted values are better than those of uncorrected values. Hence, it was established that prediction accuracy of CFD-DEM is not the same in different $\mathrm{O}_{2} / \mathrm{CO}_{2}$ mixtures. Furthermore, it was observed that flame speed in oxy-fuel atmosphere reduced to $78 \%$ of that of the air-fuel condition with same $\mathrm{O}_{2}$ concentration. This was determined both by experiment and through computation. Reduced flame speed was attributed to a higher heat capacity of $\mathrm{CO}_{2}$ and lower $\mathrm{O}_{2}$ diffusivity in $\mathrm{CO}_{2}$ whose overall effect is reduction of temperature and heating rates of fuel particles. Low mass fraction of combustible volatiles predicted in the $\mathrm{CO}_{2}$ environment also contributes to a reduced flame speed. Flame structures have similar profiles but differ in value of temperature and species quantities. As expected, temperatures in the $\mathrm{CO}_{2}$ environments were lower than those in the $\mathrm{N}_{2}$ environments. During initial stages of combustion, the amount of tar and steam is observed to be highest in 79\% $\mathrm{N}_{2}$ environment and lowest in $79 \% \mathrm{CO}_{2}$ environment. The amount of $\mathrm{CO}$ was almost equal in both environments during pyrolysis but high amount was predicted in oxy-fuel environments during char combustion stage.

\section{Acknowledgement}

This work was financially supported by both Dedan Kimathi University of Technology, Kenya and Technische Hochschule Wildau, Germany. The first author would like to thank the German Academic Exchange Service (DAAD) for granting him stipend while undertaking this work at Technische Hochschule Wildau, Germany.

\section{References}

[1] R. Marsh, J. Runyon, A. Giles, S. Morris, D. Pugh, A. Valera-Medina, P. Bowen, Premixed methane oxycombustion in nitrogen and carbon dioxide atmospheres: measurement of operating limits, flame location and emissions, Proc. Combust. Inst. 36 (2017) 3949-3958.

[2] S. Bhunia, A.K. Sadhukhan, P. Gupta, Modelling and experimental studies on oxyfuel combustion of coarse size coal char, Fuel Process. Technol. 158 (2017) 73-84.

[3] L. Álvarez, M. Gharebaghi, M. Pourkashanian, A. Williams, J. Riaza, C. Pevida, J.J. Pis, F. Rubiera, CFD modelling of oxy-coal combustion in an entrained flow reactor, Fuel Process. Technol. 92 (2011) 1489-1497.

[4] G. Scheffknecht, L Al-Makhadmeh, U. Schnell, J. Maier, Oxy-fuel coal combustion-a review of the current state-of-the-art, Int. J. Greenhouse Gas Control 5 (2011) $16-35$.

[5] S. Jiménez, J. Ballester, Influence of operating conditions and the role of sulfur in the formation of aerosols from biomass combustion, Proc. Combust. Inst. 30 (2005) 2965-2972.

[6] R. Domenichini, F. Gasparini, P. Cotone, S. Santos, Techno-economic evaluation of biomass fired or co-fired power plants with post combustion $\mathrm{CO}_{2}$ capture, Energy Procedia 4 (2011) 1851-1860.

[7] F. Shan, Q. Lin, K. Zhou, Y. Wu, W. Fu, P. Zhang, L. Song, C. Shao, B. Yi, An experimental study of ignition and combustion of single biomass pellets in air and oxy-fuel, Fuel 188 (2017) 277-284.

[8] A. Molina, C.R. Shaddix, Ignition and devolatilization of pulverized bituminous coal particles during oxygen/carbon dioxide coal combustion, Proc. Combust. Inst. 31 (2007) 1905-1912. 
[9] W. Prationo, J. Zhang, J. Cui, Y. Wang, L. Zhang, Influence of inherent moisture on the ignition and combustion of wet Victorian brown coal in air- firing and axy-fuel modes: part 1: the volatile ignition and flame propagation, Fuel Process. Technol 138 (2015) 670-679.

[10] J. Piaza, R. Khatami, Y.A. Levendis, L. Álvarez, M.V. Gil, C. Pevida, F. Rubiera, J.J. Pis, Single particle ignition and combustion of anthracite, semi-anthracite and
bituminous coals in air and simulated oxy-fuel conditions, Combust. Flame 161 (2014) 1096-1108.

[11] T.S. Farrow, C. Sun, C.E. Snape, Impact of biomass char on coal char burn-out under air and oxy-fuel conditions, Fuel 114 (2013) 128-134.

[12] L. Álvarez, C. Yin, J. Riaza, C. Pevida, J.J. Pis, F. Rubiera, Biomass co-firing under oxy-fuel conditions: a computational fluid dynamics modelling study and experimental validation, Fuel Process, Technol, 120 (2014) 22-3".

[13] NS. Yuzbasi, N. Selçuk, Air and oxy-fuel combustion characteristics of biomass/ lignite blends in TGA-FTIR, Fuel Process. Technol. 92 (2011) 1101-1108.

[14] M.F. Irfan, A. Arami-Niya, M.H. Chakrabarti, W.M.A. Wan Daud, M.R. Usman, Kinetics of gasification of coal, biomass and their blends in air $\left(\mathrm{N}_{2} / \mathrm{O}_{2}\right)$ and different oxy-fuel $\left(\mathrm{O}_{2} / \mathrm{CO}_{2}\right)$ atmospheres, Energy 37 (2012) 665-672.

[15] J.G. Pohlmann, E. Osório, A.C.F. Vilela, M.A. Diez, A.G. Borrego, Pulverized combustion under conventional $\left(\mathrm{O}_{2} / \mathrm{N}_{2}\right)$ and oxy-fuel $\left(\mathrm{O}_{2} / \mathrm{CO}_{2}\right)$ conditions of biomasses treated at different temperatures, Fuel Process. Technol. 155 (2016) 174-182.

[16] T. Hanaoka, K. Sakanishi, Y. Okumura, The effect of $\mathrm{N}_{2} / \mathrm{CO}_{2} / \mathrm{O}_{2}$ content and pressure on characteristics and $\mathrm{CO}_{2}$ gasification behavior of biomass-derived char, Fuel Process. Technol. 104 (2012) 287-294.

[17] S.R. Gubba, L. Ma, M. Pourkashanian, A. Williams, Influence of particle shape and internal thermal gradients of biomass particles on pulverised coal/biomass co- fired flames, Fuel Process. Technol. 92 (2011) 2185-2195.

[18] M.V. Gil, J. Riaza, L. Álvarez, C. Pevida, F. Rubiera, Biomass devolatilization at high temperature under $\mathrm{N}_{2}$ and $\mathrm{CO}_{2}$; char morphology and reactivity, Energy 91 (2015) $655-662$

[19] S. Heuer, O. Senneca, A. Wütscher, H. Düdder, M. Schiemann, M. Muhler, V. Scherer, Effects of oxy-fuel conditions on the products of pyrolysis in a drop tube reactor, Fuel Process. Technol. 150 (2016) 41-49.

[20] G. Wang, R. Zander, M. Costa, Oxy-fuel combustion characteristics of pulverizedcoal in a drop tube furnace, Fuel 115 (2014) 452-460.

[21] M. Fatehi, M. Kaviany, Adiabatic reverse combustion in a packed bed, Combust Flame 99 (1994) 1-17.

[22] D. Sakthivadivel, S. Iniyan, Characterization, density and size effects of fuels in an advanced micro-gasifier stove, Biofuels (2018), https://doi.org/10.1080/ 17597269.2018 .1426163$.

[23] C. Ryu, Y.B. Yang, A. Khor, N.E. Yates, V.N. Sharifi, J. Swithenbank, Effect of Fue Properties on Biomass Combustion: Part I. Experiments - Fuel Type, Equivalence Ratio and Particle Size, 85 (2006), pp. 1039-1046.

[24] S. Mahapatra, S. Kumar, S. Dasappa, Gasification of wood particles in a co-current packed bed: experiments and model analysis, Fuel Process. Technol. 145 (2016) $76-89$.

[25] S. Dasappa, P.J. Paul, Gasification of char particles in packed beds: analysis and results, Int. J. Energy Res. 25 (2001) 1053-1072.

[26] Y.B. Yang, C. Ryu, A. Khor, V.N. Sharifi, J. Swithenbank, Fuel size effect on pinewood combustion in a packed bed, Fuel 84 (2005) 2026-2038

[27] J. Porteiro, D. Patiño, J. Collazo, E. Granada, J. Moran, J.L. Miguez, Experimental analysis of the ignition front propagation of several biomass fuels in a fixed-bed combustor, Fuel 89 (2010) 26-35.

[28] S. Varunkumar, Packed Bed Gasification-Combustion in Biomass Based Domestic Stoves and Combustion Systems (PhD Thesis), 012 (INDIA) Department of Stoves and Combustion Systems (PhD Thesis), 012 (INDIA) Depar tment of

[29] CD-Adapco, STAR-CCM + Version, 11.04 (2017) www.cd-adapco.com.

[30] J.H. Lienhard IV, J.H. Lienhard V, A Heat Transfer Textbook, third ed., Phlogiston
Press, Cambridge, Massachusetts, U.S.A, 2003.

[31] F.P. Incropera, D.P. DeWitt, T.L. Bergman, A.S. Lavine, Fundamentals of Heat and Mass Transfer, sixth ed., John Wiley \& Sons, 2006.

[32] L.G. Blevins, W.M. Pitts, Modeling of bare and aspirated thermocouples in compartment fires, Fire Saf. J. 33 (1999) 239-259.

[33] B. Rashidian, Y.M. Al-Abdeli, G.H. Yeoh, D. Patiño, F. Guzzomi, Methodologies for processing fixed bed combustor data, Combust. Sci. Technol. 189 (2017) 79-102. [34] R. Mehrabian, A. Shiehnejadhesar, R. Scharler, I. Obernberger, Multi-physics modelling of packed bed biomass combustion, Fuel 122 (2014) 164-178.

[35] M.A. Gómez, J. Porteiro, D. Patiño, J.L. Míguez, CFD modelling of thermal conversion and packed bed compaction in biomass combustion, Fuel 117 ( (2014) $716-732$.

[36] J. Collazo, J. Porteiro, D. Patiño, E. Granada, Numerical modeling of the combustion of densified wood under fixed-bed conditions, Fuel 93 (2012) 149-159.

[37] N. Wakao, S. Kaguei, T. Funazkri, Effect of fluid dispersion coefficients on particleto-fluid heat transfer coefficients in packed beds: correlation of Nusselt numbers, Chem. Eng. Sci. 34 (1979) 325-336.

[38] T.F. Smith, Z.F. Shen, J.N. Friedman, Evaluation of coefficients for the weighted sum of gray gases model, J. Heat Transf. 104 (1982) 602-608.

[39] C. Yin, LC.R. Johansen, L.A. Rosendahl, S.K. Kær, New weighted sum of gray gases model applicable to computational fluid dynamics (CFD) modeling of oxy-fuel combustion: derivation, validation, and implementation, Energy Fuel 24 (2010) $6275-6282$.

[40] S. Park, J.A. Kim, C. Ryu, W. Yang, Y.J. Kim, S. Seo, Effects of gas and particle emissions on wall radiative heat flux in oxy-fuel combustion, J. Mech. Sci. Technol. 26 (2012) 1633-1641

[41] R. Johansson, H. Thunman, B. Leckner, Influence of intraparticle gradients in modeling of fixed bed combustion, Combust. Flame 149 (2007) 49-62.

[42] A.H. Mahmoudi, F. Hoffmann, B. Peters, Semi-resolved modeling of heat-up, drying and pyrolysis of biomass solid particles as a new feature in XDEM, Appl. Therm. Eng. 93 (2016) 1091-1104.

[43] C. Di Blasi, Dynamic behaviour of stratified downdraft gasifiers, Chem. Eng. Sci. 55 (2000) 2931-2944.

[44] A.H. Mahmoudi, M. Markovic, B. Peters, G. Brem, An experimental and numerical study of wood combustion in a fixed bed using Euler-Lagrange approach (XDEM), Fuel 150 (2015) 573-582.

[45] J.C. Wurzenberger, S. Wallner, H. Raupenstrauch, J.G. Khinast, Thermal conversion of biomass: comprehensive reactor and particle modeling, American Institute of Chemical Engineers, AIChE J 48 (2002) 2398-2411.

[46] F. Liu, H. Guo, G.J. Smallwood, O..L. Gülder, The chemical effects of carbon dioxide as an additive in an ethylene diffusion flame: implications for soot and $\mathrm{NO}_{\mathbf{x}}$ formation, Combust. Flame 125 (2001) 778-787.

[47] F. Liu, H. Guo, G.J. Smallwood, The chemical effect of $\mathrm{CO}_{2}$ replacement of $\mathrm{N}_{2}$ in air on the burning velocity of $\mathrm{CH}_{4}$ and $\mathrm{H}_{2}$ premixed flames, Combust. Flame 133 (2003) 495-497.

[48] H. Thunman, B. Leckner, F. Niklasson, F. Johnsson, Combustion of wood particles a particle model for Eulerian calculations, Combust. Flame 129 (2002) 30-46.

[49] M.A. Gómez, J. Porteiro, D. de la Cuesta, D. Patiño, J.L. Míguez, Numerical simulation of the combustion process of a pellet-drop-feed boiler, Fuel 184 (2016) 987-999.

[50] A.H. Mahmoudi, F. Hoffmann, M. Markovic, B. Peters, G. Brem, Numerical modeling of self-heating and self-ignition in a packed-bed of biomass using XDEM, Combust. Flame 163 (2016) 358-369.

[51] G.P. Smith, D.M. Golden, M. Frenklach, N.W. Moriarty, B. Eiteneer, M. Goldenberg, C.T. Bowman, R.K. Hanson, S. Song, W.C. Gardiner Jr., V.V. Lissianski, Z. Qin, GRIMECH 3.0, http://www.me.berkeley.edu/gri_mech/, (1999).

[52] C.K. Westbrook, F.L. Dryer, Chemical kinetic modeling of hydrocarbon combustion, Prog. Energy Combust. Sci. 10 (1984) 1-57. 


\title{
Chemical, thermal and dilution effects of carbon dioxide in oxy-fuel combustion of wood in a fixed bed ${ }^{\dagger}$
}

\author{
Josephat Kipyegon Tanui ${ }^{1,{ }^{*}}$, Paul Ndirangu Kioni ${ }^{1}$, Thomas Mirre ${ }^{2}$ and Mario Nowitzki ${ }^{2}$ \\ 'Department of Mechanical Engineering, Dedan Kimathi University of Technology, P.O. Box 657-10100, Nieri, Kenva \\ ${ }^{2}$ Fachbereich Ingenieur- und Nanurwissenschaften, Technische Hochschule Wildau, Hochschulring 1, 15745 Wildau, Germany
}

(Manuscript Received February 18, 2019; Revised September 20, 2019; Accepted October 10, 2019)

\begin{abstract}
Experimental and numerical modeling was performed on eucalyptus wood combustion under oxy-fuel conditions using a fixed bed reactor in order to isolate the role of various carbon dioxide effects on the buning rate. Wood combustion was investigated under four different mixtures of $\mathrm{O}_{2}$ and $\mathrm{Ar} / \mathrm{CO}_{2} / \mathrm{N}_{2}: 21 \% \mathrm{O}_{2} / 79 \% \mathrm{~N}_{2} ; 21 \% \mathrm{O}_{2} / 22.5 \% \mathrm{CO}_{2} / 56.5 \% \mathrm{Ar}, 40 \% \mathrm{O}_{2} / 60 \% \mathrm{CO}_{2} ;$ and $40 \% \mathrm{O}_{2} / 47 \%$ $\mathrm{CO}_{2} / 13 \% \mathrm{Ar}$. The first three mixtures were designed to have the same peak temperatures in order to isolate chemical and dilution effects of $\mathrm{CO}_{2}$. This was achieved by substituting some percentage of $\mathrm{CO}_{2}$ with $\mathrm{Ar}$ in $\mathrm{O}_{2} / \mathrm{CO}_{2}$ mixture while maintaining a constant concentration of $\mathrm{O}_{2}$. The fourth mixture was meant to isolate the thermal effect of $\mathrm{CO}_{2}$. The results were obtained from both the experimental rig and numerical simulation for a fixed bed configuration. Wood combustion in the fixed bed was modeled using Lagrange-Euler method, where gas-phase was calculated using computational fluid dynamics (CFD), that is Euler phase, while solid-phase was tracked in Lagrange phase using discrete element method (DEM). The results show that ignition time in $\mathrm{CO}_{2}$ environment decreases gradually as $\mathrm{O}_{2}$ concentration is increased. On the other hand, burning rate and flame front speed increase as $\mathrm{O}_{2}$ concentration is increased. It was established that dilution effect is the most influential parameter on the burning rate of wood combustion in an oxy-fuel system
\end{abstract}

Keywords: Buning rate; $\mathrm{CO}_{2}$ effect; Fixed bed; Oxy-fuel combustion; Wood combustion

\section{Introduction}

The demand for biomass fuel has increased due to ever increasing energy need that cannot be fully satisfied by other energy sources, such as coal. Biomass is an attractive energy source as compared to coal as it is renewable. Most of the energy scenarios indicate that biomass will be increasingly used to meet increasing energy demand in future [1]

For a long time, biomass has been converted to energy using burners which operate under air-fuel conditions. However, in the last two decades, there has been increasing use of combustion of biomass in power generation $[2,3]$. Oxy-fuel combustion is a technique of capturing $\mathrm{CO}_{2}$ by recirculating exhaust gas. It is applicable to solid fuels [4], liquid fuels [5] and gaseous fuels [6]. The technique was introduced in power plants the first time in 1982 [7]. Since then, a lot of research, for instance [8-10], have been done to understand the combustion phenomenon.

The studies on fundamental combustion phenomena - transport, chemical and thermodynamics processes - occurring in

\footnotetext{
"Comesponding author. Tel.: +254 723503095

B-msil address: josephat tamui $\varrho$ dkut ac.ke

${ }^{\dagger}$ Recommended by Associnte Editor Jeong Park

O KSNE \& Springer 2019
}

oxy-fuel combustion are based on models and experiments on laboratory-scale devices. These include studies on ignition delay time in coal [11], ignition temperature, bumout and $\mathrm{NO}_{\mathbf{x}}$ emission in biomass and coal blends [12], and gaseous emissions from biomass/coal co-firing [13]. Such studies provide insights into combustion phenomena in practical oxy-fuel environment $[12,13]$. The presence of $\mathrm{CO}_{2}$ in oxidizer alters physical and thermal properties of the gas mixture, which has impact on fuel reactivity, flame temperature and emissions. Unlike inert species such as argon and nitrogen which have only thermal and dilution effects on combustion processes, addition of reactive species such as $\mathrm{CO}_{2}$ introduces a chemical effect $[14,15]$. Dilution effect is the reduction of concentration of oxidizer caused by addition of $\mathrm{CO}_{2}$, thermal effect is the decrease in temperature caused by addition of $\mathrm{CO}_{2}$ and chemical effect is the direct active participation in the chemical reactions.

The three roles played by $\mathrm{CO}_{2}$ addition can be separated by adjusting the flame temperature to a value corresponding to a reference condition without change in oxidizer and fuel relative concentrations $[15,16]$. This technique has been applied to study the effects of $\mathrm{CO}_{2}$ on soot formation, but it can also be applied to study the effects on other combustion properties [17]. 


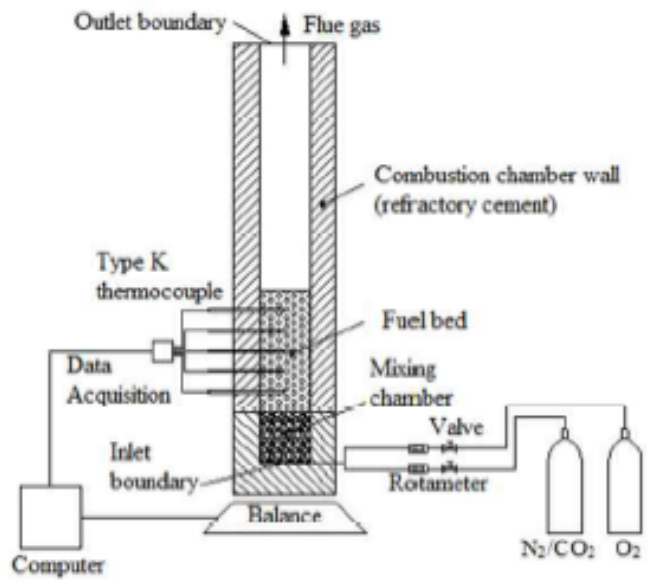

Fig. 1. Schematic diagram of experimental set-up.

Most previous studies focused on the overall effects of $\mathrm{CO}_{2}$ burning environment on ignition time [18], ignition and combustion temperature [19], bumout [20], combustion intensity [19] and thermal reactivity [21]. The individual effects in terms of chemical, thermal and dilution on the combustion properties are still not clear. An understanding of these basic mechanisms through which $\mathrm{CO}_{2}$ affects combustion processes is important because it helps in the design of optimized oxyfuel bumers.

The main objective of this work was to isolate the role of chemical, thermal and dilution effects of $\mathrm{CO}_{2}$ on wood burning rate through numerical modeling. Four different mixtures of $\mathrm{O}_{2}$ and $\mathrm{Ar} / \mathrm{CO}_{2} / \mathrm{N}_{2}$ were designed to separate $\mathrm{CO}_{2}$ effects on wood combustion. Temperature in $\mathrm{O}_{2} / \mathrm{CO}_{2}$ combustion environment was adjusted to be equal to that of $\mathrm{O}_{2} / \mathrm{N}_{2}$ environment by adding an appropriate amount of Ar while $\mathrm{O}_{2}$ amount remained the same. The model was validated by comparing temperature profiles with experimental values. Experiments were done on a laboratory-scale fixed bed.

\section{Methodology}

\subsection{Experimental set-up}

A schematic diagram of the experimental set-up used in this work is shown in the Fig. 1. It is a cylindrical burner made of stainless steel which is insulated with refractory cement. A detailed description of the set-up has been given in our previous paper [22].

For all the tests, the bumer was filled with wood up to a height of $6 \mathrm{~cm}$. Five type $\mathrm{K}$ thermocouples are located at an equidistant of $10 \mathrm{~mm}$ from one another. They are connected to a data acquisition system that records temperature every second. Temperature measurement and data acquisition using type $\mathrm{K}$ thermocouples were done in accordance to ASTM MNL12 [23]. Combined measurement uncertainty for thermocouple and data acquisition system depends on measured temperature and for the entire range was determined to be between $\pm 2.2{ }^{\circ} \mathrm{C}$ and $\pm 6.6^{\circ} \mathrm{C}$. The bumer was operated in a batch mode; fuel was fed once while oxidizer was supplied continuously.

\subsection{Numerical modeling}

Numerical simulations of combustion of wood in the fixed bed were carried out using a commercial software CD-Adapco (STAR CCM+ version 11.04) [24]. Wood burning in a fixed bed was simulated using Lagrange-Euler method, where gasphase was calculated using computational fluid dynamics, that is, the Euler phase, while solid-phase was tracked in Lagrange phase, using discrete element method. The governing equations of the model are given by Eqs. (1)-(9) and fully described in Ref. [22, 24]:

- Mass conservation equation for gas-phase, Eq. (1) and solid-phase, Eq. (2):

$\frac{\partial}{\partial t}\left(\chi \rho_{g}\right)+\nabla \cdot\left(\rho_{g} v_{g}\right)=\sum_{i, s} w_{t, 8}^{g t}$

$\frac{\partial}{\partial t}\left((1-\chi) \rho_{n}\right)=\sum_{i, s} w_{t, s}^{g}$

- Momentum conservation equation for gas-phase, Eq. (3):

$\frac{\partial}{\partial t}\left(\chi \rho_{g} v_{g}\right)+\nabla \cdot\left(\rho_{g} v_{g} v_{g}\right)=-\nabla p+\nabla \cdot \tau+\rho_{g} g+S_{w}$

where $S_{m}$ is momentum source term given as;

$S_{w}=-\left(\frac{\mu}{C_{1}} v_{g}+C_{2} \rho_{g}\left|v_{g}\right| v_{g}\right)$

- Energy conservation equation for gas-phase, Eqs. (5) and (6) and solid-phase, Eq. (7):

$\frac{\partial}{\partial t}\left(\chi \rho_{s} h_{s}\right)+\nabla \cdot\left(\rho_{s} v_{s} h_{s}\right)$

$=\frac{\partial}{\partial t}(\chi p)+\nabla \cdot\left(\lambda_{s, t} \nabla T_{s}-\sum_{t=1}^{N_{t}} h_{t s} J_{t, q}\right)+\nabla \cdot\left(v_{q} p\right)-\nabla \cdot\left(\tau \cdot v_{s}\right)+S_{g}$

where $S_{E}$ energy source term given as;

$$
\begin{aligned}
& S_{z}=A_{s} h_{c}\left(T_{x}-T_{g}\right)-\sum_{i, g} w_{i, g}^{k} H_{i, g}+q_{R} \\
& \rho_{s} c_{p z}(1-\chi) \frac{\partial T_{x}}{\partial t}=\nabla \cdot\left(\lambda_{z, s} \nabla T_{s}\right)+A_{s} h_{c}\left(T_{g}-T_{s}\right)+ \\
& \frac{A_{s}}{4} Q_{a, p}\left(G-4 \sigma T_{u}^{*}\right)+\sum_{i, s} w_{l, s}^{g s} H_{t, s}
\end{aligned}
$$

- Species conservation equation for gas-phase species $i, g$, Eq. (8) and solid-phase species $i, s, \mathrm{Eq}$. (9)

$\frac{\partial}{\partial t}\left(\chi \rho_{g} Y_{i, g}\right)+\nabla \cdot\left(\rho_{g} v_{g} Y_{i, g}\right)=\nabla \cdot\left(\rho_{g} \mathrm{D} \nabla Y_{t, g}\right)+w_{t, g}^{g \nu}$ 
Table 1. Proximate and ultimate analyses of fuel sample.

\begin{tabular}{c|c}
\hline \multicolumn{2}{c}{ Proximate amalysis (wt \%) } \\
\hline Moisture & 10.3 \\
\hline Volatile matter (wt \% dry basis) & 84.9 \\
\hline Fixed carbon (wt\% dry basis) & 14.9 \\
\hline Ash (wt\% dry basis) & 0.2 \\
\hline Ultimate analysis (wt \% dry basis) \\
\hline $\mathrm{C}$ & 50.87 \\
\hline $\mathrm{H}$ & 5.73 \\
\hline $\mathrm{N}$ & 0.3 \\
\hline O (by difference) & 43.1 \\
\hline \multicolumn{2}{c}{ Gross calonific value (MJ/kg) } \\
\hline
\end{tabular}

Table 2. Physical properties of wood.

\begin{tabular}{|c|c|}
\hline Particle size, $d_{\rho}(m)$ & 0.005 \\
\hline \multicolumn{2}{|c|}{ Eucalyptus wood } \\
\hline Density, $\rho\left(\mathrm{kg} \mathrm{m}^{3}\right)$ & 1220 \\
\hline Porosity, $\theta$ & 0.64 \\
\hline Specific heat, $c_{p}(\mathrm{~J} / \mathrm{kgK})$ & $1500+T_{2}$ \\
\hline Conductivity, $\lambda_{2}(\mathrm{~W} / \mathrm{mK})$ & 0.2 \\
\hline \multicolumn{2}{|c|}{ Char } \\
\hline Density, $\rho\left(\mathrm{kgm}^{3}\right)$ & 250 \\
\hline Porosity, $\theta$ & 0.85 \\
\hline Specific heat, $c_{p}(\mathrm{~J} / \mathrm{kgK})$ & $420+2.09 \mathrm{~T}_{2}-6.85 \times 10^{-4} \mathrm{~T}_{3}^{2}$ \\
\hline Conductivity, $\lambda_{2}(\mathrm{~W} / \mathrm{mK})$ & 0.1 \\
\hline
\end{tabular}

$$
\frac{\partial}{\partial t}\left((1-\chi) \rho_{x} Y_{i, s}\right)=w_{L, s}^{g z}
$$

The symbols are defined in Nomenclature. Exchange of species, mass and energy between the two phases was enabled by a two-way coupling model $[22,24]$.

Turbulence in both freeboard and bed region was accounted for using standard $\alpha-\varepsilon$ model. Interaction between turbulence and chemistry was solved using eddy dissipation concept. Weighted-sum-of-gray-gas-model (WSGGM) [25], was used as a property model for the radiating gases.

Proximate and ultimate analyses for the samples investigated in this study are presented in Table 1 and physical properties in Table 2. The latter are based on the Mehrabian et al. [26] work.

Chemical kinetics of wood conversion in the bed was simulated using different sub-models, which consisted of drying model, pyrolysis model, homogeneous reaction model and heterogeneous reaction model. Kinetics data of these submodels are given in Table 3. The rate expressions for these reactions are presented in Table 4 . These models were adopted from previous research on wood combustion [27-32]. However, in this work oxy-fuel combustion was accounted for by incorporating a reaction involving $\mathrm{CO}_{2}(\mathrm{R}(10))$ and its associated chain-branching reactions $(R(11)$ and $R(12))$ in the ho- mogeneous reaction sub-model. Char combustion rate was evaluated based on partial pressure of $\mathrm{O}_{2}, \mathrm{CO}_{2}$ and $\mathrm{H}_{2} \mathrm{O}$ available at its surface [33]. The stoichiometric ratio of $\mathrm{CO}_{2}$ to $\mathrm{CO}$ from char combustion is dependent on particle surface temperature [27]:

$$
\Omega=\frac{2\left(1+4.3 \exp \left[-3390 / T_{\text {parisel }}\right]\right)}{2+4.3 \exp \left[-3390 / T_{\text {pardick }}\right]} \text {. }
$$

Grid independent solutions were achieved by meshing computational domain into highly-refined unstructured grid as shown in Fig. 2. A quarter of the bumer was used for computation since it has a double symmetry. The choice of mesh size was based on a mesh independent test whose results are shown in Fig. 3. The predicted temperature profile at $5 \mathrm{~cm}$ from bed bottom under oxy-fuel condition is significantly different when using a mesh that consists of 100000 cells as compared to that of 200000 cells. The difference in temperature profiles is negligible for mesh that consists of 200000 , 300000 and 400000 cells, respectively. Therefore, a mesh with 200000 cells was used for all the cases computed.

Oxidizer enters the domain through inlet boundary located at the bottom. The concentration of oxygen and $\mathrm{N}_{2} / \mathrm{CO}_{2} / \mathrm{Ar}$ was set in accordance to the required predesigned conditions. In the first set of experiments, $\mathrm{O}_{2}$ concentration by volume was varied between $21 \%$ and $50 \%$ with diluent as either $\mathrm{N}_{2}$ or $\mathrm{CO}_{2}$. In addition, four mixtures were designed to separate the effects of $\mathrm{CO}_{2}$ environment. The four mixtures were denoted by letters $\mathrm{A}, \mathrm{B}, \mathrm{C}$ and $\mathrm{D}$ and their composition by volume was $21 \% \mathrm{O}_{2} / 79 \% \mathrm{~N}_{2} ; 21 \% \mathrm{O}_{2} / 22.5 \% \mathrm{CO}_{2} / 56.5 \% \mathrm{Ar}$; $40 \% \mathrm{O}_{2} / 60 \% \mathrm{CO}_{2}$; and $40 \% \mathrm{O}_{2} / 47 \% \mathrm{CO}_{2} / 13 \% \mathrm{Ar}$, respectively. The inlet mass flux for the mixture for all the tests was $0.1 \mathrm{~kg} / \mathrm{m}^{2} / \mathrm{s}$. The temperature for each of the mixture at the inlet was $295 \mathrm{~K}$ Top boundary was the outlet boundary with temperature and gases concentration gradient set to zero using Neumann boundary condition. A stationary wall with no-slip conditions was considered; the tangential velocity at the wall was explicitly set to zero. The model includes terms to account for heat transfer by radiation and convection at the wall. Emissivity of the surface and coefficient of heat transfer were 0.8 and $10 \mathrm{~W} / \mathrm{m}^{2} \cdot \mathrm{K}$, respectively.

\section{Results and discussion}

Measured temperature profiles at various distances from bed bottom for wood combustion in $21 \%$ oxygen in $\mathrm{N}_{2}$ and $\mathrm{CO}_{2}$ are presented in Figs. 4(a) and (b), respectively. The graphs show that the temperature profile at any given height in both environments exhibits similar behavior. They all have two peaks. When the flame front reaches an ignition point, the temperature rises rapidly to the first peak. Then it decreases gradually to another point and finally rises to the second peak.

Combustible pyrolysis products such as $\mathrm{CH}_{4}, \operatorname{tar}, \mathrm{H}_{2}$ and $\mathrm{CO}$ are oxidized through exothermic reactions which generate heat, subsequently increasing the temperature. The exothermic 
Table 3. Biomass kinetic model

\begin{tabular}{|c|c|c|c|c|}
\hline Drying & \multicolumn{3}{|c|}{ Rate expression } & Source \\
\hline $\mathrm{R}(\mathrm{l})$ Wet wood $\rightarrow$ Dhy wood $+\mathrm{H}_{2} \mathrm{O}$ (g) & \multicolumn{3}{|c|}{$R_{b y}=Y_{b} \rho_{b y w e} 1.610^{27} \exp \left(-25000 / T_{d}\right)$} & {$[27]$} \\
\hline \multicolumn{5}{|c|}{ Pyrolysis } \\
\hline \multirow{2}{*}{ Reaction } & \multicolumn{3}{|c|}{$K_{i}=A_{i} T^{*} \exp \left(-E_{i} / R T\right)$} & \multirow{2}{*}{ Source } \\
\hline & $A_{i}\left(\mathrm{~s}^{-1}\right)$ & $E_{i}(\mathrm{~kJ} / \mathrm{mol})$ & $n$ & \\
\hline$R(2)$ Dry wood $\rightarrow$ Gas & $111 \times 10^{9}$ & 177 & 0 & {$[28]$} \\
\hline$R(3)$ Dry wood $\rightarrow$ Tar & $9.28 \times 10^{9}$ & 149 & 0 & {$[28]$} \\
\hline$R(4)$ Dhy wood $\rightarrow$ Char & $30.5 \times 10^{9}$ & 125 & 0 & {$[28]$} \\
\hline $\mathrm{R}(5) \mathrm{Tar} \rightarrow \gamma_{i} \mathrm{Tar}_{\mathrm{rat}}+\gamma_{\infty} \mathrm{CO}+\gamma_{\mathrm{CO}_{2}} \mathrm{CO}_{2}+\gamma_{122} \mathrm{H}_{2}+\gamma_{\mathrm{ar} 4} \mathrm{CH}_{4}$ & $9.55 \times 10^{4}$ & 93.37 & 0 & {$[29,30]$} \\
\hline \multicolumn{5}{|c|}{ Homogeneous gas-phase reactions } \\
\hline \multirow{2}{*}{ Reaction } & \multicolumn{3}{|c|}{$K_{i}=A T^{a} \exp \left(-E_{i} / R T\right)$} & \multirow{2}{*}{ Source } \\
\hline & $A_{i}\left(\mathrm{~s}^{-1}\right)$ & $E_{i}(\mathrm{~kJ} / \mathrm{mol})$ & $n$ & \\
\hline $\mathrm{R}(6) 2 \mathrm{CO}+\mathrm{O}_{2} \rightarrow 2 \mathrm{CO}_{2}$ & $2.24 \times 10^{12}$ & 167.36 & 0 & {$[29,30]$} \\
\hline $\mathrm{R}(7) \mathrm{CH}_{4}+2 \mathrm{O}_{2} \rightarrow \mathrm{CO}_{2}+2 \mathrm{H}_{2} \mathrm{O}$ & $11.6 \times 10^{13}$ & 202.5 & 0 & {$[29,30]$} \\
\hline $\mathrm{R}(8) 2 \mathrm{H}_{2}+\mathrm{O}_{2} \rightarrow 2 \mathrm{H}_{2} \mathrm{O}$ & $2.19 \times 10^{9}$ & 109.2 & 0 & {$[29,30]$} \\
\hline $\mathrm{R}(9) \mathrm{Tar}+2.9 \mathrm{O}_{2} \rightarrow 6 \mathrm{CO}+3.1 \mathrm{H}_{2}$ & $9.2 \times 10^{6}$ & 80.2 & 0 & {$[29,30]$} \\
\hline $\mathrm{R}(10) \mathrm{CO}+\mathrm{OH} \rightarrow \mathrm{CO}_{2}+\mathrm{H}$ & $4.76 \times 10^{7}$ & 0.293 & 1.3 & {$[31]$} \\
\hline $\mathrm{R}(11) \mathrm{H}+\mathrm{O}_{2} \rightarrow \mathrm{O}+\mathrm{OH}$ & $2.65 \times 10^{16}$ & 71.347 & -0.7 & [31] \\
\hline $\mathrm{R}(12) \mathrm{H}_{2}+\mathrm{O}_{2} \rightarrow \mathrm{OH}+\mathrm{OH}$ & $2.51 \times 10^{12}$ & 163.075 & 0 & {$[32]$} \\
\hline $\mathrm{R}(13) \mathrm{H}_{2} \mathrm{O}+\mathrm{CO} \rightarrow \mathrm{CO}_{2}+\mathrm{H}_{2}$ & 2.78 & 12.55 & 0 & {$[27,28]$} \\
\hline $\mathrm{R}(14) \mathrm{CO}_{2}+\mathrm{H}_{2} \rightarrow \mathrm{H}_{2} \mathrm{O}+\mathrm{CO}$ & 93.69 & 46.594 & 0 & {$[27,28]$} \\
\hline \multicolumn{5}{|c|}{ Heterogeneous reactions } \\
\hline \multirow{2}{*}{ Reaction } & \multicolumn{3}{|c|}{$K_{l}=A_{i} T^{*} \exp \left(-E_{l} / R T\right)$} & \multirow{2}{*}{ Source } \\
\hline & $A_{i}\left(\mathrm{~s}^{-1}\right)$ & $E_{i}(\mathrm{~kJ} / \mathrm{mol})$ & $n$ & \\
\hline $\mathrm{R}(15) \Omega \mathrm{C}+\mathrm{O}_{2} \rightarrow 2(\Omega-1) \mathrm{CO}+(2-\Omega) \mathrm{CO}_{2}$ & $2.54 \times 10^{-3}$ & 74.8 & 0 & {$[29,30]$} \\
\hline $\mathrm{R}(16) \mathrm{C}+\mathrm{CO}_{2} \rightarrow 2 \mathrm{CO}$ & $1.81 \times 10^{-2}$ & 130 & 0 & {$[29,30]$} \\
\hline $\mathrm{R}(17) \mathrm{C}+\mathrm{H}_{2} \mathrm{O} \rightarrow \mathrm{CO}+\mathrm{H}_{2}$ & $1.81 \times 10^{-2}$ & 130 & 0 & {$[29,30]$} \\
\hline
\end{tabular}

Table 4. Rate expression for the reactions.

\begin{tabular}{|c|c|c|c|}
\hline Reaction & Rate expression & Reaction & Rate expression \\
\hline$R(2)$ & $w_{b}=K_{2} \rho_{b a d y}$ & $\mathrm{R}(10)$ & $\mathrm{R}_{\infty}=\mathrm{K}_{10}[\mathrm{CO}][\mathrm{OH}]$ \\
\hline$R(3)$ & $w_{b}=K_{s} \rho_{b, d y}$ & $\mathrm{R}(11)$ & $\mathrm{R}_{\mathrm{H}}=\mathrm{K}_{\mathrm{II}}[\mathrm{O}][\mathrm{OH}]$ \\
\hline$R(4)$ & $w_{b}=K_{d} \rho_{b, d y}$ & $\mathrm{R}(12)$ & $\mathrm{R}_{\mathrm{H2}}=\mathrm{K}_{12}\left[\mathrm{H}_{2}\right]\left[\mathrm{O}_{2}\right]$ \\
\hline $\mathrm{R}(5)$ & $w_{\text {Tar }}=K_{s} \rho_{\text {Tar }}$ & $R(13)$ & $\mathrm{R}_{\mathrm{HDO}}=\mathrm{K}_{13}\left[\mathrm{H}_{2} \mathrm{O}\right][\mathrm{CO}]$ \\
\hline$R(6)$ & $\mathrm{R}_{\mathrm{CO}}=\mathrm{K}[\mathrm{CO}]\left[\mathrm{O}_{2}\right]^{0.25}\left[\mathrm{H}_{2} \mathrm{O}\right]^{0.5}$ & $R(14)$ & $\mathrm{R}_{\mathrm{O} O 2}=\mathrm{K}_{14}\left[\mathrm{CO}_{2}\right]\left[\mathrm{H}_{2}\right]$ \\
\hline$R(7)$ & $\mathrm{R}_{\mathrm{CHA}}=\mathrm{K}_{7}\left[\mathrm{CH}_{4}\right]^{00}\left[\mathrm{O}_{3}\right]^{0.8}$ & $\mathrm{R}(15)$ & $w_{\text {cha } O 2}=K_{i S} P_{O 2} S_{a c h r}$ \\
\hline$R(8)$ & $\mathrm{R}_{\mathrm{H} 2}=\mathrm{K}_{6}\left[\mathrm{H}_{2}\right]\left[\mathrm{O}_{2}\right]$ & $R(16)$ & $w_{\text {char } c 02}=K_{16} P_{c o 2} S_{q, \sin }$ \\
\hline $\mathrm{R}(9)$ & $\mathrm{R}_{\mathrm{T} x}=\mathrm{K}_{0}[\mathrm{Tax}]^{0.5}\left[\mathrm{O}_{2}\right]$ & $R(17)$ & $w_{\text {chav } F D O}=K_{l} P_{\text {PDO }} S_{a c h r}$ \\
\hline
\end{tabular}

reactions occur concurrently with pyrolysis and drying of wood particles, which are endothermic reactions and cause decrease in temperature after the first peak. When pyrolysis and drying processes are completed, exothermic reactions dominate and temperature rises again to the second peak. After the second peak, the temperature gradually decreases until the end of combustion. During this phase, a wood particle has completely been devolatilized, leaving a pure char that under- goes oxidation and gasification with $\mathrm{H}_{2} \mathrm{O}$ and $\mathrm{CO}_{2}$. It is deduced that gasification, which is endothermic, is more pronounced than exothermic process (oxidation), hence the temperature decrease.

Figs. 4(a) and (b) also show that at corresponding height, air-fuel peak temperature is higher than oxy-fivel temperature by about $200 \mathrm{~K}$. This is a result of the combination of both chemical and thermal effects. Lower temperatures are seen in 


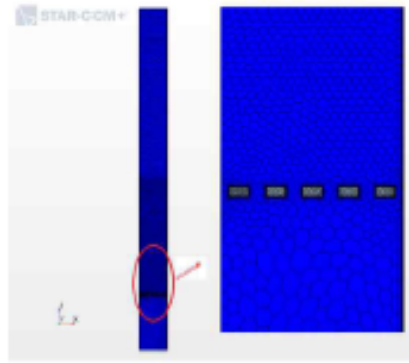

(a)

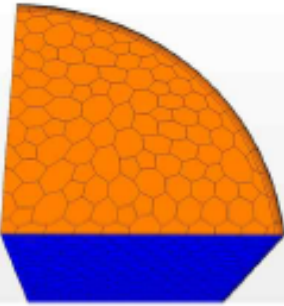

(b)
Fig. 2. Computational mesh for the fixed bed: (a) Highly refined mesh in fuel bed and grate; (b) prismatic layers near the wall.

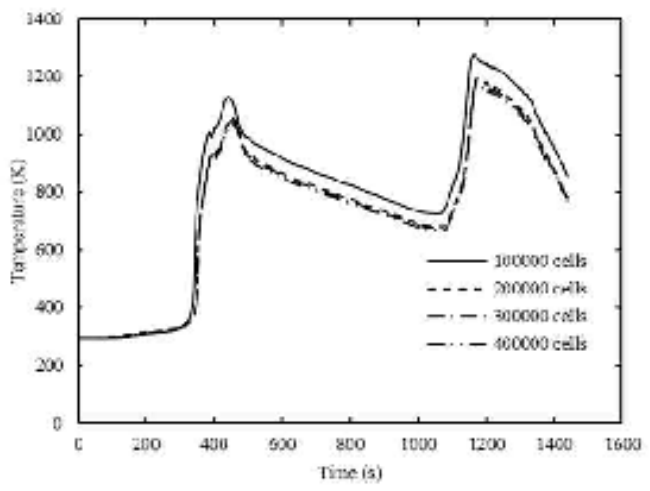

Fig. 3. Predicted temperature profiles at $5 \mathrm{~cm}$ from the bed bottom for wood combustion in $21 \% \mathrm{O}_{2} / 79 \% \mathrm{CO}_{2}$ mixture for different mesh sizes.

oxy-fuel environment because $\mathrm{CO}_{2}$ has higher heat capacity than $\mathrm{N}_{2}$. Furthermore, chemical effect through endothermic reaction of $\mathrm{CO}_{2}$ with char contributes in lowering the temperature of oxy-fuel environment.

The individual contribution of various effects of $\mathrm{CO}_{2}$, namely, chemical, thermal and oxygen concentration effects are evaluated through CFD-DEM modeling. The model results are validated by comparing them with experimental values. Shown in Fig. 5 are measured and predicted temperature profiles at $5 \mathrm{~cm}$ from bed bottom for air-fuel and oxy-fuel environments both at $21 \% \mathrm{O}_{2}$ concentration. The accuracy of model data was good with deviation of most points from measured values being within $10 \%$.

Presented in Fig. 6 are predicted temperature profiles at 5 $\mathrm{cm}$ from the bed bottom for wood combustion in different combustion atmospheres. It is observed that peak temperature occurrence time comes much earlier in $\mathrm{N}_{2}$ atmosphere than in $\mathrm{CO}_{2}$ atmosphere. This is an indication that combustion rate is slower in $\mathrm{CO}_{2}$ environment. For oxy-fuel combustion, peak. temperature value is directly proportional to $\mathrm{O}_{2}$ concentration. In addition, its occurrence time increases as $\mathrm{O}_{2}$ concentration is decreased. Peak temperature of oxy-fuel atmosphere, which is equivalent to that of standard air-fuel condition, occurs at about $40 \% \mathrm{O}_{2}$ concentration. However, its occurrence time is

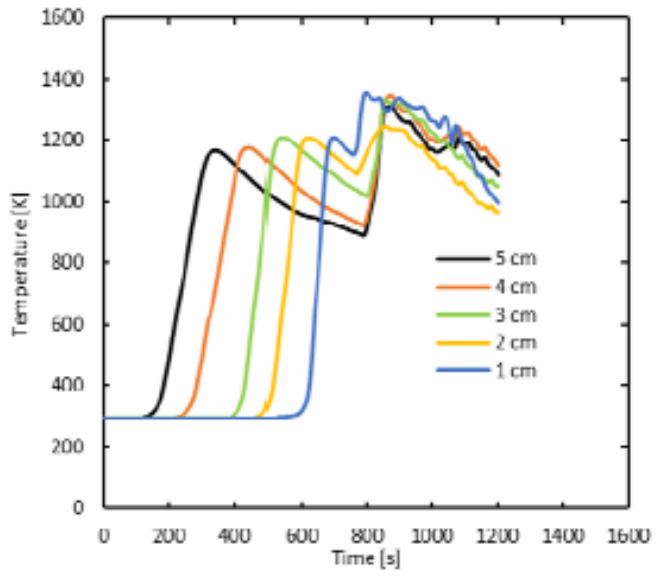

(a) $21 \% \mathrm{O}_{2} / 79 \% \mathrm{~N}_{2}$ mixture

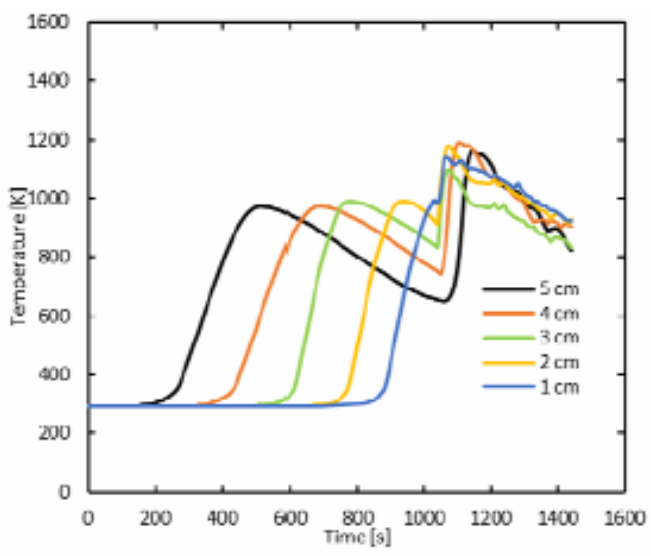

(b) $21 \% \mathrm{O}_{2} / 79 \% \mathrm{CO}_{2}$ mixture

Fig. 4. Measured temperature profiles at various distances from the bed bottom for wood combustion in different combustion atmospheres.

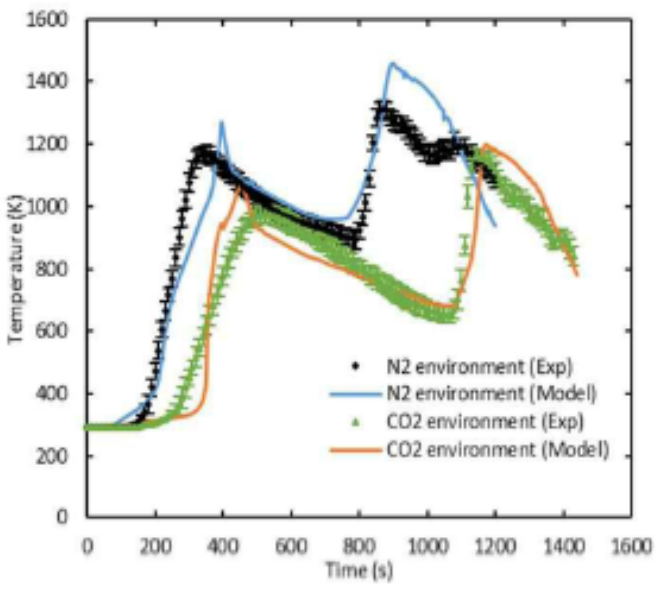

Fig. 5. Measured and predicted temperature profiles at $5 \mathrm{~cm}$ from the bed bottom for wood combustion in $21 \% \mathrm{O}_{2} / 79 \% \mathrm{~N}_{2}$ and $21 \%$ $\mathrm{O}_{2} / 79 \% \mathrm{CO}_{2}$ mixtures. Enror bars are the standard deviations. 


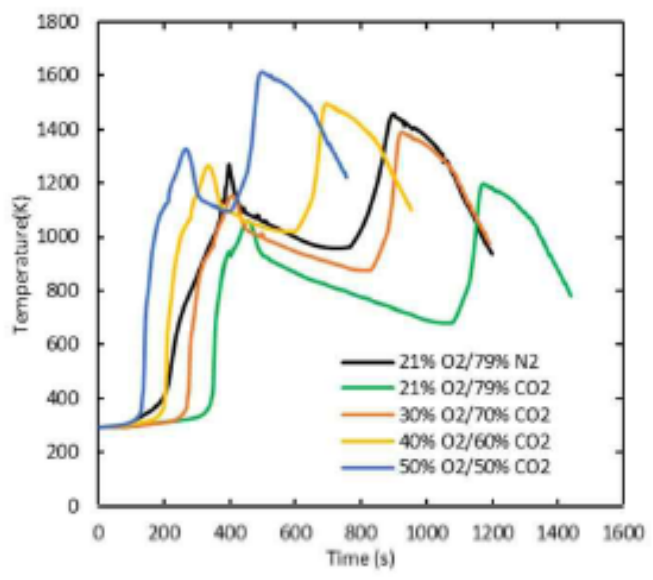

Fig. 6. Predicted temperature profiles at $5 \mathrm{~cm}$ from the bed bottom for wood combustion in different combustion atmospheres.

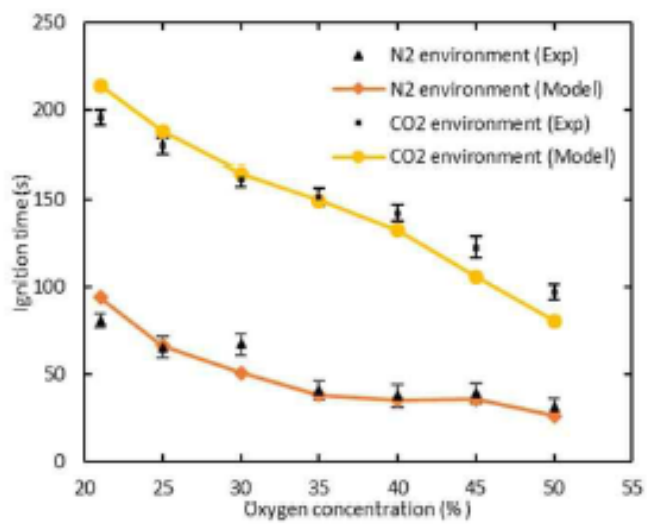

Fig. 7. Measured and predicted iguition time for fuel bed of wood combustion in $\mathrm{N}_{2}$ and $\mathrm{CO}_{2}$ environments. Error bars are the standard deviations.

slightly earlier than in air-fuel condition.

The time taken for the reaction front to start at the top surface of the fuel bed was defined as ignition time. Presented in Fig. 7 is ignition time for wood combustion in both oxy-fuel and air-fuel environments. The graph shows that any given oxygen concentration, ignition time in oxy-fuel environment is almost twice that of corresponding air-fuel condition. Retarded ignition in $\mathrm{CO}_{2}$ environment could be attributed to its high specific heat capacity and low $\mathrm{O}_{2}$ diffusivity in it. In both cases, ignition time gradually decreases as oxygen concentration is increased.

A comparison of burning rates for wood combustion in $\mathrm{N}_{2}$ and $\mathrm{CO}_{2}$ buming conditions is presented in Fig. 8. At the same $\mathrm{O}_{2}$ concentration, the buming rate in $\mathrm{CO}_{2}$ burning atmosphere is less than in $\mathrm{N}_{2}$ burning atmosphere. The burning rate of wood particles in oxy-fuel condition is lowered by the aforementioned $\mathrm{CO}_{2}$ effects, which contribute differently as will be discussed later. Thermal diffusivity of $\mathrm{CO}_{2}$ is less than that of

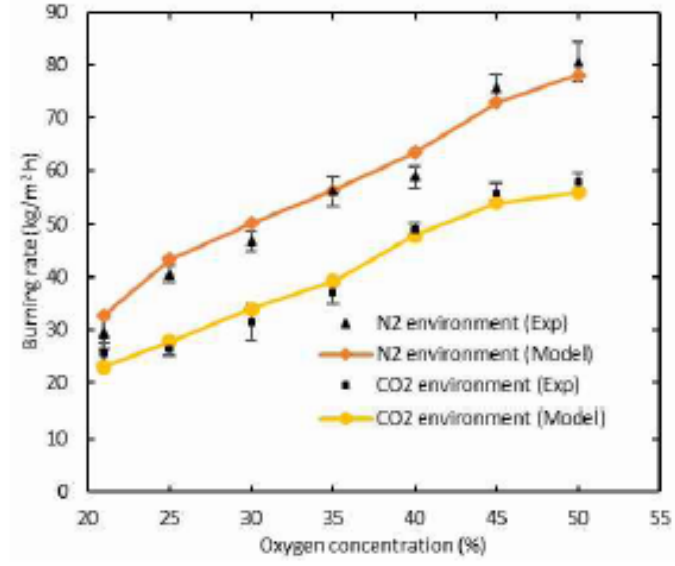

Fig. 8. Measured and predicted burning rates for fuel bed of wood combustion in $\mathrm{N}_{2}$ and $\mathrm{CO}_{2}$ environments. Enror bars are the standard deviations.

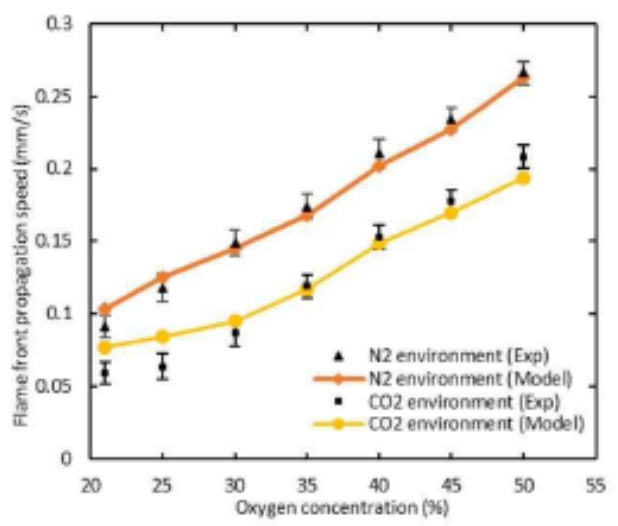

Fig. 9. Measured and predicted flame front propagation speed for fuel bed of wood combustion in $\mathrm{N}_{2}$ and $\mathrm{CO}_{2}$ enviromments. Error bars are the standard deviations.

$\mathrm{N}_{2}$ by about $35 \%$ [34]. In addition, $\mathrm{CO}_{2}$ absorbs radiative heat more than $\mathrm{N}_{2}$. The overall effect of these thermal properties of $\mathrm{CO}_{2}$ is a decrease in burning rate as seen in Fig. 8. Furthermore, the buming rate in oxy-fuel environment is also decreased by chemical effect of $\mathrm{CO}_{2}$ through Boudouard reaction $R(16)$, which is endothermic. On the other hand, the role played by dilution is clearly demonstrated in Fig. 8. In both cases, burning rate is directly proportional to $\mathrm{O}_{2}$ concentration. More $\mathrm{O}_{2}$ concentration enhances oxidation of combustible pyrolysis products and char, hence releasing more heat and increases the burning rates.

Illustrated in Fig. 9 is the flame front propagation speed for wood combustion in oxy-fuel and air-fivel buming atmospheres. For all oxygen concentrations, $\mathrm{CO}_{2}$ buming atmosphere had lower propagation speed as compared to $\mathrm{N}_{2}$ buming atmosphere. Furthermore, as oxygen concentration increased flame propagation speed also increased. Flame speed is directly linked to the buming rate. Therefore, the factors which 
reduce the burning rates in oxy-fuel environment as discussed in the preceding paragraph are also responsible for the reduced flame speed.

The species and temperature profiles along axial length of the fixed bed when the flame front is at $4 \mathrm{~cm}$ from the grate for $21 \% \mathrm{O}_{2} / 79 \% \mathrm{CO}_{2}, 30 \% \mathrm{O}_{2} / 70 \% \mathrm{CO}_{2}, 40 \% \mathrm{O}_{2} / 60 \%$ $\mathrm{CO}_{2}$ and $50 \% \mathrm{O}_{2} / 50 \% \mathrm{CO}_{2}$ are presented in Figs. 10 (a)-(d). The flame structures are similar in profile but differ in magnitude. The flame front for the mixture with high $\mathrm{O}_{2}$ concentration, $50 \%$, reaches $4 \mathrm{~cm}$ plane at $191 \mathrm{~s}$, which is earlier than those for $40 \%, 30 \%$ and $21 \%$ that reached the plane at $275 \mathrm{~s}$, $360 \mathrm{~s}$ and $482 \mathrm{~s}$, respectively. This is because flame speed increases as $\mathrm{O}_{2}$ concentration is increased. As shown in Figs. 10(a)-(d) and Table 5, the amount of tar and $\mathrm{CH}_{4}$ is high at the reaction zone of $21 \% \mathrm{O}_{2}$ concentration mixture and decreases gradually for $30 \%, 40 \%$ and $50 \% \mathrm{O}_{2}$ concentration mixtures. The graphs show that the mixture with $21 \% \mathrm{O}_{2}$ concentration is operating under fuel rich conditions and does not have enough $\mathrm{O}_{2}$ to oxidize these species through reactions $\mathrm{R}(7)$ and $R(9)$. On the other hand, the graphs show that the mixtures with $30 \%, 40 \%$ and $50 \% \mathrm{O}_{2}$ concentration are operating under fuel lean conditions and have excess $\mathrm{O}_{2}$ in their reaction zones. Thus, reduced amount of tar and $\mathrm{CH}_{4}$ are observed in these mixtures as compared to those of $21 \% \mathrm{O}_{2}$ concentration mixture. Consequently, since these reactions are exothermic, a high amount of heat is released as $\mathrm{O}_{2}$ concentration is increased. This is seen in the peak temperatures attained by these mixtures, Fig. 6 . The high amount of heat released increases the heating rates for the particles in the bed and explains the higher flame front propagation speed and burning rates for high $\mathrm{O}_{2}$ concentration mixtures. High heat energy also accelerates the ignition of the particles for mixtures with high $\mathrm{O}_{2}$ concentration.

Figs. 10(a)-(d) and Table 5 show that the amount of $\mathrm{CO}$ is highest in the reaction zone of the mixture with $30 \% \mathrm{O}_{2}$ concentration. The mixtures with $21 \%, 40 \%$ and $50 \% \mathrm{O}_{2}$ concentration have almost the same amount of $\mathrm{CO}$ in their reaction zone. Unlike tar and $\mathrm{CH}_{4}$ whose sole source is devolatilization of the wood particles, $\mathrm{CO}$ is produced from devolatilization process, oxidation of tar through reaction $R(9)$ and char gasification with $\mathrm{CO}_{2}$ through reaction $\mathrm{R}(16)$. $\mathrm{CO}$ is consumed by oxidation reaction $\mathrm{R}(6)$. For a mixture with high $\mathrm{O}_{2}$ concentration, excess $\mathrm{O}_{2}$ brings an antagonistic effect to the amount of $\mathrm{CO}$ where there is a tendency for high consumption through oxidation reaction $R(6)$ and high production by oxidation of tar through reaction $R(9)$ as compared to that of a mixture with low $\mathrm{O}_{2}$ concentration. However, for mixtures with high $\mathrm{O}_{2}$ concentration, the production of $\mathrm{CO}$ through char gasification could be less than that of low $\mathrm{O}_{2}$ concentration mixture because of low amount of $\mathrm{CO}_{2}$. The overall effect of these reactions is that there is an increase in $\mathrm{CO}$ production as $\mathrm{O}_{2}$ concentration is increased up to a peak point, then it starts to decrease.

Buming rate, ignition of fuel particles and flame front propagation speed are all influenced by thermal behavior of

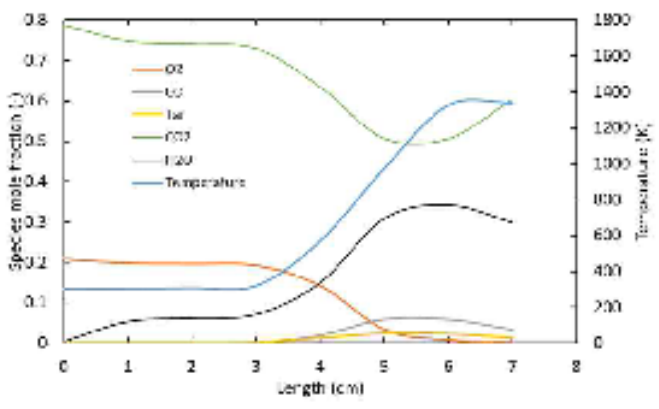

(a) $21 \% \mathrm{O}_{2} / 79 \% \mathrm{CO}_{2}$ mixture

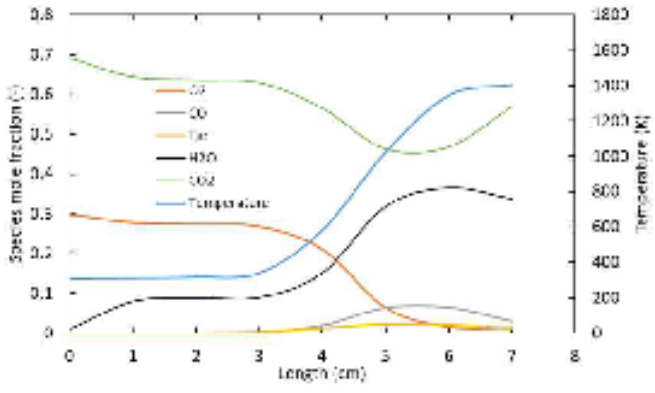

(b) $30 \% \mathrm{O}_{2} / 70 \% \mathrm{CO}_{2}$ mixture

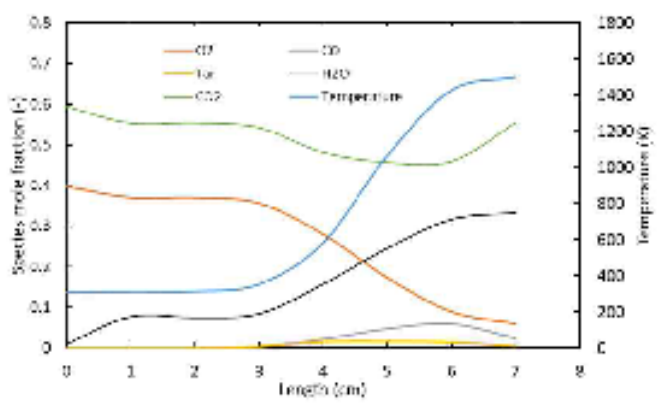

(c) $40 \% \mathrm{O}_{2} / 60 \% \mathrm{CO}_{2}$ mixture

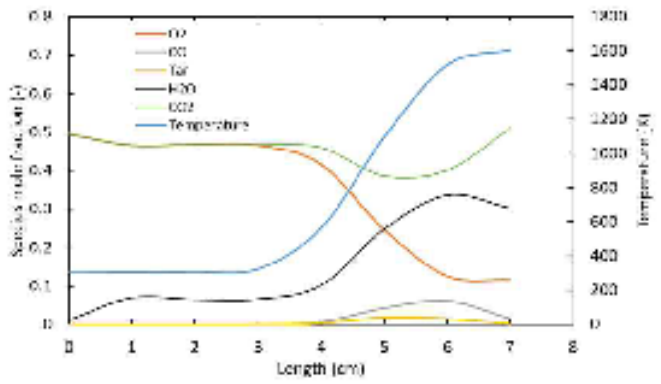

(d) $50 \% \mathrm{O}_{2} / 50 \% \mathrm{CO}_{2}$ mixture

Fig. 10. Species and temperature profiles along axial length of the bed for different $\mathrm{O}_{2} / \mathrm{CO}_{2}$ mixtures when the flame front is at $4 \mathrm{~cm}$ from the grate.

the bed. Apart from heat of combustion through chemical reactions discussed in the preceding paragraphs, flame temperature at a given point is also determined by heat flux distribution in the bed, which is mostly by radiation. $\mathrm{H}_{2} \mathrm{O}$ and $\mathrm{CO}_{2}$ are the main products of combustion that participate in radia- 
Table 5. Peak values of major combustible species and temperature profiles for wood combustion in different $\mathrm{O}_{2} / \mathrm{CO}_{2}$ mixtures.

\begin{tabular}{c|c|c|c|c}
\hline \multirow{2}{*}{$\begin{array}{c}\text { Temperature } \\
\text { species mole } \\
\text { faction (-) }\end{array}$} & $21 \% \mathrm{O}_{2}$ & $30 \% \mathrm{O}_{2}$ & $40 \% \mathrm{O}_{2}$ & $50 \% \mathrm{O}_{2}$ \\
\cline { 2 - 5 } & 1338 & 1406 & 1499 & 1605 \\
\hline $\begin{array}{c}\text { Temperature } \\
(\mathrm{K})\end{array}$ & 0.02427 & 0.02164 & 0.01605 & 0.01837 \\
\hline $\mathrm{Tax}$ & 0.05839 & 0.06488 & 0.06013 & 0.06124 \\
\hline $\mathrm{CO}$ & 0.00819 & 0.00769 & 0.00542 & 0.00684 \\
\hline $\mathrm{CH}_{4}$ & \multicolumn{4}{|c}{} \\
\hline
\end{tabular}

tion. The presence of high amount of $\mathrm{CO}_{2}$ in an oxy-fuel environment makes it more emissive than air-fuel environment. As depicted by the flame temperatures in Figs. 6 and 10, a large amount of heat energy is released in the fuel bed with a high $\mathrm{O}_{2}$ concentration mixture. In this study, the heat energy contribution from different sources has not been separated. Therefore, an increase in heat energy cannot be explicitly linked to a particular source. Though, in the region of intense combustion, heat contributed by combustion is more dominant; the contribution by radiation heat flux is only $10-15 \%$ [35].

Wood combustion in four different mixtures of $\mathrm{O}_{2}$ and $\mathrm{Ar} / \mathrm{CO}_{2} / \mathrm{N}_{2}$ was numerically simulated so as to separate the various effects of $\mathrm{CO}_{2}$ on burning rate of wood. For all the cases, temperature profiles at $5 \mathrm{~cm}$ from fuel bed were considered. A method of adjusting the flame temperature using Ar, which was initially proposed by $\mathrm{Du}$ et al [15] and previously used by other researchers $[14,16,17]$, was implemented in this study. The compositions of the four mixtures are specified in Sec. 2.2. Furthermore, other properties of the different mixtures such as mass fraction of the constituents, combined heat capacity and oxygen diffusion coefficient are provided in Table 6 . These properties were evaluated and compared at room temperature $(298 \mathrm{~K})$, ignition temperature $(500 \mathrm{~K})$ and flame temperature $(1400 \mathrm{~K})$. Combustion of wood in mixtures A, B and $C$ was designed to have the same peak temperatures, as shown in Fig. 11. A large amount of Ar in mixture B was to increase the peak temperature, which is low when $\mathrm{CO}_{2}$ alone is used as a diluent. As shown in Table 6, this mixture has a lower specific heat capacity. This enabled the mixture to have the same peak temperature as that of mixture $A$ and $C$. The peak temperature of wood combustion in mixture $\mathrm{D}$ was higher than for the other three by $167 \mathrm{~K}$

The burning rates of wood combustion in the four mixtures were evaluated and presented in Fig. 12. Burning rate in mixture $A$ was used as a datum. The difference in burning rates of combustion in mixture $A$ and $B$ is due to chemical effect because they have the same oxygen concentration and temperature values. Since temperature is the only similar parameter for combustion in mixture $\mathrm{A}$ and $\mathrm{C}$, then the difference in their burning rate is due to a combination of oxygen concentration and chemical effect. Oxygen concentration effect is achieved when oxygen concentration is increased to $40 \%$ while maintaining the same temperature in $\mathrm{CO}_{2}$ environment (combus-
Table 6. Composition, combined heat capacity and $\mathrm{O}_{2}$ diffusion coefficient of the four mixtures at different temperatures.

\begin{tabular}{|c|c|c|c|c|c|}
\hline \multirow{2}{*}{\multicolumn{2}{|c|}{ Properties }} & \multicolumn{4}{|c|}{ Gas mixtures } \\
\hline & & \multirow{2}{*}{$\frac{\mathrm{A}}{0.233}$} & \multirow{2}{*}{$\begin{array}{c}\text { B } \\
0.171\end{array}$} & \multirow{2}{*}{$\begin{array}{c}\mathrm{C} \\
0.327\end{array}$} & \multirow{2}{*}{$\begin{array}{c}\mathrm{D} \\
0.331\end{array}$} \\
\hline \multirow{4}{*}{$\begin{array}{l}\text { Mass fraction of } \\
\text { components }(-)\end{array}$} & $\mathrm{O}_{2}$ & & & & \\
\hline & $\mathrm{CO}_{2}$ & 0.000 & 0.253 & 0.673 & 0.535 \\
\hline & $\mathrm{N}_{2}$ & 0.767 & 0.000 & 0.000 & 0.000 \\
\hline & $\mathrm{Ar}$ & 0.000 & 0.576 & 0.000 & 0.134 \\
\hline \multirow{3}{*}{$\begin{array}{l}c_{p} \text { for the mixture } \\
(\mathrm{kJ} / \mathrm{kg} \mathrm{K})\end{array}$} & At $298 \mathrm{~K}$ & 1.005 & 0.670 & 0.868 & 0.825 \\
\hline & At $500 \mathrm{~K}$ & 1.030 & 0.725 & 1.006 & 0.939 \\
\hline & At $1400 \mathrm{~K}$ & 1.209 & 0.826 & 1.255 & 1.147 \\
\hline \multirow{3}{*}{$\begin{array}{l}\mathrm{O}_{2} \text { diffusion coef- } \\
\text { ficient in the mix- } \\
\text { ture }\left(\mathrm{cm}^{2} / \mathrm{s}\right)\end{array}$} & At $298 \mathrm{~K}$ & 0.209 & 0.184 & 0.156 & 0.164 \\
\hline & At $500 \mathrm{~K}$ & 0.513 & 0.462 & 0.398 & 0.415 \\
\hline & At $1400 \mathrm{~K}$ & 2.888 & 2.642 & 2.310 & 2.401 \\
\hline
\end{tabular}

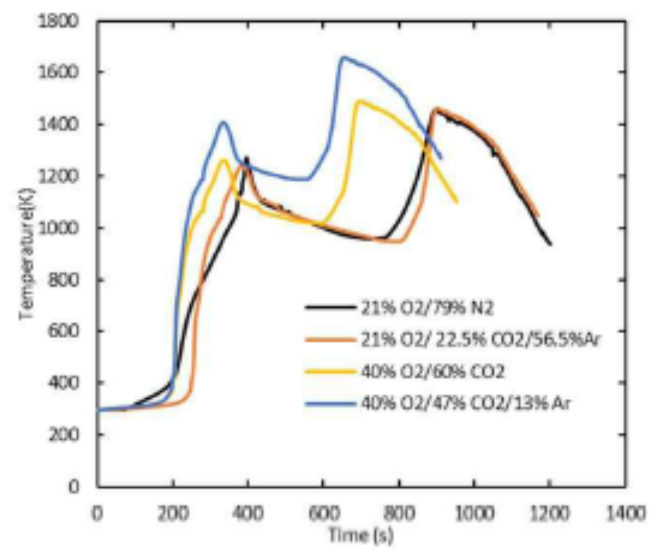

Fig. 11. Predicted temperature profiles at $5 \mathrm{~cm}$ from the bed bottom for wood combustion in four comburtion environments.

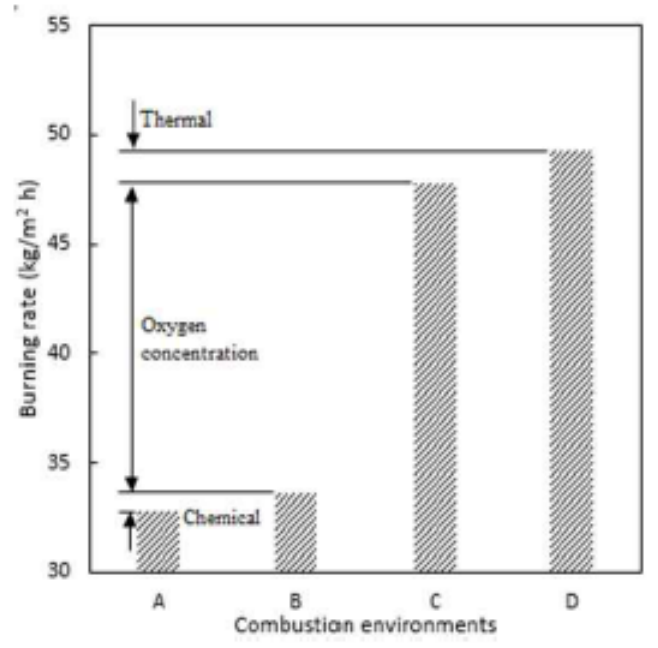

Fig. 12. Predicted separate effects of $\mathrm{CO}_{2}$ on buning rates for wood combustion in four combustion envirouments. 
tion in mixture B and C). Finally, the difference in burning rates for combustion in mixture $\mathrm{C}$ and $\mathrm{D}$ is due to thermal effect since they have the same oxygen concentration but different temperature values.

The individual contribution of $\mathrm{CO}_{2}$ effects on burning rates of wood combustion is evaluated from Fig. 12. It was established that chemical, thermal and oxygen concentration influenced buming rate of wood by $5 \%, 9 \%$ and $86 \%$, respectively. It is evident that oxygen concentration is the most influential parameter in the burning rate. As oxygen concentration is increased, oxidation of char and combustible pyrolysis products is also enhanced. Therefore, more heat is generated and fuel burning rate is significantly improved. The influence of thermal and chemical is not very significant. Thermal effect is only $9 \%$ and translate to a temperature change of $167 \mathrm{~K}$ Chemical effect on the burning rate is quite small because the rate of the chemical reactions involving $\mathrm{CO}_{2}$ consumption $(R(14)$ and $R(16))$ is far much less compared to the rate of $(\mathrm{R}(6)$ and $\mathrm{R}(13))$.

\section{Conclusions}

The overall and separate effects of $\mathrm{CO}_{2}$ burning atmosphere on the combustion properties of wood buming in a fixed bed were investigated through numerical modeling. Modeling was validated by comparison with measured data. The following are the key findings:

- The dilution effect is the most influential parameter on the burning rate of wood combustion in an oxy-fuel system The influence of thermal and chemical is not very significant.

- Peak temperature of oxy-fuel atmosphere, which is equivalent to that of standard air-fuel condition, occurs at a higher $\mathrm{O}_{2}$ concentration. However, its occurrence time is slightly earlier than in air-fuel condition.

- At any given oxygen concentration, ignition time in oxyfuel is almost twice that of corresponding air-fuel condition. In both cases, ignition time gradually decreases as oxygen concentration is increased.

- At the same oxygen concentration, burning rate and flame propagation speed in $\mathrm{CO}_{2}$ combustion environment was less than in $\mathrm{N}_{2}$ combustion environment.

\section{Acknowledgments}

This work was financially supported by both Dedan $\mathrm{Ki}$ mathi University of Technology, Kenya and Technische Hochschule Wildau, Germany. The first Author would like to thank German Academic Exchange Service (DAAD) for the financial support for his stay in Technische Hochschule Wildau, Germany.

\section{Nomenclature}

$$
\text { : Arrhenius pre-exponent factor }\left[\mathrm{s}^{-1}\left(\mathrm{~mol} \mathrm{~m}^{-3}\right)\right]
$$

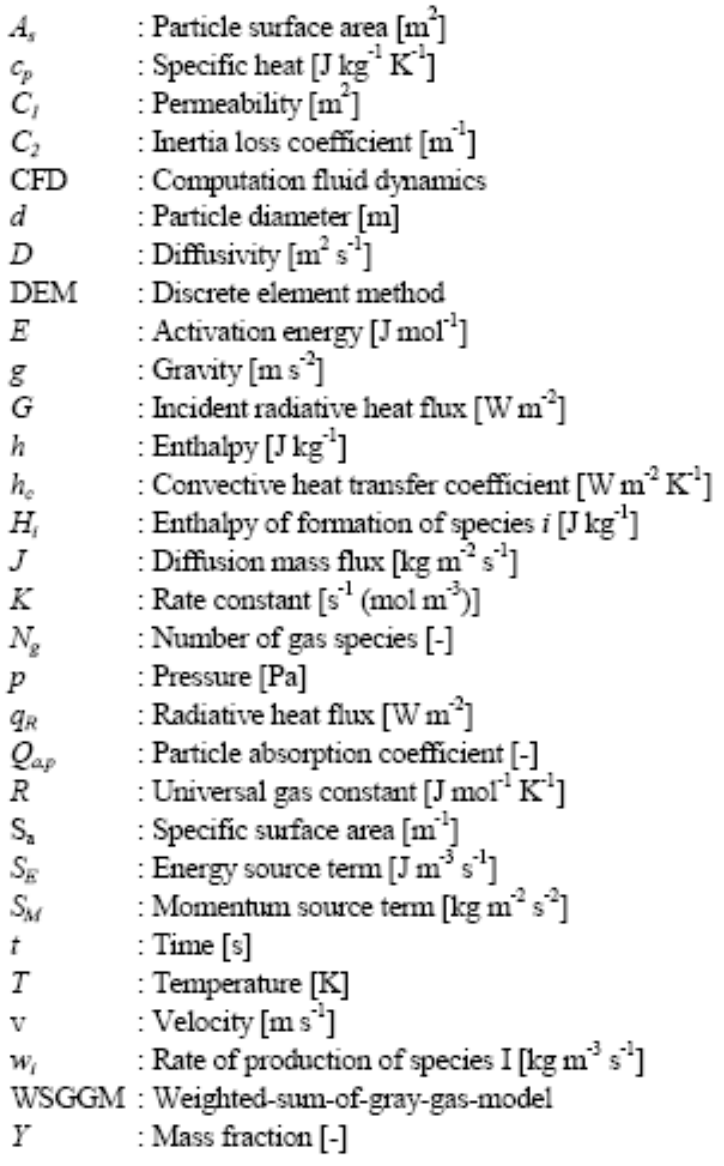

\section{Greek symbols}

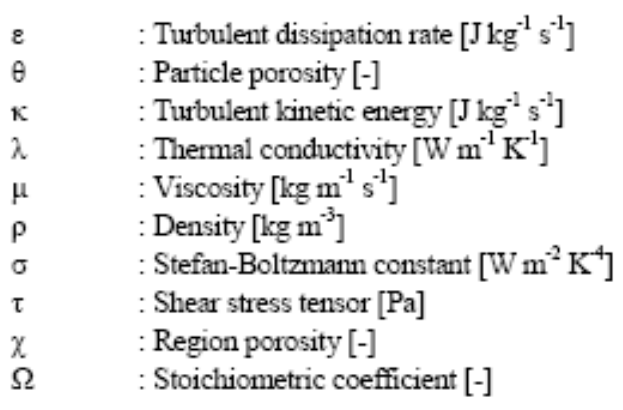




\section{Superscript}

gs : Heterogeneous reaction

$n \quad$ : Exponent

\section{Operators}

$\nabla \quad$ : Gradient operator

$\nabla$. $\quad$ : Divergence operator

\section{References}

[1] International Energy Agency, World Energy Outlook 2016. Executive Summary, https://www.iea.org (2016).

[2] S. K. Hong, D. S. Noh and J. B. Yang, Experimental study of honeycomb regenerator system for oxy-fuel combustion, J. of Mechanical Science and Technology, 27 (4) (2013) 1151-1154.

[3] S. H. Tak, S. K. Park, T. S. Kim, J. L. Sohn and Y. D. Lee, Performance analyses of oxy-fuel power generation systems including $\mathrm{CO}_{2}$ capture: Comparison of two cycles using different recirculation fluids, $J$. of Mechanical Science and Technology, 24 (9) (2010) 1947-1954.

[4] D. Kim and S. Choi, Effect of typical modeling assumptions for pulverized coal char combustion commonly used in commercial CFD codes, J. of Mechanical Science and Technology, 29 (11) (2015) 4951-4961.

[5] R. Ben-Mansour, P. Ahmed, M. A. Habib and A. Jamal, Oxy-combustion of liquid fuel in an ion transport membrane reactor, International J. of Energy and Environmental Engineering, 9 (2018) 21-37.

[6] R. Marsh, J. Runyon, A. Giles, S. Moris, D. Pugh, A. Valera-Medina and P. Bowen, Premixed methane oxycombustion in nitrogen and carbon dioxide atmospheres: Measurement of operating limits, flame location and emissions, Proceedings of the Combustion Institute, 36 (3) (2017) 3949-3958.

[7] G. Scheffknecht, L. Al-Makhadmeh, U. Schnell and J. Maier, Oxy-fuel coal combustion - A review of the current state-ofthe-art, International J. of Greenhouse Gas Control, 5 (2011) 16-35.

[8] J. Ahn, H. J. Kim and K. S. Choi, Oxy-fuel combustion boiler for $\mathrm{CO}_{2}$ capturing: $50 \mathrm{~kW}$-class model test and numerical simulation, $J$. of Mechanical Science and Technology, 24 (10) (2010) 2135-2141.

[9] S. K. Hong, K. G. Kang, D. S. Noh, E. K. Lee and H. S. Ryou, Development of an oxy-fuel combustor with fuel preheating for regenerator system, $J$. of Mechanical Science and Technology, 29 (10) (2015) 4555-4559.

[10] S. Park, J. A. Kim, C. Ryu, W. Yang, Y. J. Kim and S. Seo, Effects of gas and particle emissions on wall radiative heat flux in oxy-fuel combustion, J. of Mechanical Science and Technology, 26 (5) (2012) 1633-1641.

[11] A. Molina and C. R. Shaddix, Ignition and devolatilization of pulverized bituminous coal particles during oxy- gen/carbon dioxide coal combustion, Proceedings of the Combustion Institute, 31 (2) (2007) 1905-1912.

[12] J. Riaza, M. V. Gil, L. Allvarez, C. Pevida, J. J. Pis and F. Rubiera, Oxy-fuel combustion of coal and biomass blends, Energy, 41 (1) (2012) 429-435.

[13] L. Alvarez, C. Yin, J. Riaza, C. Pevida, J. J. Pis and F. Rubiera, Biomass co-firing under oxy-fuel conditions: A computational fluid dynamics modelling study and experimental validation, Fuel Processing Technology, 120 (2014) 22-33.

[14] Q. Wang, G. Legros, J. Bomnety and C. Morin, Experimental characterization of the different nitrogen dilution effects on soot formation in ethylene diffusion flames, Proceedings of the Combustion Institute, 36 (2) (2017) 3227-3235.

[15] D. X. Du, R. L. Axelbaum and C. K. Law, The influence of carbon dioxide and oxygen as additives on soot formation in diffusion flames, Symposium (International) on Combustion/The Combustion Institute, 23 (1) (1990) 15011507.

[16] K. Al-Qurashi, A. D. Lueking and A. L. Boehman, The deconvolution of the thermal, dilution, and chemical effects of exhaust gas recirculation (EGR) on the reactivity of engine and flame soot, Combustion and Flame, 158 (9) (2011) 1696-1704.

[17] Y. Zhou, X. Jin and Q. Jin, Numerical investigation on separate physicochemical effects of carbon dioxide on coal char combustion in $\mathrm{O}_{2} / \mathrm{CO}_{2}$ environments, Combustion and Flame, 167 (2016) 52-59.

[18] F. Shan, Q. Lin, K. Zhou, Y. Wu, W. Fu, P. Zhang, L. Song, C. Shao and B. Yi, An experimental study of ignition and combustion of single biomass pellets in air and oxy-fuel, Fuel, 188 (2017) 277-284.

[19] J. Riaza, R. Khatami, Y. A. Levendis, L. Álvarez, M. V. Gil, C. Pevida, F. Rubiera and J. J. Pis, Single particle ignition and combustion of anthracite, semi-anthracite and bituminous coals in air and simulated oxy-fuel conditions, Combustion and Flame, 161 (4) (2014) 1096-1108.

[20] J. G. Pohlmamn, E. Osóno, A. C. F. Vilela, M. A. Diez and A. G. Borrego, Pulverized combustion under conventional $\left(\mathrm{O}_{2} / \mathrm{N}_{2}\right)$ and oxy-fuel $\left(\mathrm{O}_{2} / \mathrm{CO}_{2}\right)$ conditions of biomasses treated at different temperatures, Fuel Processing Technology, 155 (2017) 174-182.

[21] M. V. Gil, J. Riaza, L. Alvarez, C. Pevida, J. J. Pis and F. Rubiera, Kinetic models for the oxy-fuel combustion of coal and coalbiomass blend chars obtained in $\mathrm{N}_{2}$ and $\mathrm{CO}_{2}$ atmospheres, Energy, 48 (1) (2012) 510-518.

[22] J. K. Tamui, P. N. Kioni, T. Mirre and M. Nowitzki, The effect of carbon dioxide on flame propagation speed of wood combustion in a fixed bed under oxy-fuel conditions, Fuel Processing Technology, 179 (2018) 285-295.

[23] R. M. Park, R. M. Carroll, P. Bliss, G. W. Bums, R. R. Desmaris, F. B. Hall, M. B. Herzkovitz, D. MacKenzie, E. F. McGuire, R. P. Reed, L. L. Sparks and T. P. Wang (eds.), ASTM MNL12 - Manual on the Use of Thermocouples in Temperature Measurement, Fourth Ed., Sponsored by 
ASTM Committee E20 on Temperature Measurement, West Conshohocken, USA (1993).

[24] CD-Adapco, STAR CCM+ Version 11.04, www.cdadapco.com (2017).

[25] T. F. Smith, Z. F. Shen and J. N. Friedman, Evaluation of coefficients for the weighted sum of gray gases model, $J$. Heat Transf., 104 (4) (1982) 602-608.

[26] R. Mehrabian, A. Shiehnejadhesar, R. Scharler and I. Obemberger, Multi-physics modelling of packed bed biomass combustion, Fuel, 122 (2014) 164-178.

[27] R. Johansson, H. Thumman and B. Leckner, Influence of intraparticle gradients in modeling of fixed bed combustion, Combustion and Flame, 149 (2007) 49-62.

[28] M. Gómez, J. Porteiro, D. de la Cuesta, D. Patiño and J. Miguez, Numerical simulation of the combustion process of a pellet-drop-feed boiler, Fuel, 184 (2016) 987-999.

[29] A. H. Mahmoudi, M. Markovic, B. Peters and G. Brem, An experimental and numerical study of wood combustion in a fixed bed using Euler-Lagrange approach (XDEM), Fuel, $150(2015)$ 573-582.

[30] A. H. Mahmoudi, F. Hoffmam, M. Markovic, B. Peters and G. Brem, Numerical modeling of self-heating and selfignition in a packed-bed of biomass using XDEM, Combustion and Flame, 163 (2016) 358-369.

[31] G. P. Smith, D. M. Golden, M. Frenklach, N. W. Moriarty, B. Eiteneer, M. Goldenberg, C. T. Bowman, R. K. Hanson, S. Song, W. C. Gardiner Jr., V. V. Lissianski and Z. Qin, GRI-MECH 3.0, http://www.me.berkeley.edu/gri_mech/ (1999).

[32] C. K Westbrook and F. L. Dryer, Chemical kinetic modeling of hydrocarbon combustion, Prog. Energy Combust. Sci., 10 (1) (1984) 1-57.

[33] D. D. Evans and H. W. Emmons, Combustion of wood charcoal, Fire Research, 1 (1977) 57-66.

[34] T. Suda, K. Masuko, J. Sato, A. Yamamoto and K Okazaki, Effect of carbon dioxide on flame propagation of pulverized coal clouds in $\mathrm{CO}_{2} / \mathrm{O}_{2}$ combustion, Fuel, 86 (2007) 20082015.

[35] N. Lallemant, A. Sayre and R. Weber, Evaluation of emissivity correlations for $\mathrm{H}_{2} \mathrm{O}-\mathrm{CO}_{2}-\mathrm{N}_{2} /$ air mixtures and coupling with solution methods of the radiative transfer equation, Prog. Energy Combust. Sci., 22 (6) (1996) 543-574.

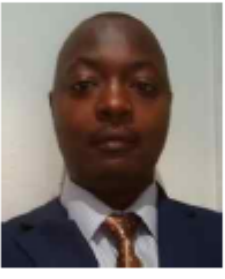

J. K. Tanui received his B.Sc. and M.Sc. in Mechanical Engineering from Jomo Kenyatta University of Agriculture and Technology (JKUAT), Nairobi, Kenya, in 2009 and 2013, respectively. $\mathrm{He}$ is currently doing his $\mathrm{Ph} . \mathrm{D}$. at Dedan $\mathrm{Ki}$ mathi University of Technology (DeKUT) with special arrangements to carry out some research at Technische Hochschule Wildau, Germany. His research interests include combustion and gasification of solid fuels, biofuels combustion and kinetics, emissions and pollutant formation in fuels.

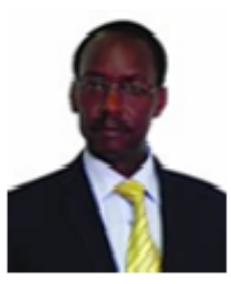

P. N. Kioni received his B.Sc. in Mechanical Engineering from University of Nairobi, Kenya, in 1988, and Ph.D. from Cambridge University, United Kingdom, in 1994. He is a Professor of Mechanical Engineering at DeKUT. His research interests include studies of reacting flows.

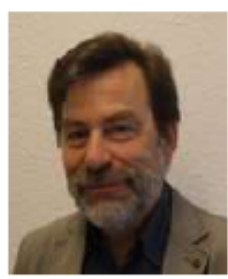

T. Mirre received his Dipl.-Ing. in power plant technology and transformation of energy, special nuclear technology from Technical University Zittau in 1982. In 1992 he became a Professor in the Faculty of Mechanical Engineering at the University of Applied Science (UAS) Wildau and from 1998 to 2010 he was the Dean of the faculty. His subject area is thermodynamics, flows and turbo-engines.

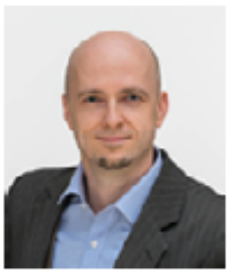

M. Nowitzli received his Dipl--Ing. in Process Engineering from UAS Wildau in 2005 . He is currently working at UAS Wildau and doing his Dr.-Ing. at the Brandenburg University of Technology Cottbus-Senftenberg. His research interests include multiphase flow simulation, Tesla microturbines, substance transition in rectification columns and heat transfer. 


\title{
The influence of particle packing density on wood combustion in a fixed bed under oxy-fuel conditions
}

\author{
J.K. Tanui ${ }^{\text {a, }}{ }^{*}$, P.N. Kioni ${ }^{\text {a }}$, T. Mirre ${ }^{\text {b }}$, M. Nowitzki ${ }^{\text {b }}$, N.W. Karuri ${ }^{\text {a }}$ \\ a Department of Mechavical Engineening, Dedan Kimathi University of Tedinology Private Bag, 10143, Dedan Kinathi, Nyeni, Kenya \\ 'Fachbereich Ingenieur- und Naturwissenschaften, Technische Hochschule Wildau, Hochschulring 1, 15745, Widau, Germany
}

\section{A R T I C L E I N F O}

\section{Anticle history:}

Received 4 November 2019

Received in revised form

20 December 2019

Accepted 26 December 2019

Available online 27 December 2019

\section{Keyword:}

Oxy-fuel combustion

Bed porosity

Packing density

Wood combustion

Fixed bed

\begin{abstract}
A B S T R A T
Presented in this paper is a study of the influence of particle packing density on fixed bed combustion of wood in an axy-fuel burning environment. The packing density, which determines the region porosity, is influenced by fuels' geometry. Size and shape were determined directly from fuel particles and used to evaluate the particle sphericity which is an input in the computational model. Euler-Lagrange method was used to model conversion of wood in a fixed bed. The computational model was validated by performing experiments in a fixed bed using wood of different shapes and sizes which formed a wide range of bed porosity. It was established that the packing density affects combustion process by changing the burning conditions and flammability limits. The combustion condition is shifted from fuel-rich to fuellean side as bed porosity is increased. Consequently, the flame front propagation speed and conversion rates increase while the ignition time reduces. The operational range with respect to porosity was decreased in an axy-fuel burning condition due to higher quenching effects of $\mathrm{CO}_{2}$. Furthermore, the study revealed that there is an optimum packing density, $\chi=0.71$, beyond which the efficiency falls due to the onset of quenching in the spaces.
\end{abstract}

๑ 2019 Elsevier Ltd. All rights reserved.

\section{Introduction}

Wood is a source of energy for both domestic and industrial application in most parts of the world. In industrial application, particularly for power plants that generate up to $40 \mathrm{MW}_{\text {th. }}$. Hermansson and Thunman [1], the chemical energy bound in wood is converted into thermal energy using fixed bed combustion in a grate furnace. The fixed bed technique is favourable because of its simplicity. Consequently, this technique has been applied in most biomass power plant all over the world [1]. This has generated research interests in approaches for increasing combustion efficiency and reduction of emissions, Costa et al. [2], Guo et al. [3] and Yahaya et al. [4]. In practice, wood particles burned in the furnace are of different shapes and sizes. Packing of these particles affects their arrangement in the bed and thus the bed porosity. Bed porosity is a complex parameter which besides being affected by the particles' physical properties also changes as combustion progresses due to bed shrinkage, Porteiro et al. [5] and Khodaei et al. [6].

\footnotetext{
- Corresponding author.

E-mal address: josephat.tanuiødkut.acke (JK. Tanui).
}

Various types of biomass and their conversion processes have been studied in fixed beds operated in $\mathrm{O}_{2} / \mathrm{N}_{2}$ mixtures, Abrego et al. [7], Chen et al. [8], Meng et al. [9] and Plis \& Wilk [10]. Lately, there is a lot of interests in utilization of wood in an oxy-fuel bumer for thermal energy generation. This is a technology where biomass is burned in a $\mathrm{O}_{2} / \mathrm{CO}_{2}$ mixture instead of a $\mathrm{O}_{2} / \mathrm{N}_{2}$ mixture. This is a clean energy technology where the $\mathrm{CO}_{2}$ is captured through recycling of flue gas, and at the same time nitrogen oxides $\left(\mathrm{NO}_{\mathrm{x}}\right)$ emissions are reduced, Scheffknecht et al. [11]. Most of the previous research on combustion of biomass under an oxy-fuel environment were done for entrained flow reactor, Riaza et al. [12] and Gil et al. [13], drop tube furnace, Heuer et al. [14] and Pohlmann et al. [15], single particle investigations, Shan et al. [16] and thermogravimetric analysis (TGA) method, Gil et al. [17]. Even though oxy-fuel combustion is a clean combustion technology, it has been established that it reduces flame temperature [15], increases ignition delay time [16] and reduces combustion rate, Riaza et al. [18].

Fixed bed combustion of wood is influenced by its shape and size amongst other factors. The influence of shape is through the following four ways: Particle overlapping; grain direction; geometry and packing in the bed. Particles with flat and concave surfaces can overlap when arranged in a chamber whereas those with 
convex surfaces such as spherical shapes, do not overlap. Overlapping of surfaces reduces effective surfaces area for fluid flow and chemical reactions. The influence of particle overlapping is analyzed by defining a particle surface availability, Trudel and Hallet [19]. Alternatively, its effect is determined using a shape factor that is included in heat and mass transfer correlations, Glaser and Thodos [20].

Biomass fuels are made of fibres which are normally aligned with one another. It has been shown that pyrolysis rate is faster along the fibres than across them, Larfeldt et al. [21]. Volatiles also flow faster along the fibres as compared to movement across them, Henriksen et al. [22]. Char produced though pyrolysis under low heating rates has fibre arrangement similar to that of raw biomass, Trudel et al. [23]. Consequently, porosity is high across the fibres. This leads to a higher gas permeability along the grain [21]. In addition, conversion rate for char is increased on the surface normal to the fibres [23]. Thus, aspect ratio plays an important role in wood and char gasification, Pattanotai et al. [24].

The geometry of the particle affects biomass conversion through surface area. Most biomass particles utilized in power plants have a wide range of irregular shapes which can impact on its conversion. The shape of a particle is defined in terms of sphericity. It has been shown that sphericity of particles has a correlation with ignition rate and bed porosity, Horttanainen et al. [25]. Particles with high sphericity have decreased surface area, which impacts negatively on burning times, Huff [26].

The shape and the size of fuel particles also have significant influence on the packing density. Thus, hydrodynamics of flow and thermal properties of the bed are affected. In fact, a number of correlations for pressure loss were developed on the basis of hydraulic diameter of the bed, Comiti and Renaud [27]. The size of fuel particles affects wood conversion in a packed bed through convective and radiation heat transfer, gas species and energy dispersion by turbulence as well as mass transfer and mixing rate of volatiles and air in the bed. Subsequently, bed packing affects the amount of volatiles released, reaction zone thickness Yang et al. [28], operational limit of air flow rate [25], burning rate, Ryu et al. [29], and ignition front velocity, Porteiro et al. [30]. Despite the significance of fixed bed combustion technology in power generation, there are few studies of this technique in an oxy-fuel environment, Tanui et al. [31]. Most of the studies only cover combustion under air-fuel condition. Specifically, the effects of bed porosity on wood conversion in a fixed bed operated in $\mathrm{O}_{2} / \mathrm{CO}_{2}$ mixture have not been investigated.

The main aim of this study was to investigate the impact of particles packing density on fixed bed combustion of wood in an oxy-fuel burning environment. Fuels with different characteristic particle size were experimentally studied in a fixed bed operated in oxy-fuel environment. A detailed analysis of bed combustion in terms temperature profiles, species generations, reaction zone thickness and conversion rates were done using Euler-Lagrange model. The model was implemented in a commercial software CD-Adapco (STAR CCM + version 11.04) [32].

\section{Material and method}

\subsection{Fuel sample properties}

The fuel samples used in all experiments in this study were of eucalyptus wood. Eucalyptus is the main source of fuel for woodfired boilers used for steam generation in process industries such as tea production in Kenya. Eucalyptus tree is an attractive source because it takes a short time to mature. The properties of fuel sample are presented in Table 1. Fuel sample sizes were determined using BS EN 15149-2:2010 standard [33]. Sieving of wood particles was done using Fritsch vibratory shaker with sieves of size between 0.5 and $7.1 \mathrm{~mm}$. In every sieving process conducted, an amplitude of $3 \mathrm{~mm}$ and time of $15 \mathrm{~min}$ was used.

The fuel particles were then grouped into three categories according to their sizes, namely, sawdust 1 (SD1), sawdust 2 (SD2) and wood chips (WC), as shown in Fig. 1 . The characteristic size, $\bar{d}$, of each group was fitted using Rosin-Rammler distribution, Eq. (1) [34].

$R(d)=100\left(1-\exp \left(\frac{d}{\bar{d}}\right)^{n}\right)$

In Eq. (1), $R(d)$ is the percentage of accumulated undersize mass and the value of $n$ was determined according to Brezáni and Zeleñak [35].

The particle diameter, $D_{\text {eq, }}$, which is equivalent to that of a sphere with the same volume, was evaluated for each fuel sample using its characteristic size $\bar{d}$ and shape. Furthermore, the sphericity, $\psi$ of the particle was determined [23].

$\psi=\frac{\pi D_{e q}^{2}}{A_{s}}=\frac{\pi^{1 / 3}\left(6 V_{p}\right)^{2 / 3}}{A_{s}}$

Bed porosity, $\chi$, was determined from the measured fuel bed density, $\rho_{b}$, and density of wood particle, $\rho_{p}$, which were related through Eq. (3) [25]:

$\chi=1-\frac{\rho_{b}}{\rho_{p}}$

The sphericity, equivalent diameters and bed porosity of different fuel samples used in this study are presented on Table 2 .

\subsection{Experimental set-up}

All experiments in this work were done using a laboratory scale combustion test rig shown in Fig. 2. The combustion module was made from a $40 \mathrm{~mm}$-diameter stainless steel tube which was $200 \mathrm{~mm}$ long. It was insulated with a refractory material, which was contained in a stainless steel tube. A full description of the combustion rig is provided in our previous paper, Tanui et al. [31].

Temperature distribution in the combustion region was obtained using Type $K$ thermocouples that were located $10 \mathrm{~mm}$ from each other along the axial length of the rig. The temperature data were acquired and recorded in every second. Temperature measurement data at various heights in the bed were used to estimate ignition time and flame propagation speed. Combined measurement uncertainty for thermocouple data acquisition depends on the measured temperature and for the entire range was determined to be between $\pm 2.2^{\circ} \mathrm{Cand} \pm 6.6^{\circ} \mathrm{C} .21 \% \mathrm{O}_{2} / 79 \% \mathrm{CO}_{2}$ mixture was supplied, mixed in a chamber of glass particles and led into combustion chamber through a stainless steel grate. Gas volumetric flow rate was controlled by rotameters with a tolerance of $\pm 2 \%$.

Experiments were done for five fuel particle types shown in Table 2, which form bed porosity in the range of $0.51-0.74$. Three replicates were performed for each experiment. For all the cases studied, the fuel bed height was $60 \mathrm{~mm}$. The bed was operated in a batch mode; the fuel particles were supplied once for each experiment. However, oxidizer was supplied continuously. Ignition was done at the top and the reaction front propagated downward into unreacted fuel particles.

\subsection{Numerical model}

Fixed bed combustion of wood was modeled using a commercial 
Table 1

Proximate and ultimate analysis of the fuel sample.

\begin{tabular}{lll}
\hline Proximate Analysis & (wt s) & Standards \\
\hline Moisture & 10.3 & CEN-TS 14774-2:2009 \\
Volatile matter (wtz dry basis) & 84.9 & CEN-TS 15148:2009 \\
Fixed carbon (wtz dry basis) - by difference & 14.9 & - \\
Ash (wtz dry basis) & 0.2 & CEN-TS 14775:2009 \\
\hline Ultimate Analysis & (wt \% dry basis) & Standards \\
\hline C & 50.87 & CEN-TS 15104:2011 \\
H & 5.73 & CEN-TS 15104:2011 \\
N & 0.3 & CEN-TS 15104:2011 \\
O (by difference) & 43.1 & - \\
Gross calorific value (Mg/kg) & 19.3 & CEN-TS 14918:2009 \\
\hline
\end{tabular}

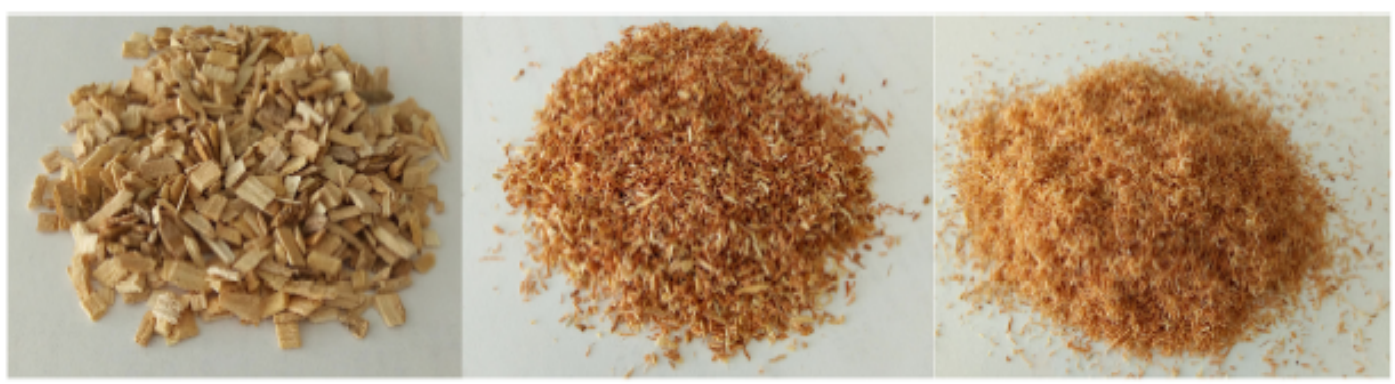

(a) Wood chips (WC)

(b) Sawdust 2 (SD2)

(c) Sawdust 1 (SD1)

Fig. 1. Wood fuel samples.

Table 2

Properties of wood samples and fixed bed.

\begin{tabular}{lllll}
\hline Fuel type & $\rho_{s}\left(\mathrm{~kg} / \mathrm{m}^{3}\right)$ & $\rho_{p}\left(\mathrm{~kg} / \mathrm{m}^{3}\right)$ & $D_{e q}(\mathrm{~mm})$ & $\chi(-)$ \\
\hline Wood chips (WC) & 597 & 1220 & 5.25 & 0.30 \\
Sawdust 1 (SD1) & 321 & 1220 & 1.28 & 0.51 \\
Sawdust 2 (SD2) & 477 & 1220 & 2.91 & 0.74 \\
Mixture of WC and SD1 (25\% WC) - WCSD1 & 390 & 1220 & 2.27 & 0.61 \\
Mixture of WC and SD2 (508 each) - WCSD2 & 537 & 1220 & 4.08 & 0.28 \\
\hline
\end{tabular}

software code CD-Adapco (STAR CCM + version 11.04) [32]. EulerLagrange simulation method was implemented in this work. In this technique, solid wood is simulated through a Lagrangian framework, Discrete Element Method (DEM), whereas fluid-phase is modeled using computational Fluid Dynamics (CFD). Governing equations for fluid-phase are presented in Table 3 while those for solid-phase are in Table 4. More details about these equations are described in our previous paper [31] and in Ref. [32]. The symbols are defined in the nomenclature section.

Exchange of mass and species between solid-phase and fluidphase were enabled by coupling equations: $\sum_{i g} w_{i g}^{g}=-\sum_{i, s} w_{i, s}^{5}$ and $w_{i g}^{s}=-w_{i s}^{s}$, respectively. Similarly, the energy source term in fluid-phase model is as a result of energy exchange between solid and fluid phases by convection and radiation. This term also accounts for the enthalpy of formation of heterogeneous species. The source terms appearing in fluid-phase energy Eq. (9) have the same magnitude as those in solid-phase energy Eq. (12) but have opposite sign. Turbulence in fluid-phase was enabled by using a standard $k-\varepsilon$ model.

The chemical kinetic mechanism that is implemented in this study is shown in Table 5. It consists of sub-models for drying. devolatilization, homogeneous reactions and char combustion, respectively. The chemical effect of $\mathrm{CO}_{2}$ environment was accounted for by inclusion of reaction R (10), that was established as the most significant in such environment, Liu et al. [36,37]. Furthermore, $R(10)$ is associated with reactions $R(11)$ and $R(12)$, which are also included. Kinetic data and rate expression for all reactions are specified in Table 5. Char combustion were modeled through oxidation reaction $\mathrm{R}(15)$. The char combustion rate were evaluated based on partial pressure of $\mathrm{O}_{2}, \mathrm{CO}_{2}$ and $\mathrm{H}_{2} \mathrm{O}$ available at its surface, Evans and Emmons [38]. The stoichiometric ratio of $\mathrm{CO}_{2}$ to $\mathrm{CO}$ was modeled in terms of particle temperature [39]:

$\Omega=\frac{2\left(1+4.3 \exp \left[-3390 / T_{\text {particle }}\right]\right)}{2+4.3 \exp \left[-3390 / T_{\text {particle }}\right]}$

In this work, radiation energy exchange between continuous region and fuel particles was considered. The radiant energy equation was computed through Discrete Ordinate Method (DOM), Fiveland [45]. Both fuel particles and gases were considered to participate in radiation. The radiation property of the fuel particles 


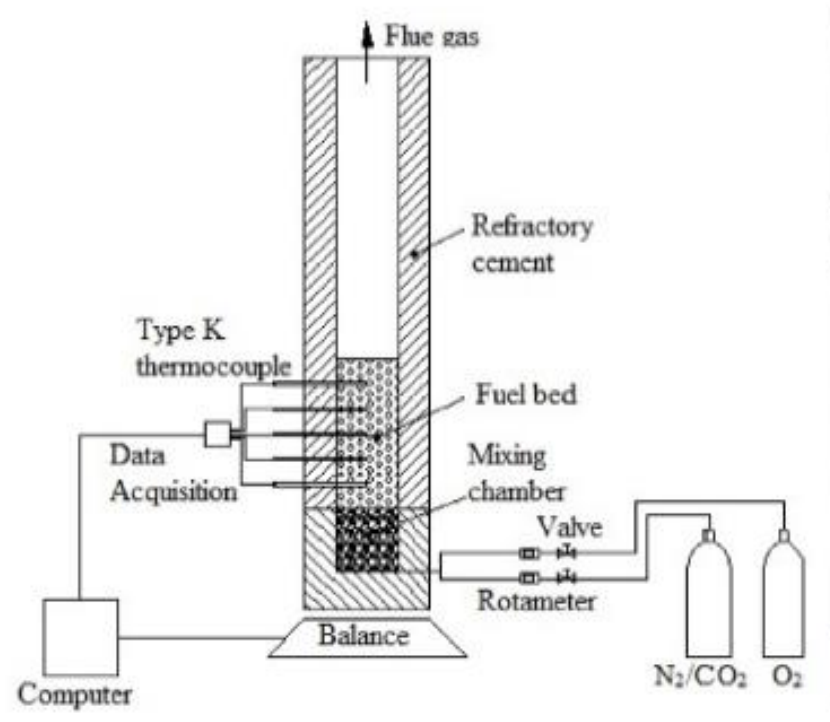

(a) Schematic diagram

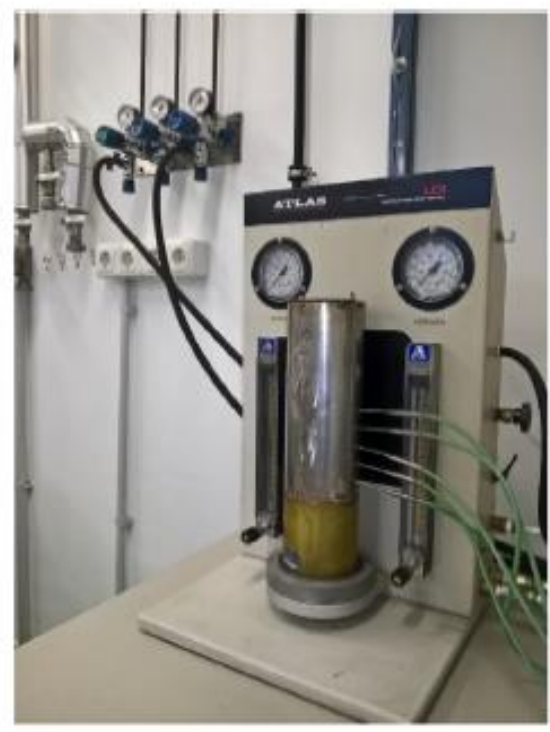

(b) A photo of laboratory set-up

Fig. 2. Experimental set-up.

Table 3

Gas-phase conservation equations

- Mass conservation equation:

$\frac{\partial}{\partial t}\left(x \rho_{g}\right)+\nabla \cdot\left(\rho_{g} v_{g}\right)-\sum_{i_{g}} w_{L_{g}}^{\sigma}$

- Momentum conservation equation:

$\frac{\partial}{\partial t}\left(x \rho_{g} v_{g}\right)+\nabla \cdot\left(\rho_{g} v_{g} v_{g}\right)--\nabla p+\nabla \cdot \tau+\rho_{g} g+S_{m}$

- Energy conservation equation:

$\frac{\partial}{\partial t}\left(x \rho_{g} h_{g}\right)+\nabla \cdot\left(\rho_{g} v_{z} h_{g}\right)-\frac{\partial}{\partial t}(x p)+\nabla \cdot\left(\lambda_{z e} \nabla T_{g}-\sum_{t=1}^{N_{g}} h_{i g} h_{t g}\right)+\nabla \cdot\left(v_{g} p\right)-\nabla \cdot\left(\tau \cdot v_{g}\right)+S_{E}$

- Species conservation equation:

$\frac{\partial}{\partial t}\left(x \rho_{g} Y_{i g}\right)+\nabla \cdot\left(\rho_{g} v_{g} Y_{i g}\right)-\nabla \cdot\left(\rho_{g} D \nabla Y_{i g}\right)+w_{i g}^{B}$

- Momentum source term:

$S_{w-}-\left(\frac{\mu}{C_{1}} v_{g}+C_{2} \rho_{g}\left|v_{g}\right| v_{g}\right)$

- Energy source term:

$S_{E}-A_{s} h_{C}\left(T_{s}-T_{g}\right)-\sum_{i s} w_{i s}^{T_{s}} H_{i g}+q_{R}$

was considered to be gray. On the other hand, gases radiation properties were modeled using unmodified Weighted-Sum-ofGray-Gas-Model (WSGGM), Smith et al. [46].

Computation was done on an unstructured grid that consisted of cells which were made of polyhedral elements. The cells closest to the walls were made of prism layers. Solutions which are independent of grid size were carried out by performing a mesh independent test as shown in Fig. 3. The graphs represent temperature profiles for particle type WC and SD1 predicted by different grid sizes. Temperature predicted using a mesh size with 100,000 cells showed a significant difference from that predicted using a mesh size of 200,000 cells. However, changing of mesh size to 300,000 cells and 400,000 cells, respectively, did not significantly change the prediction results when compared to that of 200,000 cells. Therefore, combustion of all fuel particle types were computed using a mesh with 200,000 cells.

The packing density, which determines the region porosity, is influenced by fuels' geometry. Size and shape were determined directly from fuel particles and used to evaluate the particle sphericity. All parameters of the wood particles which were input to the model are presented in Tables 1 and 2

The inlet boundary was positioned on the lower side of the fixed 
Table 4

Solid-phase conservation equations.

- Mass conservation equation:

$\frac{\partial}{\partial t}\left((1-x) \rho_{s}\right)-\sum_{i s} w_{l s}^{B s}$

- Species conservation equation:

$\frac{\partial}{\partial t}\left((1-x) \rho_{s} Y_{t s}\right)-w_{i s}^{\not}$

- Energy conservation equation:

$\rho_{s} c_{p s}(1-\chi) \frac{\partial T_{p}}{\partial t}-\nabla \cdot\left(\lambda_{s e} \nabla T_{s}\right)+A_{s} h_{c}\left(T_{g}-T_{s}\right)+\frac{A_{s}}{4} Q_{a p}\left(G-4 \sigma T_{s}^{4}\right)+\sum_{i s} w_{i s}^{g s} H_{i s}$

Table 5

Biomass kinetic model.

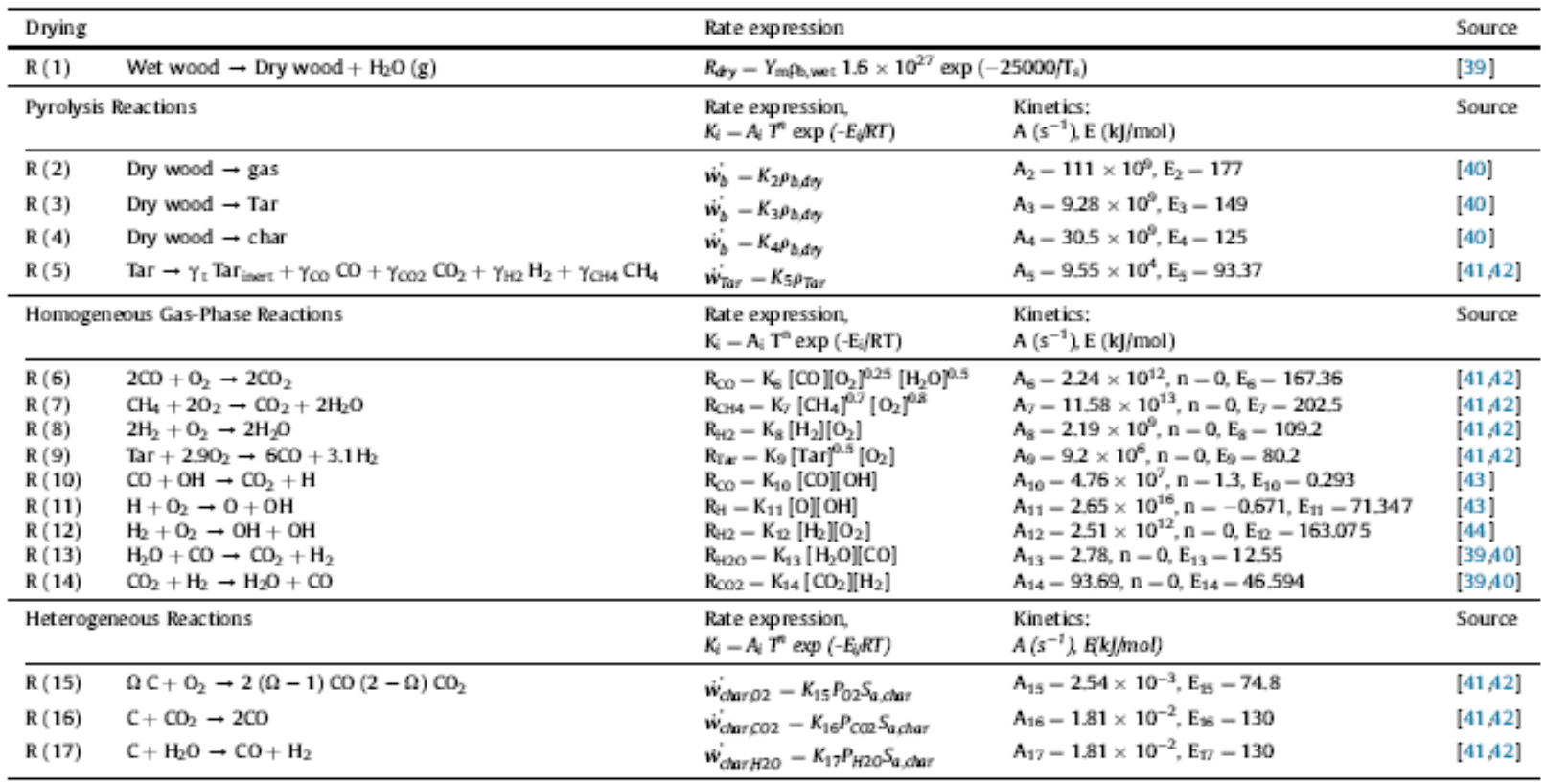
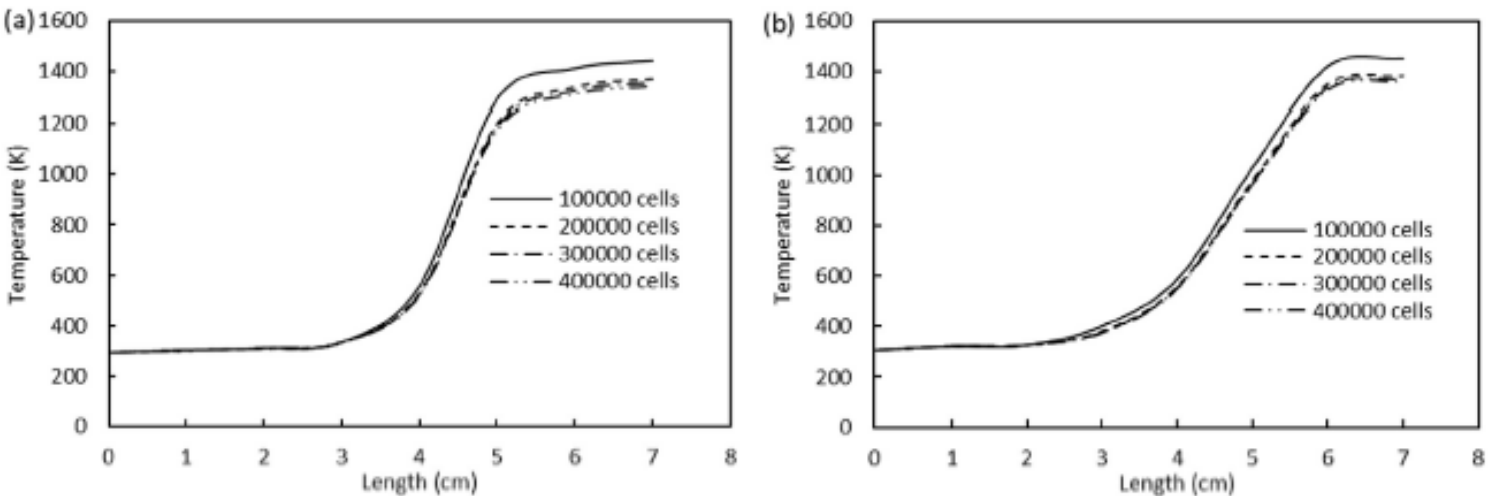

Fig 3. Comparison of temperature profiles along the axial length of the bed for particle type (a) WC $(\chi-0.51)$ and (b) SD1 ( $\chi-0.74)$ when reaction front is at $4 \mathrm{~cm}$ from the grate applying different computation mesh sizes. 
bed. At the inlet, mass flow rate, species mole fraction and temperature were specified using Dirichlet boundary condition. The temperature for the oxidizer mixture, which consisted of $21 \% \mathrm{O}_{2}$ and $79 \% \mathrm{CO}_{2}$ at the inlet, was $295 \mathrm{~K}$. Mass flow of the oxidizer mixture at the inlet was $0.1 \mathrm{~kg} / \mathrm{m}^{2} / \mathrm{s}$ for all the fuel types. At outlet boundary, which was positioned at top of the fixed bed, species concentration and temperature gradients were fixed at zero. The thermal conditions at the fixed bed were considered to be both convective and radiative. The coefficient of convective heat transfer which was adopted at the fixed bed wall was $10 \mathrm{~W} / \mathrm{m}^{2} . \mathrm{K}$. The fixed bed wall was made of stainless steel whose emissivity is 0.8 [47].

\section{Results and discussions}

The CFD-DEM model results were validated by data obtained from experiment. Fig. 4 presents a validation of temperatures at various heights in the bed for different fuel particle types. In general, deviations of $10 \%$ or less between the model and measured data indicate a good agreement. Particle type WC, WCSD2 have two distinct temperature peaks, Fig. 4(a)-(b), while particle type WCSD1 and SD1 have a single temperature peak, Fig. 4(d) and (e). Particle type SD2 is a transition case with a distinct first temperature peak and the temperature plateaus off in the second peak, Fig. 4(c). The first peak is attained during ignition front propagation phase while the second peak is attained during char oxidation phase, Khor et al. [48]. Fig. 4(a)-(b) indicate that beds with low porosity have substantial amount of char remaining in the bed after devolatilization. The char combustion phase peak temperatures for these fuel particle types are higher than ignition front propagation phase peak temperatures. In particle type SD2, some of the char produced are oxidized in the first peak region leading to a higher flame temperature being attained. Subsequently, its second peak region has a low temperature value. In case of high porosity beds, Fig. 4(d) and (e), they have a single peak temperature point with relatively higher values than those for the first peaks of the beds with low porosity. It is also observed that in all the fuel particles investigated the bed temperatures are relatively less than those for air-fuel environment in comparable burning conditions [31]. Temperature in a $\mathrm{O}_{2} / \mathrm{CO}_{2}$ mixture is reduced by its higher heat capacity.

Presented in Fig. 5 is the ignition time for the different fuel particles. Bed ignition time was considered to be the time in which the reaction front takes to starts at the top surface of the bed. Reaction front starts when the bed temperature rises rapidly from ambient value to peak value. Ignition time was estimated from temperature profiles at various heights in the bed with an assumption that the flame propagation is steady, Yang et al. [49]. Ignition time decreases with increase in initial bed porosity. For the entire range, the ignition time values are higher than those reported for wood combustion under $\mathrm{N}_{2}$ environment in the same conditions, Tanui et al. [50]. Higher ignition time in $\mathrm{CO}_{2}$ environment could be due to its decreased flame temperature and heating rates. Furthermore, chemical reactions of $\mathrm{CO}_{2}$ through reactions $R(14)$ and gasification of char, $R(16)$, contribute to retardation of ignition time. Reaction $R(16)$ is endothermic and results in decreasing the amount of heat in the bed. Consequently, it increases the ignition time delay in the fuels.

The impact of porosity on air to fuel stoichiometry and flame front propagation speed is presented in Fig. 6. The values are compared to those obtained in $\mathrm{N}_{2}$ environment under similar operating conditions. The equivalence ratio presented are the aver aged values based on the total combustion time, fuel chemical composition and air flow rates. The actual equivalence ratio varies at different combustion stages as noted later in the analysis of gas species generation in the bed: It is higher during pyrolysis phase and lower during char consumption phase. For both cases, flame front propagation speed increases with increases in bed porosity. It is correspondingly lower in $\mathrm{CO}_{2}$ environment.

Fig. 6 also shows that as bed porosity is increased the burning condition is shifted from fuel-rich to fuel-lean side. Under the same air flow rate and $\mathrm{O}_{2}$ volumetric concentration, this shift is more toward the porous region in a $\mathrm{O}_{2} / \mathrm{CO}_{2}$ mixture than in a $\mathrm{O}_{2} / \mathrm{N}_{2}$ mixture as a result of differences in molecular weight. Furthermore, as noted in the flame front propagation speed, the operational range with respect to porosity is narrowed in a $\mathrm{CO}_{2}$ environment. This is due to its high heat capacity which causes earlier quenching effects than in $\mathrm{N}_{2}$ environment.

Drying, pyrolysis, homogeneous reactions and char conversion in the bed occurs simultaneously. Overlapping of these processes depends on the burning conditions. Dry wood particles with the same amount of mass initially located at $4 \mathrm{~cm}$ from the grate for different particle types were tracked in order to monitor their conversion progression. Fig. 7(a) presents the conversion of these particles in the bed with respect to time. The mass of dry wood remains constant until the onset of pyrolysis. Amongst the cases investigated, the onset of pyrolysis in particle type WCSD1 occurred at $180 \mathrm{~s}$, which is earlier than any other particle. Pyrolysis in particle type WC started to occur at $390 \mathrm{~s}$ and took longer a time to complete, $1110 \mathrm{~s}$. This indicate that as porosity of the bed is increased, pyrolysis process takes a shorter time. Though it is observed that there is an optimum point at which pyrolysis times begins to increase even with increase in porosity. This optimum point occurs when porosity is about 0.71 . This is as a result of combustion conditions becoming too lean and the flame starts to be quenched by excess $\mathrm{CO}_{2}$ through convection cooling.

The amount of char produced in the bed decreases with increase in porosity, Fig. 7(b). Higher amount of char in low porosity bed indeed confirms the second peak temperatures attained in these particle types seen in Fig. 4(a)-(b), which arise from combustion of char that is left in the bed after devolatilization. Char, which is in essence carbon, is produced and consumed within a shorter period of time as bed porosity increases. The amount of char presented in Fig. 7(b) is the net amount at a given time for particle tracked. Char is produced from pyrolysis of dry wood through reaction $R$ (4). Once it is produced, it is consumed through reactions $\mathrm{R}(15)-\mathrm{R}$ (17) depending on bed temperature and availability of $\mathrm{O}_{2}, \mathrm{CO}_{2}$ and $\mathrm{H}_{2} \mathrm{O}$.

The actual rates for conversion of dry wood particles are pre sented in Fig. 8(a). Particle type WCSD1 and WC attained the fastest and slowest pyrolysis rate of 4.78 and $2.13 \mathrm{~kg} \mathrm{~m}^{-3} \mathrm{~s}^{-1}$, respectively. The trend of influence of porosity is similar to what was observed before; pyrolysis rate increases with increase in porosity up to the optimum point, 0.71 , where it starts to decrease. As porosity is increased, there is a quick release of volatiles. Oxidation of combustible volatiles through reaction $R(6)-R(10)$ releases intense heat which increases the conversion rate. Since the conversion processes are fast, ignition is quick and flame propagation is also fast as noted in Figs. 5 and 6, respectively. In low porosity beds, volatiles are slowly released, heating rate is low and consequently, a slow conversion rate. Subsequently, low porosity beds have higher ignition time and low flame front propagation speed. Net char formation and consumption for the particles with respect to time are presented in Fig. 8(b). Just like wood pyrolysis rate, net char formation rates, positive values, increases as porosity is increased up to an optimum value, then it starts to decrease. However, the net consumption rates, negative values, have no optimum value. Particle type WC, WCSD2 and SD2 attained almost the same peak consumption rates. Char consumption rate is directly proportional to the char specific surface area, $S_{a, c h e r}$ as indicated in reactions $\mathrm{R}$ (15)-R (17). Thus, the high specific surface area for char in porous 

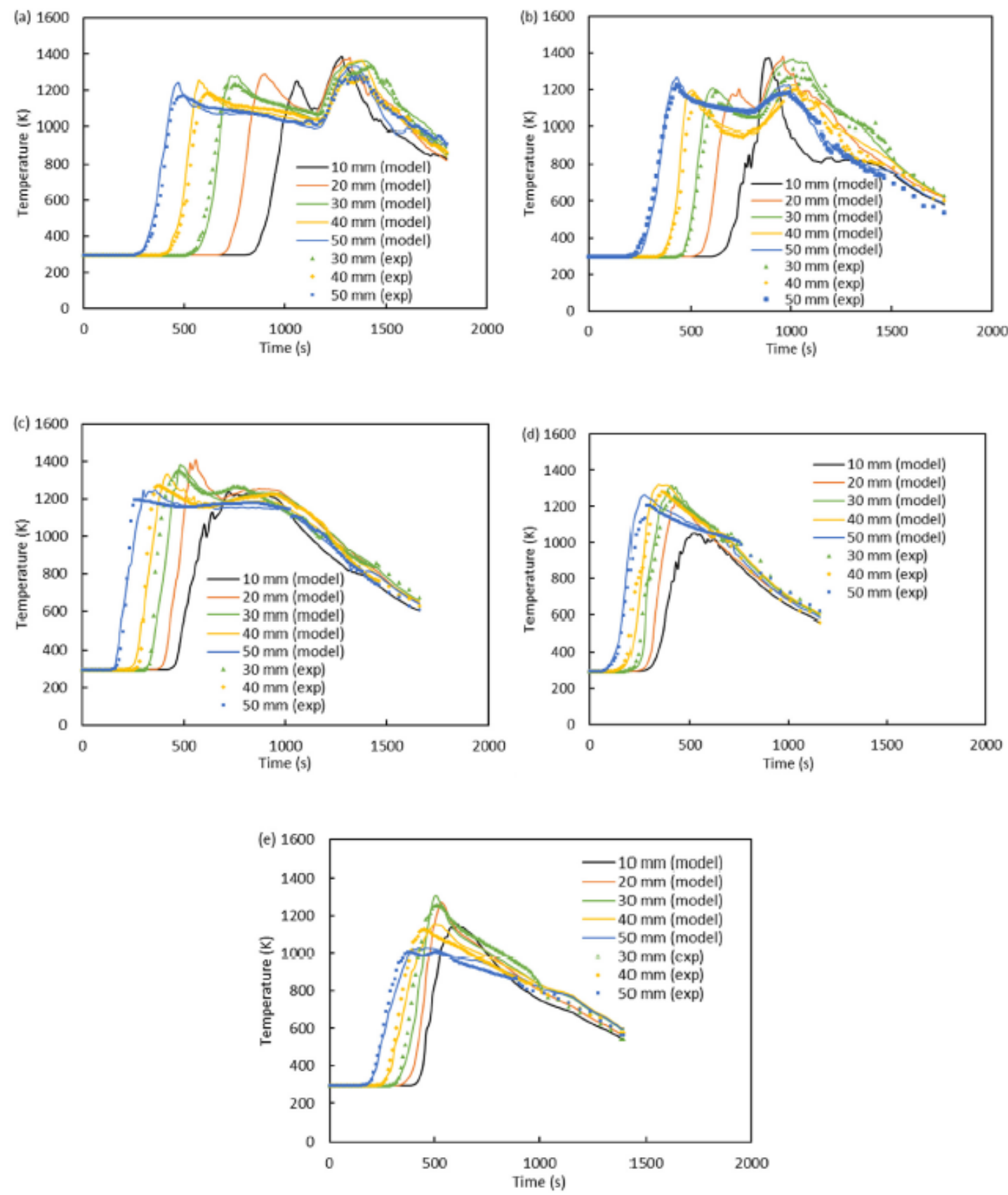

Fig 4. Measured and predicted temperature profiles at various heights above the grate for particle types (a) WC $(\chi-0.51)$ (b) WCSD2 ( $\chi$ - 0.56$)$, (c) SD2 ( $\chi-0.61)$ (d) WCSD1 $(x-0.68)$ and $(e)$ SD1 $(x-0.74)$

bed increases their consumption

Gas species concentration and temperature predicted during entire conversion of wood at a particular height is shown in Fig. 9. The values presented are taken at $4 \mathrm{~cm}$ from the grate for different particle types. The figures clearly depict the three distinct stages of wood combustion; drying, pyrolysis and char consumption. In all the cases, drying starts when the temperature reaches about $50^{\circ} \mathrm{C}$, as evident in the drying front which is always slightly ahead of the ignition front. The decrease in $\mathrm{CO}_{2}$ mole fraction at the onset of drying is due to introduction of water vapour in the bed and should not be viewed as a consumption. The absolute amount of $\mathrm{CO}_{2}$ only changes in the reaction zone as it is a product of oxidation of char 


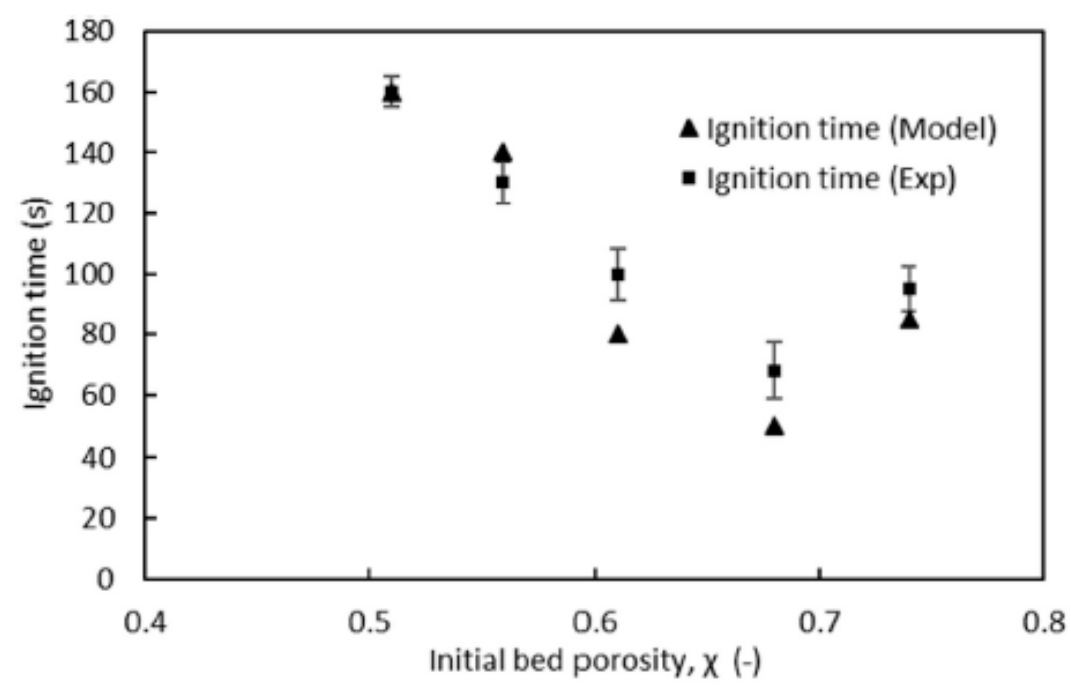

Fig. 5. Measured and predicted ignition time for wood combustion under oxy-fuel condition for different initial bed porosity. Error bars are the standard deviations.

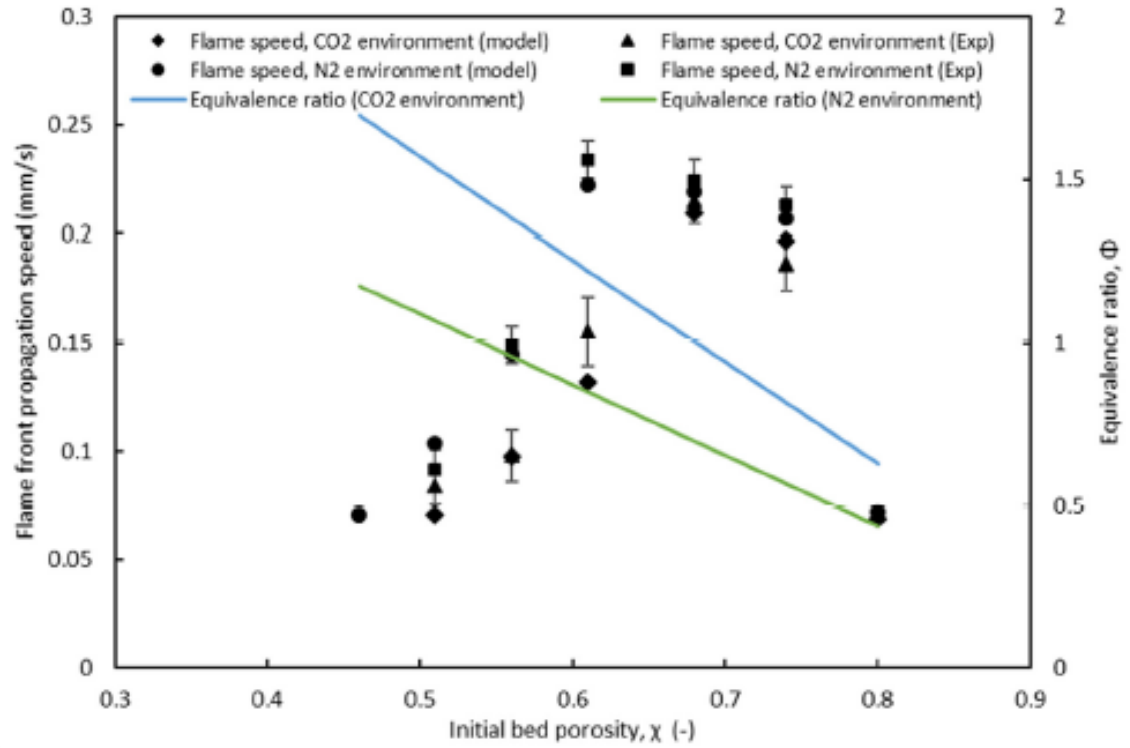

Fig. 6. Measured and predicted flame front propagation speed for wood conversion in $21 \% \mathrm{O}_{2} / 798 \mathrm{~N}_{2}$ and $21 \% \mathrm{O}_{2} / 798 \mathrm{CO}_{2}$ mixtures for different initial bed porosity.

and volatiles which contain carbon in their molecular structure. Alternatively, its amount may change through its participation in gasification of char, through reaction R (16) and in the forward and backward reactions of $\mathrm{H}_{2} \mathrm{O}$ and $\mathrm{CO}$, in $\mathrm{R}$ (13) and $\mathrm{R}$ (14).

During pyrolysis, particles at a local point absorb heat energy from oxidation of volatiles released by adjacent particles located in the upper side through radiation and conduction. Once the particle attains devolatilization temperature, then the volatiles are rapidly released. Combustible volatiles, are oxidized through reactions $R$ (5) $-R$ (10) releasing intense heat which rapidly increases the temperature to the first peak point, as seen in Fig. 9 for all the cases. During this period, $\mathrm{O}_{2}$ decreases gradually but does not go to zero immediately. Under the same oxidizer mixture mass flux as used in this study, the extent to which $\mathrm{O}_{2}$ concentration falls depends on the bed porosity. For particle type WC and WCSD2, Fig. 9(a) and (b), as pyrolysis progresses downward, the volatiles release at the lower part of the bed consume all the $\mathrm{O}_{2}$. Consequently, $\mathrm{O}_{2}$ is not able to reach the upper region. Since the wood fuels in this region are still undergoing pyrolysis, which is endothermic, the local temperature decreases. During this time, volatiles in upper region are not oxidized and their concentration remains almost constant. Similarly, char produced is not oxidized during this time. For this particle types, during devolatilization time, char is only consumed by gasification $\mathrm{H}_{2} \mathrm{O}$ and $\mathrm{CO}_{2}$. As a result, the amount of char is higher than for SD1, SD2 and WCSD1, as observed in Fig. 7(b).

Once the entire bed is completely pyrolyzed, volatiles in the 

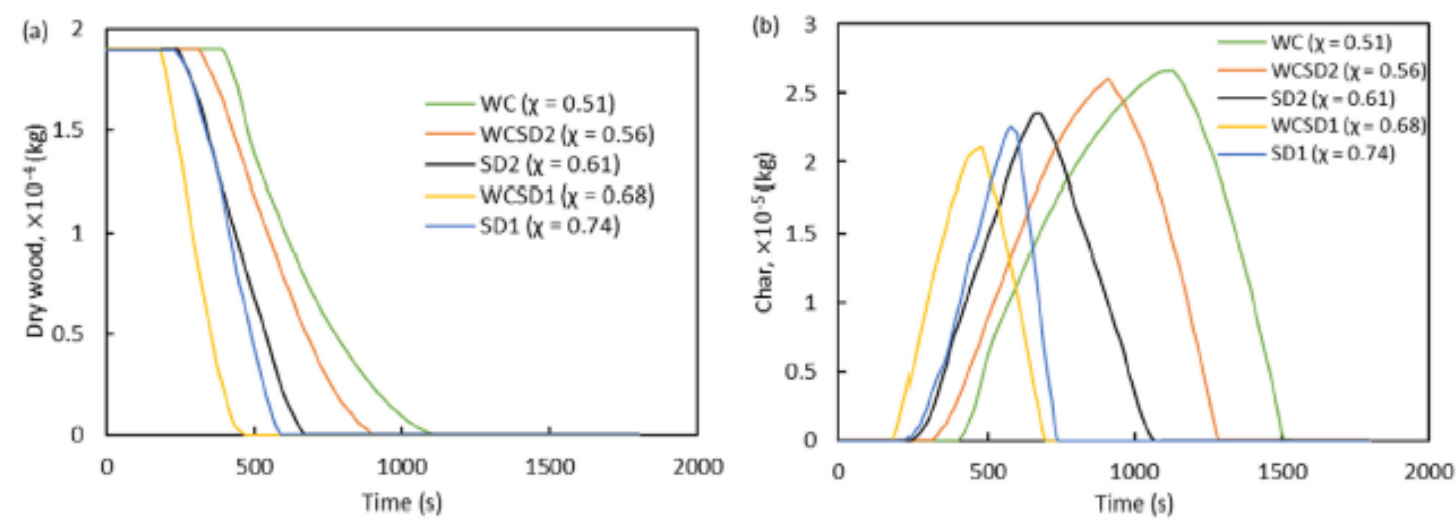

Fig 7. Predicted (a) wood onversion and (b) char formation of the particles with the same amount of mass initially located at $4 \mathrm{~cm}$ from the grate for different fuel particle types.
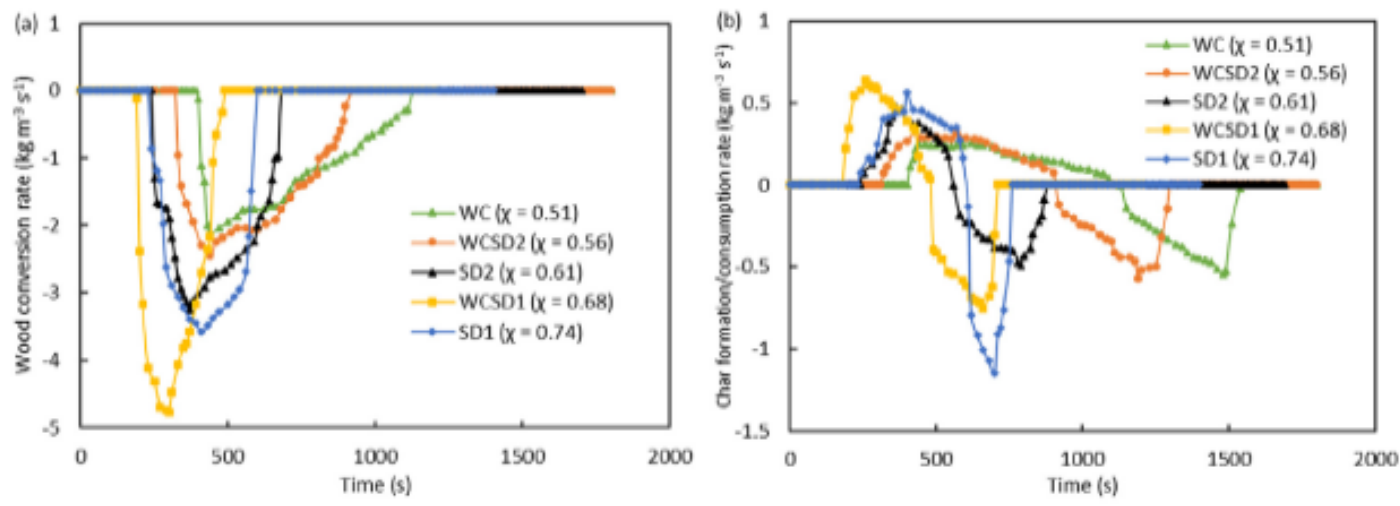

Fig 8. Predicted rate of (a) wood conversion and (b) char formation of the particles with the same amount of mass initially located at $4 \mathrm{~cm}$ from the grate for different fuel particle types.

lower region are the first to be completely oxidized since $\mathrm{O}_{2}$ is supplied from the bottom. This is evident in the steep increase in temperature of thermocouple located close to grate, Fig. 4(a) and (b). After complete oxidation of volatiles in the lower region of the bed, excess $\mathrm{O}_{2}$ is convected upward. The volatiles remaining in the bed are oxidized progressively from bottom to the top, as depicted in steep temperature rise at the end of devolatilization stage in Fig. 4(a) and (b). At a given height, $\mathrm{CO}_{2}$ concentration sharply increases at the end of devolatilization stage. This is partly due to oxidation of $\mathrm{CH}_{4}, \mathrm{CO}$ and tar. Its increase is also caused by depletion of other species through complete oxidation. Complete oxidation of volatiles end at $1200 \mathrm{~s}$ and $860 \mathrm{~s}$ for particle type WC and WCSD2, respectively, Fig, $9(\mathrm{a})$ and (b). After this point, there is excess $\mathrm{O}_{2}$ in the bed and char oxidation through reaction $\mathrm{R}$ (15) starts. Concurrently, char is consumed by $\mathrm{CO}_{2}$ through Boudouard reaction $\mathrm{R}$ (16). In overall, the amount of $\mathrm{CO}_{2}$ decreases while that of $\mathrm{CO}$ increases. Finally, $\mathrm{CO}$ is completely oxidized to $\mathrm{CO}_{2}$ toward the end of char combustion.

Pyrolysis and char consumption in particle types SD2, WCSD1 and SD1 proceed in almost a similar way. They all operate under lean conditions throughout conversion process as depicted by excess $\mathrm{O}_{2}$ in their reaction zones, Fig. $\mathrm{S}(\mathrm{c})-(\mathrm{e})$. As a result, oxidation of volatiles continues in the upper part of the bed as pyrolysis progresses downwards. This is evident in the low concentration of tar, $\mathrm{CH}_{4}, \mathrm{H}_{2}$ and $\mathrm{CO}$ in these particles as compared to those of particle types WC and WCSD2. In addition, char is oxidized concurrently with volatiles. This explains the high temperatures in the first peak of the porous fuels seen in Fig. 4(c)-(e). The low amount of char in the porous bed noted in Fig. 6(b) is also accounted for by this fact. For particle types SD1 and WCSD1, the heat release from oxidation of the char remaining in the bed after complete devolatilization is not sufficient to raise the temperature to a second peak, Fig. 9(d) and (e). However, particle type SD2 still has a substantial amount of char whose oxidation is sufficient to increase the temperature to a second peak. Though it is not as high as for particle types WCSD2 and WC1.

Flame structures along axial length of the bed for different particle types when the reaction front is at $4 \mathrm{~cm}$ from the grate are presented in Fig. 10. The graphs clearly illustrate the thickness of the reaction front for various fuel particles. Thickness of the reaction front was considered to be the axial length in the bed in which the temperature changes from ambient value to maximum as flame front passes, Yang et al. [49]. It is affected by several factors which include burning rates, flame front propagation speed and fuel particle size. In general, it was observed that reaction front thickness increases as porosity increases; the lowest and highest values being $21 \mathrm{~mm}$ and $35 \mathrm{~mm}$ for particle types WC and SD1, respectively. Thin reaction front indicates that the particles at a given 

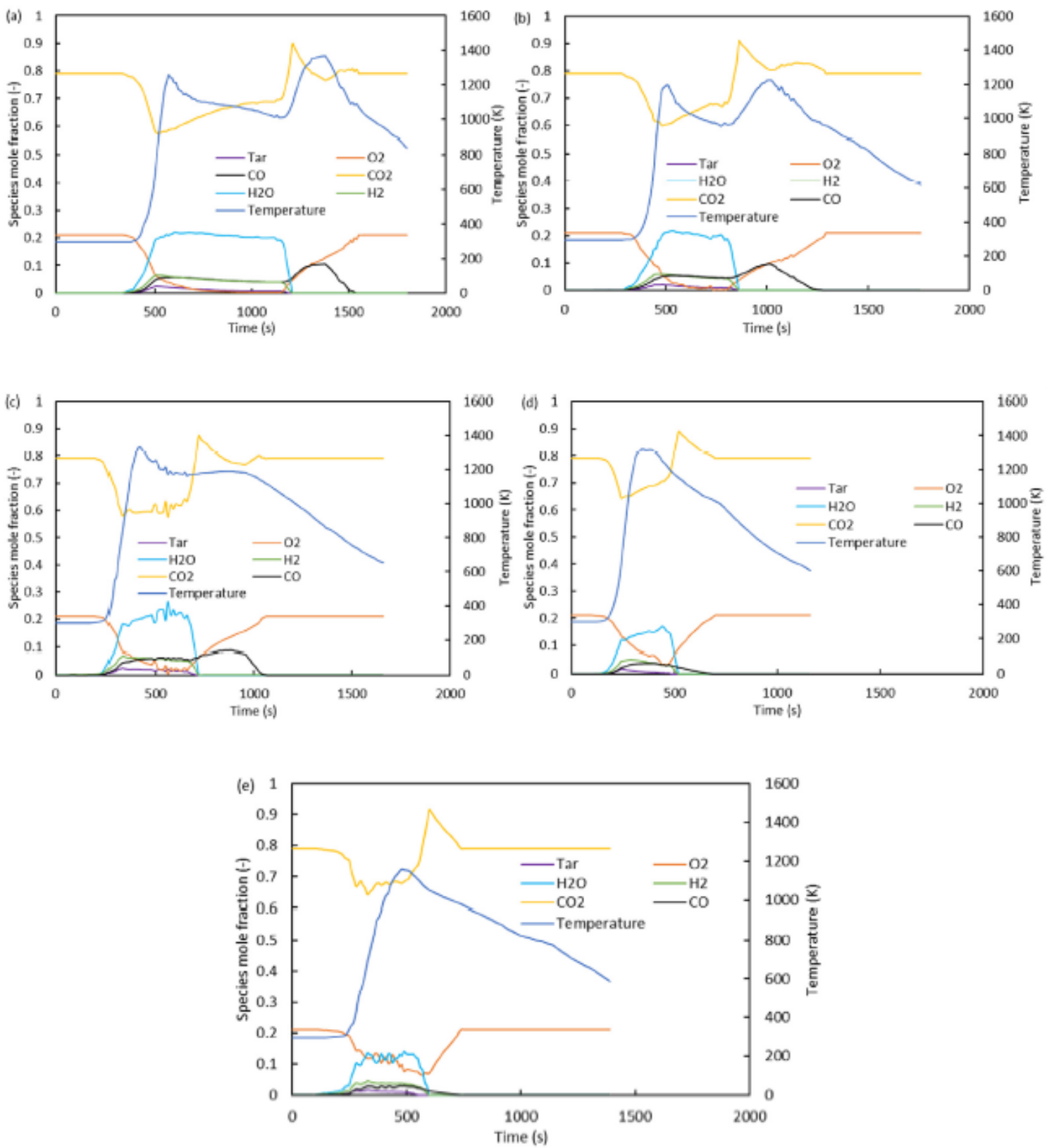

Fig. 9. Predicted species concentration and temperature profiles for particle types (a) WC $(\chi-0.51)$, (b) WCSD2 ( $\chi-0.56)$ (c) SD2 ( $\chi-0.61)$ (d) WCSD1 ( $\chi-0.68)$ and (e) SD1 $(x-0.74)$

height burn uniformly. For this case, higher amounts of volatiles are present at a given height, Fig. 10 (a)-(c). On the other hand, a thicker reaction front as seen in Fig. 10(d) and (e) is associated with a high flame front propagation speed, high burning rates and fast pyrolysis. In this case, fuel particles at a lower region start releasing small amount of volatiles which are immediately oxidized. Consequently, the amounts of volatiles are not as high as for cases with thin reaction front thickness. Furthermore, radiation energy in low porosity beds have short penetration into fuel particles in unreacted region. Therefore, their flame front propagation moves slowly as seen in Fig. 6, and the reaction zone is thin. This is opposite to high porosity bed which allows deep penetration of radiation energy to unreacted particles in the lower part of the bed making them to have high flame front propagation speed and a thicker reaction zone.

Volatiles released when the reaction front is at $4 \mathrm{~cm}$ from the grate, for all the cases, are not completely oxidized in the fuel bed, Fig. 10. Unreacted volatiles do not stay in the bed but instead, they 

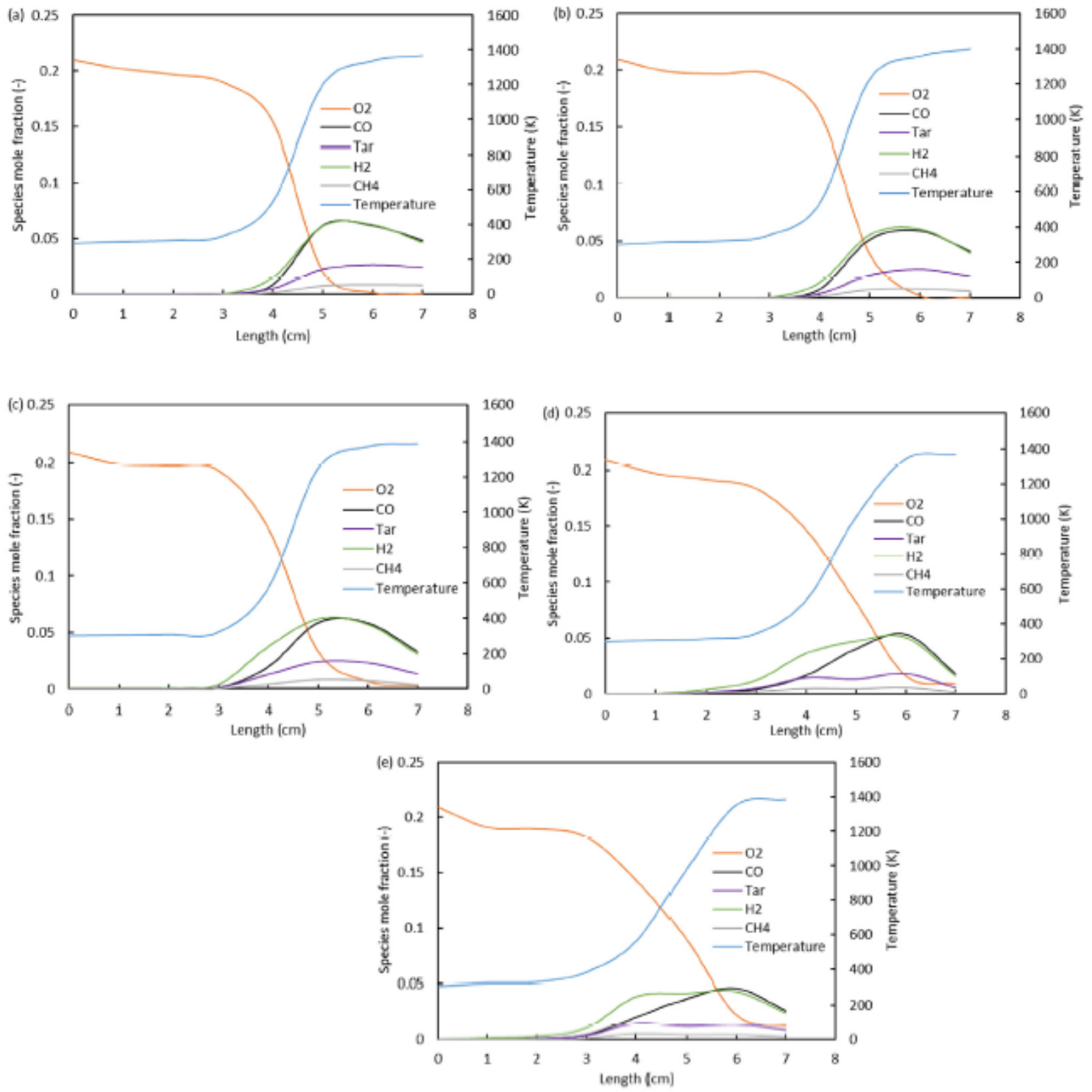

Fig 10. Predicted major species concentration and temperature along axial length of the bed for particle types (a) WC ( $\chi-0.51)$ (b) WCSD2 ( $\chi-0.56)$ (c) SD2 ( $\chi-0.61$ ), (d) WCSD1 $(x-0.68)$ and $(e)$ SD1 $(x-0.74)$.

are transported to freeboard region, height above $6 \mathrm{~cm}$, where they are reacted as indicated by their decreasing levels. Unlike in the bed region, there are no endothermic processes, pyrolysis and gasifcation, in freeboard region. Therefore, oxidation of volatiles results in higher freeboard temperature in all the cases. It is noted that for fuels with thick reaction zone thickness, Fig. $10(\mathrm{c})-(\mathrm{e}), \mathrm{H}_{2}$ is the dominant volatile in the low temperature region of about $300-800 \mathrm{~K}$. A high amount of $\mathrm{H}_{2}$ in these fuels is as a result of reaction $R$ (13). This is supported by low amount of $C O$ in this region. Furthermore, this reaction has been reported to have better prediction and works well in fuel lean conditions under which these fuels were operated, Andersen et al. [51] and Jones \& Lindstedt [52].

\section{Conclusions and recommendations}

An investigation on the influence of particle packing density on wood conversion in the fixed bed under oxy-fuel environment in the entire possible operation range were done in this study. The following are the main findings of the study.

- The packing density affects the combustion process in an oxyfuel environment by changing the burning conditions and flammability limits. The combustion condition is shifted from fuel-rich to fuel-lean side as bed porosity is increased. Consequently, the flame front propagation speed increases while the ignition time reduces. The reaction zones also thicken. 
- As bed porosity is increased, volatiles and char are concurrently oxidized during pyrolysis stage leading to a single temperature peak. On contrary, bed with low porosity has two distinct temperature peaks since volatiles and char are oxidized sequentially due to $\mathrm{O}_{2}$ deficit.

- There is an optimum packing density, $\chi=0.71$, beyond which the efficiency falls off due to the onset of quenching in the spaces.

- Increasing the porosity of the bed positively affects the pyrolysis rate up to the optimum point. At the same time, the volatiles oxidation is increased due to fuel-lean combustion condition. This leads to low concentrations of $\operatorname{tar}, \mathrm{CH}_{4}, \mathrm{H}_{2}$ and $\mathrm{CO}$ in high porosity beds.

- High porosity promotes char formation and consumption rates of the bed. The overall effect is a reduced amount of char in this bed.

- The operational range with respect to porosity was decreased in an oxy-fuel burning condition due to higher quenching effects of $\mathrm{CO}_{2}$.

In this study, particle packing density was analyzed by considering initial arrangement of particles in the bed. In practice, the packing density and porosity changes as combustion proceeds due to bed shrinkage. Channeling in the bed could also arise as combustion takes place. These were not considered in this work. Hence, there is need to consider them in a future study.

\section{CRediT authorship contribution statement}

J.K. Tanui: Conceptualization, Methodology, Investigation, Writing - original draft. P.N. Kioni: Conceptualization, Methodology, Supervision. T. Mirre: Investigation, Software, Validation. M. Nowitzki: Software, Validation. N.W. Karuri: Supervision, Writing - review \& editing.

\section{Acknowledgement}

This work was financially supported by both Dedan Kimathi University of Technology, Kenya and Technische Hochschule Wildau, Germany. The first author would like to thank the German Academic Exchange Service (DAAD), Germany, ID NO: 57314019 for the financial support for his stay in Technische Hochschule Wildau, Germany where the experiments were conducted.

\section{References}

[1] Hemansson S, Thunman H. CFD modelling of bed shrinkage and channelling in fixed-bed combustion. Combust Flame 2011;158:988-99. hittps://doi.org/ 10.1016/J.COMBUSTFLAME 2011.01.022

[2] Costa M, Massarotti N, Indrizzi V, Rajh B, Yin C, Samec N. Engineering bed models for solid fuel conversion process in grate-fired boilers. Energy 2014;77:244-53. hittps://doi.org/10.1016/j.energy_2014.07.067.

[3] Guo F, L X, Wang Y, Lu Y, L T, Guo C. Characterization of Zhundong lignite and biomass co-pyrolysis in a themogravimetric analyzer and a fixed bed reactor. Energy 2017;141:2154-63. hitps://doi.org/10.1016 jenergy_2017.11.141.

[4] Yahaya AZ, Somalu MR, Muchtar A, Sulaiman SA, Daud WRW. Effect of particle size and temperature on gasification performance of coconut and palm kernel shells in downdraft fixed-bed reactor. Energy 2019;175:931-40. https:/ doi.org/10.1016/j.energy 2019.03.138.

[5] Porteiro J, Granada E, Collazo J, Patiño D, Morán JC A model for the combustion of large particles of densified wood. Energy Fuek 2007;21:3151-9. hittps://doiorg/10.1021/efo701891.

[6] Khodaei H, Al-Abdeli YM, Guzzomi F, Yeoh GH. An overview of processes and considerations in the modelling of fixed-bed biomass combustion. Energy 2015;88:946-72. https://doi.org/10.1016/j.energy_2015.05.099.

[7] Abrego I Atienza-Martínez M, Plou F, Arauzo J. Heat requirement for fixed bed pyrolysis of beechwood chips. Energy 2019;178:145-57. https://doi.org/ $10.1016 / j$.energy 2019.04 .078

[8] Chen W, Annamalai K, Ansley RJ, Mirik M. Updraft fixed bed gasification of mesquite and juniper wood samples. Energy 2012;41:454-61. https://doi.org/
10.101 6/jenergy 2012.02 .052

[9] Meng X, Sun R, Ismail TM, Zhou W, Ren X, Zhang R. Parametric studies on com straw combustion characteristics in a fixed bed: ash and moisture content. Energy 2018:1 58:192-203. https://doi.org/10.1016/j.energy 2018.06.060.

[10] Plis P, Wilk RK. Theoretical and experimental investigation of biomass gasification process in a fixed bed gasifier. Energy 2011;36:3838-45. hitps:// doi.org/10.1016/j.energy 2010.08.039.

[11] Scheffknecht G, Al-Makhadmeh L, Schnell U, Maier J. Oxy-fuel coal combustion - a review of the current state-of-the-art. Int J Greenh Gas Control 2011;5:16-35. https://doi.org/10.1016/jijggc.2011.05.020.

[12] Riaza J. Gil MV, Álvarez L. Pevida C, Pis IJ. Rubiera F. Oxy-fuel combustion of coal and biomass blends. Energy 2012;41:429-35. https://doi.org/10.1016/ JENERGY 2012.02.057.

[13] Gil MV, Riaza], Álvarez L. Pevida C, Rubiera F. Biomass devolatilization at high temperature under $\mathrm{N}_{2}$ and $\mathrm{CO}_{2}$ : char morphology and reactivity. Energy 2015;91:655-62. https://doi.org/10.101 6/jenergy_2015.08.074

[14] Heuer S, Senneca O, Wotscher A. Dodder $H$ Schiemann $M$, Muhler M, et al. Effects of oxy-fuel conditions on the products of pyrolysis in a drop tube reactor. Fuel Process Technol 2016;150:41-9. https://doi.org/10.1016 JFUPROC 2016.04.034.

[15] Pohlmann JG, Osório E, Vilela ACF, Diez MA Borrego AG. Pulverized combustion under conventional $\left(\mathrm{O}_{2} / \mathrm{N}_{2}\right)$ and oxy-fuel $\left(\mathrm{O}_{2} / \mathrm{CO}_{2}\right)$ conditions of biomasses treated at different temperatures Fuel Process Technol 2017;155: 174-82. https://doiorg/10.1016/j.fuproc 2016.05.025.

[16] Shan $F$, Lin $Q$, Zhou K, Wu Y, Fu W, Zhang $P$, et al. An experimental study of ignition and combustion of single biomass pellets in air and oxy-fuel. Fuel 2017:188:277-84. https://doi.org/10.1016/j.fuel_2016.09.069.

[17] Gil MV, Riaza J Alvarez L, Pevida C, Pis IJ, Rubiera F. Kinetic models for the oxy-fuel combustion of coal and coal/biomass blend chars obtained in $\mathrm{N}_{2}$ and $\mathrm{CO}_{2}$ atmospheres Energy 2012;48:510-8. https://doi.org/10.1016/ jenergy 2012.10.033.

[18] Riaza J, Khatami R, Levendis YA, Álvarez L, Gil MV, Pevida C, et al. Combustion of single biomass particles in air and in oxy-fuel conditions. Biomass Bioenergy 201 4;64:162-74. hittps://doi.org/10.1016/j.biombioe.2014.03.018.

[19] Trudel E, Hallett W. Pressure drop in packed beds of angular parallelepipeds, including the effects of particle interference. Chem Eng Sci 2017;162:209-17. https://doi.org/10.1016/J.CES.2017.01.004.

[20] Glaser MB, Thodos G. Heat and momentum transfer in the flow of gases through packed beds. AIChE J 1958;4:63-8. https://doi.org/10.1002 aic.690040113.

[21] Larfeldt J. Leckner B, Melaaen MC Modelling and measurements of the pyrolysis of large wood particles. Fuel 2000;79:1637-43. hitps://doiorg/ 10.1016/50016-2361(00)00007-7.

[22] Henriksen U, Hindsgaul C, Qvale B, Fjellerup J.Jensen AD. Investigation of the anisotropic behavior of wood char particles during gasification. Energy Fuels 2006;20:2233-8. https://doi.org/10.1021/ef060140f.

[23] Trudel E, Hallett WLH, Wiens E, Neil JDO, Busigin MK Berdusco D. Fuel particle shape effects in the packed bed combustion of wood. Combust Flame 2018;198:100-11. https://doi.org/10.1 016/j.combustflame.2018.09.006.

[24] Pattanotai T, Watanabe H, Okazaki K. Effects of particle aspect ratio on pyrolysis and gasification of an isotropic wood cylinder. Fuel 2015;150:162-8. hittps://doi.org/10.1016/J.FUEL 2015.02.017.

[25] Horttanainen M, Sastamoinen I Sarkomaa P. Operational limits of ignition front propagation against airflow in packed beds of different wood fuels. Energy Fuels 2002;16:676-86. https://doi.org/10.1021/ef010209d.

[26] Huff ER Effect of size, shape, density, moisture and fumace wall temperature on burning times of wood pieces. Fundam themochem biomass conversion. Elsevier 1985:761-75.

[27] Comiti J, Renaud M. Liquid-solid mass transfer in packed beds of parallelepipedal particles: energetic correlation. Chem Eng Sci $1991 ; 46: 143-54$. https://doi.org/10.1016/0009-2509(91)80124-H.

[28] Yang Y Bin, Ryu C, Khor A, Sharifi WN, Swithenbank J. Fuel size effect on pinewood combustion in a packed bed. Fuel 2005;84:2026-38. hittps:// doi.org/10.1016/j.fuel2005.04.022.

[29] Ryu C Yang Y Bin, Khor A, Yates NE, Sharifi WN, Swithenbank f Effect of fuel properties on biomass combustion: Part L. Experiments - fuel type, equivalence ratio and particle size. Fuel 2006;85:1039-46. https://doi.org/10.1016/ jufuel 2005.09.019.

[30] Porteiro J Patiño D, Collazo J. Granada E, Moran J, Miguez JL. Experimental analysis of the ignition front propagation of several biomass fuels in a fixedbed combustor. Fuel 2010;89:26-35. https://doi.org/10.1016/ JFUEL 200901.024

[31] Tanui JK, Kioni PN. Mirre T, Nowitzki M. The effect of carton dioxide on flame propagation speed of wood combustion in a fixed bed under oxy-fuel conditions. Fuel Process Technol 2018;179:285-95. https://doi.org/10.1016/ jfuproc.2018.07.010.

[32] CD-Adapco. STAR CCM+ version 11.04. WwwCd-AdapcoCom 2017

[33] The British Standards Institution. BS EN 15149-2:2010: solid biofuels. Determination of particle size distribution. Vibrating screen method using sieve apertures of $3,15 \mathrm{~mm}$ and below. Br Stand Inst 2010 .

[34] Williams O, Newbolt G, Eastwick C, Kingman S, Giddings D, Lormor S, et al. Influence of mill type on densified biomass comminution. Appl Energy 2016;182:219-31. https://doi.org/10.1016/ja penergy_2016.08.111.

[35] Brezáni I, Zeleñak F. Improving the effectivity of work with Rosin-Rammler diagram by using MATLAB R GUI tool. Acta Montan Slovaca 2010;15:152-7. 
[36] Liu F, Guo H, Smallwood G], Gulder ŌL. The chemical effects of carton dioxide as an additive in an ethylene diffusion flame: implications for soot and NO formation. Combust Flame 2001;125:778 -87. https://doi.org/10.1016/500102180(00)00241-8.

[37] Liu F, Guo H, Smallwood G]. The chemical effect of $\mathrm{CO}_{2}$ replacement of $\mathrm{N}_{2}$ in air on the burning velocity of $\mathrm{CH}_{4}$ and $\mathrm{H}_{2}$ premixed flames. Combust Flame 2003;133:495-7. https://doi.org/10.1016/50010-21 80(03)00019-1.

[38] Evans DD, Emmons HW. Combustion of wood charcoal. Fire Saf J 1977;1: 57-66. hittps://doi.org/10.1016/0379-7112(77)90008-X.

[39] Johansson R, Thunman H, Leckner B. Influence of intraparticle gradients in modeling of fixed bed combustion. Combust Flame 2007;149:49-62. https:/] doi.org/10.101 6/j.comb ustflame.2006.12.009.

[40] Gómez MA Porteiro J, de la Cuesta D, Patiño D, Miguez JL. Numerical simulation of the combustion process of a pellet-drop-feed boiler. Fuel 2016;184 987-99. hittps://doi.org/10.1016/j.fuel2015.11.082.

[41] Mahmoudi AH, Markovic M, Peters B, Brem G. An experimental and numerica study of wood combustion in a fixed bed using Euler-Lagrange approach (XDEM ). Fuel 2015;150:573-82. https://doi.org/10.1016/jfuel2015.02.008.

[42] Mahmoudi AH Hoffmann F, Markovic M, Peters B, Brem G. Numerical modeling of self-heating and self-ignition in a packed-bed of biomass using XDEM. Combust Flame 2016;163:358-69. https://doi.org/10.1016/ j.combustflame.2015.10.010.

[43] Smith GP, Golden DM, Frenklach M, Moriarty NW, Eiteneer B, Goldenberg M, et al GRI-Mech 3.0 1999. http://combustion.berkeley.edu/gri-mech/ version 30/text30.htmL. [Accessed 13 july 2018].

[44] Westbrock CK, Dryer FL Chemical kinetic modeling of hydrocarton com bustion. Prog Energy Combust Sci 1984;10:1-57. https://doi.org/10.1016/ 0360-1285(84)90118-7.

[45] Fiveland WA. Discrete-ordinates solutions of the radiative transport equation for rectangular enclosures. J Heat Transf 1984;106:699-706. https://doi.org/ $10.1115 / 1.3246741$

[46] Smith TF, Shen ZF, Friedman JN. Evaluation of coefficients for the weighted sum of gray gases model. J Heat Transf 1982;104:602-8. https://doi.org $10.1115 / 1.3245174$

[47] Incropera F., DeWitt DP, Bergman TL, Lavine AS. Fundamentals of heat and mass transfer. Sixth. John Wiley \& Sons; 2006.

[48] Khor A, Ryu C, Yang Y Bin, Sharifi VN, Swithen bank J. Straw combustion in fixed bed combustor. Fuel 2007;86:152-60. https://doiorg/10.1016/ j.fuel 2006.07 .006

[49] Yang YB, Yamauchi H, Nasserzadeh V, Swithenbank f Effects of fuel devolatilisation on the combustion of wood chips and incineration of simulated municipal solid wastes in a packed bed. Fuel 2003;82:2205-21. https:/ doi.org/10.101 6/50016-2361(03)00145-5.

[50] Tanui JK, Kioni PN, Mime T, Nowitzki M. Chemical, thermal and dilution effects of carbon dioxide in oxy-fuel combustion of wood in a fixed bed. J Mech Sci Technol 2019;33:6063-73. https://doi.org/10.1007/s12206-019-1150-z.

[51] Andersen J, Jensen PA, Meyer KE, Hvid SL, Glarborg P. Experimental and numerical investigation of gas-phase freeboard combustion. Part 1: main combustion process Energy Fuek 2009;23:5773-82. https://doiorg/10.1021 e.900752a.

[52] Jones WP, Lindstedt RP. Global reaction schemes for hydrocarbon combustion Combust Flame 1988;73:233-49. hitps://doi, org/10.1016/0010-2180(88) 90021-1.

\section{Nomenclature}

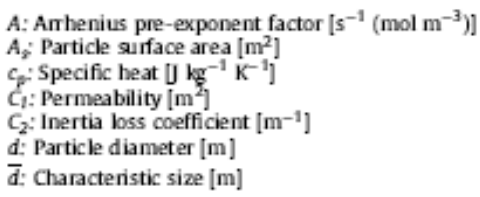

$\bar{d}$ : Characteristic size $[\mathrm{m}]$

D: Diffusivity $\left[\mathrm{m}^{2} \mathrm{~s}^{-1}\right]$

$D_{\text {ex: }}$ : Diameter of the particle which is equal to that of volume-equivalent sphere [m] E: Activation energy [J mol-1]

g: Gravity $\left[\mathrm{m} \mathrm{s}^{-2}\right]$

G: Incident radiative heat flux [ $\left.\mathrm{W} \mathrm{m}^{-2}\right]$

h: Enthalpy [ $\mathrm{kg}^{-1}$ ]

$h_{c}$ : Convective heat transfer coefficient $\left[\mathrm{W} \mathrm{m}^{-2} \mathrm{~K}^{-1}\right]$

$\mathrm{H}$ : Enthalpy of formation of species $i\left[\mathrm{~kg}^{-1}\right]$

j: Diffusion mass flux $\left[\mathrm{kg} \mathrm{m}^{-2} \mathrm{~s}^{-1}\right]$

$K$. Rate constant $\left[\mathrm{s}^{-1}\left(\mathrm{~mol} \mathrm{~m}^{-3}\right)\right]$

n: Rosin-Rammler distribution parameter [-]

$N_{\mathrm{g}}$ : Number of gas species [-]

p: Pressure [Pa]

$q_{R^{*}}$ : Radiative heat flux $\left[\mathrm{W} \mathrm{m}^{-2}\right]$

$Q_{a p}$ : Particle absorption coefficient [-]

$R$. Universal gas constant $\left[\mathrm{J} \mathrm{mol}^{-1} \mathrm{~K}^{-1}\right]$

(d): Percentage of accumulated undersize mass in Rosin-Rammler distribution [\%] $S_{\mathrm{a}}$ : Specific surface area $\left[\mathrm{m}^{-1}\right]$

SE: Energy source tem $\left[\mathrm{m}^{-1} \mathrm{~s}^{-1}\right]$

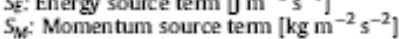

t: Time [s]

T. Temperature [K]

$v$. Velocity $\left[\mathrm{m} \mathrm{s}^{-1}\right]$

$V_{p}:$ Particle volume $\left[\mathrm{m}^{3}\right]$

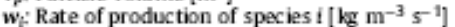

$Y$ : Mass fraction $[-]$

Greek symbals

e: Turbulent dissipation rate [J kg-1 s-1 ]

9: Particle porosity [-]

$\kappa$ : Turbulent kinetic energy [J kg-1 s-1]

2.: Thermal conductivity [W m-1 K-1]

I.' Viscosity [ $\mathrm{kg} \mathrm{m}-1 \mathrm{~s}-1]$

$\alpha$. Density [kg m-3]

o: Stefan-Boltzmann constant [W $\mathrm{m}-2 \mathrm{~K}-4$ ]

$\tau$ : Shear stress tensor [Pa]

$x$ : Bed porosity [-]

4: Sphericity [-]

Q: Stoichiometric coefficient [-]

Subscripts

b: Biomass

e: Effective

g: Gas

$i$ ith reaction

ig: Gaseous species

is: Solid-phase species

p: Particle

s: Solid

Stuperscript

gs: Heterogeneous reaction

n: Exponent

Operators

V: Gradient operator

$\nabla$ : Divergence operator 